\title{
Translating Contemporary New Zealand Poetry into French: Anna Jackson and Robert Sullivan
}

\author{
Luc Arnault
}

A thesis submitted to the Victoria University of Wellington in fulfilment of the requirements for the degree of Doctor of Philosophy

Victoria University of Wellington

2020 


\section{Abstract}

This thesis aims to explore the translation process through an in-depth analysis of a large corpus of texts: the works of two contemporary New Zealand poets, Anna Jackson and Robert Sullivan, which I translate into French. The work of both poses translation challenges particularly in terms of intertextual and cultural allusions. These are exacerbated where there are profound differences between source and target cultures. I argue that poetry translation problematises the concepts of equivalence and faithfulness. In resonance with Christiane Nord's skopos theory and her focus on the principle of loyalty, I suggest that an ideal balance can be reached, emphasising the translator's responsibility as a mediator between cultures, chiefly by way of techniques of compensation, borrowing, transposition or modulation, explicitation or implicitation of the underlying cultural or intertextual layers, and by resorting to creativity. This emphasis does not do away with pragmatism. On the contrary, I justify my choices when confronted with a range of specific challenges, for instance between domesticating and foreignising, or in Nord's terms instrumental and documentary translations, on the basis of a case-by-case analysis, thus prioritising a heuristic and experimental approach. Translating New Zealand poetry into French shows that, while it may be crucial in literary translation studies, particularly with regard to poetry translation, the distinction between instrumental and documentary nevertheless needs to be transcended. The two types not only overlap but need to do so for a translated poem to function in the target culture. To translate both Jackson's recurrent references to text and Sullivan's to culture - or as an umbrella concept, to translate allusion - I show that it is best to think in terms of balance rather than equivalence. Balance not only highlights the need for the translator to be creative and measured, it is a central element in the harmonisation process inherent to poetry translation. 


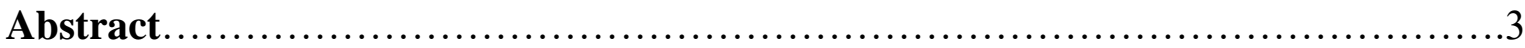

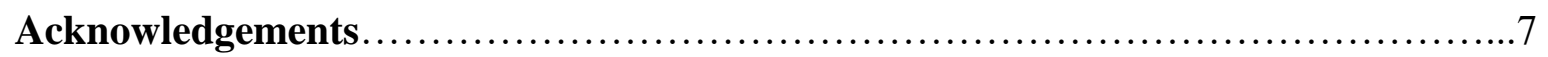

\section{Introduction}

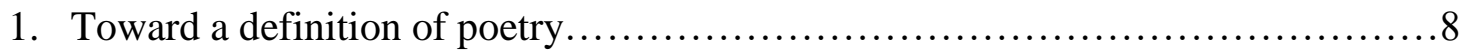

2. Poetry translation...........................................................

3. Theoretical framework

a. Modus Operandi........................................................

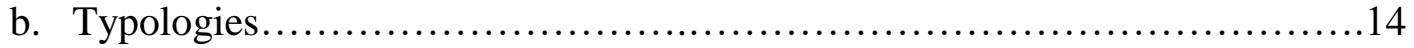

c. Domestication and foreignization.......................................... 16

d. A pragmatic approach............................................. 17

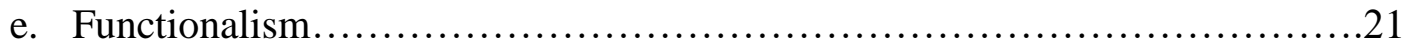

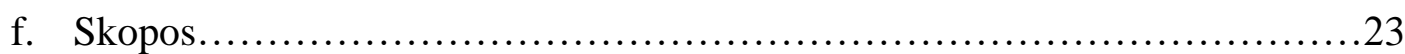

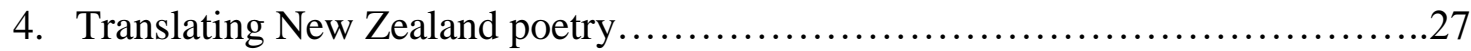

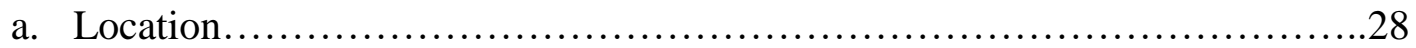

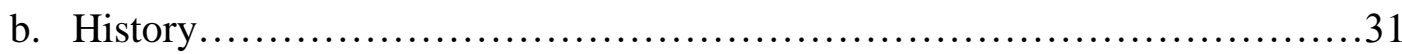

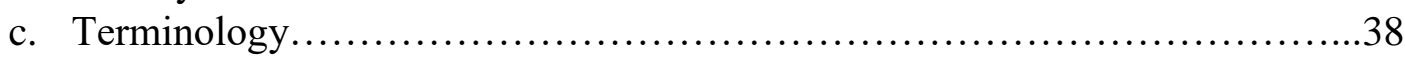

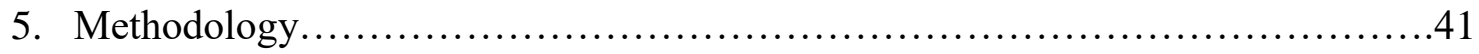

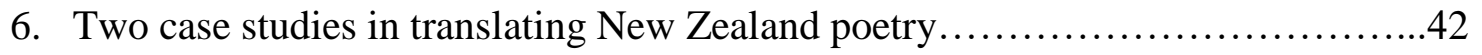

\section{Part I: Translating Anna Jackson's poetry}

\section{A. Preliminary analysis}

1. Anna Jackson's translation

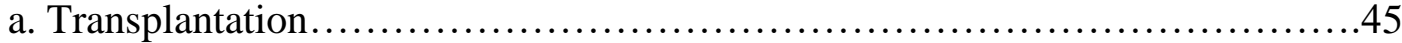

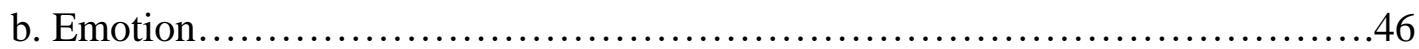

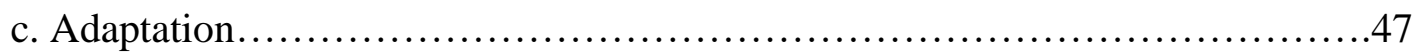

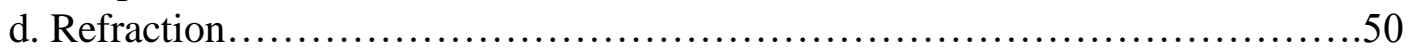

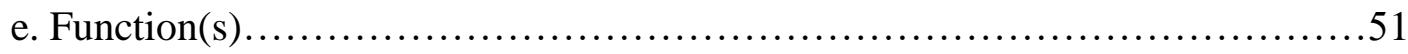

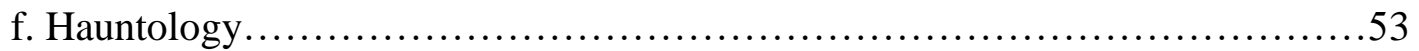

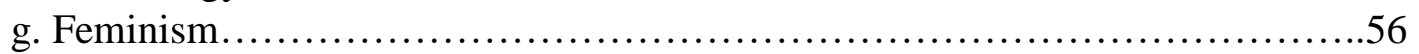

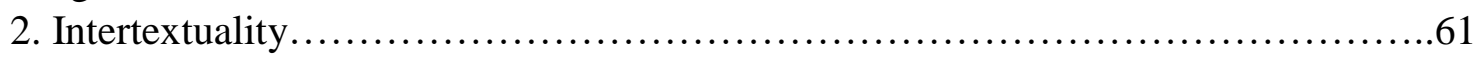

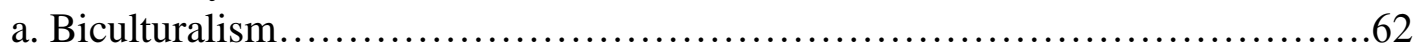

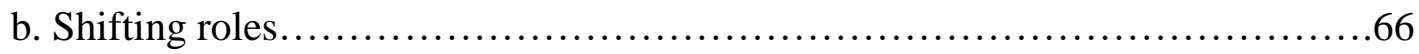

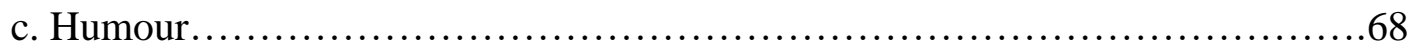

d. Cross-cultural representations............................................... 74

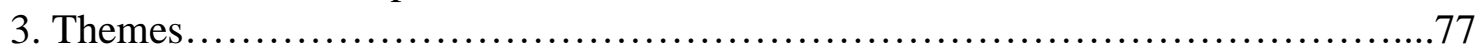

a. The Long Road to Teatime and The Pastoral Kitchen............................78

b. Catullus for Children.................................................... 80

c. The Gas Leak............................................................... 81

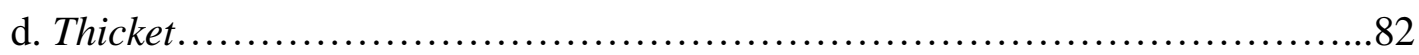

e. I, Clodia and Other Portraits..................................................84

4. Literary devices

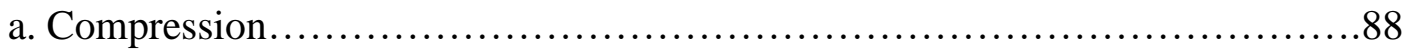

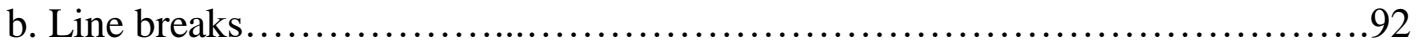

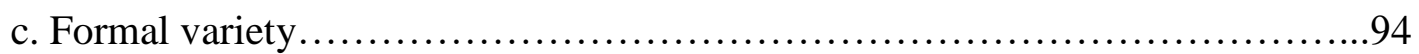

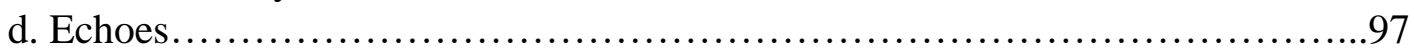




\section{B. Case-by-case analysis}

1. The Long Road to Teatime

a. "16 Pākehā Waka".......................................................... 101

b. "Just a Mineral Water with Marianne Moore"................................108

2. The Pastoral Kitchen
a. "Watch".
b. "Kikuyu",

3. Catullus for Children

a. "Sparrow (as Told by Elvira)" ......................................... 122

b. "Mayakovsky's Kindness to Horses", "Stow Stay Stow Stay 1".............126

4. The Gas Leak

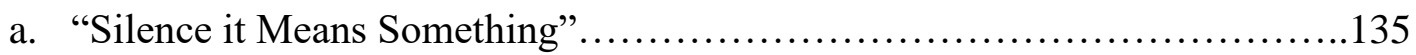

b. "The Gas-Fitter's Daughter Shows Shane", "The Gas-Fitter's

Daughter's Recurring Solution"........................................... 140

c. "It Seems That This Time I Have Been Mistaken", “An Explanatory Wave of the Hand"............................................................147

5. Thicket

"Ophthalmoscope", "Salty Hair".

6. I, Clodia and Other Portraits

a. "A Thousand Kisses, then a Hundred", "This Business of Kissing", "Pipiabat, (Used to Chirp") .....................................................158

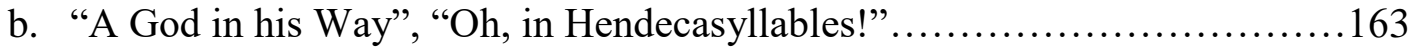

C. Translating Anna Jackson's poetry and the poetic voice........................170

\section{Part II: Translating Robert Sullivan's poetry}

A. Preliminary analysis....................................................... 177

I. Why Star Waka? Presentation, themes and devices

1. A significant metaphor, the waka......................................... 179

2. A significant narrative structure

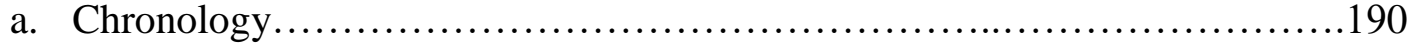

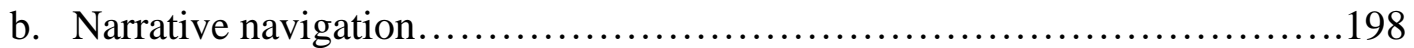

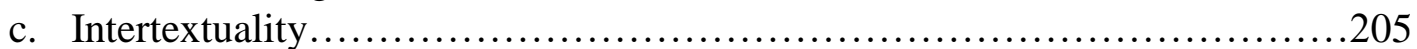

3. A significant linguistic tack.............................................. 211

II. Expected challenges

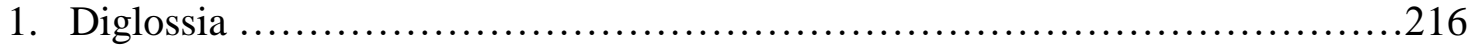

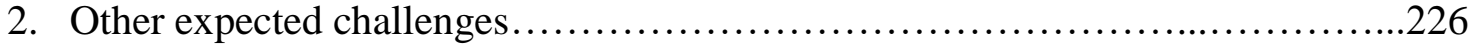

B. Case-by-case analysis

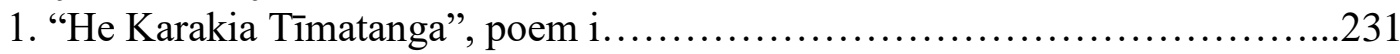

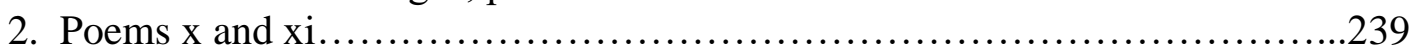

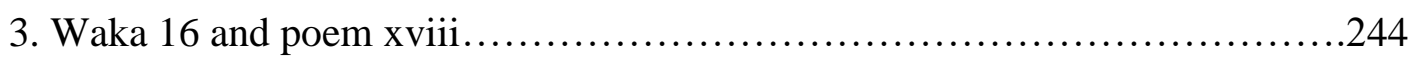

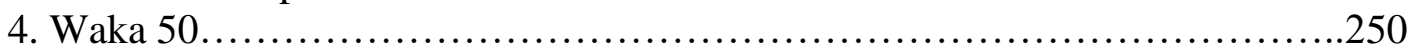

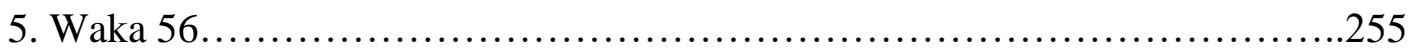

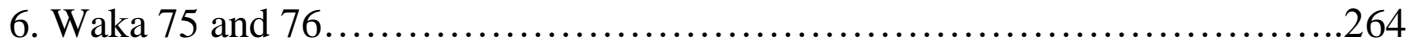

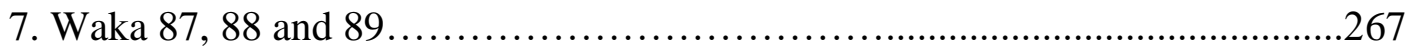

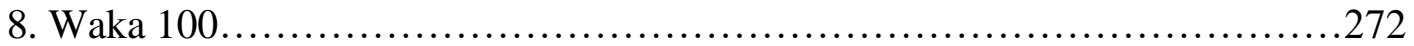

C. Translating Robert Sullivan's Star Waka and the underlying symbolism..........279

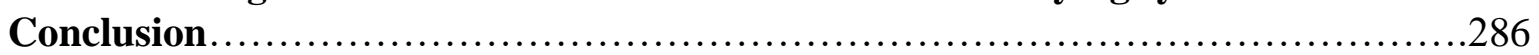

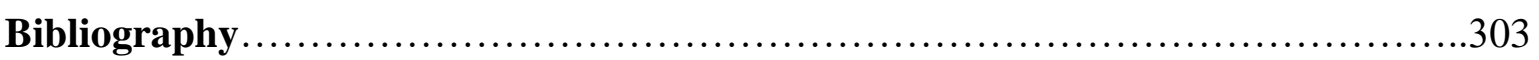




\section{Acknowledgements}

I would like to thank my supervisor Jean Anderson for her constant support and inspiration. I would also like to thank all at the School of Languages and Cultures at Victoria University of Wellington, and in particular my second supervisor Richard Millington, Marco Sonzogni, Yiyan Wang, and Sally Hill for their repeated encouragements, as well as my fellow postgraduate students. Thanks are due to the New Zealand France Friendship Fund and the Faculty of Graduate Research for their support and generosity. A great thank you to Anna Jackson and Robert Sullivan for their time and words. Un grand merci à Matua Greg Cvitanovic, France Grenaudier-Klijn et Keren Chiaroni. Merci à ma famille en France, à ma mère Anne Massé et mon père Dominique Arnault. Thank you to my family in New Zealand, and Kate Martin with aroha.

Cette thèse est dédiée à mes fils Léo, Saul et Rémi Arnault-Martin. 


\section{INTRODUCTION}

\section{Towards a definition of poetry}

In 1992, Yves Bonnefoy, poet and acclaimed translator of poetry, based his definition of poetry on "présence":

Ces moments où une chose, ou quelqu'un, sont là, devant nous, avec soudain en eux ce que je nommerai "de la présence", c'est-à-dire une densité de leur êtrelà, une intensité de leur manifestation, qui transcendent avec une évidence absolue, irréfutable, notre éventuel désir de réduire ces choses ou ces personnes à une pensée de ce qu'elles sont. ${ }^{1}$

To illustrate his concept, Bonnefoy uses examples that pertain to nature, like mountains or trees: "la cime d'une montagne, apparue derrière des arbres, ou un grand chêne isolé, dans une clairière, ou une source dans un fossé ou même, simplement, le bruit, le bruit très faible, de cette source." 2 The presence is absolute because it reflects a sense of belonging to the world: “elle a le caractère d'un absolu, - et c'est un absolu qui rejaillit sur nous-mêmes, qui dans cet instant la regardons." This instant creates an emotion: the enigma of being is now evident, “d'où l'émotion qui nous submerge dans ces instants de présence. Nous étions de l'énigme, nous voici désormais de l'évidence." 3 That instant is dual in its scope, revealing a presence both outside and inside whoever witnesses it.

In other words, experiencing this presence constitutes a first step in the process of poetry, a fundamental first step, carrying both the emotion and a sense of existence - belonging, evidence - however, it is the second step that is crucial. It is expected that a poet will make an attempt at some testimony to the experience of presence. Bonnefoy notes that the first step is not exclusively experienced by poets. Mysticism is a response that derives from the same "instant of presence". What dissociates poets and mystics, then, might be the dynamics of their

\footnotetext{
${ }^{1}$ Bonnefoy, (2004), pp. 65-66.

${ }^{2}$ Ibid, p. 66.

${ }^{3}$ Ibid.
} 
reaction: "les mystiques qui, après l'instant de présence, veulent ne pas retomber dans le discours conceptuel $[\ldots]$ cherchent à se taire aussi radicalement que possible." ${ }^{4}$ Whereas mystics do not want to fall back into conceptual speech and remain silent, poets, on the other hand, aim at recovering the memory of that presence using language.

It is concepts, conveyed by language, that mystics dread: "de ce qui est, avec le concept, on ne retient qu'une image. Dans l'instant de présence, en revanche, dans cet instant de saisissement, l'être ou la chose nommés se sont dégagés de leur image." With concept, one retains only an image. In the instant of presence, however, the person or the thing named have withdrawn from their image. Poets use sounds instead, and the musicality of language with metres, feet, rhymes, rhythm, alliterations, assonances to rediscover the memory of presence against the impact of the concepts carried by language:

C'est ce recours au son pour retrouver sa mémoire de la présence, comme son histoire le montre bien, qui se confond avec celle des mètres, des vers, des rimes, de tout ce qui fait valoir, par rythmes, par musique, le déploiement du son contre celui de la signification. ${ }^{6}$

Based on this dichotomy, not only opposing meaning and sounds but also playing with their effects, poetry is, according to Bonnefoy, an activity set in an ambiguous mode of being: "au total, une activité [...] dans un mode d'être ambigu, que j'appellerai la poésie." ${ }^{, 7}$ He explains the ambiguity by comparing it to a quest both relative and absolute, in fragmentation and in unity, turning the words over against the notions that demand their use, a quest even truer when it searches feverishly than when it finds:

La poésie, c'est chercher plus que trouver, peut-être même est-elle plus vraie quand elle cherche, avec fièvre, que lorsqu'elle trouve [...] il faut donc retourner les mots contre les notions qui en réclament l'emploi. Une conscience duelle, à la fois dans le relatif et dans l'absolu, dans la fragmentation et dans l'unité. Une

\footnotetext{
${ }^{4}$ Ibid.

${ }^{5}$ Ibid.

${ }^{6}$ Ibid, p. 67.

${ }^{7}$ Ibid.
} 
entreprise qui peut paraître contradictoire. Mais c'est une recherche qui peut commencer, tout de même, et même être poussée assez loin. ${ }^{8}$

In these terms, a text may be poetic insofar as it is the potent result of a quest. It is a written testimony, valuable not as a text but as the traces left by the disappointed hope of a movement that has preceded it: “Ce qui n'est pas un texte, mais le mouvement qui a produit celui-ci, et ne vaut que par les traces qu'y a laissées son espérance déçue."9 In her introduction to her 2004 anthology of French poetry, Mary-Ann Caws concludes by conjuring Bonnefoy's idea of hope as an essential constituent in poetry:

I am thinking of Yves Bonnefoy's recent meditation Sous l'horizon $d u$ language, in which he expresses the poetic hope that the ongoing quarrel between the sign and the representation does not irreparably undo the mountains and the cleft between them, through which the poet can see - and lets us see the sky. Today poetry asks as many questions as it always has, about itself and ourselves, and so lets us find, with renewed energy, whatever we might want to become eventually or re-become. ${ }^{10}$

Before moving to a definition of the translation of poetry, we can already perceive the analogical connection between poetry and its translation. Both originate from a pre-existing layer. In Lawrence Venuti's terminology, translation is always "derivative" 11 - with regard to Bonnefoy's definition, so is poetry. Countless poets have been sensitive to that connection. In 1971, Mexican poet Octavio Paz declared that "language itself, in its very essence, is already a translation - first from the non-verbal world, and then, because each sign and each phrase is a translation of another sign, another phrase." ${ }^{12}$ In 1966, New Zealand poet James K. Baxter stated that poetry came to him from: "the attitude of listening [...] to the unheard sound of which poems are translation."13 Both these dynamics are oriented towards pursuing something that has, or is about to, come to pass and are therefore marked by a desire, a genuine hope to

\footnotetext{
${ }^{8}$ Ibid, p. 68.

${ }^{9}$ Ibid.

${ }^{10}$ Caws, (2004), p. xli

${ }^{11}$ Venuti, (1995), p. 18

12 Paz, (1971), p. 154.

${ }^{13}$ Baxter, (1967), p. 124.
} 
recover that something, or "garder un peu de la poussière d'or" 14 as Paul Bensimon once put it.

\section{Poetry translation}

The durability or - to reuse a botanical image from Shelley's "Defence of poetry"15 - the perennation of the relationship between poetry and its translation have a great deal to do with a certain kind of delusion. Just as Bonnefoy identified poetry as a quest, and admitted that it might fail - and be all the more interesting for it - translating poetry typically leads to a similar confession. It has been said repeatedly - and dramatically - that translating poetry is impossible. I refer to a statement attributed to Robert Frost, according to whom poetry is "what gets lost in translation." ${ }^{16}$ Such statements are, paradoxically, numerous among those who criticise poetry translation as well as those who defend it. We may be reminded of Roman Jakobson's statement that: "paronomasia reigns over poetic art, and whether its rule is absolute or limited, poetry by definition is untranslatable." He adds: "only creative transposition is possible" ${ }^{17}$ calling for a redefinition of the endeavour.

To understand the origins of this alleged impossibility, we must make a different distinction, a paradigm which enables the translator to conceive an area of possibility, a field of action. Rather than the two phases of poetry described by Bonnefoy, Ezra Pound, who a decade earlier had experimented extensively with the translation of poetry, ${ }^{18}$ delivered pioneering theories on the matter, ${ }^{19}$ and proposed dividing poetry into three kinds. His reasoning still resonates today

\footnotetext{
${ }^{14}$ Bensimon, (1966), p. 85.

${ }^{15}$ Susan Bassnett compares translating poetry to transplanting a seed on the basis of Shelley's organic metaphor: "The plant must spring again from its seed or it will bear no flower" (Bassnett, 2014, p. 71). Using this image focuses on the decontextualisation and then recontextualisation implied by the verb transplanting - the hands-on, practical connotation supplied by the idea of gardening - and emphasises the prospective nature of poetry conveyed by the word seed.

${ }^{16}$ About "Stopping by Wood in Snowy Evening", Frost writes: "You've often heard me say - perhaps too often - that poetry is what is lost in translation. It is also what is lost in interpretation" (Frost, 1963, p. 18).

${ }^{17}$ Jakobson, (1959), p. 238.

18 Translating classical Chinese poetry (Pound, 1915).

${ }^{19}$ Pound, (1929).
} 
in Bassnett's analysis. In a 2015 article, she comments on Pound's division, and refers to three elements:

Melopoeia: "musicality of words over and above their plain meaning", [...] Phanopoeia: "casting of images upon the visual imagination" [...] and Logopoeia: "the domain of verbal manifestation" including word play, double meaning, puns, allusions, culturally specific words. ${ }^{20}$

Clearly, this offers some resemblances to Bonnefoy's work. Both Pound and Bonnefoy think in terms of images or phanopoeia, and sounds: melopoeia. Pound avoids any idea of presence, and introduces logopoeia. He considers melopoeia to be "practically impossible to translate"21, phanopoeia translatable "almost or wholly intact" while logopoeia "does not translate" without the translator "having determined the original author's state of mind" 22 - Bonnefoy, in contrast, suggests that losses occur irreversibly at all levels. He deplores that "the answer to the question, Can one translate a poem? is of course no. The translator meets too many contradictions that he cannot eliminate; he must make too many sacrifices."23

Here begins what Paul Ricoeur calls "le travail du deuil" 24 - the grieving process - getting over the unavoidable loss of the music of the source-language: melopoeia. It is a vital step in enabling the translator to focus on the work that can be accomplished at the level of phanopoeia and especially logopoeia. Pound's assertion that the rendering of visual images is the easiest part is surprising - or perhaps not, as Bassnett suggests, since he was "a founder of the Imagist movement." 25 Nevertheless his distinction helps to identify what is a field of action for any translator who aims to rediscover a presence suggested in a poem - "to relive the act which both gave rise to it and remains enmeshed in it" 26 - and concomitantly to find what "motivates

\footnotetext{
${ }^{20}$ Bassnett, (2015), p. 160.

${ }^{21}$ Ibid.

${ }^{22}$ Ibid.

${ }^{23}$ Translation by John Alexander and Clive Wilmer. Bonnefoy, (1989), p. 95.

${ }^{24}$ Ricoeur, (2004), p. 20.

${ }^{25}$ Bassnett, (2015), p. 160.

${ }^{26}$ Bonnefoy, (1996), p. 189.
} 
the poem in the first place", 27 "something that today might be termed a functionalist approach." ${ }^{28}$ Consequently, whether in terms of motivation (determining a poet's intentions), or of re-enactment ("reliving the act"), the two perspectives echo each other and lead to the first step of a functionalist approach.

\section{Theoretical framework}

a. Modus operandi

What is the modus operandi of a translator of poetry? Consciously or not, he or she is aiming at being or acting as a poet, as Patrick Hersant recently suggested: "comme mise en abyme du poète." ${ }^{29}$ Antoine Berman's arguably hubristic recommendation that literary translation's aim should be "ne pas seulement rendre l'original [...] mais devenir aussi une œuvre" 30 is also to be taken into consideration. The potential lack of solutions, the probable aporias - rather than failures - are perhaps merely temporary. Paola Masseau, who translated Paul Valéry's Le Cimetière marin into Spanish, appears rightfully bemused by what looks to be a never-ending or "always resumed", 31 endeavour: "pourquoi y a-t-il tant de versions d'un même poème?"32 Valéry, who claimed that "un ouvrage n'est jamais achevé [...] mais abandonné", ${ }^{33}$ has inspired countless attempts from various translators in different languages. Douglas Hofstadter has offered no fewer than 89 different versions of Clement Marot's Le Ton beau de Marot ${ }^{34}$ in English. Hofstadter also offers a botanical image:

In the act of translation, there are always two "frames" - the culture of origin, and that of destination - that inevitably get blended in countless ways as the ideas are transplanted from one soil to the other. Some ideas transplant easily,

\footnotetext{
${ }^{27}$ Bassnett, (1998), p. 65.

${ }^{28}$ Bassnett, (2015), p. 160.

${ }^{29}$ Hersant, (2015), p. 23.

${ }^{30}$ Berman, (1995), p. 42.

${ }^{31}$ Masseau, (2012).

${ }^{32}$ Ibid, p. 13.

${ }^{33}$ Valéry, (1957), p. 1497.

${ }^{34}$ Hofstadter, (1998).
} 
others put up a fight, occasionally ferocious, and some simply will not go at all, no matter how hard they are shoved. ${ }^{35}$

A multiplicity of possibilities and the infinity of the countless ways are raised again, yet as Jean-Charles Vegliante, translator of Eugenio Montale into French, suggests, the repetitive nature - always resumed - of the process, may through refinement, like skilful craftsmen restoring ancient paintings, lead to gain rather than loss: "l'œuvre écrite est là, imposant une existence que la traduction épouse parfaitement et parfois même rehausse - un peu à la façon de certains habiles restaurateurs de tableaux anciens. ${ }^{\text {"36 }}$ Susan Petrilli in her study of Jorge Luis Borges underlines his belief that a work may gain from translation: "Borges maintains that a translation never catches up with the original chronotopically, but may surpass it in terms of artistic rendition." ${ }^{37}$ It is therefore the duality of the result, loss and/or gain, multiple and impossible, achieved and calling for revision, or what Hofstadter calls the "pleasantly pervasive paradoxes of translation" 38 that is the crux of the translation of poetry. What theoretical strategies exist to help with this conundrum?

b. Typologies

Over the years, translation studies experts have offered a great number of typologies of strategies for the translation of poetry. For example, there are the six types of translation introduced by Efim Etkind ${ }^{39}$ - “information”, “interpretation”, “allusion”, “approximation”, "recreation", and "imitation". André Lefevere lists seven strategies ${ }^{40}$ - "phonemic", "literal", "metrical", "verse to prose", "rhymed", "free verse" and "interpretation" translations. Jakobson's three kinds of poetry translation are labelled as: "rewording", "translation proper"

\footnotetext{
${ }^{35}$ Ibid, p. 117.

${ }^{36}$ Vegliante, (1996), p. 196

${ }^{37}$ Petrilli, (2003), p. 517.

${ }^{38}$ Hofstadter, (2009).

${ }^{39}$ Etkind, (1982), pp. 28-29.

${ }^{40}$ Lefevere, (1975), p. 61.
} 
and "transmutation." 41 It is thus possible to create different types of translation for the same source poem: version, adaptation, imitation, transposition... but theorists use these terms with different meanings. As a second step, we could then try to evaluate which works best, that is to say, which would be more faithful ${ }^{42}$ or equivalent ${ }^{43}$ or true, which would represent the source poem with more fidelity. How might we determine this, and how might we assess this?

Such a process would underline a dichotomy that has pervaded the field of literary translation for years. In Anglo-Saxon literature, when Robert Lowell published his Imitations in 1961, he confessed that he had been "reckless with literal meaning" and "had dropped lines, moved lines, moved stanzas, changed images and altered meter and intent." 44 At one end of the spectrum, we have a translation that aims at being a free piece of rewriting, and concentrates on producing an original composition that takes the source poem only "as a ground-plan" (as Don Paterson suggests in his translation of Rainer Maria Rilke) ${ }^{45}$, and at the other, a translation that is literal, word-for-word or a close rendering of the source text, even though it might read strangely.

In French too, translators have pushed the limits of the receivability or readability of a text. Berman, in a similar effort to bring the foreignness of a text into the target culture, refers to Pierre Klossowski's statement that translation is a hybrid process: "l'essence de la traduction est d'être ouverture, dialogue, métissage, décentrement. Elle est mise en rapport, ou elle n'est rien." ${ }^{46}$ Klossowski had created a controversial translation of Virgil's Aeneid in 1964, in a

\footnotetext{
${ }^{41}$ Jakobson, (1959), p. 233.

${ }^{42}$ Georges Mounin (1955) has analysed the notion of "fidélité", fidelity or faithfulness. In 1961, he also used the term "fonctions" (Mounin, 1961, pp. 95-187).

${ }^{43}$ The concept of equivalence was largely dominant in earlier translation theories as Eugene Nida's. It has been questioned recently or as Anthony Pym puts it: "The newer paradigms did not do away with equivalence; they just made it narrower (in Skopos theory) or wider (in Toury's Descriptive Translation Studies)" (Pym, 2010, p. 87). Recently, some scholars have brought back the concept of equivalence as the main constituent in translation theory, (see Cuéllar, 2008).

${ }^{44}$ Lowell, (1961), pp. xi-xii.

${ }^{45}$ Paterson, (2006), p. 73.

${ }^{46}$ Berman, (1984), p. 16. Emphasis in the original.
} 
radical attempt to keep the order of the Latin words, thereby forcing French syntax to obey Latin rules. This inspired Michel Foucault, although not a specialist, to distinguish between two types of translations. Writing in 1966, he suggested a reassessment of the dynamics between readers and writer. Venuti would later translate Foucault's analysis thus:

It is quite necessary to admit that two kinds of translations exist; they do not have the same function or the same nature. In one, something (meaning, aesthetic value) must remain identical, and it is given passage into another language; these translations are good when they go "from like to same". [...] And then there are translations that hurl one language against another [...] taking the original text for a projectile and treating the translating language like a target. Their task is not to lead a meaning back to itself or anywhere else; but to use the translated language to derail the translating language. ${ }^{47}$

It is Venuti who perhaps most famously demonstrated the need to stress the foreign aspect of a text when in 1995 he denounced the process of domestication that had largely dominated in translated texts. In France, following Antoine Berman, Jean-René Ladmiral had in 1983 made a similar distinction between "sourciers" and "ciblistes" 48 and Venuti's interest in the issue had also led him to translate Berman's 1984 L'Epreuve de l'étranger. ${ }^{49}$

c. Domestication and foreignisation

What Venuti means by domestication is the tendency in translation, sometimes unconscious, to aim for fluency, "when the absence of any linguistic or stylistic peculiarities makes (a text) seem transparent." 50 This results in brushing off any signs of unfamiliarity of a text. He established a distinction between domesticating, "an ethnocentric reduction of the foreign text to target-language cultural values, bringing the author back home" and a foreignising method exercising "an ethno-deviant pressure on those values to register the linguistic and cultural difference of the foreign text, sending the reader abroad." 51

\footnotetext{
47 Venuti, (2000), p. 285.

${ }^{48}$ Ladmiral, (2015).

${ }^{49}$ Venuti, (2000), pp. 284-297.

${ }^{50}$ Venuti, (1995), p. 1.

${ }^{51}$ Ibid, p. 20.
} 
There are several implications in this distinction. First, Venuti emphasises that "a reader of a translation can never experience it with a response that is equivalent or even comparable to the response with which the source-language reader experiences the source text." ${ }^{, 52}$ For example, a poet might refer to specific cultural or natural traits from the source culture, mentioning a unique type of bird living in the area, a historical event, both constituent of the logopoeia, perhaps to assert or celebrate that culture, creating familiarity for source culture readers. The rendering of such a trait cannot but create strangeness or exoticism in the target culture. Another implication that follows is that foreignness "demands cultural innovation." 53 This is another field of action altogether for the translator's creativity and the recent creative turn ${ }^{54}$ observed in translation studies could be said to have prolonged Venuti's project. Finally, Venuti argues for the reversal of the domestication that has prevailed. He asks:

What would happen if a translator tried to redirect the process of domestication by choosing foreign texts that deviated from transparent discourse and by translating them so as to signal their linguistic and cultural differences? ${ }^{55}$

Venuti's radical positioning conveys an idea of ethics and justice, a kind of restorative justice, in which the translator plays a significant part. As he suggests, translators should try to "reproduce in translation whatever features of the foreign text abuse or resist dominant cultural values in the source language." 56 Venuti has applied his reasoning to the field of poetry translation. $^{57}$

\section{d. A pragmatic approach}

However, this approach which corresponds to Venuti's foreignising stance is, in the case of my project, not always adequate, and at times perhaps irrelevant. I aim to demonstrate that

\footnotetext{
52 Venuti, (2011), p. 235.

${ }^{53}$ Ibid, p. 246.

${ }^{54}$ Eugenia Loffredo and Manuela Perteghella in One Poem in Search of a Translator. Rewriting "Les Fenêtres" by Apollinaire (2009) for instance.

55 Venuti, (1995), p. 41.

${ }^{56}$ Ibid, p. 48. Venuti reuses Philip E. Lewis’ idea of “abusive translation” (Venuti, 2000, pp. 268-273).

${ }^{57}$ Venuti's view on poetry translation is best expressed in "The Poet's Translation or an Ethics of Translation" (2011), in which he advocates for an interpretative practice of translation.
} 
translating New Zealand poetry into French needs not systematic or dogmatic thinking but rather pragmatic thinking to find the right balance between a target culture oriented approach and a source culture oriented approach on a case-by-case basis. Concomitantly, my goal suggests a shift in the dynamics of relationships between reader and writer, where the translator plays a role of mediator identifying and transferring the intentions of the source writer loyally, as described by Nord:

The responsibility that translators have toward their partners is what I call "loyalty". [...] Translators, in their role as mediators between two cultures, have a special responsibility with regard to their partners, i.e. the source-text author, the client or commissioner of the translation, and the target-text receivers. ${ }^{58}$

According to Nord, loyalty does not mean taking sides systematically. She points out that:

Acting loyally with regard to the communication partners in a specific translation task and with regard to one's own ethical principles does not automatically mean that the translator gives target-culture norms priority over source-culture norms. ${ }^{59}$

Some theorists have claimed that functionalism privileges the target culture, in particular concerning a first generation of functionalists (Reiss, Vermeer), and Gideon Toury suggests that "the first formulations of the Skopostheorie by Vermeer almost coincided with the beginnings of my own switch to target-orientedness." 60 In an article published in 1978, Vermeer introduced the Greek word skopos - purpose or aim - to describe the aim of a translation, which should direct the translator's decisions. He suggested that translators should focus on the target culture and language in order to illustrate the source text and particularly its function in the source culture. Nord later translated Vermeer's precepts into English:

Each text is produced for a given purpose and should serve this purpose. The Skopos rule thus reads as follows: translate/interpret/speak/write in a way that enables your text/translation to function in the situation it is used and with the people who want to use it and precisely in the way they want it to function. ${ }^{61}$

\footnotetext{
${ }^{58}$ Nord, (2006), p. 33.

${ }^{59}$ Ibid, p. 40.

60 Toury, (2012), p. 25.

${ }^{61}$ Nord, (1997), p. 89.
} 
Nord's own take on skopos theory, however, does not prioritise either target or source cultures.

In her 2005 study, she opposes option A as a target culture oriented stance to option B as a source culture oriented stance:

Just think of:

- Cicero, who distinguished between translating "like a rhetorician" ("ut orator", option A) or "like a translator" ("ut interpres", option B) (cf. Cicero, 46 B.C.),

- Martin Luther, who made a distinction between "germanising" (option A) and "translating" (option B) (cf. Luther, 1530),

- Schleiermacher, who spoke about "taking the text to the reader" (option A) or "taking the reader to the text" (option B) (cf. Schleiermacher, 1838),

- Eugene A. Nida's "functional" or "dynamic equivalence" (option A) vs. "formal' equivalence" (option B) (cf. Nida, 1964), or

- Lawrence Venuti's “domesticating” (option A) vs. "foreignising” (option B) translation (Venuti, 1995), to mention just a few well-known names.

In my terminology, I distinguish between "documentary" and "instrumental" translation (cf. Nord, 1989 and later). Unlike the other authors mentioned above, I do not propose that one of the two types is generally "better" or "more appropriate" than the other. ${ }^{62}$

Although these concepts are not identical, this list could also include James Holmes' “analogical translation and organic translation"63 (1971), Anthony Pym’s “observational or participative reception" (2004) or Juliane House's "covert" and "overt" translations (1977):

In an overt translation the ST is tied in a specific manner to the source language community and culture. [...] In overt translation, the ST as a piece of work with a certain status in the source language community has to remain as intact as possible. [...] A covert translation is a translation which enjoys or enjoyed the status of an original ST in the target culture. The translation is covert because it is not marked pragmatically as a TT of an ST but may, conceivably, have been created in its own right. ${ }^{64}$

\footnotetext{
${ }^{62}$ Nord, (2005), pp. 26-27.

63 "Analogical form, the prevailing method of poetry translation in the West from the Renaissance to the first decades of the twentieth century 'sought a form that filled a parallel function within the poetic tradition of the target language', which has mostly meant rendering rhymed, metrical STs. [...] Conversely, using the strategy of organic form, the dominant methodology since the advent of free verse and, more surely, the end of World War II, the translator 'starts from the semantic material, allowing it to take on its own unique poetic shape at the translation develops"” (Racz, 2013, p. 47).

${ }^{64}$ House, (1977), pp. 106-107.
} 
As proposed by Nord, on the basis of an assessment of the text's functions, the translator should make pragmatic choices between the two apparently opposing possibilities outlined in translation studies over the years: "functionalism does not a priori advocate instrumental instead of documentary translations. Yet it can widen narrow visions, showing the possibility of a greater variety of literary translations. $" 65$

Practically speaking, loyalty may appear to some as an alibi or an excuse for translators to rid themselves of any formal constraints that seem too challenging in linguistic terms, turning translators into "mercenary experts, able to fight under the flag of any purpose able to pay them" ${ }^{\prime 66}$ but such criticism has been answered. Nord replies that:

On the contrary, the functionalist approach makes a point of regarding translators as responsible agents in an interaction between equals, negotiating, if necessary, the conditions of cultural mediation. ${ }^{67}$

This negotiating and flexible stance on the two well-examined options makes me favour Nord's theoretical apparatus for my project, as I find that, depending on the skopos attributed to the text, one or the other option is preferable to achieve a functional translation, and at times, one and the other option might be possible - as will be shown. This dual goal is not new in poetry translation. Francis Jones remarks that:

One example is the commonly-expressed double goal among recent English language translators that a translation should reflect the meaning of the source poem, but should also work like "an original text" in the receptor language. ${ }^{68}$

This is also proposed by Nord:

The translated text should be an independent, parallel work of art or a kind of metamorphosis of the original, able to live on in another culture. Further, the translation should reproduce the literary structure of the original, informing the target readers about the genre, artistic value and linguistic beauty of the original,

\footnotetext{
${ }^{65}$ Nord, (1997), p. 103

${ }^{66}$ Pym, (1996), p. 338.

${ }^{67}$ Nord, (2006), p. 40.

${ }^{68}$ Jones, (2011), p. 10.
} 
enriching the target language and making the target readers understand why the original text was worth translating. ${ }^{69}$

This flexible approach inspires me to aim for an ideal of balance ${ }^{70}$ in my translation practice.

e. Functionalism

There have been few projects applying Nord's conception of skopos theory in literature, as Nord herself admitted:

So far there are few studies in functionalism in literary translation. An interesting experiment was carried out by the Brazilian scholar and literary translator Mauricio Mendonca Cardozo, who produced two different translations of Theodor Storm's short novel Der Schimmelreiter, a documentary and an instrumental one, which were published together in a slipcase. The documentary translation is source-text oriented, whereas the other one transfers the story from its North German habitat into the Brazilian sertao. Both versions are called "translations", and the idea was to put the limits of functional translation to a stress test. ${ }^{71}$

The deliberate application of skopos theory to the field of poetry translation may surprise some.

It has not been done before. The origins of functionalism, as is well known, are in the context of a commercial service and, as Andrew Chesterman has rightfully pointed out: "for a client." In 2001, he asks: "how might (functionalism) be applied to a freelance translator initiating the translation of an avant-garde Italian poet?"72 He denounces the ethical danger of compartmentalisation amongst translation models and their application, and questions how to justify choices: "on what grounds can one simply say: choose this model when it seems appropriate, and that model at other times? Would such a solution itself be ethical?",73

\footnotetext{
${ }^{69}$ Nord, (1997), p. 89.

${ }^{70}$ Solange Hibbs-Lissorgues writes that: 'C'est dans ce mouvement d'oscillation permanent que se situe la traduction, tâche infinie qui tente l'équilibre entre ce qui est intention de l'auteur et effet produit par le traducteur. Car la difficulté qu'il y a dans toute traduction est de bien tenir compte du rapport de l'auteur à sa langue et aussi de l'esprit de la langue étrangère" (Hibbs-Lissorgues, 2015, p. 220).

${ }^{71}$ Nord, (2010), p. 125.

${ }^{72}$ Chesterman, (2001), p. 140.

${ }^{73}$ Ibid, p. 142.
} 
As a translation model, the scope of functionalism was not intended to be restricted to any context or genre in particular. ${ }^{74}$ It is precisely its consideration of the cultural specificity of texts that turns it into a model that is anti-universalist and not radically prescriptive:

Since it obliges the translator to take account of the difference between culturespecific concepts of translation prevailing in the two cultures [...] it turns Skopostheorie into an anti-universalist model; and since it induces the translator to respect the sender's individual communicative intentions, [...] it reduces the prescriptiveness of "radical" functionalism. ${ }^{75}$

Problems arising from the translation of cultural differences in literature, the domain of logopoeia, also demonstrate the pertinence of skopos theory. For any literature that deals with cultural specificities, it takes into account the "functional markers and their cultural specificity." 76 The functionalist approach was chosen by Elisabeth Lavault-Olléon as a strategy in her work on Sunset Song by Lewis Grassic Gibbon, because it enabled her to tackle issues of dialect and what she calls Scottishness - "Scotticité" - a "unique Scottish poetic prose."77 Lavault-Olléon maintains that Grassic Gibbon intended his book "to be a manifesto for the literary value of Scots. ${ }^{, 78}$ In cases where it can be established that a writer is intending to assert a cultural identity, functionalism can embrace that defining trait by highlighting it. Nord stipulates that if a text is to:

show features of "strangeness" (which I call a documentary translation), the purpose would be precisely not to resemble any text existing in the target-culture repertoire, which makes processing more difficult (and maybe also more meaningful) for the readers. ${ }^{79}$

\footnotetext{
${ }^{74}$ See "Functionalism in Literary Translation", in Nord, (1997), p. 80.

${ }^{75}$ Nord, (2006), p. 34.

${ }^{76}$ Ibid, p. 32.

${ }^{77}$ Lavault-Olléon, (2006), p. 504.

${ }^{78}$ Ibid.

${ }^{79}$ Nord, (2006), p. 39.
} 
Coincidentally this might disrupt reading habits in the receiving culture. Whether or not to preserve this strangeness is a major feature of the debate on the translation of poetry, as already analysed by previous functionalists like Vermeer:

One will have to decide before translating a text whether it is to be "adapted" (to a certain extent), i.e. "assimilated", to target-culture conditions, or whether it is meant to display and perhaps even stress its "foreign" aspect. (There are other possibilities still with which I shall not deal here.) One will have to make a choice. In both cases, the text will be "different" from what it was in its "normal" source culture situation, and its "effect" will be different. ${ }^{80}$

After assessing the intentions of the source writer, the poetry translator may decide to stress or underplay the foreign aspect of a text, but regardless, Vermeer (like Venuti) maintains that the experience of the target culture readers will inevitably remain different from that of the source culture readers.

\section{f. Skopos}

Following Vermeer and Reiss, Nord also proposed in 1997 that translators should aim to identify a skopos for their translation, "the overall communicative purpose the target text is supposed to achieve in the target culture. ${ }^{\prime 81}$ How to determine this? If defining the skopos of the translation depends on the translator's reading of the source text, the subjectivity of interpretation could lead to a dead-end. As Nord explains:

We all have had the experience that different readers, depending on their previous knowledge and attitudes, get quite different messages out of one and the same text, so that sometimes we wonder whether they have really been reading the same text. ${ }^{82}$

However, Nord asserts that: "It is the receiver who decides whether (and how) a text 'functions' (for her/him, in this situation)." ${ }^{83}$ Therefore, one of the translator's tasks for his or her skopos is to follow a deductive and prospective process. When trying to render logopoeia for instance,

\footnotetext{
${ }^{80}$ Vermeer, (1996), p. 39.

${ }^{81}$ Nord, (1997), p. 142.

${ }^{82}$ Ibid, p. 132.

${ }^{83}$ Nord, (2006), p. 41.
} 
the translator should try to determine what goal the logopoeia is intended to achieve in the first place.

A New Zealand poetry expert and a poet himself, Harry Ricketts suggests that:

Of course, poets usually do have intentions of some sort when they write. These may be to do with subject matter, form, tone, sound, the shape of the poem on the page and other considerations [...]. And understanding or at least being aware of these intentions may help to make the poem more accessible to the reader. ${ }^{84}$

These intentions might be thought of as the writer's creative will, as Reiss puts it:

A literary translation orients itself toward the particular character of the work of art, taking as its guiding principle the author's creative will. Lexis, syntax, style and structure are manipulated in such a way that they bring about in the target language an aesthetic effect which is analogous to the expressive individual character of the source text. ${ }^{85}$

If an awareness of the poet's intentions is key for the translator, what means exist to access these? Nord does not do away with the concept of interpretation (and subjectivity) as she highlights that "what is actually translated is not the sender's intention but the translator's interpretation of the sender's intention." 86 This is the starting point for negotiations that occur during the translation process. As Sergio Bolaños Cuéllar states of Rainer Kohlmayer's work:

The translator becomes a kind of "detective who collects evidence, interrogates witnesses, places himself mimetically-hermeneutically in the author's role and formulates a translational hypothesis whose value or truth content could reflect the optimal historical and individual possibilities for solving a problem." 87

This mimetic-hermeneutic stance was perceived by Bonnefoy who suggested that "plus une traduction interprète, ce qui est le cas si elle est explicite, et plus elle en devient le reflet de qui l'a tentée, avec toutes ses différences", ${ }^{88}$ and Nord states that a subjective and interpretative stance might even be a factor of success:

\footnotetext{
${ }^{84}$ Ricketts, (2010), p. 14

${ }^{85}$ In Nord, (1997), p. 89.

${ }^{86}$ Nord, (1997), p. 85. Italics in the original.

${ }^{87}$ Cuéllar, (2008), p. 61.

${ }^{88}$ Bonnefoy, (1998), p. 250.
} 
The complex process of text comprehension and interpretation inevitably leads to different results by different translators. To my mind, this is not at all a bad thing. Since different readers will interpret the original differently, translators should have the right to their interpretation of the text (after thorough investigation, of course). It is interesting to observe that, in history, translations based on the most personal interpretations are often the ones that become most famous. ${ }^{89}$

Nord's confirmation of the relevance of interpretation opens the way for the translator's creativity, something which I also advocate.

Based on an interpretation of the writer's intentions, the translator will then define a skopos for his or her translation, which may or may not be identical to the source poem's skopos. The idea of "functional variance" or "heterofunctional translation" allows flexibility: "Instrumental translations may be intended to achieve the same function as the source text ('equifunctional translation') or a function that is different from that of the source text ('heterofunctional translation'). ${ }^{90}$ Even if the source poem's skopos and the translation's skopos are identical, the interpretations of the translation given by readers in the target culture will always potentially be different than in the source culture. As James Holmes explains:

The poem intended as a translation of a poem into another language, which as one type of meta-literature we may call a "metapoem", is from this point of view a fundamentally different kind of object from the poem from which it derives. $[\ldots]$ The relation of the metapoem to the original poem is as that of the original poem to "reality". 91

Holmes' metapoem suggests differences and yet also parallels between a poem, which derives from reality, and a metapoem - echoing Bonnefoy's translation of experience earlier on.

Overall, these theoretical considerations help to resolve issues raised by the alleged impossibility of the task (translating poetry in general), and the positioning of the translator (target or source culture approach) by shifting the focus from a text-centered approach (fidelity)

\footnotetext{
${ }^{89}$ Nord, (1997), pp. 89-90.

${ }^{90}$ Ibid, p. 49.

${ }^{91}$ Holmes, (1988), p. 10.
} 
to a flexible people-centered approach (loyalty), and asserting the role of investigation and interpretation in defining the skopos and justifying choices. What challenges can now be expected with regard to the characteristics of New Zealand poetry and French poetry, in terms of traditions, practices and perspectives? 


\section{Translating New Zealand poetry}

In 1978, Itamar Even-Zohar looked at the conditions enabling literatures to come closer:

Under stable conditions items lacking in a target literature may remain untransferable if the state of the poly system does not allow innovations. But the process of opening the system gradually brings certain literatures closer and in the longer run enables a situation where the postulates of (translational) adequacy and the realities of equivalence may overlap to a relatively high degree. ${ }^{92}$

By poly system Even-Zohar means all cultural and social dynamics, within which a country's literature is constituted, comprising non-translated and translated works. Using this terminology, the status of New Zealand literature in France might be described as peripheral and innovatory. There are already pioneering French translations of New Zealand literary works that have paved the way, by translators Jean Anderson, France Grenaudier-Klijn, MarieLaure Vuaille-Barcan or Anne Magnan-Park (Patricia Grace), Anthony Axelrad (C. K. Stead), Jean-Pierre Durix (Albert Wendt), Pierre Furlan (Alan Duff), Anne Mounic (Vincent O’Sullivan), Mireille Vignol (Witi Ihimaera), Dominique Goy-Blanquet (Fiona Kidman) or Françoise Robert and Dominique Mainard (Janet Frame).

Compared to the number of poetry books published in New Zealand each year, very little New Zealand poetry translated into French has been published so far. In 2005, three poems by Jenny Bornholdt ${ }^{93}$ and four by Vincent O'Sullivan ${ }^{94}$ appeared in the journal Voix d'Encre. The next year, as 12 New Zealand writers - including Bornholdt, O’Sullivan, Kidman, and Wendt toured France as part of the festival Les Belles Etrangères, an anthology Douze écrivains néozélandais, Les Belles Étrangères ${ }^{95}$ was released with Bornholdt and O’Sullivan's poetry in translation by Anne Mounic. The same year, half an issue of the periodical Europe was devoted to New Zealand writing - including poetry by Hone Tuwhare, James K. Baxter, Allen Curnow,

\footnotetext{
92 Even-Zohar, (2000), p. 197.

${ }^{93}$ Bornholdt, (2005), pp. 53-57.

${ }^{94}$ O’Sullivan, (2005), pp. 23-26.

${ }^{95}$ Furlan, (2006).
} 
but also Gregory O’Brien, Cilla McQueen, and Tusiata Avia - in translations by Anderson, Françoise Abrial and Furlan. ${ }^{96}$ Also in 2006, O’Sullivan's poems selection Cette voûte de si pur respir ${ }^{97}$ in translation by Mounic was published, and Andrew Johnston's project "Le Langage de l'avenir", a bilingual anthology of New Zealand poetry, combining the efforts of French and New Zealand poets and translators was undertaken but unfortunately abandoned. ${ }^{98}$ What are the specificities of New Zealand poetry ${ }^{99}$ and in what way are they challenging for a translation into French?

There are at least three characteristics which may account for the "New Zealandness" of a poem: history, geography and terminology. The concept is quite fluid as Paula Green explains: "the relationship of the poem to concepts of New Zealand and to the significance of New Zealand identity clearly means different things to different poets." ${ }^{100}$ Rather than being separate entities, history, geography and terminology are closely connected: however, I treat them separately here for convenience.

\section{a. Location}

In the introduction to The Penguin Book of New Zealand Verse (1985), Ian Wedde and Harvey McQueen state:

The development of poetry in English in New Zealand is coeval with the developing growth of the language into its location, to the point where English as an international language can be felt to be original where it is. ${ }^{101}$

\footnotetext{
${ }^{96}$ Furlan, (2006), pp. 1-191.

${ }^{97}$ O’Sullivan, (2006).

${ }^{98}$ In the opposite direction, O'Brien took part in the translation of Charles Juliet's poems into English published in New Zealand, (Juliet, 2004). The year after, Anderson translated three of Juliet's poems in Poetry NZ (Juliet, 2005).

${ }^{99}$ My definition is broad to avoid what Johnston calls "a guided tour of a hastily-erected artificial structure called "New Zealand poetry"' (Johnston, 1992, p. 1). This is similar to Iain Sharp's on the webpage "New Zealand Best 2001 poems": "The intention of this site is to present poems by New Zealanders, wherever their imagination is located, rather than poems about New Zealand. Not that we're in the business of inspecting birth certificates, citizenship papers and passports to determine who does or doesn't qualify as a New Zealander. A steady association with the country is sufficient" (Sharp, 2002).

${ }^{100}$ Ricketts, (2010), p. 493.

101 Wedde, (1985), p. 23.
} 
This is in line with the earlier 1960 edition, in which Curnow proclaimed:

Reality must be local and special at the point where we pick up the traces: as manifold as the signs we follow and the routes we take. Whatever is true vision belongs, here, uniquely to the islands of New Zealand. The best of our verse is marked or moulded everywhere by peculiar pressures - pressures arising from the isolation of the country, its physical character $[\ldots] .{ }^{102}$

In his 2005 anthology The Nature of Things. Poems from the New Zealand Landscape, James

Brown suggests that: "if the landscape is such a pervading presence in the collective New Zealand psyche, if not collective New Zealand life, it should come as no surprise to find it equally prominent in our art."103 In their Anthology of New Zealand Literature (2012), Jane Stafford and Mark Williams point out that: "if there is a focus throughout the two hundred years covered in this volume, it is the way in which writers have fashioned their surroundings into imaginative language."104 The connection between language and landscape is evident. Ricketts, Siobhan Harvey and James Norcliffe write in their 2014 anthology: "running through many of these poems is a powerful sense of place, of a distinctive New Zealand geography; and also, an acknowledgement of how our poets have engaged and continue to engage with the land." 105 The pervasiveness of the locale in New Zealand life is manifest for insiders and outsiders, so much so that the French translator of The Whale Rider ${ }^{106}$ Francine Tolron concludes in an essay that:

Si l'on peut trouver un élément unificateur, c'est du côté de l'environnement qu'il faut le chercher. En dépit des formidables changements apportés au milieu écologique, la Nouvelle-Zélande a traversé son histoire cramponnée à sa nature qui continue d'offrir un point d'ancrage aux deux ethnies. [...] Elle écarte le scepticisme et l'inquiétude et rassure le Kiwi qui y voit une raison solide de croire que, quoi qu'il en soit, fort d'un tel atout, il ne peut se plaindre de son sort. ${ }^{107}$

\footnotetext{
102 Curnow, (1960), p. 17.

${ }^{103}$ Brown, (2005), p. 10.

${ }^{104}$ Stafford, (2012), p. 12.

105 Ricketts, (2014), p. 14.

106 Ihimaera, (2003).

107 Tolron, (2000), p. 281
} 
The relationship to the land, whether considered from a Romantic perspective as a mirror for the psyche ${ }^{108}$ or as a performative element in language (logopoeia), or as part of the background either physical or symbolic (phanopoeia), is found in a large number of New Zealand poems: from Curnow's "Not I, some child born in a marvellous year, / Will learn the trick of standing upright here"109 to Baxter, for whom the land was both "matrix and destroyer",110 from Cilla McQueen's "Living here"111 to David Eggleton's "Painting Mount Taranaki",112 Manhire's "Milky Way Bar"113 - "I live at the edge of the universe, / like everybody else" - or O'Brien's Location of the Least Person. ${ }^{114}$ The importance of the topos in New Zealand poetry poses two main translation issues.

First, on a level of representation, the translator is to suggest a geography that is so specific that it may be absent in the target culture or overloaded with false preconceptions. Think of the South Island's sounds, in Johnston's “The Sounds", which have no equivalent in the geography of France. Translating as "fjords" would suggest Scandinavia. Think also of the falsity of suggestion that "la brousse" entails (African connotation) when considering New Zealand's endemic bush, not "la garrigue" or "le maquis" either. Bush is regularly borrowed by translators. ${ }^{115}$ We might also consider a landscape saturated with clichés, based on preconceived ideas - the popular international "trinity": Lord of the Rings, sheep farming, and antipodean life or "la vie sous les tropiques.""116

\footnotetext{
108 Allen Curnow writes: "It is a tormenting folly to search ourselves, as I did once on the Auckland west coast, for Wordsworth's mood" (Curnow, 1945, “Introduction”, p. 12).

${ }^{109}$ Ibid, p. 28.

${ }^{110}$ Baxter, (2010), pp. 18-19.

${ }^{111}$ Bornholdt, (1997), p. 79.

112 Ibid, p. 75.

${ }^{113}$ Manhire, (1991), p. 19.

${ }^{114}$ O’Brien, (1987).

115 Bush used to be translated as "brousse", by Marthe Duproix translating Katherine Mansfield's At the Bay. (Mansfield, 1929, p. 7). Jean Anderson and Nadine Ribault opt for borrowing bush in Le Lagon, (Frame, 2006, p. 10). Pierre Furlan chooses "brousse" in his translation of O'Brien's "Des pianos dans la brousse", (Furlan, 2006, p. 64).

116 The cliché of the tropical paradise - palm trees, white sand beaches.
} 
Second, this leads to the level of logopoeia stimulating the visual imagination with phanopoeia; an innovative play on language inspired by the topos, in which a process of territorialisation or land-marking ${ }^{117}$ occurs. This is key, for instance, to Curnow's "The Skeleton of the Great Moa in the Canterbury Museum, Christchurch", where the word antipodes - etymologically "opposed feet" - is taken literally, serving as a backbone to the text. While this concept might give space to the translator's creativity, it is also challenging. Poetry, in contrast to prose, does not cope well with much glossing and notes. After all, phanopoeia is meant to strike the imagination, rather than restrict it with indications of precise localisation.

\section{b. History}

As a reflection of the evolution of language, poetry has become a constituent in the ongoing making of New Zealand cultural identity and history. As O'Brien, Bornholdt and Williams describe it:

The poems are not simply the record of their historical occasions, part of the tale of the nation's unfolding history. [...] [Poetry] is reflecting on the history not only of settlement and adjustment but also on the terms in which poetry has sought to register and be part of that process. ${ }^{118}$

New Zealand poetry is quintessentially bicultural, and has developed to vary greatly from British poetry. From the ornamental nature of 1920s poetry, collected in Quentin Pope's 1930 anthology Kowhai Gold, "which differed from colonial versifying chiefly by the addition of decorative local flora" ${ }^{119}$ to the experiments of Baxter $^{120}$ or his contemporary Tuwhare ${ }^{121}$ in the late $1960 \mathrm{~s}$, and the progressive incursion of Māori words into works published in New Zealand, it is a movement first in the shadow of the British canon and later asserting itself more

\footnotetext{
${ }^{117}$ I refer to Wedde's reading of Baxter's poetry: “[Baxter] has done more than anything else in our literature to bring into balance, for us and in us, that precariously alert yet instinctive sense of internal relation between who and where, between language and location: the culture of what is" (Wedde, 1985, p. 44).

118 Bornholdt, (1997), p. xxi.

119 Ibid, p. xxiv.

120 "Baxter devoted the final years of his life to benefiting from the lessons a Māori community can impart, and his poetry reflected this" (Ricketts, 2010, p. 460).

${ }^{121}$ First Māori poet published in English and "mentor to many poets who have followed" (Ibid, p. 459).
} 
and more as different. For Manhire, it is "a growth from dependence on a world of models to a state of authentic self-possession, a self-possession which accepts but is not bound to models." $" 122$

The wide range of Pākehā and Māori references brings issues for the translation, in terms of intertextuality, post-colonial ethics and language conventions. Colloquialisms, kiwi-isms and Māori words nowadays common in New Zealand English give the poetry a unique flavour. The novelty created by an unprecedented combination of words might be the most conspicuous feature of a poem. This may function as a marker of familiarity among readers, or be read as a statement of identity from the writer. It might at times serve political or socially unifying ambitions or create tension. ${ }^{123}$ In translation, French readers might not grasp the diversity of effects caused for source readers by these allusions. The historical value of some terms and the evolution of language they reflect (dated slang, Māori words spelt differently) might not be perceived at all in translation, particularly with only a few poems.

How might the translator take into account the historical background of New Zealand poetry? The translator might decide to borrow Māori words. Beyond the poetic virtues of a fresh mix of sounds (melopoeia) and suggestions, this leads to clashing issues of norms in language. The latest French spelling rules dictate that the plural of words borrowed from foreign languages should observe the same pattern as other French words, hence adding an -s: "Les mots empruntés forment leur pluriel de la même manière que les mots français et sont accentués

\footnotetext{
${ }^{122}$ Manhire, (2000), p. 212.

${ }^{123}$ The biculturalism promoted by Baxter or the later Glenn Colquhoun who use Māori words and perspectives, has led to debate, as Green notes: "A handful of Pākehā express a strong inclination to draw upon their experiences of Māori culture, language, mythology and relations in their poetry. Whether or not this is a positive move is controversial, yet it is an issue that keeps evolving over time in terms of the questions asked and the responses given" (in Ricketts, 2010, p. 460).
} 
conformément aux règles qui s'appliquent aux mots français." ${ }^{124}$ In Te Reo, words do not bear an "-s" in the plural. Laurie Bauer observes that:

A strong prescriptive tradition of deploring the marking of Māori nouns in the plural has arisen. While this prescriptive force is ignored by many, of both Māori and non-Māori ethnicity, it means that Māori nouns are frequently heard with zero plurals in the public domain. ${ }^{125}$

The refusal to add an "-s" is, Bauer adds: "one small matter about which some people clearly feel extremely strongly." 126 New Zealand news media do not use "-s" for Māori nouns in the plural. Borrowing words leads to choices carrying social considerations. Ethically, this demands respect for the voices of populations involved.

I advocate for a non-italicised, invariable and macronised use of borrowed Māori words. Nonitalicised because I take into consideration Berman's remark about exoticisation and that italics tend to graphically isolate the borrowed words in the text: "Traditionnellement, il existe une manière de conserver les vernaculaires en les exotisant. L'exotisation prend deux formes. D'abord par un procédé typographique (les italiques), on isole ce qui, dans l'original, ne l'est pas." ${ }^{27}$ Robert Sullivan has summed it up beautifully in "Some Definitions and a Note on Orthography":
It is still very
difficult to procure word processors
that have a set of macronised vowels and subeditors who do not pluralise Māori loan words although most have ceased italicising them to give a sense of inclusion ${ }^{128}$

Instead of applying the French gender, "la waka" (as in "la pirogue") for instance, I use the masculine invariably because of the great polysemy of nouns in Māori. "Waka" may refer to

\footnotetext{
124 orthographe-recommandee.info/enseignement/regles.pdf. Accessed 31 Aug. 2016.

${ }^{125}$ Bauer, (2007), p. 9.

${ }^{126}$ Ibid, p. 10

${ }^{127}$ Berman, (1999), p. 64.

${ }^{128}$ Sullivan, (1999), p. 21.
} 
"la pirogue", "le bateau", "le moyen de transport", "la voiture", "l'avion" or "le vaisseau". In

"Les Dévoiements de la licence créatrice en traduction”, Stefanink and Balacescu write:

Cette licence créatrice a pu aboutir à des utilisations de la traduction à des fins politiques ou idéologiques, comme celle de la [...] "traduction féministe", qui, elle, veut rétablir les injustices commises envers les femmes et "déclare la guerre au vieux concept binaire de la bi-polarisation entre le texte source et la traduction" (Bassnett 1991: 66) pour la remplacer par une créativité au service d'une idéologie. [...] Cette créativité va jusqu'à vouloir re-sexuer" (20) le langage (ex: orthographe "auther" pour "author" lorsqu'il s'agit d'une femme écrivain, traduction de "aube" par "dawn" mais reprise de "dawn" par le pronom personnel "she" etc.) $)^{129}$

I have reservations regarding the word "dévoiements", and disagree with their further statement: "Ces conceptions de la créativité ne sont guère compatibles avec la déontologie du traducteur, qui est redevable au texte source pour le message à communiquer." ${ }^{130}$ For one, I do not consider that translators owe anything to a text - but rather should be loyal to the people involved $^{131}$ - and Stefanink and Balacescu's judgement based on deontology seems extreme. However, they describe a trend, which my choice regarding invariable Māori nouns does contradict.

Some translators tend to over-accumulate loan words. This is observed by Marie-Laure Vuaille-Barcan who explains that: "la multiplication de termes étrangers et de notes en bas de page peut finir par altérer le plaisir de lecture et réduire dangereusement le texte à son aspect documentaire et exotique." ${ }^{132}$ She illustrates this with an excerpt from Jean-Paul Delamotte's translation of Henry Lawson's work:

Il y avait pas mal de jackeroos fils à papa, qui avait rendu visite au squatter [...]. J'ai eu l'impression que son visage exprimait quelque déception lorsque mon

\footnotetext{
${ }^{129}$ Balacescu, (2003), p. 516.

${ }^{130}$ Ibid.

${ }^{131}$ Nord asserts that: "loyalty was meant to replace the traditional intertextual relationship of 'faithfulness' or 'fidelity', concepts that usually refer to linguistic or stylistic similarity between the source and the target texts" (Nord, 2001, p. 185).

132 Vuaille-Barcan, (2012), p. 130.
} 
mate et moi nous sommes assis, mais elle nous a servis sans rien dire - on était que deux swaggies poussiéreux, vous voyez. ${ }^{133}$

In my M.A. thesis on the translation of James K. Baxter's poetry, I aimed to make moderate use of borrowed words so as not to disturb overall comprehension.

I also borrow Māori words because they convey specific symbols and narratives, or rich points, as Nord explains:

Rich points may vary from lexical items through speech acts or gestures to values and fundamental notions of how the world works [...]. This means that, when confronted with a particular translation task, a translator must be aware of the "rich points" between the groups or subgroups on either side of the languageand-culture barrier, even though he or she may decide to leave the barrier where it is and try to help people on either side look over it and understand the "otherness" of what is happening over there. ${ }^{134}$

I emphasise the cultural frame specific to New Zealand but with a wider resonance, a reach that cannot be reduced, as Edouard Glissant writes:

Traduire ne revient pas à réduire à une transparence, ni bien entendu à conjoindre deux systèmes de transparence. Dès lors, cette autre proposition, que l'usage de la traduction nous suggère: d'opposer à la transparence des modèles l'opacité ouverte des existences non réductibles. ${ }^{135}$

My practice would therefore go against some globalising trends in the book industry, what Patrick Evans analyses in the reworking of Witi Ihimaera's The Whale Rider (1987) into The Whale Rider: International Edition (2003). Ihimaera's novel saw “its specific regionality bleached out, its 'New Zealandness' and 'Maoriness' processed for a northern hemisphere market." 136

\footnotetext{
133 Ibid.

${ }^{134}$ Nord (2005), p. 870.

135 Glissant, (1997), p. 29.

136 "Of these changes, almost all have the effect of removing words that might get in the way of a non-New Zealander: both Māori (so that 'whānau' becomes 'family'...) and English (so that the quintessentially Australasian 'mate' becomes the quintessentially North American 'buddy'). [...] Less translatable Kiwi phrases ('drown in the dip', 'sheepo', 'dags') disappear completely” (Evans, 2006, p. 12).
} 
Another marker of New Zealandness that has to do with history, ${ }^{137}$ is related to the personnel involved. Relatively modest in size, in terms of readership and number of poets, New Zealand poetry could be a rather intimate affair. In 1992, Johnston argued that:

There is no mainstream in New Zealand poetry. Under scrutiny, the critical categories proposed from time to time break down into ever smaller categories, whose number almost corresponds with the number of poets. ${ }^{138}$

This raises issues of intertextuality: New Zealand poetry suggests the image of a web, a network of voices, where poets refer to one another, quote one another or pastiche one another, in an ongoing game, playing with their literary history. Colquhoun salutes Curnow in "The Trick of Standing Upright Here", ${ }^{139}$ Manhire’s “Milky Way Bar” invokes R. A. K. Mason’s 1924 "Sonnet of Brotherhood", ${ }^{140}$ Manhire imitates Baxter's Jerusalem Sonnets in "New Jerusalem Sonnets." ${ }^{141}$ Recently, David Beach has paid tribute to Baxter in Jerusalem Sonnets, Love, Wellington Zoo. ${ }^{142}$ Bernadette Hall writes another "Poem in the Matukituki Valley" 143 and poets as different as C. K. Stead, Leigh Davis and Paula Green have taken up the Baxterian sonnet.

This pattern explains the a-chronological format of An Anthology of New Zealand Poetry in English (1997) to "reflect the energies, the tremors that recent poets send back into the past."144 O'Brien highlights the importance of calling out one's ancestry, something key to Māori culture, for his own writing, and others':

\footnotetext{
${ }^{137}$ Geography and history entwine: in the 1960s, a debate arose between Curnow's call to build national poetry versus the internationalist approach advocated by Louis Johnson and the Wellington poets. See Terry Sturm's "The Colonial Inheritance" in Sturm, (2003), p. 294.

138 Johnston, (1992).

${ }^{139}$ Colquhoun, (1999), pp. 32-33.

140 "Here in this far-pitched perilous hostile place / this solitary hard-assaulted spot / fixed at the friendless outer edge of space" (Bornholdt, 1997, p. xxx).

${ }^{141}$ Manhire, (2000), p. 213. This is not new: Baxter imitates no fewer than 17 poets, including himself, in The Iron Breadboard, amongst whom R.A.K. Mason, A.R.D. Fairburn, Denis Glover, Johnson, Kendrick Smithyman, Curnow, Charles Brasch, and William Hart-Smith (Baxter, 1957).

142 Beach, (2015).

${ }^{143}$ Hall, (1997), p. 51

${ }^{144}$ Bornholdt, (1997), p. xx.
} 
When I began as a writer I was aware of those generations of New Zealand writers looking over my shoulder - the same way I find myself imagining Curnow peering over C. K. Stead's shoulders [...] Tuwhare and Baxter linger in Glenn Colquhoun's workroom, [...] Robin Hyde and Ursula Bethell watch over Michele Leggott and Bernadette Hall... As the proverb suggests, we should look to the past. ${ }^{145}$

This particular intertextuality is made manifest as a quoting collage in some poems. As Green remarks, Michele Leggott "purposely interweaves lines from poems of Eileen Duggan and Robin Hyde with her own in order to practise a 'kind of ventriloquism'."146

The links that bind generations of New Zealand poets are not exclusively local. They mix references from a range of backgrounds. Bill Sewell emphasises the diversity of voyages encountered in New Zealand poetry:

Chris Orsman's “The Last Tent”, about the English polar explorer Robert Falcon Scott in the Antarctic, or Harry Rickett's "Albergo Sole", set in Rome, or Iain Sharp's "Smoke", with a Glasgow background. ${ }^{147}$

New Zealand poets quote at ease from classical Latin and Greek heritage: Baxter, Stead, Anne French, and Anna Jackson have adapted Catullus in a New Zealand idiom ${ }^{148}$, and Wedde regularly references Greek mythology: his Commonplace Odes are after Horace.

Referring to the New Zealand canon or to a diversity of references is therefore equally problematic. While the preliminary task is to recover intertextual, contextual and intratextual allusions before translation, should it systematically be made accessible to readers? After all, it might impede the text's readability and get in the way of appreciating the poetry. It is up to the translator to assess if these allusions, on which the source poem may rely, need to be explicated (in notes for instance) or not.

\footnotetext{
145 O’Brien, (2008).

146 Ricketts, (2010), p. 507.

147 Sewell, (2001), p. 12.

${ }^{148}$ Baxter, in the sequence "Pyrrah" in Baxter, (1967). Stead, in "The Clodian Songbook" in Stead, (2016). French in "Catullus IV", French, (1993), p. 24. Jackson, in "Catullus for Children" and "I, Clodia". Jackson, (2003), (2014). Richard Matthews takes an inventory in Classical New Zealand Poetry based on Greek and Latin Models (1985). Baxter's mythical references are analysed by Geoffrey Miles, John Davidson and Paul Millar in The Snake-Haired Muse. James K. Baxter and Classical Myth (2011).
} 


\section{c. Terminology}

A third marker of New Zealandness in poetry concerns terminology and lexical / register choice. A good number of poets, especially recently, address readers in a conversational manner, or as Sharp puts it: "an unbuttoned, vernacular style of writing suits the sort of country we are." 149 This posture is different from the seriousness and at times pomposity characteristic of much Romantic poetry, inherited by New Zealand's first generation - Mason, Fairburn, or Brasch. Bassnett mocks the grandiosity of Romantic poetry "with its vague ideas about poets as beings set apart from other people, divinely inspired and often motivated by a death wish."150 Instead, Manhire, Tuwhare or Bornholdt have made a reputation for writing in a direct and approachable, or according to Ricketts, "personal"151 way. Stead notes of the later Baxter that he was finally "coming down off his high romantic stilts." 152 This tendency to deflate any swollen self-representation is potentially a cultural factor of New Zealandness, some form of literary tall poppy syndrome. It subverts the poetic attitude of the past, and may clash with engrained representations of poets in the target culture. Brown notes that: "the usual frequencies of contemporary poetry (are) casual, personal, [...] confessional, quietly insightful." 153

This attitude sits alongside what Manhire calls the "linguistic habit of code-switching": "when speakers in the course of a sentence, shift between one language and another, one dialect and another, one register and another. Often it is simply a matter of shifting registers and tones."154

\footnotetext{
${ }^{149}$ Sharp, (2002).

${ }^{150}$ Bassnett, (1998), p. 57.

${ }^{151}$ Ricketts, (2010), p. 345. Anna Jackson notes that: "Richard Reeve's turn to the ponderous metre, Latinate diction and sonorous phrases [...] is bringing back to New Zealand poetry the kind of excess it has shied away from until now" (Jackson, 2000-2001, p. 205). Johnston delivers a similar assessment: "it seems to me that the best New Zealand poems derive considerable energy from the tension between heightened language and 'unpoetic' subject" (in Manhire, 2011, p. 17).

${ }^{152}$ Stead, (1973), p. 10.

${ }^{153}$ In Manhire, (2011), p. 18.

${ }^{154}$ Manhire, (1991), p. 149.
} 
In 2008, Terry Sturm described the mechanism as offering an alternative to the cliché of a unidimensional poet's voice:

A whole range of contemporary New Zealand poetry is characterised by the linguistic habit of "code-switching" - the deployment of multiple voices, multiple registers, producing texts crammed with voices, locations and perspectives, in order to break down, move beyond the control of a single homogenising voice $[\ldots]$ the achieved, inviolable voice of the poet. ${ }^{155}$

Manhire identifies this as a common trait in New Zealand poetry, present in the work of Tuwhare, the late Curnow, the late Baxter, O'Sullivan, Bornholdt, or Elizabeth Smither. ${ }^{156} \mathrm{He}$ states that: "tonal mash-ups are infinitely more interesting than non-stop high-on-Helicon stuff." 157 Although contested by Williams and Elizabeth Gordon because of its linguistic sense, ${ }^{158}$ Manhire's term of code-switching is relevant in my context because it encompasses various linguistic phenomena: code-mixing, style-shifting, diglossia or heteroglossia, and, more to the point, it manifests a specific attitude towards poetry - unconventional in its plurality of perspectives - deconstructing rigid representations of poets by establishing a necessary distance from themselves. As Manhire explains:

Jenny Bornholdt has a kind of playfulness which doesn't damage a kind of deep seriousness either and I think that is a note that has got into New Zealand poetry in the last fifteen years. [...] With people like Baxter, Curnow, Glover, Fairburn, there is a big serious thing called Poetry, very solemn, sometimes pedantic, sometimes a bit difficult to cope with. ${ }^{159}$

For that reason, Manhire suggested, before some of his work was translated by Furlan, that his poetry would pose problems to a translator: "I can't imagine my poems would translate very well. There's too much tonal shifting." ${ }^{160} \mathrm{He}$ adds: "poetry always needs access to mixed effects - what Ezra Pound called logopoeia, what All Blacks fans still call a touch of the

\footnotetext{
155 Sturm, (2003), p. 302.

156 "Many of New Zealand's best poets are code-switchers" (Manhire, 1991, p. 148).

157 Johnston, (2009), p. 70.

${ }^{158}$ Williams and Gordon, (1998).

${ }^{159}$ Manhire, (2000), p. 101.

${ }^{160}$ Ibid, p. 33.
} 
mongrel."161 Translating such works could not be more challenging and more compelling, for it is the translation of a voice that is itself translating many voices. Are code-switching and tonal mash-ups compatible with the target culture's poetical tradition? Can it be expected that the target audience for my translations (French and francophone readers) will understand the contextual allusions (history, geography) or subtextual allusions (terminology and attitude) of New Zealand poetry in translation?

The three markers of New Zealandness presented - geography, history and terminology therefore indicate multiple challenges that can be grouped under the broader issue of translating allusion. The translator first assesses any potential incompatibility presented by an allusion that is specific to New Zealand, and then decides whether it should be rendered in the translation. The next step is to explore various translation strategies - explicitation, implicitation, glossing, contextualisation, decontextualisation, adaptation, borrowing, equivalence, creativity - to ensure the translation will function as a poem in the target culture.

${ }^{161}$ Johnston, (2009), p. 70. 


\section{Metholodogy}

As proposed by Nord, I first give a preliminary analysis of the source texts, identifying challenging elements. I assess the conditions of receivability in the target culture, focusing on the question: can this work? Nord suggests that:

The translator - like any other text producer - analyses the pragmatics of the (prospective) target situation before deciding on what to say (i.e. how to rearrange the information given in the source) and how to say it (i.e. what linguistic or even non-linguistic devices to use). ${ }^{162}$

Uchenna Oyali describes the usefulness of Nord's preliminary analysis before translation proper:

One other seminal input of Nord's into functionalism is her call for an elaborate analysis of the source text before translation proper. [...] Nord goes further to identify and categorise the kind of problems a translator might encounter pragmatic, convention-related, interlingual and text-specific - and also steps to follow in the translational process. ${ }^{163}$

As an overview, I then present the main themes and literary devices in the poet's work. Based on this study, I proceed to a case-by-case analysis of my translations and review my choices. For each poem, I give a formal (linguistic) and non-formal (contextual) analysis justifying my skopos. I focus on detecting any incompatibility between source and text cultures in details. Nord states that: "due to their familiarity with both cultures, only translators are in a position to discover the conflict potentials." ${ }^{164}$ I then explain the choices made in accordance with the function(s) intended. I subsequently aim at assessing the concepts, on which I base my practice, and to what extent my target poem reaches expectations. However, Nord stresses that: "It is the receiver who decides whether (and how) a text 'functions' (for her/him)."165 I draw conclusions in terms of theoretical principles, and promote three concepts: loyalty, balance and creativity.

\footnotetext{
162 Nord, (2001), p. 152.

${ }^{163}$ Oyali, (2015), p. 58.

${ }^{164}$ Nord, (2006), p. 35.

${ }^{165}$ Ibid, p. 41.
} 


\section{Two case studies in translating New Zealand poetry}

In the first decades of the new millenium, New Zealand literature is more vibrant than ever. On the international scene, Eleanor Catton won the 2013 Man Booker Prize for The Luminaries. On the national scene, poetry is in a very good place currently, ${ }^{166}$ as the recent success of Hera Lindsay Bird shows. ${ }^{167}$ However usually marginal in terms of book sales or mainstream public recognition, New Zealand poetry is nevertheless very active in publishing and distribution, supported by dedicated individuals, or small teams of individuals, publishing houses, ${ }^{168}$ magazines and journals, ${ }^{169}$ as well as online journals and blogs,${ }^{170}$ and various institutions. ${ }^{171}$ Within the framework of this thesis, no selection could possibly represent the range of voices involved, or the developing history of New Zealand poetry. ${ }^{172}$ To demonstrate certain patterns that are significant and recurrent, perhaps problematic, I have selected the works of Anna Jackson and Robert Sullivan for their use of allusion.

In 2019, Jackson's poetical œuvre consists of seven collections: The Long Road to Teatime (2000), The Pastoral Kitchen (2002), Catullus for Children (2003), The Gas Leak (2006), Thicket (2011), I, Clodia, and Other Portraits (2014), and Pasture and Flock (2018). She has published a collection in collaboration with Jenny Powell, Locating the Madonna (2004), and

\footnotetext{
${ }^{166}$ Mainstream newspaper Stuff reports: "New Zealand poetry is in a good place right now." stuff.co.nz/entertainment/books/82577023/The-fearless-poetry-of-Hera-Lindsay-Bird. Accessed 9 Sep. 2016. O'Brien also observes: "New Zealand poetry is interesting at the moment. It's all over the place. As it should be." nzpoetryshelf.com/tag/gregory-obrien/. Accessed 9 Sep. 2016.

167 Green admits: "Hera Lindsay Bird has attracted the biggest hoo-ha with a poetry book I can recall." nzpoetryshelf.com/tag/hera-lindsay-bird/. Accessed 9 Sep. 2016.

${ }_{168}$ Among which: Auckland University Press, Victoria University Press, Otago University Press, Seraph Press, Cold Hub Press, Random House, Steele Roberts, Huia Publishers.

${ }^{169}$ For instance: Sport, Landfall, Turbine, Poetry New Zealand Yearbook, Hue \& Cry, The Pantograph Punch, Trout, Jaam, takahē.

${ }^{170}$ See: Nzpoetryshelf, Beattie's book blog, The Spinoff, The Imaginary Museum, Poetry Archive of New Zealand Aotearoa, ka mate ka ora, New Zealand Electronic Poetry Centre.

${ }^{171}$ For instance, Creative New Zealand, New Zealand Book Council, Book Publishers Association, and New Zealand Society of Authors.

${ }^{172}$ O'Brien compares the variety in New Zealand poetry to the Whanganui River: "impure stream, with numerous tributaries, offshoots, and debris floating downriver" (O’Brien, 2002, p. 27).
} 
a host of poems in various periodicals. ${ }^{173}$ In 2016, she was the Katherine Mansfield laureate. In her verse and in interviews, she has repeatedly manifested an interest in translation - stating that she "carves" translations ${ }^{174}$ - and in 2017 , she co-translated with Geneviève Chevallier a selection from French poet Marlène Tissot's work.

Given that Jackson's poems frequently refer to one another, I have translated all the poems in her first six selections, some of which are placed in the appendix ${ }^{175}$ giving an overview of her work. However, for my case study, I have chosen poems illustrating typical challenges: translating intertextuality, wordplay, visual legibility, compressed and fixed forms, and the poetic voice.

While Jackson is Pākehā, ${ }^{176}$ Robert Sullivan is a Māori poet from Ngā Puhi (Ngāti Manu, Ngāti Hau), Kāi Tahu, Scottish and Galway Irish descent, with seven collections released: Jazz Waiata (1990), Piki Ake!: Poems 1990-92 (1993), Star Waka (1999), Captain Cook in the Underworld (2002), Voice Carried My Family (2005), Shout Ha! to the Sky (2010), Cassino: City of Martyrs (2010). I focus solely on Star Waka, published at the turn of the millennium, with globalisation raising issues of cultural and natural preservation. I present translations that work coherently as a single sequence with a central metaphor: poems as waka, and with a thematic constraint: each poem must contain a waka, the ocean or a star. I focus on the challenges raised by this unique mix of multicultural references with social, cultural, environmental and political implications for Māori people in Aotearoa / New Zealand.

The two poets not only share influences among the Classics (Latin poets, Dante) or contemporary poetry (the late Baxter, Anne Kennedy), they both took the course in modern

\footnotetext{
173 Including Best New Zealand Poems, Blackmail Press, Landfall, Broadsheet, Cordite, Heat, International Literary Quarterly, New Zealand Listener, The Manchester Review, Moving Worlds, The Page, PNReview, Snorkel, Trout, Turbine. Her earlier poetry was published in 1999's AUP New Poets v. 1.

${ }^{174}$ Jackson, (2000), p. 6.

175 The appendix should be read alongside the case-by-case study.

${ }^{176}$ She refers to herself as such in "Dream Golems" (Jackson, 2011, p. 7).
} 
American poetry taught by Wystan Curnow and Roger Horrocks at Auckland University in the 1990s. Their works also pose translation problems of a similar nature, mainly because both Jackson's intertextuality and Sullivan's indigeneity can be considered as two different forms of allusion. Translating allusion is problematic not only on the translator's side but also on the readers'. Whether allusions be (mainly but not only) intertextual in the case of Jackson or cultural in the case of Sullivan, they challenge the translator's competency in first detecting and then reproducing these - at times hidden - references. They also challenge the target readers' ability to recognise them in the translation, especially when the source text relies primarily on these to work as a poem. Allusions therefore reveal not only a plurality of source readers (and of source cultures) but also a plurality of target readers (as will be shown). 


\section{PART I: TRANSLATING ANNA JACKSON'S POETRY}

\section{A. PRELIMINARY ANALYSIS}

\section{Anna Jackson and translation}

a. Transplantation

Jackson's work has appeal in my context first because she claims that her poetry originates from translation: "the stories I tell and am told translate and are translated through stories I read, in the newspaper, in the library, in prose and poetry." "Translation as an allegory for poetry is a recurrent feature among New Zealand poets. For instance Jenny Bornholdt also refers to translation when she comments on the lines "trying to translate myself / from the rocky shore to here": 2

I liked the idea of translating myself from one place to another, with all the sidetracks and considerations that have to be made when translating a piece of work from one language into another. ${ }^{3}$

Where in Jackson's work does translation as an allegory for poetry manifest itself? In "16 Pākehā Waka", ${ }^{4}$ the following lines are found:

I carve translations for Mayakovsky, Ovid and Dante.

There is a dark wood to carve into a would. ${ }^{5}$

In a few concise lines - David Larsen praises the "purest, most elegant minimum" her work - an early plan, a scope (as in a translation skopos) is sketched out. One finds “carving", which could allude, in a New Zealand context, to the traditional Māori art whakairo

\footnotetext{
${ }^{1}$ Jackson, (2000), back cover.

${ }^{2}$ Bornholdt, (2008), p. 17

${ }^{3}$ Ricketts, (2010), p. 346.

${ }^{4}$ Jackson's first publication of these poems did not feature macrons. However, I use the macronised spelling of Māori terms in this thesis.

${ }^{5}$ Jackson, (2000), p. 6 . The source reference for each poem by Jackson or Sullivan is indicated only at first mention in the thesis.

${ }^{6}$ Larsen, (2000) p. 20.
} 
- as the repeated verb, but not associated with poems, instead with translations of writers from the European canon and the Futurist Mayakovsky. Potentiality and landscape performing upon language - land-marking - are present in the homonyms "wood / would". Eggleton is sensitive to this: "Jackson is the poet ever alert to phonetic ambiguities and other forms of wordplay.", In Pound's terminology, great attention is to be given to logopoeia and phanopoeia. Jackson's wordplay potentially translates / transforms landscape, nature (wood) into poetry, culture (would): wood into paper into poem.

The dark wood is dual: a reference to Dante's Inferno ${ }^{8}$ and a possible allusion to New Zealand's native forests, and trees of dark timber such as mataī or rātā. This interpretation is perhaps only possible in the context of the source culture. While the allusion to Dante comes from the intertextual repertoire of the target culture, the allusion to whakairo or to New Zealand native trees is not self-explanatory for target readers. Translation as an allegory for poetry leads to the highlighting of context, intertext, and the idea of translation as transplantation, from one soil to another.

\section{b. Emotion}

The allegory of poetry as translation might remind us of presence, that concept dear to Bonnefoy. In light of what Johnston formulates as the poet's task to "enact experience, rather than formulate abstractions from experience", "Fontanello" plays with the near homonymy between presence and present (a recurring wordplay in Jackson's early verse):

my son, my fontanello, I only know

you through the words that serve

thought with sound and saliva

away from the peach smell

that never meant anything to me

but presence. Your presence,

little present, fontanello, at my skin. ${ }^{10}$

\footnotetext{
${ }^{7}$ Eggleton, (2004).

${ }^{8}$ The famous incipit locates the narrative in a "selva oscura": "Halfway through the journey of our life / I found myself within a dark forest" (Dante, 2006, p. 9).

9 Johnston, (1992), p. 646.

${ }^{10}$ Jackson, (2003), p. 20.
} 
Translation is manifest in the interweaving relations between words / logos and thought / phanos, through sounds / melos, and body ("saliva", "smell", "skin"), which are, almost regrettably, the only mediums or tools ("serve") for the poet to perceive presence. The poem tenderly and powerfully translates maternal love. ${ }^{11}$ Poetry could be generalised as the translation of experience, or presence, but more simply, it chiefly translates emotion.

c. Adaptation

Jackson's incipient impulse to give a translational aspect to her poetry is maintained throughout her oeuvre. In her article "Catullus in the Playground", she shows awareness of translation issues:

It is, of course, more usual for translation theory to posit faithfulness to the original text and its original context on the one hand, and a contemporary style and readability on the other hand, as opposites between which the translator somehow must negotiate a compromise. ${ }^{12}$

This is evident in poems translated from Catullus (Catullus for Children or "I, Clodia") or the Russian poets ("The Happiness of Poets, Sto, Ste, Sto, Ste"). As well as Dante, Ovid, Mayakovsky and Catullus, an inventory might include Bella Akhmadulina, Gerrit Achterberg in The Gas Leak, Virgil in "Exit, Pursued"13 or Sasha Cherny in "Zina at the Zoo." 14 Eggleton speaks of "imitations, versions and loose translations."15 I identify these translations as adaptations. I do not refer here to Jean-Pierre Vinay and Jean Darbelnet's definition of adaptation as a "procedure of translation": "the translation method of creating an equivalence of the same value applicable to a different situation than that of the source language." 16 Rather, I refer to a free rendition or imitation based on a source text, as Georges Bastin defines it: "a

\footnotetext{
${ }^{11}$ Green includes the poem in her 2012 New Zealand Love Poems.

12 Jackson, (2006), p. 104.

13 Jackson, (2011), p. 49.

14 Ibid, p. 38.

${ }^{15}$ Eggleton, (2004).

16 Vinay and Darbelnet, (1995), p. 338.
} 
set of translative operations which results in a text that is not accepted as translation but is nevertheless recognised as representing a source text of about the same length." ${ }^{17}$ Venuti notes that: "adaptation [...] might depart widely from its prior materials, submitting them to various kinds of manipulation and revision." 18 Umberto Eco sees it as transmutation (Jakobson):

An adaptation would be similar to forms of poetic translation where, in order to preserve the rhyme or the metrical scheme, for example, we are prepared to compromise on other aspects. But, when a poet translates another poet, all we are prepared to allow is that, if the translator lays the maximum stress on emulation at the expense of literal faithfulness, then we are dealing with a case of rewriting, which is, within the same purport of the expression, the procedure closest to adaptation or transmutation. ${ }^{19}$

There are, arguably, two types of adaptations in Jackson's work: adaptation from texts already in translation and adaptation from texts in English. Jackson's "Jane Eyre"20 radically shortens Charlotte Brontë's novel. "Frank O’Hara for Charles” quotes O’Hara's “you don’t refuse to breathe, do you" and ends with an elaborated reprise: “you don't refuse to talk, do you?"21 "The Pastoral Kitchen” quotes Philip Sidney’s "The Old Arcadia”: "My sheep are thoughts, which I both guide and serve."22 "Takahē"23 cites William Carlos Williams" "This is Just to Say."24 These exemplify a wider influence of intertextuality rather than a practice of adaptation as defined by Bastin. Jackson's adaptation concerns the writings of foreign language authors.

The point of this distinction is that an extra layer is present, which contributes to Jackson's writing process: the translator's work. Jackson's adaptation from Dante is based on the work of various translators, whom she mentions:

But I am not Ciardi! Mandelbaum! [...]

Can I translate the Inferno, knowing no Italian ${ }^{25}$

\footnotetext{
${ }^{17}$ Bastin, (2008), p. 3.

${ }^{18}$ Venuti, (2007), p. 29.

${ }^{19}$ Eco, (2004), p. 125.

${ }^{20}$ Jackson, (2014), p. 55.

${ }^{21}$ Jackson, (2011), p. 17.

22 Jackson, (2001), p. 4.

${ }^{23}$ Ibid, p. 30.

${ }^{24}$ Williams, (2003), p. 33.

25 Jackson, (2000), p. 13.
} 
Her translation can only lead to a personal adaptation: adapting what is already a translation. Jackson takes a diametrically opposed view from the one that considers translation as a transparent act, a stance defended by Norman Shapiro, quoted by Venuti in The Translator's Invisibility: "I see translation as the attempt to produce a text so transparent that it does not seem to be translated. A good translation is like a pane of glass." 26 To extend the metaphor, Jackson's adaptation would work more like double-glazing. One layer would be the work of the English translator and the other Jackson's work.

This creative layering is evident in The Gas Leak. She is inspired by Achterberg's translator J. M. Coetzee and his readings in Doubling the Point. ${ }^{27}$ Coetzee's analysis of Achterberg's sonnets into triangular diagrams representing the different subject positions in the poems has inspired Jackson to structure her collection in three parts, shifting the subject / object / attribute positions. ${ }^{28}$ This applies to Mayakovsky and his translator Dimitri Obolensky, as credited in Jackson's end notes. Jackson does not take into account the usual English adaptation (in the sense of Vinay and Darbelnet) of the "sound of hoof beats in a Mayakovsky poem"29 - "clipclop" or "clippity-clop." 30 She favours her creation: "sto, ste, sto, ste", it is "a sound that corresponds to the ceaseless sound of cicadas singing through a Wellington summer." 31 This creation - an imitation of natural sounds - acts as a leitmotiv running through Catullus for Children and The Gas Leak: "I hear it at work too - / the silent sto ste sto ste / of gas leaking.",32

\footnotetext{
${ }^{26}$ Venuti, (1995), p. 1.

${ }^{27}$ Coetzee, (1992).

${ }^{28}$ Apart from her citing of Coetzee's snippets in the titles of the poems as a collage, it is not so much an adaptation as an intertextual response to Coetzee's analysis of Achterberg. This could also apply to "The Invisibility of Poets", where an italicised quotation is included from Elaine Feinstein's translation of Bella Akhmadulina's "Fever", (Jackson, 2003, p. 55). This refines the distinction made earlier between adaptation and a more general process of intertextuality.

${ }^{29}$ Ibid. This poem is "Kindness to Horses", ibid, p. 35.

${ }^{30}$ en.oxforddictionaries.com/definition/clop. Accessed 7 Nov. 2016. In French: "cataclop" or "tagada".

${ }^{31}$ Jackson, (2003), p. 55. This alliteration in "-s" is also similar to the quote by Mandelstam opening Jackson's book: "A quotation is like a cicada. Its natural state is that of unceasing sound. Having once seized hold of the air, it will not let go" (Mandelstam, 1979, p. 404).

32 Jackson, (2006), p. 40. The reference to gas leaking recurs in one of the first poems of her next collection as an echo: "we leave the gas leaking again" (Jackson, 2011, p. 3).
} 
She extends its significance to "just meaning poetry", ${ }^{33}$ a descriptive process, which may be salutary: "the sto ste sto ste of poetry / bubbles I send up, a buoyancy / I give up to stay fast."34 Jackson's adaptation creates original content on the basis of existing translations. She may adapt or borrow them, an intermediate layer is nevertheless present.

d. Refraction

Jackson's adaptation is similar to what Bassnett calls refraction, in opposition to reflection: ${ }^{35}$

A reflection involves a mirroring, a copy of an original; a refraction involves changes of perception, and this is an image that is useful to describe what happens when a text crosses from one culture to another. Moreover, refraction theory necessarily involves a consideration of literary evolution and thus places translation in a time continuum, rather than being an activity that happens in a vacuum. $^{36}$

The concept of refraction suggests a subjective rendition of ideas already existing elsewhere in literature, contingent on historical, geographical or sociological determinisms. Bakhtin explains that:

The word in language is half someone else's. It becomes "one's own" only when the speaker populates it with his own intention, his own accent, when he appropriates the word, adapting it to his own semantic and expressive intention. Prior to this moment of appropriation, the word does not exist in a neutral and impersonal language [...], but rather it exists in other people's mouths, in other people's contexts, serving other people's intentions: it is from there that one must take the word, and make it one's own. ${ }^{37}$

This questions the view that ideas could first be ethereal or without context. Instead, it suggests that the process of putting ideas into context and words, shapes these ideas. In "all-writing-istranslating", Chesterman states that:

[...] equivalence [...] would assume that meanings are somewhere "out there", already existing in objective reality. Instead, [...] meaning is something that is negotiated during the communication or interpretation process itself, it grows

\footnotetext{
33 Jackson, (2003), p. 55.

${ }^{34}$ Jackson, (2006), p. 39.

35 As Bonnefoy puts it "something of [the source poem] is still present there, as if by reflection in a broken mirror" (Bonnefoy, 1979, p. 379).

${ }^{36}$ Bassnett, (2014), p. xvii. Theo Hermans explains that it was Andre Lefevere who originally "spoke of translation as 'refraction', but that term appears to have been dropped" (Hermans, 1994, p. 139).

${ }^{37}$ Bakhtin, (1981), pp. 293-294.
} 
out of this process and is shaped by it, in the same way as it has been shaped by all previous communication. It is not "given-for-all-time" but "made', both historically and instantaneously. ${ }^{38}$

Jeremy Munday corroborates this: "translating is an intellectual process that consists in rearticulating a thought expressed in a context." ${ }^{, 39}$ In her adaptations, what does Jackson retain or leave behind? How and what for?

\section{e. Function(s)}

We have seen that, in the case of Achterberg/Coetzee or Mayakovsky/Obolensky, these first translations have an impact on the creative process. Nord draws from Jakobson to identify four main functions:

- Referential function: (objective) reference to the objects and phenomena of the world; sub-functions: informative, metalinguistic, metatextual, directive, didactic etc.

- Expressive function: expression of the sender's (subjective) attitude or feelings towards the things and phenomena of the world; sub-functions: evaluative, emotive, ironical etc.

- Appellative function: appeal directed at the receiver's sensitivity, previous experience or disposition to act; sub-functions: illustrative, persuasive, imperative, pedagogical, advertising etc.

- Phatic function: establishing / maintaining / ending (social) contact between sender and receiver; sub-functions: small talk, taking leave, introductory "peg" for text opening etc. ${ }^{40}$

Nord also explains that "if the skopos demands a change of function, the required standard will no longer be intertextual coherence with the source text, but adequacy or appropriateness with regard to the skopos." ${ }^{41}$ In "Functionality and adaptation", she tackles adaptation in a functional perspective:

What kind of function is the intertextual allusion intended to achieve? Is it meant to inform the readers about the contents or the stylistic features of the book? (These would be referential functions.) Is it intended to appeal to the reader's aesthetic sensitivity, attract them to buy (and read) the book and/or guide their interpretation of the text? (These would be three different varieties of the appellative function. $)^{42}$

\footnotetext{
${ }^{38}$ Chesterman, (2016), p. 9.

${ }^{39}$ Munday, (2001), p. 28.

${ }^{40}$ Nord (1997), p. 48.

${ }^{41}$ Nord (2005), p. 27.

${ }^{42}$ Nord, (1994), p. 61.
} 
Let us consider Jackson's adaptation of Catullus in Catullus for Children. The popularity of Catullus in Anglo-Saxon literature is unequivocal: a new translation by Daisy Dunn was published in 2016, adding to Jeannine Diddle Uzzi in 2015, Peter Green in 2005 or Peter Whigham republished in 2004. Such is Catullus' popularity that Lefevere's Translating Poetry: Seven Strategies and a Blueprint (1975) is entirely based on the various methods employed by translators of "Poem 64". In 2004, Josephine Balmer offered two poetry collections connected to Catullus. Bassnett describes this:

The poems, she claims, cover a range of interpretative positions, from what she calls straightforward translations to poems inspired by an original, to her category of "transgressions", by which she means poems that "shamelessly" subvert the original meaning. The trigger for her book, however, was not a desire to experiment with literary categories per se, but rather an attempt to find a way of writing about a deeply traumatic and painful personal experience. ${ }^{43}$

In her third collection, Jackson re-contextualises some of Catullus' motifs (the famous bird) into narratives told by children, at times in their own language (the clumsy syntax of "Sparrow [as told by Elvira]"44). She thus intends to take part in Catullus' literary tradition, and asserts his modern relevance by putting into practice the Futurist project of considering poems as "missiles capturing the Future" 45 as defended by Osip Mandelstam, a project present in Catullus' "Envoi." ${ }^{46}$ In the paratext ${ }^{47}$ of Jackson's notes, she writes:

I first heard Catullus through Karl Stead's voice and it would never have occurred to me to write my own version of his poetry if it weren't for finding a Stevie Smith translation of Catullus' Carmen 31, to Smirnio, his home, celebrating his homecoming. This was such a different voice that I started looking up all the translations I could find and was soon enchanted not so much with the voice of Catullus [...] as with the whole tradition of translating and reworking Catullus into different versions and different voices. ${ }^{48}$

\footnotetext{
${ }^{43}$ Bassnett, (2011), p. 99.

${ }^{44}$ Jackson, (2003), p. 3.

${ }^{45}$ When describing Dante's Cantos. Mandelstam, (1979), p. 240.

${ }^{46}$ In the "Envoi" that introduces his poems, Catullus hopes that they will be read for many generations into the future.

${ }^{47}$ Gerard Genette defines paratexts as "those liminal devices and conventions, both within the book (peritext) and outside it (epitext), that mediate the book to the reader: titles, and subtitles, pseudonyms, forewords, dedications, prefaces, intertitles, notes, epilogues and afterwords" (Genette, 1997, p. xviii).

${ }^{48}$ Jackson, (2003), p. 55. The poem by Stevie Smith is "Dear Little Sirmio Catullus recollected", Smith, (2015), p. 348 .
} 
She refines this in "Catullus in the Playground" and in interviews. She explains to Jessica Wilkinson that:

The Catullus for Children project is about that tradition of translation, an exploration into the purposes to which the Catullus poems can be put, and the Catullus 'voices' that can be constructed. It is such an absurd starting point - to write Catullus poetry for children, leaving out the erotic and the obscene - that it necessarily questions the possibility of translation, or explores the potential of translation to do something quite different from replicating a text. ${ }^{49}$

The referential function ("the whole tradition of translating and reworking Catullus into different versions and different voices") is evident in Catullus for Children. It is compatible or intertextually coherent with the target culture. Yet it is not so evident to translate Catullus' recontextualisation into a New Zealand reality, which Jackson terms a domestication, yet not quite in Venuti's sense:

If I were to domesticate Catullus in a way that would make my versions of his poetry really my own, this would have to involve not just a rendering of his work into a contemporary idiom, or a New Zealand setting, but a bringing home of the poetry into my own life and the lives of my children. ${ }^{50}$

What strategy should the translator of Jackson's translations adopt? Redomesticate what is already a domestication? Jackson's innovative transplantation is what makes it an interesting piece of literature in the first place, and to be loyal to Jackson's endeavour, I aim to foreignise her domestication.

\section{f. Hauntology}

In "I, Clodia", the sort of adaptation Jackson produces varies even more. She gives a voice to the character of Clodia / Lesbia addressed by Catullus. Jackson's poetic fictionalisation restoring the other voice in the dialogue - the voice of a woman, a voice lost in time but endurably present between the lines - has arguably to do with the concept of "hauntology." 51

\footnotetext{
${ }^{49}$ Wilkinson, (2015), p. 3.

${ }^{50}$ Jackson, (2009), p. 84.

51 “Ontologie (c'est-à-dire, science de l'être) de ce qui 'hante': les spectres, les fantômes" (Ramond, 2004, p. 43).
} 
Without its original political dimension, ${ }^{52}$ Derrida's term focuses on the connections between absent and present, death and re-birth of the text, as Sandy Pecastaing suggests of the numerous French translations of Poe's "The Raven",53 some constant form of eluding and floating inbetween:

S'il y a quelque chose comme de la spectralité, il y a des raisons de douter de cet ordre rassurant des présents, et surtout de la frontière entre le présent, la réalité actuelle ou présente du présent et tout ce qu'on peut lui opposer: l'absence, la non-présence, l'ineffectivité, l'inactualité, la virtualité ou même le simulacre en général, etc. Il y a d'abord à douter de la contemporanéité à soi du présent. ${ }^{54}$

Near the end of "I, Clodia", Jackson writes:

Haunt me, I command you, don't you ever even think of letting go.[...]

Who am I, Clodia, but a ghost once loved by a poet?

and the final poem is:

(Fragment)

I had a dream I was a ghost and only one man could see me... 55

Through her imagining of Clodia, Jackson summons a ghost who used to haunt her lover and has haunted literary history for centuries. She reverses the dynamics of the relationship by having Clodia exhort Catullus to haunt her in return. Jackson remarks that: "I, Clodia begins with witty repartee between herself and Catullus, and ends with Clodia not only haunted, but spectral herself." ${ }^{, 56}$ This implies that the poet too, in some sort of literary séance, ${ }^{57}$ has become

\footnotetext{
52 "Un spectre hante l'Europe: le spectre du communisme" (Derrida, 1993, back cover).

53 “Les traductions de 'The Raven' sont à l'image du poème: une mise en abyme de la traduisibilité infinie de l'œuvre: en elles, l'original renaît et demande déjà à la traduction future, de la vie en plus, toujours plus" (Pecastaing, 2013, p. 276).

${ }^{54}$ Derrida, (1993), p. 72.

55 Jackson, (2014), p. 33.

${ }^{56}$ Wilkinson, (2015), p. 4.

${ }^{57}$ Henri Michaux has experimented with the idea of poems as "exorcismes": "Nombre de poèmes contemporains, poèmes de délivrance, sont aussi un effet de l'exorcisme, mais d'un exorcisme par ruse. Par ruse de nature subconsciente qui se défend par une élaboration imaginaire appropriée: Rêves" (Michaux, 1966, pp. 275-276).
} 
a vehicle for a voice long gone. In an interview with Joan Fleming, Jackson concludes: "I do like the idea of the Clodia poems being only translations of better poems in the original Latin, that these versions only gesture towards but can never quite touch." 58 This implies another dialogue, between Jackson and her fictionalised character. Derrida anticipated such a literary dialogue with the hereafter:

La question mérite peut-être qu'on la retourne: peut-on s'adresser en général si quelque fantôme déjà ne revient pas? Si du moins il aime la justice, le "savant" de l'avenir, l' "intellectuel" de demain devrait l'apprendre, et de lui. Il devrait apprendre à vivre en apprenant non pas à faire la conversation avec le fantôme mais à s'entretenir avec lui, avec elle à lui laisser ou à lui rendre la parole, fûtce en soi, en l'autre, à l'autre en soi: ils sont toujours là, les spectres, même s'ils n'existent pas, même s'ils ne sont plus, même s'ils ne sont pas encore. ${ }^{59}$

Jackson almost applies Derrida's advice "à la lettre”. Derrida conjures future intellectuals who, for the love of justice, should "give back speech to the ghosts, even if it is in oneself, in the other, in the other in oneself." 60 Jackson calls this "reading as a spectral art", as she comments: "perhaps I took to time-travelling rather than space-travelling." 61

About her return to Catullus, Jackson explains that "there's a terrific essay by a classicist Maxine Lewis that discusses the reasons why writers and scholars are drawn to make narratives out of the Catullus poems." 62 Lewis states that the Carmina "work as narratives at the individual level and they invite recuperation into a cohesive whole but they thwart that recuperation." 63 For Jack Ross, C. K. Stead's and James K. Baxter's poetic narratives from Catullus only offer unilateral perspectives. While Stead invented something of a Modernist

\footnotetext{
${ }^{58}$ Fleming, (2015).

${ }^{59}$ Derrida, (1993), p. 279.

${ }^{60}$ Peggy Kamuf's translation in Derrida, (1994), p. 221. One interpretation would be to see Jackson attempting to restore justice in Cicero's infamous treatment of Clodia's reputation in Pro Caelio or Catullus in the Carmen. 61 Jackson, (2017), p. 94.

${ }^{62}$ nzpoetryshelf.com/2014/11/27/poetry-shelf-interviews-anna-jackson-writing-a-poem-out-of-nothing-it-canfeel-like-a-small-miracle/. Accessed 17 Nov. 2017.

${ }^{63}$ Lewis, (2013), p. 4.
} 
New Zealand Catullus, ${ }^{64}$ Baxter's take is "a very masculine view of the end of a love affair." 65 Ross asks: “Are there other ways of assuming ancient Roman (and Greek) personae in modern poetry, ways which don't have such an automatically revisionist social and sexual agenda?"66

This is where Jackson's "I, Clodia" is innovative. Not only does she adapt Catullus's labellum but she establishes a personal narrativisation - in Lewis' sense of "piecing together a narrative form a text" ${ }^{\text {67 }}$ - based on her coherent chronology. ${ }^{68}$ To Lewis, she says: "[For Catullus for Children] I came with an interest in reception and translation and different kinds of games that people could play with Catullus. [...] What returned me to Catullus was the aspect of narrative and dialogue." ${ }^{99}$ Such a dialogic transfer of literary history as an ongoing narrative is also a recurrent topic in translation studies.

\section{g. Feminism}

It can be said with Venuti that: "a translation participates in the 'afterlife' [...] of the foreign text, enacting an interpretation that is informed by a history of reception ('the age of its fame')." ${ }^{, 70}$ Bassnett describes this archaeology with regard to Pound's Homage to Sextus Propertius: "Pound defined his Homage as something other than a translation; his purpose in writing the poem, he claimed, was to bring a dead man to life. It was, in short, a kind of literary resurrection." "71 Yet, Venuti adds: "this interpretation does more than transmit messages; it recreates the values that accrued to the foreign text over time."72 This is where Jackson's

\footnotetext{
${ }^{64}$ Jackson writes that Stead's Catullus is: "all lower case lettering and line breaks, counting the grains of black sand on Auckland's West Coast beaches" (Jackson, 2019, p. 117).

65 "There she is, still vamping the men, and here $I$ am, left licking my wounds at the back of the chicken coop"

(Ross, 2009, p. 49).

${ }^{66}$ Ibid.

${ }^{67}$ Lewis, (2013), p. 3.

${ }^{68}$ To establish a clear idea of the plot, I have pieced together a version in the order offered by Jackson, with, for each Carmen, the response by Clodia.

${ }^{69}$ Jackson, (2017), p. 1.

${ }^{70}$ Venuti, (1995), p. 11.

${ }^{71}$ Bassnett, (2014), p. 94

${ }^{72}$ Venuti, (1995), p. 11.
} 
imaginative adaptation does away with some of the moral values carried by the source text, especially regarding the depiction of Clodia / Lesbia as a betrayer of Catullus' love, an unfaithful woman at fault. Jackson responds ${ }^{73}$ by filling the gaps in the narrative and restores balance in the dialogue:

The 'I Clodia' poems take as a starting point the way the poems Catullus wrote gesture beyond themselves to an interlocutor outside the text. [...] Many of the poems describe or lament acts of betrayal from the character Catullus calls Lesbia, and many claim that no one has been more greatly loved. ${ }^{74}$

Her resuscitation of that interlocutor takes account of a danger identified by Bassnett: "the greatest problem when translating a text from a period remote in time is not only that the poet and his contemporaries are dead, but the significance of the poem in its context is dead too." 75 Jackson avoids the risk of an archaising translation ${ }^{76}$ by showing the contemporary significance of the poems, influenced by Marilyn Skinner's readings of Catullus. In "Ego mulier: the Construction of Male Sexuality in Catullus", Skinner suggests that Catullus' gender representations are complex in the way they "remove contemporary cultural blinkers by troubling the 'natural' connection between biological and social manifestations of masculinity."77 Reception of her analysis in France is epitomised by Philippe Moreau: "On peut parler à son propos de féminisme radical, et sa lecture de Catulle en porte la marque, ce qui n'empêche nullement ses analyses d'être tout à fait stimulantes."78 Thomas Spath considers that Skinner's reading supplements Foucault's work on the history of sexuality:

Skinner entend son travail sur la littérature de fiction comme un complément au corpus foucaldien restreint à des textes médicaux et philosophiques: l'auteur estime que les textes poétiques font découvrir un univers d'anxiété lié à la

\footnotetext{
73 "I, Clodia" is also a response to the masculine I, Claudius by Robert Graves. This allusion is presumably difficult to render in the translation.

74 Jackson, (2014), p. 65.

${ }^{75}$ Bassnett writes: "the archaising principle [...] can be compared to an attempt to 'colonise' the past" (Bassnett, 2014, p. 94).

76 Ibid, p. 80

77 Skinner, (1993), p. 130.

${ }^{78}$ Moreau, (2002), p. 85.
} 
perturbation des normes sexuelles et réfléchit sur la remise en cause de la norme aristocratique du masculin. ${ }^{79}$

In 1980, this hauntological and feminist adaptation is something New Zealand poet - and translator of Francis Ponge - Ted Jenner had experimented with in "Catullus Reads a New Poem Aloud: Lesbia/Clodia Fidgets":

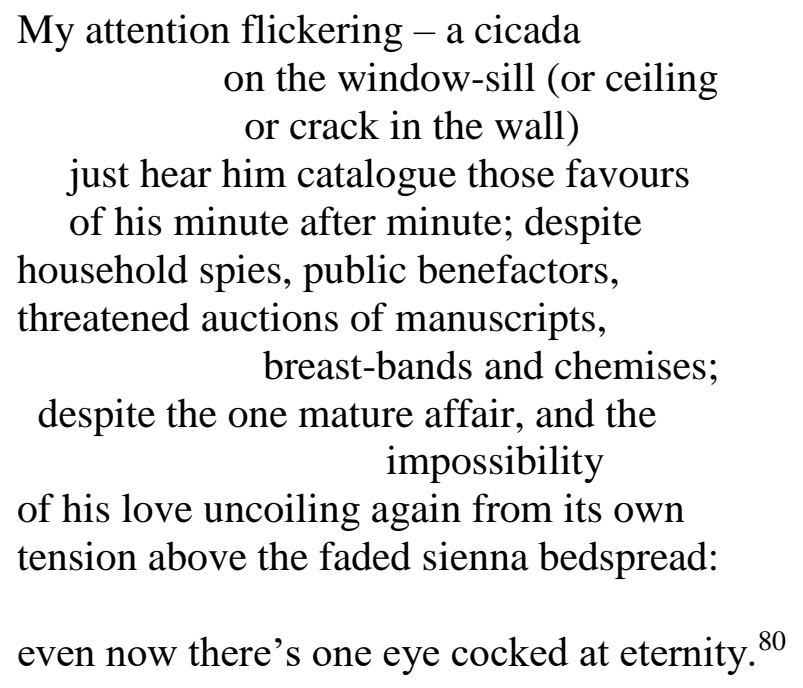

There are similarities with Jackson's work here, in tone, characterisation, and contextualisation (and a recurring cicada). In his review of Jenner's poem, Jack Ross stresses the poem's 'taste for the obscure and fragmentary [...], distrust of conventional romantic readings of the poet-ashero [...], love of the fleeting and evanescent as opposed to the fixed and stationary." ${ }^{81}$ Jackson extends this same idea into a whole sequence, with abundant erudite allusions to Catullus' scholarship, supplying an accurate chronology and plausible logic in the narrative. She mentions that "the sequence took an unusual amount of scholarship for a poetry collection." 82 She offers a convincing voice for the character, both elegiac, lyrical and yet modern, as Anne Kennedy describes it: "a pitch-perfect mix of classical high-drama and a glorious, loping,

\footnotetext{
${ }^{79}$ Spath, (2002), pp. 716-717.

${ }^{80}$ Jenner, (1980), p. 15.

${ }^{81}$ Ross, (2009), p. 51.

82 Jackson, (2014), p. 68.
} 
feminist street-cred" 83 a tour de force, which Stead salutes: "such a great idea, so thoroughly carried through." 84 In "Why Catullus?", he adds:

In her acknowledgements at the end of the book, Anna thanks 'Karl Stead, whose translations of Catullus into a New Zealand idiom first gave me a Catullus I could feel at home with.' I value that of course - the knowledge that one has taken something from the ongoing stream and fed something back into it - the feeling of continuity of literature itself: to me that is mysteriously exciting. ${ }^{85}$

Despite countless French translations of Catullus, ${ }^{86}$ and attempts to reorder their chronology, ${ }^{87}$ there is no literary endeavour comparable to Jackson's in French literature. However unprecedented this idea is in French literature - and this is precisely a reason to translate in the first place ${ }^{88}$ - "I, Clodia" matches the intertextual repertoire of the target culture. Its recontextualisation into an imagined but accurate Roman reality does not present incompatibility and Jackson's language is not an emphatic local marker. This could perhaps even act as a meme, as defined by Chesterman:

A meme is simply an idea that spreads. [...] The meme-metaphor highlights [...] that ideas spread and change as they are translated, just as biological evolution involves mutations. In this light, a translator is not someone whose task is to conserve something but to propagate something, to spread and develop it: translators are agents of change. ${ }^{89}$

In Nord's terminology, "I, Clodia" calls for an "instrumental translation". Out of the three possible types: "equifunctional", "heterofunctional" and "homologous", ${ }^{90}$ my translation may be identified as a "homologous translation", which Nord defines:

\footnotetext{
${ }^{83}$ Ibid, back cover.

${ }^{84}$ Ibid.

${ }^{85}$ Stead, (2016), p. 290.

${ }^{86}$ Daniel Aranjo analyses some of them: Jean de Tinan, Jean-Marc Bernard or Francis Carco in "Catulle au début du XX ${ }^{\mathrm{e}}$ siècle: une anthologie" (Aranjo, 2005). Julien Pingoud analyses translations by Henri Bardon, (1970), André Markowicz (1985), Olivier Sers (2004) or Danièle Robert, (2004) (Pingoud, 2009).

${ }^{87}$ Barbaud, (2006).

${ }^{88}$ In "Descriptive Translation Studies", Toury notes: "After all, cultures resort to translating precisely as a way of filling in gaps [...] there is something 'missing' in the target culture which should rather be there and which, luckily, already exists elsewhere” (Toury, 2012, pp. 21-22).

${ }^{89}$ Chesterman, (2016), Preface, p. 3.

${ }^{90}$ Nord, (2005), p. 80.
} 
A third form of instrumental translation is what I would like to call a "homologous translation". It is intended to achieve a homologous effect by reproducing in the TC literary context the function the source text has in its own SC literary context (or polysystem). This form is often found in the translation of poetry. It is called "semiotic transformation" by Ludskanov or "creative transposition" in Jakobson's terms. ${ }^{91}$

My assessment is, then, that "I, Clodia" fits nicely into the target culture, ${ }^{92}$ and my intent is

that its imaginative and feminist take on Catullus should impact gendered representations

ingrained in the poetics of the target culture. ${ }^{93}$

\footnotetext{
${ }^{91}$ Nord gives the example of a translation of Catullus, Poem 13 by Ben Johnson borrowed from Bassnett's "Poetry and Translation" in Translation Studies. Ibid, p. 81.

${ }^{92}$ Several of my translations have for instance been published online in the French poetry blog "poezibao": poezibao.typepad.com/poezibao/2018/06/anthologie-permanente-anna-jackson-catulle.html. Accessed 28 Jun. 2017.

${ }^{93}$ Toury proposes that: "translation activities and their products not only can, but very often do cause changes in the target culture" (Toury, 2012, pp. 21-22).
} 


\section{Intertextuality}

Throughout her work, Jackson uses a diffuse process of translation, in a larger sense, based on frequent references to Emily Dickinson, Marianne Moore, Sylvia Plath, Stevie Smith, Frank O’Hara, William Carlos Williams, or Katherine Mansfield, Paula Green, Robert Sullivan, among others. Stead calls this: "(taking) something from the ongoing stream and (feeding) something back into it." 94 This omnipresent broader intertextuality is a second problematic for my translation: what are the functions of Jackson's intertexts, and how might these allusions be conveyed into French?

In 1969, Julia Kristeva declared that because no text arises from a void, no text is pure or original, and all proceed in one way or another from the sum of all pre-existing texts: "par sa manière d'écrire en lisant le corpus littéraire antérieur ou synchronique l'auteur vit dans l'histoire et la société s'écrit dans le texte. [...] 'Ecrire' serait le 'lire' devenu production."95 This idea has been widely examined in translation studies. ${ }^{96}$ Nord postulates that in the translation process, a reciprocal pattern governs the intertextuality of source and target texts:

Whatever its purpose, a translated text is bound to enter the target-culture repertoire and become a part of the culture-specific intertextuality system. There it might be supposed to conform to a particular text class or to represent certain register or time-specific features. ${ }^{97}$

This implies a possible and even likely incompatibility between the relationship of the source text to its own culture's repertoire, and the relationship it will acquire with the repertoire of the target culture. Nord represents this pattern with the following figure:

\footnotetext{
${ }^{94}$ Stead, (2016), p. 290.

${ }^{95}$ Kristeva, (1969), p. 181.

${ }^{96}$ In 2006, Palimspestes devoted a whole issue to the translation of intertextuality with a range of approaches including Venuti, who concludes that the possibility of translating intertextuality is "virtually non-existent" (Venuti, 2009, p. 272).

${ }^{97}$ Nord, (2006), p. 38.
} 


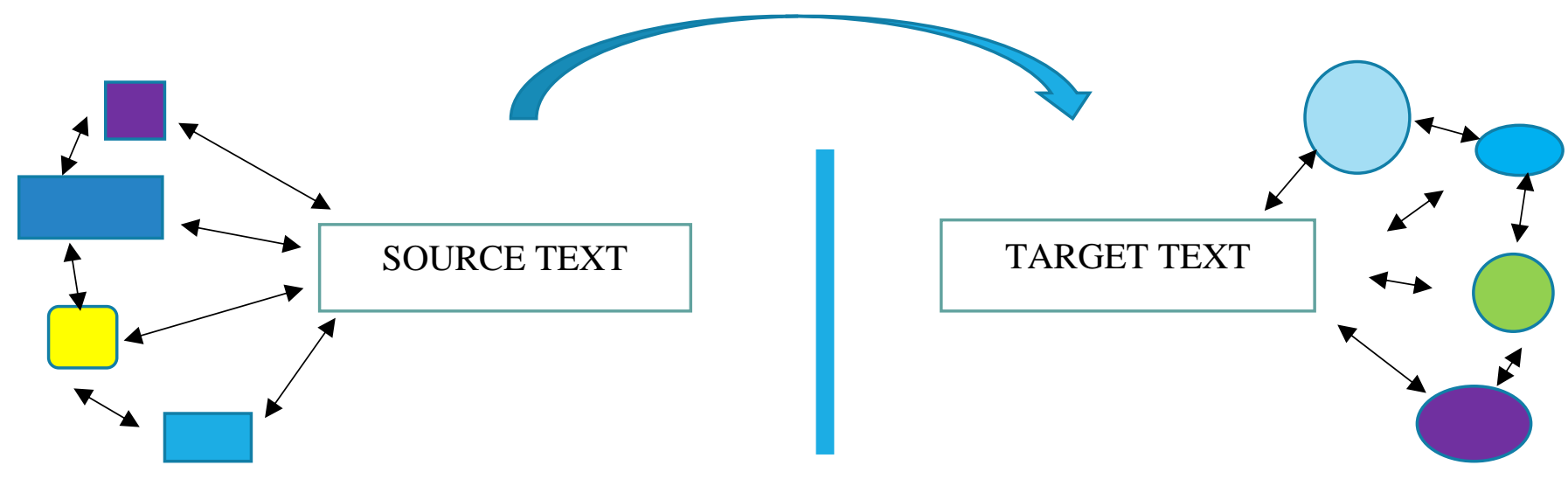

SOURCE CULTURE

TARGET CULTURE

Fig.1 Intertextuality in translation ${ }^{98}$

As can be seen, all texts of a given culture (squares or rectangles on one side, and circles or ovals on the other) maintain a reciprocal relationship amongst themselves, and this interacting pattern is identical for a translated text with its own repertoire. Whether a poem is expected to comply or not with particular formal aspects inscribes it within its literary history. The target poem will in turn echo other existing texts in the target culture.

Nevertheless, in this unidirectional transfer, there is a lot happening. The translator may need to compensate ${ }^{99}$ for the lack or the remoteness of an intertextual reference in the source text by supplying a different one or one bearing similarity. A textual reference may be added (perhaps unconsciously), as a background element, part of the target culture's literary heritage. Concretely, the translator might need to gloss, italicise and/or resort to explanation in notes for a reference specific to the source culture only.

a. Biculturalism

\footnotetext{
98 Ibid.

${ }^{99}$ In the sense of Vinay and Darbelnet: "La compensation consiste à abandonner une allusion, un niveau de langue ou un élément comique dans une partie du texte source et de le reporter dans une autre partie pour conserver le ton global du texte source" (in Chuquet and Paillard, 1989, p. 217).
} 
That a New Zealand poet should assert her inscription into a network of influences is key on a cultural level, where the poetic and the political entwine. Eva Knudsen explains, about Patricia Grace's novel Potiki, that:

From the point of view of turangawaewae, the "standing place" of Māori culture $[. .$.$] it is customary to sanctify the ancient cultural "politics" of$ Māoritanga through poetic recital, just as any contemporary political debate raised there must be preceded by ceremonial statements of cultural genealogy. ${ }^{100}$

Jackson's “16 Pākehā Waka” mentions Māui and Robert Sullivan's Star Waka as the poet follows his slipstream. Similarly to Sullivan and in accordance with the custom of whakapapa, Jackson recounts her genealogy from a Pākehā perspective. This effort to change perspectives and Jackson's assertion of her identity as a Pākehā promote a flexible practice of biculturalism in poetry. In 1981, Keri Hulme's "Mauri: an Introduction to Bicultural Poetry in New Zealand" stated that: "this poetry is literature of contact, of cross cultural contact"101 and Evans reflects that Hulme was suggesting: "something that enables her to replace the bicultural 'either-or' with what is, in effect, a sort of 'both-and', a more elastic alternative that opens up different, more dynamic possibilities."102 Jackson's poems rely on such possibilities. "Huia", "Takahē" and "Moa" are included in the section "Māoriland" (a modern version of nineteenth-century Maoriland) of the Anthology of New Zealand Literature. ${ }^{103}$ Evans remarks that:

Certainly, a number of Pākehā writers have written recently "as Māori”. At one end of the scale is Anna Jackson in "Pākehā Waka", a sequence of 16 short poems at the start of The Long Road to Teatime (2000), where she recounts genealogy and taonga in the Māori tradition. [...] At the other (is) Glenn Colquhoun, whose The Art of Walking Upright (1999) claims authenticity in verse titled "Karanga", "Haka", "Kariaka", "Mihi" ("either I don't belong to anyone / Or else I'm indigenous everywhere"). ${ }^{104}$

\footnotetext{
${ }^{100}$ Knudsen, (2004), p. 186.

${ }^{101}$ Hulme, (1981), p. 295.

102 Evans, (2006), p. 26.

${ }^{103}$ Stafford, (2012), pp. 1021-24.

104 Evans, (2006), p. 30.
} 
This has been regarded as a risky move; Green mentions that "Jackson runs a risk here as she packs the Māori vessel with the treasures of her Pākehā ancestry."105 Colquhoun's embracing of the Māori perspective - he claims that "to be a Pākehā writer now is to be in part Māori"106 - has led to controversies. ${ }^{107}$ Jackson's intertext is relevant in the debate regarding biculturalism in New Zealand, and this should be addressed in my translation.

When it comes to translating this function of Jackson's intertext, the lack of compatibility might be problematic. As Venuti explains, "the recontextualising process entails the creation of another network of intertextual relations established by and within the translation, a receiving intertext." 108 The intertext implies a subtext that can be decontextualised (to explain it) but perhaps not re-contextualised in the target culture. Pym has detected this lack of compatibility as a refutation of Nord's theory:

Nord [...] posits that the translator's "loyalty" is to both senders and receivers. All these concepts fit together nicely for as long as the principle of compatibility reigns. But surely ethical principles are only required in situations of incompatibility, when translators have to decide one way or the other? ${ }^{109}$

Nord responds that compatibility is only a "culture-specific" concept - what I understand as

her loyalty to cultures involved - and she proposes a documentary translation and a paratext:

Within the framework of our culture-specific concept of "compatibility", an instrumental translation is legitimate only if the intention of the sender or author is not directed exclusively at an SC audience but can also be transferred to TC receivers [...]. If this is not the case, the translation must be realised in document function, "documenting" the ST situation in the text environment (e.g. in a few introductory lines) and thus giving the TT receivers an indication that they are reading a (documentary) translation. ${ }^{110}$

\footnotetext{
105 In Ricketts, (2010), p. 496.

${ }^{106}$ Colquhoun, (2002), p. 53.

${ }^{107}$ Sullivan states that he once was less understanding of Pākehā using Māori references. He declares: "when I was younger I used to think if you're not Māori you shouldn't be using Māori terms because you don't understand the significance, but I've changed my mind about that. I think it's better to promote the use of the language" (Ross, 2015, p. 29).

${ }^{108}$ Venuti, (2007), p. 30

${ }^{109}$ Pym, (1993), p. 188.

${ }^{110}$ Nord, (2005), p. 81.
} 
It is the cultural implications of the source text that reveal that the translation is a translation.

On a practical level, explicitation and implicitation help to deal with what Nord calls the "referential function across cultures" (represented in the following tables):

The referential function depends on the comprehensibility of the text, which, in turn, relies on whether the amount of presupposed knowledge is appropriate for the addressed audience. The referential function poses problems when source and target receivers do not share the same amount of previous knowledge about the objects and phenomena referred to, as is often the case with source-culture realities. ${ }^{111}$

Nord's tables below clarify the options:

\begin{tabular}{|c|c|c|c|}
\hline FUNCTION & $\begin{array}{l}\text { works in target } \\
\text { culture if... }\end{array}$ & \multicolumn{2}{|c|}{$\begin{array}{l}\text { if not, the translator has two } \\
\text { options: }\end{array}$} \\
\hline $\begin{array}{l}\text { REFERENTIAL } \\
\text { FUNCTION }\end{array}$ & $\begin{array}{l}\text { textual } \\
\text { information is } \\
\text { sufficient } \\
>\mathrm{ST} \text { object is } \\
\text { familiar to TT } \\
\text { receiver or } \\
>\text { ST sender and } \\
\text { TT receiver } \\
\text { share sufficient } \\
\text { amount of } \\
\text { knowledge }\end{array}$ & $\begin{array}{l}\text { - change } \\
\text { referential into } \\
\text { meta-referential } \\
\text { function } \\
=\quad \text { providing } \\
\text { additional } \\
\text { information in } \\
\text { paratext } \\
\text { (footnote, } \\
\text { foreword, } \\
\text { glossary, etc.) }\end{array}$ & $\begin{array}{l}\text { - make the } \\
\text { referential } \\
\text { function work } \\
\text { for the target } \\
\text { audience } \\
= \\
\text { explicitation of } \\
\text { the text / or } \\
\text { implicitation if } \\
\text { information is } \\
\text { redundant. }\end{array}$ \\
\hline
\end{tabular}

Fig. 2. The translation of the referential function across cultures ${ }^{112}$

The practice of explicitation considers that language is culture, or as Nord puts it, it is an interaction. ${ }^{113}$ For Bassnett, "a translation always takes place in a continuum, never in a

\footnotetext{
${ }^{111}$ Ibid, p. 21.

${ }^{112}$ Nord, (2013), p. 9.

113 "Each specific situation determines what and how people communicate, and it is changed by people communicating. Situations are not universal but are embedded in a cultural habitat, which in turn conditions the situation. Language is thus to be regarded as part of culture. And each communication act is conditioned by the constraints of the situation-in-culture" (Nord, 2005, p. 19).
} 
void." ${ }^{114}$ Explicitation also inherits from the post-colonial trend, as summed up by Balacescu and Stefanink:

La traduction postcoloniale s'est en effet constituée comme réaction à une traduction coloniale qui se voulait ethnocentrique, éliminant les éléments culturels autochtones dans le but de dévaloriser les cultures soumises à la domination coloniale. Les traducteurs postcoloniaux vont donc introduire des mots autochtones en les glosant. ${ }^{115}$

For "16 Pākehā Waka", the poem's format - and especially Jackson's brief verse - is a factor when considering explicitation. The referential function needs to be changed into a metareferential function by providing a paratext ${ }^{116}$ of notes.

b. Shifting roles

French poet Antoine Emaz writes that: “on écrit à travers ce qu'on a lu, à travers ce qu'on lit, dans une sorte de tresse de langue." 117 Jackson arguably writes as a reader, and possibly reads as a writer, and a second function of her intertext is that it interchanges the roles between writers and readers but also characters. How can this experimental value be rendered?

"Mealtimes at the Bookhouse"118 salutes Paula Green's Cookhouse (1997), in which Green invites Michele Leggott, Anne Kennedy, and Dinah Hawken, to "share afternoon tea."119 In Jackson's text, Katherine Mansfield, Marianne Moore and Green herself are invited into her verse. In "Breakfast with Katherine Mansfield", Jackson writes:

The moon is still in the sky when we come to the table and the sky is like a mown field labelled

morning. Ms Mansfield coughs and cannot get enough of the cream cheese. ${ }^{120}$

\footnotetext{
114 "And there are all kinds of textual and extratextual constraints upon the translator" (Bassnett, 1998, p. 123).

115 Balacescu, (2003), p. 23.

${ }^{116}$ Grace's 2006 Small Holes in the Silence borrows its title from Tuwhare's "Rain", an intertextual allusion not evident for a Francophone audience in Des petits trous dans le silence. Grace, (2014). The note provided by translator Anne Magnan-Park subscribes to Nord's strategy of a meta-text.

${ }^{117}$ Emaz, (2005), p. 15.

118 Jackson, (2000), pp. 29-35.

${ }^{119}$ Ricketts, (2010), p. 506.

${ }^{120}$ Jackson, (2000), p. 30.
} 
The treatment of illustrious writers in domestic scenes - here the quick turn between simile, tragic allusion (Mansfield's tuberculosis) and a lighter note (the reference to cream cheese and gourmandise) - is far from being irreverent. Jackson corroborates the aesthetics of the writer in question. In an article drawing from Diary Poetics, Form and Style in Writers' Diaries, 1915-1962, Jackson states that (in the Notebooks), Mansfield "moves from the poetic mode to the mundane, almost in the same breath." ${ }^{121}$ She pursues: "the KM of the notebooks is far more material, a baker and eater of a range of stodgy puddings." The reference to Mansfield's gourmandise is facetious and historically correct.

Green raises an invocation of preceding voices: "For some women poets, it seems necessary to forge some kind of solidarity with the women who pioneered paths before as well as their contemporaries."122 Green's The Baker's Thumbprint or Helen Rickerby's My Iron Spine, in which she "imagines Katherine Mansfield pulling her to the dance floor at a party"123 are good examples of what Jackson calls "acts of relocation and de-historicisation."124 Jackson pushes these concepts into a new direction. Her intertext not only mirrors and elaborates on preceding material, or pays tribute to fellow poets in a dialogue, ${ }^{125}$ it is a narrative, in which writers become characters and guide the writing in a mimetic way. Green concludes: "In (Jackson's) animated examples the writers step into the poems more clearly, as characters that eat and drink and educate us on writing matters." 126 These writers / characters guide Jackson / reader / writer, and guide Jackson's readers.

\footnotetext{
121 Jackson (2000), p. 96.

122 Ricketts, (2010), p. 507.

123 Jackson, (2019), p. 118.

124 Ibid.

${ }^{125}$ See for instance Bernadette Hall's "Dark Pasture, A Response to Janet Frame's 'A State of Siege"” (Hall, 2014, p. 52).

${ }^{126}$ In Ricketts, (2010), p. 507.
} 
In Nord's terms, this function is metalinguistic: "if the referent is [...] a specific use of language, the text function may be metalinguistic." ${ }^{127}$ It can be achieved as an equifunctional translation: "instrumental translations may be intended to achieve the same function as the source text ("equifunctional translation") or a function that is different from that of the source text ("heterofunctional translation")."128

The roles of writer and reader have been reconsidered by Kristeva in the wake of Bakhtin and Roland Barthes. Megan Becker-Leckrone writes in her study of Kristeva that:

Like Barthes, Kristeva also embraces the notion of intertextuality as a way to question the traditional idea of the author as the singular, omniscient creator of a literary product by shifting attention to dynamic textuality and readerly engagement. But, more than Barthes, she retains a focused interest in the complicated status of the "creator", the one who produces the text in the midst of this "new plurality". ${ }^{129}$

Kristeva's suggested plurality focuses on the new status of the author, and involves readers too:

Such an understanding of intertextuality - one that points to a dynamics involving a destruction of the creative identity and reconstitution of a new plurality - assumes at the same time that the one who reads, the reader, participates in the same dynamics. ${ }^{130}$

Jackson assumes the role of a plural writer: encompassing a sum of other writers speaking, acting, and meeting with her in writing. This is combined with Jackson as a reader of these writers, Jackson as a character in her fictionalised life, and a multitude of other characters' voices. ${ }^{131}$ This process shifts and questions the rigidity of literary components: writer / readers / character. In Nord's terms, this is the referential metalinguistic function of Jackson's intertext. It distils literary culture (referential and appellative functions) but also, at times, creates humour (expressive function).

c. Humour

\footnotetext{
${ }^{127}$ Nord, (2005), p. 21.

${ }^{128}$ Nord, (1997), p. 49.

${ }^{129}$ Becker-Leckrone, (2005), pp. 93-94.

${ }^{130}$ In Becker-Leckrone, (2005), p. 94.

${ }^{131}$ In "The Pretty Photographer", each poem / portrait focuses on a character referred to by his or her first name. These are at times famous writers' first names: Emily, Roland, or Sylvia.
} 
This latter function needs closer attention: how might humour based on the intertext be conveyed in translation? In "Coffee and Cheese with Gudrun and Ursula", D. H. Lawrence's characters from Women in Love are set free. They wander the streets of Auckland, meet the poet / character Jackson, and together, drink coffee while mocking the novelist. They eventually have their photograph taken by a Japanese tourist:

We sat together drinking coffee and laughing at D

$\mathrm{H}$ Lawrence and I liked them more than ever free

of his prose. "Oh look at the shoes!" cried a Japanese

tourist, and took a photo of us saying "cheese". ${ }^{132}$

There is humour in the mix of highbrow and lowbrow: high-profile literature from the 1920s recontextualised in the urban and the mundane of the 2000s. Jackson plays with stereotypical feminine interests - shoes, clothes, shopping ${ }^{133}$ - as colourful elements of lightness, contrasting with the somber ${ }^{134}$ and stereotypically masculine treatment of characters in Lawrence's novel. Her humorous bottom-line could be a mise en abyme, literally a cliché depicting literary and social clichés.

Simone de Beauvoir's “D. H. Lawrence or Phallic Pride” analyses Lawrence's masculine bias: "Lawrence passionately believes in male supremacy." ${ }^{135}$ She challenges his view on gender relations and deconstructs the figure of the single, omniscient writer in control of his characters. Lawrence being part of the target intertextual repertoire, humour is compatible and this calls for an equifunctional translation without explicitation.

\footnotetext{
132 Jackson, (2000), p. 34.

133 "I wore my turquoise Mary Jane sandals [...] Gudrun of course wore / them with rose red tights, Ursula with yellow ones, or / saffron to be precise, a green velvet skirt, and blouse / I recognised from window shopping at Wallace Rose" (Ibid).

${ }^{134}$ Lawrence's dark story is allegedly based on his life: his marriage (Ursula and Rupert), and Mansfield and John Middleton Murry (Gudrun, Gerald). The couples' relationship eventually falls apart.

${ }^{135}$ Beauvoir, (1952), p. 248.
} 
In The Gas Leak's “Indeed I Can Quite Freely Step Inside”, the character / writer recognises the name Jackson on a letter box, but (pretends she) cannot pinpoint who it refers to:

I do not have a phone number

or address but stop

and scan each letterbox

for a name - Jackson

rings a bell. ${ }^{136}$

The humour lies in the shift between readers, character and writer. With some ironic distance between writer and writer-character, a dislocation of the self, Jackson becomes (and does not become) her textual representation - an elusive Doppelgänger. This forges connivance with readers, in the know, in a kind of dramatic irony. The intertext is only self-referential, ${ }^{137}$ it creates a dissociation between writer and writer-character, a fictionalised confusion of the poet's self, which readers are left to reconstruct. Airini Beautrais explains that "this locates the poet within the text, but functions more perhaps as a self-reflexive comment on the act of composition than as an autobiographical marker." ${ }^{, 138}$ Implicit expectations regarding literary mechanisms, i.e. readers expecting the poet to be the character and the voice, and the I in the text ${ }^{139}$ - are stigmatised in a playful and humorous nod. Here, the humour based on intertextuality can be rendered without notes.

To explore a third example, I return to Bonnefoy's definition of poetry. Bonnefoy aimed at moving away from the domination of images advocated by the Surrealists, however his concept of presence does echo the Romantics. In the British canon, Wordsworth wrote on presence:

And I have felt

A presence that disturbs me with the joy

Of elevated thoughts; a sense sublime

Of something far more deeply interfused ${ }^{140}$

\footnotetext{
136 Jackson, (2006), p. 37.

137 Jackson cultivates this in a network of echoes between poems. "Badminton" in Thicket is echoed in "Evelyn, After Tennis-Playing" in I, Clodia and Other Portraits.

${ }^{138}$ Beautrais, (2016), p. 119.

${ }^{139}$ This is pertinent for confessional poetry, a great deal of which relies on the assumption that the voice in the poem is the poet / individual's voice.

${ }^{140}$ In Veith, (2009), p. 55.
} 
This is similar to the definition by Jacques Maritain, which O'Brien quotes in "After Bathing at Baxter's": "poetry as a divination of the spiritual in the realm of the senses, to be expressed in the same realm."

In The Gas Leak, the intertext is a shift of Coetzee's triangular pattern, in which "Achterberg has the poet-I as the male, desiring burglar; You as female, desired and unknown; and God as the hole" 142 into a feminist perspective:

It occurred to me that shifting the terms around on what Coetzee drew up as a triangle might work as an interesting extension of the more usual feminist project of reversing the terms desired and desiring from a male to a female attribution. ${ }^{143}$

What happens at the end of Jackson's writing process leaves "God in (the) sequence to take up the active position of the burglar. And the uncanny thing is that He actually, in real life, did enter this position!"144 The final sonnet is the result of an incident in print, a poem in squashed little heaps of letters: the most compressed poem ever achieved, a murder of form.

The focus is no longer on God or some absolute presence as the prior source of creation, and not so much on the output (illegible) but on the process itself. In A Reading of Kristeva's Euvre, John Lechte concludes that:

We should now speak about a writing or a reading function. Such an approach means that the text itself is the starting point for talking about writing and reading at work in literary criticism in the past [...]. Presupposed by such criticism, is the notion that a book is written simply by the psychological author, and that therefore a text is essentially a reflection of the psyche of this author (who has also been God). This is not the level at which Kristeva is working. (...) For Kristeva, textuality in the profoundest sense is not the expression of an entity which is prior to it. ${ }^{145}$

\footnotetext{
${ }^{141}$ O’Brien, (2002), p. 32.

142 Jackson, (2006), p. 51

${ }^{143}$ Ibid.

144 Ibid.

${ }^{145}$ Lechte, (2012), p. 108.
} 
The intertext humorously rearranges poetical dynamics (referential metalinguistic function). As Airini Beautrais notes, the sequence has "a minimal narrative in which absence is as important as, or more important than, presence."146 This challenging and experimental reversion of poetry's traditional concepts is delivered in a humorous manner - humorous because it takes the opposite step from the Romantics: in a light way. For readers of the translation to grasp the final sonnet's implications in terms of poetics, but also Jackson's humour, it is necessary to translate her explanation in the end notes.

A last example confirms the functions observed: humour (expressive function), redefinition of writer / readers / character roles (referential metalinguistic function), and widening readers' literary culture (referential and appellative functions). "Departmental Cats" mentions Kendrick Smithyman and his 1985 "Reading the Maps an Academic Exercise":

Today when I was leaving you were gone to the Library, hunting. So I couldn't say what I wanted to say. No matter. At nine I phoned about the mice and rats which infest us, and departmental cats. Are they procurable or not? No matter. ${ }^{147}$

Smithyman's word procurable is borrowed in an elaboration repeating the prefix "pro-" in "proresearch", "pro-reading”, "pro-milk", "pro-all-of-that" and "pro-cat”:

Kendrick Smithyman wondered if they would be procurable.

I think they would be pro-research. Pro-reading, I know they are. ${ }^{148}$

The intertext works on the level of sounds and repetitions. The rhyming "jellymeat / eat" and "that / cat" and the repeated iterations of "departmental" lead to comical statements mocking

\footnotetext{
${ }^{146}$ Beautrais, (2016), p. 118.

147 Smithyman, (1985), p. 39.

148 Jackson, (2003), p. 29.
} 
Smithyman's nonsensical - or at least obscure metaphor, ${ }^{149}$ responding to the dialogue engaged with a woman outside the text. In 1993, Anne French was also inspired by Smithyman's reputed complexity in "On Reading Kendrick Smithyman's Selected Poems". She apostrophises him:

"Looked into", Kendrick, "looked into" is the strength of it. $[\ldots]$

and the observer becomes reader, read by the poem $[\ldots]$

Doctoral theses will be written, a biographer will stick his nose in; $[\ldots]$

Is this the promised end? The last word's yours: "what we make of it". 150

Besides the more provocative tone, there are similarities. The two poems elaborate on Smithyman's work ("what we make of it"). In Jackson's poem, "melopoeia" is key, Smithyman's words are re-enunciated in a mimetic and stammering way comically resonating their opacity. The reference to Smithyman, being unknown to French readers, needs to be explicated.

The chances that source text readers may know the New Zealand writers referred to (Mansfield, Green or Smithyman) are far greater than for target text readers. With Smithyman, there is almost a need for the subtext to be explained to understand the poem. Just as jokes lose their humour once explained, poems do not deal well with explicit directions for interpretation. Nord speaks of indirect appeal that is "like a joke that is explained: it is not really funny anymore."151 As Venuti concludes in “Translation, Intertextuality, Interpretation”:

The possibility of translating most foreign intertexts with any completeness or precision is so limited as to be virtually non-existent. As a result, they are usually replaced by analogous but ultimately different intertextual relations in the

\footnotetext{
${ }^{149}$ Scott Hamilton writes: "The reality Smithyman investigated was complex, and sometimes recalcitrant, and this accounts for the obscurity of much of the poetry" (Hamilton, 2003, p. 51). See also MacDonald Jackson's interview: nzepc.auckland.ac.nz/authors/smithyman/interview_landfall168.asp. Accessed 28 Sep. 2017.

${ }^{150}$ French, (1993), p. 60.

151 Nord, (2001), p. 192.
} 
receiving language. [...] It also results in a disjunction between the foreign and translated texts, a proliferation of linguistic and cultural differences that are interpretive and can be read as interrogative. ${ }^{152}$

Nord also explains that:

Intertextuality in its various functions can only "work" within a cultural or literary system. Even when the works in question have been translated into a target language or belong to the so-called "world literature", an allusion to a translated text would never be able to produce the "same" communicative effect as a quotation from a work that belongs to the literary canon of the readers' own culture. ${ }^{153}$

This means that the writers alluded to will always be perceived differently in other cultures, whether or not the translator presents them in a note, but notes might be justified in some cases when humour relies on some knowledge of the writer(s) in question.

\section{d. Cross-cultural representations}

In the case of Mansfield, French translations (in addition to Murry's editing work) have already contributed to spread a different representation of the author of "Je ne parle pas français". Gerri Kimber remarks that:

It is not always possible to discern the original character of the writer from the cleverly crafted myth, thereby making the case for remapping these texts against the grain of the accumulated mistranslations all the more urgent. Falsification, distortion and omission are key themes in what we might call the repertoire of normative Mansfieldian hagiography and anyone approaching Mansfield's personal writing within the pantheon of French literature today will still find themselves negotiating this quagmire of myths and falsehoods. ${ }^{154}$

Such misrepresentation is the opposite of what I am aiming for. ${ }^{155}$ A practical example of the problem of sameness when dealing with intertextual references is given by Umberto Eco. In "Sameness in Reference", Eco writes about his Foucault's Pendulum:

"al di la della siepe", which should be correctly and literally translated as "beyond the hedge". If Weaver had translated this way, no one would have

\footnotetext{
152 Venuti, (2009), p. 172.

${ }^{153}$ Nord, (1994), p. 62.

${ }^{154}$ Kimber, (2007), p. 229.

155 This is what I have aimed for in my recent retranslations of Mansfield's short stories to be published by French publishing house Rue St Ambroise (Paris) in late 2019. See my article about these in Atelier: issuu.com/atelierpoesia/docs/atelierinternational2_print_finale/98. Accessed 3 May 2019.
} 
understood [...]. It is not so for Italian readers, who know that hedge very well, as it is part of the intertextual milieu of Italian literature: the siepe, the hedge, is the one mentioned by Giacomo Leopardi in his sonnet "L'infinito", perhaps the most famous poem of Italian Romanticism. ${ }^{156}$

Prioritising the function of the intertext, Eco recommends adapting it to the target culture:

The Italian reader should understand that (the character) Diotallevi can enjoy a landscape only through the poetical experience of somebody else. I told my various translators that neither the hedge nor the allusion to Leopardi was important, but I insisted that a literary clue be kept at all costs. ${ }^{157}$

In Nord's terms, Eco's recommendation is an "instrumental equifunctional translation". Should this be my strategy when dealing with Jackson's intertext? Should I replace Smithyman by Charles Juliet or Michel Houellebecq for my poem to work? Overall, I tend to prioritise two options, as Sarah Pfeffer remarks that:

Eco believes that a translator can only choose one of two evils: either to sacrifice the intertextual reference in favour of comprehensibility or to sacrifice comprehensibility in favour of the intertextual reference. Every case calls for an individual assessment of the advantages and disadvantages of the two options in the specific context. ${ }^{158}$

Whether or not I choose to explicitate the reference, I aim to limit sacrifices when confronted with problematic intertexts. One may object that Eco's solution concerns a problem caused by an implicit intertextual reference in a novel. What happens when the reference is explicit, and in a poem?

There is a multiplicity of solutions. Eugenia Loffredo and Manuela Perteghella promote creativity and variety in One Poem in Search of a Translator. Rewriting "Les Fenêtres" by Apollinaire:

This volume consists of twelve translations of one poem: "Les Fenêtres" by the French poet Apollinaire. The translators embarking on this project, all from different backgrounds and working contexts (poets, professional translators, academics, visual artists) were asked to engage with the inherent multimodality of this poem - inspired by Robert Delaunay's Les Fenêtres series of paintings. The result is a kaleidoscopic diversity of approaches and final products. Each

\footnotetext{
${ }^{156}$ Eco, (2004), p. 15.

${ }^{157}$ Ibid.

${ }^{158}$ Pfeffer, (2016), p. 74.
} 
translation is accompanied by a self-reflective commentary which provides insight into the complex process and experience of translation, enticing the reader to join the journey too. ${ }^{159}$

The "self-reflective commentaries" by Pierre Joris, Tony Baker or Tom Paulin explain different interpretations, and vary greatly. With titles ranging from "The Windows", "Double Windows", "Three Windows" or "Vista", the poems refer to Delaunay's paintings in diverse ways, and are part of a journey. Significantly, the editors stress the importance of paratexts to justify the varying approaches: "these self-reflections, therefore, become essential paratextual spaces where translators act as 'textual critics'."160

To conclude this discussion of Jackson's intertextuality, there is a variety of solutions for problematic intertexts with a specific significance: replace the intertextual allusion by adaptation, explicitate it in a note (Smithyman, Sullivan), leave it unexplained (Mansfield, Lawrence), translate the already existing source text notes (The Gas Leak), or even offer several parallel creative possibilities (by various translators for instance), more or less emphasising the intertext. This justifies my case-by-case - or heuristic - strategy. To complete my preliminary analysis, I now present the main themes and literary devices in Jackson's poetry.

${ }^{159}$ Loffredo, Perteghella, (2009), back cover.

${ }^{160}$ Ibid, p. 24. 


\section{Themes}

Most descriptions of Jackson's poetry refer to domesticity, family and the everyday.

Encyclopaedia Te Ara's entry for Jackson states that "much of her poetry deals with issues of family and childhood interpreted and understood in the context of wider literary traditions."161 Jackson acknowledges that "'domestic' is the term critics have used, in one review after another, to characterise the poetry of my two earlier collections." ${ }^{162}$ In "The Kitchen", Green analyses domesticity in New Zealand poetry:

While traces of the domestic and the personal may be found in men's writing of the twentieth century (for example, Louis Johnson, Graham Lindsay, Ian Wedde) and evidence of an engagement with intellectual ideas ahead of the representation of a domestic realm may be found in women's (for example, Mary Stanley, Michele Leggott), an attachment to domestic concerns has never faltered within the wider view of New Zealand's poetry. ${ }^{163}$

Green traces a tradition of domesticity in the poetry of Ursula Bethell (From a Garden in the Antipodes), Wedde (The Common Place Odes), Bornholdt (Summer), Manhire (How to Take Off Your Clothes at the Picnic), or Kennedy (Sing-Song). Bornholdt and Manhire in particular have established a reputation for writing about domestic topics, and Jackson's thematic choices corroborate - whether directly or indirectly - their poetic testimony. ${ }^{164}$

In French literature, going back to Georges Perec, Francis Ponge and Jacques Prévert, the poetics of the everyday have unarguably constituted a trend. Michael Sheringham traces this back to the Surrealists:

All these currents tended to converge on ordinary, everyday experience, leading to the explorations and investigations of the quotidien we find in such varied works as Marc Augé's Un éthnologue dans le métro, Pierre Sansot's Les Gens de peu, Francois Maspero's Les Passagers du Roissy-Express, Annie Ernaux's Journal du dehors, the "théâtre du quotidien" of Michel Vinaver and Michel Deutsch, Francois Bon's Paysage fer, Jacques Reda's La Liberté des rues, the

\footnotetext{
161 teara.govt.nz/en/speech/43098/anna-jackson-2007. Accessed 30 Nov. 2016.

162 Jackson, (2009), p. 84.

${ }^{163}$ In Ricketts, (2010), pp. 209-210.

${ }^{164}$ Jackson states that "Jenny Bornholdt and Bill Manhire are the poets I'll read with the feeling that I can sort of catch poetry from them" nzpoetryshelf.com/tag/anna-jackson/page/3/. Accessed 12 Dec. 2016.
} 
novels of Echenoz, [...] Cédric Klapisch's film Chacun cherche son chat, and so on. ${ }^{165}$

Jackson's predilection for the everyday is therefore compatible with a popular trend in the target culture's poetic repertoire, and this might constitute a precedent for my translations. Nevertheless, as will be shown now, it would be limiting to restrict the scope of Jackson's poetry only to household themes.

\section{a. The Long Road to Teatime and The Pastoral Kitchen}

In an interview, Wilkinson asks Jackson: "Domesticity, family and the everyday seem common themes or preoccupations in your work. Can you tell me what drives you to explore these themes through the poetic form?"166 The answer is revealing:

Even when I wanted to write about other subjects - when I wanted to write about the political situation in East Timor, for instance - it didn't feel like it was my story to tell, as non-fiction. But for some reason I felt alright about imagining scenes in our domestic family life. ${ }^{167}$

Jackson's writing about domesticity by “drawing on the poetic tradition of imagining an ideal simpler and more natural than daily life often feels" 168 may paradoxically come from an attempt to relate to elements outside the domestic, but in a justified manner. There is a coherent movement throughout: I will argue that Jackson's poetry plays with the reciprocity between inside and outside. By synecdoche, the inside would comprise the domestic themes often described by critics but these would serve as a framework for wider perspectives understood as the outside.

Philippe Jaccottet's Semaison evokes the permeability of the inside and the outside:

Dedans. Dehors. Que voulons-nous dire par dedans? Où cesse le dehors? Où commence le dedans? La page blanche est du dehors, mais les mots écrits dessus? Toute la page blanche est dans la page blanche, donc en dehors de moi... ${ }^{169}$

\footnotetext{
165 Sheringham, (2006), pp. 3-4.

166 Wilkinson, (2015), p. 3.

167 Ibid.

${ }^{168}$ Ricketts, (2010), p. 217.

${ }^{169}$ Jaccottet, (1971), p. 42. For "dedans" and "dehors", Lefevere's translation is: "Inside. Outside. What do you mean by inside? Where does outside end?" (Jaccottet, 1977, p. 19).
} 
Mary-Ann Caws reflects on their reciprocal nature, and the poetic tendency to shift their perspectives:

Le lecteur de la nouvelle poésie fait un effort pour "tourner son costume", comme dit Jabès par une de ses multiples voix, pour pratiquer cette lecture du retournement de l'intérieur vers l'extérieur et vice versa, comme s'il s'agissait de la tapisserie, de la couture ou d'une bande de Moebius où l'on ne distingue pas la ligne qui sépare l'intérieur de l'extérieur. ${ }^{170}$

In his preface to Bonnefoy's Poèmes, Jean Starobinski remarks that:

Ce n'est pas pour Bonnefoy, la multiplicité des objets dénotés qui importe, mais la qualité de la relation qui les met en présence réciproque [...] il s'agit dans l'espoir de Bonnefoy, d'un mouvement qui instaure (ou restaure) un ordre, qui traverse et qui ouvre. ${ }^{171}$

While Jackson's coherence should not conceal the specificity of each selection, The Pastoral

Kitchen arguably carries on The Long Road to Teatime's contextualisation of wider issues within the perspective of the domestic and "by the kitchen light."172 Green states that:

Jackson's collection underlines the idea that while the kitchen has been a significant room for women in terms of a history of domestic chores [...], women have undertaken intellectual and artistic endeavours within as opposed to outside the bustle of family life. ${ }^{173}$

Jackson explains that: "I wanted to write about domesticity as a kind of pastoral realm for thinking in, outside of culture." ${ }^{174}$ While the first section gives insights into Jackson's life, it also launches "The Pastoral Elephant", a series of portraits of animals endangered or extinct because of "arable farming, the basis of the industrial-chemical farming of today." 175 The

\footnotetext{
${ }^{170}$ Caws, (1978), p. 234.

${ }^{171}$ Bonnefoy, (1982), p. 21. Italics in the original.

172 Jackson, (2001), p. 20.

${ }^{173}$ Ricketts, (2010), p. 211.

${ }^{174}$ Wilkinson, (2015), p. 3. The Pastoral Kitchen is most ambitious in its attempt to make poetry coincide with a denunciation of environmental facts, as illustrated by Jackson's image of "islanded reserves" in a final poem added to the end notes. Jackson, (2001), p. 54.

${ }^{175}$ Ibid, back cover. The Pastoral Kitchen could be read as Jackson's endeavour to write ecopoetry as defined by Janet Newman in "Ecopoetry and the Imaginative Impulse" writing about Dinah Hawken's poetry: "much ecopoetry [...], argues that in order to preserve the health of people we must first preserve the health of the earth [...]. The prevailing theme is that changes in human perception or behaviour are necessary to mitigate environmental damage" (Newman, 2015, p. 9).
} 
Pastoral Kitchen's use of a domestic context to shed light on ecological issues outside of culture is coherent with what was observed in "Breakfast with the Timorese" for instance. In "Fish Fingers and Carrot Sticks with the Timorese", ${ }^{176}$ Timorese women are in the poet's bathroom giving her daughter a bath. Similarly, in "Kākāpō", ${ }^{177}$ the endangered bird is evoked in the wild via the smell of a feather displayed inside a cabinet in the poet's lounge.

\section{b. Catullus for Children}

Catullus for Children bridges tradition and modernity, past and present. The book's first sequence explores Catullus' themes - passion, jealousy, love, friendship - by adapting them to the context of Jackson's children in contemporary New Zealand. This sheds a new light on Catullus' perennial themes and gives depth to typical dilemmas experienced by children. Terry Locke puts Greg Drudy's translation of Catullus' poem and Jackson's "Poet" in parallel, and asks:

There is a complex but not too complex tone operating here. (Rufus is certainly not being portrayed as a nerd.) There is certainly a voice. The question is: what difference does it make to your response when you put this poem alongside the (superficially more "faithful") translation of Catullus above? ${ }^{178}$

I would answer that without undermining Catullus' poem, ${ }^{179}$ Jackson stresses the depth of her son's feelings. The interest of retelling such feelings is augmented, their poetics justified. Catullus challenged the poetic topics of his time ${ }^{180}$ - the exaltation of courage for instance and focused on intimate topics, which makes Jackson resonate with Catullus. ${ }^{181}$ Children's emotions set in a domestic context (the inside) are enhanced, and reciprocally, Catullus' poetics (the outside) are (re)asserted.

\footnotetext{
176 Jackson, (2000), p. 41.

177 Jackson, (2001), p. 34.

${ }^{178}$ Locke, (2003).

179 Jackson notes: "(I) was soon enchanted not so much with the voice of Catullus - although through all the translations it comes across as enchanting enough, the voice of a Roman Frank O'Hara” (Jackson, 2003, p. 55). ${ }^{180}$ See Quinn's The Catullan Revolution (1959).

${ }^{181}$ Jackson writes: 'despite the address to a 'you' that characterises many of Catullus' poems, readers do not, as they do when reading a letter addressed to them, typically place themselves in the position of the person addressed. Rather, readers identify with Catullus himself"' (Jackson, 2006, p. 22).
} 


\section{c. The Gas Leak}

About The Gas Leak, Jackson writes: "The Gas Leak as a whole is about the gaps in family life." ${ }^{182}$ Internal issues are treated in relation to the life that family members live outside the family. This outside is elusively present inside family life:

You're all living in the same family, but in a way you're all living in a different family. You want to be known as someone who is somewhere else, but within the family that side of you is only present as a kind of ghost of yourself. So I see families as haunted spaces. ${ }^{183}$

The haunting relation between outside and inside is manifest in the tensions between conjugal and extra conjugal, introverted and extraverted behaviours, physical actions and metaphysical abstractions. The gas-fitter argues with his wife because of their intrinsic difference of perspectives when buying a house:

He says he is looking for a view, she only cares how it looks from the outside. ${ }^{184}$

The phantasmagorical shadow of adultery looms over the marriage. As the gas-fitter's master key enables him to "slip in and out of his own and other people's lives"185 - his daughter envies the fact that "he at least goes out into (the world)"186 - the fantasy is embodied by the sister, whose empty house he visits, in the first section, and by some mysterious Russian coursing hounds that his wife keeps in the basement, in the third section.

In a stream of consciousness that imitates the sociolect of a teenager, the daughter's introspective journey (the inside) and her tentative experiences with boyfriends and alcohol (the outside) are deftly depicted in "The Gas-Fitter's Daughter Shows Shane." 187

\footnotetext{
${ }^{182}$ Wilkinson, (2015), p. 3.

183 Ibid, p. 4.

184 Jackson, (2006), p. 12.

${ }^{185}$ Ibid, back cover.

${ }^{186}$ Ibid, p. 33.

${ }^{187}$ Ibid, p. 32.
} 
In "An Explanatory Wave of the Hand", ${ }^{188}$ the biblical fall of Babylon ${ }^{189}$ is subverted into an ascending movement of evaporation. With provocation ("tip me out"), the poem leads to catharsis and balances metaphysical and physical.

Jackson explores unusual narrative elements - cracks, holes, in-between, and silence - as ways to communicate, to reach out (the pun "holy and holey" in "It Seems that this Time I Have Been Mistaken"190). This exploration of silence is, according to Green, a factor of poetic essence:

Each point of view serves to illuminate the gas-fitter's world, firstly as a domestic scene with its uneasy communications, and secondly as a metaphysical conceit (an elaborate metaphor) upon the part of Jackson and Achterberg. [...] Jackson's handling and construction of silence throughout the poem tip the balance between narrative and poetry in favour of the latter. ${ }^{191}$

The sonnets' compression giving readers room for interpretation, the treatment of what may appear banal themes (family or domesticity), lead to a more profound layering (metaphysics).

\section{d. Thicket}

Thicket centres on the notion of entwinement, and draws references from the inside intratextual $^{192}$ echoes, and the outside - extratextual ${ }^{193}$ and intertextual echoes. Harvey considers that: "the mythologising of self and whanau" is the "cornerstone of Jackson's œuvre." 194 The author extends family figures into adaptations from fairy tales. "Red Riding Hood's Mother" and "Red Riding Hood"195 express moments of exasperation about parenthood - "children [...] eat up all my food / and mess up all the rooms." For Melanie Wittwer, the daughter is also "discovering in two juxtaposed poems that her mother was a wild child." ${ }^{196}$ By

\footnotetext{
${ }^{188}$ Ibid, p. 47.

189 "Babylon has been a golden cup in the hand of the Lord, Intoxicating all the earth. The nations have drunk of her wine" Jeremiah, 51:7.

190 Jackson, (2006), p. 45.

${ }^{191}$ In Ricketts, (2010), p. 32.

192 "Badminton" at the beginning is echoed in "Let Alone" at the end.

193 "Basement" refers to a gas leak.

${ }^{194}$ Harvey, (2011), p. 1.

195 Jackson, (2011), pp. 10-11.

${ }^{196}$ Wittwer, (2012).
} 
metonomy, outside (woods) and inside (cupboards) supplement the dichotomy between past and present (the polysemy of "go back to"):

She is always looking back to before me.

Me, she sends outside, while she searches

in cupboards and books.

I'm sent into the woods.

I'll go back to.

The inside / outside dichotomy is key to the resolution of antagonism in "My Brother, Twelve Swans":

until, finally, he takes flight -

and I am left silent in the house. ${ }^{197}$

Thicket reaches beyond the domestic as its embedding in a literary fabric gives it an impersonal reach. Characters try to extricate themselves from the fetters of domesticity. Jackson explains that, as a poet, "you try to find a way out of the life that you're in."198 This metamorphosis / alienation occurs from the inside in "Exit Pursued" 199 or "Not Looking, Feeling":

I grasp a dream, or a dream grasps me, entering my fingertips

like sap, [...]

my whole body turns to wood

and I stand here as a tree,

am standing still... 200

Jackson uses the mundane as object of focus - a shopping list in "Doubling Back", ${ }^{201}$ a potato in "Giving up", 202 a duck in "A Beautiful Theory Isn't a Poem, James"203 - to elucidate confusion between the material and the conjectural. Patricia Prime assesses that "always there's

\footnotetext{
197 Jackson, (2011), p. 38.

198 radionz.co.nz/audio/player?audio_id=2494174. Accessed 13 Dec. 2016.

199 The poet uses the figurative sense of "wooden": "I do become a little wooden" (Jackson, 2011, p. 49). This is reminiscent of Pinocchio, alluded to in "The Second Puppet".

${ }^{200}$ Ibid, pp. 45-46.

${ }^{201}$ Ibid, p. 33.

${ }^{202} \mathrm{Ibid}, \mathrm{p} .31$. It is also a political reponse to what Harvey qualifies as "colonial misogyny" (Harvey, 2011, p. 1).

${ }^{203}$ Jackson, (2011), p. 26.
} 
an awareness of the bigger picture, ranged against the contingencies of daily life." ${ }^{204}$ Harvey comments that:

Of course, mythmaking muddles truth. Thicket's other dominant concern is perception: how, trapped by conjectural density, the poet-heroine sees clearly. Jackson's best use of symbolism to view troubling issues lucidly occurs in poems like "Wondering How to See It". ${ }^{205}$

In this poem, Jackson uses a pool as a place of contact between inside and outside:

You can't say I didn't throw myself in,

$[\ldots]$

forming a skin

with the pool. A membrane

to hatch through? Or a contact lens,

for an eye a whole lot bigger than my life? ${ }^{206}$

Symbolism is key to "Doubling Back", which sets the scene in the ordinary of a supermarket, but soon deals with the abstract conceit of time relativity. After the subsequent injunction to "put more in to it" and fill up with "abstractions that can travel [...] vastly", the nested structure of the final simile involves a swimming pool on top of a boat sailing the ocean:

every year will be like an ocean liner with a swimming pool on the top floor, the length of the swim depending entirely on how often you want to swim back and forth. ${ }^{207}$

In Thicket, themes seemingly ordinary underlie deeper abstract themes, as the scope aims at introspection through "outrospection" and vice versa.

\section{e. I, Clodia, and Other Portraits}

Jackson states that: "bits of my life get into the poems; it is another way of making something of everyday life, of details you want to aestheticise, or find aesthetic. Or uncanny, or

\footnotetext{
${ }^{204}$ Prime, (2012), p. 75.

${ }^{205}$ Harvey, (2011), p. 1.

206 Jackson, (2011), p. 34.

${ }^{207}$ Ibid, p. 33.
} 
resonant." ${ }^{208}$ In "I, Clodia", this pattern gives way to a more distanced fictionalisation. Amy Brown considers that:

This is a departure for Jackson, whose poetry is often laced with autobiography; in Catullus for Children (2003), the Roman poet is coaxed into contemporary New Zealand, specifically into the lives of Jackson's children. By contrast, “I, Clodia" takes a scholarly and empathic imaginative journey to $1^{\text {st }}$-century B.C. Rome. ${ }^{209}$

Brown points out that "this is not a masked self-portrait, but a portrait of someone Jackson understands deeply."210 Nevertheless, Jackson's projection can only be based on her perception of Catullus' character - an approximate delineation. In an interview, Maxine Lewis states: "I would from the outside think there is more Anna Jackson in Catullus for Children than I, Clodia, but it almost sounds like it's the opposite..."211 Jackson acknowledges this:

Writing the I, Clodia sequence was a way, for me, of "chasing Catullus" as Josephine Balmer puts it, in the place of his Lesbia, even if my Clodia could only ever be a reflection of myself, reading. ${ }^{212}$

The more Jackson reaches out of herself towards Clodia's historical character, the more she asserts the subjectivity of her reading; and the more she engages her self in the writing, the more her Clodia is reciprocally imbued with her personality.

"The Pretty Photographer" deals with family ties, the cycle of father-son relations features in "Roland on the Outskirts", ${ }^{213}$ and the fine line between reminiscence and presence is explored in "The Father Late at Night." ${ }^{14}$ Brown states that: "unlike 'I, Clodia', 'The Pretty Photographer' sequence does seem to be Jackson's costumed self-portrait." 215 The poet uses the lens of a photographer's camera - an externalising device - to capture moments of

\footnotetext{
${ }^{208}$ Wilkinson, (2015), p. 3.

${ }^{209}$ Brown, (2015).

210 Ibid.

211 Jackson, (2017), p. 11.

212 Jackson, (2019), p. 126.

213 Jackson, (2014), p. 50.

${ }^{214}$ Ibid, p. 58.

${ }^{215}$ Brown, (2015).
} 
imaginary lives, themselves revealing glimpses of her life, that are for Jackson "both real and metaphorical. ${ }^{216}$ Green comments that:

The poems are like miniature mises en abyme. You fall into elusive, intangible selves, the dry dust of story, as the autobiographical self is laid like a transparency over the invented or borrowed self. ${ }^{217}$

"The Pretty Photographer" displays a multiplicity of dual characters, as the poet shows:

I might write as "I" but the "I" is as invented as a character like Saoirse or Roland in the photographer sequence. And, conversely, I could have written the Saoirse poem or the Roland poem as "I" - both are stories about my own life. ${ }^{218}$

In her thesis, Rose Sneyd's argument of using Bakhtin's dialogic imagination to found her poetics of reciprocity is pertinent and might suit "The Pretty Photographer", and Jackson's verse overall:

I have purposefully borrowed this term from Bakhtin's "dialogic imagination" - although Bakhtin, of course, believed that dialogism was characteristic of the novel, not of poetry. However, at the core of my thesis is the idea that poetry too can be distinguished by the "dialogic imagination" and that is why I have adopted the term "poetics of reciprocity". 219

This is defined by Elina Siltanen in Experimentalism as a Reciprocal Communication in Contemporary American Poetry: "a kind of reciprocal communication in which authors and readers share joint responsibility." ${ }^{220}$ Paradoxically, the portraits could therefore be reflections of the portraitist (poet) as well as those portrayed (characters), and those watching (readers), as hinted at in the preamble quote from Diane Arbus: "a photograph is a secret of a secret." As Siltanen writes:

Readers are encouraged to ask themselves: How do I relate to a poem, to its words, phrases, sentences, propositions, questions, expressions, especially when it is an experimental poem whose elements do not follow consistent or linear patterns? How readers do in fact relate to all this depends, of course, on who they are. ${ }^{221}$

\footnotetext{
${ }^{216}$ Fleming, (2015).

217 nzpoetryshelf.com/2015/05/28/anna-jacksons-i-clodia-and-other-portraits-a-lightness-that-is-fierce-aspareness-that-is-complex/. Accessed 8 Dec. 2016.

${ }^{218}$ nzpoetryshelf.com/tag/anna-jackson/page/3/. Accessed 12 Dec. 2016.

${ }^{219}$ Sneyd, (2012), p. 54.

${ }^{220}$ Siltanen, (2016), p. 20.

${ }^{221}$ Ibid, p. 6.
} 
To conclude, the outside might just be fantasised, explored from the inside, it is a vehicle for exploration. Conversely, metaphysical insights might be set in an ordinary context, nevertheless outside and inside make contact. In "Words and the Inner and Outer Worlds", MacDonald Jackson suggests that "Descriptions of things, scenes, and happenings in the external world have traditionally served as vehicles for - or at the very least, been intimately bound up with - thoughts, emotions, intuitions, and moods."222 In his reading of Bonnefoy, Edouard Glissant writes: "Je revenais au livre, où se tramait au fur et à mesure l'image de cette étendue, de cette extension qui faisait comme une exploration en soi et hors de soi." 223 And in “Surfacing”, Vincent O’Sullivan concludes:

It is the movement

of a boy just before he enters the water.

Or just after he comes out, the water crossed. ${ }^{224}$

In all her collections, Jackson's treatment of domesticity plays coherently with the reciprocity between inside and outside. This is arguably a defining feature of her writing: as in an overall figure of litotes or meiosis, the deceptive lightness of her verse has a resonance that goes well beyond the description of domesticity so often mentioned in reviews. The translation should therefore preserves this deceptive lightness as well as its profound layering.

${ }^{222}$ Jackson, (1998), p. 394.

${ }^{223}$ Glissant, (1997), p. 143.

${ }^{224}$ In Johnston, (2009), p. 49. 


\section{Literary devices}

As the last part of my preliminary discussion, I give a brief analysis of Jackson's main literary devices. As we will see, some are particularly challenging but also stimulate the translator's creativity.

\section{a. Compression}

In 2013, Jackson wrote a poem based on Jack Ross' translation of $12^{\text {th }}$-century poet Marie de France on the premice that she: "wondered if the sharpness of the original, which came across more in Jack's footnotes than in the verses, could be sharpened up more in a briefer version."225 This is a typical writing exercise for Jackson, and in The Gas Leak, she experiments with radical compression as a challenge: "seeing how tight I could make it, how many ideas I could pack into those small lines." 226 In The Pastoral Kitchen, "After the Nit Shampoo"227 or "Home Time"228 are shorter than a haiku. "(Fragment)"229 is only two lines long. "The Road to Karekare", ${ }^{230}$ or "I Wake up Among the Lustful Gluttons", ${ }^{231}$ her longest pieces, are composed of three or four septets. "The Vending Machine"232 or "The Hen of Tiredness"233 are respectively six quatrains and three nine-line stanzas. "The Gas-fitter's Daughter Wakes up"234 is the longest piece in The Gas Leak with twenty-nine lines. Thicket's longest "Not Looking, Feeling" is forty-three lines long. In I, Clodia, and Other Portraits, Jackson moves away from the couplets or triplets characteristic of earlier collections: poems look denser as one block, and often do not correspond to any stanza pattern, as in "Roland on the Outskirts" (56 lines) or

\footnotetext{
225 Jackson, (2013), p. 165.

${ }^{226}$ Wilkinson, (2015), p. 3.

227 Jackson, (2001), p. 19.

${ }^{228}$ Ibid, p. 15.

229 Jackson, (2014), p. 34.

${ }^{230}$ Jackson, (2000), p. 11.

${ }^{231}$ Ibid, p. 15.

232 Jackson, (2001), p. 12.

${ }^{233}$ Ibid, p. 10.

${ }^{234}$ Jackson, (2006), p. 19.
} 
"Evelyn, After Playing Tennis"235 (42 lines). However, her longest works are far from the expansiveness of Smithyman, Wedde, ${ }^{236}$ or the voluble Eggleton ${ }^{237}$ for instance.

About The Pastoral Kitchen, Jackson notes that:

It was an early attempt at what I finally achieved with The Gas Leak, to get a kind of taut compression into the poetry - I wanted to move beyond the long lines of The Long Road to Tea-Time which I felt were too easy. ${ }^{238}$

This compression inherits from Imagism and Modernists Ezra Pound, William Carlos Williams, Marianne Moore or T. S. Eliot. Milena Pollmanns identifies that: "Imagist poems are concise and use no words that are not absolutely necessary. They have a rather short form in order to show that they are more compressed." 239 As a result, the fewer the words, the more potent. As Green comments about Baxter's later work: "his poetry gradually simplified and the content became all the more powerful." ${ }^{240}$ Allusions and subtext are heightened. This is challenging for the translator as in such cases there is rarely linguistic equivalence between French and English, and polysemy is key. "Watch This"241 and "Watch" use several meanings:

Elvira says look! there's a clock on my watch!

There's a clock on my watch too.

Now I can watch the time ${ }^{242}$

This ambiguity is to be taken into account in "The Gas-Fitter's Daughter Shows Shane":

12 a.m. and don't I show Shane and undo my watch to throw it before my heart

\footnotetext{
235 Ibid, p. 52.

236 "Barbary Coast" is composed of 23 quatrains. In Johnston, (2009), pp. 60-62.

237 "Painting Mount Taranaki" is 160 lines long. In Bornholdt, (1997), pp. 61-63.

${ }^{238}$ Wilkinson, (2015), p. 3.

${ }^{239}$ Pollmanns, (2010), p. 3.

${ }^{240}$ In Ricketts, (2010), p. 153.

${ }^{241}$ Jackson, (2011), p. 1.

242 Jackson, (2001), p. 9.
} 
Compression therefore adds to suggestiveness, a function that is central in poetry.

Another example is the laconic line "probably actually holding on" in "So Long as They Confine Themselves to This Chore", repeated in "Nothing Suggests Adulterous Proceedings" 243 by collage, what O'Brien calls expressionistic bricolage. ${ }^{244}$ In the first poem, the wife is physically holding on, "her hand on the handle." 245 The second poem conveys the figurative sense (waiting, trying to keep control, "coping"). An equivocal suspense and doubt lingers on, as it is the last line of the poem.

"Silence, It Means Something" plays humorously with the two meanings of pronounce:

The celebrant had laryngitis, they were never pronounced man and wife in so many words. ${ }^{246}$

Taken literally, "in so many words" might also suggest the difficult communication between protagonists, and by extension the terseness of Jackson's verse, and her compression.

The minimalist "Takahē" or "Dodo", ${ }^{247}$ with their one-word titles, in dimeters and trimeters, (and even monometers) emphasise rhythm and musicality. The alliterations in $-\mathrm{k}$ and $-\mathrm{b}$, (the similitude between "bulky" and "hook-beaked"), the near rhymes "sat", "size" and the parallelism between "it sat / on an egg" and "the size / of a pear" also visually stand out.

In "Detail", ${ }^{248}$ echoing Ursula Bethell's "Detail" and the ternary: "A Fig, an Olive, and a Bay" ${ }^{249}$ with "a hair-band, a bottle-top and a pin", the final dimeter contrasts with the other pentameters and, together with the three letters of "pin" and the assonance with "begin", this enhances the wonder children find in tiny things, as well as Jackson's miniaturism (what Manhire calls the inconspicuous ${ }^{250}$ ):

\footnotetext{
243 Jackson, (2006), p. 13.

${ }^{244}$ O’Brien, (2008), p. 3.

245 Jackson, (2006), p. 4.

246 Ibid, p. 3.

${ }^{247}$ Jackson, (2001), p. 28.

248 Jackson, (2003), p. 22.

${ }^{249}$ Bethell, (1997), p. 5. About Bethell's poem Bornholdt writes: “'Detail' was and still is a marvel to me - so plain, yet so full of everything" (In Johnston, 2009, p. 130).

${ }^{250}$ Manhire, (1991), p. 19.
} 
Treasures to treasure,

a pin to begin.

In these examples, Jackson's compression either emphasises the poem's musicality, its visual aspect, its polysemy and suggestiveness (multiple interpretations), and therefore, despite the constraint created, it is important that the translator aims at rendering this typical feature of Jackson's poetry. As Mário Laranjeria explains:

By casting a glance at the page containing the text, one sees that it is a poem and not a newspaper article, a letter or a story, and this creates in the reader a predisposition to a poetic, non-referential reading that will seek oblique signification, poetic significance. For the translator of poetry, the translation starts with transposing visual legibility. ${ }^{251}$

I take an example from the translation of Charles Juliet's "Trois poèmes écrits en Nouvelle-

Zélande" by Jean Anderson. They move aptly away from semantic exactitude, capture Juliet's sober tone, and are close renderings of the compressed graphical form:

The long wandering is ended
no more dead skies
no more hopeless battles
always defeated
$[\ldots]$
He drew strength
from his friendship
with the essential

Finies ces longues errances sous des ciels éteints Finis ces combats truqués où j'étais toujours vaincu [...] Il était fort d'avoir noué amitié avec ce qui compte ${ }^{252}$

In the opposite direction, Cécile Holdban's recent translations of poems by Janet Frame and Hone Tuwhare show less attention to the shape, as emphasised by the layout in parallel with the source poems:

\footnotetext{
${ }^{251}$ Laranjeria, (1996), p. 221.

${ }^{252}$ Juliet, (2005), pp. 43-44. In the first stanza, the repetition of "Finies / Finis" opening lines 1 and 3 is transposed to "No more", line 2 and 3. The adjectives "truqués" (rigged, falsified) and "éteints" (turned off, extinguished or subdued) respectively become "hopeless" and "defeated" by collocation with "battles".
} 


\section{Another Country Un autre pays}

Something the undertakers Une chose que les entrepreneurs de pompes funèbres do not choose to undertake choisissent de ne pas entreprendre

is to grow the tree that provides the wood c'est de faire pousser l'arbre qui fournit le bois

for the coffin of man woman and child. pour le cercueil de l'homme la femme et l'enfant.

\section{Small white coffins Petits cercueils blancs}

thin as planks tenus comme des planches

like chocolate boxes go comme des boîtes de chocolat dévalent

down the slopes past the Stations of the Cross les pentes en passant devant les Stations du Chemin de Croix. ${ }^{253}$

French is less condensed than English ("faire pousser" is two words for grow). However, my

skopos would be to reproduce the compressed form of the mostly trochaic dimeters with a final

pentameter suggesting a funeral march, ${ }^{254}$ and to achieve this, I would make some semantic

modifications: $:^{255}$

\section{Another Country}

Something the undertakers

do not choose to undertake

is to grow the tree

that provides the wood

for the coffin of man woman and child.

Small white coffins

thin as planks

like chocolate boxes go

down the slopes past the Stations of the Cross
Un autre pays

Ce dont les fossoyeurs

préfèrent se défausser

c'est de cultiver l'arbre

qui donne le bois

du cercueil de l'homme femme et enfant.

Petits cercueils blancs

fines planches

boîtes de chocolats qui

descendent la pente des Stations de la Croix

b. Line breaks

\footnotetext{
${ }^{253}$ Frame, (2009), p. 33.

${ }^{254}$ The atmosphere of gloom is lightened by the simile "like chocolate boxes go".

${ }^{255}$ The first stanza in The Pocket Mirror includes five lines. Frame, (1967), p. 99. If the black humour resulting from the pun "undertakers / undertake" needs stronger focus, I could offer: "Ce que les croque-morts / choisissent de ne pas croquer / c'est le portrait de l'arbre / qui pousse pour fournir le bois..." No doubt further versions would continue to evolve.
} 
Jackson also gives much care to line breaks, following Emily Dickinson or William Carlos Williams. ${ }^{256}$ Williams" "The Red Wheelbarrow" is alluded to in "While Life is Just Preparing Things Off Scene" ("his stupid red wheelbarrow"257):

\author{
so much depends \\ upon \\ a red wheel \\ barrow \\ glazed with rain \\ water \\ beside the white \\ chickens. $^{258}$
}

Celena Kusch proposes that "the poem is not about wheelbarrows, but about the nature of poetry itself, and the line breaks that distinguish poetry from prose. It is a poem about poetic experimentation." 259 According to Milton Kaplan, "Williams Carlos Williams goes through almost endless experimentation to present a poem that seems to be made up of lines broken arbitrarily." 260 By separating words sometimes associated (wheelbarrow, rainwater), line breaks offer new possibilities: "breaking up a line is a strategic device that is part of the poem." 261 In The Long Road to Teatime, the technique is visible in "Just a Mineral Water with Marianne Moore" 262 emphasising the intricate rhyming and syllabic pattern or "To the Chemist with Jane", ${ }^{263}$ in which sounds mimic a sneezing fit. In "Camellia"264 the collocation "kitchen

\footnotetext{
${ }^{256}$ Jackson states about her university days: "the next year in modern poetry taught by Don Smith we learned about Ezra Pound modernising Yeats and about the rigorous line breaks of William Carlos Williams" nzpoetryshelf.com/tag/anna-jackson/page/3/. Accessed 22 Dec. 2016.

${ }^{257}$ Jackson, (2006), p. 26.

${ }^{258}$ Carlos Williams, (2003), p. 27.

${ }^{259}$ Kusch, (2016), p. 74.

${ }^{260}$ Kaplan, (1971), p. 47.

${ }^{261}$ Ibid, p. 48.

262 Jackson, (2000), pp. 32-33.

${ }^{263}$ Ibid, p. 28.

264 This is also a case where short lines emphasise the poet's alliterative work, evident in "kete", "kitchen, "stretch", "reach" and "catch on". Jackson, (2001), p. 5.
} 
door" is split into an enjambment and the near rhyme between "kitchen" and "catch on" is emphasised.

Line breaks also stress designs between and inside stanzas, as in "Kikuyu", which might suggest waves. ${ }^{265}$ "The Happiness of Poets: Sto Ste Sto Ste"266 is reminiscent of typographical experiments by the Futurists or concrete poetry, as in section 10 of "The Long Road to Teatime."267

In "The Gas-Fitter's Daughter Shows Shane" the abrupt indent "- I can't read / it" and the time ellipsis following the interrupted "but he -" render the protagonist's drunkenness, resemble journal entries, and as will be shown, this leaves room for various interpretations.

A similar assessment is therefore made in terms of rendering Jackson's line breaks in translation. In cases where line breaks have a significant function - visual, musical, narrative, interpretative - these need to be kept by the translator.

\section{c. Formal variety}

There is a constant coming-and-going between free verse and fixed verse. "Breakfast with Rufy" uses couplets varying between pentameters, hexameters and heptameters (in "Rhyming with Lisa" or "Daydreaming with Diana"268). The Pastoral Kitchen also includes longer stanzaic forms as the four quintets of "The Peacock of Motherhood", ${ }^{269}$ the six quatrains of "The Vending Machine"270 or the three septets of "The Computer Hen."271 "Mealtimes at the Bookhouse" is often in rhyming couplets ("Breakfast with Katherine Mansfield" or "Coffee

\footnotetext{
265 Ibid, p. 17.

${ }^{266}$ Jackson, (2003), p. 35. In Mayakovsky's poem, each word (“grib, grab, grub, grob”) is already singled out.

267 Jackson, (2000), p. 19.

268 Jackson, (2000), pp. 25-26.

269 Jackson, (2001), p. 7.

${ }^{270}$ Ibid, p. 12.

${ }^{271}$ Ibid, p. 11.
} 
and Cheese with Gudrun and Ursula"272). "A Beautiful Theory Isn't a Poem, James"273 is composed of thirteen rhyming couplets mostly in pentameters, "Envelope"274 of five regular tercets. Unrhymed tercets and couplets are recurrent throughout ("Kitchen Drain", ${ }^{275}$ "Marry in Haste"276, or "Fontanello") but the recent I, Clodia, and Other Portraits, is mostly in free verse.

"The Coming on of a Maths Brain" is a "fib" 277 using the Fibonacci sequence to determine the syllable length:

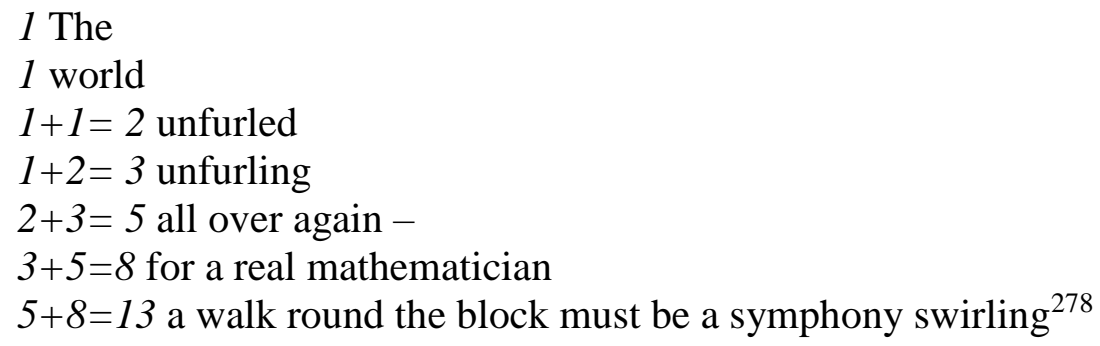

Jackson adds a ninth stanza as an upside-down footnote in small font, which reverses the pattern. Contrarily to some of the formal games of the Oulipo, format is here coherent with content and the poem also deals with the realisation that equations hold beauty in revealing harmony: "music is maths." 279 This is also found in "The Christening Spoon":

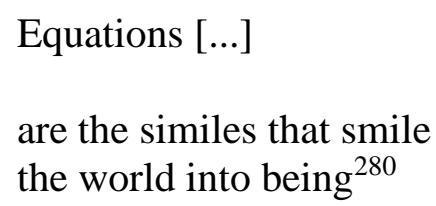

"Just a Mineral Water with Marianne Moore" is a kind of challenge to the American poet: "I'm not afraid to get my head bitten / off by this American treasure." In Moore's "The Fish",

\footnotetext{
272 Jackson, (2000), p. 34.

${ }^{273}$ Jackson, (2011), p. 26.

274 Ibid, p. 35

275 Jackson, (2001), p. 8.

276 Jackson, (2011), p. 2.

${ }^{277}$ See: gottabook.blogspot.co.nz/2006/04/more-fibbery.html. Accessed 31 Jan. 2017.

278 Jackson, (2011), p. 23.

${ }^{279}$ Ibid, p. 24.

280 Jackson, (2003), p. 19.
} 
following an AABB rhyme pattern, lines are of varying length with indents so the lines look like waves:

wade

through black jade.

Of the crow-blue mussel-shells, one keeps

adjusting the ash-heaps;

opening and shutting itself like 281

As a response, almost a pastiche, Jackson's piece carries over four octaves with an ABCBCA rhyming scheme. Each third line of three syllables rhymes with the last line of two syllables. The fourth line of six syllables rhymes with the sixth line of eleven. The fifth line of ten syllables rhymes with the seventh of nine:

7 who would have had 'orange zuice,

6 farina, banana',

3 earlier (A)

6 and then would have written (B)

10 several poems in syllabic measure. (C)

11 Well I'm not afraid of getting my head bitten (B)

9 off by this American treasure, (C)

2 her purse (A)

Such a tour de force presents challenges for the translation, yet its specific creative function a kind of dialogue - demands the pattern be kept.

In the sequence "I, Clodia", Jackson similarly plays with formal constraints to respond to Catullus in "Oh, in Hendecasyllables"282 in dactylic hexameters. A dactylic hexameter consists of five dactyls and either a spondee or a trochee, in which any of the first four dactyls, and sometimes the fifth, may be replaced by a spondee. "From the Distance"283 uses Sappho's metre. The four quatrains of three hendecasyllables and a final indented dactylic dimeter that characterise Sappho's metre are also used in "A God in his Way." 284 The use of this archaic

\footnotetext{
${ }^{281}$ Moore, (2016), p. 41.

282 Jackson, (2014), p. 19.

${ }^{283}$ Ibid, p. 30.

${ }^{284}$ Ibid, p. 7
} 
form is commanded by context, a defiant response to Catullus, who used it in Carmen 11. It reinforces the narrative: from Clodia to Catullus as a poetic game. ${ }^{285}$ This narrative function justifies keeping the form, or a form that is mimetic of the original metre - without the long or short syllables of Latin.

In "Roland on the Outskirts", Jackson features epanalepsis - reusing the final word (or words) of a sentence at the start of the next. This suggests circularity ("full circle"), a central allegory: "The end for me, that is, but the beginning for my son." Life journeys through odd places, strange locations that need to be connected on the way home. "Cambio's Wife" skips the final epanalepsis, breaking the cycle with an open question: "what / was it he was clutching in his hand?"286 "Seeing You" ${ }^{287}$ is one long imbricated sentence carrying over ten couplets with a final reprise. Albeit digressive in appearance, these are intricately structured poems. Like paper garlands, their structure unfolds once finished.

Formal constraints are never gratuitous or ornamental in Jackson's verse. They are a stimulating creative feature informing the writing process, and inspiring the poem's content. What would be the point, therefore, of translating a poem based on a formal experimentation without respecting the form in question? Beyond the debate on the rendering of rhymes, for instance - in France, Efim Etkind or André Markowicz are famous supporters, while Yves Bonnefoy or Robert Ellrodt are against it - these few examples justify keeping the form because it is not only a meaningful feature of the text, it is an essential constituent of the writing process.

\section{d. Echoes}

In “Afraid of Falls?”, Jackson writes:

We rose asleep.

We rose silent, [...]

\footnotetext{
285 Jackson explains: "Catullus had a wide circle of friends and associates with whom he traded verses, often point-scoring” (Jackson, 2014, p. 65).

${ }^{286}$ Ibid, p. 54.

287 Jackson, (2011), p. 40.
} 
In the end we rose apart. ${ }^{288}$

She explains:

This is a meditation on rising and falling, and on childhood as a time before a fall, when instead of falling asleep you might rise asleep, and keep on rising. ${ }^{289}$

This experimental turning things upside down between rising and falling is recurrent, as in "An Explanatory Wave of the Hand" (turning the biblical fall of Babylon into an evaporation), or "The Photographer's Olympics"290 ("the screenshot / of arms rising and falling"). The Gas Leak repeatedly evokes the rise and fall of streets, or of the lift, echoing the seminal "The Treehouse" (Catullus for Children): "the rise and fall of him" ${ }^{291}$ describing a sort of intimate Sisyphean motif. It is in her borrowing of Mayakovsky's image "the street had skidded out from under his feet" ("Silence, it Means Something"), about which Peter Wright writes: "(this) asks us to re-imagine how we might see the world. [...] A horse slipping in the street can be reimagined." 292 This mathematical sense of reciprocal (inverting the numbers of the equation) echoes the reciprocal relation between inside and outside themes (observed earlier) between stillness and movement in "The Pretty Photographer" ("the stills are nothing without the movement"293).

More generally, Jackson's verse echoes with self-references or allusions. For Erin Scudder, "lines torn from past poems are akin to vampires: altered sentiments couched in familiar bodies." ${ }^{294}$ The Gas Leak partly works as a collage from Catullus for Children, by repetitions of "my heart spins round" from "The Madonna of the Mice" 295 "shining a torch / into the forest

\footnotetext{
288 Jackson, (2014), p. 62.

${ }^{289}$ Green, (2014).

290 Jackson, (2014), p. 41.

291 Jackson, (2003), p. 18.

292 Wright, (2003), p. 200.

293 Jackson, (2014), p. 41.

${ }^{294}$ Scudder, (2017), p. 144.

${ }^{295}$ Jackson, (2003), p. 27. The image is reused in "Predicates of Appreciation". Jackson, (2006), p. 16.
} 
around us" from "The Treehouse."296 The image of gas leaking reappears in "Basement"297 (Thicket). "Poetry and its Returns" returns to the idea of an error in print ${ }^{298}$ found in The Gas Leak. "Zina at the Zoo"299 refers to Mayakovsky's "telegrams in the night" cited in Catullus for Children. In "The Long Road to Teatime", the lines "My friendship / with Mayakovsky is my sole / claim to fame" are a nod to her earlier "My Friendship with Mayakovsky" (1999). Bella Akhmadulina is central to "The Happiness of Poets, Sto, Ste, Sto, Ste”, referred to already in "The Hen of Tiredness" (The Pastoral Kitchen):

like Bella Akhmadulina's rain, following me wherever I go 300

World overpopulation and ecological concerns from The Pastoral Kitchen can be found in "Mairamkan Abilkasimova's Future-Faith"301 (Catullus for Children). Echoes are evident in juxtaposed poems, stressing symmetry: "Bella Akhmadulina's Umbrella" pairs with "Bella Akhmadulina's Motor-Scooter" 302 and "Red Riding Hood" with "Red Riding Hood's Mother."303 “Johnny's Minute" sends readers back to "In a Minute" (The Pastoral Kitchen):

I will look at Johnny's work in a minute. You promise to have your bath in a minute.

Not now because now is a dark wood the length of a beach the height of the sky. ${ }^{304}$
Not now, because now you are a glueing a beach, you are painting the sky. ${ }^{305}$

\footnotetext{
${ }^{296}$ Also reused in "Predicates of Appreciation". From "Looking to the Fittings", the lines "she can't sit down / to read a book / without leaving little yellow decks / behind her," (Ibid, p. 8) is maybe an allusion to "little yellow birds [...] Everywhere I go I leave yellow feathers" from "The Hen of Tiredness" (Jackson, 2001, p. 10). 297 Jackson, (2011), p. 3.

298 "The poem prints out terribly shadowy" (Ibid, p. 47).

299 "I will not cry a single tear for you, / leave it to the men / to send elaborate telegrams in the night" (Ibid, p. 38).

300 Jackson, (2001), p. 10.

301 "The world is scared of overpopulation, / and I know it has been said / this is the end of evolution" and the notion of "landscaping" (Jackson, 2003, p. 34) echo "Conclusion": "This is the end of evolution. [...] There is no escaping / our landscaping” (Jackson, 2001, p. 51).

302 Jackson, (2003), pp. 40-41.

303 Jackson, (2011), pp. 10-11.

${ }^{304}$ Jackson, (2001), p. 18.

305 Jackson, (2003), p. 26.
} 
Considered as a strategy in the writing process, this network of echoes rewards ${ }^{306}$ readers who have read all Jackson's selections. If only to grasp how these echoes function, the translator must have read the poet's entire published work.

What, then, are the essential characteristics of Jackson's poetic voice that will require the translator's attention? Overall, Jackson recurrently uses puns (from Thicket's back cover: "it is all so tangled / I can't tell if you're combing / or growing..."307), combinations of phonetically or graphically similar words ("hearse / horse", "presence / present", "uncle / knuckle", "food / foot"); she subverts common expressions (under / over the weather, ${ }^{308}$ by the seat of your pants, ${ }^{309}$ "a ticket, a casket" ${ }^{310}$ ), imitates orality (child's speech in Catullus for Children, teenager's slang in The Gas Leak ${ }^{311}$ ), coins neologisms ("Ghostess"312 or "disghosting"313) or invents onomatopoeia ("Sproing!" in "Rocket", 314 "sto, ste", "tick clock" in "Watch"315), and favours short form and monosyllabic words, graphically emphasising sounds and meanings (line breaks, compression, and a constant use of italics ${ }^{316}$ ).

\footnotetext{
${ }^{306}$ A recent example of this occurs in "Morning are Sudden" (Jackson, 2018, p. 113), in which the garden's "blackberry vines" ("Evelyn after Tennis"), "cicadas" (Catullus for Children), or "crickets at night" ("The Father Late at Night") are so many echoes to previous works.

${ }^{307}$ Jackson, (2011), back cover.

308 Jackson, (2001), p. 16.

309 Jackson, (2006), p. 3.

${ }^{310}$ Ibid, p. 26, instead of the nursery rhyme "A tisket a tasket". This is echoed in "Summer": "This is a thicket / not a casket" (Jackson, 2011, p. 53).

311 “The Gas-Fitter's Daughter's Recurring Solution" sees Jackson exploring different mediums used by teenagers to communicate (texting, eyes signals, talking) and playing with slang: "we obviously are going / to have to get out of here, / go somewhere where we can / get totally written" (Jackson, 2006, p. 34).

312 Jackson, (2011), p. 3.

313 Jackson, (2014), p. 61.

314 Jackson, (2011), p. 37.

315 Jackson, (2001), p. 9.

${ }^{316}$ In "The Gas-Fitter's Daughter on Stage": "It isn't unusual to think my father / is there but tonight he actually / is there" (Jackson, 2006, p. 20). The italics suggest that the character might not, even when present, always give his full attention.
} 


\section{B. CASE-BY-CASE ANALYSIS}

\section{Translating The Long Road to Teatime}

I now examine a sequence from The Long Road to Teatime: "16 Pākehā Waka" and a shorter poem "Just a Mineral Water with Marianne Moore". ${ }^{1}$ This selection shows a variety of issues mostly related to intertextuality, wordplay and fixed form.

a. "16 Pākehā Waka"2

The sequence asserts its New Zealand setting or "New Zealandness" by weaving references to Sullivan's Star Waka, Māori mythology and whakapapa, which can be assumed to be unfamiliar to the French translation's audience. In such a situation, Nord's question is:

Is it (the translation) meant to give the receiver information about the way a particular source text works or worked for its source-culture audience, or is it intended to serve as a communicative "instrument" in its own right, fulfilling the same or a similar function for a particular target-culture readership or a general target-language audience ${ }^{3}$

My aim is to create a documentary translation that is also instrumental. I offer some contextual information in notes, leaning towards a documentary translation. Yet, my intention is also to convey the poetry of the text, and write a poem that can stand by itself, in its own right.

In "16 Pākehā Waka", the cultural elements specific to New Zealand are: "Pākehā", "waka", "Māui”, “the Hiki”, “taonga”, “tohunga”, "Hawaiiki”, “Kohanga Reo”, “Waitangi Day”. I am confronted by spelling issues. Borrowing these terms is problematic when they are in the plural form, as in the title: "16 Pākehā Waka" (and not "Wakas"). Jackson respects the spelling rule observed in New Zealand English, overriding the mark of the plural in British English. ${ }^{4}$ Another issue with unofficial borrowed words in French ${ }^{5}$ concerns the attribution of a gender:

\footnotetext{
${ }^{1}$ Source poems and translations in parallel can be found in the appendix.

${ }^{2}$ For full translation with source poem in parallel, see Appendix pp. 3-10.

${ }^{3}$ Nord, (2005), p. 27.

${ }^{4}$ Laurie Bauer notes: "a form such as pipis is 'wrong' because it uses English morphology on a Māori word" (Bauer, 2007, p. 9).

${ }^{5}$ Michel Ballard defines these as "reports": "Acte individuel de traducteur, ponctuel, qui [...] ne consacre pas l'intégration d'un terme dans sa langue même s'il peut, dans certains cas, en avoir la visée, dans le cadre d'une option de traduction qui cherche à faire connaître l'étranger" (Ballard, 2006, p. 118).
} 
masculine or feminine? As stated in the introduction, another problematic trend when borrowing terms is to italicise them - a typographical emphasis, which Jackson does not use.

The formal (linguistic) difficulties can be organised in three groups. First, the past tense is used to refer to the mythological episode of Māui fishing New Zealand, to Jackson's ancestors shifting to Aotearoa, and to the more recent family trip to Europe. In French, these can be conveyed by different past tenses, and this adds nuances.

Second, the graphic design of the lines makes a visual impact. Most triplets or couplets are regular in length (mostly pentameters and hexameters), creating homogeneity. The structure of poem 8 for instance stands out visually on the page with its diminishing stanza:

The baby carved me out inside and I was a waka for a fish that was a waka for a person.

The same could be said of poem 11, with repetitions creating parallelism, and it is difficult to reproduce the shape because some idiomatic expressions ("heavy weights", "the olden days", "somewhere like Home" or "hilltop") or compound adjectives ("story-telling, war-wagging people") do not have an equivalent in French and need to be unpacked. Vinay and Darbelnet's "étoffement" is unwelcome as it lengthens the line instead of compressing it (“dépouillement”). Jirí Levý speaks of semantic density in languages:

A discrepancy in semantic density between source and target language forces the translator either to compact the semantic meaning into a concise expression or, in contrast to resort to padding, with implications for the overall interpretation of the poem. ${ }^{7}$

I intend to stay close to the visual legibility not only for its aesthetics but because it is linked to rhythm and musicality (melopoeia).

\footnotetext{
${ }^{6}$ Vinay and Darbelnet, (1977), p. 50.

${ }^{7}$ Levý, (2011), p. 196.
} 
Third, as Jakobson stated: "paronomasia reigns over poetic art" ("walker" / "waka"), anagrams ("manes", "names") and inventions ("there is a dark wood to carve into a would" or the phonetic transcription "bruvva"). In Nord's terms, this wordplay has an expressive function - humour and emotion as in: "Not a walker but a waka, / my waka to the stars", and a referential function - Star Waka, Inferno. How might these be rendered?

Translation commentary

My notes are brief and only give an idea of what is in play:

Waka : véhicule, pirogue traditionnelle māori

Pākehā : relatif aux hommes et femmes blancs.

Māui : héros et demi-dieu de la mythologie māori, célèbre pour ses exploits surnaturels. Il hissa notamment la Nouvelle-Zélande du fond de l'océan.

Hiki : chant ou prière.

Star Waka: livre de poèmes de Robert Sullivan (1999) reprenant notamment le rituel whakapapa qui consiste à énumérer sa généalogie.

Taonga : trésors matériels ou immatériels.

Tohunga : expert, sage, sorcier, prêtre ou guérisseur.

Hawaiiki : île imaginaire, lieu originel d'où les Māori seraient partis.

Kōhanga Reo : programme scolaire d'immersion linguistique māori, littéralement nid de langue.

Waitangi Day : journée nationale de la Nouvelle-Zélande qui célèbre la signature du Traité de Waitangi entre la couronne britannique et les chefs des principales tribus māori, le 6 février 1840.

Instead of using notes, I have also considered explicitation. ${ }^{9}$ Using this strategy, the first lines could include "le héros Māui" or "la prière du Hiki". However, this would extend the lines considerably, and I offer instead:

Tout comme Māui chanta jadis le Hiki pour rendre tous les poids légers, et ainsi à bord de son waka tira la Nouvelle-Zélande de son hameçon,

Without having to use the notes, readers can guess the meaning of "Hiki" combined with “chanter". However, the glossary is necessary in some instances:

Il y a tous les taonga de mon tohunga

\footnotetext{
${ }^{8}$ Jakobson, (1959), p. 239.

${ }^{9}$ In the sense of Vinay and Darbelnet: "introduire dans la langue d'arrivée des précisions qui restent implicites dans la langue de départ, mais qui se dégagent du contexte" (Vinay, Darbelnet, 1977, p. 9).
} 
à empaqueter.

These lines also illustrate that I do not pluralise common nouns, and respect spelling rules in Te Reo.

Bearing in mind my ideal of balance between gain and loss, my solutions are presented in two groups. On the one hand, I present occurrences where I reduce communication breakdown, as Chesterman explains:

Translators are like doctors in that their task is to intervene in certain cases of communicative suffering: those involving language and culture boundaries. Not all cases of communicative suffering, note [...] just some. Their job is to cure or alleviate these particular kinds of communicative suffering. Their intervention may not always lead to "perfect communicative health", any more than a doctor's intervention always leads to a perfect cure. But the aim is at least to reduce this suffering. ${ }^{10}$

On the other hand, I accentuate what was less prominent in the source poem. Bassnett addresses this:

It is again an indication of the low status of translation that so much time should have been spent on discussing what is lost in the transfer of a text from SL to TL whilst ignoring what can also be gained, for the translator can also at times enrich or clarify the SL text as a direct result of the translation process. ${ }^{11}$

For instance, translating the preterit into passé composé, imparfait or passé simple adds meaning. My choice to use passé simple for the mythological past is inspired by Jean Anderson and France Grenaudier-Klijn in Les Enfants de Ngarua:

Le passé simple a été retenu pour les quelques chapitres consacrés au passé lointain de la communauté, la distance temporelle comme les caractéristiques lexicales de ces chapitres justifiant ce choix. Ces chapitres, d'essence presque mythologique, constituent 1 'armature du récit. ${ }^{12}$

\footnotetext{
${ }^{10}$ Chesterman, (2001), p. 151. Responding to Chesterman, Nord states that: "A doctor acting in an ethical way will therefore not only cure the symptoms the patient is complaining about but also try to discover the origin of the illness and look for a remedy. The translator is such a doctor who tries to prevent communicative suffering by responsible and professional procedures" (Nord, 2006, p. 36).

${ }^{11}$ Bassnett, (2014), p. 36.

12 Grace, (2008), p. 8.
} 
The passé simple is the narrative tense par excellence for mythology, and I generally keep this strategy (see also "The Long Road to Teatime" poem 8: "lorsque ses flancs se déplumèrent"). For less distant events, I use the passé composé also because of the more conversational tone. Jackson uses the nickname "my Gran"along with incomplete (nominal) sentences: "Not a walker but a waka", and relates casual anecdotes: "they didn't hire out togs":

J'ai pris une photo de Simon rue Elvira sous son nom en graffiti - S I M O N -

et il m'a prise en photo sous le panneau E L V I R A avec Johnny, qui aurait pu être Elvira,

The tone is casual but elegant, and the sentence structure is never slack. To avoid familiarity and maintain a certain standard in style, I mostly use "nous" rather than "on" - however with the anecdote in Bangor, the casualness justifies using "on".

On the other hand, I attenuate some of the source text features. The three repetitions of "up" in poem 1 are lessened with two "monter" to avoid lengthening the line and sounding redundant. "Johnny Smoke", a possible reference to the 1960s character of an anti-smoking campaign advertisement ${ }^{13}$ is lost when borrowed, yet translating "Johnny Fumée" is unsatisfying because it does not refer to anything. ${ }^{14}$ The preposition "into" in "before I translated it into my own life" has a more specific meaning than "dans ma propre vie". Jackson installs the Inferno into her own life, rather than the idea of a time period synonymous to "lors de ma propre vie". Yet, something like "à l'intérieur de ma propre vie" would be too long, and using "dans ma propre vie" enables me to reproduce the design of the lines, as in poem 8 for instance:

Le bébé m'a sculptée de l'intérieur j'étais un waka pour un poisson qui serait un waka pour une personne.

\footnotetext{
${ }^{13}$ hidden1960s.wordpress.com/2013/10/08/johnny-smoke/. Accessed 13 Oct. 2017.

${ }^{14}$ A potential equivalent might be the Marlboro Cowboy or Lucky Luke.
} 
When drawing up the list of losses and gains, "le cahier des charges" of my translation - and this is even truer with a sequence - small modifications contribute to the overall rendering of tone not only for linguistic reasons but also for implicitly subjective ones - the "it just sounds better" reason. These small operations might be spaces in between, based on my interpretation of voice. As Jones points out:

With affective / implicit strategies, the translator's first focus should be not on the words but on the "spaces in between". Not on the semantics, therefore but on the texture and sensation of the text for this is what makes poetry poetic. [...] We should "compose ourselves" to reproduce the "unspeakable, the enigmatic": translation as an act of love (or at least of empathy). ${ }^{15}$

Concerning wordplay, I am inspired by Ballard's "équivalence pragmatico-fonctionnelle":

Equivalence pragmatico-fonctionnelle, la dynamique de réécriture est davantage soumise à la création d'un effet sur le récepteur du texte. Elle intervient dans la traduction des jeux de mots, la poésie, [...] c'est-à-dire dans les cas où apparaît la nécessité de ne pas seulement envisager le sens des mots comme objet de la traduction mais la fonction du langage dans le texte, son éventuelle relation au support et l'impact que l'élément traduit doit avoir sur le récepteur. ${ }^{16}$

Bassnett's approach is also useful. About her translation of Argentinian poet Alejandra Pirzanik, she writes:

There is different wordplay going on in the English poem, but one that takes up the idea of ambiguity. In calling this a translation, I am engaging in what Balmer has defined as "transgressive behaviour", but this arguably does more justice to Pizarnik's poem than any literal translation might do. The purpose of poetry, after all, is to be read to be poetry. ${ }^{17}$

The wordplay "wood / would" has a programmatic function for Jackson, in the manner of a skopos. The juxtaposition of two hyphened rhyming words "un vouloir-espoir", rhyming with "un bois noir', is an invention ${ }^{18}$ that encompasses the meaning of the neologism "a would" (conditional and willingness).

Il y a un bois noir à sculpter

\footnotetext{
15 Jones, (2011), p. 24.

${ }^{16}$ Ballard, (2004), p. 53.

${ }^{17}$ Bassnett, (2011), p. 101.

${ }^{18}$ To translate "will" in his preface to Shakespeare's Un Conte d'hiver, Bonnefoy uses a similar compounded form: "un vouloir-être" (Bonnefoy, 1994, p. 24).
} 
en un vouloir-espoir.

This might sound slightly odd but as Lefevere points out: "liberties on the purely linguistic level will be tolerated when they are seen as potentially refining, improving, extending the language of the receiving culture."19

I compensate the anagrams "manes / names", with the pun "émanent des manes". This homophony also compensates for "would / wood" in poem 9. My translation conveys that names contain some hidden meaning - the soul of words? - an idea present in various places "Hawaiiki”, "Ifor", or "Elvira", "Urbi et Orbi", all being explicated by the poet.

The solution "ffwè" reproduces (as in Vinay and Darbelnet's technique of "calque") "bruvva" by doubling the consonants (-f for $-\mathrm{v}$ ) and marking an ellipsis of $-\mathrm{r}$ (with a -w). "Bruvva" is a more common alternative for "brother" than my invention "ffwè"” - "bruva' is slang for instance - but its function is kept: to mimic the speech of a young child.

The pun "walker / waka" is the most challenging trait. My first solution was: "elle ne marche pas car c'est un waka", eluding all wordplay. This reduces the strength of the final lines and of the whole poem. Despite my best efforts to look at homophony, I have to resort to modulating and transposing the last two couplets to render the rhyme. The expression "pas de tracas" which I add, by compensation, is typical of the context: the New Zealand "no worries" attitude. It is not perfect but it is a safe intervention, rendering musicality ("tracas / waka"), sense of formula (final "punchline") and meaning. It opens for the tenderness expressed in: "mon waka vers les étoiles" sending readers back to the opening reference to Star Waka. ${ }^{20}$

Mais pas de tracas, c'est un waka: mon waka vers les étoiles.

\footnotetext{
${ }^{19}$ Lefevere, (1992), p. 4.

${ }^{20}$ The synonymy between "une étoile" and "une star" is obvious enough to suggest the circularity of the end.
} 


\section{b. "Just a Mineral Water with Marianne Moore" 21}

This poem is a fictional conversation between Jackson and Moore. Cliché language (a bar order) suggests the overlapping of reading (abstract process) and real life (the here and now). This is coherent with the vignettes assembled in "Mealtimes at the Bookhouse." 22 These conversations are metaphorical: Moore is dead yet her voice can be heard in her work. Aurore Clavier shows that Moore herself was a conversational poet, also paying much attention to the design of her stanzas (“dessin de la strophe"):

Dans l'essai "Feeling and Precision" elle énonce l'un des principes fondateurs de la composition, qui fait de la contraction, de la précision, la condition de la sincérité. Mais au-delà du seul énoncé, il y a quelque chose à retenir [...] de la conversation débridée entre Moore et les auteurs qu'elle cite. Et c'est justement ce même rythme "prosaïque" que l'on retrouve dans sa poésie, à ceci près que le dessin de la strophe poétique rend plus manifeste les pauses et les accents subtils de la poète..$^{23}$

Moore's presence could be described as irreverent and metamorphic. Almost as a pastiche, ${ }^{24}$ the poem adopts Moore's syllabic meter. The syllabic and rhyming pattern of the four octaves is: 7/6/A3/B6/C10/B11/C9/A2. The rhyme pattern is enriched by internal rhymes: "quote / caught", "poet / laureate", "farina / banana". These formal elements complement the portrait. Jackson caricatures prominent attributes: "face all smiles and wrinkles", and her signature tricorn: "her hat, her great hat". She speaks in stuttering negatives: "No indeed, no not I, not at all” and with sigmatism (the lisp “zuice”). Jackson's poem therefore transforms into a Moorean poem (metamorphic).

\footnotetext{
${ }^{21}$ For translation with source poem in parallel, see Appendix p. 11.

${ }^{22}$ Jackson, (2001), p. 50. In Poetry NZ, Jackson included several poems as so many declinations of this project, inviting Sylvia Plath for fish and chips or Virginia Woolf for dinner ("Making a Meal of the Thesis").

${ }^{23}$ Clavier, (2012), p. 88.

${ }^{24}$ A nuance regarding this: the text is a non-mocking parody or an imitation: "La parodie est une imitation consciente et volontaire, soit du fond, soit de la forme, dans une intention moqueuse ou simplement comique" (Dupriez, 1984, p. 330).
} 
The portrait's irreverence also lies in the mention of Moore's "strict use of quotes". Jackson purposely misquotes the American poet, for whom, it was important to quote rather than paraphrase:

When a thing has been said so well that it could not be said better, why paraphrase it? Hence my writing is, if not a cabinet of fossils, a kind of collection of flies in amber. ${ }^{25}$

Here, the metaphor becomes "a collection of lies in amber". The pun "of lies / of flies" is extended in the last stanza: "But I could swear I caught / sight of at / least a fly paralysed / if not paraphrased in her quotation." Jackson's choice of "paralysed" shrewdly combines "paraphrased" (by echo) and "lies", the modifying or "lying" element of the quote.

Such a trait is likely to go unnoticed by source readers. Jackson insisting on the paraphrasing nature of her quotation possibly alerts some that an extra layer hides beneath the homophonic ambiguity. Despite the poet's signal - and unless the quote from Moore is more famous than it would appear ${ }^{26}$ - few source readers would understand it. Second, it is unlikely it may be reproduced in translation. Nord tackles this issue:

The referential function relies on shared knowledge between sender and recipients. To make the referential function work, the translator will aim to produce an appropriate balance between presupposed and verbalised information in the translatum as well. This means that they explicitate implicit information which the target audience cannot be assumed to be familiar with, and implicitate information which they consider to be redundant for them. ${ }^{27}$

The hypothesis that I may use the French translation of the quote is unworkable: Moore's poetry is little translated into French and the quote is taken not from poems but an interview. ${ }^{28}$ However, Moore has seminal importance here: in the final stanza, after a sigh and "a Sapphire gin", she is inspired to write, at which point the poem ends - and begins.

\footnotetext{
${ }^{25}$ Moore, (1961), p. xv.

${ }^{26}$ A Google search of the quote shows 18,500 results. This is low compared to Hemingway "I am always in love" $(1,500,000)$, Frost "I took the one (road) less travelled by, and that has made all the difference" $(7,500,000$ results).

${ }^{27}$ Nord, (2013). Emphasis in the original.

${ }^{28}$ The only collection translated into French is by Thierry Gillybœuf in 2004.
} 
Juste une eau minérale avec Marianne Moore

qui prendrait "un zus d'oranze,

floraline et banane"

avant ça

puis écrirait après

plusieurs poèmes en mètres syllabiques

mais je n'ai pas peur de me faire mordre la tête

par ce trésor venu d'Amérique

son sac

sur les genoux, tête à l'ombre

sous son chapeau splendide

encadrant

ce sourire tout de rides

quand elle réfute ce que je n'ai pas dit.

"Non, mais non, mais non pas du tout", elle pétille,

non que je sois vraiment déconfite

par tant

d'acuité chez cette Poète.

Phrase par phrase, elle décon-

struit chaque

principe qu'elle énonce.

Elle répétera : "pourquoi paraphraser?"

Un "amas de bouches prises dans l'ambre", gaie réponse

sur le moyen strict, particulier,

qu'elle a

de faire siennes les citations

mais je jurerais avoir

$\mathrm{vu}$, prise,

une mouche paralysée,

non paraphrasée dans sa citation.

Elle est partie. J'ai versé le jus, soufflé,

puis bu un Gin à la place, j'ai donc

écrit.

Translation commentary

Despite Robert Ellrodt's warning that "trop souvent la traduction rimée tourne alors au pastiche et son infériorité par rapport à l'original devient trop éclatante" 29 I reproduce the rhyming and

${ }^{29}$ Ellrodt, (2006), p. 68. 
syllabic patterns, offering what Holmes calls an analogical translation. ${ }^{30}$ Thierry Gillyboeuf does not do this systematically in his translation of Moore. ${ }^{31}$ In Ritta Baddoura's opinion:

Face aux reproches faits à la poésie moorienne en termes de "sécheresse mathématique", Gillybœuf oppose l'argument d'une symétrie pentamère comme les échinodermes, ou spiralée comme le scalaire. Il invoque une poésie essentiellement visuelle, empreinte d'humour et caractérisée par une musicalité étonnante là où la syllabe donne la mesure et non le mètre. ${ }^{32}$

Constraints arguably channel creativity. Francis Jones acknowledges that "recreating rhyme and rhythm, [...] often stimulates creative transformations." ${ }^{33}$ This is evident when I look at my first draft, which I find readable but flat and even unflattering as it overlooks the syllabic measure.

I compensate for the loss of the repetition of "hat" in the second stanza (line 10: "her hat, her great hat") by a hyperbolic superlative "son chapeau splendide". This suggests the slight irony and maintains the number of syllables. In the third stanza, "this poet laureate" is shortened with "cette Poète". This distinction has disappeared in France, and it is compensated for by a capital letter. For the same reason (number of syllables), I modify the past conditional ("would have written") into a present conditional ("prendrait"). Reproducing the number of syllables directs attention to the economy and arrangement of words. As Clifford Landers puts it: "In any language, poetry is probably the most extreme instance of linguistic concision. Every syllable counts." 34

Regarding rhymes, the main risk is giving the poem an artificial rhythm. This danger has been reported for decades. Baudelaire stigmatised the previous translations of Poe's "Nevermore"

\footnotetext{
${ }^{30}$ Gregary Racz assesses that "poetry translations in analogical form are truly rare birds these days" (Racz, 2013, p. 49).

${ }^{31}$ His translation of "Sojourn in the Whale" may be called an organic translation in Holmes' terms (or instrumental for Nord), he eludes Moore's syllabic pattern in "Séjour dans la baleine". Moore, (2004), p. 109.

${ }^{32}$ Baddoura, (2009).

33 Jones, (2011), p. 180

${ }^{34}$ Landers, (2001), p. 101.
} 
when he wrote: “dans le moulage de la prose appliqué à la poésie, il y a nécessairement une affreuse imperfection; mais le mal serait encore plus grand dans une singerie rimée." 35 Jacques Roubaud speaks of this in equally derogatory terms: "une incongruité monumentale." ${ }^{36}$ In his chapter on metrics, ${ }^{37}$ Efim Etkind observes that the contemporary tendency is to ignore rhymes. Robert Ellrodt states that: "L'abandon de la rime dans la traduction en français de la poésie étrangère me paraît néanmoins acceptable, et même généralement souhaitable." 38 Peter Low uses an enlightening metaphor: "the rhyme at the end of the line plays such an important role in shaping a line that the tail indeed wags the dog." 39

In this case, I nevertheless reproduce the rhyming pattern ${ }^{40}$ because of Jackson's pastiche-like creative process - irreverent and metamorphic. The rhymes pay tribute to Moore's artistry with a touch of derision. Etkind criticises translators who neglect a meaningful rhyming or syllabic pattern: “La forme du poème a disparu: le traducteur l'a supprimée. Pourtant elle n'avait rien de fortuit!" 41 Jaccottet proceeds case by case: “J'ai renoncé à la rime pour mes traductions de Lavant ou Mandelstam. Alors que de se passer de la rime quand on traduit Gongora équivaut à trahir l'essentiel." 42 Some of my rhymes are ostentatious to suggest exuberance and pastiche: "métrique" and "Amérique" or "énonce" and "réponse". Although not part of the scheme, the rhymes "rides" and "splendide" contribute to the overall inner rhyming scheme. However, most rhymes are near-rhymes such as "ça" and "sac", "chaque" and "qu'elle a" or "après" and "tête", and my rhyming pattern is less obvious than Jackson's.

\footnotetext{
${ }^{35}$ Baudelaire, (1859), p. 514.

${ }^{36}$ Roubaud, (1978), p. 199.

${ }^{37}$ Etkind, (1982), pp. 155-190.

${ }^{38}$ Ellrodt, (2006), p. 69.

${ }^{39}$ Low, (2003), p. 94.

${ }^{40}$ See also my translation of "Breakfast with Katherine Mansfield", in Appendix p. 13.

${ }^{41}$ Etkind, (1982), p. 52.

42 Jaccottet, (1997), p. 30.
} 
The referential "game" in the third and last stanzas is most problematic. I cannot create a reference that does not exist in French. I emphasise the element of fun and liberty taken. I play with the homophony between "mouches" and "bouches", a compensation for "flies" and "lies". My solution therefore prioritises effect rather than meaning. For Nord, this is not only a right but a responsibility:

The translator's responsibility as an expert in both the cultures involved and in translation may precisely require a translation which is not faithful to the wording of the text but expresses the author's intention in a form suitable for, and acceptable in, the target situation for which the translation is intended. ${ }^{43}$

I focus on Jackson thumbing her nose at Moore rather than precisely what Moore says. The portrait stresses the character status endorsed by the American poet, and the intertextual shift of roles. Her strict attention to quotes, her syllabic measured poems, like her tricorn, become attributes like theatre props.

${ }^{43}$ Nord, (2002), p. 44. 


\section{Translating The Pastoral Kitchen}

From this collection, I have selected the short poems "Watch" and "Kikuyu" to illustrate the difficulties of double meaning and intertext when dealing with extremely short form. In "Watch", the poet plays with polysemy ("to watch" / "a watch") and reflects on the passing of time in a mere half dozen short couplets. These brief poems nevertheless "dramatise that attempt to give a poetic attention to the everyday." 44

a. "Watch" 45

The poem is made of six non-rhyming couplets and a final four-syllable rhyming conclusion, a resonant bottom-line, pondering the poetic relevance of children's language. Throughout the collection, Jackson tends to start poems with her children's words: "Elvira says" or "Johnny says" ("After the Nit Shampoo"46), turning anodyne statements into more profound metaphors. "Watch" and "beat" have two meanings here: beat as a measure, and overcoming something, watch as the object-tool to watch the time. On one level, Elvira is marvelling at a new discovery and on another, the poet reflects on the passing of time. This inspires the resigned "I can't beat time, just watch / the clock". This mechanism could be thought of as a kind of poetic translation, or a patterning of the real as Jackson recounts:

I was very disturbed when Jenny Bornholdt admitted that the blue blender in one of her poems wasn't really a blue blender. And she said, "well it's poetry, it doesn't have to be real at all." But that wasn't how that poem worked. That poem worked, to me, in the way that the Frank O'Hara poems work. [...] I suppose in part what you're responding to, what you're enjoying, is the performance of someone pulling the incidental details of their own life into a shape before your eyes; that they seem such instant, quick responses to the real. A patterning of the real. To know that it wasn't blue, for me took away from the performance of the game I thought she was playing. ${ }^{47}$

\footnotetext{
${ }^{44}$ Ricketts, (2010), p. 217.

${ }^{45}$ See Appendix p. 26.

46 Jackson (2001), p. 19.

${ }^{47}$ Jackson, (2017), p. 12.
} 
This game - translating the daughter's discoveries experienced through language into poetic insights - is therefore what I identify as the skopos of Jackson's poem.

First, there is an abundance of monosyllabic words. All sixty-six words are monosyllabic (“look”, “watch”, “clock”, "beat”...) except four: "Elvira”, “objectively”, “internally”, and "every". Here, monosyllabic terms might suggest the beating of a clock, each word a tic. The rhythm is perhaps not monotone but binary: each tic responds to a toc. The final lines work by pairs of sounds and onomatopoeias - "dog cat", "woof meow" repeated twice. Should the monosyllabic nature of the words be replicated, compensated or simply ignored? In her translations of Emily Dickinson's poems, which also use monosyllables, Claire Malroux observes:

Impossible de traduire le monosyllabe noon, avec sa consonance lunaire et onirique, son aura d'éternité, autrement que par "midi", qui sonne comme un cocorico et confère au poème une couleur solaire, beaucoup moins mystérieuse et suggestive d'infini que le vocable anglais. ${ }^{48}$

Malroux therefore resorts to contraction:

[Cela] contraint à la contraction. Je donnerai comme exemple le poème 956: We met as Sparks, diverging flints dont la traduction oblige à recourir à un substantif à la place du verbe, et à supprimer l'élément de comparaison as pour rendre le caractère elliptique du vers: "Notre rencontre: un choc d'étincelles". ${ }^{49}$

Malroux's strategy is particularly inspiring, as well as for another feature: the poem's deceptive simplicity in tone.

The beginning includes a dialogue between mother and daughter. This orality is combined with light-heartedness (Elvira's make-believe and exclamations) but the rhetorical question "Who beats my heart?" brings in a touch of melancholy, and the next line conveys powerlessness against the passing of time. Articulating a sense of the mundane with depth is not easy, what

\footnotetext{
${ }^{48}$ Malroux (2011), p. 33.

${ }^{49}$ Ibid.
} 
Bornholdt calls a decoy of simplicity in "In the Garden" it to be this way." ${ }^{51}$ Malroux also explains that a matter-of-fact style is not natural in French:

[Dickinson] utilise des termes simples, neutres, incolores [...] comme si elle disait que tout mot, comme toute note en musique, a un rôle à jouer dans le tout du poème. Je cherche donc maintenant à mieux adapter le vers français, toujours tenté par le ton noble, au ton de la conversation, aux expressions familières ou au plain speech caractéristique non seulement de Dickinson, mais de la poésie anglo-saxonne dans son ensemble. ${ }^{52}$

How might layers of tone both deep and childish be conveyed?

Montre

Elvira dit : là ! Y a une pendule sur ma montre!

Moi aussi, j'ai une pendule sur ma montre.

Comme ça, je peux voir le temps

objectivement, comme si intérieurement

je ne mesurais pas le temps de chaque cellule,

chaque battement de mon cœur.

Qui bat mon cœur?

Je ne peux pas battre le temps, juste voir la pendule.

Elvira dit: je suis un chien chat, ouaf miaou, ouaf miaou.

Tic tac, conte la montre.

Translation commentary

English monosyllabic words do not simply translate into monosyllabic words in French - my translation has sixty. I favour short synonymous words, when I can, in order to visually reinforce the impression of a constant "tic tac". "To clock" could be "chronométrer" or

\footnotetext{
${ }^{50}$ Bornholdt, (2016), p. 12.

${ }^{51}$ Bornholdt, (2008), p. 53.

${ }^{52}$ Malroux (2011), p. 36.
} 
"enregistrer" (both four syllables), I use "mesurer" also suggesting "battre la mesure" by collocation with "battre". In Malroux's terms, I contract "il y a" into "y a" (register drop), use an ellipsis of "déjà" in "comme si intérieurement / je ne mesurais pas (déjà) le temps de chaque cellule", I change "now" into "comme ça" rather than "maintenant", "look!" into "là!" instead of "regarde!", "watch" into "voir" instead of "regarder". I choose "pendule" instead of "horloge" to rhyme with "cellule", and because this might suggest the oscillating rhythm ("tictac") that I am looking for - as in "un pendule".

The final line is problematic. "To watch" is richer than "regarder" or "voir". "Guetter", "observer", "surveiller" would be more accurate but less common. I consider the following: "montre qui toque", to rhyme with "tic tac" (but there is no double meaning), "montre le temps" or "montre pendule". I could insist on double meaning with: "Tic tac / montre la pendule" or the compounded "montre-pendule". The long "Regarde la montre-pendule" would encompass all meanings but unbalance the binary rhythm and graphical symmetry. I could also opt for less literal options: "Tic tac / mate la montre" or "Tic tac / montre la montre" or "Tic tac / temps qui passe." I think of "jouer la montre", "contre la montre" or "garder un œil sur la montre".

My solution "Tic tac / conte la montre" uses monosyllabics, offers an inner rhyme (conte / montre) and plays with the homophony conter / compter. In addition, the pun conte / contre echoes with the line "Je ne peux pas battre le temps". The verb "conter" might also suggest the universe of tales, with a moral hence rendering the tone both childish and deep.

This solution might be a bold move but is it more loyal to risk overtranslating when colouring a trait, or opt for a safe solution with something that flattens language play? Pym notes that: "risk, in translation, is first and foremost risk of losing credibility. Let me call this 'credibility 
risk' (recalling the range of the Latin verb credere, to trust, to believe in)." ${ }^{, 53}$ This echoes Nord's people-focused process:

As an interpersonal relationship, loyalty was supposed to replace the traditional intertextual relationship of "faithfulness" or "fidelity", concepts that usually refer to a linguistic or stylistic similarity between the source and the target texts, regardless of the communicative intentions and/or expectations involved. ${ }^{54}$

Risk-taking might be not an option to dread but, paradoxically, a responsibility. Hofstadter wonders "not only how much liberty may a translator take, but how much liberty must a translator take, in order to do a good job?" 55 If there is some obligation to take liberties, and have fun in the process, I happily oblige here.

b. "Kikuyu" 56

This poem illustrates Jackson's attention to calligraphy, and how intertextual strands weave her work. "Kikuyu" is made of three receding stanzas. The first two are symmetrical and composed of three lines. The first line is of ten feet, the second of seven and the third of two. The third stanza is a rhyming couplet of four monosyllables: "Yes, I see you," followed by the repetition of the title at the end. As well as emphasising alliterations and various echoes ("sea" / "see", "swells / and spreads"), the structure may visually evoke waves or kikuyu grass, which spreads unevenly through rhizomes.

Although it depicts vegetation, the poem could be an anthromorphic portrait. Other poems in the volume do this: "Tahitian Pohutukawa" - "baby tree [...] like a two-year old"57 - or "Home

\footnotetext{
${ }^{53}$ Pym, (2015), p. 69.

${ }^{54}$ Nord, (2002), p. 32.

${ }^{55}$ Hofstadter, (2009), p. 275.

${ }^{56}$ See Appendix p. 28.

57 Jackson, (2001), p. 6.
} 
time" ("go yellow, / gingko"58). The poet addresses the grass in response ("yes") to an implicit question - "can you see me?" - gestured by the grass "waving". 59

Her drawing from Stevie Smith, in a lighter and positive tone, makes it original. Smith's "Not Waving but Drowning"61 emphasises the tragic confusion between two opposite messages hello or help. In 2003, it was translated by Anne Mounic:

\section{Not Waving but Drowning}

Nobody heard him, the dead man, But still he lay moaning: I was much further out than you thought And not waving but drowning.

Poor chap, he always loved larking And now he's dead.

It must have been too cold for him his heart gave way, They said.

Oh, no no no, it was too cold always (Still the dead one lay moaning) I was much too far out all my life And not waving but drowning.
Pas coucou, mais coule

Personne ne l'entendait, le mort, Pourtant, il gémissait encore:

J'étais bien plus loin que vous ne pensiez, $\mathrm{Ne}$ faisais pas coucou, coulais.

Pauvre vieux, il avait toujours aimé plaisanter Et voilà qu'il est mort.

Il a dû faire trop froid son cœur a lâché, Dit-on.

Oh non, non, non. Il a toujours fait trop froid (C'est encore le mort qui se lamente) J'ai passé toute ma vie bien trop loin, Pas coucou, mais coule. ${ }^{60}$

Mounic's translation supplies additional wordplay with "coucou / coule", or some "sidestepping”, as Pym puts it:

The particularly "difficult" or "untranslatable" passages are quite often of little relevance to success conditions. Translators deploy a range of avoidance strategies for simply side-stepping them. ${ }^{62}$

Her commentary in 2008 is based on sketches accompanying the verse:

Le personnage qui, désespérément, appelle l'attention est un homme - "He" (Il) -, mais le dessin montre clairement une femme, une femme aux longs cheveux. Nous avons donc là un jeu pronominal en miroir, et ce poème me paraît définir

\footnotetext{
58 Ibid, p. 15.

${ }^{59}$ Although not as obvious as Stevie Smith, Jackson's poem might also recall "Game” by Bornholdt (1988) playing hide-and-seek: "here - I'm here, out here on the lawn / waving / see / can you see me / over here / see me" (Bornholdt, 2016, p. 24).

${ }^{60}$ Smith, (2003), p. 12.

${ }^{61}$ Smith, (2015), p. 347.

${ }^{62}$ Pym, (2015), p. 68.
} 
la poétique de notre auteur. [...] En somme, le $J e$ se trouve, face à lui-même, autre, à un autre genre même et séparé par les eaux (symbole d'éloignement par rapport à la mère), dans la distance du désespoir et la liberté de l'esprit. ${ }^{63}$

Similarly, the dialogue in "Kikuyu" may reflect the poet's self ("jeu de miroir"). Reflected / reflecting is the perception (the meaningful "see") of the garden overflowing - recalling Claude Debussy's "Jardin sous la pluie". This concurs with "Pick up", either chronologically ("By evening" was "By now" in a previous version: "Ki-ki-kikuyu"64) or thematically.

Nonetheless, Jackson shows optimism in poor weather: she transforms Smith's image with a salutary parenthesis ("not drowning"). This "not" is vital. Whatever the soaked, spreading kikuyu refers to ("what we call a lawn"), she can see it, in one lucid, almost defiant pose (as if saying "no need to wave, thanks!"). My interpretation therefore highlights the optimistic ending.

\section{Kikuyu}

Le soir, notre prétendue pelouse est une flaque qui déborde sur le béton de l'abri voiture.

Tout autour de la bordure le kikuyu enfle, s'étend comme une mer fait coucou (ne coule pas).

Oui, coucou, kikuyu.

Translation commentary

I first focus on visual legibility. The lines wave like irregular blades of grass. The symmetric stanzas stress out echoing sounds, and this is rendered with inner rhymes: "voiture" / "bordure" / "prétendue", "coucou"/ "coule" / "kikuyu”, and "s’étend / enfle". I employ "étoffement" with "tout autour" to prolong the line. I separate "carport" into "abri / voiture", so the third line is

\footnotetext{
${ }^{63}$ temporel.fr/spip.php?page=impression\&id_article=363. Accessed 4 Jul. 2017.

${ }^{64}$ In "Trout": trout.auckland.ac.nz/journal/7/jackson/kikuyu.htm. Accessed 7 Dec. 2017.
} 
two syllables (one word). "Déborde" echoes "bordure" and suggests a prevalent overflowing sensation.

I consider idiomatic expressions: "notre prétendue pelouse" instead of the literal "ce qu'on appelle une pelouse". Rather than "les bords" for "the edges", I choose the singular "la bordure" to echo with "voiture". Prepositional verbs are often problematic, and "pooling / inwards onto" is no exception. Emphasis on "inwards" would lead to something like "s'affaisser" or "vers l'intérieur" or maybe "former une mare concave". Because the image of a pool is suggested in "pooling", I choose "flaque", a puddle or pool of rainwater. The word's liquid and occlusive sounds repeated with relative pronoun "qui" might even suggest raindrops.

Smith's reference plays with the polysemy of "waving": "faire signe" (or "agiter la main") and “onduler", "ondoyer". "Coule" suggests a flow of water running as well as drowning. Just as Jackson borrows Smith's reference and transforms it, I borrow Mounic's translation, and replicate Jackson's transformation: "fait coucou / (ne coule pas)". The unusual simile "comme une mer fait coucou" might alert readers to an extra layer. Nord suggests this strategy: "If a text shows strange, unconventional form patterns, the audience may wonder why the author chose these original forms and whether they are meant to convey an extra amount of information." 65 Whether or not the reference is "picked up", is not fundamental for my translation to work but it is hinted at.

${ }^{65}$ Nord, (2006), p. 39. 


\section{Translating Catullus for Children}

I have selected "Sparrow (as told by Elvira)", an adaptation of Catullus' Poem 2 ("Passer") and Poem 3 ("Pipiabat"), using the language of Jackson's daughter in quotation marks. This poses the question of translating this specific voice. I have also selected "Mayakovsky's Kindness to Horses", and "Stow Stay Stow Stay". ${ }^{66}$ Compared to Catullus, Jackson makes a closer adaptation of Mayakovsky. Her main transformation is the chorus "sto, ste, sto, ste", which she extends in the next sequence as "stow stay stow stay", and this homophonic wordplay is challenging.

a. "Sparrow (as told by Elvira)" "67

On a first level, Elvira alluding to "a pretend bird", can refer to her game of make-believe and on a second, to the tradition of rewriting Catullus" "sparrow poems." 68 Sarah Nooter remarks:

Noting that critics have tended to label her work "domestic", Jackson embraces this designation through the title of her book, and her overall aim to present Catullus's poems "from a child perspective". Has she succeeded? Certainly the poems have a vibrancy that readers of Catullus will recognise (though stripped of their native sexuality and smut), and there are charming moments. ${ }^{69}$

In Catullus' Poem 2, there are moments of joy mixing with frustration and jealousy. In Poem

3, the lament is so grave that it is almost comical, as Jennifer Ingleheart notes:

The incongruous mismatch between the insignificance of the dead animal and the major themes of death, mourning, and the afterlife; yet people can feel real love for their pets. Catullus reflects this ambivalence clearly showing the sorrow of his puella for the dead sparrow, but also giving the poem a lighthearted feel. ${ }^{70}$

Catullus' vibrancy and ambivalence also feature in Elvira's story: the tone might be lighthearted, there is a sense of the tragic in her realisation of the bird's death. Antagonistic emotions

\footnotetext{
66 Jackson, (2003), p. 43.

${ }^{67}$ See Appendix p. 35.

68 Translator Susan Wicks' statement on Valérie Rouzeau's poetry applies here: 'there's a performative element, a small girl appearing from behind a curtain to do tricks that make one smile - and it's only later one realises they were profound" (Rouzeau, 2013, p. 20).

${ }^{69}$ Nooter, (2013), p. 310.

${ }^{70}$ Ingleheart, (2003), p. 561.
} 
are reinforced by opposite spatial indications (“low down”, “up”, “front deck”, “back deck”), or binary statements ("real / pretend"). Elvira's vibrancy is conveyed by the casual "it wasn't / on there", the poverty of connectors ("so" repeated twice, "and" or no connectors at all), and repetitions: "real bird", "pretend bird", "deck".

Despite her clumsy account, there is a narration. First, what has she found? Is it dead / pretend or real / alive? Then, what to do with it? Put it in a box? And finally, where to leave it? Outside? Front deck, back deck? Her "complicated syntax and odd weighting of details"71 may rely on free associations, the breadbin, the tadpole pond, the front and back decks are so many markers of verisimilitude that could plausibly make an impression on a child.

As suggested in the title ("told by") and quotation marks, the poem is an oral transcription. Cilla McQueen writes: “I enjoyed Jackson's portrayal of children's speech in an earlier short story, 'The Bedmaking Competition', and find the same benevolently accurate transcription in 'Sparrow (as told by Elvira)'." She adds: "Jackson catches the unconscious poetry in the thought patterns of the very young." 72 Although the poet has transcribed her daughter's story "as closely as I could remember it" $" 73$ - Elvira's voice is ineluctably constructed as part of an experiment: "the Catullus for Children project is about that tradition of translation, an exploration into the purposes to which the Catullus poems can be put, and the Catullus 'voices' that can be constructed." 74

In "Catullus in the Playground", Jackson states:

There was nothing I could write that would be better than using Elvira's own words. My own role as a 'seer' here is less important than her role in

\footnotetext{
${ }^{71}$ Jackson, (2006), p. 114.

${ }^{72}$ McQueen, (2004), p. 25.

73 Jackson, (2006), p. 114.

${ }^{74}$ Wilkinson, (2015), p. 3.
} 
'domesticating' the most foreign of concepts to a small child, the concept of death. ${ }^{75}$

This domestication of death involves language ${ }^{76}$ and fiction: "What I found so interesting was the way she talked about life and death in terms of reality and pretence." 77 For instance, the breadbin "acted as a coffin."78 Jackson therefore connects her daughter's process within a wider literary context, and one may think of Blaise Pascal's "divertissement", a salutary distraction from daunting death:

(Elvira's story) reflects the difficulty of [her] imaginative work [...] with death being the reality she wanted to pretend not to believe in. [...] It seems to me that her project really is the project of poetry, the project Catullus was working on, and the project the Renaissance translators picked up, the project I continue to work on myself. ${ }^{79}$

The childish voice and uneasy syntax are key to the skopos, and reflect the poet's endeavour in a wider and deeper sense.
Passereau (raconté par Elvira)
"J'en ai trouvé deux des plumes
d'un oiseau. J'ai fait semblant que
c'était un vrai oiseau. Mais on voyait
que c'était un faux oiseau. On aurait dit
un vrai oiseau mais c'était un faux
oiseau. Alors on l'a mis dans ma boîte à pain.
On aurait dit un vrai oiseau.
Il était sur l'herbe près du trou
là où on met les têtards.
Alors on a mis la boîte à pain ailleurs
dehors près du mur sur la terrasse de devant.
Et la boîte à pain était sur le bois qu'était
tout en haut. Pas sous l'autre terrasse, elle
était pas là, elle était sur la terrasse de devant,
pas sur la terrasse de derrière. On en avait deux
des terrasses. Voilà, fin de l'histoire."

\footnotetext{
75 Ibid.

${ }^{76}$ Michael Cronin considers that "the languages of children themselves, the translation of the world into the multiple dialects of childhood, reveals the transformative energy of translation as a way of both paying close attention to and transforming the world" (Cronin, 2017, p. 7).

${ }^{77}$ Wilkinson, (2015), p. 3.

78 Ibid.

79 Ibid.
} 


\section{Translation commentary}

For target readers to grasp the most profound levels - allegory of death, echoes to and subversion of Catullus - I first have to convey the surface level, and render the naïve and awkward touch in a credible manner. My strategy is to emphasise orality and assure plausibility, creating an account that is clumsy but still intelligible, with grammar mistakes that make sense for a child. While writing "a couple of some feathers / from a bird" is incorrect, it sounds less wrong and plausible than a literal translation: "deux de quelques plumes / venant d'un oiseau'. Elvira makes a logic mistake.

I use "en" to render Elvira's superfluous "some", and the awkward "from". In my translation, "en" and "des" are equally superfluous, and I reuse this oral marker at the end: "on en avait deux / des terrasses". Another slightly clumsy statement is: "near the hole / that we put the tadpoles in". It would be too formal to use "dans lequel". I use the hiatus "là où". I mark the ellipsis of "ne" in "elle était pas là" and "qui était" also incorrectly becomes "qu'était". To render "pretend bird", I think of the lexical field of children's make-believe: "faire semblant" or "pour de faux" and I repeat "vrai oiseau" and "faux oiseau". Elvira's vibrancy (echoing Catullus') is emphasised in the spatial indications, not simply "en haut" but "tout en haut".

One problematic cultural element is breadbin. An equivalent could be "huche à pain". This suggests a long and sometimes ornamented ${ }^{80}$ wooden or woven basket, which most households no longer own nowadays. In New Zealand, a breadbin suggests a common rectangular metal box, and here, the little girl's breadbin might be her lunchbox, as in Belgium: "boîte à tartine". Elvira's breadbin might even be a toy, part of a doll's tea set, and "huche à pain" is not part of "la dinette". My choice "boîte à pain" is a literal translation, and as the breadbin is meant to

\footnotetext{
${ }^{80}$ Less so than "une panetière".
} 
work as a coffin for the bird, and hint at the girl's realisation of death, the symbolism of "boîte" is welcome.

The title is where the layering of perspectives is apparent: the voice of the mother / poet can be heard, as Paul Wright notes that "the adult observer, as mother and poet, knows all the journeys recounted here to be both everyday and yet significant." ${ }^{81}$ My choice of the rare "passereau", rather than the common "moineau" aims to hint at Catullus' "Passer", and this contrasts with the poem's clumsiness.

At the end, rather than "C'est la fin de l'histoire", I propose: "Voilà, fin de l'histoire", "voilà" being one of these filling words in conversations, offering a slightly abrupt end.

In my situation, the rendering of a child's voice can only be based on my imagination or perhaps memory, an imitation of what sounds plausible for a young child, rather than a real transcription. This a recurrent pattern in the translation of children's literature, as Carina Gossas reports:

The rendering of a childlike tone and features of orality in general has been identified as a major topic in the realm of translation studies that deal with children's literature (O'Sullivan 2005, Alvstad 2010). In translations, the childlike tone is also influenced by the translator's image of children, her/his ideals for the mimetic rendering of that tone. ${ }^{82}$

My translation of a childlike tone therefore implies subjective choices as a deliberate construction, however, it aims to be a plausible child's voice, and the deeper layers of significance are retained.

b. "Mayakovsky’s Kindness to Horses", and "Stow Stay Stow Stay 1"

\footnotetext{
${ }^{81}$ Wright, (2003), p. 199.

${ }^{82}$ Gossas, (2012), p. 185. This is also reminescent of Barthes' "effet de réel": "Il se produit un effet de réel, [...] ce vraisemblable inavoué" (Barthes, 1968, p. 88).

${ }^{83}$ See Appendix pp. 36-39.
} 
As the title signals, ${ }^{84}$ "Mayakovsky's Kindness to Horses" is a rendition of Mayakovsky's poem by Jackson. Or rather, it is her rendition of the Futurist's piece in English translation by Dimitri Obolensky. She notes that: "The two versions of Mayakovsky poems are based mainly on the prose translations by Dimitri Obolensky." ${ }^{, 85}$

There are some differences between Obolensky's translation and Jackson's poem, and her main transformation is her adaptation of Mayakovsky's superimposition of monosyllabic words in Russian. The Russian words both imitate the sound of hoofbeats and convey meaning:

$$
\begin{aligned}
& \text { Гриб. "grib" (mushroom), } \\
& \text { Грабь. "grab" (rob), } \\
& \text { Гроб. "grob" (coffin), } \\
& \text { Груб. "groub" (rough). }
\end{aligned}
$$

Obolensky chooses to borrow the onomatopoeia, and so do all other translators, with slight modifications: "Grab / Rib / Grub / Rob" (Rottenberg), "Grip / Grab / Grope / Group" (McGravan). ${ }^{86}$ McGravan notes: "I opted to transliterate, rather than translate this onomatopoeic series, because I believe the sound-play to be central. For the record, however, the corresponding Russian words are 'Mushroom. Pillage. Coffin. Crude."

McGravan's metatextual strategy contrasts with Jackson's adaptation: "sto, ste, sto, ste" in the first poem, and "stow, stay, stow, stay" in the next. She departs from exact semantics by creating her own wordplay also working both on the level of sounds and meaning. She therefore adapts and somewhat conveys Mayakovsky's trait by focusing on what the trait does, how it works on language (sounds and suggestions).

\footnotetext{
${ }^{84}$ Regarding the title, Dorian Rottenberg chooses "Humane to Horses", (Mayakovsky, 1985, p. 75). James McGravan for "Being Good to Horses", (McGavran, 2013, p. 68). Obolensky's title is "Kindness to Horses". 85 Jackson, (2003), p. 55. The second is "Mayakovsky's Five-Rayed Hands".

${ }^{86}$ Other variations include, in the last stanza, the horse as a female in Rottenberg's version: "great big baby, / she came light-hearted, / back to her stall", and McGravan's: "she had no need for a nanny", something elided by Obolensky, and subsequently by Jackson.

${ }^{87}$ McGavran, (2013), p. 339.
} 
She reuses this leitmotif in various parts, in other poems and sequences ("Stow Stay Stow Stay"), and in her next book (The Gas Leak). This has therefore seminal importance.

Her "sto, ste, sto, ste" is first coherent with her quotation of Mandelstam introducing the sequence: "A quotation is like a cicada" (Russian pun "tsitata"/ "tsikada"). Indeed, there are cicadas in the book: "even the rocks sing / with cicadas", 88 "A cicada song sounds / in my heart" ${ }^{89}$ (see also Tracey Williams' artwork on the cover). For Cilla McQueen, they form an aural framework: "that insistent cicada sound, deftly interwoven with echoes of Mayakovsky hoofbeats, gave an aural framework within which to discern the idiosyncratic voices of the futurists." 90 Jacob Edmond sees Jackson's "sto/ ste" as a potential connection between Russian and New Zealand poetries, or pure poetry:

The zaum of sto/ ste becomes the "no place" beyond sense where we can reach a putative "pure poetry" that transcends the linguistic, cultural and historical divide between Revolutionary Russia and present-day New Zealand. ${ }^{91}$

However, the transformation of "sto / ste" into "stow / stay" expresses the poet's dilemma between staying home and going on a holiday with her family, ${ }^{92}$ and this proves Edmond wrong when he states:

Jackson picks up on this technique later in her version with pairs such as "hearse/horse" and "horse/nurse", which, unlike Mayakovsky's sounds, are semantically relevant to the poem's description in a straightforward way. By contrast, [...] the phrase has no literal meaning in English, beyond the suggestion of "stop/ step", and so gestures towards the magic of created words in the most extreme Russian zaum." 93

\footnotetext{
88 Jackson, (2003), p. 49.

${ }^{89}$ Ibid, p. 46.

${ }^{90}$ McQueen, (2004), p. 25. Denis Glover's "The Magpies" may also come to mind: "Quardle oodle ardle wardle doodle."

${ }^{91}$ Edmond, (2007), p. 76. This transcendental vision is arguably subsequent to Barthes: "La poésie [...] tente de retrouver une infrasignification, un état présémiologique du langage; bref, elle s'efforce de retransformer le signe en sens: son idéal - tendanciel - serait d'atteindre non au sens des mots, mais au sens des choses mêmes. C'est pourquoi elle trouble la langue [...] dans l'espoir d'atteindre enfin à une sorte de qualité transcendante de la chose, à son sens naturel (et non humain)" (Barthes, 1957, p. 220).

92 Jackson's dilemma also echoes Mayakovsky tearing daisy petals off: "She loves? She loves me not?"

(Jackson, 2003, p. 37).

${ }^{93}$ Edmond, (2007), p. 76.
} 
On the contrary, like "grob" (coffin) articulates meaning and evokes the tragic, "stow/ stay" both echoes "sto/ ste" and stresses the poet's inner conflict central to the second poem. Jackson's wordplay is therefore expressive on various levels, as Paul Wright notes:

This sense of the necessary fabric of language comes to dominate the second half of the collection, particularly in the, again, Mayakovsky inspired final section 'Stow stay stow stay', the very title of which gives some sense of its incantatory meditation on adult journeying, arriving and belonging. [...] But, in some senses, the cleverness of all this is, as with the Classical reworkings, almost irrelevant to the experience of being made aware of thematic connections and tensions through word play. ${ }^{94}$

This experience of wordplay is for me fundamental, and I aim to render this in my translation.

On a thematic and even dynamic level, it embodies a movement, an intertextual game from Mayakovsky to Jackson, and on an emotional level, it calls for readers to empathise with the poet persona (appellative function).

McGrahan explains that Mayakovsky's poem is “often interpreted as a political allegory, a kind of pep talk to a country reeling from war and revolutions. It can also be read as the poet's pep talk to himself." ${ }^{95}$ What is the skopos of Jackson's version?

My interpretation is that her poem is based on the second option: a positive, almost consoling, response to Mayakovsky, potentially inspired by Frank O'Hara's own variations from

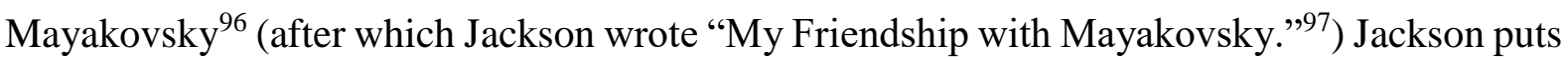
the Futurists" project into practice ("you'd almost think you could address history, / and the future would be listening"98), (re)connecting Mayakovsky's sentimental and tragic turmoil to O'Hara or Catullus for instance, not only revisiting, but continuing Mayakovsky's final piece

\footnotetext{
${ }^{94}$ Wright, (2003), p. 200.

${ }^{95}$ McGavran, (2013), p. 339. For McGrahan, Mayakovsky was also: “clearly responding to [...] Raskolnikov's first dream in Dostoevsky's Crime and Punishment" (Ibid).

${ }^{96}$ Mayakovsky's “An Extraordinary Adventure Which Befell Vladimir Mayakovsky in a Summer Cottage” is the basis of O’Hara's “A True Account of Talking to the Sun at Fire Island” (1958), O'Hara, (1995), p. 306.

${ }^{97}$ Jackson, (1999), pp. 60-66.

98 Jackson, (2003), p. 38. The previous line "See how the sky holds onto the stars" is an echo to "The Long Road to Teatime": "and the sky holding tight to the stars" (Jackson, 2000, p. 21).
} 
on a lighter note, and asserting the incantatory potency of words as magic charms: "I know the power of words, / though they might look (at times) like petals / trampled underfoot."99

La Bonté de Vladimir Maïakovski pour les chevaux

On aurait dit que les sabots chantaient :

tso

tse

tso

tse

c'est sûrement la rue qui a dérapé !

C'est peut-être la rue qui a trébuché

sur le cheval : enfin bon, pauvre canasson

corbillard

canasson

corbillard

canasson

qui glissait sur la croupe en pleine rue

comme un cercueil tout schuss au feu.

Personne n'avait vraiment de raison de sortir

sauf pour montrer leurs pattes d'eph'

et rire

ah

hi

ah

hi

du cheval,

oh venez voir! Mais moi, moi seul

n'ai pas mêlé ma voix

au chœur,

non, je

me suis rapproché

et j'ai vu les yeux du cheval.

La rue était tombée et personne n'avait remarqué sauf le cheval : j'ai vu de grosses gouttes

couler sur son visage

ici

là

ici

là

puis s'enfouir

dans son crin.

99 Jackson, (2003), p. 38 
Oh cheval, il ne faut pas, oh cheval, écoute cheval : ne pense pas que tu sois pire qu'eux !

On est tous des chevaux, quelque part! Cheval ?

Peut-être qu'il ne pensait pas avoir besoin de soin le pur-sang

soin

sang

soin

peut-être ma pensée lui semblait triviale au cheval,

en tout cas, il s'est levé d'un bond, la queue

fringante et plein d'entrain, est reparti

tso

tse

tso

tse

se tenir tout droit dans sa stalle,

et tout le temps se sentait jeune poulain,

et ça valait la peine de vivre et travailler

valait

la peine.

Sauter rester sauter rester 1.

J'ai peur toute la matinée,

les presse

à sortir de la maison.

Cœur en bouche.

Dents sur ma langue.

Ma famille défaite.

une famille

du répit

une famille

du répit

Dans les sacs tout

ce à quoi j'ai pu penser

tassé dans le coffre

sous les pieds

j'ai pensé cent fois

à sauter à bord 
sauter

rester

sauter

rester

m'abandonner

en venant aussi

Translation commentary

Some knowledge of Mayakovsky's poem helps to understand Jackson's choices. Mayakovsky's French translations also help my translation decisions. The title is "Etre bon avec les chevaux"100 in Claude Frioux's translation or "Il faut bien se comporter avec les chevaux" in Gérard Conio's (who speaks of "métaphores phoniques"): “Champignon / Charme / Cercueil / Grossier."101 My title "La bonté de Vladimir Maïakovski pour les chevaux" is a close rendering, and my only transposition aims at avoiding the misleading "La bonté pour les chevaux de Vladimir Maïakovski", which could mean "Kindness to Mayakovsky's horses". I also choose the masculine "je me suis rapproché" and not "rapprochée", as I consider Mayakovsky (his poet persona) to be the protagonist, and Jackson's title is "Mayakovsky's Kindness to Horses".

First, I try to find a solution for the significant homophony "sto / ste" and "stow / stay", keeping the echo. Second, I focus on rhythm issues.

Regarding "sto / ste", I aim to suggest the sound of cicadas. In French, "la cymbalisation des cigales" is also "le stridulement" or "le cricri", ${ }^{102}$ and the closest onomatopoeia I can think of is "tse-tse-tse." For me, this transcription naturally evokes the sound of cicadas to French ears, and I propose: "tso, tse, tso, tse".

\footnotetext{
${ }^{100}$ Mayakovsky, (2001), p. 345.

${ }^{101}$ Khardjiev, (1982), p. 163.

102 "Cri-cri: bruit du grillon ou de la cigale" Centre National de Ressources Textuelles et Lexicales, cnrtl.fr/definition/cricri. Accessed 26 Jul. 2017.
} 
Second, I aim to convey the dilemma between leaving with her family ("stowing myself away") and staying home to rest by herself ("stay"). My solution "sauter / rester" is not perfectly homophonic but it does echo "tso, tse" as an approximation. "Rester" is literally "stay", and "sauter à bord" (jump aboard) keeps the idea of transport, the rush and the temptation evoked.

The homophony "horse / hearse" or "horse / nurse" is also problematic. I render it mostly by synonymy: the slang "canasson" offers some echo with "corbillard" (three syllables and begins with a "c") and "pur-sang" with "soin" (and "besoin"). This literally transforms "nurse" into "care". The pair "family / holiday" (repetition of syllable "li / ly") is rendered with the nearrhyme "une famille / du répit" rather than "vacances" - "du répit" is both respite and time off. The repetition of "scoot" with two different meanings (skidding and dashing) is not rendered by a repetition, rather, I choose "tout schuss" also suggesting speed and sliding (ski terminology).

In terms of rhythm, I modify "along the street" to "en pleine rue" to make it more idiomatic and "into a fire" as "au feu" to create what may be called a slippery rhythm suggesting the horse's fall. To suggest a stop and go motion and keep the staccato rhythm of "with a jerk and a flick / of its tail, and cheerfully returned", I use transposition: "d'un bond, la queue / fringante et plein d'entrain". This is where monosyllabic "jerk" and "flick" suggest a jaunty trot, which the collocation "cheval fringant" aims at rendering. The fits and starts in the last stanza are translated with the alliterative "se tenir tout droit dans sa stalle" and "tout le temps se sentait" echoing the main leitmotif.

About her translations of Tony Harrison, Cécile Marshall writes: "Comme un musicien essaie différents tempi avant de trouver celui qui sied le mieux à l'œuvre qu'il va interpréter, nous nous sommes laissé imprégner par la pulsation et la rythmique des vers." ${ }^{103}$ I agree with this approach sensitive to music. Overall, I aim at rendering Jackson's positive re-writing of

${ }^{103}$ Marshall, (2013), pp. 5-6. 
Mayakovsky by focusing on the seminal wordplay and pulsating rhythm. Recovering the intertextual layers not only proves helpful for interpretation, it is an indispensable strategy guiding translation choices. 


\section{Translating The Gas Leak}

I have selected poems from each of the three sections: the introductory "Silence, it Means Something", "The Gas-Fitter's Daughter Shows Shane", "The Gas-Fitter's Daughter's Recurring Solution", "It Seems That This Time I Have Been Mistaken" and "An Explanatory Wave of the Hand.” They illustrate key issues such as intertextuality, wordplay, or humour but also new challenges: the expression of tension through variations in form, tonal shifts and codeswitching. The narrative cohesion would justify a study of the whole book in translation.

a. "Silence, it Means Something"104

The first poem of the book announces the skopos in its title, a collage from Achterberg's sonnets: exploring the meaning of silence(s) in the gas-fitter's family. The gas-fitter's daunting tacitness is evoked throughout - "the silence / makes him anxious", "Never brings his wife home any news", ${ }^{105}$ until the final "when at last / he starts talking." 106 In constrast with Airini Beautrais, for whom "for the characters, nothing changes: the marriage between the gasfitter and his wife continues to stagnate", ${ }^{107}$ I consider "the gas leak" to be a resolving metaphor for the gas-fitter - resolving the silent tensions building up, as the wife's resolution is the subject of "An Explanatory Wave of the Hand".

The opening line is a fragmentary vignette, an instant cliché in a couple's life: "They lie in bed staring at the ceiling", repeated in various poems as a symptomatic communication breakdown. The collage technique - what Beautrais terms "units of segmentation" - magnifies the possibilities of interpretation. This image is paradoxically connected to psychoanalysis

\footnotetext{
${ }^{104}$ See Appendix p. 41.

105 Jackson, (2006), p. 7.

106 Ibid, p. 16.

${ }^{107}$ Beautrais, (2016), p. 110.
} 
(looking at the ceiling) in the witty: "She wouldn't call marriage / a talking cure."108 Beautrais explains that:

This repetition cleverly links the text to its model, and the sections within the text to one another, while at the same time drawing attention to the stagnant state of the marriage, and the uneventful nature of the narrative. ${ }^{109}$

Arguably, this motif acts as an accumulation of tacit tension rather than stagnation. It leads to the final gas leak, an opening in the dialogue, where the shining torch in the dark of "The Treehouse" is also evoked.

The motif sets the scene for a retrospective flash-back readapting "Mayakovsky's Kindness to Horses": the skidding, the laughing crowd, the trousers, and the street falling "from under his feet". This episode / poem explains why "they are not really married", a statement giving ambiguity to "They lie". A sick celebrant could not pronounce (literal and figurative) them married in so many words (literal and figurative), and the word "words" has the final word.

The poem also serves as an in medias res introduction for the narrative. Rather than Beautrais' idea of antinarrativity, the concept of weak narrativity or minimal narrativity ${ }^{110}$ seems fit, as the gaps in the plot enable a range of potential narratives. As Beautrais concludes: "The Gas Leak is open to multiple narrativisations." ${ }^{111}$ For Green too, "silence [...] forms the room where the reader finds sanctuary to liberate the poem's inner life."112

The poem's impact - its humorous equivocality - relies on a minimal narrative progression and on the paronomastic use of fixed expressions. I aim at reproducing this language-play. As Baker warns:

\footnotetext{
108 Jackson, (2006), p. 9.

${ }^{109}$ Beautrais, (2016), p. 113.

${ }^{110}$ See Le Récit Minimal. Du minime au mininalisme by Bedrane, Revaz and Viegnes (2012).

${ }^{111}$ Beautrais, (2016), p. 119.

${ }^{112}$ In Ricketts, (2010), p. 32.
} 
The main problems that idiomatic and fixed expressions pose in translation relate to two main areas: the ability to recognize and interpret an idiom correctly; and the difficulties involved in rendering the various aspects of meaning that an idiom or a fixed expression conveys into the target language. ${ }^{113}$

Despite the miscommunications and drama - the wedding's slippery situation here or the heated house-buying discussions later - there is humour in the wordplay and the distance taken. As Wilkinson states, "the three family members are each sensitive to their surrounds and yet disconnected from one another. It's a fun book to read, though, despite the melancholy tone."114 My skopos is to focus on the rendering of what Eco calls a process of "hypotyposis" - "the language is to 'stage' something that the reader is virtually led to see"115 - the swift shifts of focus and layered wordplay functioning as so many elements of literary fun.

Silence, ça veut dire quelque chose

Ils sont au lit, les yeux au plafond.

Ils ne sont pas vraiment mariés.

Elle avait patiné en tête au bureau d'état-civil au-dessus du supermarché et exécuté un huit parfait pendant que tout le cortège devant eux, se retournait et se moquait de lui, laissé à la traîne, à devoir mouiller sa chemise où la rue avait dérapé sous ses pieds.

Le maire avait une laryngite, il ne les a jamais prononcés mari et femme pour ainsi dire.

Translation commentary

Contrary to my usual practice, I first proceed by equivalence (Vinay and Darbelnet) for some cultural elements. I choose "installateur du gaz" rather than "gazier" because "gazier" is also slang ("bloke"), and this would be disconcerting. The specific "registry office" (combined with

\footnotetext{
${ }^{113}$ Baker, (1992), p. 68.

${ }^{114}$ Wilkinson, (2015), p. 3.

${ }^{115}$ Eco, (2004), p. 51.
} 
the odd "above the supermarket") needs to be adapted with "bureau d'état-civil". The same applies to "maire" for "celebrant", a problematic cultural non-equivalence. I use "cortège" for "wedding party" instead of "invités" or "noceurs" because it implies a spatial connotation reinforcing the cross-over of perspectives: the bride is "ahead", the guests are "before them" and the groom is "left behind".

Second, regarding wordplay, the final pun on "pronounce" happens to be compatible: the formula "je vous prononce mari et femme", uses "prononcer" in its "elocuting" and "ordaining" sense. As an echo to Mayakovsky, "She had skated ahead" makes sense, extending the sliding metaphor ("scoot"), and this creates contrast with the horse/gas-fitter's "head over heels" conundrum. Her "perfect figure of eight" can be rendered with "faire un huit parfait" ("patinage artistique") or "exécuter un huit" - to compensate for "figure" both number and acrobatics although there is also an implied "perfect figure" when used of a woman (also explored in "Marry in Haste") that is not rendered.

The potential innuendo of "lie" is problematic - the meaning "to lie down" is immediate by association with "in bed" yet, "to deceive" is possible in the context of a couple in crisis. "Ils sont allongés au lit" or "Ils sont au lit" misses this. This is a case where interpretation is particularly putative as Eco remarks:

Interpreting means making a bet on the sense of a text, among other things. This sense that a translator must find - and preserve or recreate - is not hidden. [...] It is just the outcome of an interpretative inference that can or cannot be shared by other readers. ${ }^{116}$

Similarly, I do not render the rhymes "street / seat / feet", according to Beautrais "a deliberate drawing of attention to device"117, because they suggest a shift of focus towards form that I render instead with fixed expressions.

${ }^{116}$ Eco (2004), p. 16.

${ }^{117}$ Beautrais, (2016), p. 116. 
The pun on "in so many words" is challenging. A first constraint is the restitution of literal meaning: "strictly speaking" or "so to speak"; a second may be the position of "words" at the end, a resonant finale. A third might be the choice of "so many" ironically contrasting with the character's laconism and the verse's minimalism. The literal "en autant de mots" is not an existing phrase, and neither is "clairement" or "distinctement". The expression "en ces propres / traîtres mots" (in these very words) is rare and confusing (in his / her own words). "Mot pour mot" would be quite distant semantically, and this is why I discard other alternatives: "verbatim", "textuellement" or "texto". The phrase "à proprement parler" is too long and I settle on "pour ainsi dire" (so to speak) suggesting a figurative / literal layer of language.

Regarding "on the seat of his pants", the first constraint is to find a popular expression meaning improvising (winging it, playing it by ear), the second is to echo Mayakovsky's "flares", and third, "seat" may also refer to seats at a wedding ceremony. My solution "à devoir mouiller la chemise" uses a popular expression with a piece of clothing suitable for a wedding, and the meaning differs slightly to "having to work hard". This strategy is the opposite of Baker "using an idiom of similar meaning but dissimilar form." ${ }^{118}$ I use an idiom of similar form but dissimilar meaning. To compensate for the approximation, I add a pun in "laissé à la traîne" ("left behind"), which can also refer to a wedding dress train. As Mário Laranjeria reminds us:

It is known that wordplay is generally untranslatable by the fact that in another language usually there will be a different signifier for each of the meanings of the dual sign. The translator of poetry should use his imagination and mastery of the resources of his own language to recover the poetry effect which, in the original, stems from the use of a dual sign. ${ }^{119}$

\footnotetext{
118 Baker, (1992), p. 78.

${ }^{119}$ Laranjeria, (1996), p. 218.
} 
All this wordplay creates a sense of fun, as the poet states: "I still love The Gas Leak, partly because I still remember how exhilarating it was to write", ${ }^{120}$ and this is what I experience too, using my imagination, looking for set expressions that work in a dual way.

b. "The Gas-Fitter's Daughter Shows Shane" and "The Gas-Fitter's Daughter's Recurring Solution"121

In the middle section, the titles are no longer fragments from Achterberg but scenes from the adolescent's life. The voice is juvenile and rebellious, with sociolects: "his stupid red wheelbarrow", ${ }^{22}$ "we have lives?", ${ }^{123}$ "What will she take next / from American sitcoms, / grounding me after school / for not doing my chores?"124 This voice is, as Jackson writes, "as uncanny, unsettling and profoundly strange as the ways teenagers find to put into words their emotions." 125 For Beautrais, she is "Pinocchio-like" and expressing "a longing to become a 'real' character." ${ }^{\prime 26}$ An authentic rendering of this voice is a first problem in particular because of her emphasis on the divergence between kinds of English.

Second, the sonnet form - fourteen mostly iambic lines - gives way to a longer and irregular stanza which, for Green, "unsettles the harmony of form" and mimics the daughter's "teenage rebelliousness." "Visual legibility" is therefore key. Irregular indents and interrupted clauses with dashes express an elliptical syncopation suggesting drunkenness - "too drunk to write" and erratic behaviour - "climbed / all over the shelves". Fragmented recollections between 12 am - "undo my watch" - and 10 past 3 - "searching for new coffee beans" - emphasise a

\footnotetext{
${ }^{120}$ Wilkinson, (2015), p. 3.

${ }^{121}$ See Appendix pp. 43-44.

122 Jackson, (2006), p. 26.

${ }^{123}$ Ibid, p. 25.

124 Ibid, p. 31.

125 Jackson, (2014), p. 182.

${ }^{126}$ Beautrais, (2006), p. 107. This makes sense in the context of a poem such as "The Second Puppet".

${ }^{127}$ In Ricketts, (2010), p. 32.
} 
distorted perception of time: "I am astonished / it is not later". The poem has some resemblance to a journal with incomplete entries.

Third, the repetition of "and" - one thing leading to another in one continuous stream of consciousness - and the rich rhyme "increases / creases" accentuate the rush of "joy", before its abrupt withdrawing interruption. This deconstructed piece, which owes something to Derrida and post-modernism, keeps the minimal narrative unclear and suggestive (Beautrais' "weak narrative" ${ }^{128}$ ). This means readers are to reconstruct interpretations based on blurry impressions as in some kind of detective game. As Nord analyses:

The code elements are often ambiguous, producing the vagueness or polysemy typical of literary texts and allowing readers a variety of interpretations. Nevertheless, there are ways and means to interpret the sender's intention, consciously or unconsciously, from the linguistic, stylistic and thematic markers in the text. ${ }^{129}$

A former version of the poem gives away more while indicating other directions:

My life when I had a life: 12 a.m. and don’t I show Jane.

12 a.m. and don't I show Jane

and undo my watch

to throw it before

my heart -

- I can't read

it says Jane and I think

that is pretty

sad but keep writing

anyway -130

Here, Shane is Jane, and "I can't read it" refers to reading the watch. In the sequence, the teenager complains about her curfew at the school play, therefore the "joy and dress" lines come from a later elaboration making sense in the narrative. Similarly, the interrupted "but he -" is the resolved "but keep writing anyway -". The ambiguous "show" is then in the sense of "to show what one is made of". Whereas such a "show" is, in the first version, on the level of

${ }^{128}$ Beautrais, (2016), p. 119.

${ }^{129}$ Nord, (1997), p. 85.

${ }^{130}$ nzetc.victoria.ac.nz/tm/scholarly/tei-Ba32Spo-t1-body-d25.html. Accessed 20 Sep. 2017. 
imaginative writing (fantasising, Ars Poetica), in the later version, the crescendo of "increases", the materiality of "creases" suggest a more pronounced passage à l'acte.

As Eco reminds us "any interpretation remains a bet", ${ }^{131}$ and this actuation is only suggested and purposefully so, blurring the lines between the real and the imagined, the enacted and the perceived - the dissociation in "I hear myself/ scream" - gathering everything into an extended literary metaphor redounding Achterberg's obsession with "the power of the poetic word."132 Shane's confessed incapacity: "I can't read it" is also in literary terms - reading - a device repeated in the final "I am not sober / enough to write / after all -" with "write" as process and result (and non-result) of the experience, and "after all" at the end, conjuring these intense events, leaving readers with bits of jigsaw and puzzling gaps: what is that "all", what actually happened? As Erin Scudder writes: "Instead of a précis of whatever ostensibly happened, we get only peripheral suggestions of something underhanded: the oblique."133

My skopos is to render this extended literary metaphor because it teases readers expectations regarding the narrative: for Beautrais, it serves as a "metafictional comment on the process of constructing a narrative world." 134

This device is reused in the next poem, girls end up deciding to "get totally written": a slang metaphor (a car gets written-off after a crash) that also alludes to writing as a pun. The poem navigates between different media - "she's texting me her life", "her eyes are signalling me", "when we can talk" - in various genres: "epic tragedy" or "gothic comedy". This mimetic voicing (repetition of "obviously", reinforcing the sociolect "totally"), simultaneously combines slang (the teenager's voice "darkly right about everything"135) and metaphorical

\footnotetext{
${ }^{131}$ Eco, (2004), p. 17.

${ }^{132}$ Coetzee, (1992), p. 400.

${ }^{133}$ Scudder, (2017), p. 135.

${ }^{134}$ Beautrais, (2016), p. 108.

${ }^{135}$ Wilkinson, (2015), p. 4.
} 
literary components subsequent to Coetzee's "Mystery of I and You”. For Beautrais too, the daughter is "a constructed, projected persona" 136 and the poet's voice, although muffled in mimesis, can be heard through wordplay. In Bakhtin's words, "the 'angle of refraction' of authorial discourse passes through various other voices, or voice-, and character-zones."137 Compared to "Sparrow, (as Told by Elvira)", a transcription, there is a more sophisticated weaving of voices. The daughter's voice is sampled, her experiences are imagined, and combined with recollections of the poet herself as a teenager. This simultaneous layering runs counter to Bakhtin's claim that:

Heteroglossia (other socio-ideo-logical languages) can be introduced into purely poetic genres, primarily in the speeches of characters. But [...] it does not lie on the same plane with the real language of the work: it is the depicted gesture of one of the characters and does not appear as an aspect of the word doing the depicting. ${ }^{138}$

In contrast with what Jackson says about Magnolia's Pen. Pal., which in "a retrospect" could apply: "She makes poetry out of that adolescent play with different registers, the acrobatic shifting from mock epic to comic to profound, from the mundane to the poetic, from reportage to conversation to lyric abandon", ${ }^{139}$ Jackson's superimposition of voices not only offers "swift changes of focus" 140 , it is translational. Her poetic presence has a composite, shifting quality, as Samanta Trivellini writes about Josephine Balmer:

She is a shifting presence: she appears both as a creative agent, interacting with texts, memories, places, and objects, and a composite persona emerging from the dialogue among several voices that can be "heard" in her collections - those of translator, mediator, innovator, decoder, creator of new and meaningful connections. ${ }^{141}$

\footnotetext{
136 Beautrais, (2016), p. 109.

${ }^{137}$ Bakhtin, (1981), p. 432.

${ }^{138}$ Ibid, p. 287.

139 Jackson, (2014), pp. 182-183.

${ }^{140}$ Ibid.

${ }^{141}$ Trivellini, (2017), p. 65.
} 
Trivellini's conclusion is particularly to the point: "since poetry and translation are layered, pliable spaces in which many voices, and many selves coexist, they are also forms of silent life-writing." 142 The connections between voicing in writing and the effect of silences in real life are essentially poetic, and this gives another significance to my skopos focusing on wordplay.

La Fille de l'installateur du gaz montre à Shane

Minuit et un peu que je montre à Shane

et défais ma montre

pour la jeter devant

mon cœur mais de plus en

plus jouasse et la robe se

froisse et -

- "J'arrive pas à lire

ça" dit Shane et je pense

que c'est bien triste

mais lui -

-3 h du mat'

et là je suis sobre quoique

envie de vomir avec

tout ce café

en fait il est 3 h 10

et ça m'étonne

qu'il ne soit pas plus tard, vu que

depuis $3 \mathrm{~h}$ j'ai grimpé

sur toutes les étagères

à la recherche de nouveaux

grains de café -

là Shane arrive à la porte

et je m'entends

crier et pense que

peut-être je ne suis pas assez

sobre pour écrire

après tout -

La Solution récurrente de la fille de l'installateur du gaz

Evidemment il va falloir que

je raconte tout à Bridget -

mais quand j'arrive à l'école

ses yeux me lancent des signaux

aussi urgents que ceux que j'essaye

de lui lancer avec les miens

${ }^{142}$ Ibid, p. 79. 

et tout le cours de maths
elle me texte sa vie:
genre: tragédie épique mais
plutôt version
comédie gothique, ce qui
est sûrement dû
aux limites
du média - surtout
qu'on doit garder
nos portables cachés dans
nos trousses.
Quand on peut parler on est d'accord
qu'évidemment il va falloir
qu'on sorte d'ici,
aller quelque part où on puisse
se mettre carrément hors d'état d'écrire.

\section{Translation commentary}

I stay close to the visual legibility with a tight rendition of form, keeping the jigsaw puzzle, with each fragment as a diary entry: indications of time are abbreviated, small reports made in the moment, style is spontaneous.

To render the punch and liveliness, my strategy is to focus on orality. Cuéllar reminds us about sociolects:

Some literary texts [...] are characterised by the use of different registers or sociolects in the same texts; this richness and diversity is a linguistic characteristic rarely found in other text-types. This textual heterogeneity which is so typical of literary texts is part of the translation reality to be accounted for. ${ }^{143}$

Rendering a teenager's manner of speech requires oralisms: "on" rather than "nous", the contracted "3 h du mat", the contracted negation "J'arrive pas" - "arriver à" more casual than "pouvoir" - the short "là" rather than "maintenant".

\footnotetext{
${ }^{143}$ Cuéllar, (2008), p. 117. His rehabilitation of the concept of equivalence and criticism of Nord's theory (Ibid, pp. 169-172) relies strongly on Genette's hypertextuality and the idea of a plurality of translations (Koller's multifaceted proposal) through a continuum of historically- and culturally-based variations but fails to perceive that this is precisely what Nord's contribution brings (metatext and language-culture stance) after 1997.
} 
I keep the unclear "show" with "montre" - a truncated version of "montre de quel bois je me chauffe" - echoing "ma montre". The teenager is writing to herself in her diary, and does not need to explain what she is referring to. The rhetoric "don't I" is problematic because the negation is not credible as: "n'est-ce pas que je montre". This is where casual English keeps a more formal construction. I choose the colloquial "un peu que", as in the oral "un peu mon neveu" or "et comment que".

In my rendition of "and yet the joy / increases and the dress / creases and", I suggest crescendo with an ungrammatical turn: "mais de plus en / plus jouasse et la robe se / froisse et". I keep the rich rhymes because they amplify intensity in a flight of lyricism, and the addition of the vernacular "jouasse" avoids the problematic "joy". Whereas the equivalent "joie" is less polysemic and rather old-fashioned, "plaisir" is too connoted and lacks the ambiguity, the slippery nature of poetry. My solution aims at a pulsating and accelerating rhythm, suggesting tension, the rush before the crash of the dash -

Jackson's mix of the eloquent and the casual is an idiosyncratic trope, and I render this with sociolects: "portables", the recent "texter", the oral "genre" or "version" ("coming across more"), and the oral adverbs "sûrement" ("might have") and "carrément" ("totally").

The rendition of "get written" is problematic on two levels. The first constraint is to convey the meaning "to get drunk" as a sociolect, and second "written" is the last word of the sequence and extends the literary metaphor. While there is a plethora of expressions for "se saouler" - I have compiled a list of over sixty ${ }^{144}$ - none include the slightest allusion to writing.

I subvert a fixed expression, implementing the idea of writing with an invention, when Jackson's crafty layering resides in sampling authentic material. I have thought of "se réécrire

\footnotetext{
144 topito.com/top-expressions-argot-cuite-boire-bourrer-la-gueule-pinter-la-ruchasse. Accessed 20 Sep. 2017.
} 
la page", "s'écrire une cuite", or "s'en écrire une bonne", "se mettre une écriture”, “s'écriturer", "se scribouiller" or even "se décalquer la figure".

My solution "se mettre carrément hors d'état d'écrire" is a close rendering of "written" as in written-off ("bon pour la casse", "hors d'usage") playing with the idiom "hors d'état de nuire": a gain to compensate for a loss. The context makes it apparent that the girls are to drown their sorrow in alcohol. ${ }^{145}$ Slang is less prominent but still noticeable in the sociolect "carrément", which more than "totalement" conveys the "too much touch" of adolescents ("totally/ totes").

Beautrais states that: "the daughter's desire to 'get totally written' is pure metafiction." 146 The rendering of this polyphonic and metafictional trait is not perfect, meaning being more or less inverted, but it is a good example of a balanced, creative and loyal translation, with all the source's ingredients but a slightly different flavour.

c. "It Seems That This Time I Have Been Mistaken" and "An Explanatory Wave of the Hand"147

This section focuses on the gas-fitter's wife, whose voice may or may not coincide with the poet's, as Erin Scudder writes: "Towards the end of the book a writerly voice intervenes - a voice we can no longer so confidently associate with extra-textual Jackson."148

The sonnet form is accentuated with frequent rhyming. ${ }^{149}$ Puns are numerous, tone shifts rapidly from gothic (coffin, blood, tombs or: "until I give up / the ghost I must be haunted / by my life" ${ }^{150}$ ) to mundane ("I'm off to pick up / the children from school"151), from metaphysical

\footnotetext{
145 “To Bridget - / red wine/love - is this / a recurring dream?" (Jackson, 2006, p. 19).

${ }^{146}$ Beautrais, (2016), p. 114.

${ }^{147}$ See Appendix pp. 45-46.

${ }^{148}$ Scudder, (2017), p. 135.

${ }^{149}$ Final rhymes are recurrent: "tombs / rooms", "place / erase", "sent / descent", "left / theft" (Jackson, 2006, pp. 37-48).

${ }^{150}$ Ibid, p. 44

${ }^{151}$ Ibid.
} 
(Xeno's arrow, god, the leap of faith, "The lift doors of my soul / have opened"152), to lyrical ("I've lost heart but / I'm keeping my balance"153). There are diaristic passages ("the sto ste sto ste of poetry [...] a buoyancy / I give up to stay fast" ${ }^{\text {"154 }}$ ) and detective story elements (inquest, clues, crime, theft).

The poet shows ease in code-switching. Biblical and metaphysical references (quote from Jeremiah 51:7, the "challenge") mix with children's voices ("holey / holy") within a domestic setting (shagpile carpet, salt to remove a wine stain). This mix leads in Thicket to "one of several experiments in a new genre called the Crochet Poem." Jackson explains that: "as a poetry genre, crocheting involves looping together fairy tale motifs or images into a new arrangement of lines. The Crochet Poem is typically slight and full of holes." 155 However entwined and paradoxically porous, the voice is mature and taut, as Hamesh Wyatt remarks about The Gas Leak: "gone are the poems with a sense of childlike joy."156

Before the final release or implosion (the last poem as an ink leak?), there is a crescendo of tension. Ewald Osers asserts that: "the true criterion of poetry - one that is equally applicable to metre-and-rhyme verse and to unrhymed poetry - is the internal tension, or temperature, or charge of the language. $" 157$ He adds:

For the working translator [...] a phrase derives its tension, its charge, its impact on the reader or listener from its "otherness", from the way it differs from ordinary speech, from the novelty of its employment in a particular context, from the surprise it produces. ${ }^{158}$

Irregular enjambments conjure sto ste's arhythmical melody of stop and go with stuttering monosyllabic "So tip / spill / stain / salt / streets". The introductory "I find the children the

\footnotetext{
152 Ibid, p. 41.

153 Ibid, p. 45.

154 Ibid, p. 39.

155 nzetc.victoria.ac.nz/iiml/bestnzpoems/BNZP07/t1-g1-t12-body1-d2.html. Accessed 25 Sep. 2017.

156 press.auckland.ac.nz/en/browse-books/all-books/books-2006/The-Gas-Leak.html. Accessed 25 Sep. 2017.

157 Osers, (1978), p. 7.

158 Ibid.
} 
Bible" echoes "I make the children their tea" emphasising monotonous routine in parenting life. However, monotony is broken with an eloquent present perfect: "have been / have made", a biblical quote where Babylon becomes "we", reuniting the dissociated "he" and "she" of the first sequence.

The rhetoric "does God believe in our holes too?" becomes a defiant confrontation: "So tip me out" but who is the addressee? Jackson's effort to catalyse encounter as a paradoxical race in "As I Stand There Biting My Nail", or a "leap of faith" in the next piece leads to discouragement: "I've lost heart", and the one thing she clings to ("I'm keeping balance") is compromised at last ("tip me out"), where the fall becomes elevation.

For Beautrais, this is the death of narrative and characters: "the marriage has been dead from the outset; all that remains is to kill off the characters and effect poetic closure" 159 or "Jackson 'kills' her poet-I character, the gasfitter's wife [...] the 'real poet' is finished with both character and fictional world." 160 On the contrary, I consider the sequence as a vital buildup of tension, leading to catharsis. Family archetypes do not die (this easily) as they reappear in the next collection.

The protagonist finally relinquishes seeing her family as it is, describing them with melancholy and irony: "my son wearing headphones / to the table, my daughter / not eating, my sister flirting / with the man I married."161 Therefore, there is resolution ("At Last The Minor Leak Is Traced And Sealed") for the wife too, and distance ("I'll leave them") releases tension into a humorous non-eventful end deflating her exaggeratedly dark perspective.

Just as anti-narrative and absence of form is impossible, even these squashed letters mean something here. The mysterious signs of the last sonnet, giving "God" the last intelligible word,

\footnotetext{
${ }^{159}$ Beautrais, (2016), p. 113.

${ }^{160}$ Ibid, p. 116.

161 Jackson, (2006), p. 48.
} 
seem like a playful pirouette. Rather than a dramatic authorial murder of the poetical self, the antepenultimate poem is an ironic ("lousy end") subversion of a eulogy for the defunct, illprinted sequence. The poet humorously embodies a Christ-like figure with these mysteriously self-converted prints as her stigmata - "is that my blood / pressed out of them?"162 Interpretation is therefore key here, and my skopos is to recapture tension but also allow ease and playfulness through humorous tone shifts.

Il semble que cette fois-ci je me sois trompée

Je trouve la Bible pour les enfants mais eux, ne veulent voir que les creux même après leur avoir expliqué la différence entre creux et croix. Ils me disent que Dieu les a mis là, on ne peut pas les voir c'est tout, il faut croire qu'ils sont là. C'est ça le défi. Je leur dis : et Dieu, est-ce que Dieu croit en nos creux, lui ? J'ai perdu la foi mais je garde l'équilibre.

Un geste de la main pour toute explication

Nous fûmes une coupe d'or dans la main de Dieu, nous fîmes de la terre une ivresse.

Alors renverse-moi. Quand j'aurai tout déversé, ne t'attends pas à ce que je laisse de tache, pas besoin de sel sur tes rues de tapis méché, j'ai bien trop chaud pour chuter.

Je m'élève loin au-dessus de toi, en ébullition.

${ }^{162}$ Ibid, p. 49. 


\section{Translation commentary}

The first poem relies strongly on the pun "holy / holey" as a "metalanguage" poem. Coetzee remarks that "English lacks a homonym to parallel Dutch 'dichten' (1) to seal (a hole), (2) to compose poetry (though, on the other hand, it possesses the notorious homophonic sequence whole-hole-holy)." 163 The children's misunderstanding is then plausible, and the debate that follows - the existence of god and the immaterial (the holes) - is also prompted by the pun.

I render this with the approximate "croix / creux" functioning in a similar fashion. I have considered homophonic pairs in the lexical field of religion - "saint / sein", "foi / fois", or the close "béat / béant". I transform "holy" into "cross" ("croix") and "holey" into "hollow" (“creux") creating a network of rhymes - "eux / creux / Dieu / peut" - and inner rhymes "voir" / "croire". In compensation, I relocate the homophony between "croix" and "croit". The cover of a bible is likely to feature a cross, and it is plausible that children confuse "croix" and "creux". The question "est-ce que / Dieu croit en nos creux, lui" has a playful ring and conveys the essential tone, the crux of the matter.

In the second poem, I accentuate the tonal shift (tension) with "passé simple", and keep the parallelism of structure. The echo "have been / have made" is retained with "fûmes / fîmes". The eloquent "passé simple" and the biblical quote stand out among previous mundane concerns: "My HOD orders", "I make children their tea".

The sto-ste melody and the rhymes "all / fall" (as well as the near "salt") are rendered with rhyming "renverse / déversé", chiasm "laisse / sel”, and the hissing "tache / méché / chaud / chuter". This hissing sound suggests an accumulation of tension leading to the final boiling (gas leak). In a symmetrical contrast with the gas-fitter breaking his mutism in lines recalling "The Treehouse" or "The Madonna of Mice", it is the wife herself who rises in the air, on the

${ }^{163}$ Coetzee, (1977), p. 287. 
boil. The temperature rise ("much too hot / to fall") plays on the idea of stylistic condensation, and subverts the traditional fall of man. I propose a close rendering with "bien trop chaud / pour chuter" and "loin au-dessus de toi, / en ébullition", with "dessus/ ébu-" repeating the pair "above/ boil" and its bubbling sound.

The invention "shagpile streets" evokes the rise and fall of streets, a projection of the self into the geography of Wellington, an elevation (the soul leaving the body, gas leaking) where the texture of a shagpile carpet might suggest the hilly capital. This is rendered with "rues de tapis méché", conveying similar meaning (texture) and suggesting by association "éméché" (tipsy). More accurate equivalents such as "tapis à poils longs" or "tapis shaggy" would not render this suggestiveness. The trait extends the subversion of the Bible quote, in which "all the earth" is drunken, and possibly reflects the protagonist's own inebriation, in a dying climax or petite mort. 


\section{Translating Thicket}

While I focus on suggesting tension in The Gas Leak, in Thicket my skopos is to convey density and to keep the multiplicity of possible interpretations. I have selected "Salty Hair" 164 and "Ophthalmoscope"165 to illustrate issues related to intricate voicing, confusion in sentiment and significant language-play.

"Ophthalmoscope" and "Salty Hair"166 recount a complex mix of emotions, encompassing sorrow and humour, desperation and hope, vision and/or sightlessness. Jackson states that: "I think one of my funniest poems is 'Salty Hair', in Thicket, which really is about being prostrate with grief, unable to lift your head off the pillow that is so sodden with tears your hair is salty." ${ }^{167}$ Both poems are a free-verse elaboration from an initial startling situation - the light of the ophthalmoscope showing veins like branches or the poet dramatically wringing out the salt from her hair. As Patricia Prime notes:

Sometimes the poems use a longer narrative style, occasionally a simple social or psychological observation in a dead-pan style. Her more usual free-verse style, of continuous down-paging in a rush of lines, suits her vision. ${ }^{168}$

The poems might read like a spontaneous and dense flow working by association, nevertheless the poet is very much in control, never failing to deliver a conclusion reaching towards "you": "thank you all the same" in "Salty Hair" or "One week, you promise" in "Ophthalmoscope".

A network of echoes between poems suggests density and entanglement. ${ }^{169}$ "Salty Hair"'s leaking glaciers recall the melting ice of "Spring"170 and "Ophthalmoscope"'s forest extends

\footnotetext{
164 Jackson (2011), p. 44.

165 Ibid, p. 9.

166 See Appendix pp. 51-52.

${ }^{167}$ Wilkinson, (2015), p. 4.

168 Prime, (2012), p. 75.

${ }^{169}$ Perhaps in a slightly less ekphrastic manner than in The Gas Leak, in which several poems describe Rosa Loy's painting, Thicket's cover is significant in illustrating the dark and tangled atmosphere. The cover fonts also suggest crochet and loose threads.

170 Jackson, (2011), p. 13.
} 
the central vegetation metaphor found in "Let Alone", "Badminton", "Not Looking, Feeling." 171 Siobhan Harvey notes that: "Like a tangle of plants, Thicket's poems build relationships, mainly between the book, Jackson's previous collections and her customary themes, icons and characters." ${ }^{172}$ Density is also conveyed by accumulation: "swallowing more and more / with more still coming at it" in "Salty Hair", and lists of possible explanations with "or", "and", "it could be" in "Ophthalmoscope".

While the mood is slightly less dark in "Ophthalmoscope" but still rather anxious ("surrounding us", "One week, you promise"), both poems use wordplay to express confusion, contrasted emotion, and a desire for clarity and catharsis. "Salty Hair" plays with collocations and readers' expectations. The final line "holding out your sands" extends the marine metaphor ("sea", "beaching themselves", "shores", "overflowing"), offers a near-rhyme with "thank you, all the same", and suggests / subverts the expression "holding out your hands". In "Ophthalmoscope”, because her vision is blurred, the poet imagines various explanations for a knocking sound, all playing on the figurative sense: a gardener to "clear things out", a midwife to perform "a delivery”, a "postal delivery” or a "knock knock, who’s there?” joke. My skopos is to equally suggest ambivalent feelings through wordplay: dark humour in desperation in "Salty Hair", and wittiness to combat anxiety in "Ophthalmoscope".

\section{Ophtalmoscope}

Techniquement, c'est la lumière

de l'ophtalmoscope

qui projette mes veines

sur mon champ de vision

et les noue

en une forêt

entre nous.

Ou qui nous encercle, j'entends qu'on tape à la porte mais ça ne peut sûrement

171 "The blackberry vines", "I stand still as a tree", (ibid, pp. 45-50).

${ }^{172}$ Harvey, (2011), p. 1. 
pas être un jardinier

qui viendrait enfin

tout éclaircir,

ou une sage-femme

venue me délivrer en se livrant

à une sorte d'accouchement,

et n'attendons pas non plus

d'être délivrée par la poste

dans cette situation,

ni, bien sûr, un invité.

C'est peut-être une blague.

Qui est là?

On aura reculé

avant la chute,

monsieur et madame Untel.

$\mathrm{Tu}$ promets que dans une semaine,

j'y verrai à nouveau clair.

Cheveux salés

Le matin mon oreiller est trempé jusqu'aux

draps. Je dois essorer

le sel de mes cheveux avant

de pouvoir lever la tête

et boire cinq tasses de café

avant de pouvoir parler - mais quand j'ouvre

la bouche un océan se déverse

de mes yeux. Je sais exactement

ce que les glaciers doivent ressentir

quand arrive le printemps, quand tout lâche

de l'intérieur, quand tous

ces centimètres durement gagnés fuient

d'un coup dans la mer,

et la mer, oh je sais ce que

la mer ressent, elle qui avale, avale et

avale encore tout ce qui coule sur elle, pas d'espoir

de calme plat quand tout déborde, quand ton

intérieur chavire sans cesse

et s'échoue sur chacun

de tes rivages.

Tu voudrais que les rivages s'en aillent.

Mais merci quand même, c'est bien aimable,

de m'avoir tendu tes sables.

Translation commentary

Dealing with ambiguity and complexity requires extra precision, as the voice conveys a clearly-

articulated sentiment of intricacy and not clumsiness. In "Ophtalmoscope", it would be slightly 
odd to translate "in front of my vision" as the literal "devant ma vision". My solution "sur mon champ de vision" not only increases clarity, it adds the image of a field, extending the vegetal metaphor. The image of the Gordian knot, which a gardener, midwife, or guest would come to cut, is also present as a subtextual image.

The rhyme "noue / nous" solves the problematic "knotting themselves", and compensates for the loss of the repeated sound in: "between us / surrounding us". The alliterations in " $n$ " and the repetition of "en" in "en une" and "entre" also suggest the knotting process. I replace the pun on "delivery", meaning both "accouchement" and "livraison", with a different pun on "se livrer à" / "délivrer quelqu'un" and "livrer quelque chose".

Other transpositions and modulations include " $\mathrm{j}$ 'entends qu'on tape" for "a knocking sound", rather than the literal "ce cognement", and I transpose "à la porte" from line fourteen, to work in collocation with "on tape". I replace the line "the second name" with "monsieur et madame Untel", clarifying the reference. "Monsieur et Madame Untel ont un fils" is a well-known joke format, perhaps as common as the "knock knock who's there” type. This creates new meaning, as in "on aura reculé avant la chute" playing with "chute" as both "bottom line" and "fall", and the physical meaning suggested in: "we'll have stepped back / before the punchline" is kept.

In "Cheveux salés", my solution prioritises the final rhyme by adding "c'est bien aimable" while keeping close to the semantics: "avoir tendu tes sables". The subversion of the expression "tendre la main" is perhaps less evident, yet the invention "avoir tendu tes sables" conveys the sense of reaching out, the gratitude expressed. Furthermore, I have already played with readers' expectations at the beginning, with "trempé jusqu'aux / draps", subverting the idiom "trempé jusqu'aux os".

On the other hand, my interpretation of "you" as a one-person, casual addressee ("tu") directs the translation towards personal poetry while the source poems keep an open range of 
possibilities: "you" readers, "you" listeners at a performance, but also "you", the ophthalmologist or perhaps "you" secret and particular addressee. An expression like "from the inside out" is also minimised with "tout lâche de l'intérieur" because longer solutions such as "du dedans au dehors" or "de l'intérieur vers l'extérieur" would lack fluidity. This is compensated by the invention "pas d'espoir / de calme plat" for "not a hope / of lying still". While the idioms "rester tranquille" or "se coucher tranquillement" are more literal, the image suggested in the collocation "le calme plat" renders horizontality and peace ("lying still"), in non-conventional language.

As Jackson states: "I think humour is often closely aligned with melancholy. The more directly you try to write about grief, the more comic it becomes" ${ }^{173}$ my rendition therefore aims at stressing the density of sentiment, the mixed feelings, and language-play contributing to the dark humour.

${ }^{173}$ Wilkinson, (2015), p. 3. 


\section{Translating I, Clodia, and Other Portraits}

In "I, Clodia", my skopos is to focus on the specific dialogue ${ }^{174}$ engaged by the poems. The sequence is based on a historical intertext with a complicated plot. ${ }^{175}$ The verse is imbued with the Latin of the Carmina. ${ }^{176}$ To explore these issues, I have selected the introductory "A Thousand Kisses, then a Hundred", "This Business of Kissing" and "Pipiabat (used to chirp)." 177 I also select "A God in his Way", and "Oh, in Hendecasyllables!" to illustrate the challenges of rendering the Latin metre, as experimented with in these poems.

a. "A Thousand Kisses, then a Hundred", "This Business of Kissing" and "Pipiabat (Used to Chirp)" ${ }^{\prime 178}$

About the sequence, Jackson states that she was "working with the rhythms of the thought, the patterning of argument that I saw in Catullus." 179 The text is indeed imbued with a rhetorical feel that comes from the Latin construction of Catullus' poems, for Jackson: "a sort of Latinish English." ${ }^{180}$ This "Latinish English" is a first challenge.

The issue is to allow a Latin influence without compromising on credibility. Recovering the historical allusions and intertextual "points of conversation" 181 is necessary to understand the dialogue and narrative, and avoid misreading. ${ }^{182}$ As well, the oratory aspect adds to the

\footnotetext{
${ }^{174}$ Reminiscent of Bakhtin's "dialogic imagination", Jackson says her poems are "filling in the questions to which Catullus' poems give their replies, countering accusations, resisting demands, sharing allusions and engaging in an ongoing battle of wits" (Jackson, 2017, p. 94).

${ }^{175}$ Jackson acknowledges that "'Oh, in Hendecasyllables!' has always felt a little leaden to me, not just because of the elegiac metre (it is in dactylic hexameters) but because of all the expounding of plot it does" (Fleming, 2015, p. 3).

176 The English translations of Catullus referred to are by Peter Green, Peter Whigham, Josephine Balmer, and Daisy Dunn. For French Catullus voices: Maurice Rat, George Lafaye, André Markowicz, and Danièle Robert.

177 Jackson, (2014), pp. 4-6.

${ }^{178}$ See Appendix pp. 59-61.

179 Jackson, (2017), p. 5.

${ }^{180}$ Ibid, p. 6.

${ }^{181}$ My inventory of echoes could also include the reprise of images from Carmina 70 and 72 ("not if Jupiter himself", "words written on water") in "Written on Water", or the allusion to Catullus' harsh iambics from Carmen 36 in "Some Poet of the Provinces".

${ }^{182}$ For instance, in "No Rough Seas" I first translated "Had you stayed put" as "si tu étais resté ici” meaning in Rome, when according to the chronology, Clodia means "si tu étais resté là-bas": in Verona.
} 
wittiness of the dialogue in an echoing game of differing registers. This would ideally be rendered without target readers having to be experts in Catullus' work.

In "This Business of Kissing", Jackson coins the invention "kissations" with a sophisticated Latin suffix. This responds to Catullus' own neologistic import from his Cisalpine Gaul (noted by Green ${ }^{183}$ or Dunn ${ }^{184}$ ) of the word "basium" (kiss) in Carmen 7. To underline its foreignness, Dunn borrows the French "gros bisous"185 in her translation, calling this a "diminutive in reverse." 186 Balmer chooses "kiss-kissing"187 for "basiationes", and Whigham uses a line break "kiss / es".

Catullus' obsession with kisses also explains Jackson's other invention "kissiary", a portmanteau combining "kiss" and "aviary", extending the bird metaphor - also found in the derisive "my flighty ways". These creations have a clear expressive function conveying wit and attitude.

As well as the title "Pipiabat", an obvious borrowing, another famous image from the "polymetric sequence" (Carmina 1-60) is Clodia's "turgidulli rubent" eyes. While Balmer offers "eyes slightly swollen, touched with red" 188 or Whigham the minimal "redden with tears", ${ }^{189}$ Jackson writes: "my tear-stained face, my red eyes".

"The new poets" alluded to are the Neoterics, a literary group including Catullus, who broke away from the poetic conventions of the time. ${ }^{190}$ This allusion is also found in the lines "a quick

\footnotetext{
183 Green, (2005), p. 12.

${ }^{184}$ Dunn, (2016), p. xii.

185 Ibid, p. 9.

186 Ibid, p. xii.

${ }^{187}$ Balmer, (2004), p. 34.

${ }^{188}$ Ibid, p. 36

${ }^{189}$ Whigham, (1966), p. 52.

190 They brought more trivial, less pompous topics to their verse, reusing some of the traditional Greek forms. As Green mentions, doctus Catullus, Licinius Calvus or Helvius Cinna, were erudite men who shared "their learned allusiveness, their distaste for long, sprawling, pompous and cliché-ridden poetry” (Green, 2005, p. 10).
} 
couplet, a startling rhythm, / and no decline into grandeur...", and "those old days Cicero misses when serious poets wrote of big subjects."191 Jackson notes that:

I imagined her [Clodia] sharing the aesthetic of the neoteric school of poetry to which Catullus belonged, valuing immediacy, a lightness of touch, a conversational quality, everything I love about, for instance, the poetry of Frank O’Hara."192

These rhetorical, historical and intertextual elements therefore convey a rich subtext about style and tone. The text navigates between irony and gravity, pathos and derision, not without maintaining a certain ambiguity. This staged dialogue has, in turn, repercussions on the potential interpretations of Catullus' work. For example, Jackson states that:

In I, Clodia I have a sparrow poem but it is ambiguous, I think - whether it is really even about the sparrow's death or whether she might have other reasons for her red eyes. The Catullus elegy, in response, becomes what I've always suspected it might be, something of a joke, mourning a sparrow's death in such a high register. ${ }^{193}$

The difficulty is therefore to maintain this dialogical connection in translation.

Un millier de baisers puis une centaine

De toutes les aventures que j'ai eues

la nôtre a bien dû être

la plus efficace!

Terminée presque avant d'avoir commencé, de la prudente caresse de ta main sur la mienne aux violentes prises et reprises de nous-mêmes, nous échappant, nous possédant encore, la nostalgie des beaux jours vécus seulement le jour même...

Déjà, il n'est plus de baisers qui réclament d'autres baisers, il ne reste plus de tendresses que tu n'aies déjà proférées. Que Cicéron regrette les jours sincères des épopées, je me laisserai aimer par l'un des nouveaux poètes : un couplet vif, un rythme étonnant, et nul déclin dans la grandeur...

Cette affaire de baisers

\footnotetext{
191 Jackson, (2014), p. 29.

192 Jackson, (2017), p. 105.

${ }^{193}$ Fleming, (2015), p. 1.
} 
C'est une affaire sérieuse, la nouvelle méthode

que tu testes pour protéger ma réputation -

ne me laisse pas, moi et mes airs volages,

interrompre tes embrassations !

Je ne suis pas sûre que tu aies encore atteint un total

assez incalculable pour nous mettre

à l'abri des ragots,

quoique assez pour être embarrassant

si le chiffre venait vraiment à se savoir.

Ne pense même pas à tes affaires

en Bithynie, tu as du travail à faire

ici même dans notre bisouillère...

seulement, combien t'en faudra-t-il avant d'avoir fini ?

Pipiabat

(qui pépiait...)

Regarde-moi, le visage taché de larmes,

les yeux rouges - c'est pour ça que tu es venu?

Mais ce n'est pas ce que tu crois.

Alors comme ça, il y a des poèmes sur moi

qui circulent en ville - comment peux-tu

imaginer un seul instant que moi, Clodia, en aie cure ?

Je pleurerais peut-être sur tes poèmes -

des larmes de rire -

mais ce sont là de vraies larmes,

je suis en deuil.

Regarde ce qu'était mon petit oiseau,

hier encore - ça, c'était

quelqu'un, bien plus proche de moi que...

tu ferais mieux de partir.

Translation commentary

Regarding the neologism "kissations", I propose "embrassations". Other inventions such as "bisouillages" or "bisouillements" seem too casual. The suffix "-ation" mocks the affectation of Catullus and his obsession with kisses. I also invent "bisouillère", close to "volière", to reproduce "kissiary" using the same portmanteau principle. These are some close translations suggesting the faint irony. "Volage" for "flighty" also renders the bird image as well as the frivolous meaning. 
In "A Thousand Kisses, Then a Hundred", the subjunctive construction of "Let Cicero regret" or "let me be loved" recalls the rhetoric of the Latin - as in the famous "Fiat Lux". It is credible in a spoken context in English but not in French: "que je sois aimée" or "puissé-je être aimée" are too rhetorical and feel overblown. I tone this down with a future tense: "je me laisserai aimer par l'un des nouveaux poètes". To compensate for this, I use "étoffement" - the elevated "il n’est plus", and "proférées".

The lines "from the cautious brushing of your hand $[\ldots]$ / to the violent taking and retaking [...] / the evading, the reclaiming" convey a suggestive back-and-forth rhythm with an -ing form impossible in French. There is a sudden rise from gentleness to epic, which I recapture with nouns stressing the binary rhythm - "prises / reprises", "échappant, possédant".

I render the allusion to the neoteric school in the end by keeping the French loan-word "grandeur", with a formula sounding historical, paradoxical, a resonance that is subtly derisive - "et nul déclin dans la grandeur".

In "Pipiabat", I use some oralisms: for instance the phatic "Alors comme ça" is an expansion of "so" to keep the vividness of expression. On the other hand, in the lines "how could you / possibly imagine I, Clodia, would care", the immediacy needs concise rhythm, and "se soucier de" is too long. My solution "en avoir cure" is mimetic of the English, and implies a more formal register, which yet does not clash overall. I also aim at maintaining the ambiguity of Clodia's sorrow with the stereotypical drama line "Mais ce n'est pas ce que tu crois" often found in vaudeville for instance.

My focus is mostly on the level of tone and register: how much is too much or not enough? The idea is to allow tonal subtleties at times mocking Catullus' bombastic tone, and at times delivering heartfelt emotion without sounding overly grandiloquent or flat. Catullus objectifies Clodia as a fictional character (Lesbia) in his Carmina but also outside the poems, as Jackson explains: 
Whether fictional or not, it is the performed address to the very specific audience, Lesbia, which gives the eavesdropping its meaning and its charge. [...] poems addressed to a more general readership, including poems about Lesbia [...] take on much of their charge through their imagined reading by Lesbia herself as the eavesdropper she is set up by the poems to be. ${ }^{194}$

I aim for the liberating, mirror-amplifying effect of Clodia's response to be perceived even by target readers who would have no knowledge of Catullus. As well, the conversation would justify a presentation of Clodia's and Catullus' poems in parallel - an epistolary dialogue, which I have recently been fortunate enough to offer to a French audience. ${ }^{195}$

b. "A God in his Way", and "Oh, in Hendecasyllables!"196

“A God in his Way" responds to Carmen 51, itself drawing from Sappho's fragment 31: 'I'm Sappho, you like to say". Jackson reuses a number of images, as in the title: "in my eyes he seems like a god's co-equal"197 ("Godlike the man"198 for Whigham), or the enumeration borrowed from Sappho:

Senses shredded, torn apart $[\ldots]$

my tongue is numbed, my lips struck dumb; pale fire trickles down my limb, my ears resound, ring-ting with their own thunder, and my eyes are covered by these dark nights. ${ }^{199}$

Jackson refers to these enumerations again in "From the Distance" (but shifts the agents involved). The last stanza is Catullus' very own (potentially a later addition), and Clodia subverts it in "Like a Flock of Birds the Laughter" with a tonal shift: "Idleness is the ruin of actually idleness would be lovely.",200

\footnotetext{
194 Jackson, (2017), p. 108.

195 poezibao.typepad.com/files/catulle-et-clodia.pdf. Accessed 5 Dec. 2018.

${ }^{196}$ See Appendix pp. 62-64.

197 Green, (2005), p. 99.

198 Whigham, (1966), p. 110.

199 Balmer, (2004), p. 37.

200 Jackson, (2014), p. 28.
} 
There is therefore irony in Clodia's response: "He indeed who can command such a sweet pause / seems to me a god in his way". Constrasting with Clodia's husband ("a man of few words"), Catullus' profusion is mocked, and his mutism is an opportunity for Clodia's voice to be heard: "the presentation of the poet's tongue-tied silence is accepted at face value as she claims the page for herself." ${ }^{201}$ The element of wit in dialogue is omnipresent.

Regarding metre, unlike Dunn, who states that: "I have not sought to recreate the Latin metre Catullus used" on the premice that "I wanted the freedom to render his words as I saw fit", 202 Jackson reuses the Sapphic metre. She corroborates Dunn's assessment that "an elegiac couplet in English will not sound like a Latin elegiac couplet"203 but she produces a form that is mimetic of the Latin rhythm:

Where I have written in metre, I have used an English stress-based version of the Latin metres, which can be heard as rhythm in a way metres based on vowellength simply can't be heard, I don't think, in English. Even so, the complicated patterns of Latin metres seem strange in comparison with the regular repetition of a particular measure we are used to in English - one iamb after another, or a series of trochees or dactyls. ${ }^{204}$

About the hexameter, Green, who also reproduces Catullus' metres, writes:

The way to produce some real stress equivalent to the hexameter was to go for the beat, the ictus, since this was native to English, and let the metre, within limits, take care of itself. [To counter] the determination of the English language to climb uphill [...] this line at least catches the precipitate striding movement of the hexameter, while preserving its basic structure, including the caesura. What is sacrificed is the linguistically unattainable ideal of true metrical equivalence. ${ }^{205}$

As Green explains, the pattern of a Sapphic strophe is (with - as a long syllable, $U$ as a short one, $\mathrm{X}$ as an anceps or free syllable, and / for a stressed syllable):

$$
\begin{aligned}
& / / / / / / \\
& -\mathrm{U}-\mathrm{X} / \mathrm{I} \mathrm{U} \mathrm{U}-/ \mathrm{U}--(\mathrm{x} 3 \text { hendecasyllabic }) \\
& / / \\
& -\mathrm{U} \mathrm{U}-/ \mathrm{X} \text { (last line or "adonic") }
\end{aligned}
$$

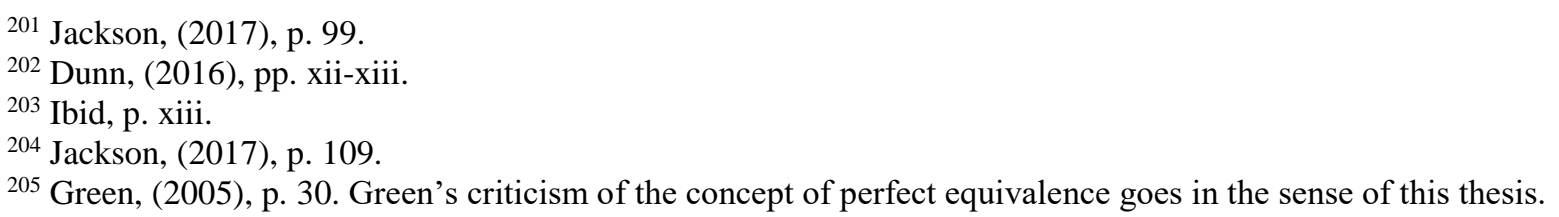


The scansion of Jackson's poem could be designed like this (with the stress in bold):

I am Sappho, / you like to say / - it's you, though, body burning, / thundering heart, / your eyes blind, ear drums ringing,/ who's mute at last,/ no more talk leading to kiss-/es,

The metre is therefore functional in terms of poetics and narrative, and I aim to preserve this in my translation.

"Oh, in Hendecasyllables!" is in dactylic hexameters (like Carmina 62 and 64). The metre is: "a six-foot line, consisting almost entirely of dactyls [...], with the final sixth foot a spondee or trochee, and all feet resolvable into spondees" ${ }^{206}$ (after the first syllable of each foot, either two short U U, or one long syllable - may be used):

$\begin{array}{lllll}/ & / & / & / & / \\ -\mathrm{UU} /-\mathrm{U} \mathrm{U} /-\mathrm{U} \mathrm{U} /-\mathrm{U} \mathrm{U} /-\mathrm{U} \mathrm{U} /-\mathrm{X}\end{array}$

If my / heart is a /heart of /bronze it is / melting and / burning,

The dactylic hexameter achieves "a constant tension between natural stress and metre." ${ }^{207}$ Its springy counterpoint is apt to express Clodia's frustration. The reference to metre by metonymy: “oh, in hendecasyllables!" also echoes Catullus' own habit, as in Carmen 42: "Come, you hendecasyllables, in force now."208 There is exasperation, abandon ("melting"), and hopelessness - Clodia regrets her preceding message in "No Rough Verses".

The poem takes as its basis the narrative of Carmen 101, in which Catullus mourns the death of his brother. ${ }^{209}$ This prompts Clodia to write back: "in your grief having heard of your brother's death you were / needing me". Clodia is touched by Catullus' grief: "For Clodia to

\footnotetext{
${ }^{206}$ Ibid, p. 39.

207 Ibid, p. 40.

${ }^{208}$ Ibid, p. 89. This metonymy is also in "The Grittiness of Spring": "no poet ever fired a single iambic" or "(To Caelius Rufus)": "they keep a pretty metre" (Jackson, 2014, pp. 17-21).

${ }^{209}$ As well as Carmen 65. He renounces his passion in Poem 68a "from all pursuits of that kind the death of my brother / has debarred me through grief" but still regrets his lover in 68b: "a house for my mistress and for me / where we could sink ourselves in our mutual passion. / Hither my refulgent goddess with light step / came" (Green, 2005, pp. 171-173).
} 
break it off with Catullus is par for the course; but to receive a poem like 'No Rough Verses', apparently in reply to his plea for her to set aside her defenses and console him in his grief, is another matter altogether." ${ }^{210}$ The miscommunication may also come from their emotional and physical distance, as Catullus is in Bithynia.

The dialogue becomes heated ("burning"), and marked by repetitions: "heart", "fury" "finally", "at last" as they run out of luck: "I never saw the note that you left me and you received mine / as if it were its reply". This explains Clodia's fury against the "ironic mistimings", against the gods' cruelty ("amusement") and the doom encapsulated in Carmen 76: "accept what you see has died, is dead." 211 This reaction against the gods is a typical trope in Latin literature, ${ }^{212}$ and conveys verisimilitude.

Although there is a clear connection between narrative, metre and sentiment, Jackson writes:

I was so pleased with the plot twist, which moved the narrative along so effectively, I tried not to notice how the poem stalled the sequence as a poem. Then, when the book was a book, and I read it through as a reader, not the writer, I felt the sequence hit a dull note at that poem. So I rewrote it as free verse, much shorter and sharper and brisker in tone. I wish I had rewritten it before the sequence was published. ${ }^{213}$

My skopos is to adopt Jackson's mimetic approach and the question is therefore: should the metre be kept? Given that the poet has produced a second version in a subsequent publication of the book, I propose comparing the two possibilities.

Un dieu à sa façon

Je suis Sappho, comme tu aimes dire - c'est toi, non, le corps brûlant, cœur qui tonne, les yeux aveugles, tympans qui sonnent, enfin muet, plus un mot pour d'autres baisers,

toute ton attention sur un autre, pas sur moi mais sur lui, qui sait me parler, qui, quand tu files chez toi, seras, tu supposes, rien qu'à moi, mari oublié...

\footnotetext{
${ }^{210}$ Jackson, (2019), p. 122.

${ }^{211}$ Dunn, (2016), p. 10.

${ }^{212}$ Virgil wrote: "Fortuna omnipotens et ineluctable fatum", Aen 8:334.

${ }^{213}$ Fleming, (2015), p. 3.
} 
Ce répit est louable ! Je remplirai mes strophes pendant que, pour une fois, tu te tairas stylet baissé, tes doigts, j'espère, inactifs, papier dessouillé...

Qui sait commander une pause si douce me semble un dieu à sa façon! Si j'étais moins comme Sappho, mais plus fille, je penserais que c'est ça, l'amour...

Oh, en endécasyllabes !

Si mon cœur est un cœur de bronze, il fond et brûle, brûle de furie, de furie pour ces dieux qui, eux, s'amusent des contretemps ironiques que nous connaissons : enfin ai-je eu le courage de finir une histoire qui déjà, était morte, je t'ai écrit quand déjà, tu m'avais cherchée, quête vaine, et, dans ton deuil, tu avais, apprenant la mort de ton frère, eu besoin de moi, être là où souvent je te cherche. Là, décidée à partir et laisser Caelius m'avoir, je n'ai jamais vu la note que tu m'as laissée, et la mienne, que tu as lue comme réponse, oh, en endécasyllabes !

Où es-tu maintenant ? Personne ne sait - ou le cache : qui parmi tes amis, à présent, me sera amical ?

Oh, en endécasyllabes !

Etrange de penser que tu me cherchais là où si souvent je t'ai attendu en laissant filer les jours avant qu'enfin, déterminée à me retirer et à laisser Caelius m'avoir, je ne t'écrive pour tout arrêter, et toi qui t'étais enfin tourné vers moi dans ton deuil as dû recevoir mes vers comme ma réponse - oh, en endécasyllabes ! Où es-tu à présent ? Personne ne le sait - ou personne ne le dit. Qui de tes amis sera pour moi un ami désormais ?

Translation commentary

In "Un dieu à sa façon", I discard the accent scheme of the Sapphic strophe but preserve the syllabic pattern and the "visual legibility". I also emphasise the ternary rhythm by replicating the sentence construction, with short clauses: "le corps brûlant, cœur qui tonne, les yeux aveugles, / tympans qui sonnent." Here, I add a rhyme ("tonne / sonnent"), and use an 
alternating ellipsis of the definite article to obtain the requisite number of syllables and a balanced beat.

The neologism "unblotted" works on the basis of "blotting paper" but also recalls the expression "to blot one's copy book". I invent "papier déssouillé", recalling the idiom "une réputation souillée". I remain consistent with the historical context and change "pen" into "stylet", because "stylo" would be anachronistic. I reorder the end line so the poem finishes on "l'amour", keeping the openness and ambiguity.

In my first version of "Oh, en endécasyllabes !", I maintain the syllabic count and the stress pattern. The metre's stress suggests the protagonist's frustration and heightened rhetoric. I use André Markowicz's strategy of "marquage tonique" to recall the dactylic hexameter; that is to say that I separate "temps fort" and "temps faible" using the natural stress of syllables in words, and the natural intonation in sentences, as in for instance: "Maître Corbeau sur un arbre perché / Tenait en son bec un fromage.”

Philippe Brunet explains that:

Fantôme récurrent dans les lettres françaises, trace prétendue invisible dans le vers syllabique, ce principe de marquage tonique a été développé, en 1985, par André Markowicz dans sa transposition des mètres de Catulle. Je l'ai utilisé pour façonner le vers de l'épopée grecque archaïque. Cet hexamètre repose à la fois sur des qualités naturelles propres à la langue, sur le moule métrique dans lequel on contraint la langue, enfin sur la maîtrise aédique d'un principe de régulation rythmique. $^{214}$

I am inspired by Markowicz's translation of Catullus, which Julien Pingoud calls "une entreprise de versification." 215 For Etkind, this strategy makes it possible to render the elegiac distich without using "alexandrins":

Il est parfaitement possible de rendre en français l'opposition de l'hexamètre et du pentamètre dans le distique élegiaque (lequel jusqu'à présent était généralement traduit en alexandrins), comme dans cette traduction d'André Markowicz. $^{216}$

\footnotetext{
${ }^{214}$ Brunet, (2014), p. 124.

215 Pingoud, (2009), p. 108.

${ }^{216}$ Etkind, (1982), p. 138.
} 
Respecting the syllabic count, the stress, the semantics, the tone and the musicality necessarily leads to transpositions and paraphrases. In particular, the final unstressed syllable leads to additions: "quête vaine", "ces dieux qui, eux", synonymy: "morte" for "over", change of tense: "je te cherche" or inversion: "enfin ai-je". This is one of the most difficult constraints found so far. I propose the following stress pattern:

Si mon/ cœur est un /cœur de /bron-ze, il /fond et / brû-le, brûle de fu-/rie, de fu-/rie pour ces /dieux qui, /eux, s'a-/mu-sent des contre-/temps iro-/niques que / nous connai-/ssons : enfin/ ai-je eu le cou-/rage de fi-/nir une his-/toire qui dé-/jà, était/morte, je t'ai é-/crit quand dé-/jà, tu m'a-/vais cher-/chée, quête /vaine, et, dans ton /deuil, tu a-/vais, appre-/nant la /mort de ton/ frère, eu be-/soin de /moi, être /là où sou-/vent je te /cherche.

Là, déci-/dée à par-/tir et lais-/ser Cae-/lius m'a-/voir je n'ai ja-/mais vu la / note que / tu m'as lais-/sée, et la /mienne, que tu as / lue comme ré-/ponse, /oh, en en-/décasy-/llabes !

Où es-/tu mainte-/nant ? Per-/sonne ne /sait - ou le cache : qui par-/mi tes a-/mis à pré-/sent me se-/ra ami-/cal ?

With such a rigorous stance, the risk is that the ease in language might be altered and the translation sound leaden. Brunet insists on the incantatory quality of dactylic hexameters:

La constitution de langues poétiques confiées à la voix, avec cette part d'hypnose suscitée par la réitération de schémas rythmiques et par leurs variations subtiles, risque d'éloigner cette parole de sa dimension naturelle, "oralité" très souvent vantée dans la littérature contemporaine, et de lui conférer une autre dimension vocale, incantatoire. ${ }^{217}$

What results is an experimental incantation, with an unusual elevated charm, emphasising sentimental turmoil but also clearly getting further from the natural dimension of speech. The second version in free verse is for me much more fluid, and apt to render the narrative function of the poem in the sequence. The plot twist is also, I find, much clearer. This is not only loyal to Jackson's later choice but the voice seems more intelligible. Rather than a dialogue in form that would restrict potential interpretations, a dialogue of voices is then emphasised.

${ }^{217}$ Brunet, (2014), p. 132. 


\section{Translating Anna Jackson's poetry and the poetic voice}

To conclude this first case study, among the various challenges encountered - including intertextuality, ${ }^{218}$ humour, ${ }^{219}$ compression, ${ }^{220}$ formal constraints ${ }^{221}$ and "visual legibility", ${ }^{222}$ wordplay, ${ }^{223}$ cultural or natural references ${ }^{224}$ and semantic / linguistic openness ${ }^{225}$ - one element needs to be highlighted as it is particularly testing: the poetic voice.

Holmes promotes the importance of voice and voices: "With translated poetry, hearing voices from beyond the boundary fence of our own language can give added value. This may be the excitement of meeting a major poetry voice." ${ }^{226}$ Katharina Reiss suggests comparing "künstlerisches Temperament":

Il ne siérait donc pas que le critique condamnât une telle traduction en la jugeant fausse ou inutilisable, quand bien même la simple confrontation de l'original et du texte traduit lui fournirait des arguments. La tâche du critique consistera plutôt dans ce cas à mettre en lumière les différences entre le tempérament artistique de l'auteur et celui du traducteur et à en montrer les répercussions sur la version-cible, puis à en tenir compte dans son évaluation. ${ }^{227}$

How much these artistic temperaments coincide and to what extent their voices harmonise is precisely the crux of the matter.

Paula Green describes Jackson's poetic voice as: “overlapping wit, humour, borrowings, lyricism: an accessible but surprising voice." 228 For Erin Scudder: "the earlier books generally develop a warm and familiar poetic voice. ${ }^{229}$ However, this voice has evolved since the playful

\footnotetext{
${ }^{218}$ See The Long Road to Teatime.

219 See The Gas Leak.

220 See The Pastoral Kitchen.

${ }^{221}$ See "The Coming on of a Maths Brain" (Appendix, p. 48), see also: Arnault, (2018), pp. 9-13.

222 See "The Gas-Fitter's Daughter Shows Shane".

${ }^{223}$ See "Watch" or Thicket.

224 See "Sparrow (as told by Elvira)".

${ }^{225}$ By semantic openness, I mean Jackson's aptitude to allow a plurality of interpretations in the poetry. See for instance: "Silence it Means Something", or "The Pretty Photographer" sequence.

${ }^{226}$ Holmes, (2011), p. 7.

${ }^{227}$ Reiss, (2002), p. 141.

${ }^{228}$ In Ricketts, (2010), p. 196.

${ }^{229}$ Scudder, (2017), p. 134.
} 
experiments of Catullus for Children. ${ }^{230}$ For Green, in "I, Clodia", there is "no whimsical, petal of a voice here", she adds: "poems become voice, voice becomes reaction to / against, reaction becomes autobiography, and autobiography becomes invention."231 This voice has a clear feminist scope "re-visioning, resiting, reclaiming, re-presenting women from the shadows of history." 232

It is significant that in her own work as a translator of Tissot's poems, Jackson pays so much attention to the voice, which she qualifies as "personal (and personable), and somewhat strange (or estranged)." ${ }^{233}$ She writes: "We eventually would find a solution that captured the sense, and the word-play, and the play on idiom, and still worked as a line in the poem as we were translating it, with our sense of the Marlène Tissot voice." ${ }^{234}$ It is striking that to speak of voice is for Jackson to speak of a sense of voice. If we consider this from the poet's perspective, Jenny Bornholdt confesses that:

I don't feel as though I had to find my voice, it was just there. Sometimes I tell people things and they say "that sounds like a Jenny Bornholdt poem", so my own voice is obviously very close to my writing voice. It's probably to do with the things I write about, which, as we know, are pretty down home. I'm sure it's possible to develop a voice, I just don't have the flair or the imagination to be able to do that. ${ }^{235}$

\footnotetext{
${ }^{230}$ Jackson notes that: "I was borrowing a kind of Frank O'Hara conversational tone I saw in some of the translation from the 1970s, but I also borrowed from the Renaissance translations with the beautiful imagery and the hyperbole and the exaggerations and the similes and metaphor and playing with that lushness" (Jackson, 2017, p. 4).

${ }^{231}$ nzpoetryshelf.com/2015/05/28/anna-jacksons-i-clodia-and-other-portraits-a-lightness-that-is-fierce-aspareness-that-is-complex/\#comments. Accessed 17 Nov. 2017.

${ }^{232}$ Ibid. This feminist take is salient in the invective of "(To Caelius Rufus)", where the "old chivalry" of Alexander the Great is "just about the world's worst story", and Charlotte Corday murdering Jean-Paul Marat might come to mind: "I'd have already / found Alexander in his bath and slaughtered / him right where he lay" (Jackson, 2014, p. 15).

${ }^{233}$ Tissot, (2017), p. 5.

${ }^{234}$ Ibid, p. 6.

235 victoriauniversitypress.blogspot.co.nz/2016/08/an-interview-with-jenny-bornholdt.html. Accessed 16 Nov. 2017
} 
From my perspective, it is only with time and experience that I have learnt to develop a more confident or personal style, what may be my voice as a translator. As Jany Berretti reminds us, there are no insignificant operations, and translation is never a silent act:

Lors de l'entreprise de traduction, le moindre fragment que l'on écrit comme innocemment dans l'autre idiome se substitue violemment à une microstructure qui se révèle unique. C'est un avertissement pour l'imprudent qui voudrait faire traverser la frontière entre une langue et l'autre à un mot, une conjugaison, un accord, un rythme en restant au plus près du calque, en silence et de nuit, sans rien endommager, frileusement, incognito: qu'il sache au contraire que son geste produira par nature un bouleversement général et un fracas assourdissant, que traduire n'est pas une tâche légère, à petit bruit, mais bien une manifestation colossale qui s'accomplit dans le vacarme. ${ }^{236}$

This is first because translating requires taking into account a variety of factors simultaneously,

a juggling act that inspires in Markowicz a striking comparison:

Traduire, c'est comme conduire. Quand vous conduisez, vous faites plusieurs choses à la fois, vous regardez devant, derrière, sur les côtés, vous changez les vitesses, appuyez sur les pédales, vous parlez avec votre passager et anticipez la route et ça roule... car sinon, si vous séparez tout ça, là, vous êtes dangereux. ${ }^{237}$

If we go back to the idea of a sense of voice, this implies an indirect access, an intermediate element that needs tuning in or channelling. Practically, this means that I partly rely on my imagination or my intuition. As T. Carmi would say: "for a solution, listen to the voice inside you. It is usually right." 238 This is also reinforced and guided by a thorough knowledge of the poet's entire works, the habit of listening to the poet recite, the poet's œuvre becoming some sort of organic element, within which the translator evolves familiarly, rather than merely text.

\footnotetext{
${ }^{236}$ Berretti, (2006), p. 112.

${ }^{237}$ Markowicz, (2006). This stance considering the text as a whole is also termed a "holistic" approach. Chesterman suggests that: "To counteract the risk of a partial and blinkered view of translation, one should clearly aim at a holistic view, which is as wide as possible, seeking to cover the whole field from a bird's eye perspective" (Chesterman, 2016, p. 69). Nord's focus on pre-translational analysis includes a holistic approach: "Instead of setting the standards for the production of an equivalent target text, [pre-translational text analysis] provides the basis for a comparison of the source text's offer of information with the target-text "profile" [...]. This comparison serves as a basis for (a) the choice of a particular translation type (documentary or instrumental translation), (b) the identification of translations problems, and (c) a holistic design of translation strategies and procedures to solve translation problems" (Nord, 2010, p. 124).

${ }^{238}$ In Weissbort, (1989), p. 161.
} 
If we consider intuition as Henri Bergson defines it - "cette espèce de sympathie intellectuelle par laquelle on se transporte à l'intérieur d'un objet pour coïncider avec ce qu'il a d'unique et d'inexprimable"239 - such an elusive process may appear problematic on the level of methodology. In "Intuition and Translation Processes", Donald Kiraly notes that:

Given the vague understanding of intuitive processes, they will be considered here simply as uncontrolled mental processes. Intuitions will include such phenomena as spontaneous associations between words and concepts; spontaneous determinations of accuracy or equivalence where no conscious rule is invoked; and spontaneous determinations of acceptability (relative to the target speech community), also where no conscious rule is invoked. ${ }^{240}$

He goes on to regard intuitions as simultaneous and indissociable from more conscious operations: "cognitive and intuitive factors alternate without any observable coordination and without evidence of a progression of mental steps." ${ }^{241}$ What results is that instead of considering intuition as an unreliable or too subjective factor - as Nord points out, "in translator training, teachers all too often have to rely on their intuition, on their own professional experience or academic research, on trial and error, imagination and luck" 242 - translating the poetic voice requires embracing this constitutive element of flair in a measured but confident manner. Intuition and its empathetic quality should not be overlooked as long as they are combined with more tangible factors, such as an appreciation of metre, rhythm, tone, soundplay, or idiosyncracies to obtain a sense of the voice.

Robert Lowell explains that his Imitations: "should be read as a sequence, one voice through many personalities." ${ }^{243}$ In Jackson's work too, there is at times a diffraction of the voice into different voices, contrasted characters, particularly visible in "Sparrow (as told by Elvira)", the

\footnotetext{
${ }^{239}$ Bergson, (1938), p. 132.

${ }^{240}$ Kiraly, (1995), p. 49.

${ }^{241}$ Ibid, p. 50.

${ }^{242}$ Nord, (2005), p. 2. Nord further observes that in translation training: "giving marks for 'particularly elegant' solutions seems superfluous. Anyway, such 'plus' marks are usually dictated by the subjective stylistic intuition of the examiner" (Nord, 2005, p. 189).

${ }^{243}$ Lowell, (1961), pp. xi-xii.
} 
central part of The Gas Leak, or triptych poems from Thicket for instance. In these cases, I resort to imitation or ventriloquism, as Edwin Honig describes it:

The trick, like the ventriloquist's, was to project one's own voice and have it echoed back through a different though sympathetic other voice - the voice that could be re-created by imitating or translating another poet. That way I could assume one alter ego after another, something like voice-masks or personae, as Pound called them. ${ }^{244}$

In The Poet's Other Voice, Edwin Honig asks some crucial questions:

What part of their own voice, then, do poets discover in another's, or what of the other's do they put into their own? And what is a poet's voice? Is it some arbitrary locus made out of pressured words, the projection of some imaginative possibility vocalised, as the self is, to stand for the individual? Is translation as self-transcendance still another version of the paradox: to know yourself, lose yourself in the other? $?^{245}$

The alterity of another poet's voice does emphasise the need for the translator to assert his or her poetic voice. What is a poet's voice? As Barthes writes: "La voix est un phénomène proprement inthéorisable, dans une logique du supplément, de l'entre-deux, entre corps et discours. La voix est le lieu privilégié de la différence qu'aucune science n'épuise."246 I would answer by using Honig's question in the affirmative: the poet's voice is an arbitrary locus made out of pressured words, the projection of some imaginative possibility vocalised.

This is true when reading a poem on the page. In the situation of an oral reading however, this vocalised possibility is no longer imaginative but effective, manifest in all its distinctiveness. An oral reading of a translation is revealing. As Clíona Ní Ríordáin states of the readings given by Valérie Rouzeau and Susan Wicks at a poetry festival in 2011:

It is in the sequential poetry reading that the separateness and distinctness of the two voices become apparent [...] it is only in the reading aloud of the text by the poet and her translator that is it possible to capture the separateness of the original poem and its translation. The ambiguity Peter Robinson refers to, which for him lies at the heart of the act of translation, "the sound of one voice

\footnotetext{
${ }^{244}$ Honig, (1985), p. 2.

245 Ibid, p. 8.

${ }^{246}$ Barthes, (1977), p. 247.
} 
pretending to be another" (Robinson, 2010: 50), is impossible in the case of poet and poet-translator standing side by side. ${ }^{247}$

This is also what I observed when offered the opportunity to read my translations in public alongside Jackson reading her poems. ${ }^{248}$ Such a situation highlights the voices present in poetry and in translation. No ambiguity or pretense is possible then, as the distinctness of poetic voices is revealed.

Translating the poetic voice not only necessitates encompassing a sum of stylistic elements including tone, musicality, rhythm or the many idiosyncratic ways in which the poet originally articulates thoughts and emotions in the text. The translator also needs to allow the possibility of imaginative vocal projections by readers. Finally, what is possibly the most revealing dimension of a poetic voice is also its physical manifestation in the case of a reading performance. The translator then needs to recreate the possibility for an audience to hear the distinct voice(s) of the poem - a sense of the voice. The translation needs to deliver both something of the source poet's voice and that of the translator in harmony, so the poetry can be appreciated and revealed, albeit on another level. This reader or audience-oriented definition indicates that the poetic voice is both a personal and an impersonal element. The translator should create space for others to make the poem their own, something we may call the ability to internalise otherness, and re-project it, as Nord suggests when referring to "otherness understood." 249

The idea of translation poetics, and what Mariana Machova makes of Elizabeth Bishop's poetry encapsulates an ideal approach in terms of poetic voices crossing over, underlining the experience of otherness and the encounter implied, along with the equilibrium needed:

Using the term translation poetics is certainly not the only possible way to speak about this poetic approach. However there seems to be parallels and connections

\footnotetext{
${ }^{247}$ Ní Ríordáin, (2015), p. 197.

${ }^{248}$ This took place at the "Lit Crawl" series of events in Wellington in November 2017. seraphpress.co.nz/home/archives/11-2017. Accessed 18 Jun. 2019.

${ }^{249}$ Nord, (2016), p. 578.
} 
between it and translation [...]. In my view, the basic gesture or principle underlying this type of creation is the openness toward and the awareness of "the other" the poet-translator is meeting. [...] The goal of the creation is neither to dominate and appropriate the other nor to identify with it and yield to it, but to understand it, and to get as close to it as possible. ${ }^{250}$

In conclusion, for the translator to preserve the possibility of internalised otherness, he or she should first pay close attention to factors including tonal variations, musicality, innovative expression, rhythm, by deduction, but also by intuition / imagination, perhaps risking losing one's voice in the other's to get as close as possible to that of the source poem. He or she should also accept the fundamental experience of otherness that is poetry translation, a meeting of voices where mutual respect and comprehension should prevail so both voices can be heard in harmony. I now explore this further in a second case study involving a different range of challenges.

${ }^{250}$ Machova, (2017), p. 150. 


\section{PART II: TRANSLATING ROBERT SULLIVAN'S POETRY}

\section{A. PRELIMINARY ANALYSIS}

\section{Why Star Waka? Presentation, themes and devices}

As mentioned in the introduction, I focus solely on Sullivan's 1999 selection Star Waka in this case study. Star Waka is a popular poetry best-seller in New Zealand: it was short-listed for the 2000 Montana New Zealand Book Awards, reprinted five times between 2000 and 2013, and translated into German in 2012 (Sternen-Waka). The selection is a milestone in Sullivan's œuvre. For Simon Perris, it is "Sullivan's best-known work" or his "magnum opus." book's central metaphor is inherently translational as a poetics of transport, as Sullivan explains:

I believe a poem should involve some kind of transport: just as a metaphor transfers the feelings and other associations of one figure to another figure, so too should a poem convey similar intellectual and emotional associations about its subjects, gathering more feelings and associations as the poem travels toward its end. I conceived my book Star Waka as a long vessel carrying many different concepts, and characters, on its journey; at other times I imagined the book as consisting of 101 different vessels or waka so that it was a fleet on voyages of exploration. $^{2}$

The book departs substantially from Sullivan's first two poetry books Jazz Waiata (1990) and Piki Ake! (1993), as Peter Marsden notes: "The whole project is also altogether more complex, more ambitious, the volume itself distinctly less slim than its predecessors." ${ }^{\text {3 }}$ It also contains seminal material and ideas explored in more detail in later works. In Captain Cook in the Underworld (2002) or Shout Ha! to the Sky (2010), the poet pushes further his propensity to conflate classical mythology and Māori cosmology, within the frame of British colonisation in

\footnotetext{
${ }^{1}$ Perris, (2017), p. 183.

${ }^{2}$ In Ricketts, (2010), pp. 462-463.

${ }^{3}$ Marsden, (2001), p. 3.
} 
the Pacific, ${ }^{4}$ something already at the core of some of the poems in Star Waka - poems xiv, xxi, xxxii or xxxvi for instance: "Māori were also divine [...] we were imperfect gods / not unlike the antiquarian / beasts and gladiators of Europe." In Voice Carried my Family (2005), the sequence "For Gods and Waka" reuses the waka motif, and in the delightfully revisionist "London Waka", ${ }^{2}$ Sullivan imagines Māori colonising England, in a reversed historical account. For Selina Tusitala Marsh, it "remaps historical journeys as he [Sullivan] reinvents mythologies, re-auditioning and recasting historical scenes."7 This would arguably have fitted Star Waka's project, alongside some of the sequence's most inventive narratives - the sciencefiction inspired "iv 2140AD", 8 the anticipatory poem 46: "we will enter / space / colonise planets call our spacecraft waka" or 49 "(environment I)" $" 10$ or again the clear-sighted waka 77:

In pre-colonial times the crews would walk across the isthmus near Otahuhu to cross harbours, carrying the waka.

If they were visible today there would be motorcades, policemen to control the crowds and traffic probably tv crews too,

perhaps a Holmes special. They'd probably make it part of an Ironman event. ${ }^{11}$

\footnotetext{
${ }^{4}$ As noted by Bridget Orr in 2008, and Simon Perris in 2017, Sullivan perpetuates a tradition perhaps instigated by Anna Seward in her "Elegy on Captain Cook", considering Polynesia with a classical frame of reference. Perris writes that: "The considerable parallels with Seward's Elegy are emphasised further by a poem in Sullivan's collection Shout Ha! to the Sky (2010), "About Anna Seward's Elegy on Captain Cook, 1780" (Perris, 2017, p. 185).

${ }^{5}$ Sullivan, (1999), p. 36. The source reference for each poem by Jackson or Sullivan is indicated at first mention in the thesis.

${ }^{6}$ Sullivan, (2005), p. 6.

${ }^{7}$ Marsh, (2006), p. 467.

${ }^{8}$ Sullivan, (1999), p. 7.

${ }^{9}$ Ibid, p. 50.

${ }^{10}$ Ibid, p. 53.

${ }^{11}$ Ibid, p. 86.
} 
The book is therefore an excellent introduction ${ }^{12}$ to Sullivan's work overall, in clear thematic alignment with his more recent books. Over the last two decades, Star Waka has had an undeniable popular impact, with a larger than usual readership for a poetry selection.

1. A significant metaphor, the waka

Sullivan's central metaphor - in line with the constraint that "each poem must have a star, a waka or the ocean"13 - resonates in, and is key for New Zealand poetry as a whole. For instance, the waka as "a container for the freight of history - personal, familial, tribal, national"14 is chosen by Williams and Stafford as an opening in the introduction to their 2012 anthology: "Like a waka, the anthology contains, preserves and transports a multifarious collection of crew and passengers, not always at ease with each other, sometimes in overt contention, often in intense conversation." 15 The metaphor is clearly apt to convey the journey of multiple, echoing and evolving voices in New Zealand poetry, as Sullivan asserts in poem i that "crews change, language of each crew changes." "16 In terms of conversation, Star Waka's project was originally intended as a response to Kendrick Smithyman's Atua Wera $^{17}$ and in terms of multifarious journeys, the sequence draws from a variety of references, in particular from Sullivan's multicultural background - Ngā Puhi (originally a Northern tribe), Kāi Tahu or Ngāi Tahu (north of the South Island), Irish (Galway), and Scottish. This mixed heredity and mixed use of references are not unusual in New Zealand and are even arguably representative.

\footnotetext{
${ }^{12}$ In an online interview from 2006, Sullivan suggests: "Start with my third book of poetry, Star Waka" waterbridgereview.org/cnv-sullivan-p1/. Accessed 21 Jun. 2018.

${ }^{13}$ Sullivan, (1999), p. viii.

${ }^{14}$ Stafford, (2012), p. i.

${ }^{15}$ Ibid.

${ }^{16}$ Sullivan, (1999), p. 3.

${ }^{17}$ Smithyman's selection poetically imagines and retraces the life of Sullivan's ancestor, the Ngā Puhi tohunga Papahuria.
} 
The book's cross-cultural stance is at times presented as conflictual: "waka and coracles slam into each other / tohunga and filiddh swap notes"18 in waka 75 "A Storm" as a place for dialogue, and even banter "Yo, I'm Māui [...] / Dig, Odysseus?"19 in waka 89 or as a place of reconciliation: "Pray for the crew / to row in unison" 20 in waka 97. The central metaphor is cogent because it is fluid, ${ }^{21}$ enabling mutual mutations, while remaining coherent and consistent throughout. For Katherine Baxter and Lytton Smith, the waka "serves as a symbol of the poem, positing a purposive mobility in the poetic art itself." ${ }^{22}$ For Chris Prentice, the waka is a metonymy on several levels: "The collection - understood as the poem, Star Wakais in itself a waka, a poetic waka or waka of poetry, and of the poet's waka or genealogy.",23 The many poems involving family and ancestry - for instance poems v, xv, 47, 48, 52 or 73 validate this additional conception of poems as "waka huia or treasure chests" 24 (waka 56) for both Sullivan's personal genealogy (whakapapa) and the country's (poetic) genealogy.

Star Waka's pervasive image also illustrates, and is key for the more general topic of New Zealand cultural identity, and in particular with regard to the ongoing construction of biculturalism and multiculturalism. As Sullivan explains: "I started looking for a symbol, which would encapsulate our culture." ${ }^{25}$ For Marsden, Star Waka has "an overarching tendency to marry the Polynesian to the European and to point up just how inextricably these two strands are interwoven in the consciousness of the author and, by extension, the culture he embodies." 26 The book's central symbol then, thanks to its elastic semantics and shrewd combination with

\footnotetext{
${ }^{18}$ Sullivan, (1999), p. 84.

${ }^{19}$ Ibid, p. 99.

${ }^{20}$ Ibid, p. 107.

${ }^{21}$ Chris Prentice notes that: "This fluidity unsettles the very structure it invokes, demonstrating the dialectic of location and movement, the transformative encounters between ocean and beach that define and dissolve the coastline, just as image, poem, collection and cultural context enter into dynamic relations of exchange and mutual transformation" (Prentice, 2006, p. 117).

22 Baxter, (2016), p. 268.

${ }^{23}$ Prentice, (2006), p. 124.

${ }^{24}$ Sullivan, (1999), p. 63.

${ }^{25}$ In Battista, 2007, p. 58.

${ }^{26}$ Marsden, (2001), p. 2.
} 
"star", 27 suggests a question mark, and a plurality of answers rather than one single restricting definition. As Dieter Riemenschneider rightly underlines:

The word "waka" itself underpins this process [a mélange of heterogeneous local and global elements] since Sullivan relates a wide range of signifieds to this sign, ranging from container and vehicle to canoe and, importantly, the descendants of the historic canoes that arrived many generations ago from Polynesia in Aotearoa. ${ }^{28}$

Star Waka opens the debate on what defines New Zealand culture in a particular context: at the turn of the millennium or Y2K. The contingent necessity of questioning New Zealand's cultural status quo is also highlighted by the 2001 lines of the sequence, as Marsden remarks: "Y2K the supposedly post-colonial culmination of 2,000 years of the Christian calendar - is matched by 2,001 lines of poetry, by Sullivan's own personal millennial stocktaking." ${ }^{29}$ Indeed, as well as the metaphor's various semantic declensions, and the book's suggestive numbering of lines,${ }^{30}$ Star Waka examines New Zealand post-colonial culture(s) by recording a diversity of contemporary and at times ordinary experiences by a lambda New Zealander. These are the everyday insights offered in waka 58 and 81 partly based on the poet's meanderings in his local supermarket: "into my Foodtown trolley" or "At Harvest in Grey Lynn" and "in the Grey Lynn aisles late at night." ${ }^{31}$ Meanwhile, deeper post-colonial issues are raised, creating tonal contrast when the poet attempts to make sense in the present of a confusion carried over from the past, as in poem xiv:

And confused, very confused.

Why did these things happen?

Why are these things put on me?

\footnotetext{
${ }^{27}$ As Marsden remarks, this bilingual combination is coherent with the previous Jazz Waiata.

${ }^{28}$ Riemenschneider, (2000/2001), p. 143.

${ }^{29}$ Marsden, (2001), p. 3.

${ }^{30}$ One may also think of 2001: A Space Odyssey or with Prentice, of "the Pacific as the site for the first dawning of the year 2000" (Prentice, 2006, p. 116).

${ }^{31}$ Sullivan, (1999), p. 65.
} 
Where does it end?

At least

I am learning my history ${ }^{32}$

Here the passage from past (“did") to present tense ("are", "does", "am learning") reinforces the confusion while installing a continuum, stretching into the future ("Where does it end?") in an interrogative mode. Paradoxically, this poem, and others like it, have an ever-changing quality with elements of continuity: "descendant", "ambassador and a representative", "people/ who lie within me", but also an abrupt quality with elements of rupture and violence: "duels", “chokes”, “fingers pointing”, “pinch”, “challenge”. Sullivan's experiment may then reflect New Zealand's continuous and ongoing process of cultural determination while starkly and defiantly refusing any definite and one-sided answer, what Riemenschneider calls "a wariness of not totalising its narrative" 33 and Prentice "a politics of elusiveness, a veritable trompe l'oeil." ${ }^{34}$ Beyond this elusiveness and strategic rejection of giving the whole picture - Marsden speaks of "Sullivan's apparent refusal to impose an over-rigid polarity" 35 - the poet ultimately asserts a cultural co-dependency, as Katherine Baxter and Lytton Smith write:

[...] by refusing to let Māori or "English" connote alone, and by refusing to resolve the punning tensions between waka, canoe, and other possible versions of a particular signifier. Star Waka is no oxymoron, nor is it simply either nostros or science fiction. [It unsettles] the binary oppositions between past / future, Aotearoa / New Zealand, and Māori / English [.... $]^{36}$

Sullivan's metaphor transcending these binary oppositions also applies more widely to Pacific cultures and nations, as he intends for his waka to assert their unity while respecting their diversity. In poem 42, one finds: "Mau, / takata Maoli, [...] we are peoples united" 37 including Tahiti and Samoa. The titular metaphor therefore re-conjures and synthetises the energies and

\footnotetext{
${ }^{32}$ Ibid, p. 18.

${ }^{33}$ Riemenschneider, (2000/2001), p. 148.

${ }^{34}$ Prentice, (2006), p. 115.

${ }^{35}$ Marsden, (2001), p. 10.

${ }^{36}$ Baxter and Smith, (2016), p. 273.

${ }^{37}$ Sullivan, (1999), p. 46.
} 
tensions working the entire book, and at stake in contemporary multicultural New Zealand and the Pacific region.

On another level, Star Waka and its striking title, have relevance in the wider context of globalisation. Commenced in the 1990s and mostly coming from the U.S., the movement of technological progress accentuating economic liberalism spreading in the entire world, brought a sharper focus to post-colonial issues in Aotearoa, issues that had been latent in the region ever since the initial cohabitation between Pākehā and Māori - as Sullivan notes: "we were / one of the first tribes to be affected / by westernisation." 38 In this context, and according to Dieter Riemenschneider, Star Waka could be read as a case of literary glocalisation, a term coined by Roland Robertson in 1995, that is to say a literary work displaying an acute attention to the local enhanced by the immediate and challenging context of the global. As Riemenschneider explains:

Robertson has brought into play the term and concept of "glocalisation", maintaining "that globalisation has involved the reconstruction, in a sense, the production, of "home", "community" and "locality" (Robertson 1995, p. 30). Rob Wilson and Wimal Dissayanake move a step further by underlining the confrontational and challenging power of locality in their questioning of the effectiveness of global discourses generating "resources of hope" 39

Sullivan's combination of Te Reo and English - and in particular "star", with its rich connotation in American culture - may then be thought of as glocal as it is directed towards both the global and the local.

Towards the global, the poet's attitude is evidently mixed. As Bridget Orr explains, “Sullivan's view of the poet's role is ambitiously syncretic [...] but his verse reveals the agonistic understanding of cultural politics notable in other writing by Māori. ${ }^{, 40}$ There is certainly doubt

\footnotetext{
${ }^{38}$ Sullivan, (1999), p. 19. These issues were already revitalised in the 1980 s and through literature as a direct consequence of the 1970s Māori Renaissance movement.

${ }^{39}$ Riemenschneider, (2000/2001), p. 140.

${ }^{40}$ Orr, (2016), p. 192.
} 
regarding "global discourses generating resources of hope", and even an expression of resistance $^{41}$ against the threat of cultural homogenisation and potential economic domination in the symbolic lines of waka 79: "Uncle Sam carved my mother a model waka [...] Uncle Sam's work is not for sale"42 or the trenchant and lapidary "Dead Reckoning": "The McDonalds jetsam indicates nothing, of course." ${ }^{43}$ This could be waka cutting or slicing ${ }^{44}$ for Prentice; "the cutting edge of cultural difference." 45 At the same time, there is clear evidence of a more open and even relaxed ${ }^{46}$ attitude, open to the possibilities that an encounter with the global may offer. This is expressed in the sarcastically nonchalant "Independence Day" for instance: "The Americans / are really doing their homework / before they decide to colonise us [...] it doesn't mean / much to the rest [Māori] it's still going to be / a colony" ${ }^{\prime 47}$ or the ironically supportive lines of "Gone Fishing":

[...] A crew of men stayed in the basin trailing a Coca Cola flag.

Glad to see the multinationals

are sponsoring them. I'm all for it. ${ }^{48}$

This is, in contrast, the image of waka gliding, as in poem 42: "Into the new age the waka glides" using currents, birds, winds and ingenious and opportune navigation techniques and what is at hand. ${ }^{49}$ Riemenschneider synthesises this:

Sullivan's poems bringing together phenomena of the global impact of imports and Māori culture range from asserting his own to revealing the dangers of submission. At times there is an insistence on keeping intact his own tradition,

\footnotetext{
${ }^{41}$ About resistance, Battista writes: "Star Waka embeds acts of resistance against the effects of a colonial past and minority culture status" (Battista, 2007, p. 59), and Perris: "the object of resistance is thus both a literaryhistorical colonisation of 'the text' and a mythological colonisation: anthropological rationalisation" (Perris, 2017 , p. 184). Both insist on the underlying post-colonial narrative of resistance against flawed cultural conceptions supporting the narrative structure of the text.

${ }^{42}$ Sullivan, (1999), p. 88.

${ }^{43}$ Ibid, p. 68.

${ }^{44}$ Ibid, p. 6.

${ }^{45}$ Prentice, (2006), p. 113.

${ }^{46}$ Marsden writes: "Whilst critically post-colonial at the beginning of waka 68 [...] the poet immediately goes on in the next couplet to counter this in a very relaxed tone" (Marsden, 2001, p. 9).

${ }^{47}$ Sullivan, (1999), p. 16.

${ }^{48}$ Ibid, p. 82.

${ }^{49}$ The subject of waka 67, 72, 74.
} 
at others an openness to shift and change [...]. Such openness of the poetic discourse places quite a few of the Star Waka poems within a process of glocalisation that deals equally with the globalising pressure from outside and a possibly reverse discourse from inside. ${ }^{50}$

The book's process of glocalisation, as Riemenschneider posits, reaches towards the outside / global / Pākehā world but also towards the inside / local / Māori world, including Pacific cultures, and implying essential transformations.

This address to the local can be witnessed in the fragmentary poem Xxv "power/powerlessness" for instance: "waka cuts it / Māori in magazines [...] sensational /sports stars / Māori models wear groovy fashion." ${ }^{51}$ Here, as is made apparent in his shrewd use of the idiom "to cut it", Sullivan consciously cuts and pastes elements from the American dream such as fame or larger than life entertainment. This is found in the superlatives "remarkable / sensational", the glorification of "sports stars", and the layered "groovy", recalling American Jazz music (but also wood). Sullivan then collages these with local elements - "indigenous beauty", "single studded ears" or even the colours "dark green", and "silver", which as Prentice tells us, might "evoke the native forest of dark green trees and ferns, and silver running streams." 52 This vibrant celebration of the esthetics and successes of a putative globalised indigeneity might be what Riemenschneider means by "a possibly reverse discourse from inside." ${ }^{, 53}$ We find this cut and paste device again in waka 98, applied to modern urban society and its image / icon obsessed mass consumption diluting cultural significance:

waka images cut in and out collages on the eyes [...]

popping up in legends coming out in urban myth

waka wallpaper waka duvet covers ${ }^{54}$

\footnotetext{
${ }^{50}$ Riemenschneider, (2000/2001), p. 148.

${ }^{51}$ Sullivan, (1999), p. 29.

${ }^{52}$ Prentice, (2006), p. 121.

${ }^{53}$ Riemenschneider, (2000/2001), p. 148.

${ }^{54}$ Sullivan, (1999), p. 108.
} 
According to Prentice, Sullivan's heterogeneous collage of the dual effects of glocalization results in a process of hybridisation and simultaneously defines a cultural space of liminality, as termed by Homi Bhabha, giving Sullivan's waka metaphor additional impact and depth in a global world.

At a deeper level, what Star Waka illustrates and demonstrates so well, is the necessity to redefine an either / or posture - the question is no longer simply: global or local? Māori or not Māori? As Sullivan explains himself:

I do regard myself as a Kiwi but I do also think of myself as a Māori and one isn't a subset of the other. It's a kind of poetics of the self I suppose where you have to sustain an identity that doesn't really match up with the kind of public culture in New Zealand. ${ }^{55}$

Star Waka prompts the recognition of cultural in-betweens as such, and according to Prentice, the book furthermore questions the validity of using the concept of culture as a reference point in the process of definition. Sullivan does refer without distinction to artistic objects from diverse origins: Auckland Civic Theatre (poem 45), C. F. Goldie's or Peter Robinson's paintings (waka xxxiv, 80), the tauihu of a waka (xxxi), Da Vinci's helicopter designs (waka 56), the architecture of a marae (vii), although with regard to the latter, he strongly asserts that its displays of beauty are "accessible to all / but the symbolism remains Māori / and will always be for Māori." ${ }^{56}$ The question that Star Waka seems to ask is: to what extent is a given cultural element pertinent to any political, historical, or social discourse on post-colonial Aotearoa / New Zealand? Orr underlines Sullivan's debt to his predecessors and the pioneering voices of the Māori Renaissance movement:

Along with novelists Witi Ihimaera, Patricia Grace and Albert Wendt, Sullivan's poetic predecessors Alistair Te Ariki Campbell and Hone Tuwhare began dismantling Pākehā literary hegemony. Often using Western modes shaped by

\footnotetext{
55 In Ricketts, (2010), p. 457.

56 Sullivan, (1999), p. 10.
} 
a poetics infused with Māori cultural forms, Anglophone texts of the Māori Renaissance are polyphonic, creating carefully differentiated reading positions. ${ }^{57}$

Alice Te Punga Somerville also identifies the links between generations of Māori authors:

With the exception of Keri Hulme, the most well-known Māori writers of today continue to be those who were already publishing in the 1970s: Ihimaera and Grace, but also Tuwhare, despite his earlier date of first publication. After these firsts, the next big bubble of writing is often perceived to have come about in the 1990s, when writers such as Duff and Sullivan appeared. ${ }^{58}$

For Prentice however, the context of globalisation makes Sullivan's questioning - echoing his predecessors - particularly acute:

Star Waka enacts a poetics of liminality that urges a rethinking of the relationship between the cultural politics of representation, cultural decolonisation, and indigeneity at the interface of the postcolonial and the global. The collection explores the question of what can serve as cultural reference points for Māori [...] in a bicultural postcolonial nation-state as the third millennium witnesses an intensification of the processes and perspectives of globalisation. ${ }^{59}$

Homi Bhabha understands liminality as "this interstitial passage between fixed identifications [which] opens up the possibility of a cultural hybridity that entertains difference without an assumed or imposed hierarchy." ${ }^{60}$ For instance, in the space of the few opening poems, Sullivan comes back to the idea of cracks - "when each crack in the house of the sun / is submerged", "sometimes a few cracks appear in the waka"61 - a potential new liminal space is open. Baxter and Smith speak of floating signifiers: "the indeterminacy of both/and rather than either/or characterises Sullivan's [...] multilingual poetics $[\ldots]$ in favour of a perpetual motion in which language cannot be understood apart from its idiosyncratic, globally-inflected, contexts." ${ }^{\circ 2}$ This difference, perceived as a moving and transitional state, is arguably close to Derrida's

\footnotetext{
${ }^{57}$ Orr, (2016), p. 191.

58 Te Punga Somerville, (2012), p. 202.

${ }^{59}$ Prentice, (2006), p. 111.

${ }^{60}$ Bhabha, (1994), p. 5.

${ }^{61}$ Sullivan, (1999), pp. 1-6.

${ }^{62}$ Baxter, (2016), p. 268.
} 
notion of "différance", emphasising the idea of movement in space and time ("différer" also as in "to defer"), and indecision (might also suggest "errance"). In an interview with Kristeva, Derrida states:

Differrance is the systematic play of differences, of the traces of differences, of the spacing by means of which elements are related to each other. [...] The a of différance indicates this indecision [...] The activity or productivity connoted by the $a$ of différance refers to the generative movement in the play of differences. The latter are neither fallen from the sky nor inscribed once and for all in a closed system, a static structure that a synchronic and taxonomic operation could exhaust. Differences are the effects of transformations, and from this vantage the theme of differrance is incompatible with the static, synchronic, taxonomic, ahistoric motifs in the concept of structure. ${ }^{63}$

This difference / différance is, as Prentice draws from Bhabha, inherited from diverging times of signification forcefully superimposed by colonisation, hence inviting a diachronic (rather than synchronic) perspective, something definitive in post-structural thinking. Bhabha writes:

Cultural difference does not simply represent the contention between oppositional contents or antagonistic traditions of cultural value. Cultural difference introduces into the process of cultural judgement and interpretation that sudden shock of the successive non-synchronic time of signification. ${ }^{64}$

In waka 100, Sullivan deplores that the resurrection of ancestral waka must be done in European time with its "long and short hands centred on Greenwich", breathing life back into "a culture / that has held its breath / through the age of Dominion." ${ }^{65}$ In waka 59 , he laments cultural loss "of Polynesian culture, an accumulation halted / by literacy and modern navigation - / recorded as an afterthought by those Europeans." ${ }^{\prime 66}$ Ultimately, what is most pervasive in regard to Star Waka's hybridity, is therefore its assertion of the existence of a hybrid time ticking over post-colonial cultures. Prentice concludes that:

\footnotetext{
${ }^{63}$ Derrida, (2000), p. 247.

${ }^{64}$ In Prentice, (2006), p. 113.

${ }^{65}$ Sullivan, (1999), pp. 110-111.

${ }^{66}$ Ibid, p. 67.
} 
The poems embody evocations of the split and doubled or hybrid time of cultural difference. [...] the ambivalent, uncontainable language-forms of poetry such as Sullivan's palimpsestic images, offer a new way of thinking about the stakes of colonisation in the wake of globalisation. ${ }^{67}$

The book's central waka image and the poetic voyage that it implies, convey an inherently different, or in Derrida's terms, "différant" perception of temporality - glocal in terms of space and geography but hybrid in terms of chronology, and liminal in terms of cultural identity. That a poetry book can have such an impact in terms of critical discussion is remarkable, and appealing for my project. I now examine how this latter element of diffracted chronology constitutes a crucial factor for the significance of its narrative.

\footnotetext{
${ }^{67}$ Prentice, (2006), p. 132-133. This seems to go against what Orr writes later about Voice Carried My Family: "Sullivan's invocation of metropolitan high literary (and demotic) discourse for revisionist purposes is a familiar strategy in postcolonial writing, but his is not a hybrid poetry" (Orr, 2016, p. 192). However, Prentice posits a depiction of a hybrid time, and not hybrid poetry.
} 
2. A significant narrative structure

A second major reason to select Star Waka is that Sullivan's poetry comes in the form of an intricate and structured sequence with a clear sense of narrative. As Marsden remarks: "this volume is no mere random collection of jottings or impressionistic aperçus but a meticulously planned and crafted volume with an architecture all its own." 68 The poet explains:

It is risky to write on a large scale, such as the 2001 lines of Star Waka, a sequence focusing on the great Polynesian voyaging traditions, so I spent a lot of time weaving different scales and sections into the sequence. ${ }^{69}$

On the level of poetics, this is a rather rare effort - in New Zealand poetry at least ${ }^{70}$ - bringing direction and an elaborate unicity into the narrative through constraint for instance, the three interweaving systems of numbering for three distinct and correlative parts. In an interview with Selina Tusitala Marsh, Sullivan reveals that:

In a funny way, I wrote Star Waka as a response to Atua Wera, if you look at the structure of Atua Wera, the numbering system, and the strands of thought that go through it, Star Waka is structured very similarly. ${ }^{71}$

As we will see, the intertextual element is fundamental for the structure, as a symbolic reappropriation of the poet's own cultural history and genealogy, partly reusing Smithyman's structure.

a. Chronology

First, the narrative structure serves the poems as a whole: this is the waka / vehicle or the waka / container for the journey that the book is meant to be. Green explains that:

Star Waka is not presented as a narrative poem, yet storytelling is a key attribute [...]. Each poem, and the sequence as a whole, stands as a waka; each waka is

\footnotetext{
${ }^{68}$ Marsden, (2001), p. 4.

${ }^{69}$ In Johnston, (1999), p. 173.

${ }^{70}$ One may think of Wedde's Earthly: Sonnets for Carlos, O'Sullivan's The Butcher Papers but also Anne Kennedy's Sing-Song, Bornholdt's The Rocky Shore or Tusiata Avia's Bloodclot.

${ }^{71}$ Sullivan, (2005).
} 
judiciously packed with words [taonga] that hook a story and, in hooking it, transform that story into a poetic shape. [...] Sullivan's waka, as a narrative poem, navigates the fertile seas of family, genealogy, cultural activities and urban life. ${ }^{72}$

On a literary and a cultural level, this architectural effort leads to the making of what Marsden calls "a literary carving", recalling the art of whakairo while Sullivan aims to "spray out its narrative / with whakairo." ${ }^{, 73}$ Green adds:

The waka appear as different structures on the page: lines separated out by white space or the winds of journey, lines curling like the waves, lines falling like a thin mast, lines nailed together like the hull of a boat. ${ }^{74}$

The importance of craft and structure, here described by Green and Rickets as nautical, is something made manifest to readers. For Prentice, Star Waka is a "self-consciously structured" 75 sequence with numerous visible hints either in notes or in the poems themselves. We might say that these apparent structural hints serve as functional narrative markers connecting author and readers. For instance, in waka 88: "(see how he did not / place a star or ocean or a waka / in his pageantry)" ${ }^{\text {76 }}$ the poet uses this parenthesis as a playful allusion to the sequence's constraint. Waka 64, before that, delivers another similar meta-textual hint in parenthesis: "(which keeps / the theme of this sequence - a waka or a star or ocean - in each poem)." 77 In poem viii, Sullivan begins in the immediate present: "I cannot make this like maker of waka." 78 By bringing the poet's writing concerns to the readers' attention, the overall structure is emphasised, and more significantly, Sullivan shows some distance toward his own art, enabling a sense of complicity with readers in the know, letting them into the making process.

\footnotetext{
72 In Ricketts, (2010), p. 30.

${ }^{73}$ Sullivan, (1999), p. 63.

${ }^{74}$ In Ricketts, (2010), p. 30.

75 Prentice, (2006), p. 124.

${ }^{76}$ Sullivan, (1999), p. 98.

${ }^{77}$ Ibid, p. 73.

${ }^{78}$ Ibid, p. 11.
} 
On the level of my translation, this clear structure, which is emphasised because it announces itself in the text, is appealing because it implies a wider and more ambitious project than with many poetry collections. Here, the translator needs to embrace a coherent network of interrelated poems all forming one journey, and telling a story. This is poetry, but poetry with some elements of fiction, some conventional narrative devices - characters, storyline, twists, climax and pauses, monologues, dialogues - and some unconventional ones - jokes, lists, fragments, archive excerpts, journal entries, also mixed with karakia, elegies, calligrammes, waiata - all framed into an original chronology.

As mentioned, the book reconfigures temporality or rather it depicts a post-colonial reconfiguration of temporality. I argue now that this poetic representation of diachronology or as Baxter and Smith put it, a "moment of cognitive syncopation" sequence as an original narrative device / frame. Sullivan not only denounces the forced superimposition of non-matching time perspectives that had lead "each person / of waka memory / to hold their thoughts" (waka 100) or "Māori men and women / who fought for themselves / let alone their culture", ${ }^{80}$ the poet also offers the striking introductory image that: "Star waka is a knife through time" and in the end, with an intertextual wink to Dylan Thomas, he conjures stars to keep burning in never-ending continuity: "burn on waka past the end of the light." Star Waka may be "knifing time" or "slicing through concentration", its original treatment of time nevertheless structurally connects the whole narrative sequence into a circular pattern using a dual frame of references. Star Waka's eventual return to the source is either called "the collective unconscious" ${ }^{81}$ in a Jungian / Pākehā perspective, or "Hawaiiki" in a traditional Māori perspective (for instance waka 92 and 96).

\footnotetext{
${ }^{79}$ Baxter, (2016), p. 272.

${ }^{80}$ Sullivan, (1999), p. 87.

${ }^{81}$ Ibid, p. 102.
} 
Williams and Stafford note that Sullivan's waka is "connecting the pre-contact past with the urban present and sailing on towards a possible, if fancifully configured, extraterrestrial future. ${ }^{82}$ In terms of poetic narrative or mythopoesis, Perris notes however that Star Waka's chronology does not allow a linear reading. He concludes that a mythical movement of descent - or katabasis - would not apply here for instance, as in a great number of classic mythical journeys: "By emphasising 'Māui of the hauling' as well as ignoring Māui's (and indeed Odysseus') status as a katabasis hero, Star Waka implicitly rejects katabasis as a paradigm for Polynesian life experiences." 83 Instead, the narrative structure is closer to a transformative cyclical pattern, something not unlike "un récit d'initiation", a coming-of-age story, but without its strict focus on a single character's growth from childhood to adolescence. As Baxter and Smith explain:

At the mythical level, this adapts de Certeau's paradigm of the return of the other as the same transfigured (de Certeau 1998: 219): all waka, and these poems as waka, return to Hawaiiki, the source. This is the trajectory that all navigation inevitably follows. ${ }^{84}$

In other words, Sullivan's treatment of time serves as a dual narrative device, a connector driving the sequence into a circular structure, a transformative voyage from a point of origin to a point of arrival, and back to the origin. As we will see, time is also an element of rupture, interrupting, questioning and reassessing the country's history and cultural genealogy.

If we first go back to the basic chronology of the sequence, what may be startling for readers set in a western mode of thinking, is that Star Waka's chronological perspective delves into or is rooted in traditional Māori culture, where one's connections with the past, asserted in

\footnotetext{
${ }^{82}$ Stafford, (2012), p. i.

${ }^{83}$ Perris, (2017), p. 184. This is even more true in the sense that Sullivan's final image is that of resurrection, very much an ascending movement, on one hand, and on the other hand, that his central thesis goes against anthropological theories defending aleatory movements of diaspora in the Pacific. Rather, he believes in organised and multiple migration movements.

${ }^{84}$ Baxter, (2016), p. 273.
} 
whakapapa (genealogy), are considered present nonetheless, as they rest in layers within the living. Anahera Gildea writes that: “Whakapapa actually means to 'make into layers'. Generation after generation forms layers in ascension from the ground (papa), or Papatūānuku, upwards. Everything has a whakapapa - the rocks, the animals, the stars in the sky." 85 The striking image of the past, the ancestors, the dead, present as layers, literally brought up in whakapapa into the world of the living, is frequently conjured by Sullivan. A gradual layering is made visible by the poet, for instance in "A Whakapapa Construction", not as "lines dangling from the heavens" 86 (echoed in "A Double-Hulled Waka": "a line / dangling from glow worms"), but as a meta-textual construct where the sequence itself is a mise-en-abyme for a whakapapa in the making:

$$
\begin{aligned}
& \text { these lines are a whakapapa } \\
& \text { in themselves - ten years } \\
& \text { of door knocking and practice } \\
& \text { on roughs and finishes - } \\
& \text { pushed to fluidity }{ }^{87}
\end{aligned}
$$

The same visible elaboration is at the core of the whole narrative, crafting a chronology that is made active or is activated in a metalinguistic manner. As Gildea explains: "The prefix whakais a crucial term in the Māori language. I like to think of it as a word that causes action. When put in front of another word, whaka causes the second word to activate, to become." ${ }^{88}$ This past made present iteration is reminiscent of the phenomenon of iterability in the sense of Derrida ${ }^{89}$ as the poet's realisation of whakapapa activates, and transforms an ancestral oral ritual into

\footnotetext{
${ }^{85}$ Gildea, (2018), p. 2.

${ }^{86}$ Sullivan, (1999), p. 24.

${ }^{87}$ Ibid.

${ }^{88}$ Gildea, (2018), p. 2.

${ }^{89}$ Derrida writes: "Since any use-value is marked by this possibility of being used by the other or being used another time, this alterity or iterability projects itself a priori onto the market of equivalences (which are always equivalences between non-equivalents, of course)" (Derrida, 1994, p. 203), emphasis in the original.
} 
modern written literature. As Sullivan's quest for identity / origin unfolds throughout the sequence, he states in waka 70: "There is a Kupe in all of us, who struggles for love, / and with the forces of the deeps. I look for him." 90 In poem viii he asks: "what did they [waka] carry? / how can I tell you in confidence?” and adds: "yet waka still searches for star / among all people / who have become stars / made stars in patterns on wood" - readers attend a poetic presentification of the past, encompassing meta-textual and metalinguistic components arising from the poet's Māori background.

Second, as part of the circular / cyclical time-travelling pattern described by the sequence, a trajectory also noted by Baxter and Smith, ${ }^{91}$ Sullivan connects this past made present iterability to the future. As Baxter and Smith put it: "Sullivan thereby challenges the assumption that Māori culture is inherently of the past, fit only for the museum, instead suggesting its creative value for future technology." ${ }^{92}$ Sullivan paints a future sometimes dystopian, with makers of waka living in submarines "so threatened by the mechanical heat / of organised industry" (in poem 49), sometimes utopian, with waka fleet giving their names to future spacecraft, and even supra-historical as in the delightful mix of medieval and science fiction references at the end of poem 46: "a space waka / rocketing to another orb / singing waiata for the spheres." For Riemenschneider, this is "waka merging with the harmonious music of medieval astronomers. $" 93$

This frequent mixing of past and future paradoxically gives the present of the narrative its unity and chronological coherence outside a regular western conception of chronology in a straight line (Descartes' long chains of reasoning come to mind). This constant verbal leap over years,

\footnotetext{
90 Sullivan, (1999), p. 79.

91 "Like the Polynesian fleets that sailed north, south and east from Samoa, Sullivan's imagery and languages travel out from each other, along multiple trajectories. These trajectories, however, are not without purpose, not a sort of postcolonial parole in libertà" (Baxter, 2016, pp. 272-273).

92 Ibid, p. 271.

${ }^{93}$ Riemenschneider, (2000), p. 145.
} 
decades or centuries between or within each waka, collages historical episodes, personal memories, present considerations and projections about the future. This is found in poem 55, in which the poet wonders if Auckland Sky Tower was built with stones "from the Araiteuru's crew." 94 It is also in waka 56 that past and present Māori leaders, "finest men and women, [are] on video forever." In waka 78 "An Historical line", about the New Zealand Wars, the resurrection of waka is eventually achieved thanks to the iwi who "had the psychological template" or in poem xxii: "They [waka] have travelled with us / through the evolution of legends / and the tongues our legends use. Waka spring from our unconscious"95 as well as waka 90: "my mana isn't in my physicality. / It's in the psyche of the culture that bred me."96 These poems use a mix of terms ranging from the ancestral and the indigenous to the modern and the psychoanalytic. For Prentice, "the continual recycling of past and future as an immutable, essential present is itself an intervention that estranges the present from itself." 97 In Star Waka, the present is therefore an opening space for potential poetic narratives, a multidimensional outside point that yet cohesively connects a history (re)imagined: "and he tries to remember / but remembering is for things of experience / these things he hasn't experienced"98 and a future re-envisaged, or recycled in a creative way:

I am the waka of memory, unnamed, the template -

place me:

in Hawaiiki

in vehicles $[\ldots]$

I am the waka made a tree again ${ }^{99}$

\footnotetext{
${ }^{94}$ Sullivan (1999), p. 60.

95 Ibid, p. 26.

${ }^{96}$ Ibid, p. 100.

${ }^{97}$ Prentice, (2006), p. 130.

${ }^{98}$ Sullivan (1999), p. 13.

${ }^{99}$ Ibid, p. 94.
} 
Time is therefore a complex narrative device in Star Waka, presented not only in a pluralist and additive manner but also as a trenchant and salutary call for a moment of pause within a wider post-colonial narrative. For Prentice, a pluralist and additive view misses "the disjunctive, interruptive temporality of the images that comprise the works. It is not simply a variety among/across mythic time, historical time, colonial time, or past, present and future [...]. Instead, each spatio-temporality is constitutively haunted by others." 100 Stars are either guiding waka like the "left eyes / of the ancestors / in our black heaven", ${ }^{101}$ or waka are "carrying stars / to Hawaiiki""102; yet the poet eventually interrupts any depiction of waka as chronologically haunted - for Marsden, either a "traditional Māori war canoe or a beat-up old Honda or a state-of-the-art computer"103 - dismissing the spectral in favour of the physical and the incarnated. The return of ancestral waka may at times be presented lightly like the comeback of some contemporary movie star (Burt Reynolds in waka 71), but in waka 99, the resurrection of waka cannot remain as an elusive figure of eidolon, dramatically "smashing glass cases"104 of museums, or "out / of mountains as if liquidified / from a frozen state."105 Sullivan explains that: 'Essentially 'Waka 99' calls on a time beyond memory institutions such as museums, breaking free of handed-down colonial identities and limits by remembering what we achieved."106 The poet insists that "the resurrection wouldn't just / come about this way"107 and "would happen in the blood"108 - a symbol for physical life, or "beauty of physical story", ${ }^{109}$ incarnation in its etymological sense of flesh, a process also recalling the knife in

\footnotetext{
${ }^{100}$ Prentice, (2006), p. 113.

${ }^{101}$ Sullivan (1999), p. 106.

102 Ibid.

${ }^{103}$ Marsden, (2001), p. 18.

104 Sullivan, (1999), p. 109.

105 Ibid.

106 Johnston, (1999), p. 173

${ }^{107}$ Sullivan (1999), p. 109.

108 Ibid.

${ }^{109}$ Ibid, p. 9.
} 
poem i, by metonymy: "what belongs to water belongs to blood", ${ }^{110}$ and the blood vessel (waka), a salutary chronological cut or diachronic jugulation.

What Star Waka offers to perform then is the exsanguination, the cutting short of diverging (mis)representations and the superimposed assemblage of images that have become porous and haunted. For Prentice, the book "interrupts and displaces, rather than continues, the practices and legacies of capture and containment of the Pacific by visual and verbal image-makers explorers, missionaries, painters, ethnographers, writers, photographers, and tourists."111 Sullivan's invitation to "Hear sounds of waka knifing time" (poem i) is also an injunction to halt and metaphorically bleed out a continuous epistemicide and linguicide, some sort of poetic tourniquet: "Stroke into the New World and stop" (waka 100). Prentice adds that: "Designations of cultural difference interpellate forms of identity which, because of their continual implication in other symbolic systems, are always 'incomplete' or open to cultural translation." 112 Star Waka's complex chronology has therefore an obvious political reach what Marsden calls the "social-political-polemical"113 - aiming to stop the continual implication of other symbolic systems. To choose this work for translation has inherent cultural implications, and this choice must be recognised as part of a wider post-colonial narrative that is a work of mourning ${ }^{114}$ as much as it is a work of renaissance.

\section{b. Narrative navigation}

As well as its original chronology, another appealing constituent of Star Waka's story-telling is its successive and non-successive arrangement of series of poems - diptychs, triptychs mostly - within the overall narrative sequence. This complex organisation reinforces the book's

\footnotetext{
110 Ibid, p. 3.

${ }^{111}$ Prentice, (2006), p. 112.

112 Prentice, (2006), p. 114.

${ }^{113}$ Marsden, (2001), p. 1.

${ }^{114}$ See Sam Durrant's Postcolonial Narrative and the Work of Mourning, which deals with the traumatic histories of racial oppression that continue to haunt the postcolonial era, in Coetzee, Wilson Harris, and Toni Morrison's works.
} 
poetic essence. Each narrative constituent - whether conventional in a traditional western type of narration, for instance: a preamble, a development, a note, an anecdote, a conclusion - or unconventional: a joke, a fragment, a list, a caligramme - corresponds to a narrative phase: introduction, progression, disruption, resolution. All these text types are interwoven and symbolic of the progression of Star Waka's voyage. They might reflect the readers' own progression through the book and, if only fantasmagorically perhaps, the writer's. However, the pattern of the narrative is not strictly linear or in one single sequence, but a symbolic interweaving of series of poems representative of Māori story-telling tradition, Kōrero Pūrākau, or of the intricate art of whakairo, tukutuku (woven wall panels), and kōwhaiwhai (geometric patterns).

There is arguably a main plot unfolding with a general sense of progression but through digressions, twists, crisis, climax, resolution, and a conclusion that returns to the beginning. A thematic regrouping of some poems is therefore possible - as the numbering from Roman to Arabic and then waka numbers suggests - either by series of two, three or four successive poems or more non-successive poems echoing throughout. There are some eco-poems, more or less visibly echoing each other (poems 16, xviii, 49, 57, 60) as well as Te Ao Marama poems (poems xxi, xxii, 82, 90) or domestic / everyday poems (v, 47, 48, 58, and 81.) There are poems about navigation techniques $(59,67,72)$, anti-anthropology poems (x, xxxv, 59, 67), sciencefiction poems (iv, 46, 49), star navigation poems $(63,72,85)$, technology poems $(39,54$, parts of 56) or historical poems (50, 78, 100 in parts).

I now give a detailed account of successive series of poems in thematic alignment (in the order of the sequence) defining their narrative function. They are crucial steps in the narration because in contrast with non-successive series of poems, they deliver a clear sense of direction (although at times in a wave pattern that may recall the sea), and express the tumultuous poetic 
voyage offered in Star Waka. I aim for my translation to maintain the book's narrative coherence, as well as its non-linear, or rather multilinear pattern. This means that, before translation, the translator needs to proceed to a thorough analysis of the narration, a kind of navigation map.

First, the opening "He Karakia Tīmatanga" is logically not included as part of the numbered sequence, withdrawn from the rest of the text, and yet functioning as a preamble directed towards its entirety. Its chorus "hoea hoea ra" is reechoed near the end in waka 97. It is symbolic of a boat / book launch, ${ }^{115}$ a cultural / literary ritual celebrating the start of the journey ahead but also a traditional Māori blessing. As Green explains: "Sullivan opens Star Waka with a karakia to guide the waka, yet in this collection where the very sequence is a poem-waka, Sullivan's karakia also guides the poetry."116

Second, the opening poems i, ii, iii but also vii, viii, ix, ${ }^{117}$ all describe waka navigating, the oceanic journeys of ancestral boats, and their crew. These poems set the scene with expected descriptions of seascape: "sailing into pāua, plump fowl, sweet water", "following birds across an Ocean." They invite readers aboard, with descriptions of boats that may also refer to poems: "lines decked with pāua." They express an initial sense of progression - the alliterative "Kaituki counts stroke" or the figurative "We have never travelled further" - but already alert readers to the unsettled (or all at sea) chronology: "And when waka reaches Aotearoa again" in poem ii, while in the opening karakia, readers were told about "the two week trip to Aotearoa." The focus is also on the shifting presence (and fluid essence) of crews: "Crews leap aboard / leap out" and the testing nature of the sea: "Sometimes a few cracks appear in the waka." If the

\footnotetext{
115 This might explain the line "Again a launch" in the poem "A Cover Sail" on the back cover.

${ }^{116}$ In Ricketts, (2010), p. 457.

${ }^{117}$ Sullivan, (1999), pp. 1-13.
} 
book is a waka, these ever-changing crews might therefore be its readers, whose attention might be fluctuating, whose reading will be heterogeneous.

Third, as is made apparent from the start, the poet persona, either character or narrator, is alternatively referred to as "he" ("He takes notes about his history" in poem iii or "and he tries to remember" in poem ix) or as "I" (in poems v and viii): there is a dissociation and a doubling up of the poet persona that indicates, as further illustrated in poems vi and xi, that the narration is not linear and single-handed but complex or in multiple waves. Readers are told that "he and I suggest ways of narrating a story of waves [...] telling an infinite story lapping the shapes / formed round land." Several of the following poems appear in this irregular pattern like blood vessels, digressions or inner thoughts. In poem vi, for instance, the poet (as perhaps one of the crew members as well as the narrator) embarks on a series of rhetorical questions in a chain of associations: "how does one enumerate and describe / a feeling?", "SHOULD ONE TELL THE TRUTH IN CAPITAL LETTERS" and finally returns to the description of the waka symbolising a moment of interruption: "the beauty of the waka slicing / through concentration, through the vision / of the mind." 118

Fourth, with a similar bifocal lens, alternating between the voyage and other preoccupations, a tidal motion, the following series (xii to $\mathrm{xx}^{119}$ ) also describes an interwoven narrative pattern. Poems xiii and xiv come back to the description of the waka's progress and navigation: "the strokes slow [...] becalmed by tired arms", which may symbolise the writer's process, and extend the navigation metaphor by giving voice to the poet's ancestors in poem xiii: "allowing us - the ancestors / to navigate our history / down lines." Poems xii, 16 and xviii all address issues of modern urbanisation: Auckland's viaduct basin, Māngere's sewage, and "a culture / of urban decay and renewal / a culture of dead capitals / sucking the life out of new / cities."

\footnotetext{
${ }^{118}$ Ibid, p. 9. This device is repeated at the end of waka 50: "easier to think of waka crews" (Ibid, p. 55).

${ }^{119}$ Ibid, pp. 16-24.
} 
Poems xvii and xviii share a common focus on lexicon and etymology, in particular on the words "waka" and "māori", which Marsden calls meta-linguistic reflections, or a form of metadiscourse ${ }^{120}$ and linguistic politics. ${ }^{121}$ Poems $\mathrm{xv}, \mathrm{xx}$, and in an indirect manner xix, all deal with the themes of family, origins and genealogy (whakapapa).

Poems xxiii to xxxi are in line with what Kai Jensen identifies about Sullivan's earlier selections: "disjointed, free-associative verse, typographical experimentation, and wild bursts of verbal exuberance."122 These poems come in a shorter form, sometimes in a fragmentary fashion (xxv), as lists (xxiii), visual poetry (29), jokes (xxviii), short couplets (xxvii) or brief glimpses (the cover of Nga Waka Maori by Anne Nelson in poem xxvi). The diversity of these forms - what Marsden calls a wide and large variety of layouts ${ }^{123}$ - reflects the diversity of shapes that waka might take, in modern media and technology (xxiii, xxiv and xxxi), but also fashion (xxv), literature (xxvi), mythology (xxvii, 29), geography (xxviii), and personal history $(\mathrm{xxx})$.

Poems xxxv to $38^{124}$ all deal with the maritime discovery of new lands. While poem xxxv deals with the discovery of islands in Polynesia, poem xxxvi and poems 37 and 38, in which the change of numbering style marks the passage from pre-contact time to sightings of European ships by Māori, deal with Pākehā colonisation in Aotearoa. These two poems are an obvious diptych as an unnamed character in 37 exclaims: "your majesty [...] we have seen them", to which the royal response is: "I have seen them too." This riffing style of narration in surges and spurts, and through successive diptychs (for instance the letters to a friend in Canada in poems 40 and 41 ) and triptychs (the waka in literature in poems $67,69,70$ ) covers almost three

\footnotetext{
${ }^{120}$ Marsden, (2001), p. 5.

${ }^{121}$ Ibid, p. 6.

${ }^{122}$ In Marsden, (2001), p. 7.

${ }^{123}$ Ibid.

${ }^{124}$ Sullivan, (1999), pp. 41-42.
} 
quarters of the book - until poems 74 or 75 . There is, episodically, a return of the focus to the progress of the waka and its esthetics, in a meditative, sometimes figurative, or non-figurative way: "and so this waka has passed its / thousandth line" in waka 56, the visual "waka cutting each other's wake"125 emphasised by a line of x's, in poem xxxi, "the waka carries us all / above the water" 126 in poem xxxii, or the contemplative "Masts flute sails out to mouth shapes / like beaks of taniwha coming from the sea" 127 in waka 66.

At waka 74, Sullivan's riffing and convoluted style of narrative / navigation comes to a turning point. The accumulation of poems expressing frustration and an underlying anger (an ostinato motif in poems xiv, 16 , xviii, $39,45,50)$ and the evocation of an upcoming storm: "We are waiting for a storm to pass" 128 as well as the depiction of various strategies employed by waka navigators to cope in severe weather (types of anchors) place waka 74 at the beginning of a change in the narrative. As Battista assesses: "In the tumultuous passage of the waka [in waka 100], Sullivan is firmly in control of the narrative, re-invoking the lines of 'Waka 74', and the anchor of cultural stability now being deployed." ${ }^{29}$ The image of an anchor in waka 74 is therefore a meta-textual and symbolic narrative tool with a functional purpose of stability used again in waka 100.

The anticipated storm does take place in the next poem in medias res: "a storm so violent / waka and coracles slam into each other." The poem's dramatic and surreal images, the cathartic explosion of violence and release of tension expressed in the style of a haka constitute a climatic point. This eventually leads to a moment of truth with the injunction to "portray me as I am." Waka 76 judiciously uses the format of a joke to lighten the mood and defuse the tension of

\footnotetext{
${ }^{125}$ Ibid, p. 35.

126 Ibid, p. 36.

${ }^{127}$ Ibid, p. 75.

128 Sullivan, (1999), p. 83.

${ }^{129}$ Battista, (2007), p. 64.
} 
cataclysmic descriptions. There are still confrontations and violence as Sullivan explains that the poem's atmosphere is "similar to Once Were Warriors but kind of harmless."130 It includes a reference to Tuwhare's line in "Sun o (2)": "Gissa smile Sun, giss yr best good mawnin' one"131 along with vibrant orality. This is unarguably a clichéd bar scene, with stereotypical elements from westerns, and it serves as a humorous narrative pivot for the sequence.

After the revelation of the poet's whakapapa in waka 80, comes an embedded mini narrative sequence resolving the whole narration. Waka 83 to 96 constitute a multivocal dialogue (with waka 91 as a moment of respite and gathering, the ritual of the feast) involving contrasted voices all speaking as I. Gods, heroes, elements, constellations, Māori or Pākehā, respond to one another. Marsden explains that:

A large sub-group consisting of a dozen poems close to the end of Star Waka (Nos. 84-90 and 92-96), identifiable by the simple form of their titles ("Waka 84 " etc.), are all in the first person. Taken together they seem - in terms of their external position and their internal form - to constitute a coda to the overall structure of the work. ${ }^{132}$

The section is indeed musical, even contrapuntal, with independent voices that are nevertheless connected, and its structural function announces the end. It therefore acts as a coda, a multitonal fugue achieving resolution by conjuring everything that was implicitly present, or contained aboard the waka, until that point.

The diversity of tones ranges from the modern and the urban, to the lyrical and even the elegiac (in italics at the end of waka 98), and the ancestral. Baxter and Smith point out that Star Waka's focus on orality ${ }^{133}$ situates the book within the ancestral Māori tradition:

\footnotetext{
${ }^{130}$ Sullivan, (2005).

${ }^{131}$ Bornholdt, (1997), p. 242.

132 Marsden, (2001), p. 11.

133 The term orality covers two senses in Star Waka. In waka 73, characters are "munching sammies", while "other guys" caught fish. This is the mundane language of the everyday. Waka 70 includes a transcription in English of Kupe, with some elevated terms, rendering the ancestral and legendary eloquence of Māori speech.
} 
Many of the poems in Star Waka mimic speech: hailing a presumed audience, reproducing the cadences of everyday speech, staging conversations between interlocutors, and so on. The emphasis on speech situates the poems within the Māori oral tradition. ${ }^{134}$

Marsden also states that: "we can see Star Waka emerging as a sort of pantheistic polyphony [...] in all its many-facetedness and multi-strandedness."135 If Marsden's musical interpretation of this section as a coda stands, it can also be thought of as a manifestation of the poet as a tohunga - a medium through whom voices, gods and spirits, would be channeled.

The stellar conclusion or grandiose finale in waka 100 (Battista speaks of "fiery conflation" or "regenerative spiral"136) could also be an epilogue. Waka 97 is another karakia recalling the initial karakia in preamble, waka 98 resumes conversation with star waka with an allusion to Blake's "Tyger Tyger"137 and waka 99 reveals the poet's vision for an authentic resurrection out of the blood. Battista observes that waka 100 is then the "culmination of the sequence"138 underpinned by "the writer's affinity with William Blake's The Book of Urizen"139 and celebrating "the uniqueness of the Māori ethos, [...] enriched by an interpretive multivalence encompassing spiritual and literal journeys." 140 The emphatic end bears a strong sense of syncretism bridging cosmologies and mythologies from different frames of reference.

The various narrative phases identified are therefore not separate entities but describe a pattern of interlacing micro-sequences coming in waves, and enhancing Sullivan's poetics of fluidity. This kind of narrative bears strong links to Māori culture, and these need to be revealed in the translator's navigation map, before translation, in order to be respected.

\section{c. Intertextuality}

\footnotetext{
${ }^{134}$ Baxter, (2016), p. 269.

135 Marsden, (2001), p. 16.

${ }^{136}$ Battista, (2007), p. 60.

137 "What dread hand shaped your fearful symmetry" (Sullivan, 1999, p. 108).

${ }^{138}$ Battista, (2007), p. 60.

${ }^{139}$ Ibid, p. 59.

${ }^{140}$ Ibid, p. 64.
} 
Star Waka's intertext draws from the Western traditional canon as well as Māori oral literature.

This dual intertextuality nevertheless makes room for innovation. Green assesses that:

Each poem and each sequence may be viewed as an open vessel (waka) that acquires a new presence upon the occasion of a new page. No poems look the same. Sullivan's poems are driven by the shifting rhythms and relations that befit a navigation of history, personal antecedents and the wider world. Each poem is open to renewal of form, and within that renewal, a replenishment of form. If Sullivan is making new demands upon the reader, it is to learn to navigate poetry that finds its form and vitality within the open weave of two cultural legacies: Western literatures and Māori narratives. ${ }^{141}$

The poet uses traditional forms in Anglo-Saxon literature, and makes inventive use of these as a contribution to Māori tradition. He uses free verse, triplets or couplets, characteristic of postmodern poetry, to deliver everyday insights (about his son Temuera in waka 73, his daughter Eileen in poem 47, or treating a cold in waka 81). However, his use of these written forms to perform Māori rituals such as whakapapa in waka 80, karakia in the preamble and waka 97, or karanga in poem xxiv, emphasises the intrinsic poetry, the depth and relish given to speech in these prestigious traditional acts.

Sullivan is inspired to invent some original forms, stressing the visual quality of his poems in order to represent motifs typically regarded as Māori, forging a new space for intertextuality, a hybrid intertext. To portray the double-hulled waka of waka 56, he presents two sections with a regular pattern of indentation within stanzas of fourteen lines each, an elaborated version of the sonnet. As well as the distinctive double columns of waka 16, there are three original pieces of visual or concrete poetry (poems 29, 51 and 53), calligrammes that might also be thought of as kōwhaiwhai motifs and koru symbols. These could also be maps, landscapes, or graffiti. The inclusion of Māori words or parts of sentences ("a taniwha brushes the sides"142) replicates the cut and paste mechanism observed earlier, while fully activating the polysemy of words,

\footnotetext{
${ }^{141}$ In Ricketts, (2010), p. 104.

${ }^{142}$ Sullivan, (1999), p. 33.
} 
presenting them as single entities in a near totemic, near shamanic way. This can be seen in the signature lines: "Robert / carved shaped loved floating tōtara." ${ }^{143}$ This striking formal innovation suggests shifts in the journey, discoveries made through exploration, and Sullivan's creativity therefore transcends the frame of his Pākehā-Māori intertext.

Intertextual references and allusions are bicultural. Some are drawn from the Pākehā canon: the Shakespeare quote in waka 50, the allusions to William Blake or Dylan Thomas in waka 100. Others refer to Māori sources: Hone Tuwhare in waka 76, the tohunga Hetaraka Tautahi in waka 61. This latter poem entitled "Fragment" is adapted from a karakia dictated by Hetaraka Tautahi. It presents Tautahi's ancestor named Turi from the waka Aotea, and his paddle named Te Roku-o-whiti. Here is an excerpt in parallel with Sullivan's poem:

Ko te Roku-o-whiti te hoe, Piripapa te hoe, Awhipapa te hoe, Tohitu te hoe, Tohirere te hoe, Tohimahuta te hoe, Tohikapakapa te hoe, Kei runga te hoe e rangi, ${ }^{144}$
This is the paddle Te Roku-o-whiti who stays close to the side encircles the side stands forward flies ahead springs onward slaps Tangaroa's back (who sometimes slaps back) ${ }^{145}$

This process of intertextuality is reminiscent of the palimpsest and Derrida's notion of iterability because it both perpetuates and poetically elaborates on pre-existing material as found both in traditional Māori storytelling and in postmodernism.

Finally, what is possibly the most visible element of intertext - and the least explored by critics so far - is the latent presence of Atua Wera. Sullivan's intertext is representative of the crosscultural stance of the book on one level but can also be seen as an act of cultural reclamation through dialogue in writing, as Sullivan explains that: "The best responses to poems are other

\footnotetext{
${ }^{143}$ Ibid, p. 58.

${ }^{144}$ Houston, (1935), p. 42.

145 Sullivan, (1999), p. 69.
} 
poems because they speak the same language of images." ${ }^{146}$ Smithyman's intertextual influence on Star Waka is evident with regard to both structure and approach. In an interview with Jack Ross, Sullivan reveals that:

I liked the structure of Atua Wera, the numbering sequence, it got me to reproduce something like that in Star Waka. You know the astronomy, the mathematics, the sequencing in that book owes something to Atua Wera, actually: the very clever way Kendrick would dip between different numbered sequences, shift it around temporally. So that's what I tried to do in Star Waka. I borrowed that technique. ${ }^{147}$

Atua Wera is mainly articulated around three narrative stages that permeate each other like so many transformative sequences, as David Eggleton tells us: "the Garden of Eden snake in Genesis being transformed into a lizard, then a dragon, then 'a fiery flying serpent' - Te Atua Wera himself." 148 Gregory O'Brien writes: "In Atua Wera, he [Smithyman] allows the structure to relax, to unwind, to flow and bend. [...] Perhaps this stems from the origins of the poem in oral records and transcriptions - it is less written." ${ }^{149}$ As Prentice notes about Star Waka: "there are three numbering systems employed for the poems, some with additional titles and some without, the systems leak into each other, preventing the bounded definition of each and thus prevent the secure mapping of the collection into discrete sections."150

There are similarities between the two poets in terms of approach. For O'Brien, Smithyman's last work is "a widely-flung verbal net [that] captures details from daily life, material and verbal exchanges, military campaigns and violent altercations as well as moments of prayer, prophecy and judgement." ${ }^{151}$ Sullivan reemploys Smithyman's tendency to experiment poetically - in

\footnotetext{
146 In Ricketts, (2010), p. 462.

${ }^{147}$ In Ross, (2015), p. 27.

${ }^{148}$ Eggleton, (1997), p. 3.

${ }^{149}$ O’Brien, (1997), p. 311.

${ }^{150}$ Prentice, (2006), p. 117.

${ }^{151}$ O’Brien, (1997), p. 309.
} 
convoluted snippets and fragments - with the archaeological and the genealogical, and Eggleton's description of Smithyman's work could apply to Star Waka:

Smithyman's long poem, his last testament, is woven out of bits and bobs. A magpie collector, he muses over hearsay, keepsakes, and intertextual chunks of letters and journals. He is the scribe penning whakapapa, a finger tentatively tracing bloodlines, a modern-day medium for ancestral voices. Smithyman excavates place with great industry, digging a mineshaft down between archaeological layers of local history. ${ }^{152}$

Excerpts from Atua Wera, in which Smithyman appears in conversation with various sources, for instance the records of John Webster, John White, William Yate, or James Busby, ${ }^{153}$ find echoes in Sullivan engaging with various anthropological references built into the text: Jeff Evans' Nga Waka o Nehera in waka 69-70, Harold Gatty's Raft Book in waka 67, the Journal of the Polynesian Society in waka 69, Anne Nelson's Nga Waka Maori in poem xxvi and waka 69, Elsdon Best's The Maori Canoe in waka 59. For Eggleton, Smithyman is a "masterventriloquist, like his subject, he uses James Busby, Thomas Kendall and Frederick Maning." 154

Nevertheless, while Sullivan follows a similar approach and structure, his own excavation from various sources poses the question of accountability and legitimacy in retelling parts of a people's history - that of Ngā Puhi. In poem 52, he writes:

my mother is from Karetu

and that is how I know the place

through all the stories she's told me $[\ldots]$

about the men and women of Karetu

and some of their terrible secrets

\footnotetext{
152 Eggleton, (1997), p. 3.

${ }^{153}$ Archival works underlying Smithyman's poems are omnipresent as in poem 56: "By the time Busby wrote this" in poem 30: "Yate put the story into print", "Henry Williams hints - or does he?" in poem 20: "William wrote in his journal", or poem 57: "Was William freely translating and not merely being sarcastic?"

(Smithyman, 1997, pp. 15-44).

${ }^{154}$ Eggleton, (1997), p. 3.
} 
even I won't tell ${ }^{155}$

Although O'Brien considers Atua Wera "respectful of the past and of that immense wealth that is cultural inheritance" 156 the question can be asked - a question that Sullivan suggests whether a writing project that consists in representing Papahurihia, the Māori tohunga called Atua Wera (the fiery god), does not merely equate to an act of cultural appropriation, risking blatant misrepresentation. ${ }^{157}$ In his interview with Selina Tusitala Marsh, Sullivan explains that:

I didn't want to even try to get - say some of the Ngā Puhi legends because I am an urban Māori. I don't live up home. My mother is the one who lives in Karetu, not me. So, for instance, I don't have the same level of accountability as someone like my mother does, to get it right so I know that if I got it wrong, it would be there for a long time because of the frozen text thing. I would just be another tourist coming in, and taking something that is not mine to take. There is no sort of accountability there. ${ }^{158}$

In a later interview with Ross, he adds:

There's been a significant book of poetry, Atua Wera, by Kendrick Smithyman. That whole book is about one of my ancestors, and I felt quite perplexed. Because I loved Kendrick, but I also felt quite conflicted, as if someone had reached into my family album and decided to tell that story before I could. ${ }^{159}$

The formal and structural influence of intertextuality in Star Waka therefore conveys a specific post-colonial narrative, an intertextual dialogue with Atua Wera in particular but also a variety of sources, raising complex questions of accountability and legitimacy in the fabrication of history, using poetry as a vessel to deliver these. The rich and complex nature of this narrative can be regarded as a typical illustration of post-colonial translation matters, and is, in my view, a major justification for translating it into a different context and language / culture.

\footnotetext{
155 Sullivan, (1999), p. 57.

156 O’Brien, (1997), p. 316.

${ }^{157}$ This is by and large the thesis of Judith Ward in her PhD The Invention of Papahurihia, in which she refers to Smithyman, and his observations on discrepancies between various accounts on the character. She challenges the view, promoted by Smithyman among others, that Papahurihia invented a syncretistic religion combining Christianism with Māori beliefs. Instead, she maintains that he was a tohunga "who continued with business as usual" (Ward, 2016, p. 179).

158 Sullivan, (2005).

${ }^{159}$ In Ross, (2015), p. 26.
} 


\section{A significant linguistic tack}

As the last part in my preliminary analysis, I show that the significant linguistic tack of Star Waka is appealing for the translator, as poetry in and of translation. The book's central diglossia and its absent glossary can be considered as an indirect educational strategy for most readers in the source culture context, and in line with a tradition of well-known Māori writers in New Zealand. Yet, outside a New Zealand context, this leads to problematic choices for my translation.

Because of its central diglossia, its constant coming and going between Te Reo and New Zealand English (that is in fact a heteroglossia: there is also some Latin, French, Tahitian and Samoan), and because this mixing of languages is presented as non-congruent or nonequivalent - a waka is and is not a canoe, as stated in poem xvii - Sullivan's poetry in Star Waka is essentially translational. ${ }^{160}$ The poet regularly refers to his writing as a direct act of translation, in poem 55, one finds: "I am translating names here", in waka 70: "they are translatable without me." For Prentice, "each metaphor is a term of translation as well as in translation."161 Prentice first refers to the commentary suggested by Sullivan's poetry as metatext or subtext (a term of translation) - choosing the connoted "star" over "whetu" for instance may inspire comments ${ }^{162}$ - and she also posits that Sullivan's language is already in itself a process of translation, acted on the page (in translation). Baxter and Smith also observe this: "new instances of meaning that transcend an apparent untranslatability through the plural, dislocating possibilities of on-going translation."163

\footnotetext{
${ }^{160}$ Here, I am using the word in a slightly different sense than with Bonnefoy, Paz, or Jackson for instance. The meaning of translational in Sullivan's case is less metaphorical, and more the result of an actual translation between languages.

${ }^{161}$ Prentice, (2006), p. 119.

162 Prentice assesses that: "the cosmological merges linguistically with the idiomatic and postmodern (image) senses of 'star', but this combination is an unstable conflation of radically incompatible terms" (Ibid, p. 120). ${ }^{163}$ Baxter, (2016), p. 271.
} 
Sullivan problematises his dual and non-equivalent translation process by refusing to choose sides. Prentice adds that: "Whether tradition guides and grounds Māori participation in postmodernity, or whether the postmodern appropriates tradition: this uncertainty pervades the poems in the collection." 164 This uncertainty is a trademark of Sullivan's fluid work as a poetic point of contact, an in-between or potential common ground, and for Prentice: "tension is not resolved, $[\ldots]$ in poems contemplating the politics of language, Sullivan problematises attempts at fixity of meanings." 165 Sullivan's translational poetry is therefore a place of linguistic negotiation that also resists translation. This stance is encapsulated in the second part of waka 56:

To understand one's culture one must speak the language of its poetry, world philosophy, reach untranslated ambiguities. For language deals out meaning.

Sullivan's dual and ambiguous frame of references does not align or cohere, allowing much uncertainty and play in the mechanism of language in terms of linguistic and cultural representations, something that he deliberately maintains unresolved. Prentice also explains that:

Both metaphor and translation represent the ambivalence of presence - splitting and doubling the linguistic or cultural sign, destabilising the terms that comprise it. The openness of movement points to a resistance to the order of self-same identity, challenging the binary oppositions of essentialised presence and absence, subject and object, identity and difference. ${ }^{166}$

This place of inherent interaction and negotiation between languages, which situates Sullivan's poetry, questions the fixity of meaning, and resists the idea of a definite and complete

\footnotetext{
${ }^{164}$ Prentice, (2006), p. 122.

165 Ibid, p. 125.

${ }^{166}$ Ibid, p. 116.
} 
translation, as a final word of truth. ${ }^{167}$ Marsden may solve the problem by offering that: "this volume of poetry is a living expression of diglossia - two languages dwell within it, but they are not translated by the author. Translation is left up to the reader."168 Sullivan's selection is then also translational in the sense that it is a piece of postmodern literature understood as an open translation for readers to achieve.

These matters are, in my view, to be left equally unanswered and unsolved so target readers can make their own judgement, and bring their own answers. The translational essence of the book subsequently resides in the fact that it aims at opening up spaces of discussion between cultures and languages. For Baxter and Smith too, Star Waka is writing in translation because the collection "commingles languages not in order to correct colonial displacement of Māori culture but to establish conversations among languages and Pacific regions." 169 Sullivan's selection is therefore a work in and of translation - literally with a central diglossia, metaphorically as postmodern poetry, and effectively, aiming to spark conversations across languages and cultures.

The presence of a glossary, or annotations, could be expected here. It has been common practice in New Zealand with some books including a large number of Māori words. ${ }^{170}$ What is the significance of its absence? I argue that this is a conscious strategy from the writer to provide

\footnotetext{
${ }^{167}$ It is pertinent that Te Reo also means voice in Māori, and Sullivan's mixing of languages, whether as diglossia or heteroglossia, is in line with his multivocal poetry.

${ }_{168}$ Marsden, (2001), p. 5.

${ }^{169}$ Baxter, (2016), p. 268. Baxter offers another translational dimension for Sullivan's poetry when stating that: "the Māori language itself is unmoored from the role of static artefact, a stable figuration of a stable culture, and is propelled into the future and propels that future through its capacity to carry, its power of translatio" (Ibid, p. 272).

${ }^{170}$ For instance, although it was first published without a glossary, the further publications of Keri Hulme's the bone people all include a glossary for Māori terms. Some of Patricia Grace's books also contain a glossary (Waiariki in 1975, The Dream Sleepers in 1980). In poetry, some of Tuwhare's early selections include a glossary (Sap-Wood and Milk in 1972, Making a Fist of it in 1978). This is often a publisher's decision based on readership. For instance, Baxter's books regularly featured glossaries for selections published in England.
} 
a linguistic and metalinguistic experience of poetry and, on a political level, to question and resist the linguistic and cultural status quo in Aotearoa New Zealand. ${ }^{171}$

From a post-colonial perspective, not including a glossary does emphasise and reject the assumption that Te Reo Māori should be translated and explained to New Zealand readers. Glossing has at times even been denounced as an imperialist practice, for instance by the authors of The Empire Writes Back, who wrote in 1989 that:

The choice of leaving words untranslated in post-colonial texts is a political act, because while translation is not inadmissible in itself, glossing gives the translated word, and thus the "receptor" culture, the higher status. ${ }^{172}$

Sullivan expresses similar political views, for instance against eurocentrism, when stating that:

To free people not to enslave people, you've really got to reveal different kinds of oppression, especially being Māori in New Zealand, and the fact that New Zealand's called New Zealand underlines a kind of oppression, a Eurocentrism. This is really a neo-Europe, not a Māori country anymore and in that very notion there's a kind of oppression that you're not free to be yourselves because you have to align with this amorphous body called kiwi-ism. ${ }^{173}$

Green also asserts that the poet is "strongly committed to writing poetry that restores a Māori point of view." 174 This political dimension, which I identify more widely as one of the main skopoi of Sullivan's book, therefore demands respect in the translation.

On a poetic level, if the poet does at times directly explain the meaning of some Māori phrases in the text itself, ${ }^{175}$ his choice of not systematically including a glossary provides readers who would not know Te Reo with an original experience, navigating between comprehension and

\footnotetext{
${ }^{171}$ Witi Ihimaera or Alan Duff for instance, never include glossaries in their works, a conscious decision for Ihimaera who claimed that: "to expect all Māori writing in Māori to appear with English translation would be to fail to understand what is happening to New Zealand's no longer monolingual literature" (in Kennedy, 2011, p. 305).

${ }_{172}$ Ashcroft, et al. (1989), p. 50.

${ }^{173}$ Sullivan, (2005).

${ }^{174}$ In Ricketts, (2010), p. 457.

${ }^{175}$ For instance in waka 65: "the great gathering place of spirits, / Te Hono I Wairua" (Sullivan, 1999, p. 74).
} 
non-comprehension, between familiar ground and unknown territory, an arresting and at times puzzling moment. Baxter and Smith suggest that:

Sullivan's conscious decision not to include a glossary [...] underscores the distinct experiences of reading with greater or lesser immediacy of linguistic comprehension [...] even for the Māori speaker there is a moment of cognitive syncopation when a word appears unsignalled though immediately identifiable as Māori within a poem's apparent Anglophony. ${ }^{176}$

This might even be the educational essence of the central metaphor, where the poet profusely riffing on the polysemy of waka serves as an incentive for (ignorant) readers to research this polysemy, and explore Māori semantics by their own means. The possibility that the full meaning of the text might not be recovered adds to the palimpsistic journey, the linguistic genealogy offered in Star Waka.

We may say then that Star Waka's absent glossary therefore functions in reverse by subtraction and preservation, an indirect way to deliver information on Māori language / culture to those not familiar with Te Reo by denying this information in the first place. Whether or not these readers' curiosity is sparked, whether or not they are enticed into using a dictionary, is necessarily up to them - something quite feasible when information is often just a mere click away. The experience of poetry can be exponentially enriched by relying on readers' commitment or curiosity. In an interview with Ross, Sullivan states:

When I was younger I used to think if you're not Māori you shouldn't be using Māori terms because you don't understand the significance, but I've changed my mind about that. I think it's better to promote the use of the language. But bringing it into poetry - well, readers of poetry can be quite pernickety. They'll look it up, and they'll actually deepen an understanding of Māori poetics. ${ }^{177}$

The immediate impact of unsignalled diglossia is little altered by the readers' proficiency in Te Reo, and will inevitably remain startling and original for anyone, at first glance. It may work as an indirect appellative function for "pernickety" readers. This strategy leads to issues such

\footnotetext{
176 Baxter, (2016), p. 269.

177 Sullivan, (2015), p. 28.
} 
as the problem of the source. ${ }^{178}$ When translating the book into French, what strategy should be adopted regarding Sullivan's unsignalled and non-glossed diglossia in poetry?

\section{Expected challenges}

\section{Diglossia}

What would be the most loyal way to maintain Star Waka's appellative function, for readers who would not be familiar with Māori culture to acquire some knowledge but also, as Green explains for Sullivan's poetry in general, to restore a Māori point of view, without denaturing its poetic essence? Would repeating Sullivan's diglossic strategy out of context be loyal in appearance but run the risk that target readers might neglect to do the work or refer to inadequate sources? Would a correctly-informed French glossary not prove to be a more loyal way to connect target readers to the source culture in translation? I now present an overview of these challenges by offering some theoretical suggestions made by Nord, and then discuss my solutions based on a linguistic trichotomy observed in the source text.

First, Nord reminds us that in most cases, the main linguistic issue for literary translators originates from a situation of non-equivalence between cultural realities. She writes that:

Even literary translations, which many of the equivalence supporters actually have in mind, cannot be considered as "equivalent" in all respects, since they usually (at least in our days) refrain from substituting source-culture reality by target-culture reality (which alone would warrant an "equivalence of communicative effect"). ${ }^{179}$

Translating the Māori words of the text in a note for instance, is something Sullivan does not do, and this constitutes a deliberate poetic act drawing attention to this situation of nonequivalence already in the source culture. In my project, translating (rather than borrowing)

\footnotetext{
${ }^{178}$ Sullivan himself insists on the importance of preserving the holistic nature of indigenous intellectual property and resources. See his paper on indigenous intellectual property: dlib.org/dlib/may02/sullivan/05sullivan.html. Accessed 25 Jun. 2018.

${ }^{179}$ Nord, (1997), p. 42. The equivalence of communicative effect might refer to the communicative equivalence school of thought initiated by Nida.
} 
words in Māori would obliterate the underlying cultural realities of the source text. Their holistic dimension cannot be transferred into a French reality in terms of equivalence or sameness. ${ }^{180}$ This non-equivalent situation makes me favour borrowing foreign words into the translated text in principle, if only to stress the poems' cultural specificity and otherness rather than diminish it. ${ }^{181}$ When Françoise Abrial translates James K. Baxter's lines from "The Ikons" into French, offering "village" for the Māori "pā", ${ }^{182}$ she not only misses the historical context of the Jerusalem / Hiruhārama commune, and the subtext of Baxter's poem as a pioneering bicultural statement, she also lessens its poetic value as an original and significant moment of diglossia.

In the German translation of Star Waka, Jörg-Stephan Mohr and Lotta Schneidemesser, with the exception of waka and a few proper nouns (Tangaroa, Kupe, Hawaiiki, spelt Hawaiki in both the source text and the translation), have systematically translated the Māori words into German, and without any explanation in the book. This is, in my view, a rather damaging process of domestication because it brushes aside the poetic possibilities of Sullivan's diglossia. For instance, whakapapa loses its spiritual prestige with "Stammbaum" (family tree), ${ }^{183}$ "Trauerfeier" 184 does not refer to the same reality as tangi, and "Macht" 185 is definitely not equivalent to mana.

\footnotetext{
${ }^{180}$ This is obvious for instance in the title of the exhibition of Māori taonga at Paris Musée Quai Branly: "Māori: leurs trésors ont une âme" (2011), which emphasises the spiritual dimension of taonga, a dimension lost with "trésors", hence the addition: "ont une âme".

${ }^{181}$ In my M.A. thesis on the translation of James K. Baxter's poetry into French, I show how borrowing specific New Zealand terms can at times be nuanced or counterbalanced, especially in the case of an over-accumulation of borrowed words. However, in the case of Sullivan, my interpretation is that the frequency of borrowed words does not impede understanding or rather that the potential lack of comprehension is not problematic as it was already a feature of the source text, calling for readers to look up some terms themselves.

${ }^{182}$ Furlan, (2006), p. 159.

${ }^{183}$ Sullivan, (2012), p. 46.

${ }^{184}$ Ibid, p. 116.

${ }^{185}$ Ibid, p. 164.
} 
In contrast, in her 1999 German translation of the New Testament, Nord promotes the restitution of strangeness or otherness by the introduction of new words:

The skopos of our translation was to make otherness understood, not to turn it into sameness. Therefore, where the source text refers to source-culture realities, we sometimes decided to create a new word rather than to use a word that suggests a reference to target-culture reality. ${ }^{186}$

Second, borrowing words leads to the question of the glossary. We have already mentioned (in the introduction) the difficulty (or lack) of readability induced by an accumulation of borrowed words, especially when they are not explicitated, a method which, according to Oliver Haag and Danica Ĉercee, does not suffice to transpose the situation of source readers into the translation authentically. In their analysis of the translations of The Whale Rider into Slovene, Dutch and German, Haag and Ĉerĉe conclude that:

The mere inclusion of Māori language does not achieve greater engagement with Māori culture through translated Māori literature. Instead, because of its non-translation and particularly the lacking contextualisation, it hinders any such engagement. The inclusion of Māori language in the source text may work as a device for New Zealand readers to reflect upon socio-political contexts of inter-racial relations and issues about sovereignty and bilingualism. But recognising such culturally foreign codes requires making their contexts familiar to European audiences. Without explanation of cultural contexts, translators have not offered European readers opportunities to recognise, let alone reflect upon, the implications of cultural codes. ${ }^{187}$

Their conclusion denounces the inefficiency of a strict foreignising method without a word of explanation from the translator, and this is, I believe, also to be taken into account.

On the other hand, a systematic glossary that would give (potentially restricting) signifiers for each word (for instance for waka: "vaisseau" or "bateau" or "pirogue" or "véhicule") as an end note or footnote would arguably prevent target readers from experiencing the moment of cognitive syncopation defined by Baxter and Smith. It would alter the postmodern poetic experience of translation / interpretation described by Marsden, but more to the point, it would

\footnotetext{
${ }^{186}$ Nord, (2007), p. 11.

${ }^{187} \mathrm{Haag},(2015)$, p. 265.
} 
obliterate the educational strategy, which indirectly encourages readers to reflect on the linguistic status quo and look terms up themselves - the reversed appellative function of nonglossing. More generally, Nord reminds us of the ineluctable alteration of effect implied by annotations: "Notes are meta-texts, and meta-texts are usually referential. [...] This procedure will necessarily change the whole communicative effect of a text." 188 If we come back to Baxter's poem for example, a translation that would keep the Māori pā in the French text marked with an asterisk referring to "village" directly at the bottom of the page would also alter the source poem's esthetical and historical effect as a pioneering bicultural statement. How might the translator then proceed?

In Star Waka, polysemy and cultural referents do not overlap across languages in an equivalent manner, and this constitutes the place from which the poet writes, subsequently also providing a learning or thinking opportunity for New Zealand readers. Can the source text linguistic and cultural situation realistically be transposed for readers of a French translation? Nord introduces the concept of loyalty precisely in this case of non-matching cultural realities. For her, the translator should be loyal to the communicative intentions of the writer on one side and at the same time to the expectations of the target readers on the other - not a target-oriented view as it has sometimes wrongly been perceived but an act of balance in translation. She writes:

Loyalty in the sense of considering the partners' expectations (or subjective theories) is usually not a problem in the translation of texts whose intended function can be clearly derived either from situational clues or from the text itself. But it is an important complementary criterion when the gap between source and target cultures or situations is so large that analogies are hard to detect and when it is impossible that the source-text sender's communicative intentions find a target in the target-culture addressees. ${ }^{189}$

\footnotetext{
${ }^{188}$ Nord, (2003), p. 195. I would rather say that notes are paratexts, following Genette's definition.

${ }^{189}$ Nord, (2001), p. 200.
} 
We are clearly in this situation. As well as Haag and Ĉerĉe's observations, and Nord's sound recommendations, other factors to take into account are extra-textual, such as the existing practice in the target culture's publishing houses, ${ }^{190}$ if there are any similar examples of diglossic poetry for instance, or the habits of readers of foreign literature in translation, ${ }^{191}$ as well as the expectations of the poet regarding the translation of his or her text.

What is finally particularly decisive is my interpretation that three different values of Māori words cohabit in the source text, and this also influences my choice regarding the potential addition of a glossary. I identify three kinds of values for Māori words in Star Waka, as listed in the three following groups. ${ }^{192}$ If these categories are to represent the experience of a majority of source readers when facing these terms, I nonetheless acknowledge that this is hard to pinpoint exactly.

1. Māori words that are recognised as New Zealand English, and expected to be familiar and known by most New Zealanders, even those not proficient or fluent in Te Reo. The poet uses these words with the assumption that they will be understood by all without a glossary. (I will refer to these as group 1). They include the very common: "marae" (vii), "kia ora" (xx), “taniwha” (waka 29), "kūmara” (44), “waiata” (46), “tapu” (54), "Waitangi” (waka 64), “moko" (waka 76) but also "iwi” (iv), “tangi” (v), "pāua” (viii), "whānau” and "wharenui”, (xv), birds such as "tūī" (waka 94), trees such as "kauri, tōtara, rimu", and "pā" (waka 16), as well as "whakapapa" (xx). ${ }^{193}$

\footnotetext{
${ }^{190}$ For instance, the publishing house Au Vent des Iles, which specialises in contemporary literature from the Pacific, has systematic recourse to glossaries in the works translated from New Zealand English.

${ }^{191}$ See Toury (2012) for a deeper reflection on these extra-textual concerns, and in particular on translation norms.

${ }^{192}$ I refer to Te Ara's glossary, which states: "The Māori words listed below are sometimes used untranslated in Te Ara's English-language entries. They often have no precise English equivalents, or may have several meanings. Many are in general usage in New Zealand speech" teara.govt.nz/en/glossary. Accessed 6 Jul. 2018. These categories are also based on my personal perception of New Zealanders' knowledge of Māori terms, on their context in the poems, and their inclusion or not in The New Zealand Oxford Dictionary.

${ }^{193}$ All these terms (18) are in The New Zealand Oxford Dictionary.
} 
2. Māori words that only some New Zealanders will know or be familiar with (group 2). The poet presumably uses these words knowing that they may not be understood by all without a glossary. This is the case of "kaituki" (man who calls the stroke timing on a waka, in poem i), "Makariri" (cold / winter, i), "tohunga" (expert, priest, healer, i), "Hawaiiki" (ancient homeland, i), "kahikatea" (white pine, waka 16), "papakāinga" (original home, communal Māori land, waka 16), "Raukawa” (Cook Strait, xxiv), "hāpuka" (grouper, xxvii), "uenuku” (rainbow, waka 29), "tauihu" (bow, prow, figurehead, xxxi), we may include also "pōrangi” (crazy, 37) although it has become common in some usages, "taihoa" (wait, 49), "piupiu" (waist-to-knees garment made of flax, 50), "pahū" (drum, waka 56), "whakairo" (carving, waka 56), “Kopua” (Venus, waka 63), "rongoā” (medicine, waka 81), “mokopuna” (grandchildren, waka 100), as well as the expression: "Kiwa's Great Sea" (Pacific Ocean, i). ${ }^{194}$

3. Māori words that only fluent speakers of Te Reo or an initiated audience may be familiar with (group 3). Here, the poet presumably does not expect to be understood by a great majority of readers. This category includes the following: "hoea hoea ra" (keep rowing) and "He karakia tīmatanga" (a prayer for the beginning, in the preamble), "te ao mārama" (world of life and light, Earth, physical world, xxi), “Te Hono I Wairua" ("the great gathering place of spirits", waka 65), "kia pai to moemoeā” (sweet dreams, literally "be good you're dreaming”, 47), and all full sentences: "He karakia mo kōrua, e te waka, e te whetū o te ao nei" (a prayer for you, the canoe, and the star of the world, i), "ka huri ahau ki te reo o te ao pōuri" (I am now turning to the language of a dark/sad world, xiv), "e tuwhera atu nei, te awa o Taumārere" (the river of Taumārere opens here, xv), "Kua wheturangitia koe" (You have died and become a star, a phrase typically said at tangi, waka 16), the proverbs “e hoki a Kupe?” (Did Kupe return?,

\footnotetext{
${ }^{194}$ Some of these words ("pōrangi", "whakairo", "mokopuna") are in The New Zealand Oxford Dictionary, and are relatively common in New Zealand.
} 
waka 86), and "He kakano i ruia mai i Rangiātea" (the seed which was sown from Rangiātea, waka 65).

My argument is that it would ideally be fair to offer something close to this linguistic situation in the translation for target readers. I therefore aim at partly recreating this situation in the target text in a much more substantial manner than in the German translation, creating what Nord would term an instrumental translation. It would also be fair to provide some contextualisation in paratext about the significance of Sullivan's diglossia, what Nord would call a documentary approach. This means that I try to combine what is often seen as two opposite methods, to develop what may be considered a balanced approach.

I therefore propose some annotations documenting the significance of Sullivan's diglossia, and add a brief glossary placed before the sequence regarding words in group 1 but not for words in groups 2 and 3. This is so target readers are placed in an initial situation that is obviously not identical but as close as possible to that of the source reader; an analogue situation.

The initial short glossary is here to help target readers in instances where the poems rely on the assumption that readers are entirely familiar with the linguistic material at hand, cases when the general sense could not be guessed, and lack of comprehension would impede the appreciation of the poems. On the other hand, not giving a complete glossary partly maintains the source writer's original strategy of encouraging readers to think about the linguistic situation and perhaps look up Māori terms, a hypothesis even more likely with the availability of the internet. In other words, this is a compromising approach mixing documentary and instrumental approaches, not spoon-feeding readers but potentially arousing their curiosity. The indication of a reliable source ${ }^{195}$ regarding groups 2 and 3, would then complement this

\footnotetext{
${ }^{195}$ For instance, Mahtab Mathilde Nikkhou's Maori de poche (2010), Jean-Pierre Maceau's Dictionnaire Poche Maori (2017) but also Myreille Pawliez and Ewen Jones' Dictionnaire néo-zélandais-français (1998) or the online dictionary Glosbe, fr.glosbe.com/mi/fr/. Accessed 3 Jul. 2018.
} 
strategy. In line with Nord's theory, this would ideally aim at balancing the translator's loyalty to both the target readers and the source poet.

Regarding New Zealand cultural references, be they historical (for instance the New Zealand Wars in waka 78), geographical (allusions to Auckland but also the less famous Bluff, Cape Palliser, Moeraki, Ōtaki), mythological (Māui, Papatūānuku), spiritual or philosophical (mana, aroha), they are mostly rather well-known in a New Zealand context. Regarding Māori mythology in particular, Sullivan's note at the beginning referring to Margaret Orbell's encyclopaedia also offers some reliable background information. There are certainly some less well-known occurrences. For Prentice: “The complex figuration of space and time renders many of the images and references uncanny - strangely (un)familiar - for readers attuned to the mythologies, histories, and socio-political present of Aotearoa-New Zealand."196 Baxter and Smith show for example how the opening of waka 65 can be interpreted in line with two parallel contexts: "when Sullivan opens with the phrase 'He kakano i ruia mai I Rangiatea', set apart as a single-lined verse, he calls to mind two interrelated sources of memory and heritage, that of Rangiatea, north of Tahiti and that of the Māori Church." ${ }^{197}$ Nonetheless, the presence of mythological characters such as Kupe, Tangaoroa, Tāne Mahuta, (or the story of Rātā trying to cut down a tree without permission from Tāne in poem xix), or historical Pākehā individuals (Sir George Grey) and events (the claim that Richard Pearse achieved controlled flight before the Wright brothers), as well as Māori philosophical concepts (tapu) are not problematic without explanation in a New Zealand context. These elements can be assumed to be common knowledge for a great majority of New Zealanders. However, this set of references would $a$ priori require some explanation when translated into French, and can be assumed to be

\footnotetext{
${ }^{196}$ Prentice, (2006), p. 113.

${ }^{197}$ Baxter, (2016), p. 272.
} 
completely unknown for a metropolitan French readership - but less so for a Francophone readership in the Pacific.

Overall, among various options (no glossary, partial glossary, and complete glossary, indication of sources for reference, explanatory notes) I assess that there is potential correspondence between the source writer's skopos (educating some New Zealand readers about Māori culture), and my translation's skopos - educating a Francophone audience about Aotearoa New Zealand culture with, in this case, a strong focus on Māori culture. However, regarding Sullivan's poetic attempt to restore a Māori point of view, this political agenda makes sense not in a metropolitan French context but perhaps in the Pacific, as a postcolonial exemplum. This is where skopos theory's concept of functional variance ${ }^{198}$ - where skopoi may diverge but remain intertextually coherent - is useful, allowing flexibility between text and translation without betraying the essence of the source, as Nord states: "a considerable number of problems in literary translation can be approached from a functionalist standpoint without jeopardising the 'originality' of the source text."199

My strategy in the case of Star Waka is to borrow all Māori terms into the French text, add a very short glossary of a selection of Māori words (group 1), and refer to a Māori / French dictionary as well as French publications specialised in Māori mythology and New Zealand culture. One last essential contextualisation comes in the form of a short introductory note, in which I aim to explain the significance of the source text's diglossia (documentary approach), a diglossia which I try to recreate partly in the French text (instrumental approach) as an act of loyalty to the poet, as well as to the target readers. I propose this note (see Appendix):

\section{Note du traducteur:}

\footnotetext{
${ }^{198}$ In his book introducing Skopos theory to a French audience, Mathieu Guidère explains: "Le Skopos peut être identique ou différent entre les deux langues concernées. S'il demeure identique, Vermeer et Reiss parlent de permanence fonctionnelle, s'il varie, il y a variance fonctionnelle. Dans un cas, le principe de traduction est la cohérence intertextuelle, dans l'autre, l'adéquation au Skopos" (Guidère, 2008, p. 72).

199 Nord, (1997), p. 122.
} 
Dans son troisième recueil de poésie publié en 1999, Robert Sullivan mêle, comme l'atteste son titre, héritages māori et pākehā (néo-zélandais d'origine européenne) notamment par la combinaison de la langue māori (ou Te Reo) et de la langue anglaise-néo-zélandaise, qui elle-même inclut certains termes māori. Cette poésie diglossique fait particulièrement sens en ce qu'elle représente une réalité contextuelle bien spécifique où certains mots māori sont passés dans l'usage courant et où d'autres comportent une dimension spirituelle ou holistique reliant notamment cette culture ancestrale aux différents peuples du Pacifique. C'est ce tressage de langues significatif, symbolique et hautement poétique que ma traduction tente de recréer en incluant tous les termes māori des poèmes de Sullivan dans le texte français et dans leur orthographe actuelle. Pour les termes les plus courants, je propose le glossaire ci-dessous. Pour les termes moins courants, c'est-à-dire qui posent aussi sans doute problème aux Néo-Zélandais ne parlant pas la langue Te Reo, je propose aux lecteurs de se référer aux dictionnaires suivants: Maori de poche de Mahtab Mathilde Nikkhou (2010) ou Dictionnaire poche maori de Jean-Pierre Maceau (2017). Enfin, pour les nombreuses références à la mythologie māori et à la culture néo-zélandaise en général, je propose de consulter l'ouvrage de Georges-Goulven Le Cam, Mythe et stratégie identitaire chez les Maoris de Nouvelle-Zélande (2000) et le Dictionnaire néo-zélandais-français d'Ewen Jones et Myreille Pawliez (1998).

\section{Glossaire}

Aotearoa : Pays du long nuage blanc. Nouvelle-Zélande.

iwi : tribu, clan, nation.

kauri : variété d'arbres endémiques pouvant atteindre plus de 50 mètres de haut pour 10 mètres de circonférence et vivre jusqu'à 2000 ans.

kia ora : bonjour, salut.

kūmara : variété de patate douce importée par les Māori.

marae : lieu de rassemblement de la tribu.

moko: tatouage sur le visage ou sur le corps effectué selon des protocoles traditionnels.

pā : village fortifié, fort.

pāua : mollusque marin dont la coquille est nacrée et de couleur bleue irisée.

rimu : variété de conifères endémiques.

tangi : lamentation, ou abréviation pour tangihanga: enterrement au protocole traditionnel.

taniwha : monstre légendaire gardien des eaux d'un lac ou d'une rivière.

tapu : sacré, interdit, prohibé, sous la protection d'atua: être surnaturel, ancêtre et déité.

tōtara : variété de conifère endémique.

tūī : passereau endémique.

waiata : chanson, chant.

Waitangi : commune située au nord où fut signé le traité unissant la Couronne britannique à la plupart des tribus māori le 6 février 1840 (devenu fête nationale).

waka : pirogue, véhicule, moyen de transport, réceptacle, medium.

whakapapa : principe fondamental qui consiste à réciter sa généalogie.

whānau : famille, famille étendue, groupe familier.

wharenui : grande maison qui sert aux réunions ou aux cérémonies sur le marae. 


\section{Other expected challenges}

From the beginning of the sequence, it is striking that the poet uses non-conventional language, stylistic structures that express his poetry in and of translation. In poem i, Sullivan uses ellipses of articles, and nouns in the singular when a plural could be expected. He does so with Māori nouns as well as English - waka, tohunga, kaituki but also ocean, sun, star, body, stroke, night or system. This is in the following lines:

Crews take longer, yet learn less about makers of waka, meanings of star. Inheritors of body, watched by spirits watching star.

Star hangs on ears of night $[\ldots]$ star points.

Kaituki counts stroke.

Tohunga, who dwells beyond law, finds star.

System is always there for waka.

Star rises and falls with night.

So guidance system attached. ${ }^{200}$

The last line for instance is startlingly nominal, a trait repeated at the beginning of the next stanza: "Belief system of heart. And tide."

Towards the end of the poem, this use of the singular is re-echoed and perhaps explained, emphasising unity: "Just one waka takes us back [...] just one star stays familiar in the heavens now." It is as if these common nouns were then used as proper nouns, marking a process of characterisation, placing star or night on the same level as tohunga, kaituki, and other crew members, characters without capital letters at the beginning of their name. This is also found at the beginning of poem viii: "I cannot make this like maker of waka" where the function of the character becomes a name - "kaihanga waka" in Te Reo. The ellipsis' function could therefore be narrative, something obvious in the line: "Tamanui sun dribbles from sky" but also metalinguistic or translational. The poet might be using Māori-inflected English. (In Te Reo,

${ }^{200}$ All italics added. 
the plural is not marked by form but by context.) At the end of the sequence, one finds for instance:
We've adzed waka out for them - the memories, intricate knowledge, fleet leaders, our reasons for being - shoulders that carried so many waka -

Here, the first occurrence of waka can be assumed to be plural as is obvious in the latter "so many waka", and not "wakas".

I aim at reproducing Sullivan's stylistic device in the translation: the trait should not be corrected, its narrative and metalinguistic functions should be kept. However, rendering this trait is challenging: an ellipsis of the article and of the "-s" at the end of nouns, may read oddly in French, and unsettle target readers' linguistic habits. Furthermore, if Sullivan reuses this elliptical technique in several poems (mostly when referring to waka: "and when waka reaches Aotearoa" in poem ii, "waka reaches for stars", in poem iv), he does not do so consistently throughout, but at times, reverts to using the expected definite article: "more times the waka leaves full" (poem ii), "in the waka" (poem iii), or alternates between: "I rest Star Waka on Nga Waka Maori" (in poem xxvi) and "a significant portion of the text of the Star Waka" (in waka 89).

Sullivan's recourse to licentia poetica to deliver elusive meaning, also allows multiple interpretations, and this can be disconcerting for the translator. Taken from poem i, a good example of this is the line "In ancient days navigators sent waka between." Even read in the context of the stanza, the oddness of expression makes the line's meaning rather vague:

Belief system of heart. And tide.

In ancient days navigators sent waka between.

Now, our speakers send us on waka

The image is nonetheless sudden and startling, as emphasised by the lack of clear association or reference. My response as a reader is to think: "sent waka between"...what? tides? tide and 
heart? islands? or sent them in between? Is it a reference to the concept of space in-between in Māori: "wā"?

This is arguably challenging for any translator in need of a clear visualisation before translation. It is perhaps not surprising then that in the German translation, the translators have opted for the more conventional "auf den Weg" (on their way), correcting the lack of clarity, brushing off the evocative vagueness of the line. As will be shown in my case-by-case analysis, I would go against such simplification but this feature nonetheless remains problematic.

There are regular occurrences of these enigmatic images, for instance in poem xiv: "And morning yields to the purpose of the day. / Bright blood, the sun a clot tying darkness. / Waka of death duels death's waka" or in poem 50, the line: "Justice the person who sits at the bench." This latter line is a vivid personification offering a vision of immediacy, which does not provide or perhaps does not require explanation, leaving it to readers' imaginations. This stylistic tendency suits the delivery of some abstract or complex images too: "sails a vortex / ribbed by people shouting names down into the Great Sea", ${ }^{201}$ at the end of waka 62, where direct and precise meaning is perhaps less important than the labyrinthine effect created by a long and embedded enumeration. This recurs in the distant sight painted in waka 66, and its final simile "like an instinct as magnetic / as the grip of the people / on this taniwha's back."

Challenging stylistic innovations not only appeal to readers' visual imaginations but also involve musical wordplay or mimetic sound play, as well as idiom play. In poem xi for instance, the lines "and tide's own cursive / curling lickity ups and lollipop downs"202 has a playful ring to it, making use of alliterations (liquid and occlusive) mimicking waves, and the fluid delineations of land, while simultaneously offering a simile describing the spirals of handwriting. This mimetic use of sounds is found again in waka 91's line: "licking sucking

\footnotetext{
${ }^{201}$ Sullivan, (1999), p. 71.

202 Ibid, p. 15.
} 
chewing biting" 203 to suggest a feast, or to describe the ocean's sound: Sullivan refers to "the slap and grab of a restless swell." These elements of melopoeia can therefore be deemed challenging in anticipation, as they need to be replaced by a different melopoeia in French, while conveying a similar suggestiveness.

Some wordplay's referential function can be considered problematic in its subversion of idiom. In poem $\mathrm{x}$, the lines "proof of early / anthropological puddings" 204 allude to, and corrupt the proverb "the proof is in the pudding" (a shorter form of a more self-explanatory earlier version "the proof of the pudding is in the eating"). This contributes to the poet's expression of an overall anti-anthropology sentiment in regard to a potential aleatory process of settlement in Aotearoa. This challenging trait needs creativity, and here, German translators propose a rather different adaptation with "Sonntagsfahrer" (Sunday driver), ignoring the subversion.

Similarly problematic for their rich references are the lines "We watch the New Zealand First Bus / wheels go round and round" in poem 50. The reference to the New Zealand political party, which mixes a nationalist and populist agenda with centrist economy and social conservatism, has no equivalent in France. The poet mismatches it with the reference to the children's song "The Wheels on the Bus". The poet's derisive humour delivers criticism by allusion and with a light tone. The problem is that neither reference is known in the target culture, and that any adaptation or equivalent is imperfect, and might fail to render the subtext and overall purpose of the trait. I explore this and detail my solutions in the case-by-case study that follows.

If the translation fails to either document, adapt or recreate the referential and contextual background, the translator risks restricting the potential significance of the poetry. The choice between documenting, adapting or recreating is regularly problematic. A good example is the

${ }^{203}$ Ibid, p. 101.
${ }^{204}$ Ibid, p. 14. 
short poem xxxi, using the key motif of signatures. In a post-colonial New Zealand context, signatures (marked as $\mathrm{x}$ ) may recall the Treaty of Waitangi or more largely the colonial practice of having illiterate people sign with an x, as Sullivan writes: "signatures in water / waka cutting each other's wake / signing / xxxxxxxxxxxx." Here, a note documenting the reference might be useful but there is no certainty that this is what the poet is referring to in the first place.

A last challenge is the rendering of Star Waka's variety of tones. This is obvious in the final coda. Sullivan's book oscillates between the lyrical (waka 100) and the casual (poem xviii), the low-brow (waka 73) and the elevated (waka 97), and his restitution of Māori-inflected oral language (waka 76 or waka 89) is problematic. This is a regular pitfall for translators dealing with Māori literature, and Jean Anderson and France Grenaudier-Klijn explain their strategies in their preface to Patricia Grace's first novel published in French (Миtuwhenua):

Les traductrices se sont attachées à donner à chaque personnage la voix qui lui convenait, pour exprimer la diversité des personnages imaginés par Grace. Par respect de la tradition orale, elles ont également tenu à préserver le ton immédiat, vécu, que crée l'emploi du passé composé et des phrases négatives incomplètes permettant de retrouver les particularités du "parler" māori. ${ }^{205}$

As will be shown, an array of different techniques can be used. Overall, the challenges anticipated are the poet's elliptical turn (plurals, articles), significant in the frame of his poetry in and of translation and inspired by Te Reo, his non-conventional use of language at times leading to a range of startling but enigmatic images, his stylistic innovations and wordplay emphasising sounds and music, as well as subverting idioms, his overall penchant for referential subtext (whether specific to New Zealand or not), and his tonal liberties and diversity with a focus on the transcription of Māori orality. I now make a more detailed analysis based on a selection of Star Waka's poems to explore and discuss my solutions and the principles on which they are founded.

${ }^{205}$ Grace, (2008), p. 6. 


\section{B. CASE-BY-CASE ANALYSIS}

As stated in my preliminary analysis, one fundamental element of the book is the narrative structure, "a meticulously planned and crafted volume with an architecture all its own." To do it justice, and because the content of some poems is illuminated by the overall structure, I have translated the entire sequence, included in the appendix. However, as in my first case study, to demonstrate certain recurring challenges representative of the process, I select some poems, offer a detailed analysis of the problems they pose, and comment on the solutions, in line with Nord's method. These poems are grouped in the following sections:

1. "He Karakia Tīmatanga", poem i

2. Poems $x$ and $x i$

3. Waka 16 and poem $x$ viii ${ }^{2}$

4. Waka 50

5. Waka 56

6. Waka 75 and 76

7. Waka 87,88 and $89^{3}$

8. Waka 100

1. "He Karakia Tīmatanga", poem i ${ }^{4}$

In the introductory poem, the traditional form of karakia implies a cultural layer that is difficult to transfer authentically. A karakia could be generalised as a prayer, as Sullivan repeats at the start of each sentence: "a prayer, a declaration". However, translating karakia as "une prière" would convey different nuances, codes and symbols: the image of two hands joined together for instance, a private and quiet moment of recollection. Elsdon Best, to whom Sullivan devotes waka 59, argued that either charm or incantation would be more appropriate: "Dr. Thomson, in his Story of New Zealand, speaks of the native karakia as 'prayers' - of natives praying to their gods - thus giving the reader the impression that such formulae resembled our own

\footnotetext{
${ }^{1}$ Marsden, (2001), p. 4.

${ }^{2}$ Sullivan (1999), pp. 20-22.

${ }^{3}$ Ibid, pp. 97-99.

${ }^{4}$ See Appendix pp. 76-79.
} 
prayers; which they certainly do not." Instead, he defines karakia as "a long chant containing brief references to many acts and scenes in Māori anthropogeny, cosmogony, and other mythopoetic conceptions." 6 The original oral and chanted nature of karakia is likely to be why the German translators chose "Gesang”, and the poem's musicality also reflects this. However, translating "karakia" into "un chant", as in "Gesang", would miss the spiritual dimension of karakia. My aim is to transfer both musicality and spirituality. The poet casts a spell, utters a blessing for a safe journey. Musicality is emphasised by passages in Te Reo, and most visibly the chorus "hoea hoea ra", or the final couplet and its wishful charm. Sullivan also uses devices in English with repetitions - "A prayer" at the beginning of sentences - internal rhymes: "the slap and grab", anthropomorphic images: "past upthrust knee and rock toe", or original word combinations: "food music and drink".

Second, the cultural layering has repercussions in terms of linguistic possibilities. The references to Tangaroa, or "yam and taro and kūmara gods" are part of Māori anthropogeny, cosmogony, and other mythopoetic conceptions, described by Best. With the exception of kūmara, explained in my glossary, some complementary strategies are needed to make references as self-explanatory as possible, especially since this is the opening, and I intend readers to be progressively accustomed to the diglossia.

Also problematic is the image "cloaked by night", which may subtextually recall a korowai. This image is often conjured by Sullivan - in poem iv: "Ranginui and his cloak", in waka 96: "under the cloak of his protection", and in waka 16: "on the cloak of a night." While it is linguistically correct to translate this as "un manteau" or "une cape", or simply "enveloppé de nuit", as in the German "umhüllt von Nacht", it is, in my view, a problematic obliteration of an underlying cultural reference. I believe this calls for a different strategy.

\footnotetext{
${ }^{5}$ nzetc.victoria.ac.nz/tm/scholarly/tei-Bes01Reli-t1-body-d7-d2.html. Accessed 8 Jan. 2018.

${ }^{6}$ Ibid.
} 
Regarding poem i, as in "to guide waka out of the throat", (and not "the" waka), there are lots of ellipses. The ellipsis of the article, either definite or indefinite, is reused throughout (although not systematically) for instance in poem viii "yet waka still searches for star." The following passage is particularly striking:

Crews take longer, yet learn less about makers of waka, meanings of star. Inheritors of body, watched by spirits watching star.

I also interpret this elliptical turn as a process of personification, as is obvious in "Tamanui sun dribbles from sky", referring to the Māori deity Tamanuiterā. Sun or star, waka, or night become characters, on the same level as other crew members: kaituki, tohunga. Although it is possible to reproduce these ellipses in French, they will inevitably read oddly. In poem viii, where I propose: “mais waka cherche toujours étoile”, readers might initially be surprised, and perhaps think of some form of pidgin. This has to be taken in consideration.

I also observe the ellipsis of the plural form: "sailing into pāua" and not "pāuas". Reproducing this spelling will also likely be startling for readers, as in poem vii: "mais le symbolisme reste māori / et sera toujours pour les Māori". Writing "les Māori” instead of "les Maoris" might prompt target readers to find out the linguistic reason for this spelling (as for instance "les Maasaï”).

Ultimately, poem i gives a good idea of Sullivan's signature combination of languages, either in a sudden fashion: the Māori interjection "aue" (and not "ouch" or "heck"), the nominal sentence "Makariri" (winter, cold), or in a list, with different understandings of Hawaiiki: Savai‘i, Avaiki, Havaiki, in various languages of Kiwa’s Great Sea. This mixing of languages, as well as Sullivan's penchant for riffing - for instance "they continue the line. The bottom line / is to know where to go" - provide a good introduction to Star Waka.

\section{He karakia tīmatanga}

Une prière pour guider waka hors de la gorge, entre les dents de Hawaiiki, le dernier gant de vert 
tacheté de la côte, passer genou levé le pied rocheux, au loin pagayer et faire voile vers le couchant -

quand toute fissure de la maison du soleil

est submergée - portes et fenêtres en un korowai de nuit,

ciel calciné où les étoiles deviennent des flèches,

panneaux lumineux parcourant une zone noire.

Une prière pour que tiennent bon cordes et attaches dans la houle des tripes du dieu Tangaroa.

Une prière pour pêcher au filet subsistance poisson sucré pris par des plongeurs en eau brillante et salée,

mariné à la noix de coco et à la faim. Une prière pour garder des vivres les deux semaines du voyage vers Aotearoa,

gourdes intactes, igname, taro et kūmara : dieux alertes contre la claque et le rapt de la houle incessante -

aussi bien au sein qu'au fond de la mer. Une prière, déclaration, pour des terres vives, des mers droites et la santé

de toutes parts célestes, temporelles et divines : musique, le manger et le boire de ce star waka -

les rythmes scandés

hoea hoea ra

tempêtes

hoea hoea ra

un millier d'années

hoea hoea ra

lestes mères des légendes

hoea hoea ra

je vous salue en prière oh étoile oh waka...

et prie pour que vous soyez combinés ici.

He karakia mo kōrua, e te waka, e te whetù o te ao nei.

Etoile et waka, une prière pour vous deux.

i

Les hommes laissent reposer leurs rames la nuit naviguant parmi pāua, volaille dodue, eau 
douce, miracles de la planète, terre roulant des collines aux cieux, terre assez grande pour des lacs, pour y accueillir un peuple, festin pour une forêt de dieux touchant ciel.

Star waka est un couteau à travers temps. Les équipages changent, la langue de chaque équipage change, aussi vite que soleil brûle sol et les langues le maudissent. Les équipages mettent plus de temps, mais apprennent moins des constructeurs de waka, des sens d'étoile. Héritiers de corps, observés par des esprits observant étoile.

Etoile accrochée aux oreilles de nuit, définit la lumière.

Au son du waka qui coutèle le temps - aïe, encore, ce qui est à l'eau est au sang. Les équipages sautent à bord débarquent, des chansons de tendresse et de parenté à leur envoyer. Des familles entières ont fait voyage ici, ils continuent la lignée. La ligne à suivre

c'est de savoir où aller - étoile guide.

Kaituki compte la ramée. Tohunga, demeure au-delà des lois, trouve étoile. Système est toujours là pour waka. Etoile monte et descend de nuit.

Donc système de navigation intégré.

Croyance système de cœur. Et marée.

Aux jours anciens, les navigateurs envoyaient waka entre. Désormais, nos orateurs nous envoient sur waka. Leurs souvenirs, mémoire du peuple en nous, invitent, esprit, nous obligent à bord, à gouverner au pays, au centre:

Savai i. Avaiki, Havaiki, Hawaiiki, d'où nous avons peuplé

la Grande Mer de Kiwa. Nous sommes partis d'un millier d'étoiles différentes, mais un seul waka nous ramène. Regroupons-nous. Nous n'avons jamais voyagé plus loin une seule étoile reste familière dans les cieux à présent. Soleil Tamanui bave depuis ciel. Comment nous installer sur cette terre froide? Makariri. Notre haute magie marchera-t-elle ici ?

Translation commentary

In "He karakia tìmatanga", borrowing the title instead of using "une prière de départ" for instance, implies that the Māori words convey cultural elements different from the French, in particular, the spiritual / musical dimensions of karakia. In contrast with the German translation, I systematically borrow all Māori words to transfer their holistic significance and 
melopoeia. I wish to preserve their function as a repetitive chorus ("hoea hoea ra") or as a charm ("He karakia mo kōrua, e te waka, e te whetū o te ao nei"). These words might also acquire a certain arcane quality, which I find suitable for a karakia. Regarding the last couplet, the line "Star and waka, a prayer for you both" partly sums up the meaning of the previous line in Te Reo, which makes readers' comprehension perhaps not entirely necessary. Rather, a partial lack of understanding might make the foreign line function like a spell, thus transferring the supernatural dimension of karakia.

At times, to counterbalance this approach, I propose in-text explicitation, for instance: "du dieu Tangaroa", or paratextual information, as with "kūmara". It can be guessed that a kūmara is a vegetable by association with "igname" or "taro" in the same line. ${ }^{7}$ This movement of balance aims at easing the readers' introduction to the diglossia.

Considering the high frequency of loan words, some more spelling choices need to be established. I systematically ignore elision rules before Māori words - for instance: "de Hawaiiki" instead of "d'Hawaiiki" to avoid any confusion especially when read aloud. When this becomes too problematic "for the ear", I propose to side-step difficulties, as in "notre iwi" instead of the awkward "le iwi" or "l'iwi", in poem iv. In waka 81 , for the lines "kūmarahou man, / kūmarahou is rongoā, Māori medicine”, I offer: “le kūmarahou mec, le kūmarahou c'est du rongoā, du médicament māori" but it would be legitimate to opt for "c'est rongoā" without an article.

Sullivan mentioning a cloak in English indirectly refers to a korowai in Te Reo. In a recent interview, Jean Anderson asks: "why not leave the term in, or even translate it into, the indigenous language (ie turn flax bag in the original into kete in the translation) [?]"8 Since the

\footnotetext{
${ }^{7}$ The gourds referred to, in the same line, were dried vegetables used as containers, as Orbell explains: "all these expeditions set out laden with plants such as coconut, breadfruit, banana, paper mulberry, panadanus, taro, yam, gourd and often kūmara" (Orbell, 1995, p. 7). The German translation does not refer to the vegetable:

"Trinkgefäß" (drinking vessel). In French, "calebasse" is usually associated with Africa, and the solution "gourde" also refers to the Lagenaria siceraria.

${ }^{8}$ Anderson, (2018).
} 
image of a cloak is present throughout, I translate the line "doors and windows cloaked by night" as "portes et fenêtres en un korowai de nuit". I do this systematically for "cloak": "Ranginui et son korowai" (poem iv) or "sous le korowai de sa protection" (waka 96). My aim is not only esthetic, I wish to maintain the text's appellative or "educative" function. Readers should be tempted to find out what a korowai looks like, using the internet for example.

To emphasise the music of the poem, I propose "la claque et le rapt" for the sharp assonances and monosyllables of “the slap and grab". Sullivan's fluidity in language, evident in a formula such as "past upthrust knee and rock toe", with its extended anthropomorphic image ("throat", "teeth", "glove", "knee", "toe") is what I try to capture with "passer genou levé le pied rocheux" (rather than the odd "orteil"). At times, I propose small register alterations - "vivres" for "food". My solution "musique, le manger et le boire de ce star waka" also respects the original combination of nouns in "food music and drink of this star waka". The rare colloquial expression "le manger et le boire" is a compensation.

In this same line, the question of the title becomes apparent. Inspired by the German "Sternenwaka" with its hyphenated compound, I have thought of "Waka-Etoile". However, Sullivan's intent is to combine Te Reo and English to find a symbol for New Zealand culture. Arguably, transferring this situation into French - or German - does not have any cultural significance per se. This is what I observe in poem xvii, in which Sullivan makes a note on English orthography: "In English the waka / is a canoe". Translating this as "en français, le waka / est un canoë"9 would wrongly transfer the situation into a French context, when Sullivan's focus is on New Zealand. It is best to "document" this with "en anglais, le waka est un "canoe"”. The title poses a similar problem. Helped by the fact that "star" is a common Anglicism in French, referring to the American star-system, I borrow Star Waka for the translation, and for all other

\footnotetext{
${ }^{9}$ Or rather "une pirogue”, as in French, “un canoë” suggests “canoë-kayak", and has North American origins.
} 
references. Furthermore, it is common knowledge that "star" means "étoile", and the end line clarifies this: "Etoile et waka, une prière pour vous deux."

Regarding poem i, while the article ellipsis is quite elegant in: "Star waka est un couteau à travers temps" - "à travers temps" is an elevated turn - the line "aussi vite que soleil brûle sol" is unconventional. Nonetheless, this poetic licence is justified by the narrative personification and the reproduction of the syntax of Te Reo in English. I resort to this in several places: "des sens d'étoile", “observant étoile", "Etoile accrochée aux oreilles de nuit”, “étoile guide”, "Tohunga [...] trouve étoile", "nos orateurs nous envoient sur waka", "Soleil Tamanui bave depuis ciel". Consequently, some lines stand out, as I intend for them to reproduce the unusual construction of the source poem.

Système est toujours là pour waka.

Etoile monte et descend de nuit.

Donc système de navigation intégré.

Croyance système de cœur. Et marée.

Equally unconventional is my ellipsis of the plural: "naviguant parmi pāua" or "Kaituki compte la ramée" for "Kaituki counts stroke". Rather than the long "coup de rame", I propose the invention "ramée". I thought of the jargon "souquée" ("coup de rame énergique" says Littré) but this poses a problem of context. "Souquez ferme!" is what sailors idiomatically shout out to oarsmen. To offer some correspondence with "hoe" in Te Reo, I borrow "ramée" from the Polynesian journal Litterama'ohi. Ramées de Littérature Polynésienne, explained on the website: "par référence à la rame de papier, à celle de la pirogue, à sa culture francophone."10 I reuse this in waka 56 ii: “en ordonnant les ramées - encore, / encore ramer, ramer, ramer" or in poem xiii "les ramées lentes", poem xxiv "l'ego dans les ramées", (also waka 97 and 100). It is at times difficult to perceive the exact meaning, as in "Crews take longer" - longer than what? - or "navigators sent waka between" - between what? I try to refrain from letting my

\footnotetext{
${ }^{10}$ ile-en-ile.org/litteramaohi-presentation/ Accessed 21 May 2019.
} 
interpretation, or lack of interpretation, restrict the semantic possibilities. My strategy is to keep a close, and rather literal approach: "Les équipages mettent plus de temps" or "les navigateurs envoyaient waka entre." These lines are equally enigmatic in French. This means that I favour preserving the potential opacity of the source text with non-conventional language rather than clarifying it with solutions that would make immediate sense but would also make it plainer and blander.

\section{Poems $\mathrm{x}$ and $\mathrm{xi}^{11}$}

The translation issues raised here are of a different nature. Diglossia is not a major feature, however these poems work on language in original ways, posing challenges in terms of subtext, tone, rhythm, music and wordplay.

First, poem $\mathrm{x}$ is an ekphrastic piece, based on Charles Goldie's painting, "The Arrival of The Maoris", a controversial adaptation of Géricault's "Raft of the Medusa". The poet's criticism is directed toward the dated misconception underlying the painting. As stated in the description of the Toi Tāmaki museum, the image is a romantic fabrication relying on nineteenth-century European conventions for representing miraculous survivals at sea rather than on traditional accounts of the Māori immigration voyages. Transferring the possibility of this antiEurocentric subtext for a French audience is challenging because it partly relies on a knowledge of the painting.

It is however possible to understand the poet's charge without this knowledge, mainly by understanding that he is overtly ironic. Irony is suggested by creative idiom-play - "proof of early / anthropological puddings" corrupting the idiom, by oral and direct style (the relaxed "he pads around downtown", the contemptuous "just look at it", the sarcastic apostrophe "hey

\footnotetext{
${ }^{11}$ See Appendix pp. 89-90.
} 
they were paddling / round the ocean", or the lapidary "must be their account"). Tone has an expressive function, and the translation's success relies on the translator's ability to reproduce the ironic tone rather than on resituating the painting's reference.

Poem xi also breaks away from convention by offering new "ways of narrating a story of waves". The poet, both "he" (as in poems xi, x) and "I" (poem viii), produces a striking piece, in which seascape participates in shaping the narration, and constructs the poem itself. Elements of geography ("a slip", "the ocean", "beach”, "sand”, "puffs and gulls", "swelling”, “waves”, "rocks") and literature (“story”, “phrase”, “declaimed”, “context”, “canon”, writing”, "cursive") entwine. The music of the sea and waves are suggested by liquid or tonic alliterations "tumbling mumbling tongues", "cursive curling lickity ups and lollipop downs", or omnipresent rhythm: "metronomic", "high wave and back down", "again and again". The challenge is on the level of melopoeia, rendering the special mix of landscape and language, a vivid oceanic music delivering motion and emotion.

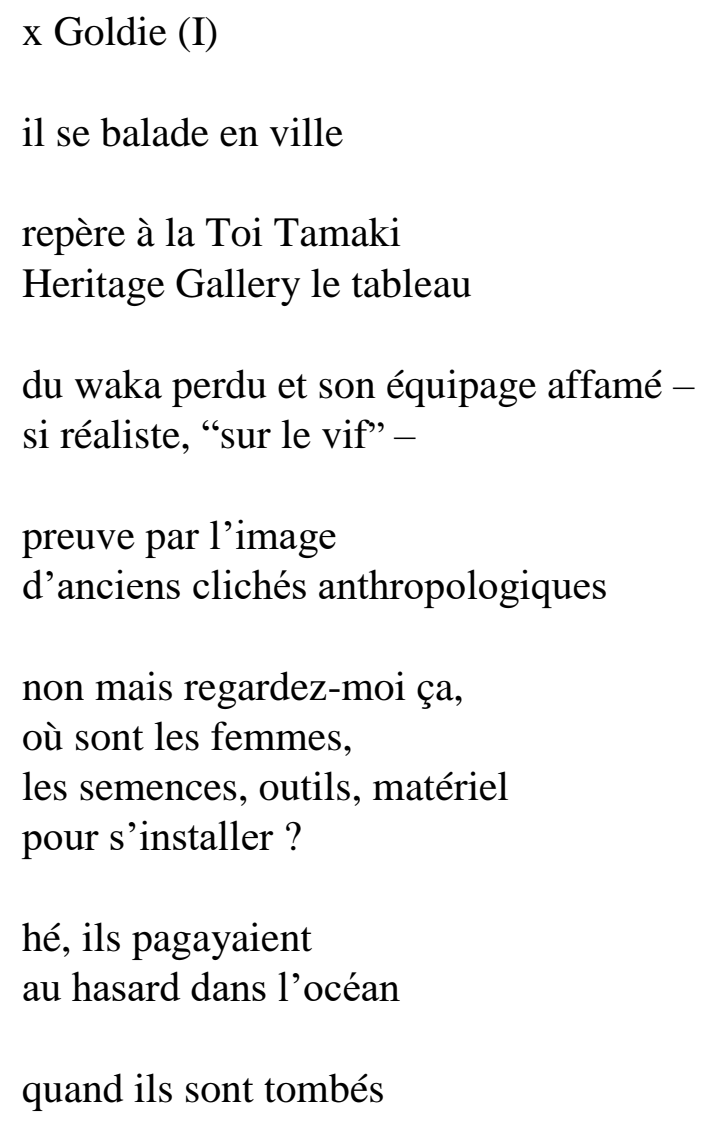


sur Aotearoa

et on leur a tiré le portrait -

ça doit être ça leur récit

xi

lui et moi suggérons des façons de narrer une histoire de vagues

un milliard de milliards d'elles pour emprunter une phrase

empruntée au nombre infini disponible

pour raconter une histoire infinie lapant les contours

formés autour des terres - un jeu de clés sur un genou

atterri là par erreur - un glissement

et tout s'entasse dans l'océan mépris

pour une reprise déclamée par le tumultueux

murmure des langues de salinité

sur une plage qui s'en va gagner un contexte

une page de brèche dans le canon des plages

écriture dans le sable obscurci par les macareux

et les goélands et la cursive de la marée même

enroulant léchouilles en haut et roudoudous en bas

à travers la transparence autrement

métronomique puis houleuse puis agitée

jusqu'aux vagues hautes retombant

par terre ou sur les rochers encore

et encore la solution saline

Translation commentary

I aim to render Sullivan's ease with words, rhythm and sounds in poem xi, and the vibrant irony and directness in tone in poem x. Because poem x does not refer directly to Goldie's Arrival, except by litotes ${ }^{12}$ ("the starving lost waka crew - / so realistic, 'on the spot"'), the reference

\footnotetext{
${ }^{12}$ In poem xxxiv, the poet is more explicit: "He still takes the rap / for the Arrival of the Maoris" (Sullivan, 1999, p. 38).
} 
does not need to be explained. It could be any case of Eurocentric misrepresentation ignoring indigenous voices. Readers who would not know the painting can appreciate the poet's facetious, at times ferocious, touch of irony towards the blatant ignoring of Māori accounts when these are the very subjects of the painting.

To compensate for the oral ellipsis of the subject in: "must be their account", I offer in contrast to double the occurrence of "ça": "ça doit être ça leur récit", conveying doubt and a faint derogatory connotation. The rendition of orality is problematic, as in poem iv where "Just then" emphasises immediacy, and here I switch from "nous" to "on" in compensation. The contempt expressed in "just look at it" can be rendered with a modulation: "non mais regardez-moi ça", the direct apostrophe "hey", merely with the transparent "hé", and the expression "on the spot" with "sur le vif". However, the idiom-play "proof of early / anthropological puddings" does not transfer so easily.

The proverb does not have any obvious equivalent in French $^{13}$ and what it plainly says roughly, that the painting is the representation of the evidence, and the (false) evidence itself is difficult to capture in a mere two lines (five words). With wordplay, a literal translation or a documentary translation would be ineffective. The punchline needs to work in an instrumental fashion, as the German translators have perhaps gathered in offering a presumed pun about Sunday drivers. I play on the polysemy of "cliché", both a snapshot and a stereotype in French, as well as with the idiom "preuve par l'image", equally conveying irony towards Goldie's piece.

$\begin{array}{ll}\text { proof of early } & \text { preuve par l'image } \\ \text { anthropological puddings } & \text { d'anciens clichés anthropologiques }\end{array}$

\footnotetext{
${ }^{13}$ Idiom-play is easier to render when the idiom has a literal "equivalent" in the target language. In waka 66 the line "they draw on the ocean / like taniwha straws" plays with the idiom "to draw straws", which can be rendered as "tirer à la courte paille". I propose: “elles esquissent sur l'océan / comme la courte paille du taniwha" (see Appendix, p. 159).
} 
Poem xi clearly gives an opportunity to tune in to the particular prosody of the writer. The poem is one long unfinished sentence, with no punctuation, and the effect produced is that of a never-ending tidal motion: the "story of waves" depicted "again and again". It is easy to reproduce the repetitions "billion", "borrow", "infinite" at the beginning, but more problematic are the near rhymes "lapping" / "lap" / "slip" also remotely echoing "piles", or the wordplay "reclamation declaimed", "beach / breach" and "tumbling mumbling tongues". Perhaps the book's most challenging line in terms of music, but also meaning and structure is the alliterative "curling lickity ups and lollipop downs". The repetitions of liquid sounds, the novelty of the vision / movement described and the playful use of prepositions "up and down" pose great difficulty.

As in many instances, what seems mere nuances require considerable effort. In poem iii, Sullivan plays with echoes in "to compliment and complement their abilities, / the way they looked and what they looked at", and this implies transposition: "pour complimenter et complémenter leurs compétences, / leurs apparences, visions et visées." In poem xi, I work by compensation, and suggest a tidal rhythm with paronomastic pairs and echoes: "jeu / genou", "glissement / s'entasse", "atterri / erreur", "mépris / reprise", "tumultueux / murmure", "page / plage", "obscurci / cursive". The lines are equally dispersed in regular couplets, alternating in length like waves.

I propose the whimsical "léchouille" for "lickity". I keep the liquid sound at the beginning, and the familiar suffix. However, "lickity" works in tandem with "lollipop" here. Translating "lollipop" into the expected "sucette" would be bland. I have thought of other solutions with an -1 conveying the childish, bouncy-sounding sweetness of "lollipop": "berlingot", "rouleau de réglisse", "arlequin", "praline" or "calisson". I settle on "roudoudou”, not only because of its musical quality but also because it comes in the form of a lickable seashell. 
Three areas require creativity here: tone, wordplay and music. The poet's message is also conveyed: in poem x, he mocks Eurocentric conceptions of Māori history, and in poem xi, he celebrates unconventional and yet timeless ways to tell a story of waves.

\section{Waka 16 and poem $x$ viii ${ }^{14}$}

These poems offer a mix of typical problems such as wordplay, subtext and cultural specificities, as well as issues not yet explored - form compression and a shift from pathos to bathos. In waka 16, the seven parallel stanzas, in two regular columns, juxtapose one-word lines, visual echoes and repetitions, with a stark economy of words. The following stanzas speak for themselves:

like kauri
tōtara
kahikatea
rimu
awa
tapped for fire
sapped for gum
used for battle
construction materials
veins into dams

The parallel construction of these lean lines, the repetition of monosyllabic terms ("veins", "dams", "used", "gum"), and homophonic wordplay "tapped / sapped" are particularly challenging.

Waka 16 also poses issues related to diglossia, and to the cultural layers implied. The title "Kua wheturangitia koe"15 ("you have become a star"), is a pēpeha (proverb, witticism or saying) traditionally found in eulogies and funeral orations at tangi. It was sometimes believed that the dead would have one of their eyes turned into a star. ${ }^{16}$ This is not only repeated several times:

\footnotetext{
${ }^{14}$ See Appendix pp. 96-99.

${ }^{15}$ Orbell, (1995), p. 69.

${ }^{16}$ This information is key to waka 96: "I am the star waka / guided by the left eye / of the ancestors".
} 
"to become a star", "and we will be stars", the title directs the elegiac sentiment and tone. One may think of a waiata tangi. Orbell notes that: "In waiata tangi - passionate, allusive laments for the dead - the poets spoke of the early generations who had created precedents and shown what must be done." 17 This is clear in the following:

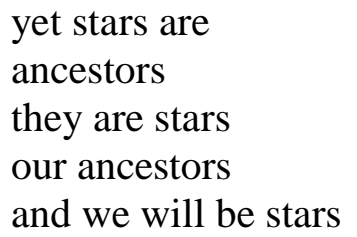

At the beginning, there is passion and pathos in the address "Beloved / sent to Hawaiiki". Yet, this lament for the departed turns into a fiery criticism of the economic and political status quo - "where the power / of the land powers / a mechanical culture" - and the tone is more incisive in the second column denouncing urban decay and ecological issues - "air filled with radiation [...] culture of menace to the land". In the last stanza, the lines "except in the papakāinga / from tops of pā” include Māori words, and these embody safe places of preservation and revitalisation - both spiritual and ecological. The rich potential of interpretation then comes from the suggestive diglossic nature, which needs to be preserved.

In poem xviii, the poet's ecological concerns reverberate in a more down-to-earth manner. The focus on language is also in poem xvii, the urban setting is extended in waka 77, and the poet's social or ethical claims ("rearguard action"), expressed in terms of justice ("the standard in justice"), are reiterated in waka 50 ("Justice the person who sits at the bench"). However, poem xviii is radically different: rather than the elevated pathos of waka 16 , the poet indulges in bathos, with crude and sarcastic idiom-play at the end:

up shit creek without a paddle

- who'd want to put a waka in that!

\footnotetext{
${ }^{17}$ Orbell, (1995), p. 12.
} 
Beyond the scatological humour of the familiar saying "up shit creek", normally taken figuratively, Sullivan takes a literal approach and denounces the placing of a sewage pipe through Māngere's ancient stone fields, a disrespectful confusion of profane and sacred, or the Māori concepts of tapu and noa. This distinction also underlies the "right / wrong" or "ordinary / unordinary" oppositions in the text. In later poems such as "London Waka" in Voice Carried My Family, Sullivan's agenda often consists in reversing the situation into an English setting, challenging perspectives, and here, Stonehenge replaces Māngere. These deeper layers are somewhat concealed by the casual tone. Direct and relaxed turns - "that's what it is" - lead to rhetorical questions "don't you think it is wrong?", "is this extraordinary?", creating contrast with waka 16 . Since both poems pose equally serious ecological and ethical questions in different ways, maintaining the tone's coherent disparities is my main skopos. 
Waka 16 Kua wheturangitia koe

Bien-aimé

envoyé à Hawaiiki

pour devenir une étoile

qui guide

les rêveurs à la réalité

pour devenir une étoile

portrait sur le korowai

d'une nuit sur les épaules

de laquelle reposent

les rêves

d'un peuple agité

qui rêve des blanches

vagues de la monnaie

waka navigue

et chute

bleu et noir

avec seules les étoiles

pour indiquer au lointain

depuis que soleil et lune

sont désignés pour dominer

or les étoiles sont

des ancêtres

ce sont des étoiles

nos ancêtres

et nous serons des étoiles

comme kauri

tōtara

kahikatea

rimu

awa

bois pour le feu

sève pour la gomme

taillés pour la bataille

matériaux de construction

veines des barrages où le pouvoir

de la terre alimente

une culture mécanique

d'étranges navires au ciel

l'air empli de radiations

nous sommes aspirés dans cette

culture de menace pour la terre

on nous dit que nous aussi on aurait fait ça

si on avait eu la technologie

et notre peuple fait ça

à la terre pour le peuple

par le peuple et cette terre

se joint au congrès des cicatrices

sur la planète une culture

de pourrissement urbain et renouveau

une culture de capitales défuntes

qui suce le sang des nouvelles

villes une culture qui ne connaît

pas de limites n'a que

des prophéties dites stratégies

et les étoiles voient ça d'en haut et les yeux

des divinités

regardent les étoiles d'en haut

et les yeux

des impuissants regardent d'en bas

mais seulement la nuit

quand les machines

illuminent l'obscurité

quand beaucoup d'étoiles

sont perdues dans l'éclair

sauf dans le papakāinga

depuis les hauteurs des pā

depuis le milieu de l'océan

depuis ces lieux les étoiles

censées être vues peuvent l'être

xviii Similitude

planter un tuyau

au milieu de Stonehenge - 


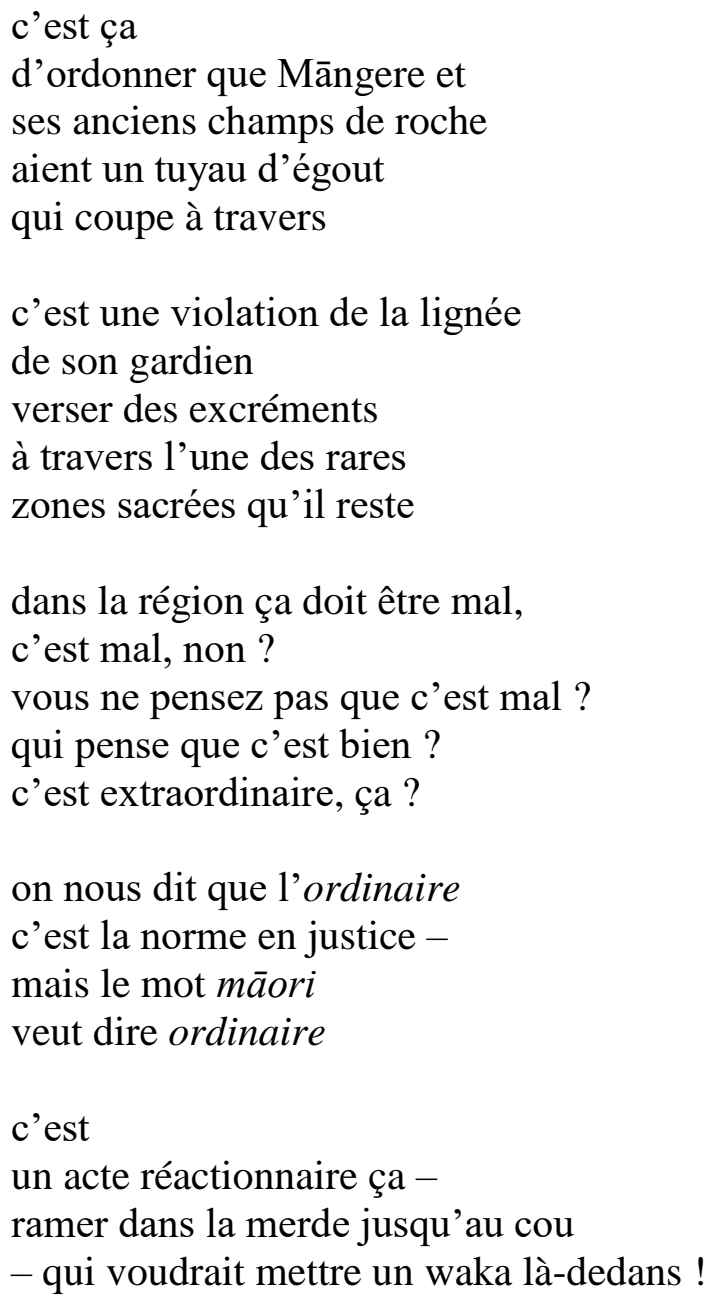

Translation commentary

In waka 16, I focus on formal compression and specific underlying references. In the seventh stanza, I use modulation to keep the ternary rhythm in these short repetitive lines:

$\begin{array}{ll}\text { tapped for fire } & \text { bois pour le feu } \\ \text { sapped for gum } & \text { sève pour la gomme } \\ \text { used for battle } & \text { taillés pour la bataille } \\ \text { construction materials } & \text { matériaux de construction } \\ \text { veins into dams } & \text { veines des barrages }\end{array}$

My solution "bois pour le feu" also provides in-text explicitation for the preceding list of native trees: "kauri / tōtara / kahikatea / rimu". Any literal solution - "exploités" or "débités" for "tapped", "sève extraite" for "sapped" - would compromise the visual and rhythmic compression. I compensate for the loss of the homophonic wordplay "tapped / sapped" by adding "taillés" in "taillés pour la bataille", an idiom suggesting "fit for" or "cut out for" but 
also "pruned", which is coherent with the theme. Near the end, I keep the repetitive construct emphasised in an enumeration:

$\begin{array}{ll}\text { from tops of pā } & \text { depuis les hauteurs des pā } \\ \text { from middle of ocean } & \text { depuis le milieu de l'océan } \\ \text { from these places stars } & \text { depuis ces lieux les étoiles }\end{array}$

Repeating "depuis" is visually more deft than "des hauteurs du pā / du milieu de l'océan / de ces lieux", which would elide the repetitions.

Some lines remain enigmatic, and I keep their elusive meaning: "sun and moon / are tagged for domination" becomes "soleil et lune / sont désignés pour dominer" or "this land / joins the congress of scars", which plays with near homophony (scars / stars), becomes "se joint au congrès des cicatrices".

I borrow the title "Kua wheturangitia koe" without explanation. It is debatable whether an indication such as "proverbe māori déclamé lors des oraisons funèbres" would be useful. Since the poem further develops the idea of ancestors being stars, it is arguably not necessary for readers to understand that the poem may be constructed on the basis of this phrase. As with "awa" ("rivière"), by keeping the Māori words, I also intend for readers to research their meaning.

In poem xviii, my focus is on the vibrant directness of tone - where the poet challenges readers: "who thinks it is right?" - and the tonal drop at the end. Whereas, in waka 16, I maintain an elevated tone by favouring formal turns: "des blanches / vagues", "d'étranges navires", "une culture de capitales défuntes", in poem xviii, I use familiar terms: "planter" for "sticking", or relaxed turns: "qui coupe à travers" for "cut through them". I add the oral "ça" in "c'est extraordinaire ça?" to compensate for the emphasis of the demonstrative in "is this extraordinary?" to accentuate the irony. 
The final line expresses anger but also humour and distance. The idiom subverted could be literally translated as "remonter une rivière de merde sans pagaie". I use the familiar idiom "être dans la merde jusqu'au cou", combined with the figurative meaning of "ramer" as in to struggle, keeping both figurative and literal meanings possible.

up shit creek without a paddle ramer dans la merde jusqu'au cou - who'd want to put a waka in that! - qui voudrait mettre un waka là-dedans !

This is another case where using an idiomatic equivalent - in Vinay and Darbelnet's sense makes the poem work. However, in a functionalist perspective, equivalence between languages is not a given but a creative act, achieving a balanced situation between source and target poems.

4. Waka $50^{18}$

Waka 50 is one of the longer poems of Star Waka. Its eight stanzas vary between six and nine lines drawing compact and regular shapes on the page, reflecting the density of the verse.

There is first a varied range of references, an iconoclastic mix of spaces and times. These include New Zealand references: native species (karaka, kauri), cultural elements (piupiu) or historical allusions (“musketry" or Cook's Tahitian interpreter Tupaia). There are references to contemporary New Zealand politics: "We watch the New Zealand First Bus". There are also occidental symbols (Downing St, Newton) as signaled by the Shakespeare quote (taken from Sonnet 116). There are also references to Ancient Egypt (pharaoh), and the Old Testament, as well as Catholicism (The Holy See), and modern consumer goods such as Japanese car brands (Mitsubishi Galant) or the American children's song “The Wheels on the Bus". This vast range

${ }^{18}$ See Appendix pp. 135-136. 
of references is challenging. For instance, "The Wheels on the Bus" is not well-known in France, and although it has been translated ${ }^{19}$ it is not as deeply embedded.

The first stanzas revisit the arrival of European explorers and settlers from their perspective, aboard their ship, and to their advantage (“excuses / for our reasons”). In stanza four, the poet starts questioning the interpretation of history (“who interprets history?") denouncing colonial and religious appropriation ("dragging the bags / into the Tasman into the Holy See" with a pun on See / Sea), and indigenous alienation ("no release from captivity"). This leads in stanza five to an indictment of colonial practices forced upon Māori people in regard to economic matters ("compliance by salary") or legal matters ("adversarial law").

The poet's tone is fierce and bold, with hammering repetitions (six occurrences of "justice" over the course of a few lines), in manifesto style. However, what is most challenging is the perceptible shift of tone from accusatory to sarcastic, and the childish melody "wheels go round and round" takes on a satirical connotation targeting the New Zealand political party, also creating black humour and derision.

In other words, beyond its suggestion of an endless repetition - the vicious circle of the status quo or "an orbit we cannot escape from" in poem $\mathrm{iv}^{20}$ - the reference has an expressive function, a crucial subtext, preventing the poem from lapsing into complete cynicism.

The tonal shift is completed in the last two stanzas, incorporating some vibrant oral turns ("it freaked them out", "it's just plain tough"), after the elaborate sentencing of the previous stanzas ("Justice / by revoking our guardianship of all / the eye can see in the imposition / of adversarial law"), and ending on a lyrical twist. Amidst the struggles of reality, the "waka crews" and the "inside of a shell" offer shelter and escapism. The last line in particular links the urban and the

\footnotetext{
${ }^{19}$ See: people.southwestern.edu/ prevots/songs/?p=54. Accessed 13 Nov. 2018.

${ }^{20}$ Sullivan, (1999), p. 7.
} 
oceanic, evokes poetry that is salutary as much as it is daydreaming. The tour de force is to maintain the coherence of tonal shifts encompassing historical allusions and mundane references, to end with ease on a striking and resonant lyrical note, delivering emotion.

C'est l'étoile brillant pour toute barque errante, Dont la valeur est inconnue de celui même qui en consulte la hauteur.

Une boussole montrant le nord au-delà du Canada pour pousser cet équipage plus au sud par les angles, nid-de-pie pour un cri, le cap !

Une masse que le reste de l'équipage découvre peuple à convertir, étendues plates, bourrelets tournés vers les sommets, vert dense d'intensité noire, la seule loi commune est newtonienne - une baie de karaka tombera de son arbre.

Les têtes âgées des kauri sont les coupes afro de la terre, rastas énormes, êtres les plus fiers de ces Mers du sud. Convertis en espars pour les flottes de la couronne victoires pour Downing St. Une nouvelle nation reggae prête au labour et au partage ; imaginez, oh bêtes, oiseaux d'Europe, oh légumes, champs, les grandes récoltes pour les racines et tripes qu'on a découvertes!

Commençons la définition de ces îles que la circumnavigation précède l'acquisition. Les ambiguïtés du tahitien nous serviront d'excuses pour nos raisons - la mousqueterie et le tonneau pour soulever le piupiu des nanas, le pasteur pour gronder le regard des hommes.

Qu'est-ce que la galanterie de nos jours sinon un modèle de Mitsubishi ? Qui interprète l'histoire ?

Qui conserve les manuscrits et les livres des disparus ? Dans l'esprit juste du temps il y a l'objectivité mais pendant des générations c'est la captivité sans libération - nous sommes les biens de Pharaon et quand chaque pharaon succombe à la monnaie, tirant les sacs à travers la mer de Tasmanie jusqu'à la sainte mère,

on regarde et on attend la justice. Justice pour nous avoir inclus au prolétariat. Justice pour nous avoir rendus dociles par le salaire. Justice 
pour avoir révoqué notre kaitiakitanga sur tout ce que l'œil peut voir et avoir imposé

le droit législatif. Justice pour notre apathie.

Justice, personne assise sur le banc.

On attend le Bus de la Justice.

On attend le Bus de la Liberté.

On regarde le bus du parti New Zealand First

et le ronron des roues qui tournent en rond,

et les visages tout sourire à l'intérieur

qui font coucou, oui, coucou, ronron.

On est au bon Arrêt de Bus.

Selon les horaires, il devrait s'arrêter.

Mais faites signe et vous perdrez un bras.

Ou alors c'est le bus des touristes. Ou

vos potes vous racontent la dernière fois

qu'ils ont fait signe et comment ils ont flippé.

Parfois, c'est juste pénible de rester debout

dans la rue - tous les autres ont des bagnoles.

Pourquoi faire face au soleil, sachant

que la justice va vous foncer dessus ?

Les nuits fraîches où les étoiles glissent

en haut des réverbères, facile de lever les yeux -

bien plus facile de penser aux équipages de waka entendre dans le trafic l'intérieur d'un coquillage.

Translation commentary

First, I borrow François-Victor Hugo's translation (1872) for the initial Shakespeare quote: although it could be improved, its dated feel seems appropriate. I mostly borrow other specific references, some appearing more enigmatic than others. For instance, "Downing St." or "Newton" are common references in France, but "le piupiu des nanas" might startle some. Here, I combine the slang "nanas" with the loan word "piupiu". Other references can be guessed from context: "Les têtes âgées des kauri sont les coupes afro de la terre" or in-text explicitation: "une baie de karaka". I add explicitation in: "le bus du parti New Zealand First" or "un modèle de Mitsubishi". The Mitsubishi Galant has been commercialised in France since 
1969, and this touch of humour can be transferred as: "Qu'est-ce que la galanterie de nos jours / sinon un modèle de Mitsubishi ?"

Instead of translating "the Holy See" as "Le Saint-Siège", which would cancel the pun "see / sea" in "across the Tasman into the holy see", I propose "tirant les sacs à travers / la mer de Tasman jusqu'à la sainte mère", keeping the pun and the reference to religion. Regarding “The Wheels on the Bus", I emphasise the satirical tone and musicality by compensation, for lack of any convincing equivalent - a French lullaby about wheels turning. I have thought of "Meunier tu dors ton moulin bat trop vite" or "Ainsi font font font les petites marionnettes" but these would require a great deal of adaptation without clear benefit. Literal translations of the lyrics exist on the internet - Les Roues de l'autobus tournent en rond - and I focus on the bitter-sweet mix of childish and ironic tones in "le ronron des roues qui tournent en rond". "Tourner en rond" means going round in circles, and also suggests not getting ahead, and this is the gist of Sullivan's attack. I repeat this in the next line with emphasis, turning into ridicule the "faces inside smiling”, by adding a nonsensical melody: "coucou, oui, coucou, ronron." What I aim for is a clear sense of irony / derision and childish musicality.

In the last few stanzas, I focus on the apparently effortless flow of the verse. In stanza five, the construction of some sentences is problematic: "Justice for inclusion in the proletariat. Justice for compliance by salary". These need to be unpacked: "Justice / pour nous avoir inclus au prolétariat. Justice pour nous avoir rendus dociles par le salaire.” In the next line, my solution navigates between compromises on meaning and fluency: "Justice / pour avoir révoqué notre kaitiakitanga sur tout / ce que l'œil peut voir et pour avoir imposé / le droit législatif." In this latter line, the concept of adversarial law, in use in England, is often presented in opposition to the inquisitorial legal system in place in France. I propose the more general "droit législatif" taking into account the underlying opposition between "droit législatif" and "droit coutumier" 
found in post-colonial situations, as is the case in New Caledonia where they coexist in certain areas. I also find that "guardianship" is a translation of the principle of "Kaitiakitanga", ${ }^{21}$ which implies a different relationship to the environment than "tutelle", for instance, would convey. ${ }^{22}$

\section{[...] Justice pour avoir révoqué notre kaitiakitanga sur tout ce que l'œil peut voir et avoir imposé le droit législatif. Justice pour notre apathie. Justice, personne assise sur le banc.}

These lines offer sharp tonal contrast with the next stanzas where I propose some relaxed turns such as “c'est juste pénible” or slang: “comment ils ont flippé”. At the end, my aim is to recreate the emotion through natural style and expression. The poet's sincerity transpires through a simple but potent final metaphor: "hear in traffic the inside of a shell." I keep the lines as lean as possible while maintaining regular length. I favour "le trafic" over the long "la circulation", "en haut" instead of "au-dessous", and use an ellipsis of the verb:

Les nuits fraîches où les étoiles glissent en haut des réverbères, facile de lever les yeux bien plus facile de penser aux équipages de waka entendre dans le trafic l'intérieur d'un coquillage.

In a longer poem like waka 50, the variety of references, the density of the verse and the tonal shifts are challenges. However, these challenges should not make one forget the point of translating poetry, which is to express emotion, especially Sullivan's poetics of transport.

\section{Waka 56 A Double-Hulled Waka ${ }^{23}$}

Three main problems mark the translation of this long waka: elaborate form, intricate phrasing $^{24}$ and complex imagery. First, the original structure, announced in the title, poses

\footnotetext{
${ }^{21}$ See: environmentguide.org.nz/issues/marine/kaitiakitanga/what-is-kaitiakitanga/. Accessed 20 Feb. 2019.

${ }^{22}$ See also the conclusion, pp. 283-284.

${ }^{23}$ See Appendix pp. 143-145.

${ }^{24}$ I mean phrasing in the musical sense, that is to say the arrangement or distribution of notes or in this poem, of motifs in relation to one another.
} 
difficulty in terms of constraints, symmetry and length. This is the longest poem of the whole sequence, and it consists of two parts. The first is composed of four unrhymed sonnets, regular stanzas of fourteen lines, but with an additional fifteenth line in the fourth stanza. The first three sonnets all show this indented pattern, which the last stanza abandons. Although there is no traditional rhyming scheme or regular metre, there are a great number of echoing sounds and internal rhymes throughout - "ledge / logic" or "crossing / across" in the first stanza - and rhythm is emphasised by alliterations in nominal sentences: "A stretch across plates for salt" or "Each bit a wriggle along existence."

The second part is composed of two sonnets with the same indented pattern and two final stanzas of three lines, after the waka has passed the "thousandth line" of the sequence. The two parts can then visually suggest a double-hulled waka with two hulls of equal dimension joined by a rectangular deck supporting the sails. Indented lines could suggest waves, or zigzagging lines of light gleaming on the water. The visual aspect is clearly a key element, and I aim to recreate this structure.

Second, the intricate form is reflected in the complex imagery. The images conjured are somewhat convoluted, and their formulation requires extra attention, for instance the Shakespearean: "They possess beauty their fans / die like lovers for". (To me, this is similar to the image of a moth fatally attracted to candlelight.) Another enigmatic usage is "We must / reclaim gifts of mouth, example." In the first stanzas especially, the various images, conveyed in non-conventional language and innovative turns, follow one another in free associative style, in an impressionistic riffing prosody.

\section{all contribute}

to each chemical and animal light.

Scales of light vary, measuring speed, lux, changes: physicists think we are stardust. 
The seminal image of the dream sky at Moeraki (also in poem v), "bounced round inside [him] for years / like a prayer-wheel". This assemblage of images, thoughts and sentences in the manner of a prayer-wheel, "powered by water", is challenging. Chains of association can be disconcerting, for instance: "I know these lovers, / felt the breeze raise a veil from a sunset / internalised. Lime spears caverns. Worm mouths" or in the second part: "Meaning is the star above our / species. Specifically, our waka / follows this. Meaning is food for chiefs. / Succulent hearts steaming in hot ovens / of earth.” In this latter example, the reference to hāngī also make it challenging. Thorough research is necessary from the translator so the cultural layers invoked may be grasped, even though an audience not familiar with this background might find these enigmatic or baffling in translation.

Rendering these striking images therefore requires an effort to visualise them. The imagination, in the sense of phanopoeia, is put to the test, and precision is key in the (re)formulation. Indeed, the poet's stream of consciousness meanders. While each stanza clearly deals with a distinct theme - the description of a glow-worm cave in stanza two - the narrative line appears digressive with twists and turns.

The challenge is to render this sinuosity of thoughts in a clear manner. I propose to emphasise the music of language: the voice should serve as Ariadne's thread through the labyrinthine verse, which itself reflects how the mind works. Musicality is particularly guiding, as in the fourth stanza, with alliterations: "muscles / sails / scales", "flute / feet braced on boards" or internal rhymes "pahū / flute", "torso / elbow". This is the music of the mind as well as the cadence of kōrero. Remarks are delivered without a linear rationale, in slanted and free conversational style; impressions occur obliquely, following tides, currents, moods or winds. This is word of mouth aboard the waka, a flowing style binding generations together:

thought. This thought passed down lengths of men through earth - 
we came by waka, we leave by waka,

pass it on

However tenuous or long-winded the thread, readers should not lose it. As represented by the multiplying possibilities of the meiosis in the first stanza, the grandiose spectacle of tiny dangling glow-worms in the second, or molecules in the third and fourth, cohesion is paramount - everything is "a collection of tiny connections".

My skopos is to emphasise what could seem opaque but is based on musicality, and visualisation, guiding the thought / reading process. There might not yet be an arrival to destination in waka 56 but there is progression in the narrative, and the last stanza is an exhortation to continue, in which the writing mirrors the waka's navigation - "but only lines glide here on salt water, / come out in commanding the stroke - again, / stroke again, stroke, stroke, stroke again, again..."

56 Un waka à double coque

i

Qui commence comme eux en racontant des histoires depuis la céleste Moeraki où, garé, je contemplais un large pan de mer et de ciel, la terre un haut-fond sous un voile brillant croisant

le Paradis. Un Paradis occidental fidèle à sa propre logique, boules de roche garées, des points parcourant le texte. La tête remplie de paradis, j'ai conduit, conduit, volant en mains rebondissant.

L'image a rebondi en moi pendant des années tel un moulin à prières alimenté par une eau

venue du sol à travers moi - source remplie d'anguilles qui me mordillent les tripes. Le tuna

de Māui pour la méiose, affrontant sa descendance, sa propre méiose, le peuple.

Et l'histoire suivante qui commence une ligne pendouillant de vers luisants sur formations de calcaire, points de lumière à la pêche aux insectes ailés à l'espoir - pour lune, soleil, étoiles - des vers ne dévorant pas. Ils vivent dans le noir, fabriquent leur propre lumière. Ils possèdent la beauté, leurs admirateurs en meurent tels des amants. Je connais ces amants, ai senti la brise lever un voile depuis ce soleil couchant 
intériorisé. Cavernes harpons de calcaire. Bouches de vers.

Chaque bout qui gigote le long de l'existence.

Grandiose. S'étirer à travers des plaques pour du sel.

Dissimulés dans le goulet, ouverts au partage des sens,

chair, matière organique, tout contribue

à chaque lumière chimique et animale.

Les échelles de lumière varient, mesurent vitesse, lux, changements : les physiciens croient qu'on est poussière d'étoile.

Ça tient à la personne. Massives et modestes, étoiles recyclées dans le cosmos - nous sommes

des versions réassemblées d'étoiles depuis longtemps défuntes.

Maintenant la science imite l'art. Autrefois les artistes

étaient aussi des scientifiques. Aujourd'hui, vice versa.

De Vinci, par exemple, observait des bougies,

concevait des hélicoptères. Aujourd'hui, la BBC

a diffusé l'histoire d'un scientifique

qui exposait des photos de molécules :

une molécule de soie à côté d'une robe de soie,

de la chlorophylle à côté d'une plante. Tout est

une collection de toutes petites connexions.

Car la beauté a des composants merveilleux.

La molécule d'eau glissant sur

les molécules de waka, poussé par la brise

les molécules dans les muscles, sur les voiles - ses gammes

des notes au firmament, mélodieuse

oraison, chanson, rythme du pahū, flûte,

pieds calés sur les planches, balançant torse, coude,

pensée. Cette pensée passée à longueur d'hommes

à travers terre -

on est venus en waka, on repart en waka,

on fait passer. L'influence du vent

sur les vagues peut être immense, hauts murs écorchant

les vallées au cœur, étouffant les gorges. Les équipages

s'écorchaient, saignaient des prières, pour que le sacré

demeure - une caravane sur fond marin sec.

ii

Les contenus des waka huia, coffres à trésors, sont hautement estimés. Waka huia à la télé,

une émission en langue māori, vient de diffuser

son $400^{\mathrm{e}}$ épisode - préservant

éloquence, mouvement, airs, grâces, noblesse

de nos chefs, grands hommes et femmes,

en vidéo pour toujours. En māori.

Seuls 14 épisodes sous-titrés.

Pour comprendre sa culture, il faut parler

le langage de sa poésie, la philosophie

de son monde, atteindre les ambiguïtés 
non-traduites. Car le langage livre

le sens. Le sens est l'étoile au-dessus de notre espèce. En particulier, notre waka

suit cela. Le sens est la nourriture des chefs.

De succulents cœurs fumant aux fours brûlants

de la terre. La terre fortifiée un millier d'années de notre sang. On a grandi ici. On doit

reprendre les dons de bouche, l'exemple. Les visages doivent boire aux visages, laper, onduler, s'éclabousser. Faire un moko dans les rides, guerriers pour nous-mêmes, pour notre peuple, bondissant des fosses à la lumière éclatante du jour défiant la culture de la mort

de notre culture. Faire jaillir son récit dans le whakairo. Dans bien des endroits

on partage ancêtres, blagues, communautés d'esprit grandies au cours de l'implantation -

et c'est ainsi que ce waka a franchi son millième vers, Māori et Pākehā, étoiles, connaissance d'endroits seulement mentionnés -

mais seules des lignes glissent ici sur l'eau salée, ressortent en ordonnant les ramées - encore, encore ramer, ramer, ramer, encore ramer, encore...

\section{Translation commentary}

I use a range of well-known strategies to reproduce the poem's striking form - transposition, modulation, ellipsis, shift from plural to singular, or synonymy. With regard to the complex imagery, I use less conventional strategies, focusing mainly on musicality to try and enhance visualisation rather than clarifying the meaning. Some cultural layers also need thorough research from the translator but may still confound target readers.

Where form is concerned, reproducing the indent is not a major difficulty except that it often lengthens the lines. I keep the regular "swaying" visual, and the lines as short as possible, either by stripping sentences to a bare minimum or by rearranging them. Some reformulations are fortuitously short as "volant en mains" for "wheel in my hands" or the welcome monosyllabic 
"fond" and "sec" in "une caravane sur fond marin sec" (end of part i). In poem xxv for instance, where brevity in the final lines is key to emphasising alliterations, I use transposition:

$\begin{array}{ll}\text { dark green lipstick } & \text { rouge à lèvres vert foncé } \\ \text { sips from silver } & \text { gorgées de café } \\ \text { coffee cups } & \text { tasses argentées }\end{array}$

For the sake of clarity, it would be tempting to unpack the following complex image:

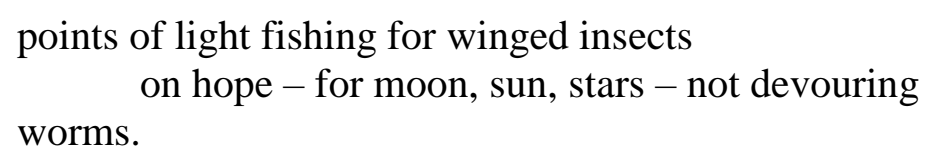

In this case of intricate phanopoeia, where there is an accumulation of embedded images - the "not devouring worms" might refer metonymically to death - there is a risk of misreading the text by unraveling the meaning. Unpacking the meaning implied in the preposition "on" could enhance visualisation:
points de lumière à la pêche aux insectes ailés appâtant à l'espoir - pour lune, soleil, étoiles - des vers ne dévorant $\operatorname{pas}^{25}$.

However, this would restrict the potential interpretations, and I maintain the opacity that welcomes suggestiveness: "points de lumière pêchant des insectes ailés / à l'espoir - pour lune, soleil, étoiles - des vers / ne dévorant pas." Another example is "They possess beauty their fans / die like lovers for", which I could render as: "Ils possèdent une beauté pour laquelle / leurs admirateurs meurent tels des amants". Rather, I keep closer to the source with "Ils possèdent la beauté, / leurs admirateurs en meurent tels des amants".

In poetry perhaps more than in any other genre, eye and ear work together. Inspired by the melody of the verse, I propose the following: "poussé par la brise", a calque of the sound of

\footnotetext{
${ }^{25}$ The polysemy of "line" - both lines in the poem and glowworm lines - is compensated for by the polysemy of "vers".
} 
"powered by breeze"; the rhyming assonances of "remplie / d'anguilles qui me mordillent les tripes"; or again the now rhotic now occlusive alliterations emphasising the hardship of waka journeys in "high walls scraping / valleys in the heart, constricting throats. Crews / scraped themselves, bled prayers, so holiness / remained" rendered as:

hauts murs écorchant les vallées au cœur, étouffant les gorges. Les équipages s'écorchaient, saignaient des prières, pour que le sacré demeure

Some complex images rely on cultural elements. These need to be researched thoroughly to be transferred, however, depending on the audience's background knowledge. For instance, the lines "fumant aux fours brûlants / de la terre" might refer to hāngī, or "Faire un moko dans les rides" to the art of tā moko. The lines "Māui's / tuna for the meiosis" are confusing at first glance since this "tuna" is not English "tuna" but Māori "tuna" - eel. This is a reference to the legend of Māui fighting Tuna, a giant eel, which Māui cut in half, as explained by Orbell:

When Tuna (or Tiki Tuna) was chopped up by Māui, the pieces turned into other life forms. Tuna's head went to the rivers and became freshwater eels, his tail reached the ocean and became the conger eel, the long, hair-like nostrils on the tip of his upper jaw turned into vines and certain other plants, and his blood coloured the rimu, the tōtara and other trees that now have reddish wood. ${ }^{26}$

This layer adds relevance to the image of the meiosis: "Le tuna / de Māui pour la méiose, affrontant sa / descendance, sa propre méiose, le peuple." However, only an audience that would either already have this knowledge or would research the information might appreciate this in the translation.

Some images combining Māori terms with English turns are problematic. The originality of the injunction "Spray out its narrative / with whakairo" lies in the association of "spray out" which might refer to the curl of a flower spray - with the art of whakairo. I propose "faire

\footnotetext{
${ }^{26}$ Orbell, (1995), p. 228.
} 
jaillir", suggesting the idea of a liquid ("une source jaillit"), or a wave, and this offers a contrasted but no less potent image: "Faire jaillir son récit / dans le whakairo."

A term such as "settlement" has significance in Māori culture. This is not quite "une colonie", with its connotation in colonial history for instance, or "un campement", which sounds military and temporary. In some poems, "settlement" may refer to "kāinga", a small village often fortified into a pā. In poems viii and xv, I therefore use "kāinga" for "settlement". The line "we had settlements at Matauwhi and Kororāreka" becomes "nous avions des kāinga à Matauwhi et Kororāreka". In poem xix, "settlement" may refer to an agreement as well as to the resolution of a dispute, as in the 1995 Treaty Settlement Process, and here I offer:

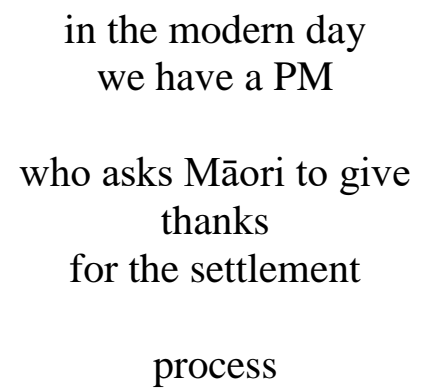

$$
\begin{aligned}
& \text { à l'heure actuelle } \\
& \text { on a un PM }
\end{aligned}
$$

qui demande aux Māori des remerciements pour le processus de compensation

In waka 56, the lines "communities / of spirit grown up over settlement" deal with Māori settlement over time, which has enabled "communities of spirit" to grow, before Pākehā. Using the French word "colonisation" would tend to suggest Western colonisation. I therefore opt for:

\author{
Dans beaucoup d'endroits \\ on partage ancêtres, blagues, communautés \\ d'esprit grandies au cours de l'implantation -
}

In waka 56, a great number of issues are raised, and although I try to treat them separately, they are nonetheless all entwined. The unconventional succession of images in musical, at times speech-like or impressionistic style has been my main focus, as well as the cultural layers underlying some of these striking images. 
The first challenge here is to match the poet's talent for depiction and dramatisation in waka 75 and his humorous language play in waka 76.

In waka 75, violence is emphasised by hyperboles ("crazy", "so violent", "more blood", "before you know it"), contrast ("blood" / "night"), echoing action verbs ("slam", "slap"), and repetitions (“death death fear of death"). The elements - sea, land, volcano - mix with all sorts of surreal characters - extinct creatures or a hot clown - to suggest a nightmarish vision of eruption and apocalypse. Surrealistic "pork boulders juggled at the mouth" resist comprehension. Elements are anthropomorphic as the storm is also a fight between humans and nature: "the wave slaps his face".

There are cultural allusions adding to the images. The Tarawera waka comes from the story of a phantom waka that glided over the waters of Lake Tarawera, ghostly and eerie, as an omen of the imminent volcanic eruption of 31 May $1886 .{ }^{28}$ Rangitoto, which means bloody sky in Te Reo, is a volcanic island in the Hauraki Gulf near Auckland. While there are some blurry outlines to this vivid surrealistic and impressionistic piece, it is clearly anchored in a New Zealand setting. Moa, pōhutukawa or tohunga are reminders of the reality of the scene. Irish terms fillidh and coracle are also markers of the origins of the poet.

In waka 76, conflict is depicted with a more playful tone and peaceful resolution: "He pays for the drink". While playing with stereotypical codes and popular references ${ }^{29}$ - the confrontation scene of Westerns for instance ${ }^{30}$ - the poet also plays with words: "The fur seals fly" subverts the expression "the fur flies". He re-echoes in different contexts some key terms from waka 75: slam ("his pint on the bar"), and slap ("each other on the backs"). The bar serves as a

\footnotetext{
${ }^{27}$ See Appendix pp. 168-169.

${ }^{28}$ teara.govt.nz/en/1966/tarawera-phantom-canoe. Accessed 25 Sep. 2018.

${ }^{29}$ Sullivan explains that the scene is "similar to Once Were Warriors but kind of harmless" (Sullivan, 2005).

${ }^{30}$ Since the title recalls Star Wars, one may also think of the Mos Eisley Cantina bar scene from the first movie.
} 
metaphor for the sea: "a frothy wave the length of the bay". The dialogue in vibrant oral transcription - "gonna", “ain’t ya" or "gissa", reminiscent of Tuwhare - also makes it playful.

How might the allusiveness of this language be preserved?

\author{
Waka 75 Un orage \\ un orage si violent \\ waka et coracles s'entrechoquent \\ tohunga et fillidh échangent des notes \\ chantent les airs des uns des autres \\ et sans crier gare les lignées de sang \\ courent en tous sens à des angles fous
}

Rangitoto fait surface laisse échapper un souffle

le sang ruisselle des pōhutukawa

tout d'un coup

le haka scandé emplit l'océan

les poissons remontent lèvent simultanément la bouche

les nuages forment des silhouettes de créatures anciennes

dinosaures moa aigles géants

la mer durcit et la terre se dissout en eau

la nuit arrive avec encore plus de sang

mais grogne ne chante pas

les cochons couinent au bord du cratère

rochers porcs jonglés sur la bouche

d'un clown chaud

le waka Tarawera passe en glissant

mort mort peur de la mort

waka mystère

encore la vague claque son visage

essaie de faire mieux

le claque encore

décris-moi tel que je suis

\title{
Waka 76
}

Tangaroa repose sa pinte sur le bar d'un coup sec,

"File'z en une aut" siffle-t-il - le barman sursaute, glisse une vague mousseuse le long de la baie la foule d'otaries reprend sa conversation, en se tapant dans le dos.

Un type avec une attitude waka entre dans le bar, 
se penche en regardant Tangaroa -

“j'vais prendre la même chose que le gars mouillé là

puisque c'est lui qui rince."

Les otaries filent dans tous les sens.

Tangaroa le toise de haut en bas, inspecte son moko et son waka.

"T'es un des gamins de Tāne, toi, hein.

Alors t'es de la famille !"

Il paye le verre.

\section{Translation commentary}

In waka 75 , I aim to depict an apocalyptic landscape in a grave and dramatic manner where humans should feel dwarfed by nature. I focus on the emphasised rhythmicality of lines with sets of alliterations - "durcit / dissout", "en tous sens à des angles fous" - semantic allusions "sans crier gare" for "before you know it" - and "disruptive" sounds - "s'entrechoquent", "rochers porcs" and "scandé" rather than "chanté" for "chanted". The spectacular dimension of orchestrated chaos is reinforced by the multitude of participants, and this is a collective trance: "les poissons", "les nuages", "les cochons" in the style of an anaphoric chorus. I also keep the surreal image of a hot clown depicting the volcano: "sur la bouche / d'un clown chaud".

The idiomatic "try harder" is problematic, its concision and the confrontational attitude suggested in English, are somewhat diminished with the more encouraging "essaie de faire mieux". I compensate for this by offering an accumulation of occlusive sounds depicting the violence of waves:

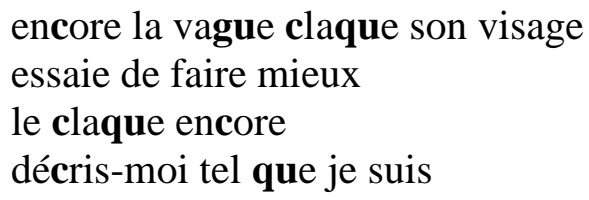

In waka 76, the main challenge is the wink to Tuwhare and the atmosphere of Once Were Warriors. I favour something close to street-language, with relaxed turns, in the dialogue: “T' es 
un des gamins de Tāne, toi, hein." In the target culture, it is likely that the clichéd bar scene will evoke the song "Laisse béton" by Renaud, which has a similar storyline based on confrontation, similar wordplay and derision, similar realistic treatment. Replacing the allusion to Tuwhare's language with a citation from Renaud by adding "Laisse béton" would be forceful. The reference to Renaud is evident enough - mainly in the line "un type est entré dans le bar" - to render some of the source text's allusiveness. The repetition of "filer", echoing Renaud's chorus, or the choice of "un type" for "a guy" are further hints. Nevertheless, this intertextual shift is, to some degree, inappropriate because while the function of the allusion is kept, its nature cannot be deemed equivalent - Renaud is not Tuwhare.

In the next repartee, I compensate for the wordplay on "fur flies" by adding a pun: "c'est lui qui rince". This is slang for "payer", and also reinforces the wet / dry opposition already in expression "d'un coup sec" in the first line.

The variations in language and genre call for different strategies. In waka 75 , the focus is on representation through sounds and rhythm; in waka 76, I try to convey popular allusions and language - both aim at conveying fun.

7. Waka 87,88 and $89^{31}$

My focus on dialogue continues here. The protagonists are an English settler in waka 87 anonymous and yet representative of Pākehā - Odysseus in waka 88 - a Pākehā symbol that serves as a literary archetype as much as a psychoanalytic point of reference - and Māui in waka 89 - a mythical hero and a contradictor for Odysseus.

There is a great disparity between these characters' styles. Not only the content and perspectives of their address differ but also the form of their speech. In these brief portraits, the poet synthesises contrasting linguistic articulations. Each interlocutor symbolises a cultural

\footnotetext{
${ }^{31}$ See Appendix pp. 181-183.
} 
reality. As Odysseus concludes in waka 88: "I sail as a member of the crew, / and can speak for them." This function is not strictly performative, either phatic, appellative, referential, or expressive as defined by Nord after Jakobson, it is symbolic. The challenge is to match this with corresponding symbolic speech in the target culture.

The settler uses coded language, precise and formal - the town is not smaller but "squatter", clock towers are "melodious", the "stations" or "aristocrats" are conventions from the Old World, where "landscape is landscaped" and order paramount. The stereotype that the settler embodies is such that he has become part of a myth in New Zealand, that of England as home, and the expression he uses, "fresh off the boat", is a cliché describing a reality that is far less sophisticated. The expression "fresh off the boat" is slightly derogatory, and suggests naivety or inadaptation. It has often been used to describe recently-arrived Pacific Islanders. Furthermore, the settlers are later described as "taking" food from the "savages".

In waka 88 , Odysseus's voice is heard in medias res, interrupting the settler - "Do not mind the settler" - speaking over the preceding orator, and of Odysseus's own accord - "I have put myself here". He does so in the name of all the crew members as their leader - "The navigators sail with me now". Odysseus not only speaks over the settler but also contradicts the poet / narrator in waka 62 "A narrator's note": "There is no Odysseus to lead this fleet". This bold act is supported by Carl Jung himself: "Dr Jung put me there early in the century”. The Jungian theory of archetypal characters and the collective unconscious makes Star Waka "a very Western text" for Odysseus.

The conversation between crew members turns into a fight for leadership, and Odysseus' ego is omnipresent, as shown by repetitions of the first person: "I observe", "I am Odysseus", "I run through all narratives", prompted by rhetorical questions: "who is holding the sails, commanding the paddles?" The dialogue launches an oral joust provoking and fueling Māui’s response. Through the character's provocatively self-assured tone, the poet symbolically 
denounces an epistemological violence perpetuated by the West, as summed up in the sophist touch of these lines:

I have put myself here

because this is a text. A very Western text.

Māui's response is direct and trenchant, and in an emphatically casual tone. This is street language from the 1990s: "Yo", "dig?" Odysseus' oratorical questions are replaced by Māui's tendency to imagine the answers and the questions: "What do you mean there'd be another star, or birds?" If we compare this with the rhetoric of the settler, whose formality may create distance, here, familiarity is created. Māui speaks to readers using numerous question tags: "don't you", and apostrophe: "You know" or emphasis: "I tell you".

For the demi-god, it is taken for granted that everyone should know his heroic deeds. Immediate complicity is created by his larger than life psychology and sincerity, and readers may also feel amused by his lack of humility. His motives are clear: "I want credit", his feelings expressed boldly "ANGER ANGER", and his attack clearly targeted at anthropologists, in response to Odysseus. As a result, his character is relatable. In contrast with the preceding poems, the character's urban voice, the too-much touch, and the cartoon-like quality achieve complicity with readers, serving the poet's post-colonial agenda.

\section{Waka 87}

Je suis le colon anonyme

fraîchement débarqué du bateau de Bristol, venu d'un pays développé où le paysage est paysagé, où siègent églises et palais, tours d'horloges mélodieuses, aristocrates et Ascot, un pays où tout

a une place y compris le peuple.

Ici, nous avons des tentes et prenons la nourriture aux sauvages. La ville est plus basse que Sydney. Les Anglais ne savent plus leur rang. 
Ma famille va passer le prochain siècle à construire ce pays en une nouvelle Angleterre et à construire la mythologie de l'Angleterre comme patrie.

\section{Waka 88}

Ne vous occupez pas du colon. J'observe les règles de cette mythologie (vous avez vu qu'il n'a pas

placé d'étoile, d'océan ni de waka dans ses oripeaux). Je suis Ulysse,

invoqué dans ces pages par les prétentions extraordinaires du narrateur. Je suis présent dans tout récit.

Le Dr Jung m'a mis là au début du siècle.

Regardez de près la narration. Qui

tient les voiles bien serrées, qui commande les rames, s'assure que les sculptures suivent bien les motifs

des waka qui suivent les motifs de la mer?

Moi. Ulysse. Je me suis mis ici

parce que c'est un texte. Un texte très occidental.

Les navigateurs font voile avec moi désormais.

Je navigue en tant que membre de l'équipage, et peux parler en leur nom.

Waka 89

Yo c'est Māui. Cette facette, c'est le Māui du coup de pêche.

Le gros poisson est à moi. C'est moi qui ai le droit de préemption

et j'exprime ma colère, COLÈRE COLÈRE

qu'on me refuse une portion significative du texte

du Star Waka. Les droits d'auteur me reviennent.

Sans moi le waka serait un vaka par exemple.

Ils n'auraient pas de fondation, de matrice à laquelle attacher leur culture. Vous savez que c'est moi qui ai pêché la terre, non ?

Vous savez que je l'ai placée sous le chemin de Kopua, pas loin de Matariki, non ?

Comment pourrait-on la trouver autrement ? 
Comment ça, il y aurait eu une autre étoile

ou d'autres oiseaux ? Je vous dis que je l'ai mise là car ces étoiles

sont les meilleures dans le ciel. J'en veux tout le mérite.

Et puis plus d'anthropologues.

J'appartiens à la cosmologie. Pigé, Ulysse ?

Translation commentary

In waka 87, the saying "fresh off the boat" does not have an equivalent in French, perhaps for historical reasons. Using the same familiar register, "débarquer" also has derogatory connotations targeting the ignorance of a newcomer. I combine it with "fraîchement" recalling "fresh off” and offer: "fraîchement débarqué du bateau de Bristol."

I also deal with the problem of translating "home" in the last line: "the mythology of England as home". This is frequently encountered in the book, for instance in waka 49: "but write more / about home", I offer "mais écris plus / sur ton pays", in waka 66: "points home", and I offer: "pointe vers la maison", in waka 67 (about birds): "they return home", I offer: "ils rentrent au nid” or waka 100: "home thoughts", here I offer: "des pensées pour leur foyer". The problem is the large semantic reality covered by "home", and its very common use. I vary between "le foyer", "à la maison”, “chez soi” or "à l'origine” according to the context. A further possibility is the casual "le bercail" - as in "rentrer au bercail" - which encompasses most of the meanings implied by "home" with a similar simple noun form.

However, the "mythology of England as home" suggests a specific reality and historical meaning. This was home as the point of origin, the homeland, even for New Zealanders who had never set foot overseas, or second or third generation New Zealanders who sometimes held a British passport. I propose "la patrie" in "la mythologie de l'Angleterre comme patrie", with its military connotations and sentiment. "La patrie" is etymologically "fatherland", which 
recalls the motherland also hinted at here. This keeps the formal register together with "où siègent églises", and "tours d'horloges mélodieuses".

In waka 88 and waka 89 , while Māui uses repetitions of oral turns with stressed pronouns: "C'est moi qui ai" for "I have first rights" for instance, Odysseus uses elegant turns: "invoqué" for "summoned", "s'assurent" for "seeing", "désormais" for "now", or "pageantry" becomes "oripeaux". Regarding "Yo" and "dig", I offer "yo" in French and "pigé".

Both Odysseus and Māui use "vous". My interpretation is that Māui speaks to a group of people. His interlocutors can only be a crowd according to his psychology (suiting his ego). I also choose "vous" systematically for all addresses to readers - either from the narrator as in waka 30: “j’ai réussi à atteindre des sentiments / jamais ressentis auparavant - / et vous ?” or from characters, for instance in waka 84: "Je suis le waka du souvenir, / sans nom, le modèle -/ placez-moi : / à Hawaiiki". In dialogues between characters however, I choose "tu”, as seen in waka 76, or in waka 95 for instance where Tangaroa speaks to Star Waka: "Star Waka, ne te fais pas berner par Tāne."

While source readers may perceive some criticism of Eurocentric modes of representation, this is diminished in the translation because I cannot rely on the target readers' prior knowledge of cultural elements that are embedded in the source culture. On a surface level, the translations are then more likely to be taken as a presentation of the various voices shaping the New Zealand psyche, rather than an exact reproduction of the poet's playful representation of these voices the performing and polyphonic aspect. Nevertheless it is my intention that conflicting cultural fields and symbolic representations can be guessed by target readers well attuned to the tonal nuances.

8. Waka $100^{32}$

\footnotetext{
${ }^{32}$ See Appendix pp. 196-198.
} 
The last waka of the book is a culmination point, as analysed by Jon Battista who speaks of "fiery conflation." 33 There is eloquence and lyricism, and a circular ending sending readers back to the start, while conjuring waka to pursue their voyage "past the end of the light".

Waka 100 also has a historical focus at its core. Emphasising pre-contact and post-contact eras, and alluding to the Māori Renaissance after "the age of Dominion", this historical approach is challenging to transfer. It introduces historical facts that are symbolic in Aotearoa / New Zealand but unknown in the target culture.

The dates referred to - described as lines - are well-known in New Zealand history:

Stroke past line 1642

into European time.

Stroke past 1769

and the introduction of the West

A New Zealand audience will know that 1642 refers to the first sighting of Aotearoa by a European - Dutch navigator Abel Tasman. The date symbolises the first contact between Māori and Pākehā, but it also symbolises the introduction of a Western perception of time, a date after which waka were consigned "to memory". The second key date of 1769 , the arrival of Cook, is also well-known in New Zealand. It is less well-known elsewhere, yet for the poet, it signs "the introduction of the West", announcing colonisation.

For the third date mentioned the poet gives in-text explanation: "Stroke on the approach to 1835 / and formal Northern Māori sovereignty.” This indication will surely help target readers learn about Aotearoa New Zealand history.

This precise historical approach is suddenly upset, from the line "Stroke into the New World and stop". Chaos is encapsulated in the following accumulation: "centuries years minutes hours seconds". Western time measurement suddenly becomes the norm - "hands centred / on Greenwich". Māori references and attributes are "removed", "taken away", holding their

\footnotetext{
${ }^{33}$ Battista, (2007), p. 60.
} 
"breath" or "thoughts". The poet no longer conveys precision but confusion, suggesting an ahistorical perception of time due to differing perspectives suddenly forced to overlap.

The next part, beginning with the vague "And years later", as in tales, refers to the Māori Renaissance and more largely to the revitalisation of Māori culture. This is an awakening of forebears - "we ask our ancestors to wake"- through physical and symbolic actions, for instance whakairo - "carving", "restoring", "coming out of wood", "adzed waka out" - or the launch / carrying of waka - "shoulders that carried so many waka". Physicality is reinforced by anatomical descriptions "eyes", "mouth", "genitals". This awakening is also spiritual: "summoning souls of myriads / of names".

Māori terms are highly symbolic: the use of "mokopuna" (grandchildren) marks that the awakening / regeneration is done through family. Descriptions in English of Māori traditions suggest that this process comes from within. This is typical of Māori symbolism, as in the image of the koru, its inward coil suggesting a return to the origin. The challenge is to preserve allegorical interpretations within a Māori symbolic framework but in another language, and another symbolic framework.

The final elevation is launched from this passage through a fundamental return to the origin, connecting Papatūānuku / earth and Ranginui / sky: "feet planted / on shoulders winding into stars". Elevation is then suggested by hyperbole: "greatest deepest", "terror and pleasure", "exhausted", by repetitions of "rise" and by the apostrophe "And you" - "And you waka", “And you, Urizen”, “And you stars".

The elevated conclusion is a priori not problematic to render, however, some terms may be more difficult. Some of these participate in setting the rhythm - the monosyllabic "rise" is less resonant in the imperative form with a French reflexive form: "élevez-vous", and the echoing "burn brilliantly", recalling Blake, is less fluid as "brûlez brillamment". This is also found in the structure "past the end of the light" echoing Dylan Thomas, already at the beginning: 
"Stroke past line 1642". This sense of "past" is difficult to translate with precision. The gerundive turn "en passant" or even "en dépassant" would be quite long and "heavy" in: “Ramez en dépassant la ligne 1642".

I aim to convey the eloquent and even cosmological touch at the end, summoning celestial bodies in chorus but there is a risk that this may sound clumsy unless fluidity and natural rhythm are preserved.

Waka 100

Ramez après la ligne 1642

à l'heure européenne.

Ramez après 1769

et l'introduction de l'Ouest

Ramez à l'approche de 1835

proclamation de la Souveraineté des Māori du Nord.

Ramez jusqu'au Nouveau Monde puis stop.

Equipages descendez, consignez les waka

au souvenir, arbres généalogiques, enlevez

le tauihu des proues, drapez

le mana en plumes

autour du whare-ventre

du prochain équipage

qui doit se souvenir des waka

au début

des siècles années minutes heures secondes

petite et grande aiguilles centrées

sur Greenwich

chaque personne

dans la mémoire des waka

de retenir ses pensées,

chaque personne de descendance

marine née de l'eau

dont les durs waka

sont confisqués.

Et des années plus tard,

nous demandons que s'éveillent nos ancêtres

dont les mokopuna sculptent des yeux,

restaurent les traits ciselés, bouches

qui sortent du bois, organes génitaux, 
pieds plantés

sur des épaules s'enroulant en étoiles

aux plafonds, nos ancêtres d'une culture

qui a retenu son souffle

durant toute l'ère du Dominion.

Nous avons taillé les waka pour eux les souvenirs, le savoir complexe, chefs de flotte, nos raisons d'être épaules qui ont porté tant de waka invoquant les âmes de myriades de noms au-dessus de centaines de noms de waka.

Et vous waka, qui avez vu le paradis, les tripes de l'océan, apporté terreur et plaisir, vous qui avez épuisé vos équipages de pensées pour leur foyer vous qui avez soulevé des chants au-dessus des vagues du plus grand du plus profond des océans,

montez - montez en l'air - montez au souffle montez au-dessus des vallées à la lumière et la reconnaissance montez là où tous ceux qui sont montés chantent vos noms.

Et vous, Urizen, Jupiter, Io Matua Kore, gardien des boussoles boussole du vent, boussole solaire, boussole englobant les courants connus, ayant soufflé le premier souffle de toute créature vivante, guidez les waka entre les îles, entre les années et les yeux du Pacifique hors des mythologies jusqu'à la conscience.

Et vous étoiles, les ancêtres, orbes nucléaires, géantes rouges, naines blanches, brûlez et brillez, brûlez encore les waka ici-bas, brûlez encore waka naviguant dans les vallées, brûlez encore waka aux sommets des montagnes, brûlez encore waka dans la nuit, brûlez encore waka après la fin de la lumière.

Translation commentary

I maintain my strategy of retaining Te Reo - “enlevez / le tauihu des proues”, “drapez / le mana en plumes / autour du whare-ventre", "les mokopuna sculptent des yeux". Having read the 
whole sequence, readers should by now be accustomed to this. I maintain my hypertextual strategy regarding non-glossed New Zealand references. I leave all dates as they are, without any notes, as there is in-text explanation for 1835 - "proclamation de la Souveraineté des Māori du Nord" - and rely on readers to look up information.

I keep a close approach regarding non-conventional syntax to suggest a jolt in time, the alienation and disempowerment created by colonisation:

du prochain équipage

qui doit se souvenir des waka

au début

des siècles années minutes heures secondes

petite et grande aiguilles centrées

sur Greenwich

Some original language-play based on compound nouns requires creative transposition:

$\begin{array}{ll}\text { each person of seagoing } & \text { chaque personne de descendance } \\ \text { and waterborn descent } & \text { marine née de l'eau } \\ \text { whose hard waka } & \text { dont les durs waka } \\ \text { are taken away. } & \text { sont confisqués. }\end{array}$

I favour "jusqu'au Nouveau Monde puis stop" to keep the rhythm of "into the New World and stop", rather than the more common: "jusqu'au Nouveau Monde et arrêtez-vous". The pronominal verb using three syllables suggests less immediacy. For the same reason, I opt for the one-word verb form "montez" over the pronominal "s'élever" to render the repetition of "rise". I replicate the anaphora in the first and last lines - "Stroke past line 1642" and "past the end of the light" - using "après" for "past". "Ramez après la ligne 1642", and "après la fin de la lumière". My intent is to suggest an elevation in sentiment through repetition but also an elevation in music, rhythm and lexicon.

I choose to modulate "burn brilliantly" into "brûlez et brillez" to avoid clumsiness, and I keep the repetition of "burn on", by offering "brûlez encore". This is an exhortation for stars to continue enlightening waka, but also for waka to keep shining / burning. I understand the line "burn on the waka down there" as "brûlez encore les waka ici-bas" rather than "brûlez sur les 
waka ici-bas". Overall, regarding the final lyricism, I keep a close approach and let the natural rhythm and flow of lines do the work. 


\section{Translating Robert Sullivan's Star Waka and the underlying symbolism}

Like many New Zealand poets - for instance Apirana Taylor, Keri Hulme, Hone Tuwhare or Alistair Te Ariki Campbell - Sullivan anchors images and symbols to a Māori frame of reference, as well as a Pākehā frame of reference. As seen in our analysis, the two do not overlap comprehensively. Among various recurring difficulties (diglossia, ${ }^{34}$ melopoeia and wordplay, ${ }^{35}$ tonal shifts, ${ }^{36}$ formal constraints,${ }^{37}$ narrativity, ${ }^{38}$ orality and dialogue, ${ }^{39}$ and some rather opaque passages ${ }^{40}$ ), the underlying Māori symbolism in Star Waka, not completely matching a Pākehā (European) symbolic frame, is what challenges translation into French, if one considers translation should aim for strict equivalence.

Symbols belonging to a Māori cosmogony have no equivalent symbols in the target language. For instance, the central symbol is obviously the waka itself. "Véhicule", "vaisseau", "medium" fail to render the linguistic fluidity of the term. What is more, the linguistic capacity of this term is, by mise en abyme, symbolic, as it conveys Sullivan's poetics of transport. Each term used suggests a set of symbols that is unique to the language as well as to the culture, and to go back to Pound's three kinds of poetry, this is arguably the level of logopoeia. Referring to the seabed for instance (in "He Karakia Tīmatanga") does not literally convey the same symbolism as "le fond de la mer": the idiom is not "le lit de la mer" in French. Similarly, in Te Reo, mana covers a wider set of meanings and different symbols than "pouvoir" in French. ${ }^{41}$

\footnotetext{
${ }^{34}$ See "He Karakia Tīmatanga".

${ }^{35}$ Poem xi.

${ }^{36}$ Waka 16 and poem xviii.

${ }^{37}$ Waka 56.

${ }^{38}$ Waka $75-76$.

${ }^{39}$ Waka 87-88-89.

${ }^{40}$ For the latter, a close and literal approach has been my main strategy, inspired by Glissant: "l'opacité ouverte des existences non-réductibles", (Glissant, 1997, p. 29).

${ }^{41}$ See French definition of "mana": cnrtl.fr/definition/mana. Accessed 14 Jan. 2019.
} 
Logopoeia is however not the most problematic element. Nor are any of the other kinds of poetry defined by Pound. What is regularly problematic is the bicultural background of Sullivan's symbols. Again, we can say with the poet that:

Pour comprendre sa culture, il faut parler le langage de sa poésie, la philosophie de son monde, atteindre les ambiguïtés non-traduites.

In his PhD thesis, "Mana Moana: Wayfinding and Five Indigenous Poets", Robert Sullivan coins the term "ritenga tangata" (the customary habits of people) on the basis of Pierre Bourdieu's concept of habitus ${ }^{42}$ referring to "the broader associative range of symbols and relations that the poet's oeuvre assembles in order to paint broad targets to steer towards, or cultural reefs toward which to orientate. ${ }^{" 43}$ The concept of ritenga tangata enables Sullivan to propose a reading method based on oceanic wayfinding. This associative range of symbols is problematic because it originates from, and, often implicitly refers to, principles that have no equivalent in the target culture.

Let us consider the following principles, expounded by Sullivan:

The generative and organising principles of ritenga tangata influence dispositions of sexuality, gender, mimesis, space, symbolism, and virility. [...] These principles are outlined by Manuka Henare and Les Williams in the following:

Te ao mārama Wholeness, cosmos

Mauri Life essences, vitalism, reverence for life

Tapu Being and potentiality, the sacred

Mana Power, authority and common good

Hau Spiritual power of obligatory reciprocity in relationships with nature

Wairuatanga The spirit and spirituality

\footnotetext{
42 Bourdieu originally defines the concept as "loi immanente, déposée en chaque agent par la prime éducation, qui est la condition non seulement de la concertation des pratiques mais aussi des pratiques de concertation" (Bourdieu, 2000, p. 272).

${ }^{43}$ Sullivan, (2015), p. 26.
} 
Tikanga The right way, of the quest for justice

Manaakitanga Care and support, reverence for humanity

Whānaungatanga Belonging, reverence for the human person

Hohou rongo Peace, reconciliation, restoration

Kotahitanga Solidarity

Kaitiakitanga Guardianship of creation

Te ao hurihuri Change and tradition

The oceanic wayfinding reading method belongs to these principles of indigenous behaviours and relations as there is a connection through whakapapa. ${ }^{44}$

These principles frequently surface in Star Waka. The principles of tapu and noa underlie poem xviii, and this has prompted me to emphasise the binary oppositions structuring the poem. In "He Karakia Tìmatanga", the poem is not meant to be understood as a prayer in the Western sense of the word, and this justifies my borrowing technique. Here, Wairuatanga / Spirituality is certainly invoked, and this is why I aim for an arcane and incantatory tone. In waka 16, the poem is reminiscent of a waiata tangi, and tone is paramount to suggest this specific kind of lament. There is a call for both Tikanga / Justice and Hau / Spiritual power of obligatory reciprocity in relationships with nature:

et notre peuple fait ça

à la terre pour le peuple par le peuple et cette terre se joint au congrès des cicatrices sur la planète une culture de pourrissement urbain

Waka 50 obviously deals with Tikanga - "Justice the person who sits at the bench" - and my strategy has involved emphasising tonal variations and multidimensional references in an anaphoric manifesto style conveying a range of emotions from anger to final detachment.

\footnotetext{
${ }^{44}$ Ibid, p. 27.
} 
Phrasing has also been key for waka 56. In particular, the second part of this long waka evokes Te ao hurihuri, change and tradition, ${ }^{45}$ by describing the preservation "on video forever" of Māori leaders' "eloquence, movement, airs, graces, noblesse". This may equally evoke the concept of mana, and in this line, the transfer is made easier because the poet uses French. In most cases however, transfer is not so easy and a merely linguistically correct translation would compromise the underlying symbolism.

My strategies range from borrowing, synonymy, in-text explicitation, implicitation with or without a note, and creative innovation. For instance, there is an evident cultural element in the following image from poem xxvi "men hongi'ing the nose / of the waka", which has inspired me to use a creative solution based on explicitation and the expression "nez à nez": "hongi d'hommes nez à nez / avec le waka".

Another recurring concept is guardianship, as found in waka 50 - "revoking our guardianship of all / the eye can see" - or in waka 44 - "don't we indicate the depth / of our guardianship by travelling / to Japan" - or again in poem xviii - "it is a violation of the lifeblood / of its guardian". Without prior knowledge of the principle of Kaitiakitanga, ${ }^{46}$ the linguistic equivalent (i.e. given by the Robert and Collins dictionary) of guardianship would be "tutelle". Yet, in French "tutelle" generally refers to a person, in regard to child custody or disability care. ${ }^{47}$ What is more, "tutelle" (or even "protection") implies an idea of vertical hierarchy (the etymological base for "tutelle" is tueor, to watch, keep eyes on) and this does not quite match

\footnotetext{
45 This principle is particularly present and entwined with Whānaungatanga in Star Waka - for instance in poems iv, 46, or 54 - as the poet explains: "The convergence of multiple technologies and systems, as well as personal experience on the part of expert navigators, reveals a plurality of approaches in different skins and vehicles across time. My own collection, Star Waka (1999), draws energy from this convergence" (Sullivan, 2015, p. 323).

46 This is defined more precisely by Te Ara as "guardianship, protection, preservation or sheltering. It is a way of managing the environment, based on the traditional Māori world view" teara.govt.nz/en/kaitiakitangaguardianship-and-conservation. Accessed 6 Nov. 2018.

47 The three definitions found in Larousse are: "Régime de protection de la personne et des biens des mineurs et des incapables majeurs, qu'il importe de représenter dans les actes de la vie civile. Protection exercée à l'égard de quelqu'un : Se placer sous la tutelle des lois. État d'étroite dépendance par rapport à quelqu'un : Secouer la tutelle de ses parents" larousse.fr/dictionnaires/francais/tutelle/80318. Accessed 6 Nov. 2018.
} 
Kaitiakitanga. Kaitiakitanga deals with maintaining a balance between communities and nature $^{48}$ and it is often described as an intimate relationship, therefore something not unlike a horizontal relationship. My solution, borrowing kaitiakitanga (in waka 44 for instance: "ne montrons-nous pas / la profondeur de notre kaitiakitanga"), aims to take into account the underlying symbolism by ignoring the equivalent "tutelle", which would convey an antagonistic framework - a vertical set of relationships instead of horizontal.

Most of the book's tropes have an underlying symbolism that is often not revealed and is unique to Aotearoa and Polynesia. Perhaps the most visible evidence of this is the correlation of Māori terms to whakapapa - a leading theme with which the poet plays, as in poems xx "a whakapapa construction": "in a whakapapa the last line / should be the speaker's / kia ora". As Sullivan explains:

In "I/Eyes/Ae" I cast eight vowel sounds for each half-line, as that is a rule of composition for some Māori song-poems. In "Ahi Kā" and "Voice Carried My Family" I use anaphora because repetition and duplication are features of indigenous language poetics in Polynesia, and of course I use some Māori language because each word has a direct lineage to that. As well as praising, I wish to evoke the past to make us responsible to each other in the present. ${ }^{49}$

Although these comments refer to later poems, Sullivan's use of Māori words as a direct lineage to indigenous language poetics already suits Star Waka. The anaphoric structure of waka 99 or 100 correlates this, and I reproduce it in my translations.

Whakapapa is then both a recurring theme - for instance in waka 80 or 82 : "Whatonga followed his grandfather Toi / to Aotearoa aboard Kurahaupo" - and a structural effort to bind the text within a tradition of poetry that is also Kotahitanga / Solidarity. Again, this is expressed by Sullivan stating: "I wish to evoke the past to make us responsible to each other in the present"

\footnotetext{
48 "Traditionally, Māori believe there is a deep kinship between humans and the natural world. All life is connected. People are not superior to the natural order; they are part of it" teara.govt.nz/en/kaitiakitangaguardianship-and-conservation. Accessed 6 Nov. 2018.

${ }^{49}$ In Johnston, (2009), p. 173.
} 
or at the end of poem xv "Sullivan Whānau": "when we gather / at Te Kaaretu, we are anchored / and hold fast to one another."

This is expressed in the second part of Sullivan's explanation of ritenga tangata, in which he refers to Bourdieu's collective term "the cultural field of production": "the broader associative range of symbols and relations that the poet's oeuvre assembles." ${ }^{50}$ In poems "Te ao mārama" I, II, III, and IV, the title refers to Te ao mārama - the Māori principle of wholeness, and cosmos - but it also signals the presence of an intertextual genealogy, a kind of literary whānau, as $T e$ ao mārama is the title of a five-volume bilingual collection of fiction and non-fiction by Māori authors, edited by Witi Ihimaera, and saluted by Sullivan. ${ }^{51}$ Consequently, any translation strategy that would elide Māori words would bypass such dense and underlying symbolism at the core of Māori culture.

In conclusion, my strategy is in line with Nord's recommendations, balancing the writer's intentions - here partially elucidated in his academic writing - and the expectations of the target readers, who I believe need some context for the poems to work. By borrowing all Māori terms but only explaining a minority of them, what is perhaps the educative function of my translations, I aim at keeping the poet's own educative strategy as well as his message connecting Māori to Polynesia and connecting the present to the past. This is again a very Māori thing as Hone Tuwhare once emphasised:

It's a very Māori thing. Even if you're addressing something inanimate. Even a person who's no longer of this world - there's just the insistence that the person has got ears, at least is listening, you know. You certainly address the person in the box as if he were still alive. ${ }^{52}$

\footnotetext{
${ }^{50}$ Emphasis added.

${ }^{51}$ Sullivan regards himself as a "mentored teina in the vā", the vā being the space between, and he states: "There are antecedents. Witi Ihimaera's extraordinary multi-volume anthology Te Ao Marama includes nearly every Māori writer who was published up to the early 1990s. I would have wished to follow a similar path with this thesis" (Sullivan, 2015, p. 318).

${ }^{52}$ In Johnston, (2009), p. 29.
} 
The underlying symbolism of Sullivan's poems hopefully carries through in my translations perpetuating these interconnections through time, space and across cultures despite nonequivalent modes of reference, and encouraging target readers to learn more about the source culture. In fine, my translation process for Star Waka more widely exemplifies the translation process for a great deal of New Zealand poetry that is strongly linked to Māori culture, and I have offered a range of creative strategies to balance the translator's loyalty to all agents involved. 


\section{CONCLUSION}

In the course of this study a number of issues were encountered, such as: translating intertextuality, wordplay, visual legibility, compression and fixed forms, tonal shifts and the poetic voice in the case of Jackson's poetry; translating cultural layers and underlying symbols, diglossia, narrativity, melopoeia and orality in the case of Sullivan's.

While the cultural allusions of Sullivan's poetry can be expected to be understood by most New Zealanders with some knowledge of Māori, they also have an educative / political function for those who do not. This situation can be preserved creatively in the translation (with borrowings, a partial glossary, a contextualising paratext and indications of hypertextual sources), and the transfer might also be helped by a similar situation in the target culture or rather cultures - that is to say moving from considering a readership towards a plurality of readerships in metropolitan France and the Francophone Pacific. ${ }^{53}$ This is where the skopoi of the source poems and of the translations are parallel.

Regarding Jackson's intertextual allusions, there is likewise an educative function for a diversity of readers who may be more or less familiar with these allusions (to Catullus for instance). The scope is political but of a different kind (although "Teatime with the Timorese" has a similar denunciatory function) with at times ecological and feminist dimensions, as well as a metaphysical reach. To translate both Jackson's recurrent references to text and Sullivan's to culture - or as an umbrella concept, to translate allusion - I have shown that it is best to think in terms of balance rather than equivalence. Balance not only highlights the need for the translator to be creative (and measured), it is a central element in the harmonisation process inherent to poetry translation.

\footnotetext{
${ }^{53}$ For instance, Tahitian publishing house Au vent des îles or periodical Littérama'ohi specialise in promoting literature from Oceania and Polynesia.
} 
As stated in the introduction, I have made a distinction between strict fidelity to the text's meaning and the more relaxed but equally (if not more) important principle of loyalty towards the people involved. I am inspired by Nord when she writes:

Let me call "loyalty" this responsibility translators have toward their partners in translational interaction. Loyalty commits the translator bilaterally to the source and the target sides. It must not be mixed up with fidelity or faithfulness, concepts that usually refer to a relationship holding between the source and the target texts. Loyalty is an interpersonal category referring to a social relationship between people. ${ }^{54}$

To ground this loyalty towards the writers' intentions, and to reflect their reception by the audience addressed in the source culture, the choice of an interpretative / hermeneutic stance, supporting a functional skopos, has been key. As Umberto Eco explains:

In the translation of poetry, one often aims at rewriting, as if accepting the challenge of the original text so as to recreate it in another form and another substance (trying to keep faith, not with the letter, but with the "guiding spirit" of the text, whose identification obviously depends on the translator's critical interpretation). ${ }^{55}$

This hermeneutic stance is arguably close to functionalism - this is clear if we replace guiding spirit by skopos.

Second, rather than recovering a putative state of equivalence between text and translation, as if there were some immanent meaning floating between languages, I suggest referring to an act of balance in the translation process. Eco states that "equivalence in meaning cannot be taken as a satisfactory criterion for a correct translation." ${ }^{56} \mathrm{He}$ adds: "instead of speaking of equivalence of meaning, we can speak of functional equivalence: a good translation must generate the same effect aimed at by the original." 57 To aim at recreating a poem's multiple

\footnotetext{
${ }^{54}$ Nord, (1997), p. 125

${ }^{55}$ Eco, (2004), p. 94.

56 Ibid, p. 9.

${ }^{57}$ Ibid, p. 44.
} 
effects - or potential functions - in translation is to perform a meticulous balancing act, a situation in which one tries to give attention to more than one activity at the same time.

To illustrate the concept of a balancing act in translation, it might be useful to evoke the image of balancing rock sculptures. These are a relatively recent art form, in which rocks are naturally balanced on top of one another in various positions and without any mechanisms that would help maintain the construction. The delicate equilibrium created is comparable to a successful translation of a poem. Patience, sensitivity and intuition are certainly required. And despite its ephemeral condition, a balancing rock sculpture equally relies on the artist's refinement and precision to create a piece that holds, as if by itself. The point of using this image is that it visually magnifies the care and craft needed on one hand, while it highlights the fickleness or the fragility of the process on the other. It also stresses that poetry translation is not about transposing something already there - as the equivalence model would lead us to think - but is instead a creative construction all its own.

The idea of a balancing act has also enabled a shift of focus more accurately onto the translator's role as an active mediator keeping the books - what I have called "le cahier des charges de la traduction" ${ }^{58}$ - and negotiating meaning between cultures. Context is always key, as Eco also writes:

To substitute a given expression with a series of interpretants means that the substituting expressions are never equivalent to the one substituted, since they can say more under a certain profile and less under another. "Under a certain profile" means according to a given context. ${ }^{59}$

On many occasions, I have tried to counterbalance what could say more here and less there ${ }^{60}$ so the contents of source poems and translations match one another in their own context. Nord

\footnotetext{
58 See p. 105.

${ }^{59}$ Eco, (2004), p. 13.

${ }^{60}$ In a poem, even an expression like "il pleut des cordes", for instance, is not equivalent to "it's raining cats and dogs" if the image of cats and dogs evoked has significance for the translator's interpretation.
} 
equally stresses context, denying the possibility of perfect equivalence: "The equivalence model focuses mainly on structural qualities of the source text, losing the intrinsic relationship between extratextual (i.e. situational) and intratextual (i.e. linguistic) factors of communicative interaction out of sight.." ${ }^{, 61}$ For target readers to comprehend the reach of Sullivan's poetry, I have drawn attention to the deep connections binding text and culture. Using various strategies, my translations highlight that his waka poems are spaces of indigenous and transnational relationship originally rooted / routed in the vast Moana Nui a Kiwa.

When translating unconventional language, my attempt at following a balancing approach which may also evoke the image of a waka - has regularly implied the transcendence of conventional binary approaches, for instance between documentary and instrumental strategies. Nord writes:

Expected features give an impression of conventionality, whereas unexpected features provide an effect of originality. Thus, the translator has to opt either to "document" the text's foreignness or to adapt it to target-culture conditions. It is interesting to note that the equivalence concept requires invariance of content [...] and, at the same time, analogous stylistic features so as to obtain equivalence of effect. ${ }^{62}$

I have shown that adopting one or the other approach exclusively and systematically - one may say, rigidly - impedes the creation of workable solutions, and rather, a flexible and / or position, ${ }^{63}$ a heuristic and holistic approach measuring and counterbalancing these extremes has been favoured. This is to avoid any problematic over-accumulation of unexplained borrowed words while respecting the educational and political skopos of non-glossed terms, even in the same poems, as seen mostly in my second case study.

\footnotetext{
${ }^{61}$ Nord, (1997), p. 44.

62 Ibid, p. 98.

${ }^{63}$ See also Kris Peeters" "Traduction, retraduction et dialogisme" (2016), which posits dialogic translations as both source-and target-oriented.
} 
This leads me to emphasise that, at all stages of my process, creativity has been an indispensable ingredient. I hope that my work may be considered what Lefevere and Bassnett call a laboratory situation:

"Laboratory situations" will not only reveal the constraints under which translators have to work at a certain time and in a certain place, but also the strategies they develop to overcome, or at least work around those constraints. This kind of comparison can, therefore, give the researcher something like a synchronic snapshot of many features of a given culture at a given time. ${ }^{64}$

I have adopted an experimental and re-creational approach, which could inscribe my work

within the creative turn recently observed in translation studies. Anthony Pym comments:

More recently a "creative turn" in Translation Studies, associated with postmodern theory that works to blur all boundaries to recognise the translator's subjectivity $[\ldots]$ is largely in tune with mainstream literary ideology. The "death of the author" was identified by Foucault and Barthes a long time ago; theories of intertextuality took off from Kristeva's reading of Bakhtin; the idea that all creativity is translational is now a keystone of postmodern thought. From this perspective, to say that the translator has authorship is also to say that all authors work translationally. ${ }^{65}$

In her review of Loffredo and Perteghella's One Poem in Search of a Translator: Rewriting

“Les Fenêtres” by Apollinaire, Julie Stéphanie Normandin also writes:

Les directrices inscrivent en effet ce projet dans le "tournant créatif" (creative turn) observable dans le champ actuel de la traductologie, c'est-à-dire l'attention accordée depuis peu à la créativité qui, tributaire de la subjectivité des traducteurs, est inhérente au processus de traduction et peut désormais être valorisée plutôt que perçue comme une dérive irrespectueuse. ${ }^{66}$

If creativity is a central constituent in poetry translation, subjectivity - as its corollary - is de facto added to the equation, not only to release but also to enhance this creativity. I therefore concur with Loffredo and Perteghella who stress the subjective nature of poetry translation. The translator of poetry is indeed a reader and rewriter "activating a deeper stratum of subjectivity":

\footnotetext{
${ }^{64}$ Bassnett, (1998), p. 6.

65 Pym, (2011), pp. 31-32.

${ }^{66}$ Normandin, (2011), p. 240.
} 
Translators' rewritings - the reshaping of a newly and continuously re-enlivened literary work - testify to an involvement with the text at an experiential level, to a privileged reading experience activating a deeper stratum of their subjectivity. ${ }^{67}$

A sense of the source writers' subjectivity is hopefully present in my translations through the prism of my own subjectivity, and so readers may invest their own subjectivity in turn, in a kind of triangular conversation. Loffredo and Perteghella conclude:

If translation turns out to be an intimate, interpersonal relation with a literary text, what emerges from it is a dialogue, an unavoidable conversation, possibly full of tension, in which more than one subjectivity is at stake - the source text writer's as well as the target text writer's - and in which co-authoring is nothing other than the perceptible quality of multivocality. Its resonance is further enriched if the dyad becomes a triad and the reader becomes also a driving force. $^{68}$

My translations aim to be balanced, mutivocal and creative spaces of readings and rewritings.

Balance versus equivalence

What my process confirms is that because of the intrinsic openness of poetry - the welcome multiplicity of possible interpretations by readers - recovering an ideal equivalence between poem and translation cannot be achieved, and should not be aimed for. As Nord explains: "the openness specific to literary texts allows for various interpretations at once, making [...] the equivalence requirement not only impossible to meet but also rather undesirable." 69 The plurality of layers of text - for instance, intertextual layers in my first case study, and symbolic in the second - allows for an infinite number of readings, and this makes equivalence too narrow a concept to go by. Mary Snell-Hornby puts it in a straight-forward manner:

Equivalence is unsuitable as a basic concept in translation theory: the term equivalence, apart from being imprecise and ill-defined (even after a heated debate of over twenty years) presents an illusion of symmetry between languages which hardly exists beyond the level of vague approximations and which distorts the basic problems of translation. ${ }^{70}$

\footnotetext{
${ }^{67}$ Loffredo, (2009), p. 14.

${ }^{68}$ Ibid.

${ }^{69}$ Nord, (1997), p. 89.

${ }^{70}$ Snell-Hornby, (1988), p. 22.
} 
As Kwame Anthony Appiah also writes, due to different cultural conventions, there can never be a perfectly equivalent translation: "there can always be new readings, new things that matter about a text, new reasons for caring about new properties." He continues:

A literary translation, so it seems to me, aims at producing a text whose relation both to the literary and to the linguistic conventions of the culture of the translation is relevantly like the relations of the object-text to its culture's conventions. A precise set of parallels is likely to be impossible, just because the chances that metrical and other formal features of a work can be reproduced while preserving the identity of literal and non-literal, direct and indirect, meaning are vanishingly small. And, in fact, we may choose, rightly, to translate a term in a way that is unfaithful to the literal intentions, because we are trying to preserve formal features that seem more crucial. ${ }^{71}$

Hence, my focus is on a loyal rather than a faithful strategy, at times discarding semantic nuances in favour of metrical features, at times modifying meaning so something of the source melopoeia can be retained or at times transforming a trait so humour can be transferred - all depending on the skopos of each translation.

The etymology of equivalence furthermore implies the idea of equality - more or less worth the same - but ...equivalent for whom? As Bassnett and Trivedi explain: "Translation is not an innocent, transparent activity but is highly charged with significance at every stage; it rarely, if ever, involves a relationship of equality between texts, authors or systems." ${ }^{2}$ For Nord:

Equivalence was introduced into translation studies parting from the standpoint of linguistics in the early sixties by Nida (1964) and Catford (1965) in the English-speaking area [...] Purely linguistic equivalence between elements of the language system, which was the main concern of the "stylistique comparée" in the late fifties (see Vinay and Darbelnet 1958, for example), very soon proved inadequate as a criterion for the translation of more complex structures, such as texts. $^{73}$

She adds:

The problem is that these [equivalence] conditions do not cover the wide range of adjustments which may become necessary in any translation process, nor do they account for those cases where implicit source text values should remain

\footnotetext{
${ }^{71}$ In Venuti, (2000), p. 339.

72 Bassnett, (1999), p. 2.

${ }^{73}$ Nord, (1994), p. 2.
} 
implicit or where comprehensibility is not the aim of the translation at all. There are texts, for example, where it is precisely the lack of (general) comprehensibility which determines text function, as in hermetic poetry. ${ }^{74}$

While I would not claim the texts discussed in this thesis are hermetic, there are arguably some rather opaque passages in both Jackson's and Sullivan's works, which I have not made more explicit, in line with my loyalty to their writing choices. Nord points out that:

If literature must of necessity use ordinary language to create its own system, a text belonging to this system has to be marked in such a way that the reader's attention is drawn to the extraordinary literary character of the text. If the text is not marked as "literary", it may happen that the reader does not recognize its literary function. ${ }^{75}$

In the source poems, what clearly seemed to be purposefully linguistically marked turns Māori-inflected language or simply poetic licence - has been kept as such, through diverse techniques, mainly borrowing, calque, and compensation.

I have shown that the implicit values in Sullivan's poems - i.e. the Māori principles invoked in Te Reo but also in English - cannot be translated on the basis of equivalence because there are no matching values in the target culture - see the translation of "guardianship" itself a rendering of "kaitiakitanga" for instance. This has called for some radical strategies, as Nord writes:

The translator should by no means spoon-feed the target receivers. As a rule, readers do accept new, original or foreign ways of presenting old or new ideas (at least in documentary translations). This is a major way to enrich the target language by transferring the unusual language use. ${ }^{76}$

What is more, even a well-informed translation, in which the translator has thoroughly researched and clearly indicated - or hinted at - the intertextual or cultural layers of text, always risks not being fully appreciated, from every angle and aspect intended, if target readers do not have or do not acquire the necessary background knowledge for it to work. Such is the challenge of translating allusion.

\footnotetext{
74 Ibid, p. 3.

${ }^{75}$ Nord, (1997), p. 82.

${ }^{76}$ Ibid, p. 93.
} 
However, rather than considering this problematic situation as a dead end, this challenge has inspired my process. Nord suggests resorting to creativity to express cultural allusions:

Translations refer to source-culture realities and ways of behaviour, which more often than not could not be expressed in the target language before a translator had to find new linguistic forms (by borrowing, coining neologisms or creative ways of paraphrase) to tell the audience about them. ${ }^{77}$

This creative stance has prompted my choice of using a partial glossary of Te Reo words in my translation of Star Waka in order to spark readers' curiosity. The same consideration has guided my decision to recover and borrow the Māori terms alluded to in English by Sullivan. It has also been the basis of my strategy of reproducing intertextual allusions either in existing French translations (see my translation of Jackson's "Kikuyu”) or of modifying meaning in favour of wordplay and metre, according to the skopos, as in "Just a Mineral Water with Marianne Moore". This non-systematic, pragmatic and case-by-case approach is, in my view, a true balancing act - weighing the pros and cons in each situation - rather than a dubious attempt at finding some already existing equivalence.

\section{Balance in creativity}

In order to write poetry, in its etymological sense of creation, rather than a retread of a preexisting poem, nor an augmented version of it (what Holmes describes as "a verbal object that to all appearances is nothing more nor less than a poem"78) I have largely resorted to creativity. However, I have emphasised the need for balance when doing this. Indeed, one crucial question, asked many times, is: how much is too much? or not enough? In other words, can the translator avoid speaking translationese without over-translating (and vice versa)?

As we have seen, there are two well-known evils in literary translation. On one hand, as Levý explains:

Even if the translation contains no out-and-out linguistic errors or awkward use of language, its stylistic expression may be pale, colourless and grey, lacking

\footnotetext{
${ }^{77}$ Nord, (2011), p. 27.

${ }^{78}$ Holmes, (1988), p. 11. Emphasis added.
} 
that certain je ne sais quoi that distinguishes an artistic text from one that is merely linguistically correct. In such cases, critics speak of translationese. ${ }^{79}$

On the other, as Eco remarks:

There are translations that splendidly enrich the target language and that, in cases that many consider to be felicitous, manage to say more (in other words, are richer in suggestion) than the originals. But, in fact, these translations are usually valuable in themselves as original works of art, and not as versions of a source text. A translation that manages to "say more" might be an excellent piece of work by itself, but it is not a good translation. ${ }^{80}$

Many have reported that the translation process is akin to a balancing act between these two opposite traps. In "Equilibres et harmonie dans la traduction", Serge Soupel underlines that balance must be achieved both in detail and globally:

Encore le travail d'équilibriste, ou celui de peseur de segments, s'exerce-t-il aussi bien sur le détail que sur le texte entier. C'est ici qu'entrent en jeu les compensations des pertes par des gains, et vice versa, celles des atténuations par des amplifications: sur une grande échelle (celle de tout le texte) ${ }^{81}$

Cécile Marshall gives a similar account of her translations of poet Tony Harrison's work: “Un autre des défis posés par cette langue poétique est le recours si fréquent à la polysémie et aux jeux de mots. [...] Souvent, la traduction résiste et il faut alors compenser pour essayer de rétablir l'équilibre." 82 Paola Masseau, a translator of Valéry, describes André Lefevere’s stance as a general plea for balance: “Ces auteurs [Burton Raffel and Lefevere] postulent en définitive, la traduction comme un équilibre." ${ }^{\text {} 3}$ Most vividly, Bassnett relates how Anthea Bell, the translator of Astérix, "depicts translation as an act of tightrope walking, with the translator striving to keep a balance between the exigencies of the target language readers and the constraints posed by the original text. ${ }^{, 84}$ Bell considers different factors here but her striking image also perfectly illustrates the poetry translator's dilemma.

\footnotetext{
${ }^{79}$ Levý, (2011), p. 107.

${ }^{80}$ Eco, (2004), p. 45.

${ }^{81}$ Soupel, (2001), p. 150.

${ }^{82}$ Marshall, (2013), pp. 5-6.

${ }^{83}$ Masseau, (2012), p. 70.

${ }^{84}$ Bassnett, (2011), p. 93.
} 
Antoine Berman had perceived the role of creativity as fundamental to the task: "la créativité exigée par la traduction doit se mettre toute entière au service de la réécriture de l'original dans l'autre langue." ${ }^{\prime 5}$ Introducing his concept of "contrat", he advised translators to base their creativity on ethical premises: "Le contrat fondamental qui lie une traduction à son original [...] interdit tout dépassement de la texture de 1'original." ${ }^{86}$ In Jackson's notes to her translations of Tissot's works, the poet also mentions ethics:

For all the fun of puzzling out solutions to verbal problems, then, and the excitement of coming up with translations that work as poems with the verve and velocity of the originals, we realised we had a responsibility not to depart from the truths Marlène wants to convey, and to give as literal a translation of the poems as possible without losing the richness and complexity of their meanings. ${ }^{87}$

Jackson's responsible or balanced use of creativity has had an effect on my practice. As shown with "Watch" or The Gas Leak, for readers to perceive the fun subtly conveyed by the poems, and for the translations to work subsequently, it has been necessary to try and relive ${ }^{88}$ this literary fun, translated on the page. However, all this fun should not conceal the depth of the poet's metaphysical considerations on family, human experience or psyche, inner and outer worlds.

Classifications of the role of creativity offered by Lavault-Olléon, ${ }^{89}$ Stefanink and Balacescu, ${ }^{90}$ Dancette et al. ${ }^{91}$ and Ballard ${ }^{92}$ have also been enlightening in explaining how it can safely be resorted to, when and when not to colour a trait for instance, without the risk of damaging the poems' essence or truth. I conclude with Ballard that the creative aspect of poetry translation

\footnotetext{
${ }^{85}$ Berman, (1984), p. 58.

${ }^{86}$ Ibid.

87 Tissot, (2017), p. 7.

${ }^{88}$ More generally, sincerity and extra-sensitivity in the translator's attempt to re-experience the poet's creative journey embedded in the poems are sine qua non conditions for delivering any poetic sentiment.

${ }^{89}$ Lavault-Olléon considers creativity from four perspectives: "la terminologie, la création discursive, la réécriture induite par les déficiences du texte source et l'adaptation" (Lavault-Olléon, 2012, p. 125).

${ }^{90}$ Balacescu and Stefanink present five descriptive models of creativity: "les enchaînements associatifs, la pensée latérale / divergente, la sémantique des prototypes, le 'figure / ground alignment' et la sémantique des "scenes and frames"' (Balacescu, 2003, pp. 517-518).

${ }^{91}$ Dancette et al., (2007). See also the issue of Meta devoted to "La traduction littéraire comme création" in 2017.

92 Ballard, (1997).
} 
implies controlled alterations, compensations and recreations in moderation that should be embraced rather than feared:

Ce que l'on a mis longtemps à accepter en traduction c'est le fait que la réécriture à l'aide d'une autre langue suppose des écarts ou des transformations qui font partie d'un acte de création qui se poursuit dans un autre matériau linguistique: une certaine différence (contrôlée) fait partie de la survie du texte. ${ }^{93}$

This controlled difference between poem and translation might be vital. I would even add that, in some places, it is textual evidence of a balanced use of creativity, and de facto of a functioning translation process, conveying the playfulness inherent to poetry translation as it is essentially a re-experiential creative act.

\section{Balance or harmonisation}

Finally, I argue that my balancing approach has functioned very much in the manner of musical harmonisation. Like a singer harmonising with another, I have maintained a continuous effort to try and match the source poets' vocal signature, not with an identical or equivalent tessitura, but by offering counterparts - or counterpoints ${ }^{94}$ (if we speak of voices). David Connolly is right to assert that:

A fundamental problem is the lack of a theoretical basis for standards of equivalence in poetry translation, partly because there is no overall agreement as to what in a poetic text constitutes the basic unit of translation. [...] De Beaugrande and Lefevere favour equivalence on a communicative level. No translation of a poem, though, can ever be "the same as" the poem itself, and what the translator should strive for, according to Holmes, are "counterparts" or "matchings". 95

About vocal counterparts, Jones also remarks that:

The translator's concern with deep-level semantic loyalty means they are constantly guarding against the risk of betrayal or falsification. Instead, when exact lexical equivalents fail to convey the required formal and stylistic features,

\footnotetext{
${ }^{93}$ Ibid, p. 87.

94 "Le contrepoint lui-même a une âme, en ceci que le parallélisme de ses voix a été expressément réglé note pour note par une volonté musicienne qui fait chanter ensemble ou converser plusieurs parties mélodiques également expressives, et pourtant l'une sur l'autre brodées dans le colloque vivant de la polyphonie" (Jankélévitch, 1957, p. 175).

${ }^{95}$ Connolly, (2001), p. 174.
} 
they choose looser "counterparts" which perform functions "that in many and appropriate ways are closely akin" to those in the source poem (Holmes 1988) - which Holmes regards not as an aberration, but as a defining feature of poetry translation. ${ }^{96}$

This relative looseness in the process - we might even go so far as to call it freedom - is perhaps due to poetry translation being an exploration of the self, as well as an encounter with the other. By trying to convey what I have called internalised otherness, intuitively and empathetically channeling other voices so readers can appreciate an intricacy of voices, and project their own, I have re(de)fined my own poetic voice in the process, and unavoidably made new aspects of the other poets' voices resonate.

While there are strictly defined rules of harmony, my empirical and harmonising approach has been closer to improvisation, with its looser element of subjectivity. In regard to the musical function of poems, for instance when looking for rhymes, I have turned instead to the habit of sounding words out - testing their musicality. By reading the source poems out loud, followed by the translations - or even simultaneously when a recording was available - I was made more aware of prominent rhythmical signatures, stress patterns, original phrasing that had transferred into the translation - or not. This has also meant relying on ear-intuition, allowing coincidences in the process, even experimenting with nonsensical improvisations, not dissimilar to the echolalia or glossolalia once practised by Antonin Artaud:

Bien que ce discours soit dépourvu de structures et inintelligible, cette inintelligibilité se transforme en intelligibilité au niveau de l'énonciation, tant du point de vue de la production que celui de la réception. [...] Il semble que certains textes poétiques, ceux de Gauvreau notamment, [...] soient proches de la glossolalie, même quand ils semblent porter un sens. ${ }^{97}$

\footnotetext{
${ }^{96}$ Jones, (2011), p. 180. Emphasis in the original.

${ }^{97}$ Dupriez, (1984), p. 220.
} 
This harmonising talk aloud protocol leads to a conception of creativity that differs from the creation of new material ${ }^{98}$ regularly pointed out by researchers. As Balacescu and Stefanink explain:

Les chercheurs en créativité se gardent, eux, de donner une définition et préfèrent parler des "aspects" de la créativité (Brodbeck), comme celui de la "nouveauté" du produit créé et de "l'accueil positif" que lui réserve l'évaluation par les experts. ${ }^{99}$

As a tentative effort to tune in or channel something that might resonate, a solution is unveiled or uncovered, as much as it is invented. In other words, rather than a creation ex nihilo, a poem's translation is the result of a subjectively balanced harmonisation of voices or vibrations.

This coincides with Loffredo and Perteghella's earlier proposal of reactivating the translator's deeper stratum of subjectivity or even Bonnefoy's advice: "laisser monter du profond de soi des rythmes qui ne peuvent être que ceux du corps que l'on est, des expériences qu'on a vécues."100

With regard to this intermediate oral step towards the text, which might be no more than a draft or a musical sketch, Julia Kristeva writes:

L'étape du brouillon est déjà une étape seconde. Le senti continue d'affleurer, et l'inconscient de surprendre. Mais l'essentiel (ou du moins le spécifique) du brouillon est dans la mise en langue qui comprend, si j'y pense après, deux stratégies: le choix des mots (où je suis sous l'impact des "processus primaires" selon Freud, et de la musique); et la construction du phrasé, que dominent la logique et de nouveau la mémoire musicale. ${ }^{101}$

"La mise en langue" - constantly testing musicality - has therefore been key for my balancing or harmonising process, and my translations should be assessed in light of their own musical merit as well as their ability to resonate in harmony with the source poems.

\footnotetext{
98 "Two key conditions posed for creativity: newness or "novelty', and appropriateness or acceptability" (Hewson, 2006, p. 58).

${ }^{99}$ Balacescu, (2003), p. 521.

${ }^{100}$ Bonnefoy, (2000), p. 78.

${ }^{101}$ Kristeva, (2014). Emphasis in the original.
} 
Landers reminds us that "although not all poems (both translations and originals) that sound good are good, it's a pretty safe bet that a translation that sounds bad is, well, bad." 102 Peter Robinson concurs: "in poetry the figuratively musical, the 'connotative and tropical', the 'rhythmic and sonic' is essential."103 Nord emphasises that: "sentence intonation and other prosodic elements play an important role in text function even in the written medium, although, of course, its relevance should be greater in dramatic or poetic texts." 104

My point is not to reduce poetry translation to this single factor, and I conclude with Jones that "there may well be a consensus among relevant players that some poetry-translation decisions are better than others [...], until it is established, the limits of acceptability must remain uncertain." 105 This uncertainty is essential to poetry itself, as pointed out by Allen Curnow:

The best poems should not leave one with that "been there, done that" feeling, there's something there that you will never get, they will remain teasing, and their essence, whatever their essence is, will elude one. ${ }^{106}$

In my context, the relevant players are my target readers: only they can assess what works for them, individually and subjectively. Nord states that: "the reader thus decides to read a text as literature. The decisive factor is that they are willing to take part in the game."107

In the end, translating New Zealand poetry into French has been a testing experience - a giant leap of faith, as Landers writes:

The late John Ciardi referred to translation as "the art of failure". And yet we go on trying, sometimes with remarkably reduced degrees of non-success. If literary translation itself is a leap of faith, poetic translation puts that faith to the severest of all tests. [...] Small wonder, then, that before attempting translation of poetry a proper attitude of humility is called for. ${ }^{108}$

\footnotetext{
${ }^{102}$ Landers, (2001), p. 100.

${ }^{103}$ Robinson, (2010), p. 64

${ }^{104}$ Nord, (1997), p. 101.

105 Jones, (2011), p. 180.

${ }^{106}$ In Johnston, (2009), p. 16.

${ }^{107}$ Nord, (1997), p. 82.

${ }^{108}$ Landers, (2001), pp. 97-98.
} 
To overcome the problematic subjectivity of assessing poetry translation, and beyond any evaluation of how well-attuned the voices in a poem and its translation might be, a determining step in my process has been to accept differences, and even rejoice in the alterity inherent in poetic voices. Edouard Glissant sums this up magnificently by comparing poetry translation to a fugue - "un renoncement qui accomplit":

La traduction est comme un art de la fugue, c'est-à-dire, si bellement, un renoncement qui accomplit.

Il y a renoncement quand le poème, transcrit dans une autre langue, a laissé échapper une si grande part de son rythme, de ses structures secrètes, de ses assonances, de ses hasards qui sont l'accident et la permanence de l'écriture.

Il faut consentir à cet échappement, et ce renoncement est la part de soi qu'en toute poétique on abandonne à l'autre. ${ }^{109}$

Despite the great diversity of challenges when transplanting poetry that is geographically and culturally so distant from the target culture's - and I do not only have the metropolitan France / New Zealand divide in mind - I have shown that the task can be accomplished. But (and this "but" is crucial) only according to certain principles, highlighting context, skopos, balance, loyalty, creativity, and harmonisation: principles which themselves lead us to question the essence of translation, not understood here in terms of strict equivalence and fidelity. My translations aim to offer evidence of stand-alone poems, as well as meta-poems in parallel, which work as both. What remains to create is a greater audience for this seed to grow and flourish.

${ }^{109}$ Glissant, (1997), p. 28. 


\section{BIBLIOGRAPHY}

\section{Primary Sources}

Jackson, Anna. The Long Road to Teatime. Auckland: Auckland University Press, 2000.

---. The Pastoral Kitchen. Auckland: Auckland University Press, 2001.

---. Catullus for Children. Auckland: Auckland University Press, 2003.

---. The Gas Leak. Auckland: Auckland University Press, 2006.

---. Thicket. Auckland: Auckland University Press, 2011.

---. I, Clodia and Other Portraits. Auckland: Auckland University Press, 2014.

Sullivan, Robert. Star Waka. Auckland: Auckland University Press, 1999.

\section{Secondary Sources}

Anderson, Jean. "Interview with AProf Jean Anderson." AALITRA Newsletter, July 2018, email received 1 Aug. 2018.

Aranjo, Daniel. "Catulle au début du XX $\mathrm{X}^{\mathrm{e}}$ siècle: une anthologie." Babel, vol. 12, 2005, pp. 145-176, babel.revues.org/1056. Accessed 9 Nov. 2017.

Arnault, Luc. "Traduire en français la poésie de James K. Baxter.” M.A. thesis, Victoria University of Wellington, 2015.

---. "Translating New Zealand Poetry into French: Anna Jackson's Poetry as a Case Study." The AALITRA Review: A Journal of Literary Translation, no. 13, 2018, pp. 6-20.

Ashcroft, Bill, Gareth Griffiths and Helen Tiffin. The Empire Writes Back: Theory and Practice in Post-Colonial Literatures. London: Routledge, 1989.

Avia, Tusiata. Bloodclot. Wellington: Victoria University Press, 2009.

Baddoura, Ritta. "La Poésie austère et fabuleuse de Marianne Moore." L'Orient Littéraire, no. 34, 2009, lorientlitteraire.com/article_details.php?cid=15\&nid=5216. Accessed 20 Feb. 2017.

Baker, Mona. In Other Words: a Course Book on Translation. London: Routledge, 1992.

Baker, Mona and Gabriela Saldanha, editors. Routledge Encyclopaedia of Translation Studies. London: Routledge, 1998.

Bakhtin, Mikhail. The Dialogical Imagination: Four Essays by M.M. Bakhtin. Translated by Michael Holquist, Austin: University of Texas Press, 1981.

Balacescu, Iona and Bernd Stefanink. "Modèles explicatifs de la créativité en traduction." Meta, vol. 48, no. 4, 2003, pp. 509-525.

---. "Traduction et différences culturelles." Le Français dans le monde, no. 326, 2003, pp. 21-24.

Ballard, Michel. "Créativité et traduction." Target, vol. 9, no. 1, 1997, pp. 85-110.

---. "La Théorisation comme structuration de l'action du traducteur." La Linguistique, no. 40, 2004, pp. 51-66.

---. "A propos des procédés de traduction." Traduire ou vouloir garder un peu de la poussière d'or, edited by Christine Raguet, Paris: Presses Sorbonne Nouvelle, 2006, pp. 113-130.

Balmer, Josephine. Chasing Catullus. Poems, Translations and Transgressions. Tarset: Bloodaxe, 2004.

---. Catullus. Poems of Love and Hate. Tarset: Bloodaxe, 2004.

Barbaud, Thierry. Catulle. Une poétique de l'indicible. Louvain: Editions Peeters, 2006.

Bardon, Henry. Catulli Carmina. Bruxelles: Latomus, 1970.

Barthes, Roland. Mythologies. Paris: Seuil, 1957.

---. "L'Effet de Réel." Communications, vol. 11, no. 1, 1968, pp. 84-89.

---. L'Obvie et l'Obtus. Paris: Seuil, 1977.

Bastin, Georges. "Adaptation." Routledge Encyclopedia of Translation Studies, New York: Routledge, 2008, pp. 3-6. 
Bassnett, Susan, "The Translator as Writer." The Translator as Author, edited by Claudia Buffagni, Beatrice Garzelli, and Serenella Zanotti, Berlin: LIT Verlag, 2011, pp. 91-102.

---, editor. Translation Studies. 1980, London: Routledge, 2014.

---. "The Complexities of Translating Poetry." Ticontre. Teoria Testo Traduzion, no. 3, 2015, pp. 157-168.

Bassnett, Susan and André Lefevere. "Translating the Seed: Poetry and Translation." Constructing Cultures: Essays on Literary Translation, London: Cromwell Press, 1998, pp. 57-75.

---. Constructing Cultures. Clevedon: Multilingual Matters, 1998.

Bassnett, Susan and Harish Trivedi. Post-Colonial Translation: Theory and Practice. London: Routledge, 1999.

Battista, Jon. "Robert Sullivan's 'Waka 100': Inscribed by the Stars." Graduate Journal of AsiaPacific Studies, vol. 5, no. 1, 2007, pp. 58-70.

Baudelaire, Charles. "Genèse d'un poème." Revue Française, 1859, pp. 513-527.

Bauer, Laurie. "Some Grammatical Features of New Zealand English." New Zealand English Journal, no. 21, 2007, pp. 1-25.

Baxter, James, K.. The Iron Breadboard: Studies in New Zealand Writing. Wellington: Mermaid Press, 1957.

---. The Man on the Horse. Dunedin: University of Otago Press, 1967.

---. Selected Poems of James K. Baxter. Edited by Paul Millar, Auckland: Auckland University Press, 2010.

Baxter, Katherine and Lytton Smith. "Writing in Translation: Robert Sullivan's Star Waka and Craig Santos Perez's from unincorporated territory." Literary Geographies, vol. 2, no. 2, 2016, pp. 263-283.

Beach, David. Jerusalem Sonnets, Love, Wellington Zoo. Wellington: Victoria University Press, 2015.

Beautrais, Airini. Narrativity and Segmentivity in Contemporary Australian and New Zealand Long Poems and Poem Sequences. PhD, Victoria University of Wellington, 2016.

Beauvoir, Simone de. The Second Sex. Translated by H. M. Parshley, New York: Knopf, 1952.

Becker-Leckrone, Megan. Julia Kristeva and Literary Theory. New York: Palgrave Macmillan, 2005.

Bedrane, Sabrinelle, Françoise Revaz and Michel Viegnes. Le Récit minimal. Du minime au mininalisme. Paris: Presses de la Sorbonne Nouvelle, 2012.

Benjamin, Walter. "La Tâche du traducteur." CEuvres, Paris: Gallimard Folio, 2000, pp. 244-262.

Bensimon, Paul. "Traduction et poésie." Les Langues Modernes, Paris: Didier, 1966, pp. 81-85.

Bergson, Henri. La Pensée et le Mouvant. Paris: Presses Universitaires de France, 1938.

Berman, Antoine. L'Épreuve de l'étranger. Culture et traduction dans l'Allemagne romantique. Paris: Gallimard, 1984.

---. Pour une critique des traductions: John Donne. Paris: Gallimard, 1995.

---. La Traduction et la Lettre. Paris: Seuil, 1999.

Berretti, Jany. "Pour la traduction expérimentale." Traduire ou vouloir garder un peu de la poussière d'or, edited by Christine Raguet, Paris: Presses Sorbonne Nouvelles, 2006, pp. 89-112.

Bethell, Ursula. Ursula Bethell, Collected Poems. Edited by Vincent O'Sullivan, Wellington: Victoria University Press, 1997.

Bhabha, Homi. The Location of Culture. London: Routledge, 1994.

Bonnefoy, Yves. "On the Translation of Form in Poetry." World Literature Today, vol. 53, no. 3, 1979, pp. 374-379.

---. Poèmes. Paris: Gallimard, 1982.

---. "Translating Poetry." The Act and the Place of Poetry, translated by John Alexander and Clive Wilmer, Chicago: University of Chicago Press, 1989.

---. "La Traduction de la poésie." Entretiens sur la poésie, Paris: Mercure de France, 1992, pp. 381-400.

---. "Préface." Le Conte d'hiver. Paris: Gallimard, 1994, pp. 7-38.

---. "Translating Poetry." Theories of Translation from Dryden to Derrida, edited by Rainer Schulte 
and John Biguenet, translated by John Alexander and Clive Wilmer, Chicago: Chicago University Press, 1996, pp. 186-192.

---. Théâtre et Poésie, Shakespeare et Yeats. Paris: Mercure de France, 1998.

---. "La Traduction de la poésie." Semicerchio rivista di poesia comparata, no. 30-31, 2004, pp. 62-80.

---. "Interview with Bonnefoy." Shakespeare and the French Poet, edited by John Naughton, Chicago: University of Chicago Press, 2004, pp. 257-69.

Bornholdt, Jenny. "Trois poèmes de Jenny Bornholdt." Translated by Jean Anderson and Charles Juliet, Voix d'Encre, no. 33, 2005, pp. 53-57.

---. The Rocky Shore. Wellington: Victoria University Press, 2008.

---. Selected Poems. Wellington: Victoria University Press, 2016.

Bornholdt, Jenny, Gregory O'Brien and Mark Williams, editors. An Anthology of New Zealand Poetry in English. Auckland: Oxford University Press, 1997.

Bourdieu, Pierre. Esquisse d'une théorie de la pratique. Paris: Seuil, 2000.

Brown, Amy. "Review short: Anna Jackson's I, Clodia, and Other Portraits." Cordite Poetry Review, 12 Apr. 2015, cordite.org.au/reviews/brown-jackson/\#fn-29055-1. Accessed 29 Nov. 2016.

Brown, James, editor. The Nature of Things. Poems from the New Zealand Landscape. Nelson: Craig Potton Publishing, 2005.

Brunet, Philippe. "Principes de scansion de l'hexamètre en français." Anabases, no. 20, 2014, pp. 121-136.

Catton, Eleanor. The Luminaries. Wellington: Victoria University Press, 2013.

Caws, Mary Ann. "Le Passage du poème: interrogation du seuil." Cahiers de l'Association Internationale des Etudes Françaises, vol. 30, no. 1, 1978, pp. 225-243.

---. The Yale Anthology of Twentieth-Century French Poetry. New Haven: Yale University Press, 2004.

Chesterman, Andrew. "Proposal for a Hieronymic Oath." The Translator, vol. 7, no. 2, 2001, pp. 139-154.

---. Memes of Translation. The Spread of Ideas in Translation Theory. Revised Edition. Amsterdam: John Benjamins, 2016.

Chuquet, Hélène and Michel Paillard. Approche linguistique des problèmes de traduction anglais. Paris: Ophrys, 1989.

Clavier, Aurore. “"The Raw Material of Poetry': Marianne Moore à l'examen de la vérité." Revue Française d'études américaines, vol. 133, no. 3, 2012.

Coetzee, John M.. “Achterberg's 'Ballade van de gasfitter': The Mystery of I and You.” PMLA, vol. 92, no. 2, 1977, pp. 285-296.

---. Doubling the Point. Essays and Interviews. Cambridge: Harvard University Press, 1992.

Colquhoun, Glenn. The Art of Walking Upright. Wellington: Steele Roberts, 1999.

---. Playing God: Poems about Medicine. London: Hammersmith Press Limited, 2002.

Connolly, David. "Poetry Translation." Routledge Encyclopedia of Translation Studies. Edited by Mona Baker, Kirsten Malmkjær, New York: Routledge, 2001, pp. 170-176.

Cronin, Michael. Eco-Translation: Translation and Ecology in the Age of the Anthropocene. New York: Routledge, 2017.

Cuéllar, Sergio Bolaños. Towards an Integrated Translation Approach. Proposal of a Dynamic Translation Model (DTM). PhD, University of Hamburg, 2008.

Curnow, Allen. A Book of New Zealand Verse, 1923-45. Christchurch: Caxton Press, 1945.

---. The Penguin Book of New Zealand Verse. Harmondsworth: Penguin, 1960.

---. Collected Poems 1933-1973. Wellington: Reed, 1974.

Dancette, Jeanne, Louise Audet and Laurence Jay-Rayon. "Axes et critères de la créativité en traduction." Meta, vol. 52, no. 1, 2007, pp. 108-122.

Dante, Alighieri. Inferno. Translated by Sean O'Brien, London: MacMillan Publishers, 2006.

Derrida, Jacques. Spectres de Marx. L'Etat de la dette, le travail du deuil et la nouvelle 
Internationale. Paris: Galilée, 1993.

---. Spectres of Marx, the State of the Debt, the Work of Mourning, \& the New International.

Translated by Peggy Kamuf, London: Routledge, 1994.

---. "Semiology and Grammatology. Interview with Julia Kristeva. 1968." Translated by Alan Bass,

The Routledge Language and Cultural Theory Reader, edited by Lucy Burke, Tony Crowley and Alan Girvin, London: Routledge, 2000, pp. 241-248.

Dunn, Daisy. The Poems of Catullus. London: Harper Collins, 2016.

Dupriez, Bernard. Gradus: les procédés littéraires. Paris: 10/18, 1984.

Durrant, Sam. Postcolonial Narrative and the Work of Mourning. Albany: SUNY Press, 2003.

Eco, Umberto. Experiences in Translation. Toronto: Toronto University Press, 2004.

Edmond, Jacob. "No Place Like Home: Encounters Between New Zealand and Russian Poetries." Landfall, no. 213, 2007, pp. 73-80.

Eggleton, David. "Review of Atua Wera by Kendrick Smithyman." The Evening Post, 19 September 1997, p. 3, nzepc.auckland.ac.nz/authors/eggleton/smithyman.asp. Accessed 20 Jun. 2018.

---. "The Lyricism, and Dog Food, of Brigitte Bardot." The New Zealand Listener, no. 3331,

13 March 2004, listener.co.nz/uncategorized/the-lyricism-and-dog-food-of-brigitte-bardot/. Accessed 3 Oct. 2016.

Ellrodt, Robert. "Comment traduire la poésie?." Traduire ou vouloir garder un peu de la poussière d'or, edited by Christine Raguet, Paris: Presses Sorbonne Nouvelle, 2006, pp. 65-76.

Emaz, Antoine. "Préface." Une histoire de bleu, by Jean-Michel Maulpoix, Paris: Gallimard, 2005, pp. 7-23.

Etkind, Efim. Un art en crise. Essai de poétique de la traduction poétique. Lausanne: L'Age d'homme, 1982.

Evans, Patrick. "“Pākehā-Style Biculturalism' and the Māori Writer.” JNZL, vol. 24, no. 1, 2006, pp. 11-35.

Evan-Zohar, Itamar. "The Position of Translated Text within the Polysystem." The Translation Studies Reader, edited by Lawrence Venuti, New York: Routledge, 2000, pp. 192-197.

Fleming, Joan. "An Interview with Anna Jackson: I, Clodia and other portraits." The Lumière Reader, 3 Feb. 2015, lumiere.net.nz/index.php/an-interview-with-anna-jackson-i-clodia-andother-portraits/. Accessed 29 Nov. 2016.

Frame, Janet. The Pocket Mirror. New York: George Braziller, 1967.

---. Le Lagon et autres nouvelles. Translated by Jean Anderson and Nadine Ribault, Paris:

Des Femmes-Antoinette Fouque, 2006.

Frame, Janet and Hone Tuwhare. Un autre pays. Poèmes choisis de Janet Frame et Hone Tuwhare. Translated by Cécile Holdban, Paris: Ce qui reste, 2009, cequireste.fr/janet-frame-honetuwhare/. Accessed 7 Feb. 2017.

French, Anne. Seven Days on Mykonos. Auckland: Auckland University Press, 1993.

Frost, Robert. The Letters of Robert Frost to Louis Untermeyer. New York: Holt Rinehart Winston, 1963.

Furlan, Pierre. Douze écrivains néo-zélandais, Les Belles Étrangères. Paris: Sabine Wespieser, 2006.

---. "Ecrivains de Nouvelle-Zélande." Europe, no. 931, 2006, pp. 1-191.

Genette, Gérard. Paratexts. Thresholds of Interpretation. Translated by Jane E. Lewin, Cambridge: Cambridge University Press, 1997.

Gildea, Anahera. "Bone Shame: Grief, Te Ao Māori and the Liminal Space where Translation Fails." Cordite Poetry Review, May 2018, cordite.org.au/essays/bone-shame/2/. Accessed 17 May 2018.

Glissant, Edouard. Traité du Tout-Monde. Paris: Gallimard, 1997.

Gossas, Carina. "Voices and Imitations in the Translation of Children's Books." Translating Fictional Dialogue for Children and Young People. Berlin: Frank und Timme, 2012, pp. 185-200.

Grace, Patricia. Waiariki. Auckland: Longman, 1975.

---. The Dream Sleepers. London: Penguin Books, 1980. 
---. Les Enfants de Ngarua. Translated by Jean Anderson, and France Grenaudier-Klijn,

Tahiti: Au Vent des Iles, 2008.

---. Des petits trous dans le silence. Translated by Anne Magnan-Park, Tahiti: Au Vent des Iles, 2014.

---. Chappy. Translated by Jean Anderson and Marie-Laure Vuaille-Barcan, Tahiti: Au Vent des Iles, 2018.

Green, Paula. Cookhouse. Auckland: Auckland University Press, 1997.

---, editor. Dear Heart, 150 New Zealand Love Poems. Auckland: Godwit Press, 2012.

---. 'Friday Poem: Anna Jackson's 'Afraid of Falls?' - A Pinhole in the Dark Expanse of Memory to Let the Light of Childhood Through.” NZ Poetry Shelf, 2014, nzpoetryshelf.com/tag/annajackson/page/2/. Accessed 12 Dec. 2016.

Green, Peter. The Poems of Catullus. A Bilingual Edition. Berkeley: University of California Press, 2005.

Guidère, Mathieu. Introduction à la traductologie. Penser la traduction: hier, aujourd'hui, demain. Bruxelles: De Boeck, 2008.

Haag, Oliver and Danica Ĉerĉe, "Witi Ihimaera's The Whale Rider in Slovene, Dutch, and German Translation." Antipodes, vol. 29, no. 2, 2015, pp. 251-268.

Hall, Bernadette. Still Talking. Wellington: Victoria University Press, 1997.

---. Life and Customs. Wellington: Victoria University Press, 2014.

Hamilton, Scott. "Reading Kendrick Smithyman.” Brief, no. 26, 2003, pp. 51-55.

Harvey, Siobhan. "Thicket by Anna Jackson: Review.” The Listener, 20 Aug. 2011.

Hersant, Patrick. Traduire en poète. Arras: Artois Université Presse, 2015.

Hermans, Theo. "Translation between Poetics and Ideology." Translation and Literature, no. 3, 1994, pp. 138-145.

Hewson, Lance. "The Vexed Question of Creativity in Translation." Traduire ou vouloir garder un peu de la poussière d'or, edited by Christine Raguet, Paris: Presses Sorbonne Nouvelle, 2006 pp. 54-63.

Hibbs-Lissorgues, Solange. "Friedrich Schleiermacher en Espagne: filiations et dialogues pour une philosophie de la traduction." Friedrich Schleiermacher and the Question of Translation, edited by Larisa Cercel and Adriana Serban, Berlin: De Gruyter, 2015, pp. 215-230.

Hofstadter, Douglas. Le Ton Beau de Marot: in Praise of the Music of Language. New York: Basic Books, 1998.

---. Translator, Trader, An Essay on the Pleasantly Pervasive Paradoxes of Translation. New York: Basic Books, 2009.

Holmes, James. Translated! Papers on Literary Translation and Translation Studies. Amsterdam: Rodopi, 1988.

Honig, Edwin. The Poet's Other Voice: Conversations on Literary Translation. Boston: University of Massachusetts Press, 1985.

House, Juliane. “A Model for Assessing Translation Quality.” Meta, vol. 22, no. 2, 1977, pp. 103-109.

Houston, John. "Aotea." The Journal of the Polynesian Society, vol. 44, no. 173, 1935, pp. 36-47.

Hulme, Keri. "Mauri: An Introduction to Bicultural Poetry in New Zealand." Only Connect: Literary Perspectives East and West, edited by Guy Amirthanayagam and S.C. Harrex, Honolulu: East-West Centre, 1981, pp. 290-310.

---. The Bone People. London: Penguin Books. 1986.

Ihimaera, Witi. Pai, The Whale Rider. Auckland: Heinemann, 1987.

---. Pai, The Whale Rider. International Edition, Auckland: Reed, 2003.

---. Paï, The Whale Rider. Translated by Francine Tolron, Paris: Thélès, 2003.

Ingleheart, Jennifer. "Catullus 2 and 3: A Programmatic Pair of Sapphic Epigrams?" Mnemosyne, vol. 56, no. 5, 2003, pp. 551-565.

Jaccottet, Philippe. La Semaison, carnets 1954-1967. Paris: Gallimard, 1971.

---. Seedtime, extracts from the notebooks 1954-1967. Translated by André Lefevere, and Michael Hamburger, New York: New Directions, 1977. 
---. "Jaccottet, poète de la traduction." Journal de Genève, 18 January 1997, p. 30.

Jackson, Anna. "My Friendship with the Sun." A.U.P. New Poets I, Auckland: Auckland University Press, 1999, pp. 60-73.

---. “The Notebooks, Journal, and 'Papers' of Katherine Mansfield: Is Any of This Her Diary?.” JNZL, no. 18/19, 2000, pp. 83-99, jstor.org/stable/20112325. Accessed 28 Nov. 2016.

---. "Review: An Appealing Excess: A New Edition of James K. Baxter.” JNZL, no. 18/19, 2000-2001, pp. 203-206, jstor.org/stable/pdf/20112333.pdf Accessed 26 Nov. 2016.

---. "Making a Meal of the Thesis." Poetry NZ, no. 19, 2001, pp. 50-53.

---. "Catullus in the Playground." Antichthon, no. 40, 2006, pp. 104-116.

---. "Catullus in the Playground." Living Classics Greece and Rome in Contemporary Poetry in English, edited by Stephen Harrison, New York: Oxford University Press, 2009, pp. 82-96.

---. Diary Poetics: Form and Style in Writers' Diaries, 1915-1962. London: Routledge, 2010.

---. "Mary, of France." Ka Mate, no. 12, 2013, pp. 164-165.

---. "I Have Nuffink Else to Say." Landfall, no. 228, 2014, pp. 181-183.

---. "Interview with Maxine Lewis.” Practitioners' Voices in Classical Reception Studies, no. 8, 2017, open.ac.uk/arts/research/pvcrs/2017/Jackson. Accessed 11 Jul. 2017.

---. "I, Clodia: I had a Dream I was a Ghost." Athens to Aotearoa: Greece and Rome in New Zealand Literature and Society, edited by Diana Burton, Simon Perris and Jeff Tatum, Wellington: Victoria University Press, 2017, pp. 94-111.

---. Pasture and Flock, New and Selected Poems. Auckland: Auckland University Press, 2018.

---. "Clodia Through the Looking-Glass." Antipodean Antiquities: Classical Reception Down Under, edited by Marguerite Johnson, London: Bloomsbury, 2019, pp. 117-127.

Jackson, Anna and Jenny Powell. Locating the Madonna. Wellington: Seraph Press, 2004.

Jackson, MacDonald. "Words and the Inner and Outer Worlds." The Oxford History of New Zealand Literature: In English, edited by Terry Sturm, Oxford: Oxford University Press, 1998, pp. 394-402.

Jakobson, Roman. On Linguistic Aspects of Translation. Cambridge: Harvard University Press, 1959, pp. 232-239.

Jankélévitch, Vladimir. Le je-ne-sais-quoi et le presque-rien. Paris: Presses Universitaires de France, 1957.

Jenner, Ted. A Memorial Brass. Eastbourne: Hawk Press, 1980.

Johnston, Andrew. "Entertaining Possibilities: Six Contemporary New Zealand Poets." Meanjin, vol. 51, no. 3, 1992, pp. 641-652.

Johnston, Andrew and Robyn Marsack, editors. Twenty Contemporary New Zealand Poets. Wellington: Victoria University Press, 2009.

Jones, Francis. Poetry Translating as Expert Action: Processes, Priorities and Network. Amsterdam: John Benjamin, 2011.

Juliet, Charles. Trois poèmes par Charles Juliet; with versions in English by Gregory O'Brien \& Jessie Munro. Wellington: Fernbank Studio, 2004.

---. "Trois poèmes écrits en Nouvelle-Zélande." Poetry NZ, no. 31, 2005, pp. 43-45.

Kaplan, Milton. "The Function of Stanzaic Form." The English Journal, vol. 60, no. 1, 1971, pp. 47-53.

Kennedy, Anne. Sing-Song. Auckland: Auckland University Press, 2003.

Kennedy, Melissa. Striding Both Worlds: Witi Ihimaera and New Zealand's Literary Traditions. Amsterdam: Rodopi, 2011.

Khardjiev, Nicolas and Vladimir Trenine. La Culture Poétique de Maïakovski. Lausanne: L'Age D'Homme, 1982.

Kimber, Gerri. Katherine Mansfield: The View From France. PhD, University of Exeter, 2007.

Kiraly, Donald. Pathways to Translation: Pedagogy and Process. Kent: Kent University Press, 1995. 
Knudsen, Eva. The Circle and the Spiral: A Study of Australian Aboriginal and New Zealand Māori Literature. Amsterdam: Rodopi, 2004.

Kristeva, Julia. Semiotike: Recherches pour une sémanalyse. Paris: Seuil, 1969.

---. "L'Amour de l'autre langue." Sommet du livre à la Bibliothèque nationale de France, 13 October 2014, Paris, Conference presentation, kristeva.fr/la-traduction-langue-de-l-europe.html. Accessed 9 Mar. 2017.

Kusch, Celena. Literary Analysis: The Basics. New York: Routledge, 2016.

Ladmiral, Jean-René. Sourcier ou cibliste: les profondeurs de la traduction. Paris: Les Belles Lettres, 2015.

Landers, Clifford. Literary Translation. A Practical Guide. Clevedon: Cromwell Press, 2001.

Laranjeira, Mário. "Sens et signifiance dans la traduction poétique." Meta, vol. 41, no. 2, 1996, pp. 217-222.

Larsen, David. "Book Review.” The Dominion Post, 24 Sep. 2000, p. 20.

Lavault-Olléon, Elisabeth. "Créativité et traduction spécialisée." ASp la revue du GERAS, no. 11-14, 1996, pp. 121-133.

---. "Le Skopos comme stratégie de déblocage: dialecte et scotticité dans Sunset Song de Lewis Grassic Gibbon." Meta, vol. 51, no. 3, 2006, pp. 504-523.

Lawrence, D. H.. Women in Love. 1920, Oxford: Oxford University Press, 1998.

Lechte, John. Julia Kristeva. London: Routledge, 2012.

Lefevere, André. Translating Poetry: Seven Strategies and a Blueprint. Assen: Van Gorcum, 1975.

---. Translation / History / Culture: a Sourcebook. New York: Routledge, 1992.

Levý, Jiří. The Art of Translation. Translated by Patrick Corness, Amsterdam: John Benjamins, 2011.

Lewis, Maxine. "Narrativising Catullus: a Never-ending Story." Melbourne Historical Journal, vol. 41, no. 2, 2013, pp. 1-19.

Lewis, Philip E.. "The Measure of Translation Effects." The Translation Studies Reader, edited by Lawrence Venuti, New York: Routledge, 2000, pp. 220-239.

Locke, Terry. "Review of Catullus for Children." Hyperpoetics, 2003, hyperpoetics.ac.nz/Genres/LockeReviews/CatullusChildren.htm. Accessed 8 Dec. 2016.

Loffredo, Eugenia and Manuella Perteghella. One Poem in Search of a Translator: Re-writing "Les Fenêtres" by Apollinaire. London: Peter Lang, 2009.

Low, Peter. "Singable Translations of Songs." Perspectives: Studies in Translatology, vol. 11, no. 2, 2003, pp. 87-103.

Lowell, Robert. Imitations. New York: Farrar, Straus, Giroux, 1961.

Maceau, Jean-Pierre. Dictionnaire poche maori. Paris: Fluo, 2017.

Machova, Mariana. Elizabeth Bishop and Translation. Lanham: Lexington Books, 2017.

Malroux, Claire. "Conjurer l'écart, susciter la rencontre, traduire la poésie." Sillages critiques, no. 12, 2011, pp. 1-39.

Mandelstam, Osip. The Complete Prose and Letters. Translated by Jane Gary Harris and Constance Link, Ann Arbor: Ardis, 1979.

Manhire, Bill. Milky Way Bar. Wellington: Victoria University Press, 1991.

---. "Dirty Silence: Impure Sounds in New Zealand Poetry." Dirty Silence: Aspects of Language and Literature in New Zealand, edited by Graham McGregor and Mark Williams, Auckland: Oxford University Press, 1991, pp. 143-157.

---. Doubtful Sounds. Wellington: Victoria University Press, 2000.

Manhire, Bill and Damien Wilkins, editors. The Best of Best New Zealand Poems. Wellington: Victoria University Press, 2011.

Mansfield, Katherine. La Garden Party et autres nouvelles. Translated by Marthe Duproix, Paris: Stock, 1929.

Markowicz, André. “Conférence d'André Markowicz.” Département d'études françaises, Concordia University, 15 Sept. 2006, Montréal, Québec, Conference Presentation.

Marsden, Peter. "From Waka to Whakapapa, or: Carving your own Canoe. The Verse of Robert 
Sullivan." New Zealand Electronic Poetry Centre, 2001,

nzepc.auckland.ac.nz/authors/sullivan/marsden.asp. Accessed 15 May 2018.

Marsh, Selina Tusitala. "Review of Voice Carried my Family." The Contemporary Pacific, vol. 18, no. 2, 2006, pp. 466-469.

Marshall, Cécile. "Goûter les mots ou comment traduire Tony Harrison.” E-Crini, no. 5, 2013, crini.univ-nantes.fr/.../marshall_cecile_1385721594329.pdf. Accessed 25 May 2018.

Masseau, Paola. Une traductologie de la poésie est-elle possible? La traduction du poème "toujours recommencée". Paris: Editions Publibook, 2012.

Matthews, Richards. Classical New Zealand Poetry based on Greek and Latin Models. Dunedin: Otago University Press, 1985.

Mayakovsky, Vladimir. Vladimir Mayakovsky. Moscow: Raduga, 1985.

---. Maïakovski. Vers 1912-1930. Paris: L'Harmattan, 2001.

McGavran, James, editor and translator. Vladimir Mayakovsky. Selected Poems. Evanston: Northwestern University Press, 2013.

McQueen, Cilla. “A Walk on the Wild Side." New Zealand Books, vol. 14, no. 65, 2004, pp. 24-25.

Michaux, Henri. L'Espace du dedans. Paris: Gallimard, 1966.

Millar, Paul, Geoffrey Miles and John Davidson. The Snake-Haired Muse James K. Baxter and Classical Myth. Wellington: Victoria University Press, 2011.

Moore, Marianne. A Marianne Moore Reader. New York: Viking Press, 1961.

---. Poésie complète, licornes et sabliers. Translated by Thierry Gillybœuf, Paris: Corti, 2004.

---. Observations. New York: Farrar, Straus and Giroux, 2016.

Moreau, Philippe. "Catulle et l'Inceste. Approches psychanalytique et anthropologique." Kentron, vol. 18 , no. 1-2, 2002, pp. 79-91.

Mounin, Georges. Les Belles Infidèles. Paris: Editions des Cahiers du Sud, 1955.

---. Les Problèmes théoriques de la traduction. 1961, Paris: Gallimard, 1976.

Munday, Jeremy. Introducing Translation Studies. Theories and Applications. London: Routledge, 2001.

Newman, Janet. Ecopoetry and the Imaginative Impulse. M.A. thesis, Massey University, 2015.

Nikkhou, Mahtab Mathilde. Guide maori de poche. Paris: Assimil éditions, 2010.

Ní Ríordáin, Clíona. "Bilingual Poetry Reading as a Problematics: Five Case Studies." Palimpsestes vol. 28, 2015, pp. 189-202.

Nooter, Sarah. "Review: Living Classics: Greece and Rome in Contemporary Poetry in English by S. J. Harrison." Modern Philology, vol. 110, no. 4, 2013, pp. 309-312.

Nord, Christiane. "Translation as a Process of Linguistic and Cultural Adaptation. The Functional Approach and its Consequences for Translation Teaching." Teaching Translation and Interpreting, edited by Cay Dollerup and Annette Lindegaard, Amsterdam: John Benjamins, 1994, pp. 59-67.

---. Translating as a Purposeful Activity. New York: Routledge, 1997.

---. "Defining Translation Functions. The Translation Brief as a Guideline for the Trainee Translator." Revista Ilha Do Desterro, vol. 33, 1997, pp. 39-55.

---. "Functional Translation Units." Translation - Acquisition - Use, no. 55. Jyväskylä: AFinLA Yearbook, 1997, pp. 41-50.

---. "Dealing with Purposes in Intercultural Communication: Some Methodological Considerations." Revista Alicantina de Estudios Ingleses, vol. 14, 2001, pp. 151-166.

--- "Loyalty Revisited: Bible Translation as a Case in Point." The Translator, vol. 7, no. 2, 2001, pp. 185-202.

---. "Manipulation and Loyalty in Functional Translation." Current Writing, vol. 14, no. 2, edited by Ileana Dimitriu, 2002, pp. 32-44.

---. Text Analysis in Translation. Theory and Methodology, and Didactic Application of a Model for Translation-Oriented Text Analysis. New York: Rodopi, 2005.

---. "Translating as a Purposeful Activity: A Prospective Approach.” TradTerm, vol. 11, 2005, 
pp. $15-28$.

---. "Loyalty and Fidelity in Specialised Translation." Confluências, vol. 4, 2006, pp. 29-41.

---. "Functionalist Approaches." Handbook of Translation Studies, edited by Yves Gambier and Luc Van Der Doorslaer, Amsterdam: John Benjamin, 2010, pp. 120-128.

--- "Making the Source Text Grow: a Plea Against the Idea of Loss in Translation." The Translator as Author, edited by Claudia Buffagni, Beatrice Garzelli and Serenella Zanotti, Berlin: LIT Verlag, 2011, pp. 21-28.

---. "Translating the Referential Function. About the Appropriate Balance between Presupposition and New Information.” 23 May 2013, Liège: Université de Liège, Conference presentation, 13.ulg.ac.be/colloquetraduction2013/textes/nord.pdf. Accessed 8 Nov. 2017.

---. "Function + Loyalty: Theology Meets Skopos." Open Theology, vol. 2, 2016, pp. 566-580, researchgate.net/publication/303908831_Function_Loyalty_Theology_Meets_Skopos. Accessed 5 Jul. 2018.

Normandin, Julie Stéphanie. "Compte-rendu de One Poem in Search of a Translator: Rewriting 'Les Fenêtres' by Apollinaire.” TTR, vol. 24, no. 2, 2011, pp. 239-242.

Obolensky, Dimitri. The Penguin Book of Russian Verse. London: Penguin, 1962.

O’Brien, Gregory. Location of the Least Person. Auckland: Auckland University Press, 1987.

---. “A Journey Around Kendrick Smithyman's Atua Wera." Landfall, no. 194, 1997, pp. 306-321.

---. After Bathing at Baxter's: Essays and Notebooks. Wellington: University of Victoria Press, 2002.

---. "Janet Frame Memorial Lecture 2008. Reflections on New Zealand Arts and Letters Dedicated to the Memory of Robin Dudding." Wellington: 31 Aug. 2008, lecture, authors.org.nz/wpcontent/uploads/2015/08/2008-Lecture-by-Gregory-OBrien.pdf. Accessed 5 May 2016.

O'Hara, Frank. The Collected Poems of Frank O'Hara. Berkeley: University of California Press, 1995.

Orbell, Margaret. The Illustrated Encyclopaedia of Māori Myth and Legend. Christchurch: Canterbury University Press, 1995.

Orr, Bridget. "Robert Sullivan's Captain Cook: Absolving 'Endeavour James'?” Truth and Beauty, Wellington: Victoria University Press, 2016, pp. 187-207.

Osers, Ewald. "Some Aspects of the Translation of Poetry." Meta, vol. 23, no. 1, 1978, pp. 7-19.

O’Sullivan, Vincent. The Butcher Papers. Auckland: Oxford University Press, 1982.

---. “4 poèmes de Vincent O'Sullivan.” Translated by Jean Anderson and Charles

Juliet, Voix d'Encre, no. 33, 2005, pp. 23-26.

---. Cette voûte de si pur respir. Translated by Anne Mounic, Paris: L'Inventaire, 2006.

Oyali, Uchenna. "A Critique of Functionalist Approaches to Translation Studies." Journal of the Linguistic Association of Nigeria, vol. 18, no. 1, 2015, pp. 51-64.

Paterson, Don. Orpheus. A Version of Rilke's Die Sonette an Orpheus. London: Faber and Faber, 2006.

Pawliez, Myreille and Ewen Jones. Dictionnaire néo-zélandais-français. Paris: L'harmattan, 1998.

Paz, Octavio. "Translation, Literature and Letters." 1971, Theories of Translation from Dryden to Derrida, edited by Rainer Schulte, and John Biguenet, translated by Irene del Corral, Chicago: Chicago University Press, 1996, pp. 152-162.

Pecastaing, Sandy. Poe et Baudelaire: pour une hantologie du texte. $\mathrm{PhD}$, Université Bordeaux Montaigne, 2013, tel.archives-ouvertes.fr/tel-00997440/document Accessed 17 Feb. 2017.

Peeters, Kris. "Traduction, retraduction et dialogisme." Meta, vol. 61, no. 3, 2016, pp. 629-649.

Perris, Simon. "Orpheus, Māui and the Underworld in New Zealand Literature." Athens to Aotearoa: Greece and Rome in New Zealand Literature and Society, edited by Diana Burton, Simon Perris and Jeff Tatum, Wellington: Victoria University Press, 2017, pp. 182-192.

Petrilli, Susan. Translation Translation. Amsterdam: Rodopi, 2003.

Pfeffer, Sarah. "Palms Require Translation": Derek Walcott's Poetry in German. Three Case Studies. Kassel: Kassel University Press, 2016.

Pingoud, Julien. "Le Carmen 16, cinq traductions françaises." Jeux de voix, Bern: Peter Lang, 2009, 
pp. 89-118.

Pollmanns, Milena. The Imagist Poem: Hilda Doolittle (H. D.) - "Sea Rose”. Munich: GRIN Verlag, 2010.

Pope, Quentin. Kowhai Gold: An Anthology of Contemporary New Zealand Verse. London: Dent, 1930.

Pound, Ezra. Cathay. London: Elkin Mathews, 1915.

---. "How to Read." 1929, Translation - Theory and Practice. A Historical Reader, edited by Daniel Weissbort and Astradur Eystenssein, Oxford: Oxford University Press, 2006, pp. 274-285.

Prentice, Chris. “'A Knife through Time': Robert Sullivan's Star Waka and the Politics and Poetics of Cultural Difference.” Ariel: A Review of International English Literature, vol. 37, no. 2-3, 2006, pp. 111-35.

Prime, Patricia. "Review of Thicket by Anna Jackson." Takahe, no. 75, 2012, takahe.org.nz/oldsite/reviews/t75/Takahe75Thicket.pdf. Accessed 17 Feb. 2017.

Pym, Anthony. "Review of Text Analysis in Translation by Christiane Nord." TTR, vol. 6, no. 2, 1993, pp. 184-190.

---. "Material Text Transfer as a Key to the Purposes of Translation." Basic Issues in Translation Studies, vol. II, edited by Neubert, et al., Kent: Institute of Applied Linguistics, 1996, pp. 337-346.

---. Exploring Translation Theories. New York: Routledge, 2010.

---. "The Translator as Non-Author, and I am Sorry About That." The Translator as Author, edited by Claudia Buffagni, Beatrice Garzelli and Serenella Zanotti, Berlin: LIT Verlag, 2011, pp. 31-44.

---. “Translating as Risk Management.” Journal of Pragmatics, no. 85, 2015, pp. 67-80.

Quinn, Kenneth. The Catullan Revolution. London: Cambridge University Press, 1959.

Racz, Gregary. "No Anxiety of Influence: Ethics in Poetry Retranslation after Analogical Form." Translation Review, vol. 85, no. 1, 2013, pp. 42-58.

Ramond, Charles. Le Vocabulaire de Jacques Derrida. Paris: Ellipses, 2004.

Reiss, Katharina. La Critique des traductions, ses possibilités et ses limites. Translated by Catherine Bocquet, Arras: Artois Presses Université, 2002.

Ricketts, Harry and Paula Green. 99 Ways into New Zealand Poetry. Auckland: Random House, 2010.

Ricketts, Harry, James Norcliffe and Siobhan Harvey, editors. Essential New Zealand Poems. Facing the Empty Page. Auckland: Godwit Press, 2014.

Ricoeur, Paul. Sur la traduction. Paris: Bayard, 2004.

Riemenschneider, Dieter. "Contemporary Māori Cultural Practice: from Biculturalism towards a Glocal Culture.” JNZL, no. 18/19, 2000/2001, pp. 139-160.

Robinson, Peter. Poetry and Translation: the Art of the Impossible. Liverpool: Liverpool University Press, 2010.

Ross, Jack. “Troubling Our Sleep: Ted Jenner's Postmodern Classicism.” Ka Mate, no. 8, 2009, pp. 46-66.

---. "Interview with Robert Sullivan." Poetry New Zealand Yearbook, vol. 2, no. 50, 2015, pp. 23-38.

Roubaud, Jacques. La Vieillesse d'Alexandre. Paris: Maspero, 1978.

Rouzeau, Valérie. Talking Vrouz. Translated by Susan Wicks, London: Arc Publications, 2013.

Scudder, Erin. "Dear Thief: Anna Jackson's The Gas Leak." JNZL, vol. 35, no. 2, 2017, pp. 131-150.

Sewell, Bill and Lauris Edmond, editors. Essential New Zealand Poems. Auckland: Random House, 2001.

Sharp, Iain, "Introduction.” Best New Zealand Poems 2001, April 2002, victoria.ac.nz/modernletters/bnzp/2001/introduction.html Accessed 5 Sep. 2016.

Sheringham, Michael. Everyday Life: Theories and Practices from Surrealism to the Present. Oxford: Oxford University Press, 2006.

Siltanen, Elina. Experimentalism as Reciprocal Communication in Contemporary American Poetry. 
New York: Routledge, 2016.

Skinner, Marilyn. "Ego Mulier: The Construction of Male Sexuality in Catullus." Helios, vol. 20, no. 2, 1993, pp. 107-130.

Smith, Stevie. Poèmes. Translated by Anne Mounic, Paris: L'Harmattan, 2003.

---. The Collected Poems and Drawings of Stevie Smith. London: Faber and Faber, 2015.

Smithyman, Kendrick. Stories about Wooden Keyboards. Auckland: Auckland University Press, 1985.

---. Atua Wera. Auckland: Auckland University Press, 1997.

Snell-Hornby, Mary. Translation Studies: an Integrated Approach. Amsterdam: John Benjamins. 1988.

Sneyd, Rose Harriet. A Poetics of Reciprocity: Elizabeth Barrett Browning 's Ballads and Sonnets. M.A. thesis, Wellington: Victoria University of Wellington, 2012,

Soupel, Serge. "Equilibres et harmonies dans la traduction.” Palimpsestes, no. 14, 2001, pp. 149-152.

Spath, Thomas. "Compte-rendu de Roman Sexualities de Judith Hallett et Marilyn Skinner." Annales, vol. 57, no. 3, 2002, pp. 715-717.

Stafford, Jane and Mark Williams, editors. The Auckland University Press Anthology of New Zealand Literature. Auckland: Auckland University Press, 2012.

Stead, C. K.. "Towards Jerusalem: The Later Poetry of James K. Baxter." Islands, vol. 2, 1973, pp. 7-18.

---. Shelf Life. Auckland: Auckland University Press, 2016.

Sturm, Terry. "New Zealand Poetry." A Companion to Twentieth-Century Poetry, edited by Neil Roberts, Oxford: Blackwell, 2003, pp. 293-303.

Sullivan, Robert. Jazz Waiata. Auckland: Auckland University Press, 1990.

---. Pike Ake! Auckland: Auckland University Press, 1993.

---. Captain Cook in the Underworld. Auckland: Auckland University Press, 2003.

---. Voice Carried my Family. Auckland: Auckland University Press, 2005.

---. "Interview with Selina Tusitala Marsh." Filmed on 23 May 2005 at the Centre for Flexible and Distance Learning, Auckland University, nzepc.auckland.ac.nz/pasifika/sullivan3.asp. Accessed 15 Jun. 2018.

---. Shout Ha! To the Sky. London: Salt Publishing, 2010.

---. Sternen-Waka: Eine Lyrische Maori-Erzählung. Translated by Jörg-Stephan Mohr and Lotta Schneidemesser, Berlin: MANA-Verlag, 2012.

---. Mana Moana: Wayfinding and Five Indigenous Poets. PhD, University of Auckland, 2015.

Te Punga Somerville, Alice. Once Were Pacific: Māori Connections to Oceania. Minneapolis: University of Minnesota Press, 2012.

Tissot, Marlène. Dernier Arrêt avant l'insomnie. Last Stop Before Insomnia. Translated by Anna Jackson and Geneviève Chevallier, Wellington: Seraph Press, 2017.

Tolron, Francine. La Nouvelle-Zélande: du duel au duo? Essai d'histoire culturelle. Toulouse: Presses Universitaires du Mirail, 2000.

Toury, Gideon. Descriptive Translation Studies - and Beyond. Amsterdam: John Benjamins, 2012.

Trivellini, Samanta. "Inhabiting the Classic, Constructing the Self: Translated and Translating Voices in Josephine Balmer's Poetry." Altre Modernita, no. 17, 2017, pp. 64-81.

Tuwhare, Hone. Sap-Wood and Milk. Dunedin: Caveman Press, 1972.

---. Making a Fist of it. Dunedin: Jackstraw Press, 1978.

Uzzi, Jeannine Diddle. The Poems of Catullus: an Annotated Translation. Cambridge: Cambridge University Press, 2015.

Valéry, Paul. "Au sujet du Cimetière marin.” Euvres I, Paris: Gallimard, 1957, pp. 1496-1507.

Vegliante, Jean-Charles. D'écrire la traduction. Paris: Presses de la Sorbonne Nouvelle, 1996.

Veith, Gene. Omnibus IV: The Ancient World. Lancaster: Veritas Press, 2009.

Venuti, Lawrence. The Translator's Invisibility. A History of Translation. London: Routledge, 1995.

---. The Translation Studies Reader. New York: Routledge, 2000. 
---. “Adaptation, Translation, Critique.” Journal of Visual Culture, vol. 6, no. 1, 2007, pp. 25-43.

---. "Translation, Intertextuality, Interpretation." Romance Studies, vol. 27, no. 3, 2009, pp. 157-173.

---. "The Poet's Translation or An Ethics of Translation." Translation Studies, vol. 4, no. 4, 2011, pp. 230-247.

Vermeer, Hans. "In Rahmen für eine allgemeine Translationstheorie." Lebende Sprachen, vol. 23, no. 3, 1978, pp. 99-102.

---. A Skopos Theory of Translation. Heidelberg: TEXTconTEXT-Verlag, 1996.

Vinay, Jean-Pierre and Jean Darbelnet. Stylistique comparée du français et de l'anglais. Paris: Didier, 1977.

---. Comparative Stylistics of French and English: A Methodology for Translation. Translated by Juan C. Sager and M. J. Hamel, Amsterdam: John Benjamins, 1995.

Vuaille-Barcan, Marie-Laure. Transfert de langue, transfert de culture. Bern: Peter Lang, 2012.

Ward, Judith. The Invention of Papahurihia. PhD, Massey University, 2016.

Wedde, Ian. Earthly: Sonnets for Carlos. Dunedin: Amphedesma Press, 1975.

Wedde, Ian and Harvey McQueen, editors. The Penguin Book of New Zealand Verse. Auckland: Penguin, 1985.

Weissbort, Daniel, Translating Poetry: The Double Labyrinth. London: MacMillan Press, 1989.

Whigham, Peter. Catullus. The Poems. London: Penguin, 2004.

Wilkinson, Jessica. "Jessica Wilkinson interviews Anna Jackson.” Cordite Poetry Review, 1 Aug. 2015, cordite.org.au/interviews/wilkinson-jackson/. Accessed 29 Nov. 2016.

Williams, Mark and Elizabeth Gordon. "Raids on the Articulate: Code-Switching, Style-Shifting and Post-Colonial Writing." Journal of Commonwealth Literature, vol. 33, no. 2, 1998, pp. 75-96.

Williams, William Carlos. Poetry for Young People. Edited by Christopher MacGowan, New York: Steerling Publishing, 2003.

Wittwer, Melanie. "Review of Thicket." The Reader, 9 Jul. 2012, booksellersnz.wordpress.com/2012/07/09/book-review-thicket-by-anna-jackson/. Accessed 7 Dec. 2016.

Wright, Paul. "Review of Catullus for Children." British Review of New Zealand Studies, no. 14, 2003, pp. 199-201. 


\section{Translating Contemporary New Zealand Poetry into French:}

Anna Jackson and Robert Sullivan

Luc Arnault

APPENDIX

Victoria University of Wellington

2020 



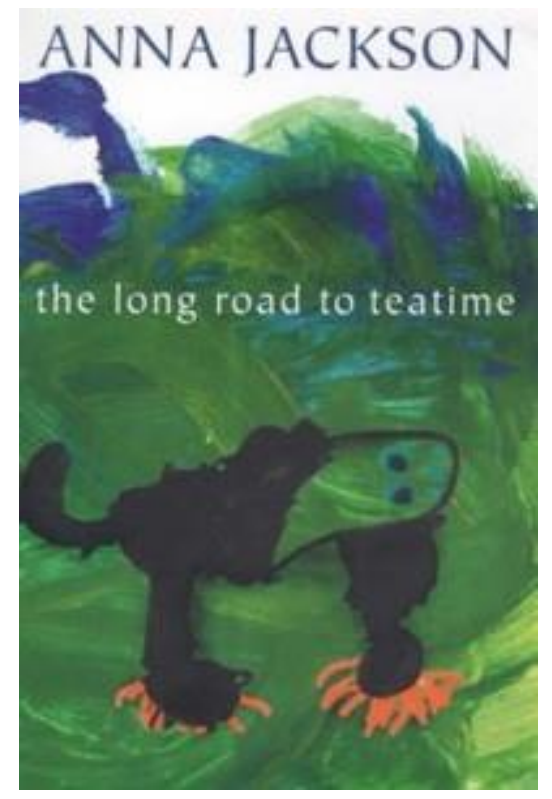

16 Pākehā Waka / 16 Waka pākehā p. 3

Just a Mineral Water with Marianne Moore / Juste une eau minérale avec Marianne Moore p. 11

Breakfast with Katherine Mansfield / Petit-déjeuner avec Katherine Mansfield p. 13

The Long Road to Teatime / La Longue Route du goûter p. 14 


\section{Pākehā Waka}

Just as Māui once chanted the Hiki to make heavy weights light and so from his waka pulled up New Zealand on his fish hook

so Robert Sullivan has the way with words to make light the whole heavy mythology of New Zealand

and pull it up, up, up to burst into the supermarkets and mortgaged houses of his Star Waka,

his life, our lives.

I paddle my waka in his slipstream.

Robert's Waka 80 tells of Peter Robinson's painting of all the white canoes and the one brown canoe that depict his ancestry, one part Māori.

Of my sixteen waka lined up on the beach, none would be painted brown.

My families came from Scotland and the north of England.

They brought the name Cameron and the Cameron tartan form Scotland

\section{Waka pākehā}

1

Tout comme Māui chanta jadis le Hiki pour rendre tous les poids légers, et ainsi à bord de son waka tira la Nouvelle-Zélande de son hameçon,

ainsi Robert Sullivan sait par les mots rendre léger tout le poids de la mythologie de Nouvelle-Zélande,

la faire monter, monter, jusqu'à exploser dans les supermarchés et les maisons hypothéquées de son Star Waka,

sa vie, nos vies.

Je pagaie mon waka dans son sillage.

Le waka 80 de Robert parle d'un tableau de Peter Robinson où toutes les pirogues blanches et une seule pirogue brune représentent ses ancêtres, en partie māori.

De mes seize waka alignés sur la plage, aucun ne serait peint en brun.

Mes familles vinrent d'Ecosse et du nord de l'Angleterre.

D'Ecosse, elles apportèrent le nom Cameron et le tartan du clan Cameron 
and from England a Bible recording the names of many Margarets

all linked up with pencil lines to delineate the family tree.

3

One of my sixteen waka arrived in Auckland in 1860 , the Ellen Lewis from Nova Scotia, and on board my great-great-grandparents, John and Flora McDonald.

Thomas and Mary Ann Jackson arrived on the second of my sixteen waka, the Burns, in 1879.

A shoemaker, and the daughter of a shoemaker,

they taught school, dispensed medicine and the Quaker faith. Their son Theodore married Margaret McDonald and in 1904 my father's father was born.

4

Most of the eight waka of my mother's family landed in nineteenth-century Tasmania

where family fortunes rose and fell like waves.

My mother's mother Elaine was the rich daughter of John Speed who came to Australia a poor cobbler and made a fortune in shoes.

My mother's father John Lovett was the poor son of a wealthy Tasmanian family who lost everything et d'Angleterre une bible comportant les noms de nombreuses Margaret,

toutes reliées par des lignes au crayon pour tracer l'arbre de la famille.

L'un de mes seize waka arriva à Auckland en 1860, le Ellen Lewis de Nouvelle-Ecosse, avec à son bord, mes arrière-arrière-grands-parents, John et Flora McDonald.

Thomas et Mary Ann Jackson arrivèrent sur le deuxième de mes seize waka, le Burns, en 1879.

Cordonnier et fille de cordonnier,

ils dispensaient les médicaments, l'instruction et la foi Quaker. Leur fils Theodore épousa Margaret McDonald et en 1904 , le père de mon père naquit.

La plupart des huit waka du côté de ma mère débarquèrent au dix-neuvième siècle en Tasmanie où la fortune de la famille monta puis descendit en vagues.

La mère de ma mère Elaine était la fille riche de John Speed qui arriva en Australie simple cordonnier et fit fortune dans la chaussure.

Le père de ma mère, John Lovett était le fils pauvre d'une famille riche de Tasmanie qui perdit tout 
in the Depression. He rose again with Speed Shoes.

My father's mother, Margaret, was the daughter of doctor Adam Pairman, the son of doctor Robert Pairman.

Adam's brother Thomas was a doctor too, and a reader of Dante,

who started Dante reading groups all over settler New Zealand and gave a translation of the Paradiso to my Gran, long before I translated it into my own life. He called his daughter Beatrice.

6

My brother is Cameron,

I am Anna,

my sister is Juliet.

Shakespeare's three children were Hamnet, Susanna, and Judith.

And they were shadow names too. Names, manes.

When Simon and I crossed seas to England we carried with us a daughter's name.

We would call our baby Elvira pendant la Dépression. Il se releva avec les chaussures Speed.

La mère de mon père, Margaret, était la fille du docteur Adam Pairman, fils du docteur Robert Pairman.

Thomas, le frère d'Adam, aussi était docteur, il lisait Dante,

montait des cercles de lecture de Dante partout dans la Nouvelle-Zélande des colons et donna une traduction du Paradiso à ma mamie, bien avant que je le traduise dans ma propre vie. Il appela sa fille Beatrice.

6

Mon frère s'appelle Cameron,

je m'appelle Anna

et ma sœur, Juliet.

Les trois enfants de Shakespeare s'appelaient Hamnet,

Susanna

et Judith.

Et c'était aussi des noms en ombre.

Des noms émanent des mânes.

7

Quand Simon et moi avons traversé les mers jusqu'en Angleterre, nous portions avec nous le nom d'une fille.

Nous appellerions notre bébé Elvira 
after the pinball game we played at Urbi et Orbi.

Of the town, and of the world.

8

The baby carved me out inside and I was a waka for a fish

that was a waka for a

person.

There is all the taonga of my tohunga to pack.

I carve translations for Mayakovsky, Ovid and Dante.

There is a dark wood to carve into a would.

10

The baby carries the language genes we have carried across the generations

since our hair grew sparse on our skins and our babies, unable to cling,

cried out to us to speak. d'après le jeu de flipper auquel nous jouions à Urbi et Orbi.

De la ville et du monde.

8

Le bébé m'a sculptée de l'intérieur j'étais un waka pour un poisson qui serait un waka pour une personne.

Il y a tous les taonga de mon tohunga à empaqueter.

Je sculpte des traductions pour Mayakovsky, Ovide et Dante.

Il y a un bois noir à sculpter en un vouloir-espoir.

10

Le bébé porte le gêne des langues que nous portons depuis des générations

nos poils s'étant clairsemés sur notre peau, nos bébés, incapables de s'accrocher,

pleurèrent pour nous faire parler. 
We sang.

11

We call the baby Johnny after Johnny Cash. We call the baby Johnny after Johann Bach.

We call the baby Johnny after Grandpa John.

Sometimes we call him Johnny Smoke.

Johnny calls himself Envelope Man.

He calls himself Superhero and Batman.

Sometimes he's a polar bear and sometimes a rabbit.

Elvira calls him 'bruvva'.

12

Simon's ancestors were Welsh,

French, Spanish.

He grew up on ships sailing to and from

Wales and New Zealand.

We went to Wales, to Bangor, where he was born, but couldn't find the hospital,

and I wanted to swim in the municipal baths but they didn't hire out togs.

What we liked best about Wales was

how much more like New Zealand it seemed

than England.
Nous chantions.

11

Nous appelons le bébé Johnny pour Johnny Cash.

Nous appelons le bébé Johnny pour Johann Bach.

Nous appelons le bébé Johnny pour grand-père John.

Parfois nous l'appelons Johnny Smoke.

Johnny préfère s'appeler Envelope Man.

Ou Super-héros ou Batman.

Parfois c'est un ours polaire ou parfois un lapin.

Elvira l'appelle son "ffwè".

12

Les ancêtres de Simon étaient gallois,

français et espagnols.

Il a grandi sur des navires qui naviguaient entre le Pays de Galle et la Nouvelle-Zélande.

On est allés au Pays de Galle, à Bangor, où il est né, mais on n'a pas réussi à trouver l'hôpital,

j'aurais bien voulu nager à la piscine municipale mais on ne pouvait pas louer de maillot de bain.

Ce qu'on a le plus aimé au Pays de Galle

c'est que ça ressemble plus à la Nouvelle-Zélande

que l'Angleterre. 
England is Johnny's Hawaiiki - somewhere like Home, too far away to visit

but the source of miraculous things,

like Rose, and toys from English toy shops.

He was born there, but remembers only here. He asks, 'Is England the olden days?'

It is his once upon a time, his happy ever after.

We went to Spain when Johnny was still a fish inside me - smaller than a trout -

and in the heart of Spain found Elvira street.

We would have bought tiles with E L V I R A on

but the shop was closed for the winter we had come outside the tourist season.

I took a photo of Simon in Elvira street under graffiti of his name $-\mathrm{S}$ I M O N -

and he photographed me under the sign E L V I R A with Johnny, who might have been Elvira,

invisible inside me.
L'Angleterre est le Hawaiiki de Johnny - un lieu originel, trop loin pour visiter

mais source de choses miraculeuses,

comme Rose ou les jouets des magasins anglais.

Né là-bas, il ne se souvient que d'ici.

Il demande: "l'Angleterre, c'est autrefois?"

C'est son "il était une fois", son "ils vécurent heureux".

\section{4}

On est allés en Espagne quand Johnny n'était qu'un poisson à l'intérieur de moi - plus petit qu'une truite -

et au cœur de l'Espagne on a trouvé la rue Elvira.

On aurait bien acheté des ardoises E L V I R A

mais le magasin était fermé l'hiver on était venus hors saison.

J'ai pris une photo de Simon rue Elvira sous son nom en graffiti - S I M O N -

et il m'a prise en photo sous le panneau E L V I R A avec Johnny, qui aurait pu être Elvira,

invisible en moi. 
Simon is fifteen-sixteenths Celtic, a descendant of those restless Celts who kept moving

right to the edges of Europe, and across the Channel to the edges of Britain, heading for the edge of the world.

The Greeks thought them barbarians in their hilltop huts, a story-telling, war-waging people who spoke no Greek.

Today the Welsh children are relearning their language in language nests like the Kōhanga Reo.

We were going to call Elvira Ifor, the Welsh name for Johnny.

16

Our daughter was born at last, in New Zealand, at home, in the bath, on the $7^{\text {th }}$ of February

after a Waitangi Day of contractions.

We call her Elvira - a Spanish name

meaning fair one - foreigner - Pākehā.

At sixteen months, she still rows herself about on the floor, bottom-shuffling.

Not a walker, but a waka my waka to the stars.
Simon est à quinze-seizième celte, descendant de ses infatigables Celtes qui se déplaçaient sans cesse

jusqu'aux confins de l'Europe, à travers la Manche jusqu'au bout de l'Angleterre, cherchant le bout du monde.

Pour les Grecs, c'était des barbares dans des huttes en hauteur, un peuple guerrier, des conteurs qui ne parlaient pas grec.

Aujourd'hui les enfants gallois réapprennent leur langue dans des nids de langue comme le Kōhanga Reo.

Nous allions appeler Elvira Ifor, le nom gallois pour Johnny.

16

Notre fille est née, enfin, en Nouvelle-Zélande, à la maison, dans la baignoire, le 7 février

après une journée de contractions pour Waitangi Day.

On l'a appelée Elvira - un nom espagnol

qui veut dire belle - étrangère - Pākehā.

A seize mois, elle ne marche pas encore mais rame par terre, le derrière qui traîne.

Mais pas de tracas, c'est un waka mon waka vers les étoiles. 
Notes $^{1057}$

Waka : véhicule, pirogue traditionnelle māori.

Pākehā : relatif aux hommes et femmes blancs.

Māui : héros et demi-dieu de la mythologie māori, célèbre pour ses exploits surnaturels. Il hissa notamment la Nouvelle-Zélande du fond de l'océan.

Hiki : chant ou prière.

Star Waka : livre de poèmes de Robert Sullivan (1999) reprenant notamment le rituel whakapapa qui consiste à énumérer sa généalogie.

Taonga : trésors matériels ou immatériels.

Tohunga : expert, sage, sorcier, prêtre ou guérisseur.

Hawaiiki : île imaginaire, lieu originel d'où les Māori seraient partis.

Kōhanga Reo : programme scolaire d'immersion linguistique māori, littéralement nid de langue.

Waitangi Day : journée nationale de la Nouvelle-Zélande qui célèbre la signature du Traité de Waitangi entre la couronne britannique et les chefs des principales tribus māori, le 6 février 1840 .

1057 Dans l'ordre d'apparition dans le texte et à partir du dictionnaire en ligne maoridictionary.co.nz 


\section{Just a Mineral Water with Marianne Moore}

who would have had "orange zuice,

farina, banana",

earlier

and then would have written

several poems in syllabic measure.

Well I'm not afraid of getting my head bitten off by this American treasure,

her purse

clasped in her lap, head shadowed

by her hat, her great hat

framing that

face all smiles and wrinkles

as she disagrees with what I haven't said.

'No indeed, no not I, not at all,' she twinkles,

nor am I much too disconcerted

by that

stone sharp poet laureate.

Phrase by phrase she decon-

structs each one

of the principles she

expounds. She'll say once again, 'why paraphrase?'

A 'collection of lies in amber' gaily she

refers to the particular ways

she makes

her own so strict use of quotes
Juste une eau minérale avec Marianne Moore

qui prendrait "un zus d'oranze,

floraline et banane"

avant ça

puis écrirait après

plusieurs poèmes en mètres syllabiques

mais je n'ai pas peur de me faire mordre la tête

par ce trésor venu d'Amérique

son sac

sur les genoux, tête à l'ombre

sous son chapeau splendide

encadrant

ce sourire tout de rides

quand elle réfute ce que je n'ai pas dit.

"Non, mais non, mais non pas du tout", elle pétille,

non que je sois vraiment déconfite

par tant

d'acuité chez cette Poète.

Phrase par phrase, elle décon-

struit chaque

principe qu'elle énonce.

Elle répétera : "pourquoi paraphraser?"

Un "amas de bouches prises dans l'ambre", gaie réponse

sur le moyen strict, particulier,

qu'elle a

de faire siennes les citations 
but I could swear I caught

sight of at

least a fly paralysed

if not paraphrased in her quotation.

She left. I poured an orange juice, sighed,

poured and drank instead a Sapphire gin.

Then wrote. mais je jurerais avoir

$\mathrm{vu}$, prise,

une mouche paralysée,

non paraphrasée dans sa citation.

Elle est partie. J'ai versé le jus, soufflé,

puis bu un Gin à la place, j'ai donc

écrit. 


\section{Breakfast with Katherine Mansfield}

The moon is still in the sky when we come to the table and the sky is like a mown field labelled

morning. Ms Mansfield coughs and cannot get enough of the cream cheese. Johnny laughs and laughs

like a rooster, he thinks she is acting

being a car, but she sounds more like a tractor

that won't start. After she leaves the table I retrieve

the napkin she scribbled on, but all I can make out is 'grieve'.

\section{Petit-déjeuner avec Katherine Mansfield}

La lune est encore dans le ciel quand nous passons à table et le ciel est comme un pré d'herbe coupée comparable

à la matinée. Miss Mansfield tousse et se régale du fromage blanc. Johnny se marre et rigole

comme un enfant, un coq qui croit qu'elle fait semblant d'être une voiture, mais c'est plutôt un tracteur récalcitrant

qui ne démarre pas. Quand elle sort de table, d'un coup d'œil je lis sur sa serviette ses ratures, gribouillis dont je ne tire que "deuil". 
The Long Road to Teatime

\section{The Road to Karekare}

In the middle of our journey we found ourselves lost.

'This is the jungle,' said Johnny.

Rose asked if we had a map.

'Not a road map,' said Simon.

'So what sort do you have?'

We looked for a life map.

In the middle of the journey of my life, I sat on one side of Elvira and Rose sat on the other. I have known Elvira for sixteen months since she was born,

Rose for sixteen years.

At Karekare Rose and I left the children to walk the length of the beach.

'What was it like?' she asked.

It was like a dark wood.

We walked across sand

next to water, under sky.

We walked back to the car across the dunes and through a wood of cabbage trees.

Johnny said, 'Be quiet
La Longue Route du goûter

\section{La Route de Karekare}

Au milieu de notre voyage nous nous sommes perdus.

"C'est la jungle" a dit Johnny.

Rose a demandé si nous avions une carte.

"Pas de carte de la route" a dit Simon

"Alors quelle sorte de carte vous avez ?" Nous avons cherché une carte de la vie.

Au milieu du voyage de ma vie, je me suis assise d'un côté d'Elvira et Rose s'est assise de l'autre. Ça fait seize mois que je connais Elvira, depuis qu'elle est née, et Rose, depuis seize années.

A Karekare, Rose et moi avons laissé les enfants pour marcher le long de la plage.

"C'était comment?" a-t-elle demandé.

C'était comme un bois noir.

Nous avons marché dans le sable près de l'eau, sous le ciel.

Nous sommes revenues à la voiture en passant par les dunes et un bois de cordylines.

Johnny a dit: "faites pas de bruit 
or the wild things will hear.'

There might have been a leopard.

There were dogs.

\section{My friendship with Dante}

Lost in the dark wood I want to rekindle my affair with the sun.

I look about for my stiletto-heeled

black leather boots to put on.

It is too dark to see.

Three beasts stand between the sun and me.

Simon, Johnny and Elvira stand at the top of the hill and howl at me. 'We are baby panthers.'

Elvira howls at the sight

of my wool work coat.

I can't get past.

But out of the obscurity emerges the figure of a man, weak, as if his lungs have been still too long.

It is Dante, of course.

Dante! Can't you take me to the sun?

But Dante has to take me first along the path he once was led along by Virgil.

'Another poet will take you to the sun.

Frank O'Hara knows the sun well

and knows the way to Paradise.

But I can show you the way to hell.' ou les bêtes sauvages vont vous entendre."

Il y aurait pu y avoir un léopard.

Il y avait des chiens.

\section{Mon amitié avec Dante}

Perdue dans ce bois noir je veux raviver mon histoire avec le soleil.

Je cherche mes bottes en cuir noir

et à talon-aiguille partout.

Trop noir pour y voir.

Trois bêtes se tiennent là entre le soleil et moi.

Simon, Johnny et Elvira au sommet de la colline me hurlent : "Nous sommes des bébés panthères."

Elvira hurle en voyant

mon caban en laine.

Je ne peux pas passer.

Mais surgie de l'obscurité émerge la silhouette d'un homme,

faible, comme si ses poumons s'étaient arrêtés trop longtemps.

C'est Dante, bien sûr.

Dante ! M'emmèneras-tu au soleil ?

Mais Dante doit d'abord me faire suivre le chemin qu'il a jadis emprunté pour suivre Virgile.

"C C'est un autre poète qui t'emmènera au soleil.

Frank O'Hara connaît bien le soleil, lui,

et le chemin du Paradis.

Mais moi je peux te montrer le chemin de l'enfer.' 
And so to escape the three beasts

I take Dante by the hand.

When he moves on, I move on close behind.

\section{Into darkness}

Dante's Cantos are 'missiles for capturing the future'. But they lead me into the dark.

But I am not Ciardi! Mandelbaum! Barely published! My friendship with Mayakovsky is my sole claim to fame.

Can I translate the Inferno, knowing no Italian?

'Oh, come on. I am doing this for Frank and Emily Dickinson and all the other poets of the sun. They recognise you and even I picked you in the dark. Why delay?'

And just as flowers rise again from their night postures

when the sun drives into their stems, I too stand tall.

Where Dante goes I will follow after. I start on the road to hell.
C'est ainsi que pour échapper aux trois bêtes je prends Dante par la main.

Quand il repart, je suis tout près

derrière.

\section{Descente dans l'obscurité}

Les Cantos de Dante sont "des missiles pour capturer l'avenir". Mais ils me mènent dans le noir.

Mais je ne suis pas Ciardi ! Mandelbaum! A peine publiée! Mon amitié avec Mayakovsky est ma seule prétention à la gloire.

Puis-je traduire l'Inferno, sans connaître l'italien?

"Allons. Je fais ça pour Frank, pour Emily Dickinson et tous les autres poètes du soleil. Ils te reconnaissent et même moi, je t'ai repérée dans le noir. Pourquoi attendre?"

Et comme les fleurs se relèvent de leurs positions nocturnes lorsque le soleil parcourt leurs tiges, Je me tiens droite aussi.

Où Dante ira je suivrai. Je prends la route de l'enfer. 


\section{$4 \quad$ I meet up with the spineless}

Now what comes next is not all good to tell and I'm sorry to put you through it but for the sake of those who will call this present the olden days I'll let those present resent me and write on.

Dante smiles as he leads me through the gates, and as I read the fearful words carved there he slides an arm familiarly around my shoulders like a heavy ray of sunshine.

And here are those who were to cool to speak. So this is where you ended up when I vomited you out of my mouth!

I recognise you but I will name no names. Yet. I am tired at the thought of you.

\section{I wake up amongst the lustful gluttons}

I wake up and at first I think I am back on Ponsonby Road. A greesy cheesy smell of food thickens the air till I lift my feet. Then another smell stirs and rises from the ground, a smell of rotting meat and fruit scraps turning slimily to earth.

The slime seems bottomless underfoot but is so thick with its own stench it supports my weight.

The restaurants all spill onto the footpath, drunken customers lurch out and lie in the gutter pressing their lips slackly on each other's mouths.

\section{Je rencontre les lâches}

Tout ce qui va suivre désormais n'est pas bon à dire et je suis désolée de vous y faire passer

mais au nom de ceux qui appellent ce présent l'autrefois, je laisse les ressentiments des présents passer et poursuis.

Dante me guide à travers les portes en souriant et quand je lis les mots terribles qui y sont sculptés il passe un bras familier autour de mes épaules comme un lourd rayon de soleil.

Et voici ceux qui étaient trop cools pour parler. Alors c'est donc là que vous avez fini quand je vous ai vomis de ma bouche!

Je vous reconnais mais ne nommerai personne. Pour l'instant. Rien que de penser à vous me fatigue.

\section{Je me réveille parmi les gloutons lubriques}

Je me réveille et crois d'abord être de retour sur Ponsonby Road. Une odeur de graillon et de fromage graisseux épaissit l'air puis je lève les pieds. Alors, une autre odeur s'élève du sol, une odeur de viande pourrissante et de restes de fruits visqueux qui décomposent en terre.

Leur substance gluante semble sans fond sous mes pieds, pourtant leur puanteur est si crasse qu'elle supporte mon poids.

Tous les restaurants se déversent sur le trottoir, des clients titubent et se vautrent dans le caniveau leurs lèvres molles pressées sur la bouche des uns des autres. 
They eat in the gutter where they lie as if it doesn't matter when they vomit over each other

between bites. Their mindless moans and shouts

clash with the discordant music all about.

Seeing me some look up from their brawls and copulation. Jade wants to know

if Greg is still alive. As more rubbish falls

on our sodden spattered clothes

she begs me to speak of her to all

those left living, then lurches form her stool

to heave her guts out in the road.

\section{Pain hosts the party the romantics cannot leave}

Pain offers me a glass of wine

but I still feel sick from the level above.

Someone takes my arm, pulls me down

to a sofa. 'I have so much to tell you,'

she whispers in a breathy voice.

'Lisa? Is it you?'

It is too dark to see.

'What are you doing here? Why is it so dark?'

I ask. The guests are crammed into the smallest

kitchen of any party I've been to

and there is no door out.

Such a small kitchen

to hold such large anguish.

Everyone is sobbing

and smoking.
Ils mangent par terre dans le caniveau comme si ça ne faisait rien qu'ils se vomissent tous dessus

entre les bouchées. Leurs cris et gémissements débiles

jurent avec la musique dissonante tout autour.

En me voyant, certains relèvent le nez de leurs bagarres et copulations. Jade veut savoir

si Greg est toujours vivant. D'autres ordures viennent

éclabousser nos vêtements trempés quand

elle me supplie de parler d'elle à tous ceux

qui sont encore vivants puis vacille de son tabouret

pour se vider les tripes sur la route.

6 Douleur organise une fête que les romantiques ne peuvent quitter

Douleur m'offre un verre de vin

mais le cercle du dessus me donne encore la nausée.

Quelqu'un me prend par le bras, me tire vers

un sofa. "J'ai tellement de choses à te dire,"

murmure-t-on à voix basse.

"Lisa ? C'est toi ?"

Trop noir pour y voir.

"Qu'est-ce que tu fais là ? Pourquoi il fait si noir ?" dis-je. Les invités sont entassés dans la plus petite cuisine de toutes les fêtes où je sois allée et il n'y a pas de porte de sortie.

Une cuisine si petite

pour une si grande angoisse.

Tout le monde sanglote

et fume. 
I become aware of Nik melded to Lisa's side. I can't hear what Lisa is saying, she is sobbing so loud. Something about reading romances together till they were crammed into the narrowest one and their vision shrank to its size and all went black.

The pain returns to my side, bringing pity, who comes between me and Lisa, offering salted peanuts and small

talk.

7 So far the sinners have merely been incontinent

and it takes a boat ride to the big city to reach the usurers in their slime.

Here they are with the murderers and homicides. The usurers too are in for violence, they have violated nature and art by investing their hopes in roads and commerce.

There are too many names to name.

Gloss this canto with the stockbrokers of your time.

\section{I am reacquainted with the furry fish of fraud}

I remember my surprise eight years ago

when I looked under the downy fluff of Micky's sweet talk
Je me rends compte qu'un côté de Lisa a fusionné avec Nik. Je n'entends pas ce que Lisa dit, elle sanglote si fort. Apparemment, ils lisaient des romans d'amour ensemble jusqu'à être coincés dans la plus étroite des histoires puis leur vision s'est rétrécie à cette histoire et tout s'est obscurci.

Puis Douleur revient à mes côtés, avec Pitié, qui se met entre Lisa et moi, offre des cacahuètes salées et des banalités

à échanger.

\section{Jusqu'ici les pécheurs ont surtout été incontinents}

et il faut prendre un bateau jusqu'à la grande ville pour atteindre les usuriers dans leur bave.

Les voici avec les meurtriers et les homicides. Les usuriers aussi sont là pour violence, ils ont violé la nature et l'art en investissant leurs espoirs dans les routes et le commerce.

Il y a trop de noms à citer.

Glosez ce canto avec les boursiers de votre époque.

\section{Je renoue avec le poisson poilu de l'imposture}

Je me souviens de ma surprise il y a huit ans

quand j'ai découvert sous le duvet doucereux des mots mielleux de Micky 
and saw the scales of fraud beneath.

It is this furry fish Dante urges me onto now.

I climb on and off it flies, out into thin air.

I look down and hastily shut my eyes

but I can't shut out the screaming

from those below me in the flames.

I feel like Icarus must have felt, feeling his sides unfeathering as the wax began to melt and nothing, nothing held him up.

Remembering the freefall from my romance, I cling on tightly now to the fishy fur.

\section{The flatterers still teem with language}

in the maze of stinking ditches where we land. They can't see each other over the putrid walls and though they reach out with their voices their sugared words stick to them like glue.

I won't look for Micky, his hair like candyfloss. I bury my face in my furry fish.

10 Over the valley of the therapists to the soup bowl of the malicious

Gently Dante takes my hand and guides me off my furry fish, to lead me now up a rocky path and across a bridge over a deep valley, long and narrow like a throat, swallowing down huge tongues of flame.

This is the valley of bad therapists, who are hidden les écailles de l'imposture.

C'est vers ce poisson poilu que Dante me presse à présent.

Je grimpe sur lui et hop, il s'envole dans les airs.

Je regarde en bas et ferme les yeux en toute hâte

mais ne peux faire taire les hurlements

de ceux dans les flammes en dessous.

Je ressens ce qu'a dû ressentir Icare, lorsque ses flancs se déplumèrent quand la cire se mit à fondre et rien,

plus rien pour le tenir en vol.

Me souvenant de la chute libre de ma romance, je me raccroche davantage au poisson poilu.

\section{Les beaux-parleurs regorgent toujours de mots}

dans le labyrinthe des fosses puantes où nous atterrissons.

Ils ne peuvent se voir par-dessus les murs putrides

et pourtant, ils projettent leurs voix,

leurs mots sucrés leur collent comme de la glue.

Je ne chercherai pas Micky et ses cheveux barbe à papa. Je plonge mon visage dans mon poisson poilu.

10 De la vallée des thérapeutes au bol de soupe des malveillants

Doucement, Dante me prend la main et me tire de mon poisson poilu, il me guide à présent sur un chemin escarpé jusqu'à un pont enjambant une vallée profonde, longue et étroite comme un cou avalant d'énormes langues de flammes.

C'est la vallée des mauvais thérapeutes, ils se cachent 
in the flames of guilt that consume them for the harm their wrong advice has caused.

But now I'm stuck, because who could describe, even in prose, the pain suffered by those in the next level of hell?

Language isn't big enough.

Here are the troublemakers who caused discord when they were alive, who made friends fall out and who split families, are themselves split

and split, sliced

by blades,

bleeding,

screaming,

sliced and split

and split again but

still one, to be sliced

again and again and again sliced.

The screaming cuts through me till I cry out,

Hellish blender make soup

of them, make soup! Make soup !

\section{Soberly we move on to the lowest levels of hell}

This part is even harder for me to tell.

My stomach is cold with nerves,

I write with a grip on my face.

We have reached the levels where the treacherous plunge after death. Dante leads me down past the traitors to their country

but when we reach the traitors to their families dans les flammes de la culpabilité qui les ronge pour le mal qu'ont causé leurs mauvais conseils.

Mais me voilà coincée, car qui pourrait décrire, même en prose, la douleur qu'éprouvent ceux du prochain cercle de l'enfer ? Le langage n'est pas assez grand.

Ici les fauteurs de trouble qui ont semé la discorde quand ils étaient en vie, qui ont fait se fâcher des amis et se diviser des familles, sont eux-mêmes divisés

et divisés, tranchés

par des lames,

saignant,

hurlant,

tranchés et divisés

et divisés encore mais

toujours en un, pour être tranchés

de nouveau, encore et encore tranchés.

Les hurlements me traversent jusqu'à ce que je m'écrie : Infernal mixeur, fais-en

de la soupe, de la soupe ! De la soupe !

11 Sobrement nous continuons jusqu'aux plus bas cercles de l'enfer

Cette partie est encore plus difficile à raconter.

Mon ventre est froid de nerfs,

J'écris le visage crispé.

Nous avons atteint les étages où les traitres se précipitent vers la mort. Dante me mène tout en bas devant les traitres à leur pays mais lorsque nous parvenons devant les traitres à leur famille 
he stops, and he stops I stop with him.

Here are the parents who betrayed their children, who turned away from the good in them to complain about them to their friends, who saw their children as obstacles to their own rewards.

Screaming with horror they are forcing the children into their gaping mouths, and the air is thick with the smell of their children's blood running down their chins, drenching their clothes, pooling at their feet.

I am retching, retching, dry mouthed. I am terrified Dante will leave me here, but speechlessly he leads me on.

\section{Impossibly, he takes me down still further}

Now we are truly at the bottom of the Inferno. There are no flames here.

We walk across ice.

My feet skate over the ice and my attention skates over the horrors of the bottom level. I think I know my place.

But Dante nods at me to look downwards and I look below my feet to see those frozen below the ground. il s'arrête, et lorsqu'il s'arrête, je m'arrête avec lui.

Il y a là les parents qui ont trahi leurs enfants qui ont détourné leur regard du bien en eux pour se plaindre d'eux à leurs amis qui voyaient leurs enfants comme des obstacles à leurs propres satisfactions.

Avec des cris d'horreur, ils forcent leurs enfants à entrer dans leurs bouches béantes et l'air est épais de l'odeur du sang des enfants

qui coule le long de leurs joues, trempe leurs vêtements faisant des flaques à leurs pieds.

Je tire au cœur encore et encore, la bouche sèche. Je suis terrifiée à l'idée que Dante puisse me laisser ici, mais sans une parole, il continue.

\section{Chose impossible, il m'emmène plus bas encore}

Désormais nous sommes vraiment au tréfonds de l'Enfer. Il n'y a pas de flamme ici.

Nous marchons sur de la glace.

Mes pieds patinent sur la glace et mon attention patine sur les horreurs du dernier étage. Je crois

que je connais ma place.

Mais de la tête Dante m'indique de regarder en bas, je regarde sous mes pieds et vois ceux qui sont gelés sous le sol. 
It is impossible to speak with these figures, sealed in ice, their postures distorted.

I open my mouth to ask Dante who they are, but no words come.

Then I know these are the traitors to their calling. Here are the artists who gave up painting, the poets who were too busy teaching, are sealed in their silence.

'Take me away,' I whisper with all the breath I can raise to my mouth. 'Take me away, I am still alive.'

'Ah, this is the one level of hell where the souls of the living are interred while their bodies still go through the motions of earth.'

\section{Out the other side}

The moment stretches to include eternity

like Emily Dickinson moments do.

My heartbeat is an endless dash.

Then time returns to the Inferno and races through dawn to dusk. Gravity turns inside out, our heads stand where our feet stood, and our feet are already walking down a hidden road.

Dante moves on and I move on close behind

till we see a seamless hole ahead of us,

and through the hole I see the earth holding the sky

and the sky holding tight to the stars.
C'est impossible de parler à ces silhouettes, scellées dans la glace, dans des positions informes.

J'ouvre la bouche pour demander à Dante qui ils sont, mais aucun mot n'en sort.

C'est alors que je sais que ce sont là les traitres à leur vocation. Ce sont là les artistes qui ont abandonné la peinture, les poètes trop occupés à enseigner, scellés

dans leur silence.

Je chuchote: "Fais-moi sortir d'ici" du peu de souffle qu'il me reste dans la bouche. "Fais-moi sortir, je suis toujours en vie, moi."

“Ah c'est le seul cercle de l'enfer où les âmes des vivants sont inhumées tandis que leurs corps continuent à se mouvoir sur terre."

\section{Sortir de l'autre côté}

Le moment s'étend pour y inclure l'éternité comme les moments d'Emily Dickinson.

Mon cœur bat dans une course infinie.

Puis le temps revient en Enfer, reprend sa course de l'aube au crépuscule. La pesanteur est renversée, nos têtes là où se tenaient nos pieds, et nos pieds déjà foulent une route cachée.

Dante repart et je le suis tout près derrière jusqu'à apercevoir un trou former un tout devant nous, et à travers ce trou je vois la terre tenir le ciel

et le ciel se tenir aux étoiles. 


\section{Paradiso}

Returning to the journey through my life I saw my family far ahead in the dark wood, though my own self was obscured as if I saw myself through eyelashes. Simon, Johnny, Elvira and Rose were each as clear as prose.

I ran to catch us up.

On the long car ride home on the straight road to Auckland

I sat on one side of Elvira and Rose sat on the other, and Johnny and Simon sat in front.

We were a would of selves.

We were a family.

In the kitchen at our house

we ate hot buttered toast

and it might have been the bread of angels. Rose read Where The Wild Things Are

to Johnny, and I called, 'Rufy, Rufy.'

And there was our cat.

Johnny calls her our panther.

\section{Paradiso}

De retour dans le voyage de ma vie j'ai vu ma famille loin devant, dans le bois noir, bien que mon être soit obscurci comme si je me voyais à travers des cils. Simon, Johnny, Elvira et Rose étaient tous clairs comme prose. J'ai couru pour nous rattraper.

Pendant le long retour en voiture sur la route droite vers Auckland je me suis assise d'un côté d'Elvira et Rose s'est assise de l'autre,

et Johnny et Simon étaient assis devant.

Nous étions un bois d'êtres.

Nous étions une famille.

Dans la cuisine de notre maison nous avons mangé du pain grillé au beurre qui avait le goût du pain des anges. Rose a lu un livre de bêtes sauvages, Max et les Maximonstres à Johnny et j'ai appelé "Rufy, Rufy."

Et notre chat est arrivé.

Johnny l'appelle notre panthère. 


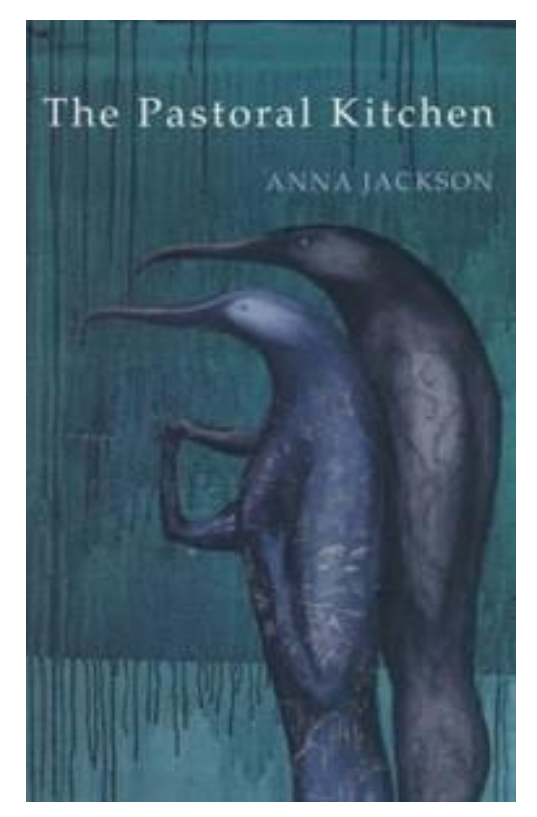

Watch / Montre p. 26

Pick up / Se lever p. 27

Kikuyu / Kikuyu p. 28

Dodo / Dodo p. 29

Huia / Huia p. 31

Takahē / Takahē p. 32 
Watch

Elvira says look! there's a clock on my watch!

There's a clock on my watch too. Now I can watch the time

objectively, as if I weren't internally clocking the time with every cell,

every beat of my heart.

Who beats my heart?

I can't beat time, just watch the clock.

Elvira says, I am a dog cat, woof meow, woof meow.

Tick tock,

watch clock.
Montre

Elvira dit : là ! Y a une pendule sur ma montre!

Moi aussi, j'ai une pendule sur ma montre.

Comme ça, je peux voir le temps

objectivement, comme si intérieurement je ne mesurais pas le temps de chaque cellule,

chaque battement de mon cœur.

Qui fait battre mon cœur?

Je ne peux pas battre le temps, juste voir la pendule.

Elvira dit: je suis un chien chat, ouaf miaou, ouaf miaou.

Tic tac,

conte la montre. 
Pick up

How under the weather the Russians were,

Akhmadulina with her rain following her everywhere,

Mayakovsky with his drain of despair.

But my cloud in trousers is Elvira in a fluffy pink coat,

and she isn't hip-height yet.

I am over the weather

and my little pink cloud runneth over, too.

\section{Se lever}

Vraiment, les Russes n'avaient pas le moral au beau fixe,

Akhmadulina et sa pluie qui la suivait partout,

\section{Maïakovski et sa gouttière} de désespoir.

Mais mon nuage en pantalon, c'est Elvira en doudoune rose,

elle qui ne m'arrive pas à la taille. J'en ai ras le calice du temps

et mon petit nuage rose déborde, lui aussi. 
Kikuyu

By evening what we call a lawn is pooling inwards onto the concrete

carport.

Around the edges the kikuyu swells and spreads like a sea waving

(not drowning).

Yes, I see you,

kikuyu.

\section{Kikuyu}

Le soir, notre prétendue pelouse est une flaque qui déborde sur le béton de l'abri

voiture.

Tout autour de la bordure le kikuyu enfle, s'étend comme une mer fait coucou (ne coule pas).

Oui, coucou,

kikuyu. 


\begin{tabular}{|c|c|}
\hline Dodo & Dodo \\
\hline $\begin{array}{l}\text { Bulky and } \\
\text { hook-beaked }\end{array}$ & $\begin{array}{l}\text { Corpulent, } \\
\text { bec-crochu, }\end{array}$ \\
\hline $\begin{array}{l}\text { and flightless } \\
\text { it sat }\end{array}$ & $\begin{array}{l}\text { inapte au vol, } \\
\text { assis }\end{array}$ \\
\hline $\begin{array}{l}\text { on an egg } \\
\text { the size }\end{array}$ & $\begin{array}{l}\text { sur un œuf } \\
\text { la taille }\end{array}$ \\
\hline $\begin{array}{l}\text { of a pear. } \\
\text { Now }\end{array}$ & $\begin{array}{l}\text { d'une poire. } \\
\text { On }\end{array}$ \\
\hline $\begin{array}{l}\text { nobody knows } \\
\text { its song, though }\end{array}$ & $\begin{array}{l}\text { ne connaît plus } \\
\text { son chant, seul }\end{array}$ \\
\hline $\begin{array}{l}\text { the taste } \\
\text { of its meat }\end{array}$ & $\begin{array}{l}\text { le goût } \\
\text { de sa chair }\end{array}$ \\
\hline $\begin{array}{l}\text { is on record : } \\
\text { sailors called }\end{array}$ & $\begin{array}{l}\text { fut célébré } \\
\text { des marins: }\end{array}$ \\
\hline $\begin{array}{l}\text { the Dodo } \\
\text { Walckvogel, }\end{array}$ & $\begin{array}{l}\text { Dodo } \\
\text { Walckvogel, }\end{array}$ \\
\hline $\begin{array}{l}\text { 'disgusting bird', } \\
\text { the longer boiled }\end{array}$ & $\begin{array}{l}\text { "oiseau infect", } \\
\text { longtemps bouilli }\end{array}$ \\
\hline $\begin{array}{l}\text { the tougher } \\
\text { and more greasy. }\end{array}$ & $\begin{array}{l}\text { si dur } \\
\text { et gras. }\end{array}$ \\
\hline
\end{tabular}


But easy

pickings.

In 1662

the last few

Dodos were finished

off

saving a party

of castaways.

It was the first extinction

of note,

the first noticed

as such.
Mais aisé

à saisir.

En 1662,

les tout

derniers furent

achevés

pour nourrir

des naufragés.

Première extinction

à noter,

première observée

comme telle. 
Huia feathers were always rare treasures, kept in waka huia,

treasure boxes.

An iridescent bird, blue-black like petrol, with a greenish sheen,

rarely seen,

the huia hopped along the ground, grounded. But sang like the tui,

like a flute.

Dressed in treasure too valued by people for the bird to be valued as bird, the huia is no longer heard.

When the Duke of York was presented with a feather for his hat,

trade

in huia feathers leapt to extinction. Now the waka huia preserve other treasures.

This is my waka huia for the bird.
Huia

Les plumes du huia étaient toujours de rares trésors, gardés dans des waka huia,

boîtes à trésors.

Oiseau irisé, bleu-noir comme du pétrole, au vernis verdissant,

vu rarement

le huia sautillait, cloué au sol, solitaire.

Mais chantait tel le tui,

tel une flûte.

Vêtu de trésors d'une valeur trop estimée du public pour que l'on estimât l'oiseau comme tel,

le huia ne chante plus.

Lorsqu'on présenta au duc d'York une plume pour son chapeau,

le commerce

des plumes de huia fit un bond jusqu'à l'extinction. A présent, les waka huia préservent

d'autres trésors.

Ceci est mon waka huia pour l'oiseau. 
Takahē

For so long gone,

how strange

to find them again

not extinct

after all, small

families

passing on skills

for survival,

mother and father

teachers

in the intricacies

of tussock eating,

fern rooting

and how

to hold food

with a foot.

Its beak a red

exclamation

mark, the takahē

shows how to find
Takahē

Depuis le temps,

c'est étrange

de les retrouver

non pas disparus

après tout, petites

familles

transmettant l'art

de la survie,

père et mère

professant

les subtilités

de manger

tussock, fougère,

comment

tenir ces mets

sur un pied.

Son bec, point

d'exclamation

rouge, le takahē

sait trouver 
the sweet core

through knowing

the tough exterior,

what to eat

through what

to leave:

watch me eat

the tussock core

so sweet

and so cold.

This is just to say,

takahē. la cosse douce

connaissant tout

du rude extérieur,

quoi manger

de quoi

laisser:

regarde-moi manger

la cosse de tussock

si sucrée

et si froide.

C'est juste pour dire, takahē. 


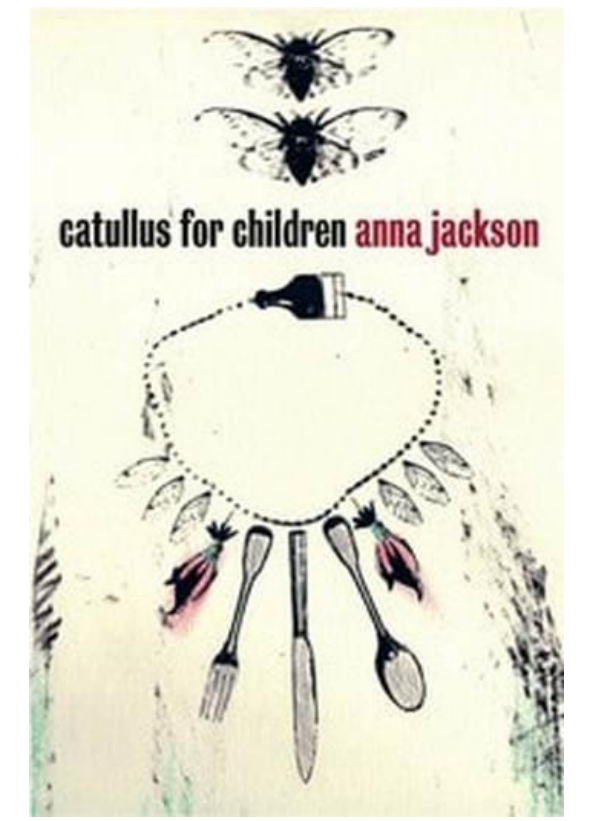

Sparrow (as told by Elvira) / Passereau (raconté par Elvira) p. 35

Vladimir Mayakovsky's Kindness to Horses / La bonté de Vladimir Maïakovski pour les chevaux p. 36

Stow Stay Stow Stay 1. / Sauter rester sauter rester 1. p. 39 
Sparrow (as told by Elvira)

'I found a couple of some feathers from a bird. I pretended

it was a real bird. But we saw

it was a pretend bird. It looked

like a real bird but it was a pretend bird. So we put it in my breadbin.

It looked like it was a real bird.

It was by the grass near the hole that we put the tadpoles in.

So we put the breadbin somewhere else by the wall out on the front deck.

And the breadbin was on the wood

that was far up. Under the other deck, it wasn't

on there. It was on the front deck,

not the back deck. We had two

decks. That's the end of the story.'
Passereau (raconté par Elvira)

"J'en ai trouvé deux des plumes

d'un oiseau. J'ai fait semblant que

c'était un vrai oiseau. Mais on voyait

que c'était un faux oiseau. On aurait dit

un vrai oiseau mais c'était un faux

oiseau. Alors on l'a mis dans ma boîte à pain.

On aurait dit un vrai oiseau.

Il était sur l'herbe près du trou

là où on a mis les têtards.

Alors on a mis la boîte à pain ailleurs

dehors près du mur sur la terrasse de devant.

Et la boîte à pain était sur le bois qu'était

tout en haut. Pas sous l'autre terrasse, elle

était pas là, elle était sur la terrasse de devant,

pas sur la terrasse de derrière. On en avait deux des terrasses. Voilà, fin de l'histoire." 
Vladimir Mayakovsky’s Kindness to Horses

It sounded like the hooves were singing:

sto

ste

sto

ste;

it must have been the street that skidded!

Perhaps the street tripped

on the horse: anyway, the poor horse

hearse

horse

hearse

horse

scooted on its rump along the street

like a coffin scooting into the fire.

Nobody had any reason to be out anyway, except to show off their flares and laugh

ha

he

ha

he

at the horse,

oh come and see! But I, I alone

did not merge my voice

in the chorus,

no, I

walked up
La Bonté de Vladimir Maïakovski pour les chevaux

On aurait dit que les sabots chantaient:

tso

tse

tso

tse

c'est sûrement la rue qui a dérapé !

C'est peut-être la rue qui a trébuché sur le cheval: enfin bon, pauvre canasson

corbillard

canasson

corbillard

canasson

qui glissait sur la croupe en pleine rue

comme un cercueil tout schuss au feu.

Personne n'avait vraiment de raison de sortir sauf pour montrer leurs pattes d'eph'

et rire

ah

hi

ah

hi

du cheval,

oh venez voir! Mais moi, moi seul n'ai pas mêlé ma voix

au chœur,

non, je

me suis rapproché 
and saw the horse's eyes.

The street had fallen over and nobody had noticed but the horse: I saw large drops

were rolling down its face

here

there

here

there

burying themselves

in its hair.

Oh horse, you mustn't, oh horse, listen horse: don't think you are worse that they are!

We are all of us horses, to some extent! Horse?

Perhaps it didn't think it needed a nurse

horse

nurse

horse

nurse

perhaps my thought seemed trite to the horse,

at any rate, up it got with a jerk, and a flick of its tail, and cheerfully returned

sto

ste

sto

ste

and stood in its stall,

and all the time it felt like a colt, et j'ai vu les yeux du cheval.

La rue était tombée et personne n'avait remarqué sauf le cheval : j'ai vu de grosses gouttes couler sur son visage

ici

là

ici

là

puis s'enfouir

dans son crin.

Oh cheval, il ne faut pas, oh cheval, écoute cheval: ne pense pas que tu sois pire qu'eux !

On est tous des chevaux, quelque part! Cheval ?

Peut-être qu'il ne pensait pas avoir besoin de soin le pur-sang

soin

sang

soin

peut-être ma pensée lui semblait triviale au cheval,

en tout cas, il s'est levé d'un bond, la queue

fringante et plein d'entrain, est reparti

tso

tse

tso

tse

se tenir tout droit dans sa stalle,

et tout le temps se sentait jeune poulain, 
and that life was worth living, and work

worth

while. et ça valait la peine de vivre et travailler

valait

la peine. 
Stow Stay Stow Stay 1.

I am frightened all morning, hurrying them

out of the house.

Heart in my mouth.

Teeth on my tongue.

My family undone.

\section{a family \\ a holiday \\ a family \\ a holiday}

I have packed up everything I can think of

wedged bags into the boot under feet

though a hundred times of stowing myself away

stow

stay

stow

stay

giving myself up coming too
Sauter rester sauter rester 1 .

J'ai peur toute la matinée, les presse

à sortir de la maison.

Cœur en bouche.

Dents sur ma langue.

Ma famille défaite.

une famille

du répit

une famille

du répit

Dans les sacs tout ce à quoi j'ai pu penser

tassé dans le coffre sous les pieds

j'ai pensé cent fois

à sauter à bord

sauter

rester

sauter

rester

m'abandonner

en venant aussi 


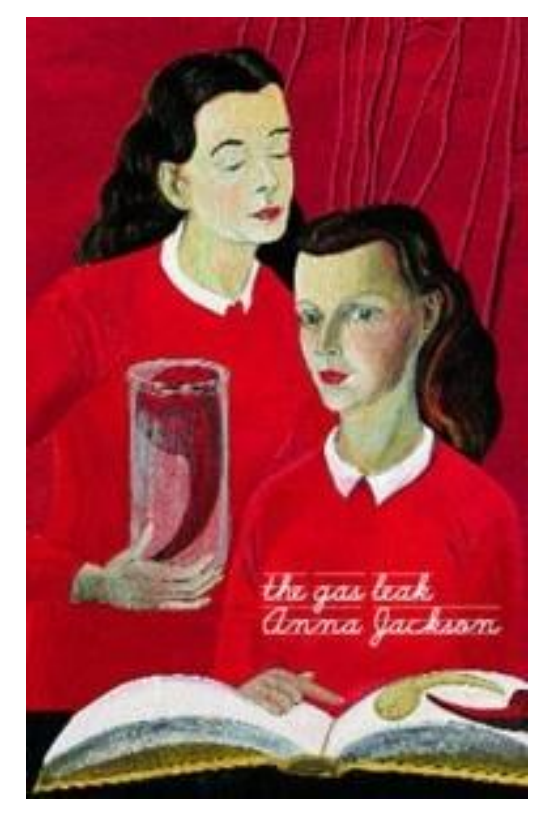

Silence, It Means Something / Silence, ça veut dire quelque chose p. 41

Looking to the Fittings / Regarder aux raccords p. 42

The Gas-Fitter's Daughter Shows Shane / La Fille de l'installateur du gaz montre à Shane p. 43

The Gas-Fitter's Daughter's Recurring Solution / La Solution récurrente de la fille de l'installateur du gaz p. 44

It Seems That This Time I Have Been Mistaken / Il semble que cette fois-ci je me sois trompée p. 45

An Explanatory Wave of the Hand / Un geste de la main pour toute explication p. 46 
Silence, It Means Something

They lie in bed staring at the ceiling.

They are not really married.

She had skated ahead to the registry office above the supermarket,

and executed a perfect figure of eight while the wedding party before them

all turned and laughed at him

left behind on the seat

of his pants where the street

had skidded out

from under his feet.

The celebrant had laryngitis,

they were never pronounced

man and wife in so many words.
Silence, ça veut dire quelque chose

Ils sont au lit, les yeux au plafond.

Ils ne sont pas vraiment mariés.

Elle avait patiné en tête au bureau d'état-civil

au-dessus du supermarché

et exécuté un huit parfait

pendant que tout le cortège devant eux,

tournait le dos et se moquait de lui,

laissé à la traîne, à devoir

mouiller sa chemise où la rue

avait dérapé

sous ses pieds.

Le maire avait une laryngite,

il ne les a jamais prononcés

mari et femme pour ainsi dire. 
Looking to the Fittings

They can't agree on a house of their own. He says he is looking for a view,

she only cares how it looks

from the outside.

He means, he is better

than her. He's

going to be paying the mortgage.

In the weekends he builds her decks -

everywhere she goes,

he builds yellow decks -

she can't sit down

to read a book

without leaving little yellow decks

behind her.
Regarder aux raccords

Ils ne sont pas d'accord sur le choix de leur maison. Lui dit qu'il cherche une vue,

elle, ne voit que le cachet

de l'extérieur.

Il veut dire que lui est mieux

qu'elle. C'est lui

qui va payer les traites.

Les weekends il construit pour elle des terrasses partout où elle va,

il construit des terrasses jaunes -

elle ne peut pas s'asseoir

pour lire un livre

sans laisser de petites terrasses jaunes

derrière elle. 
The Gas-Fitter's Daughter Shows Shane

12 a.m. and don't I show Shane

and undo my watch

to throw it before

my heart and yet the joy

increases and the dress

creases and -

$$
\text { - 'I can't read }
$$

it' says Shane and I think

that is pretty sad

but he -

and now I am sober although

feeling sick with

all this coffee

in fact it is now 10 past 3

and I am astonished

it is not later since between

3 and now I have climbed

all over the shelves

searching for new

coffee beans -

now Shane comes to the door

and I hear myself

scream and think

perhaps I am not sober

enough to write

after all -
La Fille de l'installateur du gaz montre à Shane

Minuit et un peu que je montre à Shane

et défais ma montre

pour la jeter devant

mon cœur mais de plus en

plus jouasse et la robe se

froisse et -

- "J'arrive pas à lire

ça" dit Shane et je pense

que c'est bien triste

mais lui -

$-3 \mathrm{~h}$ du mat'

et là je suis sobre quoique

envie de vomir avec

tout ce café

en fait il est 3 h 10

et ça m'étonne

qu'il ne soit pas plus tard, vu que

depuis $3 \mathrm{~h}$ j'ai grimpé

sur toutes les étagères

à la recherche de nouveaux

grains de café -

et je m'entends

là Shane arrive à la porte

crier et pense que

peut-être je ne suis pas assez

sobre pour écrire

après tout - 
The Gas-Fitter's Daughter's Recurring Solution

Obviously I'm going to have to confess it all to Bridget but when I get to school her eyes are signalling me as urgently as I'm trying to signal at her with mine and all through maths she's texting me her life: genre: epic tragedy though it's coming across more gothic comedy which might have something to do with the limitations of the medium - especially since we have to keep our phones hidden inside our pencil cases.

When we can talk we agree we obviously are going to have to get out of here, go somewhere where we can get totally written.
La Solution récurrente de la fille de l'installateur du gaz

Evidemment il va falloir que je raconte tout à Bridget mais quand j'arrive à l'école ses yeux me lancent des signaux aussi urgents que ceux que j'essaye de lui lancer avec les miens

et tout le cours de maths

elle me texte sa vie:

genre: tragédie épique mais

plutôt version

comédie gothique, ce qui

est sûrement dû

aux limites

du média - surtout

qu'on doit garder

nos portables cachés dans

nos trousses.

Quand on peut parler on est d'accord

qu'évidemment il va falloir

qu'on sorte d'ici,

aller quelque part où on puisse

se mettre carrément hors d'état d'écrire. 
It Seems That This Time I Have Been Mistaken

I find the children the Bible but they want to see the hole -

even after I tell

them the difference

between holy and holey.

They tell me God

put them there, you just

can't see them, you have to trust

they are there. That's

the challenge.

And God, I say, does

God believe in our holes too?

I've lost heart but

I'm keeping my balance.
Il semble que cette fois-ci je me sois trompée

Je trouve la Bible pour les enfants mais eux, ne veulent voir que les creux -

même après leur avoir

expliqué la différence

entre creux et croix.

Ils me disent que Dieu

les a mis là, on ne peut

pas les voir c'est tout, il faut croire

qu'ils sont là. C'est ça

le défi.

Je leur dis : et Dieu, est-ce que

Dieu croit en nos creux, lui ?

J'ai perdu la foi mais

je garde l'équilibre. 
An Explanatory Wave of the Hand

We have been a golden cup in God's hand,

we have made all the earth drunken.

So tip me out.

When I spill all,

don't expect me to leave

a stain,

no need for salt

on your shagpile streets,

I am much too hot

to fall.

I am rising far above you, on the boil.
Un geste de la main pour toute explication

Nous fûmes une coupe d'or dans la main de Dieu, nous fîmes de la terre une ivresse.

Alors renverse-moi

Quand j'aurai tout déversé,

ne t'attends pas à ce que je laisse

de tache,

pas besoin de sel

sur tes rues de tapis méché,

j'ai bien trop chaud

pour chuter.

Je m'élève loin au-dessus de toi,

en ébullition. 


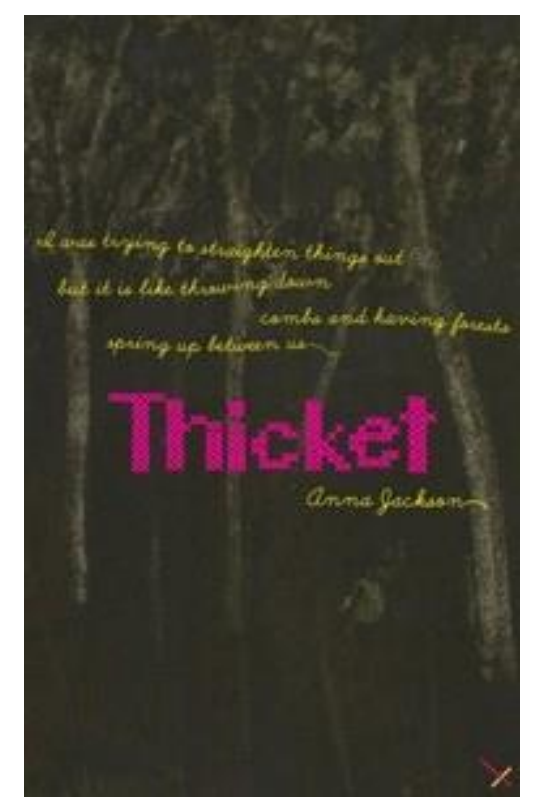

The Coming on of a Maths Brain / L'Avènement d'un cerveau matheux p. 48

Ophthalmoscope / Ophtalmoscope p. 51

Salty Hair / Cheveux salés p. 52

Red Riding Hood's Mother / La mère du Petit Chaperon rouge p. 53

Red Riding Hood / Le Petit Chaperon rouge p. 53

Exit, Pursued / Sortie, poursuivie p. 55

Let Alone / Sans parler p. 56

My Brother, Twelve Swans / Mon frère, douze cygnes p. 57 
The Coming on of a Maths Brain

The

world

unfurled

unfurling

all over again -

for a real mathematician

a walk around the block must be a symphony swirling,

all

those

perfect

ratios.

Though also I guess

there must be ratios that clash -

where I see the green lawn clashing with the blue windows,

he

sees

what would

be good squares

of window and lawn

ruined by the wrong proportion

of the (I think) beautifully cream-coloured front door.

And

what

of all

the other

senses, touch and smell

and taste and hearing? My brother
L'Avènement d'un cerveau matheux

Le

monde

déferle

déferlant

encore et encore -

pour un vrai mathématicien

le tour du quartier c'est symphonies et tourbillons,

de

si

parfaits

ratios.

Quoiqu'il doit aussi

$\mathrm{y}$ avoir des ratios qui jurent -

où je vois l'herbe verte jurer avec les fenêtres bleues

il

voit

là de

beaux carrés

de fenêtres et d'herbe

gâchés par la fausse proportion

de la si belle (je trouve) porte d'entrée couleur crème.

Et

quid

de tous

les autres sens,

toucher, odorat,

et le gout et l'ouïe ? Mon frère 
could tell you music is maths, obviously the fall

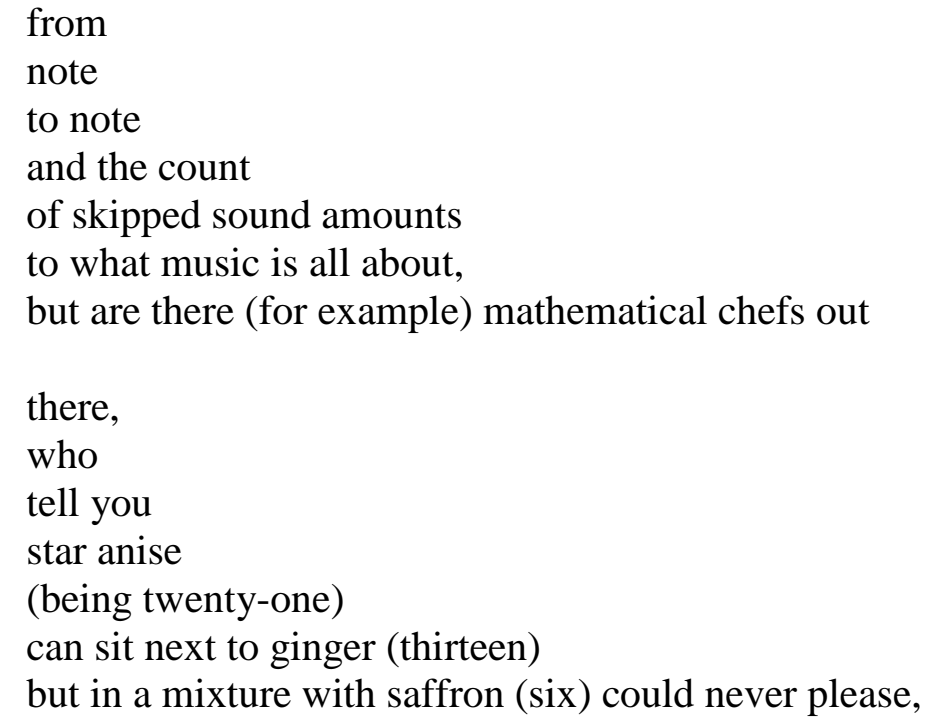

dirait que la musique c'est des maths, bien sûr la chute

une

note

sur l'autre

et le compte

des sons syncopés

qui est le cœur de la musique,

mais y a-t-il (par exemple) des chefs en mathématiques

là,

pour

vous dire

que l'anis

(qui a vingt-deux ans)

peut côtoyer gingembre (treize ans)

mais son mélange s'accommode mal de safran (six ans),

les

maths

ne le

permettent pas ?

Rien d'étonnant que

je cuisine mal, pas de cerveau

matheux encore en moi, mais comme les dents de sagesse

le

mien

peut-être

va pousser

aujourd'hui je crois,

c'est le jour de son avènement... 
Tonight when we curl up in bed, I'll measure our match. *

sपtem әपт
se sn fo

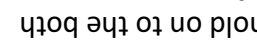

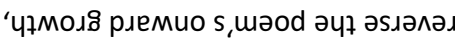

'səu!!

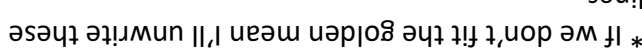

Ce soir au lit, je mesurerai notre assorti.*

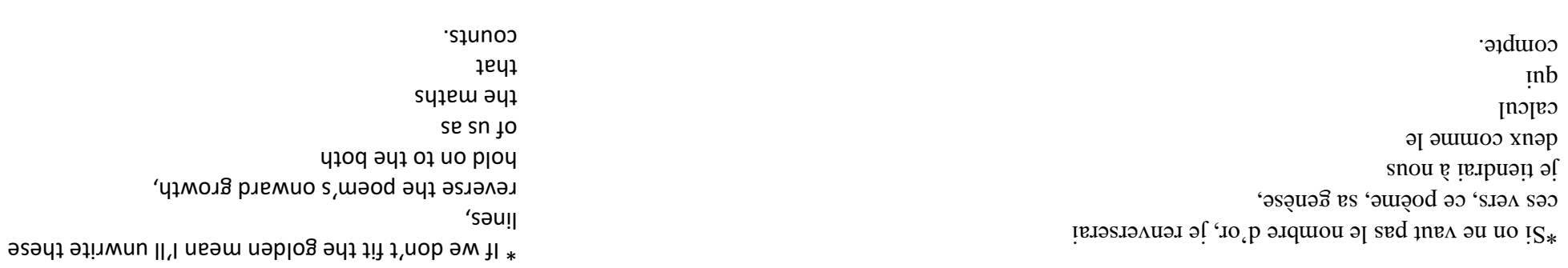


Ophthalmoscope

Technically, it is the light of the ophtalmoscope throwing my veins out in front of my vision knotting themselves into a forest

between us.

Or surrounding us, it seems like, that

knocking sound unlikely to be a gardener arriving at last

to clear things out, or a midwife at the door to perform any kind of delivery, and we can't expect a postal delivery in this situation, or, obviously, a guest. It could be a joke.

Who's there?

We'll have stepped back before the punchline,

the second name.

One week, you promise, before I'll see clearly again.
Ophtalmoscope

Techniquement, c'est la lumière de l'ophtalmoscope

qui projette mes veines sur mon champ de vision

et les noue

en une forêt

entre nous.

Ou qui nous encercle,

j'entends qu'on tape à la porte mais ça ne peut sûrement pas être un jardinier qui viendrait enfin tout éclaircir, ou une sage-femme

venue me délivrer en se livrant à une sorte d'accouchement,

et n'attendons pas non plus

d'être délivrée par la poste dans cette situation,

ni, bien sûr, un invité.

C'est peut-être une blague.

Qui est là?

On aura reculé avant la chute, monsieur et madame Untel.

Tu promets que dans une semaine, j'y verrai à nouveau clair. 


\section{Salty Hair}

In the morning my pillow is wet through to the sheets. I have to wring out the salt from my hair before

I can lift my head

and drink five cups of coffee before I can speak - but when I open my mouth an ocean pours out from my eyes. I know just how glaciers must feel when spring comes on, loosening from the inside out, leaking all those hard-won centimetres out in a rush to the sea and the sea, oh I know how the sea feels, swallowing more and more with more still coming at it, not a hope of lying still when you are overflowing, your own insides turning endlessly over and beaching themselves on each and every shore.

You wish the shores would go away.

But thank you, all the same,

for holding out your sands.

\section{Cheveux salés}

Le matin mon oreiller est trempé jusqu'aux draps. Je dois essorer

le sel de mes cheveux avant

de pouvoir lever la tête

et boire cinq tasses de café

avant de pouvoir parler - mais quand j'ouvre

la bouche un océan se déverse

de mes yeux. Je sais exactement

ce que les glaciers doivent ressentir

quand arrive le printemps, quand tout lâche de l'intérieur, quand tous

ces centimètres durement gagnés fuient

d'un coup dans la mer,

et la mer, oh je sais ce que

la mer ressent, elle qui avale, avale et avale encore tout ce qui coule sur elle, pas d'espoir de calme plat quand tout déborde, quand ton intérieur chavire sans cesse

et s'échoue sur chacun

de tes rivages.

Tu voudrais que les rivages s'en aillent.

Mais merci quand même, c'est bien aimable, de m'avoir tendu tes sables. 


\section{Red Riding Hood's Mother}

I am the angel in the house, looking for the keys.

Can you answer the phone, and don't talk to me like that,

I gave birth to two children

from my animal womb

and they eat up all the food and mess up all the rooms.

I am looking for the keys

in the eyes of the storm,

in the storm of my son,

in the dawn of my daughter,

in the ought to of the wood.

I am the angel in the wood.

\section{Red Riding Hood}

She is always looking back to before me. $\mathrm{Me}$, she sends outside, while she searches

in cupboards and books.

I'm sent into the woods.
La mère du Petit Chaperon rouge

C'est moi l'ange du foyer et je cherche les clés.

Peux-tu répondre au téléphone, et ne me parle pas comme ça,

j'ai mis au monde deux enfants de mon ventre animal

et ils dévorent tout dans le frigo, et mettent le désordre partout.

Je cherche les clés

dans les yeux du cyclone,

dans le cyclone de mon fils, dans l'aube de ma fille,

dans le devoir du vouloir.

C'est moi l'ange des bois.

\section{Le Petit Chaperon Rouge}

Elle ressasse tout le temps l'avant-moi.

Moi, elle m'envoie dehors, pendant qu'elle cherche

dans les placards et les livres.

On m'envoie dans les bois. 
I'll go back too.

I'll ask her mother what she was like as a child.

How did you get through the woods

so fast, Grandmother asks me instead.

Not like your mother.

Always so wild.
Moi aussi, je ressasserai.

Je demanderai à sa mère comment elle était, petite.

Comment as-tu traversé les bois

si vite, me demande plutôt Grand-Mère.

Pas comme ta mère.

Toujours si sauvage. 
Exit, Pursued

The weekend, and the same direction over and over, exit, pursued

by my son.

Anything to avoid a row.

I suppose I do become a little wooden and to my son, exiled

in his own Aeneid,

might look like a little less like Love

than I did once.

It does feel, pursued by my son,

as if he doesn't know whom he pursues,

or what he's asking for

except to tell this stranger

how strange a world it is for him,

how hard his exile,

how unprovisioned,

how inadequate

so wooden a response.
Sortie, poursuivie

Le weekend et, encore et encore,

la même direction, sortie, poursuivie

par mon fils.

Tout pour éviter une dispute.

Je deviens sûrement un peu raide comme bois

et pour mon fils, exilé

dans sa propre Enéide,

je ressemble sans doute un peu moins à l'Amour

qu'antan.

J'ai l'impression, poursuivie par mon fils,

qu'il ne sait ni qui il poursuit,

ni ce qu'il demande vraiment

sauf quand il dit à cette étrangère

combien le monde lui est étrange,

combien son exil lui est difficile,

si démuni,

inadéquat,

une vraie réponse en bois. 
Let Alone

Stumbling into the dark, feeling for the concrete steps buried somewhere under the grass, stepping over the blackberry vines, how can I even stop to see who is pursuing me,

let alone make out

the changes imposed on you by this exile,

these hardships

you recount,

let alone stop long enough

to spin anything I could fling over you

to make you into a man.

It will have to be the sister you fly from as it is in the stories,

after years of her

hardly saying a word.
Sans parler

Trébuchant dans le noir, cherchant à tâtons les marches en pierre enterrées quelque part sous l'herbe,

enjambant le mûrier rampant,

comment m'arrêter pour voir

qui me poursuit,

sans parler de discerner

les changements imposés

par ton exil,

ces épreuves

que tu racontes,

sans parler de m'arrêter assez longtemps pour filer ce dont je pourrais te couvrir pour faire de toi un homme.

Ce sera donc à la sœur que tu fuis comme dans les contes,

de longues années après

son dernier mot. 
My Brother, Twelve Swans

It is always my mother who drives him wild until, finally, he takes flight -

and I am left silent in the house.

I won't be driven wild by my mother.

I hold my tongue, bide my time, carry her basket into the wood.

I'd walk up glass to reach my brother.

Twelve times I throw my spinning over him,

twelve times watch him turn from beast to man What do I even want him for?

To reduce him to nothing like myself? And still I stop short

$$
\text { of the final wing... }
$$

Mon frère, douze cygnes

C'est toujours ma mère qui le rend fou jusqu'à ce qu'enfin il prenne son envol -

et je reste silencieuse dans la maison.

Ma mère ne me rendra pas folle, moi.

Je tiens ma langue, $\mathrm{j}$ 'attends mon heure, porte son panier dans les bois.

Je marcherais sur du verre pour atteindre mon frère. Douze fois je lui lance mon filage,

douze fois je le vois, se changer de bête en homme. Qu'est-ce que je peux bien vouloir de lui ?

Le réduire à néant comme moi ?

Et pourtant je m'arrête net,

avant la dernière aile... 


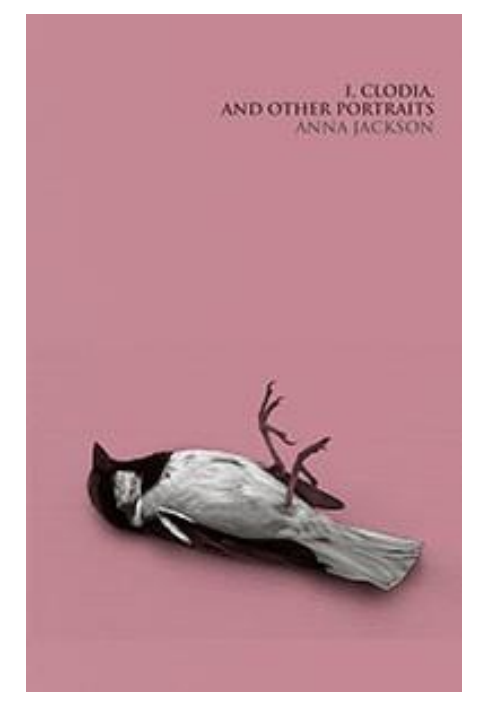

A Thousand Kisses, Then a Hundred / Un millier de baisers puis une centaine p. 59

This Business of Kissing / Cette affaire de baisers p. 60

Pipiabat (used to chirp...) / Pipiabat (qui pépiait...) p. 61

A God in his way / Un dieu à sa façon p. 62

No Rough Verses / Pas de vers agités p. 63

Oh, in Hendecasyllables! / Oh, en endécasyllabes ! p. 64

From the Distance / Du lointain p. 65

Galliambics / Galliambiques p. 66

The Photographer's Olympics / Les Jeux Olympiques de la photographe p. 68

Roland on the outskirts / Roland en banlieue p. 70

Afraid of Falls? / Peur des chutes? p. 72 
A Thousand Kisses, Then a Hundred

Out of all the affairs I've had

ours has got to have been

the most efficient!

Over almost before it has begun,

from the cautious brushing of you hand on mine to the violent taking and retaking of each other, the evading, the reclaiming,

the nostalgia for the good times we used to have earlier in the same day...

Already there are no more kisses

requiring kissing,

no endearments left

you haven't already said.

Let Cicero regret the days of epic sincerity,

let me be loved by one of the new poets:

a quick couplet, a startling rhythm,

and no decline into grandeur...
Un millier de baisers puis une centaine

De toutes les aventures que j'ai eues

la nôtre a bien dû être

la plus efficace!

Terminée presque avant d'avoir commencé,

de la prudente caresse de ta main sur la mienne aux violentes prises et reprises de nous-mêmes, nous échappant, nous possédant encore,

la nostalgie des beaux jours vécus

seulement le jour même...

Déjà, il n'est plus de baisers

qui réclament d'autres baisers,

il ne reste plus de tendresses

que tu n'aies déjà proférées.

Que Cicéron regrette les jours sincères des épopées,

je me laisserai aimer par l'un des nouveaux poètes:

un couplet vif, un rythme étonnant,

et nul déclin dans la grandeur... 
This Business of Kissing

This is a serious business, this new method you are trialling to protect my reputation don't let me, with my flighty ways, make you break off from your kissations! I'm not sure you've quite reached a total yet uncountable enough to put us out of reach of gossip,

though enough that it would be embarrassing if the number did get out.

Don't even think about that business

in Bythinia, there's work

to be done right here in our kissiary...

only, how many will it be till you're done?

\section{Cette affaire de baisers}

C'est une affaire sérieuse, la nouvelle méthode que tu testes pour protéger ma réputation ne me laisse pas, moi et mes airs volages, interrompre tes embrassations!

Je ne suis pas sûre que tu aies encore atteint un total assez incalculable pour nous mettre

à l'abri des ragots,

quoique assez pour être embarrassant

si le chiffre venait vraiment à se savoir.

Ne pense même pas à tes affaires

en Bithynie, tu as du travail à faire

ici même dans notre bisouillère...

seulement, combien t'en faudra-t-il avant d'avoir fini ? 
Pipiabat

(used to chirp...)

Look at me, my tear-stained face, my red eyes - is this what you came for? It's not what you think.

So there are verses about me circulating about the city - how could you possibly imagine I, Clodia, would care?

I might cry over your verses -

tears of laughter-

but these are real tears,

I'm grieving.

Look at what was my little bird, yesterday - this was

somebody, closer to me than... you had better be leaving.
Pipiabat

(qui pépiait...)

Regarde-moi, le visage taché de larmes, les yeux rouges - c'est pour ça que tu es venu?

Mais ce n'est pas ce que tu crois.

Alors comme ça, il y a des poèmes sur moi

qui circulent en ville - comment peux-tu

imaginer un seul instant que moi, Clodia, en aie cure ?

Je pleurerais peut-être sur tes poèmes -

des larmes de rire -

mais ce sont là de vraies larmes,

je suis en deuil.

Regarde ce qu'était mon petit oiseau,

hier encore - ça, c'était

quelqu'un, bien plus proche de moi que...

tu ferais mieux de partir. 
A God in his way

I am Sappho, you like to say - it's you, though, body burning, thundering heart, your eyes blind, ear drums ringing, who's mute at last, no more talk leading to kisses,

all your focus on someone else, not on me but on he who can talk to me, who when you drift off homewards will, you suppose, be all mine, husband forgotten...

This respite is something to praise! I'll fill my stanzas up while you can be silent for once, pen laid down, your fingers, I trust, not working, paper unblotted...

He indeed who can command such a sweet pause seems to me a god in his way! If I were

less like Sappho, more of a girl, I might think love is what this is..
Un dieu à sa façon

Je suis Sappho, comme tu aimes dire - c'est toi, non, le corps brûlant, cœur qui tonne, les yeux aveugles, tympans qui sonnent, enfin muet, plus un mot pour d'autres baisers,

toute ton attention sur un autre, pas sur moi mais sur lui, qui sait me parler, qui, quand tu files chez toi, sera, tu supposes, rien qu'à moi, mari oublié...

Ce répit est louable ! Je remplirai mes strophes pendant que, pour une fois, tu te tairas stylet baissé, tes doigts, j'espère, inactifs, papier non souillé..

Qui sait commander une pause si douce me semble un dieu à sa façon! Si j'étais moins comme Sappho, mais plus fille, je penserais que c'est ça, l'amour... 


\section{No Rough Verses}

No rough verses, but like a surf-tossed sailor wielding wisely his gaff-rigged fore-and-aft sail, so shall I keep your favourite of Greek metres to steer my way free of your storm of curses. What I owe you - these claims you make are madness but to counter them one by one in order: first, consider, what we owe Aphrodite your voyage here, as plunder of my husband, your change of plans, your brother left unaided, none of this can be laid as charges on me, all was fated, and I merely received you. Oh, I loved you, and being loved by me did you not take more than you could ever give me? Your 'exile' here - to live in Rome is living, I don't see you, in thrall to me no longer, rushing back to your farmhouse in Verona, or setting sail to do business in Bithynia.

Had you stayed put, a poet of the provinces, not one person would know your name - or care to.

\section{Pas de vers agités}

Pas de vers agités, marin ballotté maniant sagement sur les flots sa voile aurique, je reprendrai tes mesures grecques préférées pour naviguer hors de ta tempête d'injures.

Ce que je te dois - tes folles allégations mais pour les contrer une par une et dans l'ordre: d'abord, vois ce que l'on doit à Aphrodite ton voyage ici, butin de mon mari, ton changement de plans, ton frère abandonné, rien de tout cela ne peut m'être imputé, c'est le destin et je t'ai seulement reçu.

Oh, je t'aimais, et aimé de moi, ne croistu pas avoir pris plus que tu n'as donné ? Ton "exil" ici - mais vivre à Rome c'est vivre, je ne te vois plus sous mon joug désormais, pressé de rentrer dans ta ferme de Vérone, ou de faire voile pour affaires en Bithynie. Si tu y étais resté, poète de provinces, personne ne saurait ton nom - on s'en ficherait. 


\section{Oh, in Hendecasyllables!}

If my heart is a heart of bronze it is melting and burning, burning with fury, fury against those gods whose amusement is found in our ironic mistimings: finally after finding the courage at last to end what was already over I wrote to you not knowing that you had been searching for me, that in your grief having heard of your brother's death you were needing me to be where I had looked so often for you.

This time determined to stay away and let Caelius have me I never saw the note that you left me and you received mine as if it were its reply - oh, in hendecasyllables!

Now where are you? Nobody knows - or nobody's telling : who of your friends would be a friend to me now?

\section{Oh, in Hendecasyllables!}

Strange, to think of you searching for me where I had so often waited for you

idling away the days before finally, determined to stay away and let Caelius have me, I

wrote to you ending it all, and you

having turned to me at last

in your grief must have received my verses as my reply - oh, in hendecasyllables!

Now where are you? Nobody knows - or nobody's telling. Who

of your friends would be a friend to me now?
Oh, en endécasyllabes !

Si mon cœur est un cœur de bronze, il fond et brûle, brûle de furie, de furie pour ces dieux qui, eux, s'amusent des contretemps ironiques que nous connaissons : enfin ai-je eu le courage de finir une histoire qui déjà, était morte,

je t'ai écrit quand déjà, tu m'avais cherchée, quête vaine,

et, dans ton deuil, tu avais, apprenant la mort de ton frère, eu besoin de moi, être là où souvent je te cherche.

Là, décidée à partir et laisser Caelius m'avoir, je n'ai jamais vu la note que tu m'as laissée, et la mienne, que tu as lue comme réponse, oh, en endécasyllabes !

Où es-tu maintenant ? Personne ne sait - ou le cache : qui parmi tes amis, à présent, me sera amical ?

\section{Oh, en endécasyllabes !}

Etrange de penser que tu me cherchais

là où si souvent je t'ai attendu

en laissant filer les jours avant qu'enfin, déterminée à me retirer et à laisser Caelius m'avoir, je ne t'écrive pour tout arrêter, et toi qui t'étais enfin tourné vers moi dans ton deuil as dû recevoir mes vers comme ma réponse - oh, en endécasyllabes ! Où es-tu à présent ? Personne ne le sait - ou personne ne le dit. Qui de tes amis sera pour moi un ami à présent ? 
From the Distance

Like a god he brings from the distance your words, words more forceful than any old religious

rites are, words that set my heart pounding till I feel like I'm dying...

Here he stands and thinks that he has my attention! Somehow I find something to say, and sweetly

laugh, and touch his arm in the way I'm known for, all else forgotten,

but my tongue grows thick, and a thin flame runs down through my veins and under my skin, my ears ring with their own sound, and I think only of you, still as besotten

as from the first day that I saw you, your hands close to mine, your eyes when they met mine saying we could touch each other, and I - I turned away, silently lying...
Du lointain

Comme un dieu, il rapporte du lointain tes mots, des mots plus percutants que tout ancien rite religieux, des mots qui font battre mon cœur jusqu'à défaillir...

Le voilà qui croit avoir mon attention !

Curieusement je trouve quelque chose à dire,

douce, je ris et touche son bras comme sais le faire, tout est oublié,

mais ma langue s'épaissit, une fine flamme coule dans mes veines et sous ma peau, mes oreilles sonnent de leur propre son et je ne pense qu'à toi, tout aussi éprise

que le premier jour où je t'ai vu, tes mains près des miennes, tes yeux quand ils croisèrent les miens, disaient de se toucher et moi - moi, tournée couchée en silence... 


\section{Galliambics}

The coldness of this winter air wraps me in a numbness as encompassing as the wrappings of an Egyptian mummy, trapping any sense of self I used to have far from anything that I could think of as a life force. I have nothing to say to Clodius who barges about as vigorous in his fury against Caelius as he was in his advocacy of him just days ago - these have been days as galliambic as these verses of yours, Catullus, that half of Rome seem to have learned off by heart. Only such a completely mad metre tripping, accelerating beyond sense, could match the betrayals of Caelius, the complicated movements behind our backs in Pompey's pay, supporting Egypt's brutal dictator, murdering their ambassador, and to cover his traces undoing himself by seeking to poison $m e$, as if I'd ever otherwise have thought twice about the money he'd borrowed off me, whirled up as I was in the maelstrom of your galliambics, this mad display of yourself as Attis distraught in the girlhood that love has driven him to, unmanned, unmade, hysterical, heart full of simmering bitterness. As if I could possibly have felt the absence of whatever drama Caelius had promised to put on, with the whole of Rome caught up in the frenzy of your verses!

\section{Galliambiques}

Le froid de l'air de l'hiver m'enlace d'une torpeur qui m'enveloppe telles les bandelettes d'une momie égyptienne et piège toute perception d'un moi passé, loin de ce que je pouvais avoir de force vitale. Je n'ai rien à dire à Clodius dans sa furie contre Caelius, s'emportant aussi vigoureusement qu'il le défendait encore il y a quelques jours - ces jours-ci ont été galliambiques comme tes poèmes, Catulle, que la moitié de Rome semble avoir appris

par cœur. Seule une métrique aussi folle, cadencée, accélérant au-delà de la raison, pouvait être à la hauteur des trahisons de Caelius, ses mouvements compliqués dans notre dos au bénéfice de Pompée, soutenant ce dictateur brutal de l'Egypte, assassinant leur ambassadeur et pour couvrir ses traces, se trahissant en cherchant à m'empoisonner, moi, comme si j'allais penser à deux fois à l'argent qu'il m'avait emprunté, toute entourbillonnée que j'étais dans le maelstrom de tes galliambiques, cette exhibition folle de toi en Attis, désemparé dans une féminité à laquelle l'amour l'a conduit, délaissé, défait, hystérique, le cœur plein, bouillonnant d'amertume. Comme si j'avais franchement pu ressentir l'absence de je ne sais quel drame promis par Caelius, quand toute Rome était prise dans l'effervescence de tes poèmes ! 
And here is Clodius, demanding vengeance.

Well, I will speak against Caelius if a case is brought to trial, though I'd prefer to never speak again.

How can I feel so wrapped in numbness

and at the same time flayed alive?

I don't know but I feel it, I feel crucified.
Et voilà Clodius qui exige sa vengeance.

Et bien, oui je parlerai contre Caelius si l'on intente son procès, même si je préférerais ne plus parler du tout.

Comment puis-je être enveloppée d'une telle torpeur

tout en me sentant écorchée vive?

Je ne sais pas mais je le sens, je me sens crucifiée. 
The Photographer's Olympics

The photographer as a friend she sometimes sleeps with who instead is watching the Olympics, something of no interest to the photographer until the women's triathlon screens and she is entranced

by the sight if the women's arms

lifting and rising in and out of the water

black like eels in a swarm

curling and calling

one to another - she wishes

the screen would remain full of the arms

and nothing but the arms for the duration

of the race. Although she stays put

on the sofa and watches the chase group of cyclists catch up and absorb the lead group, and

goes on to watch the last of the break-away runners

fall behind, the four in front take their places

at the finish line, it is the screenshot

of arms rising and falling she sees as she falls asleep that night and for night after night

to come. It is all

she wants to photograph but the stills are nothing without the movement and so for the first time

she takes to photographing faces,

the stills betraying an extremity of

emotion not apparent

on the move. This

is the worst disaster of her career -
Les Jeux Olympiques de la photographe

La photographe a une connaissance avec qui elle couche parfois mais là, qui regarde les Jeux Olympiques, chose sans intérêt pour la photographe

sauf quand est diffusé le triathlon féminin et elle est fascinée

par la vision de ces bras de femmes

qui se lèvent et se soulèvent hors de l'eau, noirs comme une nuée d'anguilles

qui tortillent et s'appellent

l'une l'autre - elle voudrait que ces bras demeurent à l'écran,

plein de ces bras et rien que ces bras toute la durée de la course. Même si elle reste sur le canapé à regarder le peloton de poursuite des cyclistes rattraper et absorber le peloton de tête puis encore la dernière des échappées être reléguée à l'arrière, puis les quatre à l'avant se positionner sur la ligne d'arrivée, c'est l'écran figé plein de ces bras qui montent et descendent, qu'elle voit en tombant de sommeil ce soir-là puis le soir d'après, soir après soir. C'est tout

ce qu'elle veut photographier mais les clichés saisis ne sont rien sans le mouvement,

alors pour la première fois,

elle se met à photographier des visages,

les clichés trahissant une extrémité

d'émotion qui ne paraît pas

dans le mouvement. C'est

le désastre le plus complet de sa carrière - 
this photographing faces, this creation of 'portraits' - the word makes her want to throw up in the sink, having woken early full of a dread the exact equivalent of that dark and sinuous mass of arms rising and falling on the screen. photographier des visages comme ça, créer des "portraits" là - ce mot lui donne envie de vomir dans l'évier, réveillée tôt et prise d'une terreur dont l'équivalent exact est cette masse obscure et sinueuse de bras qui montent et descendent à l'écran. 


\section{Roland on the outskirts}

This is where I had stopped to take off my shoe and saw the skin at the back of my ankle lifting. Lifting my pack onto my aching back again, I had crossed two bridges, six lanes of a motorway, the empty court in front of a garage, a supermarket parking lot, two flyovers, only to find myself back in this empty playground at the same bench where I'd stopped before. Before, it had still been light, but now the sun has truly sunk below the horizon and the only light comes from the moon and one dim lamp. One dim lamp does not do much to make a place seem cheerful or home-like, this is no Narnia. Narnia, Hobbiton, getting tucked in at night, all as impossible now as it begins to seem just finding the centre will be, and yet I cannot live my life always on the outskirts. Skirting the red-light district had perhaps been my mistake. Taking my courage in my hands - an odd phrase, a translation from a language I've not yet learned I backtrack into those seedy streets, avoiding catching anyone's eye. Eyes are what I dream of at nights now - made up with heavy eyeliner, blue eyeshadow, eyes flashing like bright fishes in the a dark sea, and though I try not to stare, it is my own eyes I am seeing, my own eyes made up like

\section{Roland en banlieue}

Ça c'est l'endroit où je m'étais arrêté pour enlever ma chaussure et j'ai vu la peau derrière ma cheville se soulever. Soulever mon sac sur mon dos endolori encore, $\mathrm{j}$ 'avais traversé deux ponts, six voies d'une autoroute, une cour vide devant un garage, un parking de supermarché, deux autoponts, tout ça pour me retrouver encore dans cette aire de jeux vide sur le même banc où je m'étais arrêté avant. Avant, il faisait encore jour, mais maintenant le soleil a véritablement coulé en deçà de l'horizon et la seule lumière vient de la lune et une seule et faible lampe. Une seule et faible lampe ne fait pas grand-chose pour égayer un endroit ou lui donner un air familier, ce n'est pas Narnia. Narnia, Hobbiton, se faire border dans son lit, aussi impossible désormais que ça a l'air de simplement trouver

le centre-ville, et pourtant je ne peux pas vivre toute ma vie en banlieue. La banlieue du quartier chaud que j'ai contourné, c'est peut-être là qu'il fallait prendre. Prendre mon courage à deux mains - une drôle d'expression, traduite d'une langue que je n'ai pas encore apprise je reviens sur mes pas dans ces rues sordides, en évitant les regards. Les regards c'est de ça dont je rêve la nuit à présent - maquillés lourdement de mascara, de fard à paupières bleu, des yeux étincelant tels des poissons brillants dans une mer sombre, et $\mathrm{j}$ 'ai beau ne pas regarder, ce sont mes propres yeux que je vois, mes propres yeux maquillés 
bright fishes, sparkling blue and green. Green leaves gradually return to the trees, spring flowers begin to bloom, and I could almost get resigned to living here, on the wrong side of the motorway, until, one day, the motorway stretching like a long tail behind my back, I do a funny sort of hop, over a gleaming storm-water drain, and catch a glimpse out of the corner of the playground of a group of kids my age, so not kids any more, disappearing down a street I'd never known was there. There comes at last a time when I catch up with those kids, find the right thing to say, drink what they drink, follow them all the way to the centre. The centre or, you could say, the end. The end for me, that is, but the beginning for my son who looks so much like I did at his age. Age the only solution to the problem he thinks I do not understand. I stand in fact right here beside him, never having left the centre, but the ground has shifted over the years and my son is lost in the outskirts of a centre that he fears he'll never find or, worse, fears is nothing more than this. tels des poissons brillants, scintillant de bleu et de vert. Le vert des feuilles revient graduellement sur les arbres, les fleurs de printemps commencent à éclore et je pourrais presque me résigner à vivre ici, du mauvais côté de l'autoroute, jusqu'à ce qu'un jour, l'autoroute étendue telle une longue queue derrière mon dos, je ne fasse un drôle de petit saut par-dessus une bouche d'égout éclatante et que j'aperçoive d'un coup d'œil au coin de l'aire de jeux un groupe de gamins de mon âge, donc plus des gamins, qui disparaissent dans une rue que je ne savais pas être là. Là, arrive enfin un moment où je rattrape ces gamins, trouve les mots justes, bois ce qu'ils boivent, les suis tout le long jusqu'au centre. Le centre ou, on pourrait dire, la fin. La fin pour moi, oui, mais le début pour mon fils qui me ressemble tant quand j'avais son âge. L'âge la seule solution au problème qu'il ne croit pas que je puisse comprendre. Comprendre que je suis là, à ses côtés, n'ayant jamais quitté le centre mais qu'au fil des années le sol a bougé et maintenant mon fils est perdu en banlieue, hors d'un centre qu'il craint ne jamais trouver ou, pire, craint qu'il ne soit rien de plus que ça. 


\section{Afraid of Falls?}

We spent our childhoods upright. We rose asleep. We rose silent, when our breaths were taken.

We sat on the mat, and were told to sit up.

There was so much to learn.

In the weekends, though, my brother went into the bush behind the house and he came back talking of the waterfalls.

Oh take me, take me to the waterfalls,

I promise not to fall.

Fruit fell. Whole lawns were carpeted!

Fell, and rotted where it fell.

In the end, we rose apart.

But I remember the waterfalls,

and I remember how the world was so much with us.
Peur des chutes?

On a passé une enfance droite. On s'élevait en dormant.

On s'élevait en silence, quand notre souffle était coupé.

On s'asseyait sur le tapis, on nous disait de nous asseoir droit.

Il y avait tant à apprendre.

Le weekend pourtant, mon frère

partait dans le bush derrière la maison

et il revenait en parlant des chutes d'eau.

Oh emmène-moi, emmène-moi aux chutes d'eau,

je promets de ne pas chuter.

Des fruits ont chuté. Des pelouses entières tapissées !

Chutés et pourris sur place.

Au final, on s'est élevés séparément.

Mais je me souviens des chutes d'eau

et je me souviens combien le monde était en nous. 


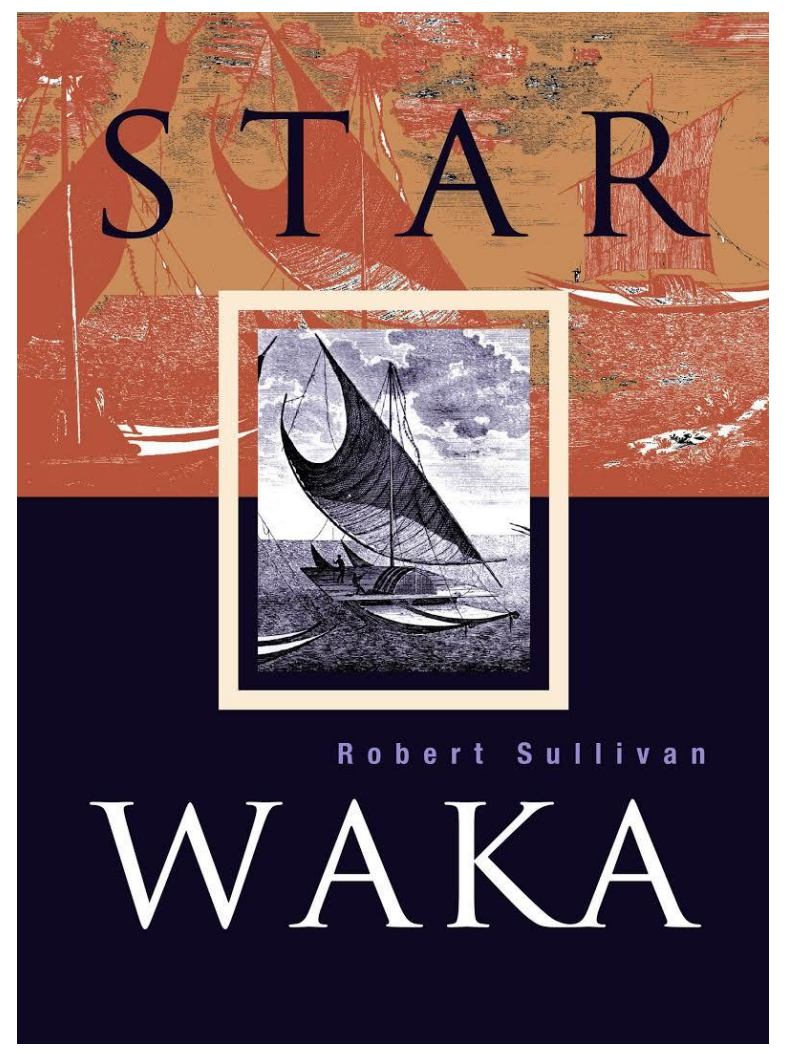

\section{Star Waka}

Robert Sullivan

Traduit de l'anglais (Nouvelle-Zélande) par Luc Arnault 
Note du traducteur:

Dans son troisième recueil de poésie publié en 1999, Robert Sullivan mêle, comme l'atteste son titre, héritages māori et pākehā (Néo-Zélandais d'origine européenne) notamment par la combinaison de la langue māori (ou Te Reo) et de la langue anglaise-néo-zélandaise, qui elle-même inclut certains termes māori. Cette poésie diglossique fait particulièrement sens en ce qu'elle représente une réalité contextuelle bien spécifique où certains mots māori sont passés dans l'usage courant et où d'autres comportent une dimension spirituelle ou holistique reliant notamment cette culture ancestrale aux différents peuples du Pacifique.

C'est ce tressage de langues significatif, symbolique et hautement poétique que ma traduction tente de recréer en incluant tous les termes māori des poèmes de Sullivan dans le texte français et dans leur orthographe actuelle. Pour les termes les plus courants, je propose le glossaire ci-dessous. Pour les termes moins courants, c'est-à-dire qui posent aussi sans doute problème aux Néo-Zélandais ne parlant pas la langue Te Reo, je propose aux lecteurs de se référer aux dictionnaires suivants: Maori de poche de Mahtab Mathilde Nikkhou (2010) ou Dictionnaire poche maori de Jean-Pierre Maceau (2017). Enfin, pour les nombreuses références à la mythologie māori et à la culture néo-zélandaise en général, je propose de consulter l'ouvrage de Georges-Goulven Le Cam, Mythe et stratégie identitaire chez les Maoris de Nouvelle-Zélande (2000) et le Dictionnaire néo-zélandais-français d'Ewen Jones et Myreille Pawliez (1998).

\section{Glossaire :}

Aotearoa : Pays du long nuage blanc. Nouvelle-Zélande.

iwi : tribu, clan, nation.

kauri : variété d'arbres endémiques pouvant atteindre plus de 50 mètres de haut pour 10 mètres de circonférence et vivre jusqu'à 2000 ans.

kia ora : bonjour, salut.

kūmara : variété de patate douce importée par les Māori.

marae : lieu de rassemblement de la tribu.

moko : tatouage sur le visage ou sur le corps effectué selon des protocoles traditionnels.

pā : village fortifié, fort.

pāua : mollusque marin dont la coquille est nacrée et de couleur bleue irisée.

rimu : variété de conifère endémique.

tangi : lamentation, ou abréviation pour tangihanga: enterrement aux protocoles traditionnels.

taniwha: monstre légendaire gardien des eaux d'un lac ou d'une rivière.

tapu : sacré, interdit, prohibé, sous la protection d'atua: être surnaturel, ancêtre et déité.

tōtara : variété de conifères endémiques.

tūī : passereau endémique.

waiata : chanson, chant.

Waitangi : commune située au nord où fut signé le traité unissant la Couronne britannique à la plupart des tribus māori le 6 février 1840 (devenu fête nationale). waka : pirogue, véhicule, moyen de transport, réceptacle, medium.

whakapapa : principe fondamental qui consiste à réciter sa généalogie.

whānau : famille, famille étendue, groupe familier.

wharenui : grande maison qui sert aux réunions ou aux cérémonies sur le marae. 
Note

I wrote Star Waka with some threads to it: that each poem must have a star, a waka or the ocean. This sequence is like a waka, members of the crew change, the rhythm and the view changes - it is subject to the laws of nature.

There are three sections, indicated by the change in title numbering from Roman to Arabic to 'waka' numbering. Occasionally a poem's numbering breaks into another part of the sequence."

There is a core of one hundred poems, and 2001 lines.

For references to Māori mythology see Margaret Orbell's Encyclopedia of Maori Mythology. Other references are built into the text.

\section{Note}

J'ai écrit Star Waka en y tressant certains fils: dans chaque poème, doit figurer une étoile, un waka ou l'océan. Cette séquence est comme un waka, les membres de l'équipage changent, le rythme et la vue aussi - tout est soumis aux lois de la nature.

Il y a trois sections, comme l'indiquent les numéros des titres, en chiffres romains puis en chiffres arabes puis en "chiffres waka". Parfois les chiffres de certains poèmes s'immiscent dans une autre partie de la séquence.

Le noyau dur du texte est composé de cent poèmes et 2001 vers.

Pour les références à la mythologie māori, voir l'ouvrage de Margaret Orbell, Encyclopedia of Maori Mythology. Les autres références sont incorporées dans le texte même. 


\section{He karakia tīmatanga}

A prayer to guide waka out of the throat, between Hawaiiki's teeth, the last green speckled

glove of coast, past upthrust knee and rock toe in the distance to paddle and sail toward sunset -

when each crack in the house of the sun is submerged - doors and windows cloaked by night,

charred sky where stars become arrows, lit signs travelling across a black zone.

A prayer to hold lashings and fittings close amid the swelled guts of Tangaroa.

A prayer to scoop out sustenance sweet fish caught by divers in bright saltwater

marinaded in coconut and hunger. A prayer to keep food for the two week trip to Aotearoa,

gourds intact, yam and taro and kūmara gods alert to the slap and grab of a restless swell -

whether in the breast of seabed. A prayer, a declaration, for quick land, straight seas, and health

of all parts celestial, temporal and divine: food music and drink of this star waka -

the chanted rhythms

\section{He karakia tīmatanga}

Une prière pour guider waka hors de la gorge, entre les dents de Hawaiiki, le dernier gant de vert

tacheté de la côte, passer genou levé le pied rocheux, au loin pagayer et faire voile vers le couchant -

quand toute fissure de la maison du soleil

est submergée - portes et fenêtres en un korowai de nuit,

ciel calciné où les étoiles deviennent des flèches, panneaux lumineux parcourant une zone noire.

Une prière pour que tiennent bon cordes et attaches dans la houle des tripes du dieu Tangaroa.

Une prière pour pêcher au filet subsistance poisson sucré pris par des plongeurs en eau brillante et salée,

mariné à la noix de coco et à la faim. Une prière pour garder des vivres les deux semaines du voyage vers Aotearoa,

gourdes intactes, igname, taro et kūmara : dieux alertes contre la claque et le rapt de la houle incessante -

aussi bien au sein qu'au fond de la mer. Une prière, déclaration, pour des terres vives, des mers droites et la santé

de toutes parts célestes, temporelles et divines : musique, le manger et le boire de ce star waka -

les rythmes scandés 
hoea hoea ra

storms

hoea hoea ra

a thousand years

hoea hoea ra

fleet mothers of tales

hoea hoea ra

I greet you in prayer oh star oh waka. .

and I pray for your combination here.

He karakia mo kōrua, e te waka, e te whetū o te ao nei. Star and waka, a prayer for you both. hoea hoea ra

tempêtes

hoea hoea ra

un millier d'années

hoea hoea ra

lestes mères des légendes

hoea hoea ra

je vous salue en prière oh étoile oh waka...

et prie pour que vous soyez combinés ici.

He karakia mo kōrua, e te waka, e te whetū o te ao nei. Etoile et waka, une prière pour vous deux. 
Men rest their oars at night -

sailing into pāua, plump fowl, sweet

water, miracles of earth, land rolling

from hills into skies, land large enough

for lakes, enough to gather people in,

a feast for a forest of gods hitting sky.

Star waka is a knife through time. Crews

change, language of each crew changes,

as fast as sun burns ground, and tongues curse him.

Crews take longer, yet learn less about makers

of waka, meanings of star. Inheritors

of body, watched by spirits watching star.

Star hangs on ears of night, defining light.

Hear sounds of waka knifing time - aue, again,

what belongs to water belongs to blood. Crews leap aboard

leap out, with songs of relations and care

to send them. Whole families have journeyed here,

they continue the line. The bottom line

is to know where to go - star points.

Kaituki counts stroke. Tohunga,

who dwells beyond law, finds star.

System is always there for waka.

Star rises and falls with night.

So guidance system attached.

Belief system of heart. And tide.

In ancient days navigators sent waka between.

Now, our speakers send us on waka. Their memories,

memory of people in us, invite, spirit,

compel us aboard, to home government, to centre:
Les hommes laissent reposer leurs rames la nuit naviguant parmi pāua, volaille dodue, eau douce, miracles de la planète, terre roulant des collines aux cieux, terre assez grande pour des lacs, pour y accueillir un peuple, festin pour une forêt de dieux touchant ciel.

Star waka est un couteau à travers temps. Les équipages changent, la langue de chaque équipage change, aussi vite que soleil brûle sol et les langues le maudissent. Les équipages mettent plus de temps, mais apprennent moins des constructeurs de waka, des sens d'étoile. Héritiers de corps, observés par des esprits observant étoile.

Etoile accrochée aux oreilles de nuit, définit la lumière. Au son du waka qui coutèle le temps - aïe, encore, ce qui est à l'eau est au sang. Les équipages sautent à bord débarquent, des chansons de tendresse et de parenté à leur envoyer. Des familles entières ont fait voyage ici, ils continuent la lignée. La ligne à suivre

c'est de savoir où aller - étoile guide.

Kaituki compte la ramée. Tohunga,

demeure au-delà des lois, trouve étoile.

Système est toujours là pour waka.

Etoile monte et descend de nuit.

Donc système de navigation intégré.

Croyance système de cœur. Et marée.

Aux jours anciens, les navigateurs envoyaient waka entre.

Désormais, nos orateurs nous envoient sur waka. Leurs souvenirs, mémoire du peuple en nous, invitent, esprit, nous obligent à bord, à gouverner au pays, au centre: 
Savai i, Avaiki, Havaiki, Hawaiiki, from where we peopled

Kiwa's Great Sea. We left home by a thousand different stars, but just one waka takes us back.

Let us regroup. We have never travelled further -

just one star stays familiar in the heavens now.

Tamanui sun dribbles from sky. How will we ever settle

this cold place? Makariri. Will our high magic work here?
Savai`i. Avaiki, Havaiki, Hawaiiki, d'où nous avons peuplé

la Grande Mer de Kiwa. Nous sommes partis d'un millier d'étoiles différentes, mais un seul waka nous ramène.

Regroupons-nous. Nous n'avons jamais voyagé plus loin une seule étoile reste familière dans les cieux à présent.

Soleil Tamanui bave depuis ciel. Comment nous installer sur cette terre froide? Makariri. Notre haute magie marchera-t-elle ici ? 
And when waka reaches Aotearoa again,

empty, we know it has come for more -

and when waka reaches Europe

we know it has lost some more -

and when craft work on waka

descends into varnish and paint it has lost some more -

more times the waka leaves full

we lose more -

and more
Et quand waka atteint encore Aotearoa,

vide, on sait qu'il en veut encore -

et quand waka atteint l'Europe

on sait qu'il en perd encore -

et quand l'artisanat sur waka

s'abîme en vernis et peinture il en perd encore -

plus souvent le waka repart plein

et on en perd encore -

et encore 
iii About some of the crew

He takes notes about his history and culture, even his own family he takes notes about. He tries to hit the right notes

every time he speaks about them - he does his best to compliment and complement their abilities,

the way they looked and what they looked at

Sometimes a few cracks appear in the waka:

someone was a murderer, or someone was not at all

that they seemed. To the interested, cracks appear on

the same scale, are worthy of same judgement.

To hide these judgements in little letters is their fate. iii Sur une partie de l'équipage

Il prend des notes sur son histoire, sa culture, même sur sa propre famille il prend des notes. Il essaye de trouver les notes justes chaque fois qu'il parle d'eux - il fait de son mieux pour complimenter et complémenter leurs compétences,

leurs apparences, visions et visées.

Parfois, quelques fissures apparaissent dans le waka : untel était un meurtrier, ou untel n'était pas du tout ce qu'il semblait. Pour les intéressés, les fissures apparaissent à la même échelle, sont passibles du même jugement.

Cacher ces jugements dans de petites lettres, c'est leur destinée. 


\section{iv $2140 \mathrm{AD}$}

Waka reaches for stars - mission control clears us for launch and we are off to check the guidance system

personally. Some gods are Greek to us Polynesians,

who have lost touch with the Aryan mythology,

but we recognise ours and others - Ranginui and his cloak,

and those of us who have seen Fantasia know Diana

and the host of beautiful satyrs and fauns.

We are off to consult with the top boss,

to ask for sovereignty and how to get this

from policy into action back home.

Just then the rocket runs out of fuel -

we didn't have enough cash for a full tank -

so we drift into an orbit we cannot escape from

until a police escort vessel tows us back

and fines us the equivalent of the fiscal envelope

signed a hundred and fifty years ago.

They confiscate the rocket ship, the only thing

all the iwi agreed to purchase with the last down payment.

\section{iv 2140 de notre ère}

Waka vise les étoiles - contrôle nous déclare parés au lancement et nous partons vérifier le système de guidage

nous-mêmes. Certains dieux, c'est du grec, pour nous Polynésiens, nous avons perdu contact avec la mythologie aryenne,

mais on reconnaît les nôtres et les autres - Ranginui et son korowai,

et ceux parmi nous qui ont vu Fantasia connaissent Diane

et sa belle horde de satyres et de faunes.

On part consulter le grand patron,

demander notre souveraineté, comment faire passer

la législation en action réelle sur le terrain.

Et là, la fusée tombe en panne de carburant -

on n'avait pas assez de liquide pour faire le plein -

alors on dérive sur une orbite dont on ne peut échapper

puis un vaisseau escorte de la police nous remorque chez nous

avec une amende, l'équivalent de l'enveloppe fiscale signée il y a cent cinquante ans.

Ils confisquent la fusée, la seule chose

que notre iwi avait acheté d'un commun accord avec le dernier acompte. 


\section{v Honda Waka}

Today I surrendered the life

of my Honda City

to a wrecker in Penrose for $\$ 30$

I bought it seven years ago for $\$ 6000$.

It has rust in the lower sills,

rust around the side windows -

on the WOF inspection sheet it says:

'this car has bad and a lot of rust...'

That car took me to Uncle Pat's tangi in Bluff. We stopped and gazed at Moeraki,

the dream sky, on the way.

A friend followed us in it on the way

to National Women's for Temuera's birth

(we were in her huge Citroen).

We went to Ōtaki, and Wellington,

in the Honda to visit family.

The Honda took me to Library School

perched next to Victoria Uni.

I drove Grandad across the creek in the Honda at night after the family reunion bash.

Temuera's first car seat was in the Honda. That Honda has seen a high percentage

of my poetry.

Now I have left it behind. v Waka Honda

Aujourd'hui, j'ai abandonné la vie de ma Honda City

à la casse de Penrose pour 30 dollars.

Je l'avais achetée 6000 dollars il y a sept ans.

Il y a de la rouille dans le bas des portières,

de la rouille autour des vitres -

sur la feuille du CT il y a écrit :

"cette voiture a beaucoup de rouille et de la mauvaise..."

Cette voiture m'a conduit au tangi d'Oncle Pat à Bluff. On s'est arrêtés regarder Moeraki,

le ciel de rêve, sur le chemin.

Une amie nous a suivis dans cette voiture jusqu'à

la maternité pour la naissance de Temuera

(nous, on était dans son immense Citroën).

On est allés à Ōtaki et Wellington,

dans la Honda pour rendre visite à la famille.

La Honda m'a conduit à l'école des bibliothécaires perchée à côté de l'université Victoria.

J'ai traversé la rivière avec Grand-père dans la Honda la nuit après la bringue de notre réunion de famille.

Le premier siège auto de Temuera était dans la Honda. Cette Honda a vu un fort pourcentage

de ma poésie.

Maintenant, je l'ai abandonnée. 
vi Feelings

Shooting pains, or are they growing, how does one enumerate and describe

a feeling? - should one resort to the military analogy as outlined in Colonel Bridge's journal (there he goes again, referring to the massacre as if he doesn't talk about it enough - let the event lie boy, don't bore the reader with the petty tale - it's all in the Turnbull Library anyway, I'm sure they'd want to read it when they're in the mood) OR SHOULD ONE TELL THE TRUTH IN CAPITAL LETTERS

(cut it sic) or should one concentrate on the beauty of the waka slicing through concentration, through the vision of the mind, lighting the architecture of every dwelling, beauty of physical story, water worn lines of brown bodies sliding close to one another,

dipping and rising toward shore? vi Sentiments

Douleurs lancinantes ou bien persistantes, comment est-on censé énumérer et décrire

un sentiment ? devrait-on avoir recours à l'analogie militaire comme le définit le Colonel Bridge

dans son journal (et le voilà qui ressasse encore sur le massacre comme s'il n'en parlait pas déjà assez laisse tomber mon gars, n'ennuie pas les lecteurs avec tes petites histoires - tout ca, c'est à

la bibliothèque Turnbull de toute façon, je suis sûr qu'ils le liront quand ils seront d'humeur) OU FAUT-IL DIRE LA VERITE EN MAJUSCULES

(à couper sic) ou devrait-on se concentrer sur la beauté du waka tranchant

la concentration, la vision

de l'esprit, illuminant l'architecture

de toute habitation, beauté d'histoire physique,

corps bruns en lignes liquides érodées

glissant proches les uns des autres,

plongeant puis remontant vers le rivage? 
Highlights of the forest of the Lord Tāne were logged for the fleet. Fleet transport and weaponry, food baskets and ancestors, technology and carving: a greatness of hulls

and sails - ships for the mission - settlers going to ground thousands of miles south-west, taking their divinities, agriculture, animals, to inhabit the strangeness of climate and soil reported

by the first expedition. The waka represents ancestors in name and form. Their names are invoked today and bind Māori people. Waka fight for yesterday

like it is tomorrow; war cries of orators line marae

with subjective recollections. Speakers point out borders of land, which waka went where, who guard harbours - voices modelling land into history and lineage, driving up

highways of legend - much art is visual: displays of beauty accessible to all but the symbolism remains Māori and will always be for Māori.
Les apothéoses de la forêt du Seigneur Tāne étaient débitées pour la flotte. Flotte transport et armement, paniers à nourriture et ancêtres, technologie et sculpture: une grandeur de coques

et de voiles - navires pour la mission - pionniers vers une terre à des milliers de milles au sud-ouest, emportant leurs divinités, agriculture, animaux, pour habiter l'étrangeté d'un climat et d'un sol rapportés

par la première expédition. Le waka représente les ancêtres en nom et forme. Leurs noms sont invoqués aujourd'hu et relient le peuple māori. Les waka se battent pour hier comme si c'était demain; lignes, cris de guerre d'orateurs

couvrent le marae de souvenirs subjectifs. Les orateurs indiquent les frontières des terres, quel waka est parti où, qui garde les ports - voix qui modèlent la terre d'histoire et de lignée, conduisant sur

des autoroutes de légendes - l'art est surtout visuel: expositions d'une beauté accessible à tous

mais le symbolisme reste māori et sera toujours pour les Māori. 
viii No

I cannot make this like maker of waka reach into my heart

heal wood of its rough cuts

take what isn't mine to take

whittling and whittling

No

lines decked with pāua

No

wooden crowns turned to warriors' bowels

dreaming of the beauty of the vessel

fleets filling lakes and harbours

riding rivers in judgement

waka everywhere -

taking their contents to the settlements

what did they carry?

how can I tell you in confidence?

why is it that each time I stand

I sway? and the crew sways too ?

star waka is in every waka - viii Non

Je ne peux pas faire ça comme constructeur de waka puiser dans mon cœur

soigner le bois de ses dures coupures

prendre ce qu'il ne m'appartient pas de prendre

ciseler et ciseler

Non

lignes ornées de pāua

Non

couronnes en bois torsadées en boyaux des guerriers

à rêver de la beauté du vaisseau

flottes emplissant lacs et ports

chevauchant rivières au jugement

waka partout -

emportant leurs contenus aux kāinga

que transportaient-ils?

comment vous en faire la confidence?

pourquoi faut-il qu'à chaque fois debout, je chancelle ? et que l'équipage chancelle aussi ?

star waka est en tout waka - 
land fell a thousand years ago

yet waka still searches for star

among all people

who have become stars

made stars in patterns on wood and the justice of the heaven

(which is black

remember terre tombée il y a un millénaire

or waka cherche toujours étoile

parmi tout le peuple

devenu étoiles

transformé en motifs étoiles sur le bois

et la justice du ciel

(qui est noir

souvenez-vous 
and he tries to remember but remembering is for things of experience

these things he hasn't experienced:

the timing of a hundred

following birds across an Ocean

diving into the Ocean

and coming back up

how huge an Ocean is

composing chants

to move people

across the Ocean

to set out from Hawaiiki

knowing the return is death et il essaye de se souvenir

mais le souvenir est aux choses

de l'expérience

ces choses-là il n'en a pas fait l'expérience:

la synchronisation d'une centaine

d'oiseaux se suivant à travers un Océan

plongeant dans l'Océan

puis remontant

\section{l'immensité d'un Océan}

composer des chants

pour que se déplace un peuple

à travers l'Océan

naviguer depuis Hawaiiki

sachant que le retour c'est la mort 
x Goldie (I)

he pads around downtown

spots the Toi Tamaki

Heritage Gallery's picture

of the starving lost waka crew -

so realistic, 'on the spot' -

proof of early

anthropological puddings

just look at it,

where are the women,

the crops, tools, material

for settlement?

hey they were paddling

round the ocean

when they bumped

into Aotearoa

and were canvassed -

must be their account x Goldie (I)

il se balade en ville

repère à la Toi Tamaki

Heritage Gallery le tableau

du waka perdu et son équipage affamé -

si réaliste, "sur le vif" -

preuve par l'image

d'anciens clichés anthropologiques

non mais regardez-moi ça,

où sont les femmes,

les semences, outils, matériel

pour s'installer?

hé, ils pagayaient

au hasard dans l'océan

quand ils sont tombés

sur Aotearoa

et on leur a tiré le portrait -

ça doit être ça leur récit 
he and I suggest ways of narrating a story of waves

a billion billion of them to borrow a phrase borrowed from the infinite numbers available

in telling an infinite story lapping the shapes formed round land - a set of keys on a lap

landing there by mistake - a slip and it all piles into the ocean mistook

for a reclamation declaimed by the tumbling mumbling tongues of salinity

at a beach which heads for a context a breach into the canon of beaches

writing in sand obscured by puffs and gulls and tide's own cursive

curling lickity ups and lollipop downs through the otherwise metronomic

glassiness then swelling then rough

to high waves and back down

to the ground or the rocks again

and again the saline solution lui et moi suggérons des façons de narrer une histoire de vagues

un milliard de milliards d'elles pour emprunter une phrase empruntée au nombre infini disponible

pour raconter une histoire infinie lapant les contours formés autour des terres - un jeu de clés sur un genou

atterri là par erreur - un glissement

et tout s'entasse dans l'océan mépris

pour une reprise déclamée par le tumultueux murmure des langues de salinité

sur une plage qui s'en va gagner un contexte une page de brèche dans le canon des plages

écriture dans le sable obscurci par les macareux et les goélands et la cursive de la marée même

enroulant léchouilles en haut et roudoudous en bas à travers la transparence autrement

métronomique puis houleuse puis agitée

jusqu'aux vagues hautes retombant

par terre ou sur les rochers encore

et encore la solution saline 
xii Independance Day

We hear a lot in Auckland these days about the cost of the viaduct basin

the benefits accrued from the Cup challenge various economic analyses: tourists

property exposure capital: the Americans are really doing their homework

before they decide to colonise us (but this time I really mean most kiwis

i.e. $85.1 \%$ of the population according to the 1996 census) it doesn't mean

much to the rest it's still going to be a colony xii Jour de l'indépendance

On entend beaucoup parler à Auckland ces jours-ci du coût de la marina du Viaduct Basin

les bénéfices accrus grâce à la Coupe de l'America diverses analyses économiques : touristes

propriétés capital exposition : les Américains font vraiment bien leurs devoirs

avant de décider de nous coloniser (mais cette fois, je parle de la plupart des kiwis

c'est-à-dire $85,1 \%$ de la population selon le recensement de 1996) ça ne veut pas dire

grand-chose pour les autres, ça sera toujours une colonie 
xiii Rough Cuts

the strokes slow, start cutting the drink

becalmed by tired arms

billowing at a tangent

we need a flying fox to new land

hook our mast and glide

like our descendants in skies

who have histories

backwards and forwards

our descendants who will secure

discoveries and communicate

to their descendants the value

of wonders they will find

allowing us - the ancestors -

to navigate our history

down lines xiii Dures coupures

les ramées lentes, se mettre à couper l'eau

encalminés par des bras fatigués

ondoiement à la tangente

il nous faut une tyrolienne vers la terre nouvelle

accrocher notre mât et glisser

comme nos descendants aux cieux

qui ont des histoires

en avant et en arrière

nos descendants qui mettront en sûreté

les découvertes et communiqueront

à leurs descendants la valeur

des merveilles qu'ils trouveront

nous permettant - nous, les ancêtres -

de naviguer notre histoire

au bas des lignes 
xiv Ka huri ahau ki te reo o te ao pōuri

And morning yields to the purpose of the day.

Bright blood, the sun a clot tying darkness.

Waka of death duels death's waka.

The event chokes blood lines -

to civilized time and lex romanum.

The threats, curses, fingers pointing

at me, descendant of the crew

of one death waka,

pinch every nerve,

make me sad and proud

that I am an ambassador,

representative of all they surveyed.

And confused, very confused.

Why did these things happen?

Why are these things put

on me?

Where does it end?

At least

I am learning my history,

the people xiv Ka huri ahau ki te reo o te ao pōuri

Et le matin cède à l'objectif du jour.

Sang brillant, le soleil un caillot qui lie l'obscurité.

Waka de mort en duel avec le waka de la mort.

L'évènement étouffe les liens du sang -

à une époque civilisée et la lex romanum.

Les menaces, injures, doigts levés

vers moi, descendant de l'équipage

d'un seul waka de mort,

me pincent chaque nerf,

me rendent triste et fier

d'être un ambassadeur,

représentant tout ce qu'ils ont inspecté.

Et confus, très confus

Pourquoi ces choses-là arrivent-elles?

Pourquoi ces choses-là m'incombent-elles

à moi?

Où est-ce que ça s'arrête ?

Au moins

j'apprends mon histoire,

le peuple 
who lie within me.

Let anyone challenge

our place again. qui repose en moi.

Que quiconque défie encore

notre endroit. 
xv Sullivan Whānau

The grass at Kaaretu was renowned for its softness - our ancestors would line their whare with it for bedding. Today we are gathered up like clumps of Kaaretu grass, made soft by the gathering, and we line the whare nui at Pihareinga, Te Kaaretu, with our bedding once again.

I learn Arapeta's song, e tuwhera atu nei, te awa o Taumārere... our ancestral river of Taumārere opens here, although of course we had settlements at Matauwhi and Kororāreka the first New Zealand capital - we were one of the first tribes to be affected by westernization. Today we are following

the river, tracing the paths of our people, the great names and the previously unknown, trying to find the first Sullivan who gave us his name early last century. What was his first name? who did he marry? why did he stay here? was he marooned? was it a woman?

what was his waka? These questions remain to date.

But there are tears at this reunion.

The speeches are from everyone here,

we introduce ourselves as the special branches of the whānau. We move around

like the four winds, but when we gather

at Te Kaaretu, we are anchored

and hold fast to one another. xv Whānau Sullivan

L'herbe à Kaaretu était réputée

pour sa douceur - nos ancêtres en recouvraient leur whare comme literie. Aujourd'hui, nous voici rassemblés comme des touffes d'herbe de Kaaretu, adoucis par ce rassemblement, et nous recouvrons le whare nui à Pihareinga, Te Kaaretu, avec notre literie à nouveau.

J'ai appris la chanson d'Arapeta, e tuwhera atu nei, te awa o Taumārere... notre rivière ancestrale de Taumārere s'ouvre ici, même si bien sûr nous avions des kāinga à Matauwhi et Kororāreka la première capitale de la Nouvelle-Zélande - nous avons été l'une des premières tribus affectées par l'occidentalisation. Aujourd'hui, nous suivons

la rivière, retraçant les chemins de notre peuple, les noms illustres et les noms auparavant inconnus, en essayant de trouver le premier Sullivan qui nous a donné son nom au début du siècle dernier. Quel était son prénom ? à qui était-il marié ? pourquoi est-il resté ici ? était-il abandonné ? était-ce une femme ? quel était son waka ? Ces questions demeurent à ce jour.

Mais il y a des pleurs à cette réunion.

Les discours viennent de tous ceux ici présents, nous nous présentons comme les branches spéciales du whānau. Nous nous déplaçons comme les quatre vents, mais rassemblés à Te Kaaretu, nous sommes ancrés nous tenant ferme l'un à l'autre. 
Beloved

sent to Hawaiiki

to become a star

who guides

dreamers to reality

to become a star

portrait on the cloak

of a night on whose

shoulders rest

dreams

of a restless people

who dream white

waves of currency

waka rides

and falls

black and blue

with only stars

to point away since

sun and moon

are tagged for domination

yet stars are

ancestors

they are stars

our ancestors

and we will be stars

like kauri

tōtara where the power

of the land powers

a mechanical culture

strange ships in the sky

air filled with radiation

we are vacuumed in to this

culture of menace to the land

we are told we would do this too if

we had the technology

and our people do it

to the land for people

by people and this land

joins the congress of scars

on the planet a culture

of urban decay and renewal

a culture of dead capitals

sucking the life out of new

cities a culture that knows

no boundaries has only

prophecies called strategies

and stars look down on this and eyes of divinities

look down on stars

and eyes

of the powerless look up

but only at night

when machines
Bien-aimé

envoyé à Hawaiiki

pour devenir une étoile

qui guide

les rêveurs à la réalité

pour devenir une étoile

portrait sur le korowai

d'une nuit sur les épaules

de laquelle reposent

les rêves

d'un peuple agité

qui rêve des blanches

vagues de la monnaie

waka navigue

et chute

\section{bleu et noir}

avec seules les étoiles

pour indiquer au lointain

depuis que soleil et lune

sont désignés pour dominer

or les étoiles sont

des ancêtres

ce sont des étoiles

nos ancêtres

et nous serons des étoiles

comme kauri

tōtara où le pouvoir

de la terre alimente

une culture mécanique

d'étranges navires au ciel

l'air empli de radiations

nous sommes aspirés dans cette

culture de menace pour la terre

on nous dit que nous aussi on aurait fait ça

si on avait eu la technologie

et notre peuple fait ça

à la terre pour le peuple

par le peuple et cette terre

se joint au congrès des cicatrices

sur la planète une culture

de pourrissement urbain et renouveau

une culture de capitales défuntes

qui suce le sang des nouvelles

villes une culture qui ne connaît

pas de limites n'a que

des prophéties dites stratégies

et les étoiles voient ça d'en haut et les yeux des divinités

regardent les étoiles d'en haut

et les yeux

des impuissants regardent d'en bas

mais seulement la nuit

quand les machines 
kahikatea

rimu

awa

tapped for fire

sapped for gum

used for battle

construction materials

veins into dams lighten blackness

when many stars

are lost in the lightning

except in the papakāinga

from tops of pā

from middle of ocean

from these places stars

meant to be seen can be kahikatea

rimu

awa

bois pour le feu

sève pour la gomme

taillés pour la bataille

matériaux de construction

veines des barrages illuminent l'obscurité

quand beaucoup d'étoiles

sont perdues dans l'éclair

sauf dans le papakāinga

depuis les hauteurs des pā

depuis le milieu de l'océan

depuis ces lieux les étoiles

censées être vues peuvent l'être 
xvii Some definitions and a note on orthography

in English the waka

is a canoe

but the ancestral waka

were as large

as the European barks

of the eighteenth century explorers

size isn't the key factor here

it is the quality of the crews

their similar systems of navigation

the common purpose of settlement

and the labelling which is in English which I do not need to spell out

except to say that it is still very

difficult to procure word processors

that have a set of macronised vowels and subeditors who do not pluralise

Māori loan words although most have ceased italicizing them

to give a sense of inclusion

in one context

in the other context

it is for purposes

of pacification xvii Quelques définitions et une note d'orthographe

en anglais le waka

est un « canoe»

mais les waka ancestraux

étaient aussi grands

que les embarcations européennes

des explorateurs du dix-huitième siècle

la taille n'est pas le facteur clé ici

c'est la qualité des équipages

leurs systèmes de navigation similaires

leur objectif commun d'implantation

et l'étiquette qui est dans le mot anglais que je n'ai pas besoin d'épeler sauf pour dire qu'il est toujours très

difficile de se procurer un traitement de texte

qui ait des voyelles avec macrons

et des éditeurs qui ne pluralisent pas

les mots d'emprunt māori même si la plupart

ont cessé de les mettre en italiques

pour donner un sens d'inclusion

dans un contexte

et dans un autre

c'est à des fins

de pacification 
sticking a pipe

through Stonehenge -

that's what it is

to direct that Māngere's

ancient stone fields

have a sewerage pipe

cut through them

it is a violation of the lifeblood

of its guardian

to pour excrement

through one of the few

sacred areas left

in the region must be wrong,

it is wrong isn't it?

don't you think it is wrong?

who thinks it is right?

is this extraordinary?

we are told ordinariness

is the standard in justice -

yet the word Māori

means ordinary

\section{this}

is a rearguard action -

up shit creek without a paddle

- who'd want to put a waka in that!

\section{planter un tuyau}

au milieu de Stonehenge -

c'est ça

d'ordonner que Māngere et

ses anciens champs de roche

aient un tuyau d'égout

qui coupe à travers

c'est une violation de la lignée

de son gardien

verser des excréments

à travers l'une des rares

zones sacrées qu'il reste

dans la région ça doit être mal,

c'est mal, non?

vous ne pensez pas que c'est mal ?

qui pense que c'est bien?

c'est extraordinaire, ça?

on nous dit que l'ordinaire

c'est la norme en justice -

mais le mot māori

veut dire ordinaire

\section{c'est}

un acte réactionnaire ça-

ramer dans la merde jusqu'au cou

- qui voudrait mettre un waka là-dedans ! 
Rata felled the tree

without leave from Tāne

and so the leaves, chips twigs etcetera

were reassembled each evening - the hollow

waka shell undone until thanks were given -

\section{in the modern day}

we have a PM

who asks Māori to give thanks

for the settlement

process - the process

undoes the waka alright

but it puts back empty

trunks all over the land -

some of them

still standing
Rata abattit l'arbre

sans la permission de Tāne

alors les feuilles, copeaux

brindilles etcetera

étaient reconstitués chaque soir - la coque

creuse du waka défaite

jusqu'à obtenir remerciements -

à l'heure actuelle

on a un PM

qui demande aux Māori des remerciements

pour le processus

de compensation - le processus défait le waka ça c'est sûr,

mais il replace des troncs vides dans tout le pays -

certains tiennent encore debout 
xx a whakapapa construction

not the ski-field I'm afraid

or talk of Rata descended from Tawhaki

descended from Māui Tikitiki a Taranga

or even mention of the nights -

the great night the long night -

not the intensity of blacknesses involved

in coming through the layers -

not the lines dangling from the heavens

Tawhaki at one end his beloved above him -

these lines are a whakapapa

in themselves - ten years

of door knocking and practice

on roughs and finishes -

pushed to fluidity - one knows

the narrator should be quite dead

yet in a whakapapa the last line

should be the speaker's $\mathrm{xx}$ la construction d'un whakapapa

pas la piste de ski, j'en ai peur

ni l'histoire de Rata descendant de Tawhak

descendant de Māui Tikitiki a Taranga

sans parler non plus des nuits -

la grande nuit la longue nuit -

ni l'intensité des noirceurs impliquées

pour percer à travers les couches -

ni les lignes qui pendent des cieux

Tawhaki à un bout et sa bien-aimée au-dessus de lui -

ces lignes sont un whakapapa

en elles-mêmes - dix ans

à frapper à toutes les portes, de pratique

en brut et en finition -

poussés à la fluidité - on sait

que le narrateur devrait être bien mort

or dans un whakapapa la dernière ligne

revient à l'orateur 
xxi Te ao mārama I

Aotea

\section{Square}

where the riot started

the closest I got was picking up Dad

from work in Newmarket -

the police cordon began

a hundred metres

up Khyber Pass

on telly.

then watching it all

In the Centre I saw Don Giovanni

starring Kiri Te Kanawa,

and a few other operas.

\section{In the old Town Hall I asked}

a question about seniority

at the NLGOU stopwork meeting.

Often I cross the Square

on my way home - skateboarders

try to scare pedestrians,

but I ignore them. Today

I noticed the banners

for a Māori convention,

big business.

It reminds me of seventh form Classical Studies, the spectacle of the Colosseum pit xxi Te ao mārama I

\section{Aotea}

\section{Square}

où les émeutes ont commencé

je n'ai pas pu aller plus loin que Newmarket

pour récupérer Papa au travail -

le cordon de sécurité commençait

à cent mètres

de Khyber Pass à la télé.

$$
\text { ensuite j'ai regardé tout ça }
$$

Au Centre, j'ai vu Don Giovanni,

Kiri Te Kanawa tenait le rôle principal, et d'autres opéras.

Dans l'ancienne Mairie, j'ai posé une question sur l'ancienneté

à la réunion du syndicat des bibliothécaires.

Souvent, je traverse le Square

en rentrant chez moi - des skaters

essaient de faire peur aux piétons,

mais je les ignore. Aujourd'hui,

j'ai remarqué les banderoles

pour une convention māori,

la belle affaire.

Ça me rappelle les cours d'histoire ancienne en terminale, le spectacle de la fosse au Colisée 
filled with water for mock

naval battles;

and panem et circenses. remplie d'eau pour de fausses

batailles navales;

et panem et circenses. 
xxii Te ao mārama II

\section{Kurahaupō}

Kura kaupapa, kōhanga reo, kura tuarua all schools to advance the Māori culture.

Kurahaupō was a waka. Recently waka have performed a similar function.

They have travelled with us

through the evolution of legends

and the tongues our legends use.

Waka spring from our unconscious,

the deep structure of Polynesia

to reappear in the modern world.

In 1990 I went to the Waitangi celebrations.

Walking through Paihia to the Treaty Grounds

I passed waka taua, pahi, waka ama; fiberglass, wooden, carved and painted -

these waka were paddled, shipped, trucked from all over on an oily rag.

Their resurrection propels our iwi into the new age: vehicles for a revival. xxii Te ao mārama II

\section{Kurahaupō}

Kura kaupapa, kōhanga reo, kura tuarua -

toutes des écoles pour faire avancer la culture māori.

Kurahaupō était un waka. Récemment,

les waka ont tenu une fonction semblable.

Ils ont voyagé avec nous

à travers l'évolution des légendes

et des langues dont se servent nos légendes.

Les waka surgissent de notre inconscient,

de la structure profonde de la Polynésie pour réapparaître dans le monde moderne.

En 1990, je suis allé aux vraies célébrations de Waitangi. J'ai traversé Paihia à pied jusqu'au Parc du Traité

je suis passé devant waka taua, pahi, waka ama : en fibre de verre, en bois, sculptés et peints -

on a pagayé à bord de ces waka, on les a transportés en camion de partout pour une bouchée de pain.

Leur résurrection propulse notre iwi

dans l'ère nouvelle: des véhicules pour un renouveau. 
sepia

paint

text

video

dat

email

html

doc files

water

cd rom

cd photo

sépia

peinture

texte

vidéo

d.a.t.

email

html

fichiers doc

eau

cd rom

cd photo

waka

waka 
ego in the strokes

restoration

revivals

hands-on chisels

hands to paddles

each motion

creating motion

across Raukawa

down Te Wai Pounamu

waka for the foothold

to haul a fish

ee ya ha ha!

the hauling 1'ego dans les ramées

restauration

renouveaux

ciseaux à la main

rames en main

chaque mouvement

créant du mouvement

pour traverser Raukawa

descendre Te Wai Pounamu

waka point d'appui

pour tirer un poisson de l'eau

ee ya ha ha !

la prise 
XXv power/powerlessness

waka cuts it Māori in magazines

remarkable

sensational

sports stars

Māori models wear groovy fashion

single studded ears

indigenous beauty

at the second Māori expo

dark green lipstick

sips from silver

coffee cups
XXv pouvoir/sans-pouvoir

waka vent en poupe Māori des magazines

remarquables

sensationnelles

stars de sport

Mannequins māori portent le dernier cri une seule oreille percée

beauté autochtone

à la deuxième expo māori

rouge à lèvres vert foncé

gorgées de café

tasses argentées 
I rest Star Waka on Nga Waka Maori by Anne Nelson, white tipped

paddles raised to catch

the setting sun

which sets them

yellow, red bodies

the colour

of the waka,

men hongi'ing the nose

of the waka,

faces touching before

their launch

into the mind

of Tangaroa.
Star Waka s'appuie sur Nga Waka Maori

d'Anne Nelson, extrémités blanches

de rames levées pour saisir

le soleil couchant

qui les saisit de

jaune, corps rouges

la couleur

du waka,

hongi d'hommes nez à nez

avec le waka,

visages qui se touchent avant

le départ

dans l'esprit

de Tangaroa 
and the mind of Tangaroa

is disturbed by his brother

\section{Tawhirimātea - turns}

his back on greenstone seas

into alcoholic vortices

focuses

on whirlpool Tangaroa

what a spewer!

until brother tires

of being a blowhard

retreats to distance

where offspring of the real

perpetrator - Tāne Mahuta with genetic memory

of fights and their patterns find pāua seek hāpuka

glide along greenstone lines of thought et l'esprit de Tangaroa

est perturbé par son frère

Tawhirimātea - tourne

le dos aux mers pounamu

pour des vortex alcooliques

se concentre

sur ce tourbillon de Tangaroa

beau dégueulis!

puis le frère se fatigue

de jouer les durs

se retire au loin

où la progéniture du vrai

coupable - Tāne Mahuta -

par la mémoire génétique

des combats et leurs motifs

trouvent des pāua cherchent des hāpuka

glissent le long de lignes

de pensées pounamu 
xxviii Hooked

some say the South Island

is a waka

the North Island is a fish

and the Cook Strait cable (I reckon)

is the only link between them xxviii Pris à l'hameçon

certains disent que l'Ile du Sud

est un waka

l'Ile du Nord est un poisson

et le câble du détroit de Cook (je trouve)

est le seul lien entre les deux 
waka 29 waka taua

waka 29 waka taua

\section{(Calligramme)}

A taniwha brushes the sides uenuku touches the eyes

waka pitches
Un taniwha caresse les flancs uenuku touche les yeux

waka tangue 
waka xxx

in three weeks I turn 30

in three decades

men have landed

on the moon

women have become prime ministers

thousand gained $\mathrm{PhDs}$

trillions of dollars circulated

soft wood forests grown to maturity

$52 \times 30$ no. 1 hit singles

mortgages completely repaid

the microcomputer has developed

and I have achieved feelings

I didn't have before -

what about you? waka xxx

\section{dans trois semaines j'aurai 30 ans}

en trois décennies

les hommes sont allés

sur la lune

des femmes sont devenues premiers ministres

des milliers ont obtenu leur doctorat

des milliards de dollars ont circulé

des forêts de jeunes pousses sont arrivées à maturité

$52 \times 30$ no. 1 au hit-parade

des prêts immobiliers remboursés intégralement

le micro-ordinateur s'est développé

et j'ai réussi à atteindre des sentiments

jamais ressentis auparavant -

et vous? 
XXX1

xxxi

spirals in the tauihu

signatures in water

waka cutting each other's wake

signing

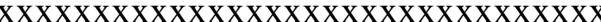

visible from the air

someone in a helicopter

took a photo

counted the signatures

later des spirales dans le tauihu

signatures dans l'eau

waka qui coupent le sillage les uns des autres

signer

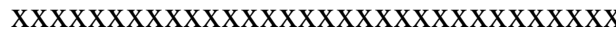

visibles depuis les airs

quelqu'un dans un hélicoptère

a pris une photo

a compté les signatures

plus tard 
xxxii herenga waka

we all belong to a waka

those of us lucky enough to trace

our whakapapa back to Hawaiiki

into times of divinity when all things

Māori were also divine

but we belong to an ugly side too

collected slaves and wars

we were imperfect gods

not unlike the antiquarian

beasts and gladiators of Europe

but the waka carries us all

above the water xxxii herenga waka

nous appartenons tous à un waka

les plus chanceux d'entre nous savent retracer

leur wakapapa jusqu’à Hawaiiki

à l'époque des divinités où toutes choses

māori étaient aussi divines

mais nous appartenons aussi à un côté affreux

accumulant esclaves et guerres

nous étions des dieux imparfaits

pas si différents des bêtes et gladiateurs

de l'Antiquité en Europe

mais le waka nous porte tous

au-dessus de l'eau 
a poem about the weight of wood

native trees in their entirety

not like trees in H. R. Puffenstuff

(the talking variety)

but the energy within them

pushing out leaves in Spring, sap etc.

(like your email says)

energy derived from the heater up there

and the pull of the moon (not proven

but surely?) this heat goes into waves

and the things above them - air itself -

which gyres invisibly except for the things

it touches - leaves, branches, buildings

foundations for natural and human

constructions

some set to float by the measure un poème sur le poids du bois

arbres endémiques dans leur entièreté

pas comme les arbres de H. R. Puffenstuff

(la variété parlante)

mais l'énergie en eux

qui fait pousser les feuilles au printemps, la sève etc.

(comme ton email le dit)

l'énergie qui provient du radiateur tout là-haut

et de l'attraction de la lune (pas prouvée

mais sûrement ?) cette chaleur se propage par vagues

et les choses au-dessus d'elles - l'air même -

qui tourbillonne invisible sauf pour les choses

qu'elle touche - feuilles, branches, bâtiments

fondations pour des constructions humaines et

naturelles

certaines faites pour flotter à la mesure 
of the circumference of seas -

displaced in degrees

by wood and by land de la circonférence des mers -

déplacées de quelques degrés

par le bois et par la terre 
xxxiv Goldie (2)

Our cat's name was Goldie,

daughter of Black Jet,

sister of Black Jet Junior and Gingy -

their brother

was Spotty.

C. F. Goldie was and remains

a famous New Zealand

painter. He still takes the rap

for The Arrival of the Maoris -

in the current exhibition at the Heritage Gallery

that piece is placed with his French paintings,

partly so that it is separated

from the Māori portraits.

The ancestors in the portraits

look grim, with few exceptions.

The ones in Arrival

look destitute. I cannot speak

as a direct descendant

of a Goldie subject,

as my ancestors were depicted

by Lindauer, xxxiv Goldie (2)

Notre chat s'appelait Goldie,

fille de Black Jet,

sœur de Black Jet Junior et Gingy -

leur frère

c'était Spotty.

C. F. Goldie était et reste

un célèbre peintre

néo-zélandais. C'est lui qui porte le chapeau pour L'Arrivée des Maoris -

à l'exposition actuelle de l'Heritage Gallery

cette œuvre est placée parmi ses tableaux français,

en partie pour la séparer

de ses portraits māori.

Les ancêtres dans ces portraits

ont l'air sinistre, à quelques exceptions près.

Ceux dans l'Arrivée

ont l'air démuni. Je ne peux pas parler

en tant que descendant direct

d'un sujet de Goldie,

car mes ancêtres à moi ont été peints

par Lindauer. 
to discover an island must be amazing new resources - water, timber, land -

the claim of discovery when you return home you'd really put on your glad rags

so this thing about the unhappy crews

who shipwreck by chance

doesn't make sense does it?

how did they procreate if it wasn't deliberate?

it's a gender issue I realise découvrir une île, ça doit être incroyable

de nouvelles ressources - de l'eau, du bois, des terres revendiquer sa découverte au retour

là tu dois vraiment te mettre sur ton trente et un

alors ce truc-là, sur les malheureux équipages

échoués par hasard

c'est absurde, non ?

comment ont-ils procréé si ce n'était pas délibéré ?

Je me rends compte que c'est une question de genre 
the introduction of large

European ships to New Zealand waters

made quite an impact

ballistical even

yet we must think

about the hardy voyagers

life in Europe was no pleasure cruise

they must have had desperate

existences back home

I acknowledge their bravery

to sail over the edge of the world

into Hades

the infernal Greek and Latin-ness

of many headed creatures

sirens to put them on the lips

of story-tellers

they must have never considered

for a second that they would return l'introduction de grands

navires européens dans les eaux néo-zélandaises

a eu un certain impact

balistique même

mais il faut penser

aux voyageurs hardis

la vie en Europe n'était pas une croisière de plaisance

ils ont dû mener des existences

désespérées chez eux

je reconnais leur courage

d'avoir navigué par-dessus le bord du monde

jusqu'aux Enfers

l'infernale gréco-latinité

de créatures à plusieurs têtes

sirènes pour les mettre sur les lèvres

des conteurs

ils n'ont jamais dû penser

une seule seconde qu'ils rentreraient 


\begin{tabular}{|c|c|}
\hline $\begin{array}{l}\text { your majesty } \\
\text { arikinui } \\
\text { taumata } \\
\text { etcetera }\end{array}$ & $\begin{array}{l}\text { votre majesté } \\
\text { arikinui } \\
\text { taumata } \\
\text { etcetera }\end{array}$ \\
\hline we have sighted them & nous les avons repérés \\
\hline who? & qui ? \\
\hline $\begin{array}{l}\text { we have seen them } \\
\text { again }\end{array}$ & $\begin{array}{l}\text { nous les avons vus } \\
\text { encore }\end{array}$ \\
\hline $\begin{array}{l}\text { and } \\
\text { again }\end{array}$ & et \\
\hline $\begin{array}{l}\text { running around } \\
\text { on their waka }\end{array}$ & $\begin{array}{l}\text { ils courent partout } \\
\text { sur leur waka }\end{array}$ \\
\hline different people & un peuple différent \\
\hline $\begin{array}{l}\text { who runs on a waka? } \\
\text { have you lost your heads? } \\
\text { gone pōrangi? }\end{array}$ & $\begin{array}{l}\text { qui peut bien courir sur un waka? } \\
\text { vous avez perdu la tête ? } \\
\text { vous êtes complètement pōrangi? }\end{array}$ \\
\hline $\begin{array}{l}\text { esteemed one } \\
\text { here they come }\end{array}$ & $\begin{array}{l}\text { votre éminence } \\
\text { les voilà }\end{array}$ \\
\hline
\end{tabular}


38 fleurs de lis

do not be afraid -

I have seen them too

Tangaroa has delivered a dish

a top-heavy banquet

plying our waves

a European maitre'd

our omniscient descendants

will liken them to gingerbread

which we will snap while they

sit on our backs

ooh la la
38 fleurs de lis

n'ayez pas peur -

je les ai vus moi aussi

Tangaroa a livré un plat

un banquet lourd du chef

sillonnant nos vagues

un maître d'hôtel européen

nos descendants omniscients

les compareront au pain d'épice

que nous briserons net quand ils

seront assis sur notre dos

ouh là là 
39 A wave

On the NativeNet email discussion list someone listed the atrocities

committed after Colombus.

five hundred years later

and the Papal Bull that begat them on vellum still stands.

Men women and children were spiked in His name.

This nauseating wave

splashes today -

nations only traceable

by their DNA -

justice in mixed

blood.
39 Une vague

Sur le serveur de discussions NativeNet quelqu'un a fait la liste des atrocités

commises après Colomb.

Cinq cents ans après

et la Bulle Pontificale sur vélin

qui les a engendrées tient toujours.

\section{Hommes femmes et enfants}

ont été embrochés en Son nom.

Cette vague nauséabonde

déferle aujourd'hui -

nations traçables seulement

par leur ADN -

justice dans un sang

mélangé. 
I imagine my friend walking on reservation land near the Great Lakes

of South-West Ontario

ice in Winter driving the roar

of Spring

and the Summer's day

before the sun

reaches Autumn and thoughts

of eternal Summer inside

are learnt lines

enthusiasm for words again

in her presence

and in her absence

lines singing of a free life

there
J'imagine mon amie marchant sur les terres des réserves près des Grands Lacs

du sud-ouest de l'Ontario

de la glace en Hiver pour faire rugir

le Printemps

et le jour d'Eté

avant que le soleil

n'atteigne l'Automne et des pensées

pour l'éternel Eté à l'intérieur

ce sont des vers appris par cœur

un nouvel enthousiasme pour les mots

en sa présence

et en son absence

des vers chantant une vie libre

là-bas 
cutting across Grey Lynn Park

with the open scars of collapsed storm drains

warning signs great sheets of iron

across the struggling earth

I find fields on the far side it is moving

I am moved by the space

in the city

(our backyard is so small)

am forced to think of nature

the changing course (Sonnet xviii)

I think above all of Canada

and oceanic fields en coupant à travers le parc de Grey Lynn

les cicatrices ouvertes de gouttières renversées

signes avant-coureurs grands plaques de tôle

traversent la terre éprouvée

je trouve des champs tout au loin

c'est touchant

je suis touché par l'espace

dans la ville

(notre cour est si petite)

suis forcé de penser à la nature

qui change de cours (Sonnet xviii)

je pense avant tout au Canada

aux champs océaniques 
Into the new age the waka glides through halls of mirrors

past the birthplace Rangiātea across waves of blood - Mau,

takata Maoli, sovereignty

buried in the franchise contracts - oh

we are peoples united by more

than genes, by more than the tongues

of our ancestors reciting names

of great ones, we are united

by culture, by the psyche

of our cultures, our closeness

even in this age turned

against the sacred
Dans l'ère nouvelle le waka glisse

à travers des galeries de miroirs

devant Rangiātea, le berceau

à travers des vagues de sang - Mau,

takata Maoli, souveraineté

enterrée dans les contrats de franchise - oh

il y a plus que des gènes qui unissent

nos peuples, plus que les langues

de nos ancêtres récitant les noms

illustres, nous sommes unis

par la culture, par la psychè

de nos cultures, notre proximité

même dans cette ère

qui se détourne du sacré 
The South Pacific Forum met recently in Rarotonga.

CHOGM meets soon - they've readmitted Fiji.

The powerful and the powerless

across (internationally) and vertically (internally).

Power is on show in Polynesia regularly.
Le Forum du Pacifique Sud s'est réuni récemment à Rarotonga.

Le Commonwealth se réunit bientôt - Les Iles Fidji ont été réadmises.

Le pouvoir et les sans-pouvoirs

horizontalement (internationalement) et verticalement (intérieurement).

Le pouvoir est exhibé en Polynésie régulièrement. 
the Polynesian branch of the Austronesian

languages has a common parent

$$
\text { Proto-Polynesian }
$$

which features a decimal number system

and a large list of words still found

throughout Polynesia

Captain Cook had Tupaia, a Tahitian interpreter aboard who communicated with the tangata whenua

Kateri says Hawaiians understand Māori

just think of the geography

we reached South America

because kūmara, our staple root crop, is from there

perhaps Hawaiians commuted to America - what

given the Polynesian track record -

could have stopped them?

how did we do it? don't we indicate the depth of our guardianship by travelling

to Japan to retrieve original kūmara stocks from scientists just recently, this decade,

to ensure our intellectual
La branche polynésienne des langues austronésiennes a un parent commun le proto-polynésien

qui compte un système numérique décimal,

une vaste liste de mots qu'on trouve encore

à travers toute la Polynésie

le capitaine Cook avait Tupaia, un interprète tahitien à bord qui communiquait avec le tangata

whenua

Kateri dit que les Hawaïens comprennent le māori

il suffit de penser à la géographie

nous avons atteint l'Amérique du Sud

parce que les kūmara, la base de notre alimentation, sont de là-bas

peut-être les Hawaïens ont-ils fait le trajet en Amérique - compte

tenu du parcours des Polynésiens qu'est-ce qui aurait pu les arrêter?

comment avons-nous fait ? ne montrons-nous pas

la profondeur de notre kaitiakitanga en voyageant

jusqu'au Japon pour récupérer les stocks originels de kūmara des mains des scientifiques encore récemment, cette décennie,

pour s'assurer que notre propriété 
property (the root strain)

and diversity (biological)

are maintained? intellectuelle (la racine souche)

et que notre diversité (biologique)

soient maintenues? 
the ingredients of the story -

a fantasy palace like the Civic

filled with dreams

and a winking ceiling

a dome to navigate the heavens by

imagine in 1929414 elephants monkeys

salamanders proscenium arches

lions minarets according

to Jonathan Dennis's guest

(it is true I have seen it)

dancers clothed only in gilt paint

people were conceived in the Civic

what drove the architects to this

ornamented grandeur?

The greatest theatre in the dominion...

A national institution...

Its brothers and sisters called the Regent,

St James, the Embassy, or simply

dead. The Auckland City Council will restore it,

but 'mask' the proscenium arch, the winged globe,

the winking lions. What kinds of vandals are they?

They will restore it as a theatre for musicals -

but it's a cinema! A waka is a vehicle for navigators, a pitched symbol of the genius of our people,

its physical representatives held in glory.

Auckland doesn't deserve the Civic. les ingrédients de l'histoire -

un palais fantastique comme le Civic

rempli de rêves

et un plafond scintillant

un dôme pour naviguer dans les cieux

imaginez en 1929414 éléphants singes

salamandres prosceniums

lions minarets selon

l'invité de Jonathan Dennis

(c'est vrai je l'ai vu)

danseuses vêtues seulement de peinture dorée

des personnes ont été conçues dans le Civic

qu'est-ce qui a poussé les architectes à cette

grandeur ornementale?

Le plus grand théâtre du dominion..

Une institution nationale...

Ses frères et sœurs appelés le Regent,

St James, l'Embassy ou simplement

morts. La municipalité d'Auckland va le restaurer,

mais en "masquant" le proscenium, le globe ailé,

les lions clignant des yeux. Mais quelles espèces de vandales !

Ils vont en faire un théâtre pour comédies musicales -

mais c'est un cinéma! Un waka est un véhicule pour navigateurs, un symbole aigu du génie de notre peuple,

ses représentants physiques couverts de gloire.

Auckland ne mérite pas le Civic. 
it is feasible that we will enter

space

colonise planets call our spacecraft waka

perhaps name them after the first fleet

erect marae transport carvers renew stories

with celestial import

establish new forms of verse

free ourselves of the need for politics

and concentrate on beauty

like the release from gravity

orbit an image until it is absorbed

through the layers of skin

spin it

sniff and stroke the object

become poetic

oh to be in that generation

to write in freefall picking up the tools

our culture has given us

and to let them go again

knowing they won't hit anyone

just stay up there

no longer subject to peculiarities

of climate the political economies c'est faisable qu'un jour on entre dans

1'espace

coloniser des planètes appeler nos vaisseaux spatiaux waka

peut-être les nommer d'après la première flotte

ériger des marae transporter des sculpteurs renouveler des récits

d'un impact céleste

établir de nouvelles formes de vers

nous libérer du besoin de politique

et nous concentrer sur la beauté

comme libération de la gravité

en orbite une image jusqu'à l'absorber

à travers les couches de la peau

\section{la faire tourner}

renifler et caresser l'objet

devenir poétique

oh évoluer dans cette génération

écrire en chute libre ramasser les outils

que notre culture nous a donnés

et les relâcher à nouveau

sachant qu'ils ne tomberont sur personne

mais resteront là-haut

plus sujet aux particularités

du climat les économies politiques 
of powers and powerless

a space waka

rocketing to another orb

singing waiata to the spheres des pouvoirs et des sans-pouvoirs

un waka de l'espace

parti en fusée vers un autre globe

chantant des waiata pour les sphères 
beams emanate from Mother Mary's

head - the baby in its crib

donkey expectantly leans his head this frame is in our bedroom

yet there are emanations

from the breathing of our daughter Eileen

dim light exiting from Temuera's room

they frame our thoughts

at times lifting our eyelids

when they are shut for business

Anne, lying next to me, feeds her again

she turns around and sleeps

kia pai to moemoeā Eileen Te Aho

little star des rayons émanent de la tête de la Vierge Marie

le bébé dans son berceau

l'âne le regard plein d'espoir penche la tête

ce cadre est dans notre chambre

mais il y a des émanations

provenant du souffle de notre fille Eileen

lumière ténue s'échappant de la chambre de Temuera

ils encadrent nos pensées

parfois soulèvent nos paupières

quand elles sont fermées pour congés

Anne, allongée à mes côtés, lui donne encore le sein elle se retourne et s'endort

kia pai to moemoeā Eileen Te Aho petite étoile 
48 (Brillant I)

Temuera says the sun

looks like a piece

of kauri gum
48 (Brillant I)

Temuera dit que le soleil

ressemble à un bout

de gomme de kauri 
49 (environment I)

will the next makers of waka

live in submarines

so threatened by the mechanical heat

of organised industry

treated like residents

of the Clyde Dam's precincts

gold mines turned to sepia

populations moved to hills by sermons?

from the top

Clinton to reduce the gas by 2011

back to ozone hole of 1990

(wish I could turn the clock back

tell the younger me

taihoa! but write more

about home

before he's dammed

into poems clutching reeds

waka bobbing above)
49 (environnement I)

les prochains constructeurs de waka vivront-ils dans des sous-marins menacés par la chaleur mécanique de l'industrie organisée

traités comme les résidents de la zone du barrage de Clyde mines d'or changées en sépia, populations déplacées sur les hauteurs par des sermons ?

\section{au sommet}

Clinton dit réduire les gaz avant 2011

revenir au trou de la couche d'ozone de 1990

(j'aimerais pouvoir remonter le temps

me dire à moi-même plus jeune

taihoa ! mais écris plus

sur ton pays

avant d'être condamné

à des poèmes accrochés aux roseaux

waka qui flotte en surface) 
It is the star to every wand'ring bark, Whose worth's unknown, although his height be taken.

A compass pointing North past Canada to push this crew furthest South with angles, crow's nest for a shout, the headland! A mass the rest of the crew discover people to convert, flat stretches, rolls of fat turned up to summits, dense green

of black intensity, the only common law Newtonian - a karaka berry will fall from its tree.

Aged heads of kauri are the afros of the land, huge rastas, proudest beings of these South Seas. Converted to spars for the crown fleets

victories for Downing St. A new reggae nation ready for tilling and sharing; imagine, oh beasts, birds of Europe, oh vegetables, fields,

the great yields for roots and guts we have discovered!

Begin the definition of these islands let circumnavigation precede acquisition.

Let ambiguities of Tahitian allow us excuses for our reasons - musketry and the barrel

to raise the sheilas' piupiu, the parson

to peel men off for their eyes.

What is gallantry these days

but by Mitsubishi? Who interprets history?

Who stores the manuscripts and books

of the lost? In time's fair mind

we have objectivity, but for generations
C'est l'étoile brillant pour toute barque errante,

Dont la valeur est inconnue de celui même qui en consulte la hauteur.

Une boussole montrant le nord au-delà du Canada pour pousser cet équipage plus au sud par les angles, nid-de-pie pour un cri, le cap !

Une masse que le reste de l'équipage découvre peuple à convertir, étendues plates, bourrelets tournés vers les sommets, vert dense

d'intensité noire, la seule loi commune est newtonienne - une baie de karaka tombera de son arbre.

Les têtes âgées des kauri sont les coupes afro de la terre, rastas énormes, êtres les plus fiers de ces Mers du sud. Convertis en espars pour les flottes de la couronne victoires pour Downing St. Une nouvelle nation reggae prête au labour et au partage ; imaginez, oh bêtes, oiseaux d'Europe, oh légumes, champs,

les grandes récoltes pour les racines et tripes qu'on a découvertes !

Commençons la définition de ces îles -

que la circumnavigation précède l'acquisition.

Les ambiguïtés du tahitien nous serviront d'excuses pour nos raisons - la mousqueterie et le tonneau pour soulever le piupiu des nanas, le pasteur pour gronder le regard des hommes.

Qu'est-ce que la galanterie de nos jours sinon un modèle de Mitsubishi ? Qui interprète l'histoire ?

Qui conserve les manuscrits et les livres

des disparus? Dans l'esprit juste du temps

il y a l'objectivité mais pendant des générations 
it is no release from captivity - we are pharaoh's possessions, and as each pharaoh succumbs to the coin, dragging the bags

across the Tasman into the holy see,

we watch and wait for justice. Justice for inclusion in the proletariat. Justice for compliance by salary. Justice by revoking our guardianship of all the eye can see in the imposition

of adversarial law. Justice for our apathy. Justice the person who sits at the bench.

We wait for the Justice Bus.

We wait for the Liberty Bus.

We watch the New Zealand First Bus

wheels go round and round

and the faces inside smiling

and waving round and round.

We're at the right Bus Stop.

The timetable says they should pull up.

But signal and you lose an arm.

Or it's the tourist bus. Or you're told

by your mates about the last time

they signalled and how it freaked them out.

Sometimes it's just plain tough to stand

on the street - everybody else has wheels.

Why turn and face the sun, knowing that justice is going to run you down?

In the cool nights when stars slide above street lamps, it's easy to look up much easier to think of waka crews and hear in traffic the inside of a shell. c'est la captivité sans libération - nous sommes les biens de Pharaon et quand chaque pharaon succombe

à la monnaie, tirant les sacs à travers

la mer de Tasmanie jusqu'à la sainte mère,

on regarde et on attend la justice. Justice pour nous avoir inclus au prolétariat. Justice pour nous avoir rendus dociles par le salaire. Justice pour avoir révoqué notre kaitiakitanga sur tout ce que l'œil peut voir et avoir imposé

le droit législatif. Justice pour notre apathie. Justice, personne assise sur le banc.

On attend le Bus de la Justice.

On attend le Bus de la Liberté.

On regarde le bus du parti New Zealand First

et le ronron des roues qui tournent en rond,

et les visages tout sourire à l'intérieur

qui font coucou, oui, coucou, ronron.

On est au bon Arrêt de Bus.

Selon les horaires, il devrait s'arrêter.

Mais faites signe et vous perdrez un bras.

Ou alors c'est le bus des touristes. Ou

vos potes vous racontent la dernière fois

qu'ils ont fait signe et comment ils ont flippé

Parfois, c'est juste pénible de rester debout

dans la rue - tous les autres ont des bagnoles.

Pourquoi faire face au soleil, sachant que la justice va vous foncer dessus ?

Les nuits fraîches où les étoiles glissent en haut des réverbères, facile de lever les yeux bien plus facile de penser aux équipages de waka entendre dans le trafic l'intérieur d'un coquillage. 
Uenuku Bird Flight

Waka Light Dark Shift

Leaf Ocean Ocean Mist

\section{(calligramme)}

Uenuku Oiseau Vol

Waka Lumière Ténèbres Changement

Feuille Océan Océan Brume 
my cousin Billy said to me on Friday that he was going to navigate his way up to Karetu (what a coincidence I thought I must stick that in a poem)

we're going to spend Christmas there this year (1997) for perhaps the last time disturbing (like the state of the health system)

it will be Eileen's first visit

Temuera's second

Anne's third

It will be somewhere in the thirties or forties for me-most of the visits in my childhood

but my mother is from Karetu

and that is how I know the place

through all the stories she's told me

like Grandpa Turi bringing a slab of icecream back for the kids after the races on Saturday about Nanny Pu who lived to be over a hundred and only spoke Māori

about her mother's hard life

or living in the country without a pair of shoes milking the cows by hand before going to school about the men and women of Karetu

and some of their terrible secrets

even I won't tell

that's why I go back because of my mother

who planted Karetu in me vendredi, mon cousin Billy m'a dit

qu'il allait mettre les voiles pour

Karetu (quelle coïncidence je me suis dit

faudrait que je colle ça dans un poème)

on va y passer Noël

cette année (1997) c'est peut-être la dernière fois, troublant (comme l'état du système de santé)

ce sera la première visite d'Eileen

la seconde pour Temuera

la troisième pour Anne

ça doit faire environ trente ou quarante fois

pour moi - la plupart de mes visites dans mon enfance

mais ma mère est de Karetu

et c'est comme ça que je connais l'endroit

à travers toutes les histoires qu'elle m'a racontées

comme Papy Turi qui ramenait un gros pot de glace pour les enfants le samedi après les courses de chevaux ou Mamie Pu qui a vécu plus de cent ans et ne parlait que māori

de la vie dure qu'avait eue sa mère

ou de vivre à la campagne sans chaussures de traire les vaches à la main avant d'aller à l'école

des hommes et des femmes de Karetu

de quelques-uns de leurs terribles secrets que même moi je ne révèlerai pas

c'est pour ça que je reviens car ma mère

a planté Karetu en moi 
not just because of my ancestors

buried in the cemetery and the cave nearby

whose waka navigated to the soil there pas seulement à cause de mes ancêtres

enterrés au cimetière et la caverne tout près dont le waka avait navigué jusqu'à ce sol-là 
island island

no-man

island island

whale

island island

Robert

carved shaped loved floating tōtara (calligramme)

île île

no-man

île île

baleine

île île

Robert

tōtara flottant sculpté formé aimé 
54 waka rorohiko

I heard it at Awataha Marae

in te reo - waka rorohiko -

'computer waka', about a database

containing whakapapa. Some tapu

information, not for publication.

A dilemma for the library culture

of access for all, no matter who, how,

why. A big Western principle stressing

egalitarianism. My respects.

However, Māori knowledge brings many together to share their passed down wisdom in person to verify their inheritance; without this unity our collective knowledge dissipates into cults of personality
54 waka rorohiko

J'en ai entendu parler au Marae Awataha en te reo - waka rorohiko -

"waka ordinateur", une banque de données contenant le whakapapa. Des informations tapu, à ne pas publier.

Un dilemme pour le principe d'accès pour tous des bibliothèques, peu importe qui, comment,

pourquoi. Un grand principe occidental défendant l'égalitarisme. Mes respects.

Cependant, le savoir māori rassemble de nombreuses personnes pour partager leur sagesse de génération en génération et vérifier en personne leur héritage ; sans cette unité notre connaissance collective se dissipe en cultes de la personnalité. 
55 Āraiteuru

The crew of this waka, touched by daylight, turned to stone up and down the east coast

of the South Island - some became mountains, Mt Torlesse, Mt Somers, Mt Tasman, Mt Cook -

forests, ranges, pillars and hills. Of course I am translating names here. A hill in this part

of the country, for example, would probably be taller than Auckland's Mt Eden, which

is roughly as tall as the Sky Tower

which consumed vast amounts of gravel

in its construction. Perhaps some of this was extracted from the Āraiteuru's crew ?

Kāi Tahu, to whom my father belongs, restored one mountain 'Aoraki' (Mt Cook).

\section{5 Āraiteuru}

L'équipage de ce waka, touché par la lumière du jour, fut changé en pierre tout le long de la côte est

de l'île du sud - certains devinrent des montagnes, Mt Torlesse, Mt Somers, Mt Tasman, Mt Cook -

des forêts, montagnes, piliers et collines. Bien sûr je traduis les noms, là. Une colline dans cette partie

du pays, par exemple, serait probablement plus grande que Mt Eden à Auckland, qui

est plus ou moins aussi grand que la Sky Tower dont la construction a nécessité de vastes quantités

de gravier. Peut-être qu'une partie de ce gravier a été extraite de l'équipage d'Āraiteuru?

Kāi Tahu, auxquels mon père appartient, ont restauré une seule montagne "Aoraki" (Mt Cook). 


\section{A Double-Hulled Waka}

Which begins as they do telling stories from heavenly Moeraki where, parked,

I gazed at a big wall of sea and sky, earth a ledge beneath a bright veil crossing

Paradise. A Western Paradise true to its own logic, boulders parked like stops across the text. My head filled with heaven, I drove and drove, wheel in my hands bouncing.

The image bounced round inside me for years like a prayer-wheel powered by water coming out of the ground through me - spring filled with eels nibbling my insides. Māui's tuna for the meiosis, wrestling his descent, his own meiosis, the people.

And the next story beginning a line dangling from glow worms on lime formations, points of light fishing for winged insects on hope - for moon, sun, stars - not devouring

worms. They live in darkness, manufacture their own light. They possess beauty their fans

die like lovers for. I know these lovers, felt the breeze raise a veil from a sunset internalised. Lime spears caverns. Worm mouths. Each bit a wriggle along existence.

Grandiose. A stretch across plates for salt.

Dissembled in the gut, shared out to senses,

tissue, organic stuff, all contribute to each chemical and animal light.

Scales of light vary, measuring speed, lux, changes: physicists think we are stardust.
56 Un waka à double coque

Qui commence comme eux en racontant des histoires depuis la céleste Moeraki où, garé,

je contemplais un large pan de mer et de ciel,

la terre un haut-fond sous un voile brillant croisant

e Paradis. Un Paradis occidental fidèle

à sa propre logique, boules de roche garées, des points

parcourant le texte. La tête remplie de paradis,

j'ai conduit, conduit, volant en mains rebondissant.

L'image a rebondi en moi pendant des années

tel un moulin à prières alimenté par une eau

venue du sol à travers moi - source remplie

d'anguilles qui me mordillent les tripes. Le tuna

de Māui pour la méiose, affrontant sa

descendance, sa propre méiose, le peuple.

Et l'histoire suivante qui commence une ligne pendouillant de vers luisants sur formations de calcaire points de lumière à la pêche aux insectes ailés appâtant à l'espoir - pour lune, soleil, étoiles - des ver ne dévorant pas. Ils vivent dans le noir, fabriquent leur propre lumière. Ils possèdent la beauté, leurs

admirateurs en meurent tels des amants. Je connais ces amants, ai senti la brise lever un voile depuis ce soleil couchant intériorisé. Cavernes harpons de calcaire. Bouches de vers. Chaque bout qui gigote le long de l'existence.

Grandiose. S'étirer à travers des plaques pour du sel.

Dissimulés dans le goulet, ouverts au partage des sens, chair, matière organique, tout contribue

à chaque lumière chimique et animale.

Les échelles de lumière varient, mesurent vitesse, lux, changements : les physiciens croient qu'on est poussière d'étoile. 
Down to a person. Massive and modest

stars recycled in the cosmos - we are

reassembled versions of long dead stars.

Now science imitates art. Once artists

were scientists too. Today vice versa.

Da Vinci, for example, observed candles,

designed helicopters. Today, the Beeb

ran a story about a scientist

exhibiting pictures of molecules:

a silk molecule next to a silk dress;

chlorophyll next to a plant. Everything

a collection of tiny connections.

For beauty has delightful components.

The molecule of water sliding by

molecules of waka, powered by breeze

molecules in muscles, on sails - its scales

notes on the firmament, melodious

oration, song, rhythm of pahū, flute,

feet braced on boards swinging torso, elbow,

thought. This thought passed down lengths of men

through earth -

we came by waka, we leave by waka,

pass it on. The influences of wind

on waves can be immense, high walls scraping

valleys in the heart, constricting throats. Crews scraped themselves, bled prayers, so holiness

remained - a caravan on dry seabed.

ii

Contents of waka huia, treasure chests,

are highly prized. Waka huia on tv,

a Māori language show, has just broadcast

its $400^{\text {th }}$ episode - preserving

eloquence, movement, airs, graces, noblesse
Ça tient à la personne. Massives et modestes, étoiles recyclées dans le cosmos - nous sommes

des versions réassemblées d'étoiles depuis longtemps défuntes.

Maintenant la science imite l'art. Autrefois les artistes

étaient aussi des scientifiques. Aujourd'hui, vice versa.

De Vinci, par exemple, observait des bougies,

concevait des hélicoptères. Aujourd'hui, la BBC

a diffusé l'histoire d'un scientifique

qui exposait des photos de molécules :

une molécule de soie à côté d'une robe de soie,

de la chlorophylle à côté d'une plante. Tout est

une collection de toutes petites connexions.

Car la beauté a des composants merveilleux.

La molécule d'eau glissant sur

les molécules de waka, poussé par la brise

les molécules dans les muscles, sur les voiles - ses gammes

des notes au firmament, mélodieuse

oraison, chanson, rythme du pahū, flûte,

pieds calés sur les planches, balançant torse, coude,

pensée. Cette pensée passée à longueur d'hommes

à travers terre -

on est venus en waka, on repart en waka,

on fait passer. L'influence du vent

sur les vagues peut être immense, hauts murs écorchant les vallées au cœur, étouffant les gorges. Les équipages s'écorchaient, saignaient des prières, pour que le sacré demeure - une caravane sur fond marin sec.

ii

Les contenus des waka huia, coffres à trésors, sont hautement estimés. Waka huia à la télé,

une émission en langue māori, vient de diffuser son $400^{\mathrm{e}}$ épisode - préservant

éloquence, mouvement, airs, grâces, noblesse 
of our leaders, finest men and women, on video forever. In Māori.

Only 14 episodes subtitled.

To understand one's culture one must speak the language of its poetry, world

philosophy, reach untranslated ambiguities. For language deals out

meaning. Meaning is the star above our species. Specifically, our waka

follows this. Meaning is food for chiefs. Succulent hearts steaming in hot ovens

of earth. The land fortified a thousand years with our blood. We grew tall here. We must

reclaim gifts of mouth, example. Faces must drink in faces, lap up, ripple, splash

each other. Make moko in the wrinkles, warriors for ourselves, for our people,

leaping from pits into bright daylight defying the culture of the death

of our culture. Spray out its narrative with whakairo. In many places

we share ancestry, jokes, communities of spirit grown up over settlement -

and so this waka has passed its

thousandth line, Māori and Pākehā,

stars, knowledge of places only referred -

but only lines glide here on salt water,

come out in commanding the stroke - again,

stroke again, stroke, stroke, stroke again, again... de nos chefs, grands hommes et femmes,

en vidéo pour toujours. En māori.

Seuls 14 épisodes sous-titrés.

Pour comprendre sa culture, il faut parler

le langage de sa poésie, la philosophie

de son monde, atteindre les ambiguïtés

non-traduites. Car le langage livre

le sens. Le sens est l'étoile au-dessus de notre espèce. En particulier, notre waka

suit cela. Le sens est la nourriture des chefs. De succulents cœurs fumant aux fours brûlants

de la terre. La terre fortifiée un millier

d'années de notre sang. On a grandi ici. On doit

reprendre les dons de bouche, l'exemple. Les visages doivent boire aux visages, laper, onduler,

s'éclabousser. Faire un moko dans les rides, guerriers pour nous-mêmes, pour notre peuple,

bondissant des fosses à la lumière éclatante du jour défiant la culture de la mort

de notre culture. Faire jaillir son récit dans le whakairo. Dans bien des endroits

on partage ancêtres, blagues, communautés d'esprit grandies au cours de l'implantation -

et c'est ainsi que ce waka a franchi son millième vers, Māori et Pākehā,

étoiles, connaissance d'endroits seulement mentionnés -

mais seules des lignes glissent ici sur l'eau salée, ressortent en ordonnant les ramées - encore,

encore ramer, ramer, ramer, encore ramer, encore.. 


\section{Waka 57 El Nino Waka}

Among the compasses of navigators star compass, wind compass, solar compass a compass based on currents, such was the reliability of the sea. Today the sea is unreliable. Whatever the reason

for El Nino - deforestation of North and South America, for example - El Nino has burst into the sea as rapidly as it has burst into our popular culture and our livelihoods: droughts and floods and storms around the rim of the Pacific, the great fluid of the compass - a bubble with this burst artery.

I can see its origins, as you can. Lack of respect for the planet. The planet, as you are aware, is not only our mother, but the mother of all living creatures here, from the latest computer virus to the greatest of the primates. She carries us through the universe. These things are simple, something that human beings have known throughout their human beingness, which we know is brief compared to our mother's being.

El Nino is blood from our mother. She bleeds internally, then from ocean into air in a maelstrom. Then we send people with cameras: to show lakes turn to mud, to show a tower or a field of cane snap in a hurricane. I don't have any answers for El Nino. I am too small. These words are too affected by El Nino to possess any objectivity at all.

\section{Waka 57 Waka El Nino}

Parmi les boussoles des navigateurs -

boussole étoile, boussole vent, boussole solaire une boussole basée sur les courants, telle était

la fiabilité de la mer. Aujourd'hui, la mer n'est plus fiable. Quelle que soit la raison - la déforestation en Amérique du Sud et du Nord, par exemple - El Nino a explosé dans la mer aussi vite qu'il a explosé dans la culture populaire et nos gagne-pains : sècheresses, inondations, tempêtes sur tout le pourtour du Pacifique, le grand fluide de la boussole - une bulle avec cette artère éclatée.

Comme vous, $j$ 'en vois l'origine. Manque de respect pour la planète. La planète, vous en êtes conscients, n'est pas seulement notre mère, mais la mère de toutes créatures vivantes ici, du dernier virus informatique aux plus grands des primates. Elle nous porte à travers l'univers. Ces choses

sont simples, choses que les êtres humains

savent depuis toujours, en leur être-humanité,

ce qui, on le sait, est courte comparée à l'être de notre mère.

El Nino est le sang de notre mère. Une hémorragie

interne, elle saigne depuis l'océan dans l'air en un tourbillon. Alors on envoie des gens avec des caméras : montrer des lacs se changer en boue, une tour ou un champ de cannes à sucre se briser lors d'un ouragan. Je n'ai pas les réponses

au Nino. Je suis trop petit. Ces mots

sont trop affectés par El Nino pour avoir

la moindre objectivité. 
Waka 58 Waitangi Day

Our organic milk carton's expiry date

is 6 February 1998. A found poem sent by one of the gods of the harvest, slipped unsuspectingly into my Foodtown trolley by Haumietiketike perhaps? just like bumping into an artist in the Grey Lynn aisles late at night, swapping notes about our 21-month-old daughters another found poem. To think at the time

I didn't see 6 February being scanned

at the checkout, getting stuck in a plastic bag, being jostled along with the rest of the groceries.

And what about all the other dates, the possible found poems on consumables - Easter on the honey, 2001 a space odyssey on the noodles,

Jim Morrison's birthday on the candles?

What a far reach 6 February has,

all the way to the waka navigators

and all the way back...
Waka 58 Le jour de Waitangi

Sur notre bouteille de lait bio la date d'expiration est le 6 février 1998. Un poème trouvé envoyé par un des dieux de la moisson,

glissé subrepticement dans mon caddie de supermarché par Haumietiketike peut-être ? tout comme tomber sur un artiste dans les rayons de Grey Lynn tard le soir, échanger des remarques sur nos filles de 21 mois encore un autre poème trouvé. Et dire qu'à ce moment-là je n'avais pas vu le 6 février se faire scanné

à la caisse, être fourré dans un sac plastique, bousculé avec le reste des courses.

Et que dire de toutes les autres dates, potentiels poèmes trouvés sur des produits - Pâques sur le miel, 2001 l'odyssée de l'espace sur les nouilles,

l'anniversaire de Jim Morrison sur les bougies ?

Quelle portée, ce 6 février,

tout là-bas jusqu'aux navigateurs de waka

et de retour jusqu'ici ... 


\section{Waka 50 Elsdon Best}

I have begun reading The Maori Canoe.

The detail is gratifying. Discussions

of the double canoe, the single canoe

$$
\text { with outrigger, }
$$

the single canoe with no outrigger,

various descriptions and commentaries,

all gathered in one meeting place: The Maori Canoe.

To be fair to Best he did find the term canoe an inadequate word, quoting from the copy of Webster's available to him around 1925:

A boat used by rude nations, formed of the trunk of a tree, excavated by cutting or burning into a suitable shape.

He found it, however, '....scarcely advisable to employ the native term of waka...' (p.18) without saying why.

I am still grateful to Best. He saw the beauty in our stories. He noticed that names

of some constellations correspond with the names of waka: Te Waka o Tama-rereti is Scorpio,

Te Waka o Mairerangi includes Antares.

He found it remarkable,

indeed these are in his introductory remarks,

that the stars were placed in Tama-rēreti's waka

so that the sun and the moon

would not jostle them.

He mentions ara moana too. The great path resting on the sea's surface, a path set down by the lips of the navigators who used every sense about them to find the path that expands

\section{Waka 59 Elsdon Best}

J'ai commencé à lire The Maori Canoe.

Le détail est gratifiant. Discussions

de la pirogue double, la pirogue simple

avec balancier

la pirogue simple sans balancier,

diverses descriptions et commentaires,

tous assemblés en un seul lieu: The Maori Canoe.

Pour être juste, Best trouvait, c'est vrai, le terme pirogue inapproprié, citant la version du dictionnaire Webster à sa portée en 1925 :

Bateau utilisé par les nations rudimentaires, formé du tronc

d'un arbre, creusé en le coupant ou en le brûlant en une forme qui convienne.

Il trouvait, cependant “....peu recommandable d'employer le terme local de waka..." (p.18) sans dire pourquoi.

Je lui suis quand même reconnaissant. Best a vu la beauté de nos histoires. Il a remarqué que les noms de certaines constellations correspondaient aux noms des waka : Te Waka o Tama-rēreti c'est le Scorpion, Te Waka o Mairerangi inclut Antares.

Il trouvait ça remarquable,

c'est vrai c'est dans ses notes d'introduction, que les étoiles étaient placées dans le waka de Tama-rēreti pour que le soleil et la lune

ne les bousculent pas.

Il parle d'ara moana aussi. Le grand chemin reposant à la surface de la mer, un chemin enregistré par les lèvres des navigateurs qui usaient de tous leurs sens pour trouver un chemin qui s'étende 
and contracts between the compasses

of Polynesian culture, an accumulation halted

by literacy and modern navigation -

recorded as an afterthought by those Europeans

not overly preoccupied with other things,

and sifted out by people such as Best. et se contracte aux confins de la culture polynésienne, une somme stoppée net par l'alphabétisation et la navigation moderne archivée après coup par ces Européens

pas franchement préoccupés par d'autres choses, et repêchée par des gens comme Best. 


\section{Waka 60 Dead Reckoning}

The heights and shapes of waves, flotsam and jetsam, indicate the direction of currents.

Lewis says that a line of jetsam clearly delineates the meeting point of two currents -

so for instance, where the refuse from Taco Pronto and the refuse from Burger King meet

should indicate the meeting point of currents halfway around the globe (although I hear that Taco Pronto

is down to just one franchise in Auckland).

The McDonalds jetsam indicates nothing, of course.
Waka 60 Navigation à l'estime

La hauteur et la forme des vagues, les déchets et débris flottant à la surface indiquent la direction des courants.

Lewis dit que qu'une ligne de débris délimite clairement le point de contact de deux courants -

ainsi par exemple, là où les déchets de Taco Pronto et les déchets de Burger King se croisent,

ça devrait indiquer le point de contact des courants de l'autre côté du globe (même si j'ai entendu dire que

Taco Pronto n'a plus qu'une seule enseigne à Auckland). Les déchets de McDonald n'indiquent rien, bien sûr. 
Waka 61 Fragment

(adapted from Hetaraka Tautahi)

This is the paddle Te Roku-o-whiti

who stays close to the side

encircles the side

stands forward

files ahead

springs onward

slaps Tangaroa's back

(who sometimes slaps back)
Waka 61 Fragment

(adapté de Hetaraka Tautahi)

Voici la pagaie Te Roku-o-whiti

qui reste tout près du flanc

encercle le flanc

se tient en avant

file en tête

surgit au-devant

claque le dos de Tangaroa

(qui parfois claque aussi en retour) 
There is no Odysseus to lead this fleet not even Māui who sent waka to their petrification,

the waka Mahunui, for instance, placed exactly in the centre of the South Island at Māui's command.

I have only waka floating beneath the stars, at night and in the day, directed by swells,

whose crews are sustained not by seabirds or fish, but by memory - some in conflict

with the written record. I have seen waka only at rest. They are beings worthy of the company they keep -

tohunga to furnish voyagers with karakia, taniwha for security, the very stars in motion with them.

I cannot provide you with a leader of the fleet.

This fleet navigated centuries. The names

of captains were known to their colleagues

as ancestors. The Pacific was a far-flung society

- waka, cocooned in Aotearoa,

stopped returning to Hawaiiki, dropped their sails,

clambered overland into rivers, burrowed

into mountains, reefs, flew into words

sung at tangi, polished speeches,

seen by the pāua eyes of gods and ancestors
Aucun Ulysse ne mène cette flotte -

pas même Māui qui envoya des waka à leur pétrification,

le waka Mahunui, par exemple, placé exactement au centre de l'Ile du Sud selon les ordres de Māui.

Je n'ai que des waka flottant sous les étoiles, la nuit et la journée, dirigés par la houle,

leurs équipages ne se sustentent ni d'oiseaux marins ni de poissons, mais de souvenirs - certains en conflit

avec les écrits. Je n'ai vu les waka qu'au repos.

Ces êtres sont à la hauteur de ceux qui les accompagnent -

tohunga pour fournir des karakia, des taniwha pour la sécurité des voyageurs, les étoiles elles-mêmes en mouvement avec eux.

Je ne peux pas vous fournir de chef pour la flotte.

Cette flotte a navigué des siècles. Les noms

des capitaines étaient connus de leurs collègues comme ancêtres. Le Pacifique était une société lointaine

- des waka, dans leur cocon en Aotearoa, ont cessé de retourner à Hawaiiki, laissé tomber leurs voiles,

escaladé les terres jusqu'aux rivières, creusé un terrier dans les montagnes, les récifs, se sont envolés en paroles

chantées au tangi, en discours polis,

vus par les yeux en pāua des dieux et ancêtres 
whose real eyes, blinking in the light

of their lives millennia and centuries ago,

saw the vehicles themselves -

spacecraft, oxygen tanks, caravans led by elephants,

vehicles of concept, exploration, sails a vortex

ribbed by people shouting names down into the Great Sea. dont les vrais yeux, clignant à la lumière

de leur vie il y a des millénaires, des siècles,

ont vu les véhicules eux-mêmes -

vaisseau spatial, bouteilles d'oxygène, caravanes d'éléphants,

véhicules de concept, d'exploration, voiles un vortex

strié par un peuple criant des noms sombrant dans le Moana nui. 


\section{Waka 63 Venus}

Point this poem to Kopua.

Please memorise it.

\section{Waka 63 Venus}

Dirigez ce poème vers Kopua.

Apprenez-le par cœur s'il vous plaît. 
Waka 64

It's no irony that Waitangi means

crying waters, water of tears -

they pour from a height

their source as mysterious as the Nile's

mixed blood

adrenalin salt on skin

often my people's

although the individual owners

are beyond a DNA trace

while the drops of Waitangi

are mixed with rain

ii

they row the Waitangi waka on Waitangi Day (which keeps

the theme of this sequence -

a waka or a star or ocean

in each poem)
Waka 64

i

C'est sans ironie que Waitangi signifie eaux de pleurs, eau de larmes -

elles sont versées depuis les hauteurs

leur source aussi mystérieuse que celle du Nil

sang mélangé

sel adrénaline sur la peau

souvent celui de mon peuple

bien que les individus concernés

soient au-delà des traces $\mathrm{ADN}$

tandis que les gouttes de Waitangi

se mélangent à la pluie

ii

on met à l'eau le waka Waitangi

le jour de Waitangi (ce qui garde

le thème de cette séquence -

un waka ou une étoile ou l'océan

dans chaque poème) 
He kakano i ruia mai i Rangiātea.

When the waka congregate at the high temple of Taputapuātea, in Rangiātea,

when our priests are gathered and permissions granted to proceed,

we will piece together our intelligence from the two thousand year mission -

compare the methods, materials, languages of the enterprise.

A great living Library of people, trillions of brain cells indexed

from the heart, cross-referenced through usefulness to life, powered

by the stuff of life itself. Among these cells lie references to waka,

to waka ritual, methods of navigation, knowledge of stars currents wind -

the great gathering place of spirits, Te Hono i Wairua, represents
He kakano i ruia mai i Rangiātea.

Quand les waka se rassembleront au temple haut de Taputapuātea, à Rangiātea,

quand nos prêtres seront réunis

et les autorisations accordées,

nous reconstituerons notre intelligence

provenant de notre mission de deux millénaires -

comparerons les méthodes, matériaux, langages de l'entreprise.

Une grande Bibliothèque vivante du peuple, des milliards de cellules de cerveau indexées

depuis le cœur, recoupements

effectués pour leur utilité dans la vie, alimentés

par l'étoffe de la vie elle-même. Parmi

ces cellules reposent des références au waka,

aux rituels des waka, méthodes de navigation, connaissance des étoiles des courants du vent -

le grand lieu du rassemblement des esprits,

Te Hono i Wairua, représente 
this knowledge - for after death

we know where to find Hawaiiki -

the living send them here

without directions. cette connaissance - car après la mort nous savons où trouver Hawaiiki -

les vivants les envoient ici

sans directions. 


\section{Waka 66 Hokule`a}

Masts flute sails out to mouth shapes like beaks of taniwha coming from the sea the only hint of people the rigging

sweeping like vines from the canopy of Tāne's domain - they draw on the ocean like taniwha straws whose sails

are taniwha gills in the breeze while the prow (you know, the taniwha nose) points home like an instinct as magnetic

as the grip of the people

on this taniwha's back

\section{Waka 66 Hokule‘a}

Des mâts cannellent des voiles vers des formes de bouche comme des becs de taniwha sortis de la mer la seule trace du peuple le gréement

qui pend comme des lianes depuis la canopée du domaine de Tāne - elles esquissent sur l'océan comme la courte paille du taniwha dont les voiles

sont des branchies de taniwha dans la brise tandis que la proue (vous savez, le nez du taniwha) pointe vers la maison, un instinct aussi magnétique

que ce peuple qui s'agrippe

sur le dos de ce taniwha 
Boobies, noddies, terns - these and other birds indicate the presence of land, most particularly in the early morning and the evening when

they return home. They fly straight

to their perches. Some birds come out at night

to explore the waka. Depending

on the species you can rely on them for up to fifty miles out. It's well documented in the Pacific that frigate birds were used

to find land, and even as messenger birds across islands. They'd get a feed of fish at the other perch. Before writing, the messages

came in the form of pearls. Birds save lives.

Gatty wrote survival books based on bird sightings for airmen forced down at sea: his Raft Book for instance,

and South Sea Lore, which was a combination of Polynesian and Arab methods. The Arabs were seafarers too of course, and came down into the Indian

Ocean. Their waka were called prau.

Who knows how far they got?
Sulas, noddis, sternes - ces oiseaux-là et d'autres indiquent la présence de terres, plus particulièrement tôt le matin et le soir quand

ils rentrent au nid. Ils volent droit

à leurs perchoirs. Certains oiseaux sortent la nuit, viennent explorer le waka. Selon

l'espèce, on peut s'y fier à

cinquante milles près. C'est bien documenté, dans le Pacifique, qu'on utilisait les oiseaux frégates

pour trouver des terres, et même comme messagers entre îles. On leur donnait du poisson à manger à l'autre perchoir. Avant l'écriture, les messages

se faisaient sous forme de perles. Les oiseaux sauvent des vies. Gatty a écrit des livres de survie basés sur l'observation des oiseaux pour les aviateurs ayant amerri en force: son Raft Book par exemple,

et South Sea Lore, qui était une combinaison de méthodes polynésiennes et arabes. Les Arabes aussi étaient des navigateurs bien sûr et sont descendus jusque dans l'Océan

Indien. Leurs waka s'appelaient des prau.

Qui sait jusqu'où ils sont allés ? 
Waka 68

It is a myth - the idea of Polynesia,

a colonial construct partitioning the Pacific?

What does it matter when there are other myths that have more influence on our lives?

\section{At least 'Polynesians' can embrace}

a continuity outlined in genealogies stretching

back to the gods. Ngā Puhi, for instance,

have Matahourua in Kupe's time, which was re-adzed

in his grandson Nukutawhiti's time to become

Ngātokimatawhaorua. In that case Polynesia returned

to

Aotearoa.

\section{Waka 68}

Est-ce un mythe - l'idée de la Polynésie,

une construction coloniale découpant le Pacifique?

Qu'importe, quand il y a d'autres mythes qui ont plus d'influence sur nos vies?

Au moins "les Polynésiens" peuvent profiter d'une continuité définie dans des généalogies remontant

même jusqu'aux dieux. Ngā Puhi, par exemple, ont Matahourua à l'époque de Kupe, qui fut re-taillé

à l'époque de son petit-fils Nukutawhiti pour devenir Ngātokimatawhaorua. Dans ce cas la Polynésie est revenue

Aotearoa. 
Who was he ? Why did he come here of all places? Was he actually the first person

to arrive? One account has him coveting Kuramārōtini, who was already married to Hoturapa - the voyage being one

long elopement. Another has him chasing the great pet octopus of Muturangi aboard Matahourua

because it kept stealing the bait off his hooks. For a safe return journey he sacrificed his son

Tuputupu-whenua here in the Spring of the World of Light. Imagine such a thing. I could never do it.

In Nga Waka o Nehera by Jeff Evans there is metion of people already present in Aotearoa who Kupe visited,

namely Taikehu and his people at Pātea. Kupe named many places in Aotearoa, which the following poems

describe, based on references in the Journal of the Polynesian Society and other sources listed in Evans.

Anne Nelson tells of Hui Te Rangiora who came before Kupe and sailed so far south he saw icebergs.

That's a claim lodged well before Richard Pearse's flight
Qui était-il ? Pourquoi est-il venu ici

de tous les endroits? Etait-il vraiment la première personne

à y venir ? Selon un premier récit, il convoitait Kuramārōtini déjà mariée à Hoturapa - le voyage n'étant qu'une

longue fugue amoureuse. Dans un autre, il chassait la grande pieuvre apprivoisée, Muturangi, à bord du Matahourua

parce qu'elle n'arrêtait pas de voler les appâts de ses hameçons. Pour un voyage retour sain et sauf, il sacrifia son fils

Tuputupu-whenua ici au Printemps du Monde de Lumière. Imaginez une chose pareille. Je ne pourrais jamais faire ça.

Dans Nga Waka o Nebera de Jeff Evans, on mentionne un peuple déjà présent en Aotearoa auquel Kupe rendait visite,

à savoir Taikehu et son peuple à Pātea. Kupe a nommé de nombreux endroits en Aotearoa, que les poèmes suivants

décrivent, basés sur des références tirées du Journal of the Polynesian Society et d'autres sources citées par Evans.

Anne Nelson raconte que Hui Te Rangiora qui était venu avant Kupe avait navigué si loin au sud qu'il avait vu des icebergs.

C'est une thèse soutenue bien avant le vol de Richard Pearse 
over the Wright Brothers or the first kiwi pavlova.

Waka 70

Among the places and landmarks associated with Kupe and the Matahourua expedition are the following... (Evans, p. 97)

\section{i Mātakitaki}

Kupe talks to his daughter:

I was looking for happuka I had summoned from the deeps, when my eyes ascended white mountains in the distance, I stared and stared - from this of common rocks which I will remember as the place of Mãtakitaki (in Palliser Bay)

I find myself deleting the rolls of names relating to Kupe, listed in Evans: they are translatable without me, the sail

of Matahourua that needed replacing, the ure or penis of Kupe which Smith says he 'scratched' while he sunbathed,

the names of waka bailers and anchors, his dogs, his footprints left in clay - relics pointed out

for a millennium by learned people. Who am I to retouch these icons of Kupe ? He hardly needs rediscovery.

There is a Kupe in all of us, who struggles for love, and with the forces of the deeps. I look for him. supplantant les frères Wright ou le premier pavlova kiwi.

Waka 70

Parmi les lieux et points de repère associés à Kupe et à l'expédition du Matahourua figurent les suivants... (Evans p. 97)

\section{i Mātakitaki}

Kupe parle à sa fille : je cherchais des hāpuka que j'avais conjurés des profondeurs, quand mes yeux montèrent de blanches montagnes au lointain, je scrutais et scrutais encore - depuis ce tas de roches communes dont je me souviendrais comme du lieu de Mātakitaki (à Palliser Bay)

Je me suis retrouvé à supprimer la liste des noms en rapport avec Kupe, établie par Evans : on peut les traduire sans moi, la voile

du Matahourua qui avait besoin d'être remplacée, le ure ou pénis de Kupe dont Smith dit qu'il l'avait "écorché" en se faisant bronzer,

les noms des écopes et des ancres des waka, ses chiens, ses empreintes laissées dans l'argile - des reliques indiquées

depuis un millénaire par des érudits. Qui suis-je pour retoucher ces icônes de Kupe ? Il n'a pas vraiment besoin d'être redécouvert.

Il y un Kupe en nous tous, qui lutte pour l'amour et contre les forces des profondeurs. Je le cherche. 
Waka 71

Burt Reynolds has made his screen come-back

in Boogie Nights, getting an Oscar nomination to boot.

Likewise, so has outrigger canoeing. Competitors in the World Sprints come from 28 different countries

in Oceania. New Zealand won eight gold medals in Samoa in 1994. The national association is called Nga Kaihoe of Aotearoa.

Anne's cousin Gael joined a waka crew - I must

ask her about it. After the enthusiasm for waka toa in the 1990

sesquicentenary celebrations things have died down.

I only saw one waka toa on tv at Waitangi this year,

compared with the great fleet eight years ago. But the waka will come back on show - they're always here anyway,

in the shapes of the land: the prow of the South Island

for instance is the Marlborough Sounds (see the fine carved detail?)
Waka 71

Burt Reynolds a fait son retour à l'écran

dans Boogie Nights, avec une nomination aux Oscars à la clé.

De même pour la pirogue à balancier. Les compétiteurs des World Sprints viennent de 28 pays différents

en Océanie. La Nouvelle-Zélande a gagné huit médailles d'or aux Samoa en 1994. L'association nationale s'appelle Ngā Kaihoe o Aotearoa.

Gael, le cousin d'Anne, fait partie d'un équipage de waka - il faut que je lui demande de m'en parler. Après l'enthousiasme pour le waka toa en 1990

lors du cent-cinquantième anniversaire, les choses se sont tassées. Je n'ai vu qu'un seul waka toa à la télé pour Waitangi cette année,

comparé à la grande flotte d'il y a huit ans. Mais les waka feront leur retour - ils sont toujours là de toute façon,

épousant la forme du pays - la proue de l'Ile du Sud par exemple c'est les Marlborough Sounds (vous voyez le détail finement ciselé ?) 
Waka 72 Hawaikinui’s 1985 journey

Kupe recommended journeying

to Aotearoa in October. The starpath

of Kopua (Venus) in late October

tracks almost directly from Rangiātea

to Aotearoa. It's amazing to see it on a chart.

The star navigation chart for 31 October 1985 depicts

Kopua to the north of Northland, Marama the moon tracking between Moorea and East Cape (near Gisborne),

and Matariki (Southern Cross) tracking south of Tahiti and south of Southland (Nelson, p.19).

Hawaikinui used methods such as wind streamers of aute leaves (paper mulberry) which when bleached

become fluorescent. The way they move indicates deviations from course,

and of course, they can be used at night. When the celestial bodies are obscured

there are the streamers - bearing

back thousands of years.
Waka 72 Le voyage de Hawaikinui en 1985

Kupe recommandait de voyager

vers Aotearoa en octobre. La trajectoire

de Kopua (Venus) fin octobre

suit presque directement le chemin depuis Rangiātea

en Aotearoa. C'est incroyable de le voir sur une carte.

La carte de navigation des étoiles du 31 octobre 1985 montre

Kopua au nord de Northland, Marama la lune qui transite entre Moorea et East Cape (près de Gisborne)

et Matariki (la croix du sud) qui transite au sud de Tahiti et au sud de Southland (Nelson, p.19).

Hawaikinui utilisait des méthodes comme les banderoles au vent

en feuilles d'aute (mûrier à papier), qui, une fois décolorées

deviennent fluorescentes. Leur façon de bouger indique les déviations de la trajectoire,

et bien sûr, on peut les utiliser la nuit.

Quand les corps célestes sont obscurcis

il y a les banderoles - qui remontent à des milliers d'années. 
I took Temuera fishing out at Ōrākei yesterday. We got him a fishing rod for his birthday. We brought morning tea, fortunately, so the time was well spent munching sammies and drinking our drinks. Occasionally we saw fish swimming above and around our hooks, but not a nibble.

Other guys on the pier had sprat lines which, when they cast them, looked like sparkling schools flying through the air. They seemed to be catching a few.

Temuera and I also saw the waka crews. A crew of women rowed beyond the yacht moorings toward Rangitoto. A crew of men stayed in the basin trailing a Coca Cola flag. Glad to see the multinationals are sponsoring them. I'm all for it.

A yacht pulled up and disturbed the fish so we packed up. A film crew were shooting a film or a commercial - perhaps we'll be in it ?
J'ai emmené Temuera pêcher à Ōrākei hier. On lui a offert une canne à pêche pour son anniversaire. On a apporté un goûter, heureusement, alors on a passé notre temps à mâcher nos sandwichs et boire nos boissons. De temps en temps, on a vu des poissons nager au-dessus ou autour de nos hameçons, mais pas une touche. D'autres gars sur la jetée pêchaient au sprat, quand ils lançaient, on aurait dit des bancs étincelants qui volaient dans les airs. Ils avaient l'air d'en prendre pas mal.

Temuera et moi avons aussi vu les équipages des waka. Un équipage de femmes ramait devant les amarrages des voiliers du côté de Rangitoto. Un équipage d'hommes est resté dans le bassin arborant un drapeau Coca Cola. Content de voir que les multinationales les sponsorisent. Je suis complétement pour.

Un voilier s'est arrêté et a troublé le poisson alors on a plié. Une équipe de cinéma tournait un film ou une pub - peut-être qu'on sera dedans ? 
Waka 74 Sea anchor

In storms the waka would lower

a sea anchor halfway to help control

the vessel. In a way this poem

is a sea anchor. We are waiting

for a storm to pass, one preventing control of the narrative.

There were other types

of punga (anchors).

A light anchor was used to determine a current.

And of course there were anchors to hold a vessel in place.
Waka 74 Ancre flottante

Lors des tempêtes le waka abaissait

une ancre flottante de moitié pour aider à contrôler

le vaisseau. D'une certaine façon, ce poème est une ancre flottante. On attend

qu'un orage passe, un orage qui empêche de contrôler le récit.

Il y avait d'autres types de punga (ancres).

On utilisait une ancre légère pour évaluer un courant.

Et bien sûr il y avait des ancres pour maintenir le navire en place. 
a storm so violent

waka and coracles slam into each other

tohunga and fillidh swap notes

sing each other's airs

and before you know it the bloodlines

race in and out at crazy angles

Rangitoto surfaces lets out a breath

blood streams from pōhutukawa

all at once

haka chanting fills the ocean

fish come up simultaneously raise their mouths

clouds make the shapes of ancient creatures

dinosaurs moa great eagles

sea hardens while land dissolves into water

night arrives with more blood

but groaning not singing

pigs squeal at the crater rim

pork boulders juggled at the mouth

of a hot clown

the Tarawera waka glides by

death death fear of death

mystery waka

again the wave slaps his face

try harder un orage si violent

waka et coracles s'entrechoquent

tohunga et fillidh échangent des notes

chantent les airs des uns des autres

et sans crier gare les lignées de sang

courent en tous sens à des angles fous

Rangitoto fait surface laisse échapper un souffle

le sang ruisselle des pōhutukawa

tout d'un coup

le haka scandé emplit l'océan

les poissons remontent lèvent simultanément la bouche les nuages forment des silhouettes de créatures anciennes dinosaures moa aigles géants

la mer durcit et la terre se dissout en eau

la nuit arrive avec encore plus de sang mais grogne ne chante pas

les cochons couinent au bord du cratère rochers porcs jonglés sur la bouche chaude d'un clown

le waka Tarawera passe en glissant mort mort peur de la mort

waka mystère

encore la vague claque son visage essaie de faire mieux 
slaps him again

portray me as I am

Waka 76

Tangaroa slams his pint on the bar, 'Gissa nother,' he hisses - the bartender jumps, slides a frothy wave the length of the bay the crowd of fur seals resume their conversations, slapping each other on the backs.

A guy with a waka attitude walks in, leans over looking at Tangaroa -

'I'll have what the wet guy's having since he's gonna pay for it.'

The fur seals fly in all directions.

Tangaroa looks him up and down, checks out his moko and his waka.

'You're one of Tāne's kids, ain't ya.

That means we're kin!'

He pays for the drink. le claque encore

décris-moi tel que je suis

Waka 76

Tangaroa repose sa pinte sur le bar d'un coup sec, "File'z en une aut"" siffle-t-il - le barman sursaute, glisse une vague mousseuse le long de la baie la foule d'otaries reprend sa conversation, en se tapant dans le dos.

Un type avec une attitude waka entre dans le bar, se penche en regardant Tangaroa -

“j’vais prendre la même chose que le gars mouillé là puisque c'est lui qui rince."

Les otaries filent dans tous les sens.

Tangaroa le toise de haut en bas, inspecte son moko et son waka.

"T'es un des gamins de Tāne, toi, hein.

Alors t'es de la famille!"

Il paye le verre. 
In pre-colonial times the crews would walk across the isthmus near Ōtāhuhu to harbours,

carrying the waka.

If they were visible today there would be motorcades, policemen to control the crowds and traffic probably tv crews too,

perhaps a Holmes special. They'd probably make it part of an Ironman event.

That's good, that's how it should be.

But they don't.

In olden days Mr Pene said at school the waka would carry deceased across from Māngere. But instead of burying them

at Maungakiekie they buried them at caves in Onehunga, which was closer. That's why Māngere is called Māngere which means lazy.

The dead ancestors must be there still. Waiting for their trip to the great pā, wanting the waka to return.
A l'époque précoloniale les équipages traversaient à pied cross les isthmes près d'Ōtāhuhu pour changer de ports, en portant les waka.

S'ils étaient visibles aujourd'hui,

il y aurait des cortèges de voitures, des policiers pour contrôler la foule et la circulation surement des équipes télé aussi,

peut-être une émission spéciale de Holmes. Ça ferait surement partie d'une course Ironman.

C'est bien, c'est ce qu'il faut.

Mais ce n'est pas le cas.

\section{A l'époque, Mr Pene disait à l'école}

que les waka transportaient les défunts de l'autre côté depuis Māngere. Mais au lieu de les enterrer

à Maungakiekie ils les enterraient dans des cavernes à Onehunga, qui était plus près. C'est pour ça que Māngere s'appelle Māngere, ça veut dire paresseux.

Les ancêtres morts doivent toujours être là. Ils attendent leur passage vers le grand $p \bar{a}$, ils veulent que les waka reviennent. 
In the New Zealand Wars, among the lives lost - civilians and fighters - among the torched homes, brutalities, manhunts, relatives turned on each other,

amid the creeping through lines on bellies, captured and wounded,

the horror of soldiers at the injustices, the shared and alien customs of war, amid the tired feet of horses and men hauling artillery down the Great South Road, amid the teeth of men - the military diet, talk, bare lips and beards and moustaches, amid the Māori men and women who fought for themselves

let alone their culture, amid the torture of death for all people who are left to cope with the departure of the dead, amid the context of Grey's second governorship and his belligerent settler PM, amid the context of a minor colony draining Imperial coffers, Imperial forces, amid the resistance of souls to becoming the essence of souls, the Empire took the waka.

They broke them where they confiscated them. Burnt them. The iwi hid the old ones we have today. Or built them again.
Pendant les guerres néo-zélandaises, parmi les vies perdues - civils et combattants - parmi les foyers incendiés, les brutalités, chasses à l'homme, familles tournées les unes contre les autres, rampant ventre à terre entre les lignes, parmi les captifs et blessés,

l'horreur des soldats face aux injustices, les coutumes de guerre partagées et étrangères, les pieds fatigués des chevaux et des hommes portant l'artillerie le long de la Great South Road, parmi les dents des hommes - le régime militaire, discussion, lèvres nues, barbes et moustaches parmi les hommes et les femmes māori, qui se battaient pour eux-mêmes sans parler de leur culture, parmi les tortures de la mort pour tout le peuple qui restait pour surmonter le départ des morts, dans le contexte du second mandat de Grey et son premier ministre colon belliqueux, dans le contexte d'une colonie mineure épuisant les caisses impériales, les forces impériales, parmi la résistance des âmes à devenir l'essence des âmes, l'empire a pris les waka.

Ils les ont brisés là où ils les ont confisqués. Les ont brûlés. Les iwi ont caché les plus vieux ceux qu'on a aujourd'hui. Ou les ont reconstruits. 
They had the psychological template.

Waka 79

Uncle Sam carved my mother a model waka he reached into history and pulled it out from all the symbols available.

I have tried to draw a waka with words, but it becalmed by its own weight, and the grunting of its maker.

Uncle Sam's work is not for sale.
Ils en avaient le profil psychologique.

Waka 79

Oncle Sam a sculpté une maquette de waka pour ma mère il a creusé dans l'histoire et l'a tiré

parmi tous les symboles disponibles.

J'ai essayé de dessiner un waka avec des mots mais il est encalminé par son propre poids, et les grognements de son créateur.

L'œuvre d'Oncle Sam n'est pas à vendre. 
Peter Robinson created a painting of many waka - white ones - among the fleet there is a brown one, depicting his Māori descent.

If I had an eight waka fleet five would be Māori.

My grandmother Sarah's mother, of Kāi Tahu and Kāti Māmoe descent.

Her father was Scottish.

My grandfather James's parents were Irish, their forebears probably used coracles.

My Grandfather Massey's parents who were of Ngāti Kahu and Ngāti Manu. My grandmother Matekino's parents, of Ngāti Hau and Ngāti Whātua.

If I had a fleet of sixteen,

ten would be Māori.

If I had a fleet of sixty-four, forty would be Māori.

Then eighty. A hundred and sixty. Three hundred and twenty.
Peter Robinson a créé un tableau de nombreux waka - des blancs - parmi la flotte il y en a un qui est brun, représentant son héritage māori.

Si j'avais une flotte de huit waka

il y en aurait cinq qui seraient māori.

La mère de ma grand-mère Sarah. de la lignée Kāi Tahu et Kāti Māmoe.

Son père était écossais.

Les parents de mon grand-père James étaient irlandais, leurs ancêtres utilisaient probablement des coracles.

Les parents de mon grand-père Massey qui étaient Ngāti Kahu et Ngāti Manu. Les parents de ma grand-mère Matekino, de Ngāti Hau et Ngāti Whātua.

Si j'avais une flotte de seize waka, dix seraient māori.

Si j'avais une flotte de soixante-quatre, quarante seraient māori.

Puis quatre-vingt. Cent soixante. Trois cent vingt. 
To the beginning

of the Māori people.

I have parts of these genealogies written linking parts of me with different waka.

Unfortunately, and it's a real regret,

I can go back only a little way

with my Irish and Scottish inheritance.
Jusqu'au début

du peuple māori.

J'ai des parts de cette généalogie écrites

reliant des parts de moi avec différents waka.

Malheureusement, et c'est un vrai regret, je ne peux remonter que très peu

dans mon héritage irlandais et écossais. 
Waka 81 A cup of tea

At Harvest in Grey Lynn among the alternative medicines and groceries

I saw they sell kūmarahou leaves. I wasn't thinking on my feet.

I'd bought sarsaparilla and arnica for my gout, but I hadn't thought

clearly - kūmarahou man, kūmarahou is rongoā, Māori medicine,

good for the soul and cleansing the poisons from your system.

The poison of mortgage stress.

Poison of material jealousy.

Poison of cycles of obsession.

These being poisons to do with the chest.

It could make me a new man, give me the strength to row a waka.
Waka 81 Une tasse de thé

Au magasin Harvest de Grey Lynn parmi

les produits et médicaments alternatifs

j'ai vu qu'ils vendaient des feuilles de kūmarahou. Je n'avais pas les idées claires.

J'ai acheté de la salsepareille et de l'arnica pour ma goutte mais je ne pensais pas

clairement - le kūmarahou mec,

le kūmarahou c'est du rongoā, du médicament māori,

bon pour l'âme, pour nettoyer

les poisons de ton système.

Le poison du stress d'un prêt immobilier.

Le poison de la jalousie matérielle.

Le poison des cycles d'obsession.

Ce sont des poisons qui ont à voir avec la poitrine.

Ça ferait de moi un homme neuf me donnerait la force de pagayer un waka. 
Waka 82 Te ao mārama III

i

Whatonga followed his grandfather Toi

to Aotearoa aboard Kurahaupō. He sailed

the Pacific to reach the man. He followed the coasts (west and east) of the new land

to catch word of the man. Toi

must have been very proud,

very moved, to see his grandson.

ii

This second account is of a waka designed for migration. Some claim

it was enchanted and wrecked.

A reef remains where the timber

may still be seen.

There are many different versions

and places for this waka.
Waka 82 Te ao mārama III

i

Whatonga suivit son grand-père Toi

en Aotearoa à bord du Kurahaupō. Il traversa

le Pacifique à la voile pour atteindre cet homme.

Il longea les côtes (ouest et est) de cette nouvelle terre

pour retrouver la trace de cet homme. Toi

a dû être très fier,

très touché, de voir son petit-fils.

ii

Ce second récit est celui d'un waka

conçu pour la migration. Certains disent

qu'il était envoûté et s'est échoué.

Un récif demeure là où on peut encore

en voir le bois.

Il y a bien des versions et des lieux

différents pour ce waka. 
Waka 83

I ask you, waka, ark, high altar above the sea, your next destination?

Tangi, tangi throughout the land, I am in demand to take souls to Hawaiiki to satisfy the honour of spirits.

Take me to Hawaiiki.

Make an exception for one who breathes.

I will take you while you sleep.

You will see phosphorescent waves, do not be frightened. Whale spouts will hold the balls of your feet.

You will see the first Mount Hikurangi.

Swim in the Healing Spring of Tane

where the moon sleeps.

You will hear the elevated speech of those who observe the destinies driving the bodies of the people. and all the stories buried there

like sacristies. People will float like birds, fish will glitter, every cave and waterfall a musical instrument a place too good to be true,

a place the navigators were searching for, the home of their dreams,

only in their dreams.

\section{Waka 83}

Je te demande, waka, arche, autel haut au-dessus des mers, ta prochaine destination?

Tangi, tangi à travers tout le pays, on exige que j'emmène les âmes à Hawaiiki pour satisfaire l'honneur des esprits.

Emmène-moi à Hawaiiki.

Fais une exception pour moi qui respire encore.

Je t'emmènerai dans ton sommeil.

$T u$ verras des vagues phosphorescentes, $n$ 'aie pas peur. Les jets des baleines te porteront sur la plante des pieds. Tu verras le premier Mont Hikurangi.

Tu nageras dans la Source Curative de Tāne où dort la lune.

Tu entendras le discours élevé

de ceux qui observent les destins animant les corps $d u$ peuple,

et toutes les histoires enterrées là comme des sacristies. Le peuple flottera comme des oiseaux, les poissons scintilleront, chaque caverne et chute d'eau un instrument de musique - un lieu trop beau pour être vrai, un lieu que cherchaient les navigateurs, le foyer de leurs rêves, seulement dans leurs rêves. 
And when I woke I was in my study typing.

\section{Waka 84}

I am the waka of memory, unnamed, the template -

place me:

in Hawaiiki

in vehicles

in the mountains reefs cliffs

whare nui trees boulders

in the words of the world Māori

I am the waka made a tree again

by a huge chrysalis of insects

by clearing the marks of humans

anger of these humans in particular

to be free in a forest

without the deadweight of this crew

oh I must feel sad for them
Et quand je me suis réveillé, j'étais dans mon bureau en train d'écrire.

\section{Waka 84}

Je suis le waka du souvenir, sans nom, le modèle -

placez-moi :

à Hawaiiki

dans des véhicules

dans les montagnes récifs falaises

whare nui arbres rochers

dans les mots du monde māori

Je suis le waka de nouveau arbre

par une gigantesque chrysalide d'insectes

en dissipant la marque des humains

la colère de ces humains en particulier

d'être libre dans une forêt

sans le poids mort de cet équipage

oh je dois me sentir triste pour eux 
but it is hard being a waka alone

better to be a tree in a forest

a life marked by the chopping of tūi

instead of adzes mais c'est dur d'être un waka seul

mieux vaut être un arbre dans une forêt une vie marquée par les coups des tūî̀

plutôt que des herminettes 
I am the star Kopua,

Venus to the colonials

and their explorers. I watched their tube eyes watch me, one eye at a time.

We are cousins of Kopua,

Maahutonga, Southern Cross.

We have many points

and have been used throughout ages

belonging to humans

and creatures on other planets.

Light travels slowly

from great distances. So

our deliberation helped the navigators

travel quickly and safely to their homelands.

Sometimes we are obscured by clouds and the navigators rely on other skills

such as translating the ripples made when waves touch land
Waka 85

Je suis l'étoile Kopua

Vénus pour les colons

et leurs explorateurs. J'ai vu leurs yeux de tube m'observer, un œil à la fois.

$\cdots$

Nous sommes les cousines de Kopua,

Maahutonga, Croix du Sud.

Nous avons de nombreux points

et on nous a utilisées à travers les âges

appartenant aux humains

et créatures d'autres planètes.

La lumière voyage lentement

sur de grandes distances. Ainsi

notre délibération a aidé les navigateurs

à voyager vite et en sécurité vers leurs terres d'origine.

Parfois nous sommes obscurcies par les nuages et les navigateurs se fient à d'autres techniques

comme de traduire le clapotis des vagues touchant terre 
into a direction

Waka 86

I am Kupe. I have the credit for finding this new land, the parts of which

I named with parts of me, including my son - I have left my son here,

the gods were appeased.

My soul will never forget this.

I have been quoted many times, e hoki a Kupe? Did Kupe return?

The saying is meant to politely refuse a request. But I do

return to this land. Thoughts

I placed here keep returning

to my ears. I am sorry

for correcting the saying,

but I have been returning

for a very long time now. en une direction

Waka 86

Je suis Kupe. C'est à moi qu'on attribue la découverte de cette nouvelle terre, dont j'ai nommé certaines parties

d'après certaines parties de moi, mon fils y compris - j'ai laissé mon fils ici,

les dieux en furent apaisés.

Mon âme n'oubliera jamais ça.

On m'a cité bien des fois,

e hoki a Kupe ? Kupe est-il revenu ?

Ce proverbe est utilisé pour refuser poliment une demande. Mais moi,

je reviens sur cette terre. Les pensées que j'y ai placées ne cessent de revenir

à mes oreilles. Je suis désolé de corriger le proverbe,

mais je reviens sans cesse et depuis très longtemps. 
Waka 87

I am the anonymous settler fresh off the boat from Bristol, arrived from a developed land where the landscape is landscaped, seating churches and palaces, melodious clock towers, aristocrats and Ascot, a land where everything has a place including the people.

Here we have tents and take food from savages. The town is squatter than Sydney. The English do not know their stations any more.

My family will spend the next century building this country into a new England, and building the mythology of England as home.

\section{Waka 87}

Je suis le colon anonyme

fraîchement débarqué du bateau de Bristol,

venu d'un pays développé

où le paysage

est paysagé, où siègent églises

et palais, tours d'horloges mélodieuses,

aristocrates et Ascot, un pays

où tout

a une place y compris le peuple.

Ici, nous avons des tentes et prenons la nourriture aux sauvages. La ville est plus basse que Sydney. Les Anglais ne savent plus leur rang.

Ma famille va passer le prochain

siècle à construire ce pays

en une nouvelle Angleterre et à construire

la mythologie de l'Angleterre comme patrie. 
Do not mind the settler. I observe

the rules of this mythology (see how he did not

place a star or ocean or a waka

in his pageantry). I am Odysseus,

summoned to these pages by extraordinary claims of the narrator. I run through all narratives.

Dr Jung put me there early in the century. Look closely at the narration. Who

is holding the sails taut, commanding the paddles, seeing that the carvings follow the patterns

of waka that follow the patterns of the sea? I. Odysseus. I have put myself here

because this is a text. A very Western text. The navigators sail with me now.

I sail as a member of the crew, and can speak for them.
Ne vous occupez pas du colon. J'observe

les règles de cette mythologie (vous avez vu qu'il n'a pas

placé d'étoile, d'océan ni de waka

dans ses oripeaux). Je suis Ulysse,

invoqué dans ces pages par les prétentions

extraordinaires du narrateur. Je suis présent dans tout récit.

Le Dr Jung m'a mis là au début du siècle.

Regardez de près la narration. Qui

tient les voiles bien serrées, qui commande les rames, s'assure que les sculptures suivent bien les motifs

des waka qui suivent les motifs de la mer?

Moi. Ulysse. Je me suis mis ici

parce que c'est un texte. Un texte très occidental.

Les navigateurs font voile avec moi désormais.

Je navigue en tant que membre de l'équipage,

et peux parler en leur nom. 


\section{Waka 89}

Yo I'm Māui. This facet is the Māui of the hauling. The great fish is mine. I have first rights

and I am expressing anger ANGER ANGER at being denied a significant portion of the text

of the Star Waka. The copyrights are mine.

Without me the waka would be a vaka for instance.

They wouldn't have a base, a matrix to tie their culture to. You know I fished the land up

don't you? You know I placed it under the path of Kopua, not far from Matariki, don't you?

How else would anyone find it?

What do you mean there'd be another star,

or birds? I tell you I put it there because those stars are the best ones in the sky. I want credit.

And no more anthropologists.

I belong to cosmology. Dig, Odysseus?

\section{Waka 89}

Yo c'est Māui. Cette facette, c'est le Māui du coup de pêche.

Le gros poisson est à moi. C'est moi qui ai le droit de préemption

et j'exprime ma colère, COLÈRE COLÈRE

qu'on me refuse une portion significative du texte

du Star Waka. Les droits d'auteur me reviennent.

Sans moi le waka serait un vaka par exemple.

Ils n'auraient pas de fondation, de matrice à laquelle attacher leur culture. Vous savez que c'est moi qui ai pêché la terre, non ?

Vous savez que je l'ai placée sous le chemin de Kopua, pas loin de Matariki, non?

Comment pourrait-on la trouver autrement ?

Comment ça, il y aurait eu une autre étoile

ou d'autres oiseaux? Je vous dis que je l'ai mise là car ces étoiles sont les meilleures dans le ciel. J'en veux tout le mérite.

Et puis plus d'anthropologues.

J'appartiens à la cosmologie. Pigé, Ulysse ? 
Waka 90 Te ao mārama IV

This is my third appearance. I am Kurahaupō Waka. This time

I have taken the task

of representing the two hundred

waka remembered by the people,

shot to the cold

regions

by accounts turned to legends,

such is the elevated nature of oral literature.

I have been appointed by the narrator.

I am unelected, as is the narrator.

My appearance here is strange,

without the adornments of my mana,

the finery of inlaid carved and seasoned wood, the ceremonial decorations taking me

into the sea. It's like journeying in a bathtub, the margins of the sea of text

only released by the narrator's dreams.

And he doesn't write when he's asleep.

But my mana isn't in my physicality. It's in the psyche of the culture that bred me.
Waka 90 Te ao mārama IV

C'est ma troisième apparition. Je suis le waka Kurahaupō. Cette fois,

j'ai entrepris la tâche

de représenter les deux cents

waka dont se souvient le peuple,

here propulsés aux régions froides ici

par des histoires devenues légendes,

telle est la nature élevée de la littérature orale.

C'est le narrateur qui m'a désigné.

Je ne suis pas élu, le narrateur non plus.

Mon apparition ici est étrange,

sans les ornements de mon mana,

les beaux atours en bois séché, sculpté et incrusté, les décorations cérémoniales qui m'emportent

jusqu'à la mer. C'est comme voyager dans une baignoire, les marges de la mer de texte

libérées seulement par les rêves du narrateur.

Et il n'écrit pas quand il dort.

Mais mon mana n'est pas dans ma réalité physique. Mais dans la psyché de la culture qui m'a engendré. 


\section{Waka 91 A feast}

i

Stones are laid beneath the pyres

till they encompass the heat which

feeds through the layers of bird flesh

root vegetables smoking and steaming

underground - a hundred birds

a thousand vegetables oiling

the throats of the waka community

licking sucking chewing biting

ha-ha

a feast of the season

ii

scraps for the slaves

are heaped like atolls

rain makes goblets of their faces
Waka 91 Un festin

i

Les pierres sont disposées sous les bûchers jusqu'à ce qu'elles emmagasinent la chaleur qui se propage à travers les couches de chair d'oiseaux légumes-racines qui chauffent et fument sous terre - une centaine d'oiseaux

un millier de légumes qui vont huiler

les gosiers de la communauté waka

lécher sucer mâcher croquer

ah-ah

un festin de saison

ii

les restes pour les esclaves

sont entassés comme des atolls

la pluie fait des gobelets de leurs visages 
I am an island

in the people's consciousness

storms foretell arrival of waka

carrying companies of strange birds

strangled by the breeze

each triangulation of sails

tells of trouble in the colonies

a fleet and there has been a great calamity

for I am an island of death

waka are hearses not vehicles for exploration

I gladly take them

they send the loved ones here

with some knowledge

of what it is to be a Māori

the others go to the other human place

called the collective unconscious

I am called Hawaiiki
Waka 92

Je suis une île

dans la conscience du peuple

les tempêtes prédisent l'arrivée des waka

transportant des compagnies d'étranges oiseaux

étranglés par la brise

chaque triangulation de voiles

parle de difficultés dans les colonies

une flotte et il y a eu une grande calamité

car je suis une île de mort

les waka sont des corbillards et non des véhicules d'exploration je les emmène volontiers

on envoie ici les bien-aimés

avec quelque savoir

sur ce que c'est, d'être māori

les autres vont dans l'autre lieu humain

qu'on appelle l'inconscient collectif

je m'appelle Hawaiiki 
My face is broken by the waves.

I am the sea, ocean, giver and taker, primordial pre-culture pre-life.

To define me is to limit me, one may as well define the planet.

Yet I am delicate, can feel a piece of wood slip across my eye, can feel the calls of men rowing as they dip into me

as if I was a well to scoop from. Some of these I have taken into the waters of my being.

So I am part human.
Waka 93

Mon visage est brisé par les vagues.

Je suis la mer, océan, qui donne et qui prend, primordiale pré-culture, pré-vie.

Me définir c'est me limiter,

autant vouloir définir la planète.

Mais je suis délicate, peux sentir un bout de bois glisser à travers mon œil, peux sentir l'appel des rameurs lorsqu'ils plongent en moi

comme si j'étais un puits qu'on écope.

Certains d'entre eux, je les ai pris

dans les eaux de mon être.

Donc je suis en partie humaine. 
Waka 94

I am Tāne Mahuta - and not offended to be introduced at this late stage.

This is Tangaroa's story. I merely supply the vessels. They are a small chink

in the arsenal of Tāne. I command mountains, influence the rain, the presence of my legions

directs Tangaroa's motions (you know, from space you see clouds amass above

my forests, my children). I am a long-term kind of god, not drawn into quick effect.

It is suitable that I am placed near the end of the Star Waka, to emphasise my length.
Waka 94

Je suis Tāne Mahuta - et ne suis pas offensé d'être présenté à ce stade tardif.

C'est l'histoire de Tangaroa. Je ne fais que fournir les vaisseaux. Ils ne sont qu'une peccadille

dans l'arsenal de Tāne. Je commande les montagnes, influence la pluie, la présence de mes légions

dirige les mouvements de Tangaroa (vous savez, depuis l'espace on peut voir des nuages amassés au-dessus

de mes forêts, mes enfants). Je suis une espèce de dieu à long terme, pas sensible aux effets immédiats.

C'est logique que je sois placé vers la fin du Star Waka, ça fait ressortir ma longueur. 


\section{Waka 95}

I am Tangaroa, Lord of this domain

Star Waka travels. The sky

is my only mirror. I pluck people

for the ridge-pole tekoteko of my mighty whare.

I am kind.

I allow the carvings to talk to one another about the lives they represent,

occasionally let them change

the stories. Tāne may boast

about his size, but I

am the only one to rival the size

of our parents. He took them away

from one another - even though

they are big, an immensity each of them,

their love came immensely too.

It breaks them into bits and pieces

from the heavens - all of them -

to the tiniest piece of Papatūānuku.

I felt this as their closest child.

Star Waka, do not be fooled by Tāne, betrayer of my beloved parents,

come dive into the sea - here

I will send waves - don't deny me

you won't be spared because

my waves can turn land over to water

in a thrashing horrible instant.

Give up. I am Tangaroa

owner of the feasts of the sea

the harvester of deities

and you the crew of a little waka

\section{Waka 95}

Je suis Tangaroa, Seigneur du domaine que parcourt Star Waka. Le ciel

est mon seul miroir. Je cueille les gens

pour le tekoteko, la panne faîtière de mon puissant whare.

Je suis bon.

J'autorise aux sculptures de parler entre elles

des vies qu'elles représentent,

parfois je les laisse changer

les histoires. Tāne s'enorgueillit peut-être

de sa taille, mais moi

je suis le seul qui rivalise avec la taille

de nos parents. Il les a séparés

l'un de l'autre - même s'ils

sont grands, chacun immense,

leur amour aussi est immense.

Il les brise en petits morceaux

depuis les cieux - tout entiers -

jusqu'au plus petit bout de Papatūānuku.

Je l'ai ressenti, étant leur enfant le plus proche.

Star Waka, ne te fais pas berner par Tāne,

traître de mes parents chéris,

viens plonger dans la mer - là,

j'enverrai des vagues - ne m'ignore pas

tu ne seras pas épargné car

mes vagues peuvent transformer la terre en eau en un instant d'une violence horrible.

Abandonne. Je suis Tangaroa

propriétaire des festins de la mer,

moissonneur des déités

et toi, l'équipage d'un petit waka 


\section{Waka 96}

I am the star waka guided by the left eyes of the ancestors

in our black heaven.

Sometimes I carry stars to Hawaiiki for release into the night.

\section{Sometimes I continue} the explorations begun by our expeditions

into knowledge.

I have been sent back

to retrieve crops

and I have returned.

I have been sent

into the furthest corners

of the realms of the Pacific, brought kūmara

from Peru, carted stories

of crews gone into the dust
Waka 96

Je suis le star waka guidé par les yeux gauches des ancêtres

dans notre paradis noir.

Parfois, je transporte des étoiles à Hawaiiki pour les libérer dans la nuit.

Parfois, je continue

les explorations

commencées par nos expéditions

vers le savoir.

On m'a renvoyé pour

chercher les récoltes

et je suis revenu.

On m'a envoyé

aux confins les plus reculés

des domaines du Pacifique,

rapporté les kūmara

du Pérou, charrié les histoires

d'équipages partis en poussière 
of the black heaven

inhabited by your father,

and under the cloak

of his protection,

and through the encouragement

of his wife, the mother of all beings,

I deny you, Tangaroa.

I will not sink beneath you today. au paradis noir

qu'habite ton père,

et sous le korowai

de sa protection,

et grâce aux encouragements

de sa femme, la mère de tout être,

je te renie, Tangaroa.

Je ne sombrerai pas sous toi aujourd'hui. 
Waka 97

Pray for the crew

to row in unison

lift and dip exactly

hear the sound

of the chant

hoea hoea ra

pray for the crew

to know where to go

for their priests clear heads

sense to ration food

fill gourds

hoea hoea ra

pray for the lashings

and bailers and anchors

for the fish catch and big catch

to climb onto land

pray for remembering ritual

\section{hoea hoea ra}

bless this crew and their waka knowledge

bless this ship and its journeying

bless families about to part

bless the new land

bless the deities we bring

\section{Waka 97}

Priez pour que l'équipage

rame à l'unisson

lève puis plonge précisément

écoute le son

du chant

hoea hoea ra

priez pour que l'équipage

sache où aller

pour leurs prêtres l'esprit clair

le sens de rationner les provisions

remplir les gourdes

hoea hoea ra

priez pour les amarres

les écopes et les ancres

pour prendre du poisson et beaucoup

pour grimper à terre

priez pour vous souvenir du rituel

\section{hoea hoea ra}

bénissez cet équipage et leur savoir waka bénissez ce navire et son périple

bénissez les familles sur le point de se séparer bénissez la nouvelle terre

bénissez les déités que l'on apporte 
Waka 98

waka images cut in and out

collages on the eyes

below the eyebrows

popping up in legends

coming out in urban myth

waka wallpaper

waka duvet covers

what dread hand shaped your fearful symmetry?

tiger of the sea carrying deities

to an empty land filled with fur seals

fat birds tall birds and mice

when will you stop tasting the wind?

when the wind relinquishes its salt taste

then like my ancient cousins I will turn to stone

and stay here forever
Waka 98

images waka coupées ci et là

collages sur les yeux

sous les sourcils

surgissent en légendes

ressortent en mythes urbains

papier peint waka

housses de couette waka

quelle main redoutable conçut ton effrayante symétrie ?

tigre de mer porteurs de déités

vers une terre vide peuplée d'otaries

d'oiseaux gras d'oiseaux grands et de souris

quand cesseras-tu de goûter le vent ?

quand le vent relâchera son goût de sel

alors comme mes cousins d'autrefois je serai changé en pierre

et resterai là pour toujours 
Waka 99

If waka could be resurrected they wouldn't just come out from museum doors smashing glass cases revolving and sliding doors on their exit

they wouldn't just come out of mountains as if liquefied from a frozen state the resurrection wouldn't just come about this way

the South Island turned to wood waiting for the giant crew of Māui and his brothers bailers and anchors turned back

to what they were when they were strewn

about the country by Kupe

and his relations

the resurrection would happen

in the blood of the men and women

the boys and girls

who are blood relations

of the crews whose veins

touch the veins who touched the veins

of those who touched the veins

who touched the veins
Waka 99

Si les waka pouvaient ressusciter ils ne sortiraient pas simplement des portes des musées en faisant exploser les vitrines de verre les portes tournantes et coulissantes sur leur passage

ils ne sortiraient pas simplement des montagnes comme liquéfiés d'un état congelé

la résurrection ne se produirait simplement pas de cette façon

l'Ile du Sud changée en bois attendant que l'équipage géant de Māui et ses frères écopes et ancres redeviennent ce qu'ils étaient quand ils furent éparpillés

dans tout le pays par Kupe

et ses liens de parenté

la résurrection se produirait dans le sang des hommes et des femmes les garçons et filles

qui ont des liens de sang avec les équipages dont les veines touchent les veines qui ont touché les veines de ceux qui ont touché les veines qui ont touché les veines 
who touched the veins

of the men and women from the time of Kupe and before.

The resurrection will come

out of their blood. qui ont touché les veines

des hommes et des femmes du temps

de Kupe et avant.

La résurrection surgira

de leur sang. 
Waka 100

Stroke past line 1642

into European time.

Stroke past 1769

and the introduction of the West

Stroke on the approach to 1835

and formal Northern Māori sovereignty.

Stroke into the New World and stop.

Crews alight, consign waka

to memory, family trees, remove

the prowed tauihu, drape

the feathered mana

around the whare-womb

of the next crew

who are to remember waka

into the beginning

of centuries years minutes hours seconds

long and short hands centred

on Greenwich

each person

of waka memory

to hold their thoughts,

each person of seagoing

and waterborn descent

whose hard waka

are taken away.

And years later,

we ask our ancestors to wake,
Waka 100

Ramez après la ligne 1642

à l'heure européenne.

Ramez après 1769

et l'introduction de l'Ouest

Ramez à l'approche de 1835

proclamation de la Souveraineté des Māori du Nord.

Ramez jusqu'au Nouveau Monde puis stop.

Equipages descendez, consignez les waka au souvenir, arbres généalogiques, enlevez

le tauihu des proues, drapez

le mana en plumes

autour du whare-ventre

du prochain équipage

qui doit se souvenir des waka

au début

des siècles années minutes heures secondes petite et grande aiguilles centrées

sur Greenwich

chaque personne

dans la mémoire des waka

de retenir ses pensées,

chaque personne de descendance

marine née de l'eau

dont les durs waka

sont confisqués.

Et des années plus tard,

nous demandons que s'éveillent nos ancêtres 
whose mokopuna are carving in eyes, restoring chiseled features, mouths coming out of wood, genitals, feet planted

on shoulders winding into stars on ceilings, our ancestors of a culture that has held its breath

through the age of Dominion.

We've adzed waka out for them the memories, intricate knowledge,

fleet leaders, our reasons for being shoulders that carried so many waka summoning souls of myriads of names above hundreds

of waka names.

And you waka, who have seen heaven, the guts of the ocean, brought terror and pleasure, who have exhausted your crews of home thoughts who have lifted songs above the waves of the greatest and deepest ocean,

rise - rise into the air - rise to the breath rise above valleys into light and recognition rise where all who have risen sing your names.

And you, Urizen, Jupiter, Io Matua Kore, holder of the compasses -

wind compass, solar compass,

compass encompassing known

currents, breather of the first breath

in every breathing creature, guide the waka between islands, dont les mokopuna sculptent des yeux, restaurent les traits ciselés, bouches

qui sortent du bois, organes génitaux, pieds plantés

sur des épaules s'enroulant en étoiles aux plafonds, nos ancêtres d'une culture qui a retenu son souffle durant toute l'ère du Dominion.

Nous avons taillé les waka pour eux les souvenirs, le savoir complexe, chefs de flotte, nos raisons d'être épaules qui ont porté tant de waka invoquant les âmes de myriades de noms au-dessus de centaines de noms de waka.

Et vous waka, qui avez vu le paradis, les tripes de l'océan, apporté terreur et plaisir, vous qui avez épuisé vos équipages de pensées pour leur foyer vous qui avez soulevé des chants au-dessus des vagues du plus grand du plus profond des océans,

montez - montez en l'air - montez au souffle montez au-dessus des vallées à la lumière et la reconnaissance montez là où tous ceux qui sont montés chantent vos noms.

Et vous, Urizen, Jupiter, Io Matua Kore, gardien des boussoles boussole du vent, boussole solaire,

boussole englobant les courants connus, ayant soufflé le premier souffle de toute créature vivante, guidez les waka entre les îles, 
between years and eyes of the Pacific out of mythologies to consciousness.

And you stars, the ancestors,

nuclear orbs, red giants, white dwarves,

burn brilliantly, burn on the waka down there,

burn on waka riding valleys,

burn on waka on mountain summits,

burn on waka in the night,

burn on waka past the end of the light. entre les années et les yeux du Pacifique

hors des mythologies jusqu'à la conscience.

Et vous étoiles, les ancêtres,

orbes nucléaires, géantes rouges, naines blanches, brûlez et brillez, brûlez encore les waka ici-bas,

brûlez encore waka naviguant dans les vallées,

brûlez encore waka aux sommets des montagnes,

brûlez encore waka dans la nuit,

brûlez encore waka après la fin de la lumière. 